Universidad de Lima

Facultad de Ingeniería y Arquitectura

Carrera de Arquitectura

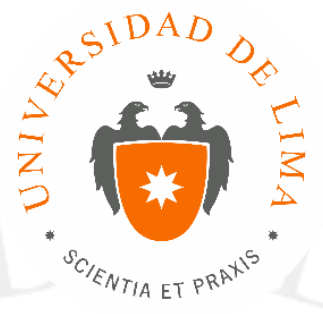

\title{
TERMINAL TERRESTRE YERBATEROS COMO REGENERADOR URBANO
}

Tesis para optar el Título Profesional de Arquitecto

\author{
Fabrizio Andre Chiappe Flores \\ 20111435 \\ Claudia Nicole Kleffmann Ghiglino \\ 20111446
}

Asesor

Enrique Gonzalo Santillana Ciriani

Lima - Perú

Febrero de 2018 


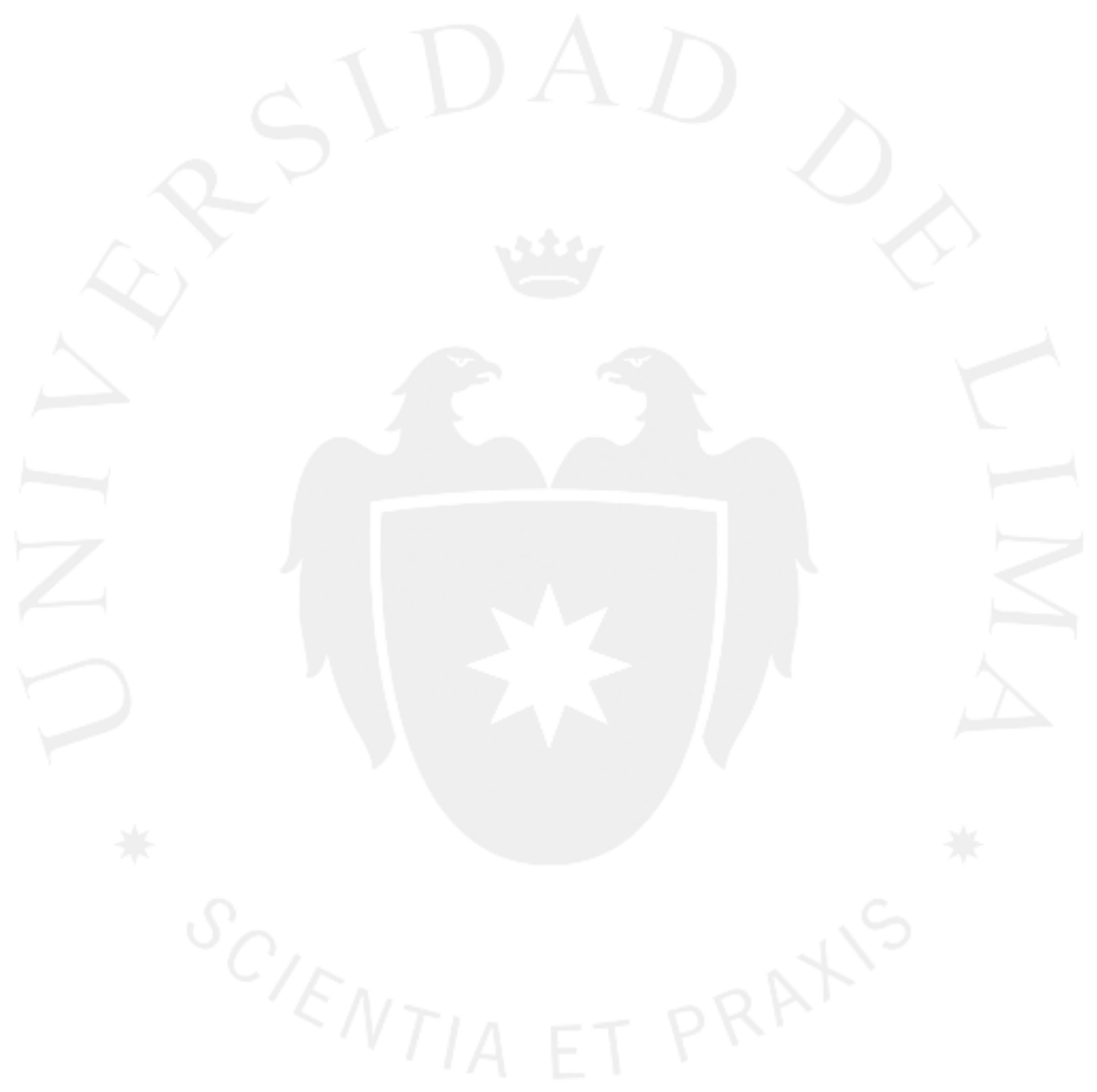




\section{TERMINAL TERRESTRE YERBATEROS COMO REGENERADOR URBANO}




\section{TABLA DE CONTENIDO}

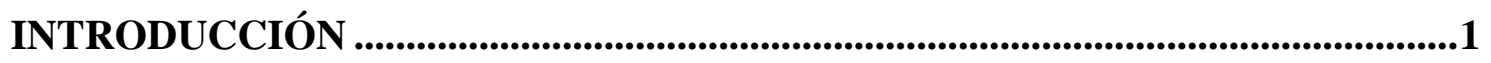

CAPÍTULO I: GENERALIDADES....................................................................3

1.1 Tema

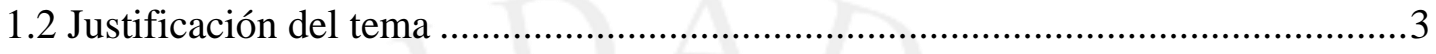

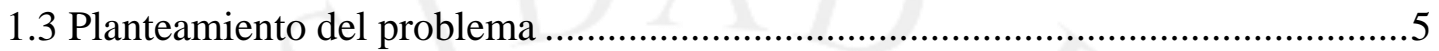

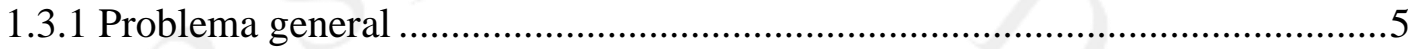

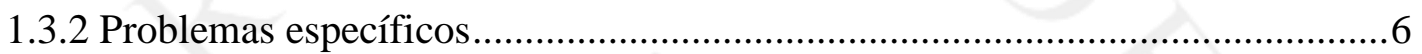

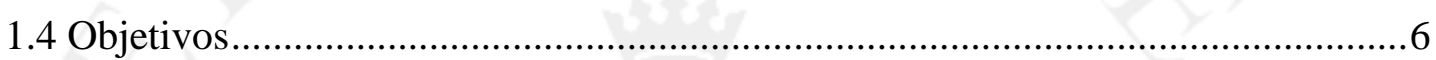

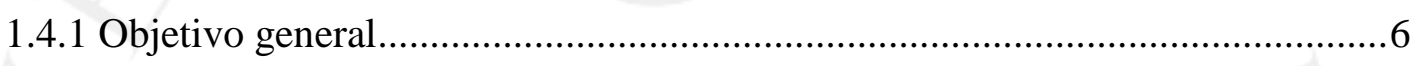

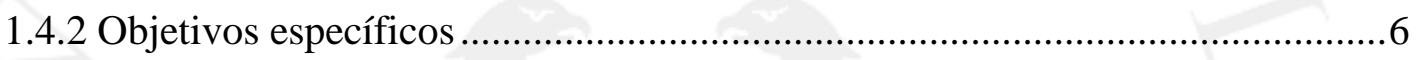

1.5 Supuestos básicos de investigación ...................................................................

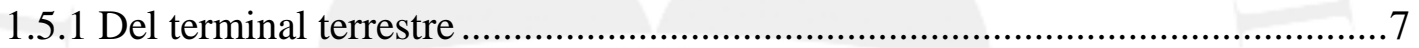

1.5.2 Del terminal terrestre como regenerador urbano ........................................

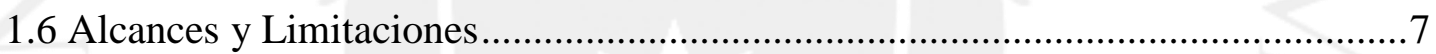

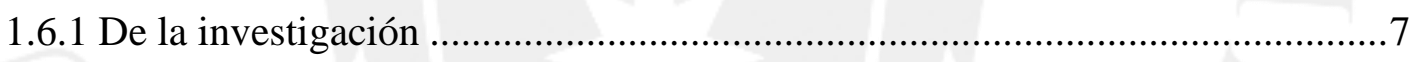

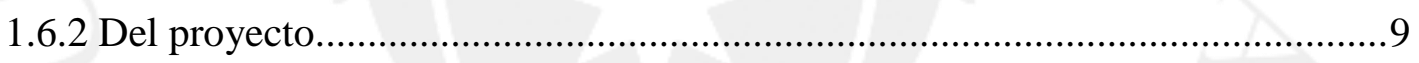

1.7 Diseño de la Investigación........................................................................ 10

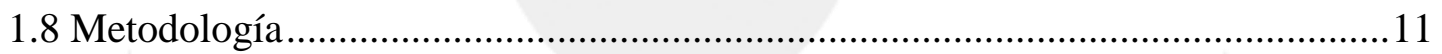

1.8.1 Forma de consulta y recopilación de la información ......................................11

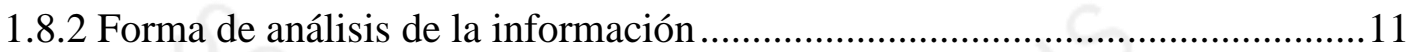

1.8.3 Forma de presentación de la información.....................................................11

CAPÍTULO II: MARCO REFERENCIAL ...........................................................12

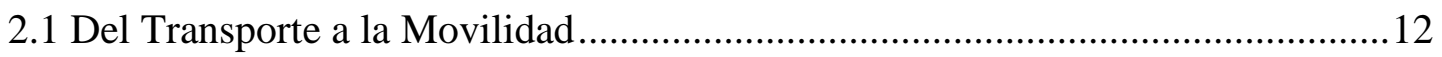

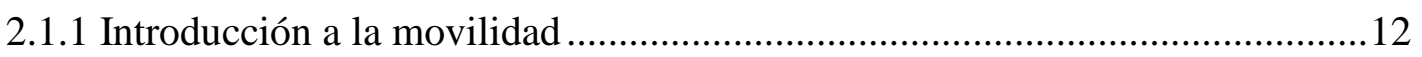

2.1.2 Los enfoques de la movilidad en el tiempo ................................................ 14

2.1.3 Cambiando la manera de hacer ciudad .......................................................18

2.2 El transporte terrestre en el Perú.................................................................24

2.2.1 La historia del transporte terrestre en Lima...............................................26

2.2.2 Gestión del transporte interprovincial de pasajeros........................................32 
2.2.2.1 Entidades gubernamentales .32

2.2.2.2 Estructura y categoría de vías 35

2.2.3 Situación actual de los terminales de Lima .36

2.2.4 Estrategias de ordenamiento para el transporte público e interprovincial de Lima 43

2.3 Zona de estudio: situación socio-cultural y económica........................................54

2.3.1 Lima: urbanismo inverso y la consolidación de Lima.....................................54

2.3.2 Ubicación y contextualización de la zona de estudio ......................................56

2.3.2.1 La primera barriada de Lima: Cerro San Cosme ........................................56

2.3.2.2 La continuación de las barriadas: Cerro el Agustino ..................................57

2.3.2.3 La urbanización de Lima Este .................................................................58

2.3.3 Zona de estudio en la actualidad................................................................60

2.3.4 El espacio público en la zona de estudio ....................................................67

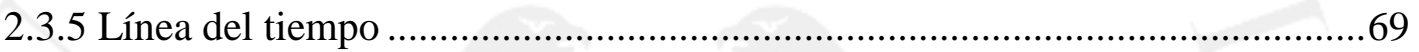

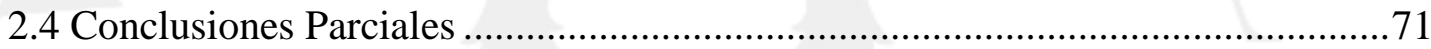

CAPÍTULO III: MARCO TEÓRICO ....................................................................74

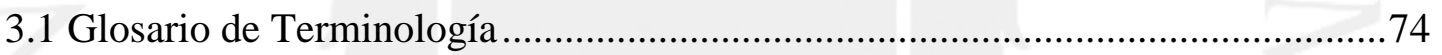

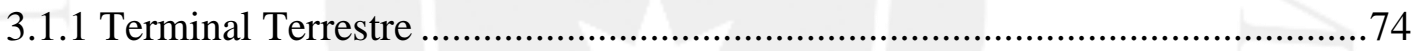

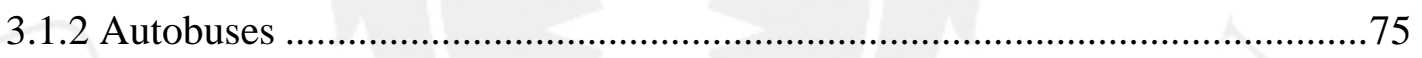

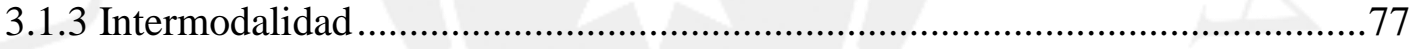

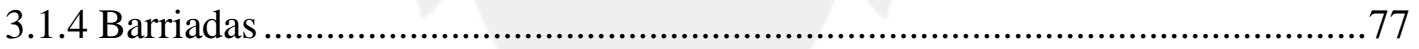

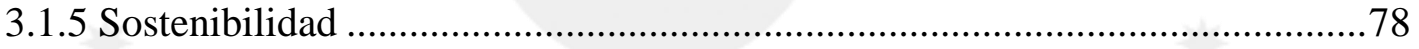

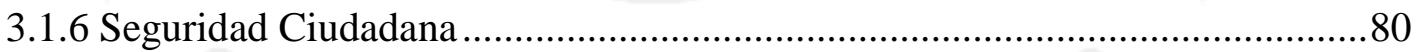

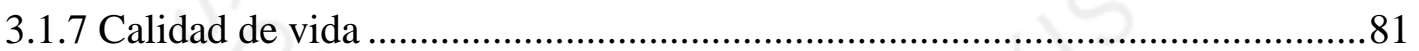

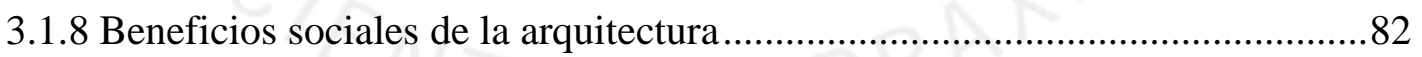

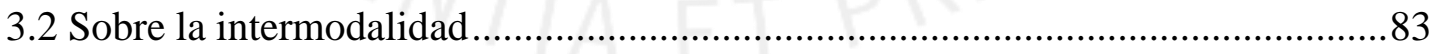

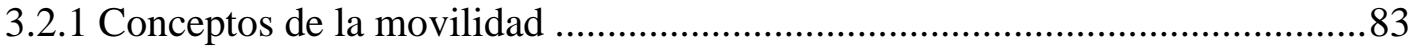

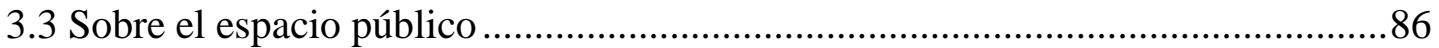

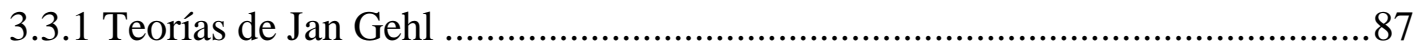

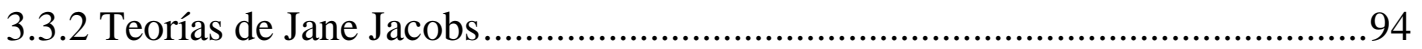

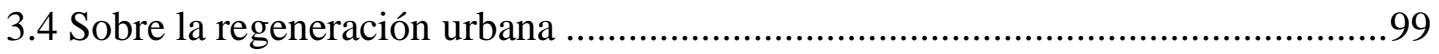

3.4.1 Teorías aplicadas para la recuperación de zonas degradadas ........................ 100

3.4.1.1 Urbanismo Social: Proyectos de infraestructura en barrios marginados .. 100 
3.4.1.2 Metodologías para la regeneración de espacios degradados 102

3.4.2 Conceptos de la Acupuntura Urbana y Urban Upgrading 110

3.5 Lineamientos y normas básicas para un terminal terrestre. 112

3.5.1 Requerimientos previos 113

3.5.2 Consideraciones generales de diseño 114

3.5.2.1 Arquitectura: Lineamientos guía 115

3.5.2.2 Esquema básico de funcionamiento 118

3.5.3 Programa requerido 120

3.5.4 Valores y fórmulas para la estimación de áreas.

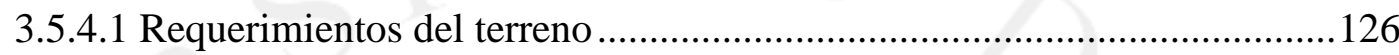

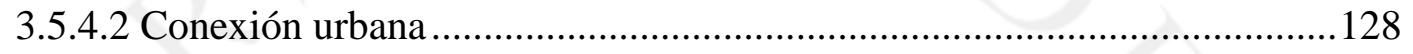

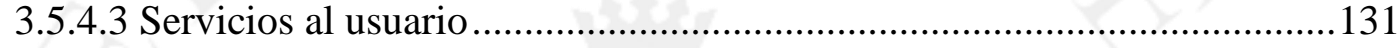

3.5.4.4 Servicios para operadores de autobuses............................................... 141

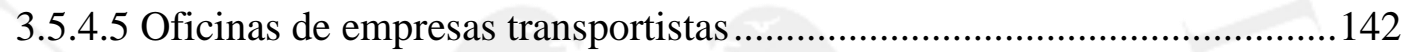

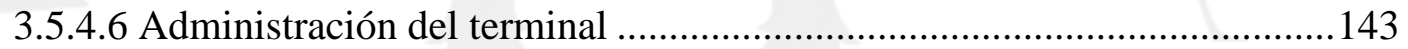

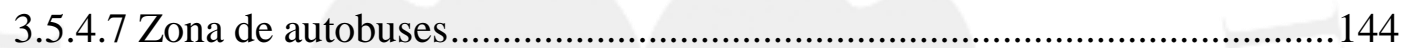

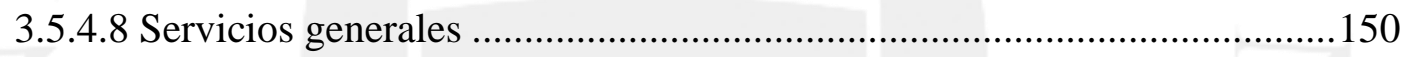

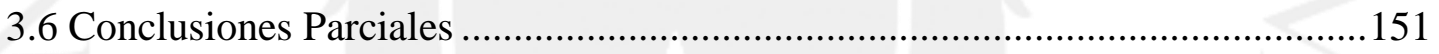

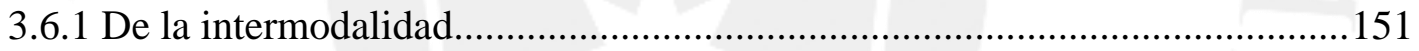

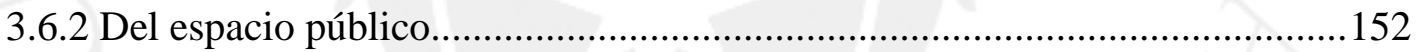

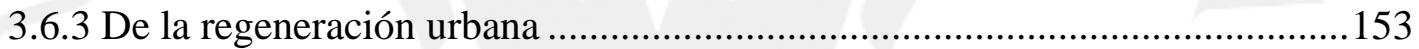

3.6.4 De los lineamientos y normas básicas para un terminal terrestre ................... 154

CAPÍTULO IV: MARCO OPERATIVO ..........................................................156

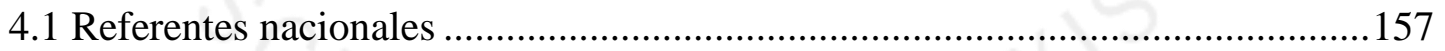

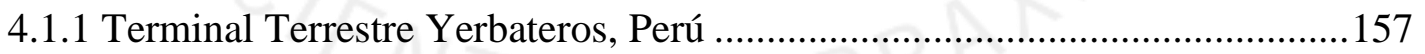

4.1.2 Terminal Terrestre Plaza Lima Norte, Perú................................................... 164

4.1.3 Terminal Terrestre Cruz del Sur, Perú.......................................................... 170

4.2 Referentes en América Latina: realidades similares.........................................176

4.2.1 Terminal Terrestre de Guayaquil, Ecuador ............................................... 176

4.2.2 Terminal de Autobuses de Pasajeros de Oriente, México ..............................184

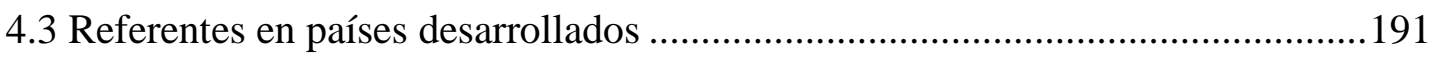

4.3.1 Terminal Terrestre de Nueva York, EEUU .................................................. 191

4.3.2 Terminal Terrestre de Múnich, Alemania ................................................... 199 
4.4 Referentes de espacio público .206

4.4.1 Zhengzhou Vanke Central Plaza, China.......................................................206

4.4.2 High Line New York City, EE.UU..........................................................209

4.5 Referentes de sistemas constructivos para techados.......................................213

4.5.1 Campus Restaurant Ditzingen, Alemania...................................................213

4.5.2 Bodegas Protos de Peñafiel, España .............................................................216

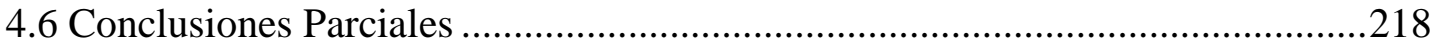

CAPÍTULO V: MARCO CONTEXTUAL ............................................................223

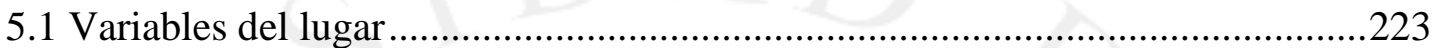

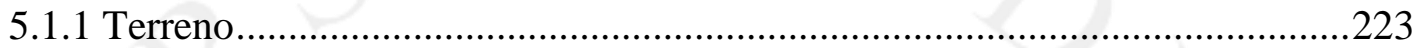

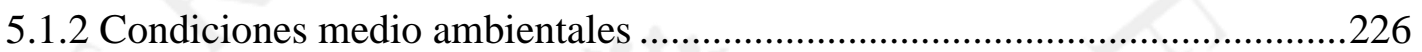

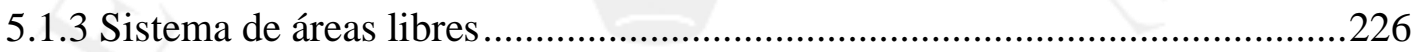

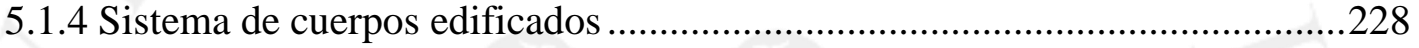

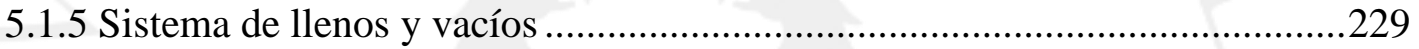

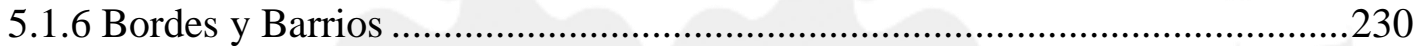

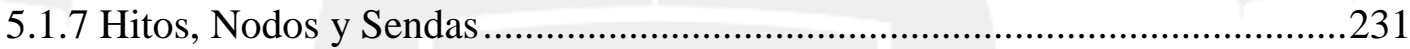

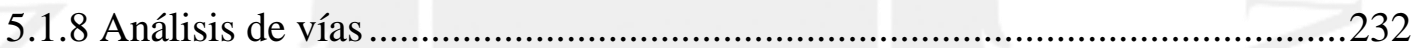

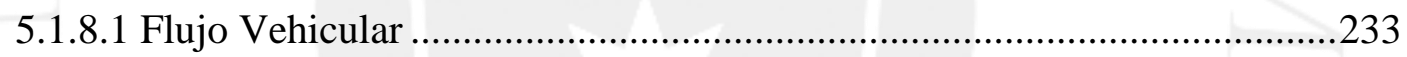

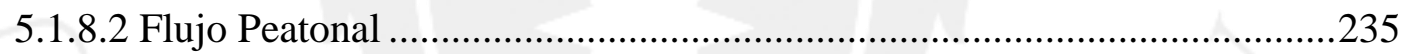

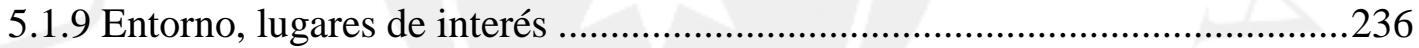

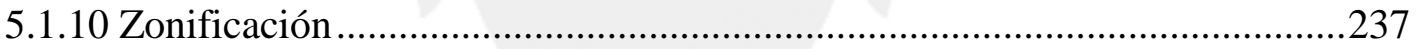

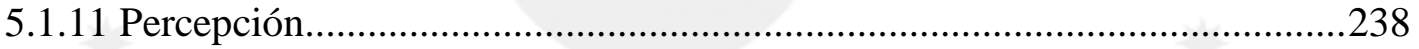

5.1.12 Levantamiento fotográfico: Lote y entorno ..............................................240

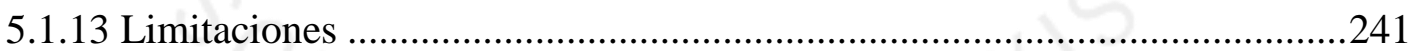

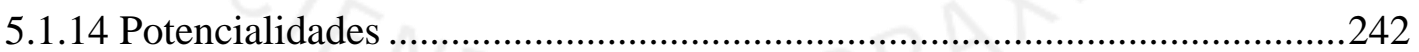

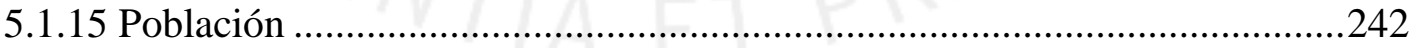

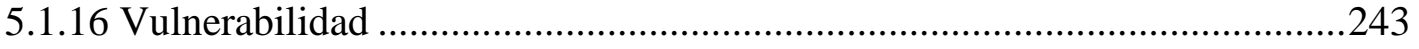

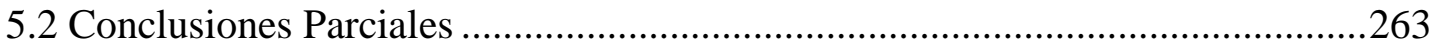

CAPÍTULO VI: CONCLUSIONES FINALES ............................................................266

CAPÍTULO VII: PROYECTO TERMINAL TERRESTRE ....................................271

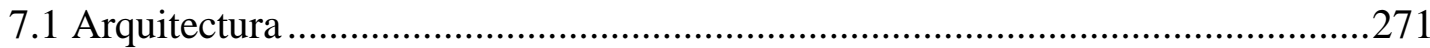

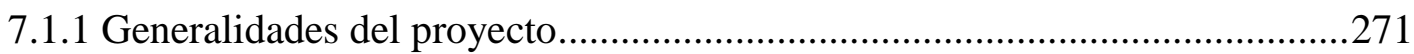


7.1.2 Estrategias proyectuales .272

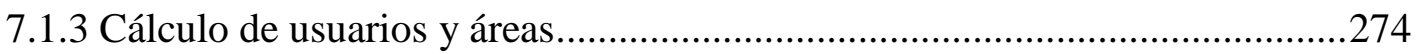

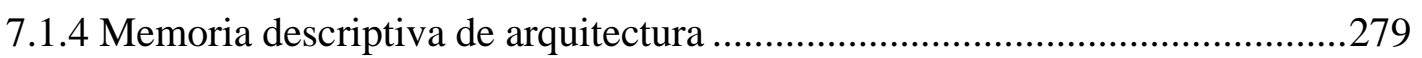

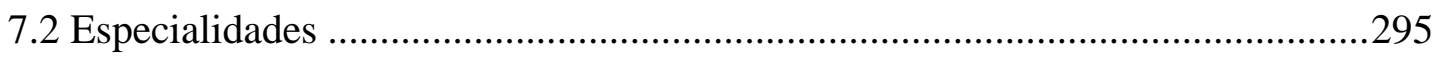

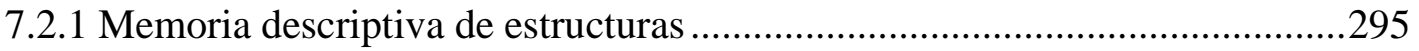

7.2.2 Memoria descriptiva de instalaciones eléctricas.........................................299

7.2.3 Memoria descriptiva de instalaciones mecánicas .......................................301

7.2.4 Memoria descriptiva de instalaciones sanitarias...........................................301

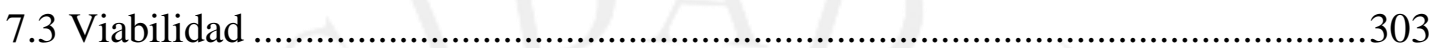

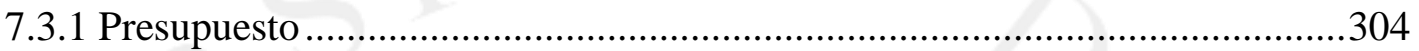

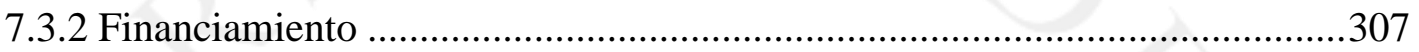

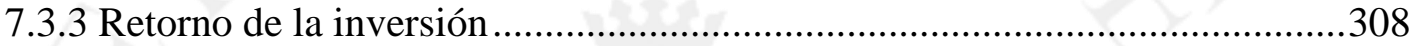

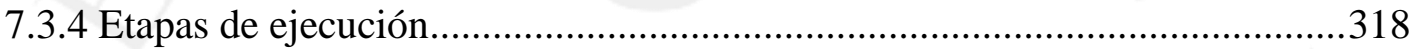

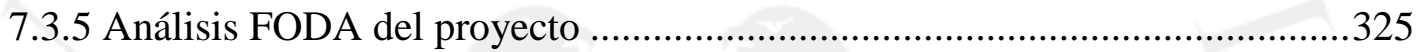

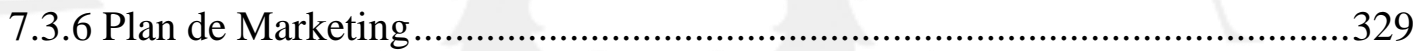

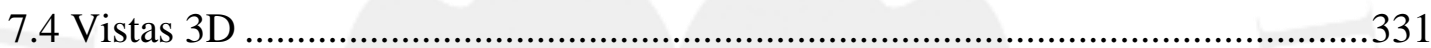

REFERENCIAS BIBLIOGRAFICAS .................................................................335

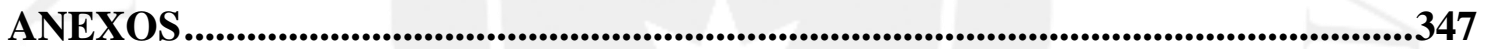




\section{INDICE DE TABLAS}

Tabla 1: Evolución del concepto de transporte vs. movilidad ........................................18

Tabla 2: Sistema Nacional de Carreteras del Perú............................................................36

Tabla 3: Número de terminales según cantidad de empresas ........................................40

Tabla 4: Distribución de terminales según área construida ...........................................40

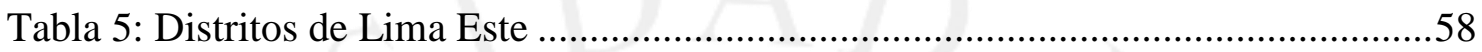

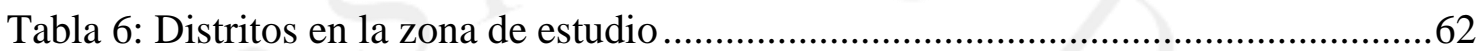

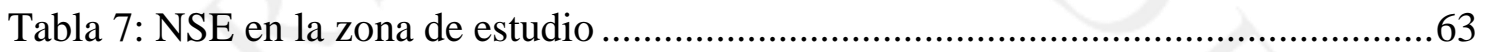

Tabla 8: Número de empresas en la zona de estudio ..................................................65

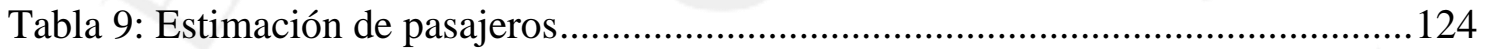

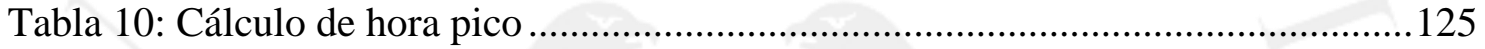

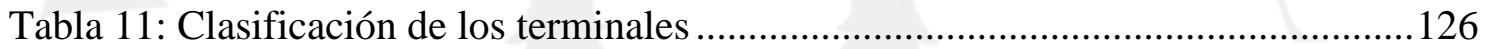

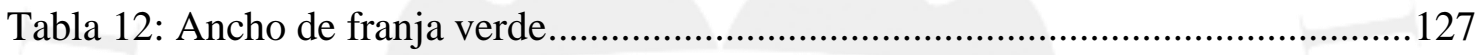

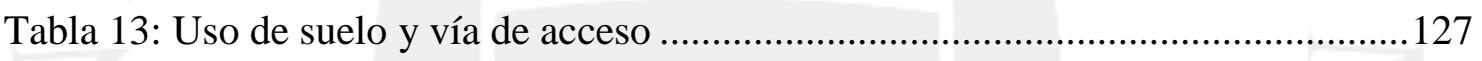

Tabla 14: Dimensiones mínimas para tránsito peatonal …............................................129

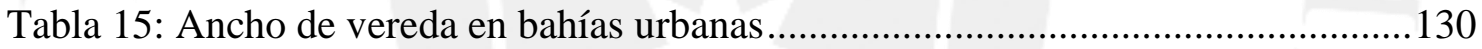

Tabla 16: Dotación de servicios - Patio de comidas I................................................... 135

Tabla 17: Dotación de servicios - Patio de comidas II .................................................. 136

Tabla 18: Dotación de servicios - Salas de espera........................................................... 138

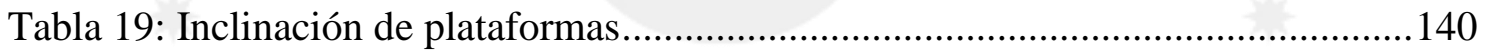

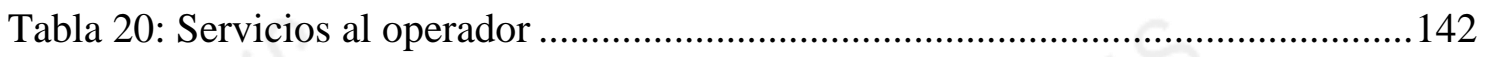

Tabla 21: Dotación de servicios - Zona administrativa ...............................................143

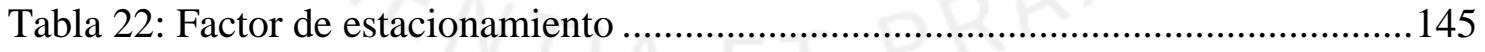

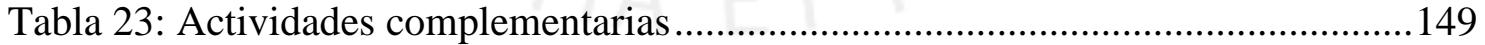

Tabla 24: Dotación de servicios - Zona de talleres ..................................................... 149

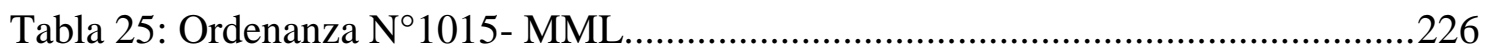

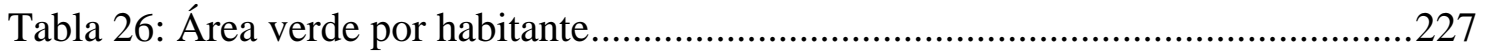

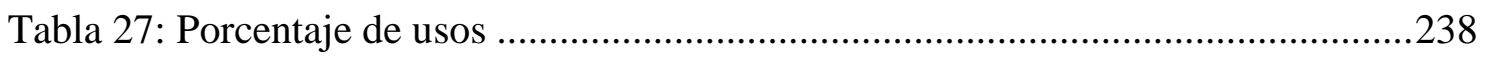

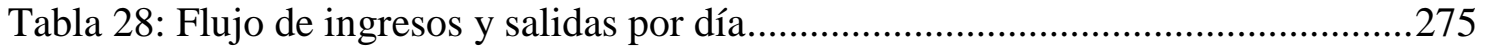

Tabla 29: Flujo de ingresos y salidas por año ........................................................2 275 
Tabla 30: Metrado arquitectónico y cuadro de áreas ...................................................290

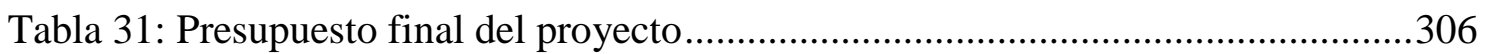

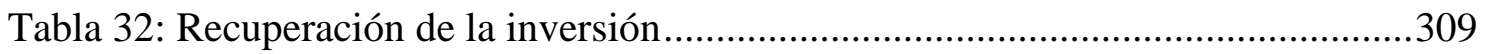

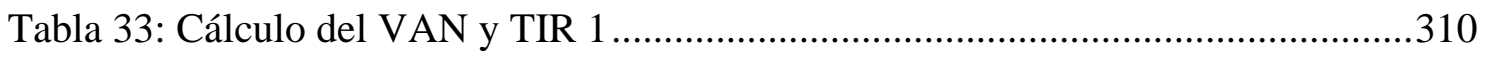

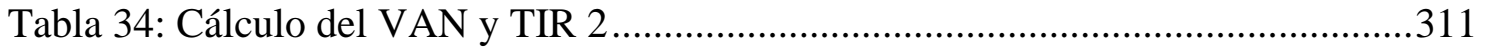

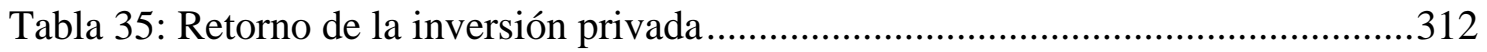

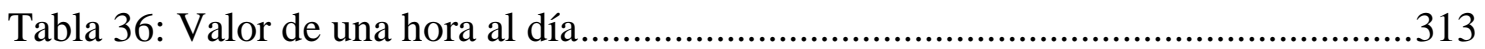

Tabla 37: Ahorro económico por reducción de tiempo de transporte ...........................314

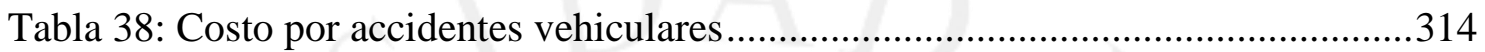

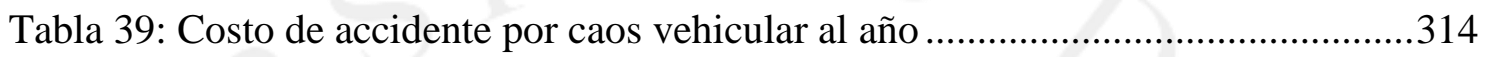

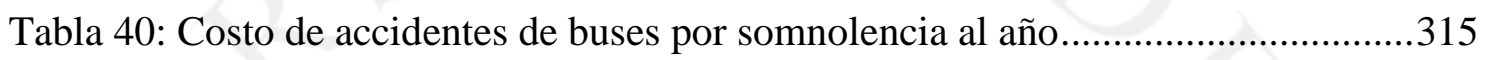

Tabla 41: Ahorro energético por absorción de CO2 …................................................315

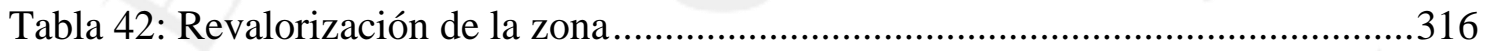

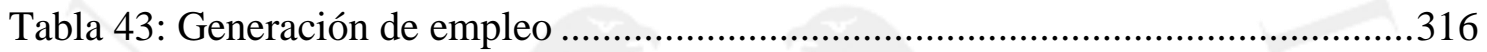

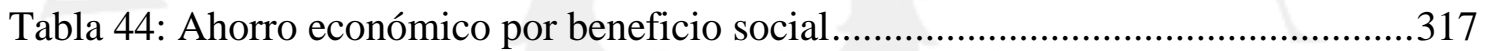

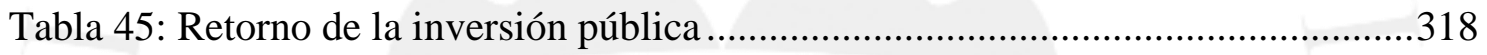

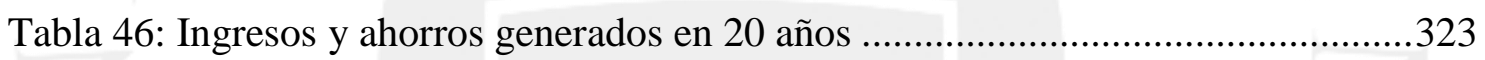




\section{INDICE DE FIGURAS}

Figura 1: Comparación de la distribución del transito...................................................20

Figura 2: Ubicación de terminales terrestres en Lima ...................................................39

Figura 3: Sistema Integrado de Transporte Urbano de Lima.........................................43

Figura 4: Repartición de terminales según tipo ..........................................................47

Figura 5: Plan Maestro de Transporte Urbano 2025 _....................................................48

Figura 6: Distribución de terminales terrestres en Lima............................................49

Figura 7: Movimiento de ingresos y salidas en Lima...............................................50

Figura 8: Rutas de transporte y ubicación de terrapuertos según PLAM2035 …............51

Figura 9: Corredores y área de influencia según PLAM2035 ...................................52

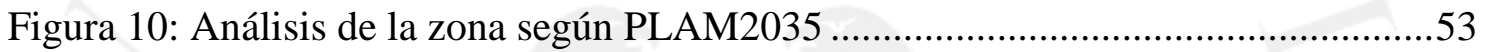

Figura 11: Nodos comerciales en zona de estudio .......................................................60

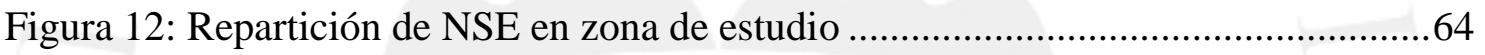

Figura 13: Concentración de establecimientos comerciales ........................................66

Figura 14: Mapa de denuncias por comisión de delitos...............................................69

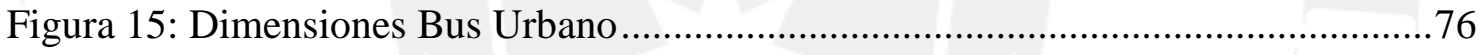

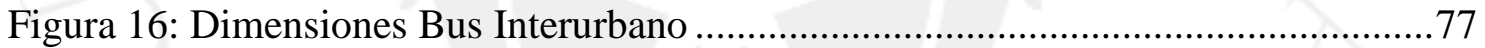

Figura 17: Pirámide de prioridades en movilidad - Evolución ........................................85

Figura 18: Cinco formas de controlar el contacto.........................................................91

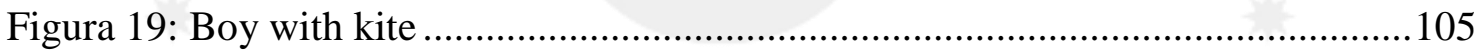

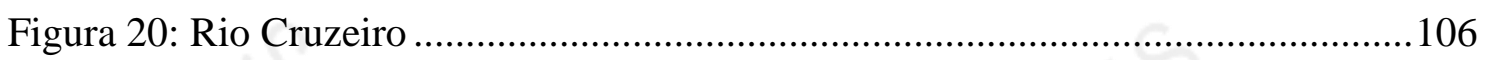

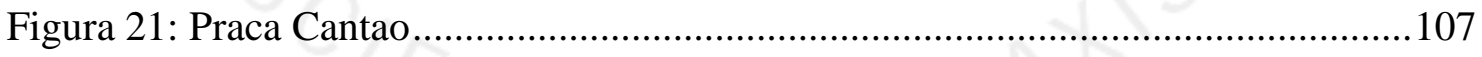

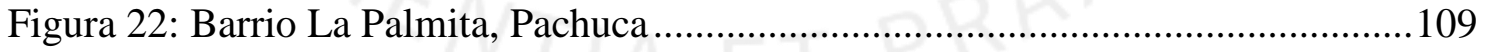

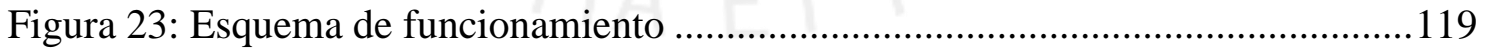

Figura 24: Consideraciones para el diseño de Bahías.................................................... 139

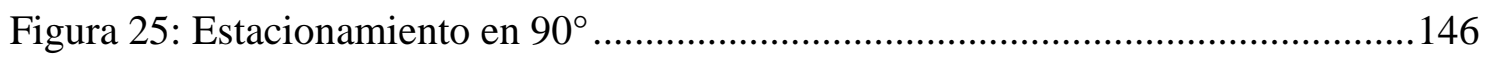

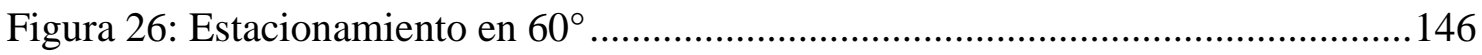

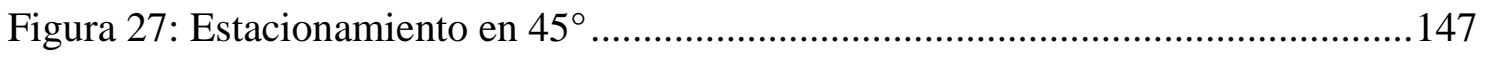

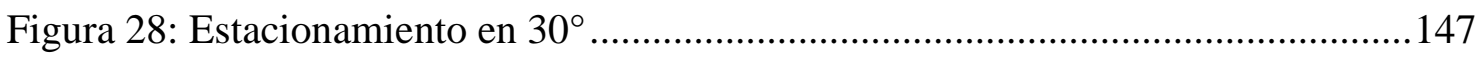

Figura 29: Patio de maniobras - Terminal Terrestre Yerbateros ..................................158 
Figura 30: Ingreso de buses - Terminal Terrestre Plaza Lima Norte. 166

Figura 31: Terminal Terrestre Cruz del Sur.

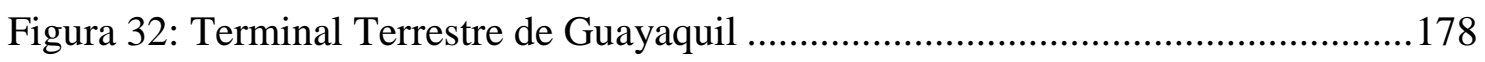

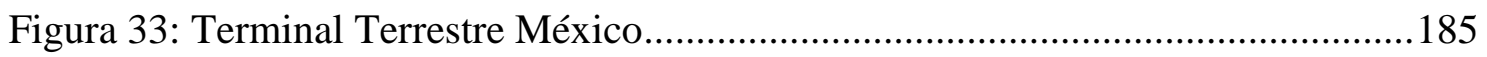

Figura 34: Terminal Terrestre de Buses en Nueva York entre 1950 y 1960 ................. 192

Figura 35: Terminal Terrestre de Buses en Nueva York hoy ..................................... 193

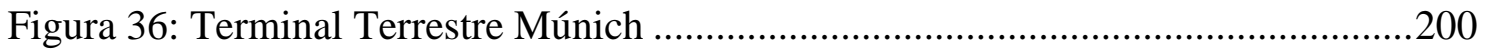

Figura 37: Espacio público - Zhengzhou Vanke Central Plaza ...................................207

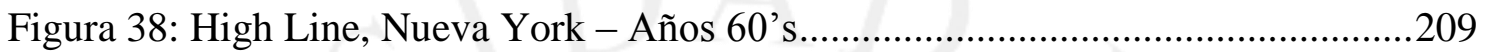

Figura 39: High Line en su estado natural y previo a la remodelación ........................210

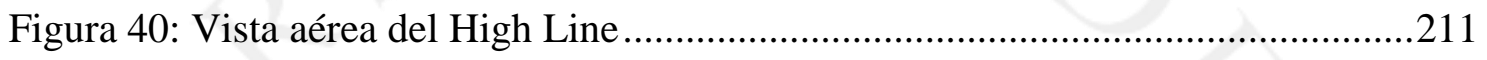

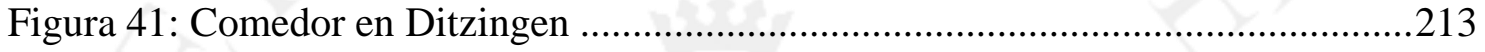

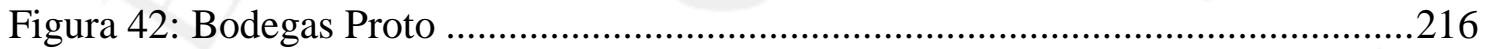

Figura 43: Dos opciones para ubicar un terminal terrestre ......................................223

Figura 44: Terreno a analizar en zona de estudio .....................................................224

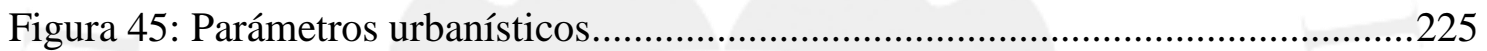

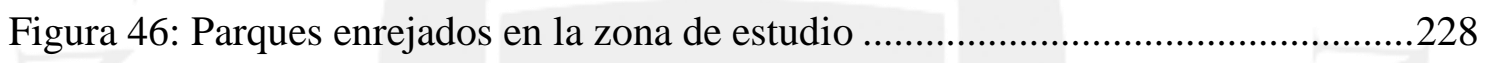

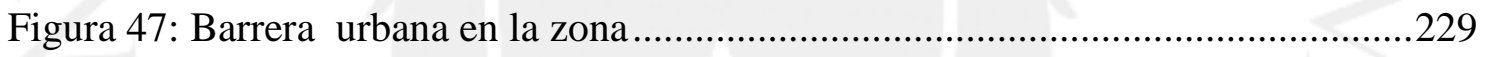

Figura 48: Bordes naturales - El Agustino y El Pino...................................................230

Figura 49: Bordes artificiales - Sección de avenidas .................................................2231

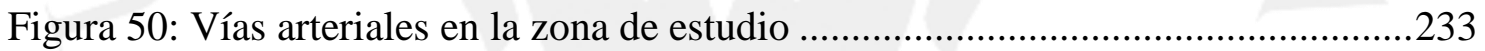

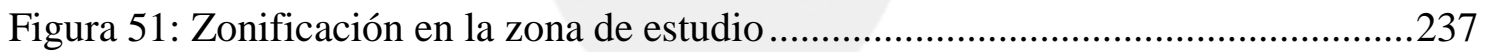

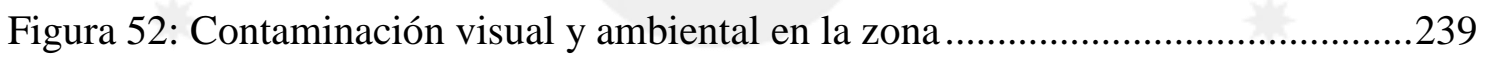

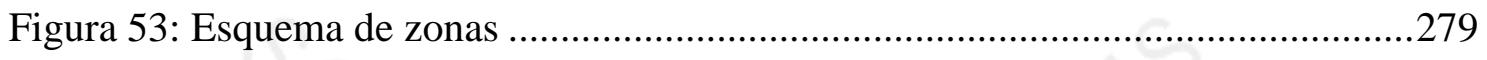

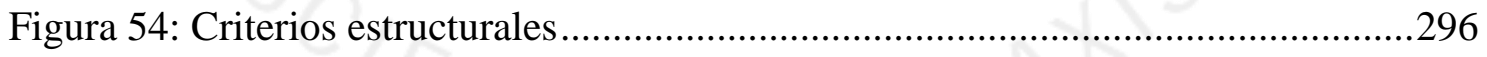

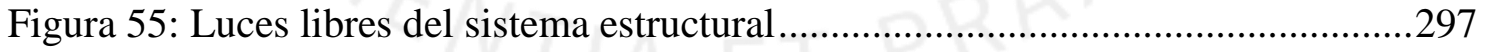

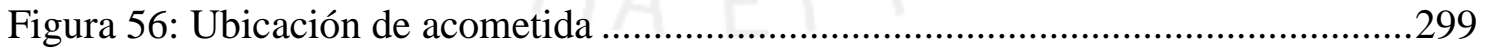

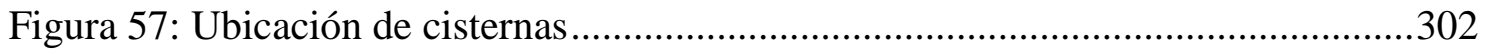

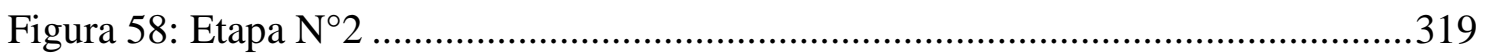

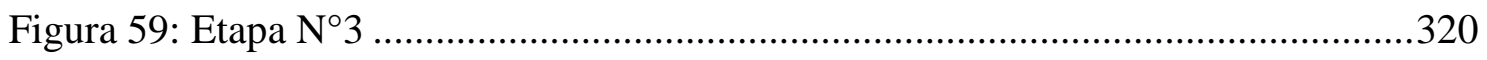

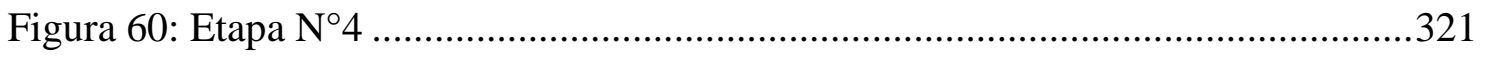

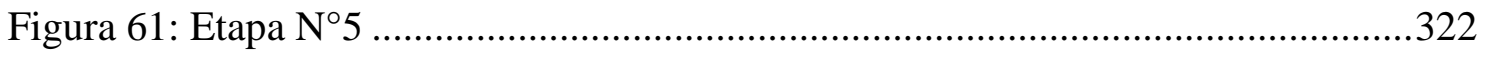

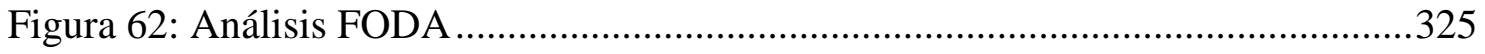




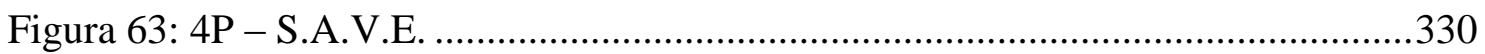

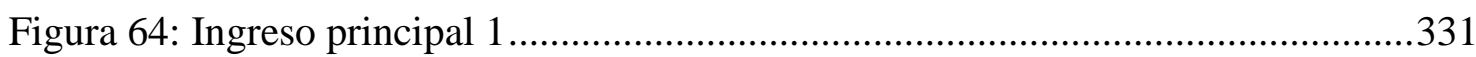

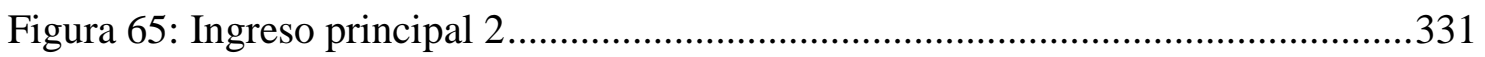

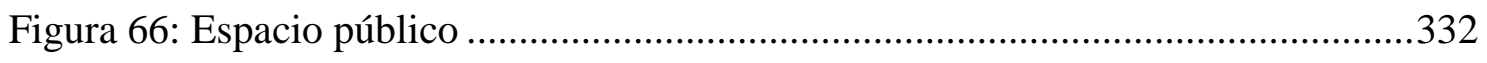

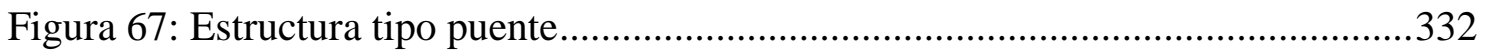

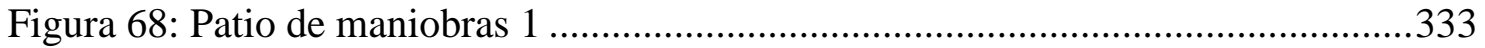

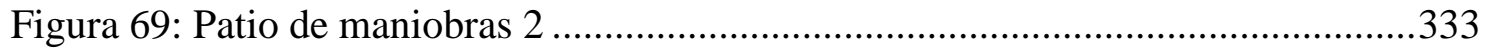

Figura 70: Anillo peatonal y edificio tectónico 1 .........................................................334

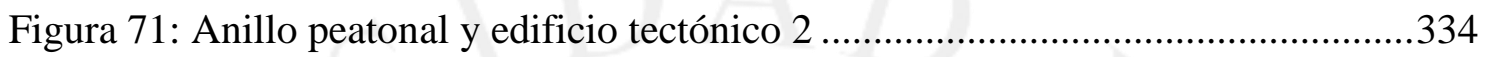




\section{INDICE DE FICHAS}

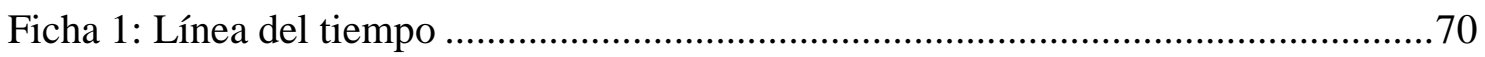

Ficha 2: Terminal Terrestre Yerbateros, Perú ............................................................. 160

Ficha 3: Terminal Terrestre Plaza Lima Norte, Perú ..................................................... 167

Ficha 4: Terminal Terrestre Cruz del Sur, Perú.......................................................... 173

Ficha 5: Terminal Terrestre de Guayaquil, Ecuador..................................................... 180

Ficha 6: Terminal Terrestre de Pasajeros de Oriente, México ....................................187

Ficha 7: Terminal Terrestre de Nueva York, EE.UU. …............................................. 195

Ficha 8: Terminal Terrestre de Múnich, Alemania...................................................201

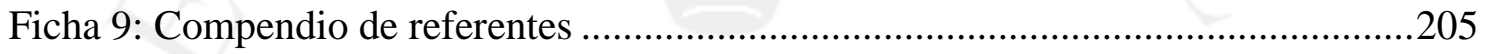

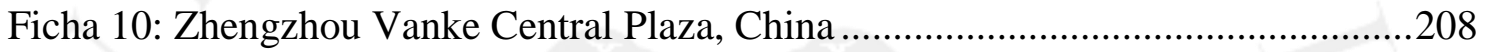

Ficha 11: High Line New York City, EE.UU...........................................................2. 212

Ficha 12: Campus Restaurant Ditzingen, Alemania ................................................2. 215

Ficha 13: Bodegas Protos de Peñafiel, España ......................................................217

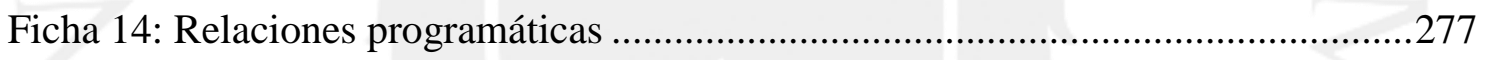

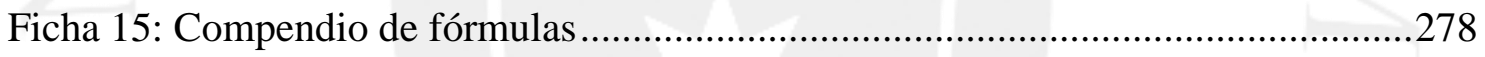

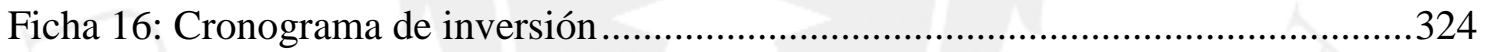




\section{INDICE DE LAMINAS}

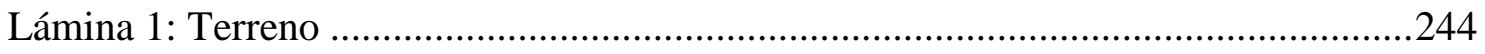

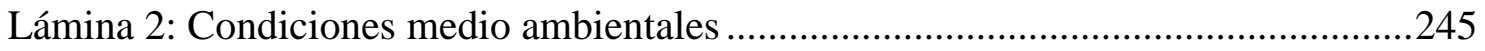

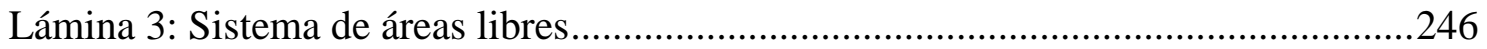

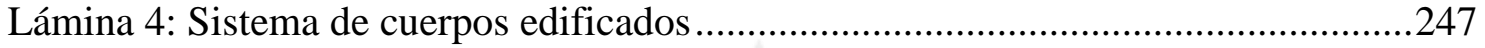

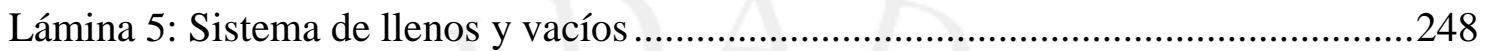

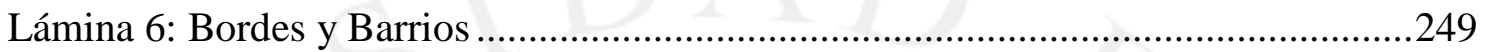

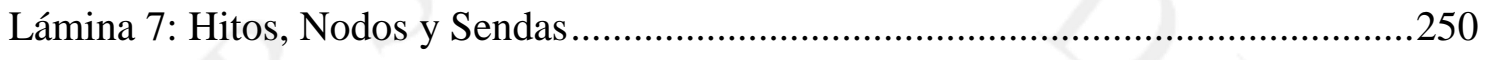

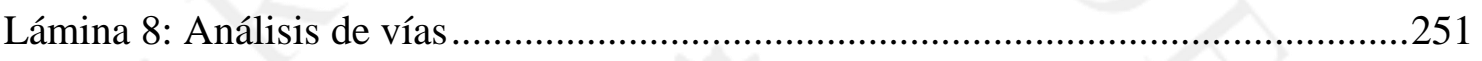

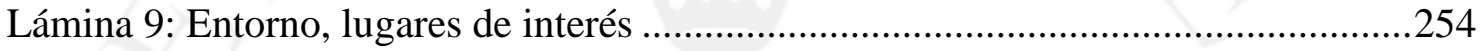

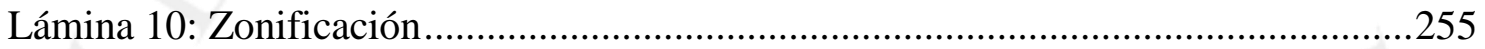

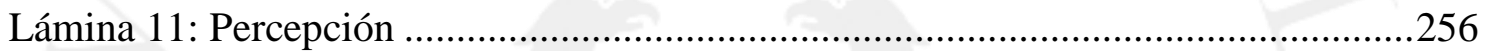

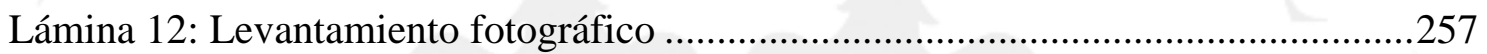

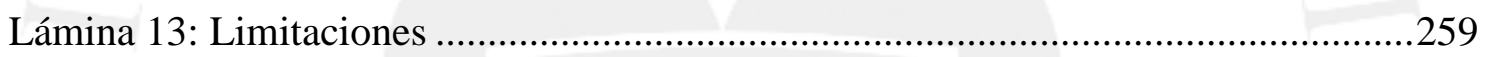

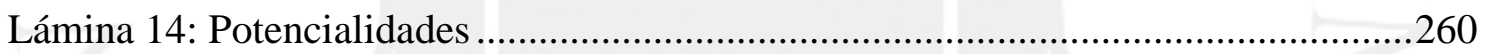

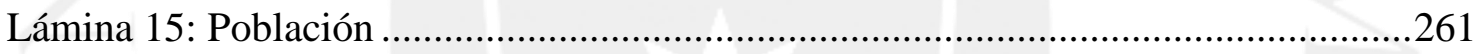

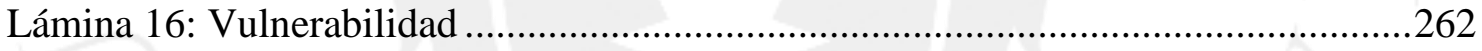




\section{INTRODUCCIÓN}

"Viajar es marcharse de casa, es vestirse de loco diciendo todo y nada con una postal, Es dormir en otra cama, sentir que el tiempo es corto, viajar es regresar."

-Gabriel García Márquez

Viajar es "trasladarse de un lugar a otro, generalmente distante, por cualquier medio de locomoción" (RAE, 2014). En países desarrollados por lo general implica movilizarse ya sea en avión, carro particular o en tren. Este último suele ser el preferido siempre y cuando los precios sean aceptables, debido a su velocidad, comodidad y eficiencia. Cuando el precio no lo permite, la siguiente alternativa es la de viajar en bus, modalidad que cada día se incrementa en los países de Europa, a pesar de ser un poco más incomodos. En países como Estados Unidos la modalidad de viaje en bus existe desde los años 30, gracias a la gran extensión de autopistas por todo el país, pero también se utilizan trenes con gran frecuencia.

Sin importar la modalidad que uno escoja, el viaje suele ser placentero, desde el momento en el que uno deja su hogar y parte hacia la estación para abordar su medio de transporte favorito. Como norma general, el caos no es parte de esta experiencia.

Caos: "Comportamiento aparentemente errático e impredecible de algunos sistemas dinámicos . . Estado amorfo e indefinido . . Confusión, desorden” (RAE, 2014).

Caos... definición acertada de Lima.

En el Perú la historia de un viaje es otra. Para empezar, las opciones son sumamente restringidas, pues se limitan a tomar un avión probablemente sobrevaluado, utilizar un auto particular o un bus... y en el peor de los casos un colectivo. 
Lamentablemente en el Perú son mínimas las vías férreas implementadas, ya que se utilizan casi exclusivamente para el trasporte de carga.

Cuando uno deja su hogar para dirigirse a la estación tiene que lidiar, en primera instancia, con el caos vehicular de la ciudad de Lima, además de varias horas de congestión en las vías. Dependiendo de la empresa de autobuses por la que uno haya optado, los resultados de la experiencia serán diferentes. Pero si uno optó por partir del Terminal de Yerbateros, sin importar la empresa, se puede garantizar que su experiencia será fuera de lo normal. En primer lugar, se accede por la carretera central, vía de la ciudad altamente caótica y por lo general congestionada con un gran porcentaje de camiones. Luego, una vez frente al terminal, surge la duda de haber efectivamente llegado al terminal correcto y no haber sido estafado por el conductor del taxi o micro.

El Terminal Terrestre de Yerbateros tiene la particularidad de no poder ser reconocido por ningún cartel ni infraestructura. Se encuentra camuflado en una edificación predominantemente rosada con el nombre "Terminal Terrestre Molina", pero a pesar de esto cualquier persona en el lugar confirmará la correcta ubicación. La segunda particularidad, es la configuración libremente integrada a la Carretera Central, que permite la confusa circulación de buses, taxis, autos e incluso personas. Pero la percepción sobre cuán caótico es el lugar, varía considerablemente según la hora y fecha, ya que bajo otras circunstancias el terminal resulta como un desierto de concreto deshabitado.

El Terminal Terrestre de Yerbateros es particular en todas sus dimensiones y a pesar de todo esto debe cumplir sus funciones como uno de los principales puntos de salida hacia la sierra y selva central. De esta manera, se convierte en un punto de encuentro para peruanos y extranjeros que emprenden o regresan de su viaje por el país.

Y así se inician los viajes por el centro del Perú. 


\section{CAPÍTULO I: GENERALIDADES}

\subsection{Tema}

Actualmente, en el distrito de San Luis, se encuentra el Terminal Terrestre de Yerbateros, también conocido como Terminal Terrestre Molina. Compuesto por un terreno de $10,000 \mathrm{~m}^{2}$, se ubica en una zona fuertemente deteriorada y carece de infraestructura adecuada para atender la demanda creciente de pasajeros. Por lo tanto, para nuestra tesis de grado queremos estudiar el correcto funcionamiento de un terminal terrestre y las estrategias necesarias para regenerar zonas degradadas. Así podremos desarrollar un proyecto idóneo que reemplazará al viejo terminal, atendiendo correctamente las necesidades de los usuarios y aportando una mejora significativa a la zona.

\subsection{Justificación del tema}

En el Perú el medio de transporte más utilizado es el terrestre. Al año ingresan aproximadamente 28 millones de personas a la ciudad de Lima mediante esta vía, es decir tres veces su población (Instituto Nacional de Estadística e Informática, 2013).

El transporte terrestre mediante autobuses es el que predomina en la región de Lima, ya que no existe transporte de pasajeros en ferrovías. Idealmente, para atender este medio de transporte, se deberían implementar tres terminales que trabajen con múltiples empresas; uno al norte, otro al este y otro al sur. En la actualidad, Lima ya cuenta con uno de estos tres terminales, que además es el único diseñado con la escala, infraestructura y estándares de calidad correspondientes: el Terminal Lima Norte. Para atender la demanda de Lima Sur y Lima Este, la ciudad cuenta con múltiples terminales dispersos, algunos informales o mal ubicados y la mayoría sin la infraestructura necesaria. Estos terminales se organizan entorno a un terminal principal: Atocongo en la zona sur y Yerbateros en la zona este. En ambos casos se trata de terminales que carecen de la infraestructura y capacidad para trabajar como terminales centrales.

Ciertos terminales, que pertenecen a empresas de mayor renombre, tienen una buena infraestructura, pero el problema es, que al haber varios y estar dispersos en la ciudad, empeoran la congestión vehicular además de generar múltiples problemas 
adicionales. La mayoría cuenta con un flujo constante de buses y se ubican en la zona intermedia entre Lima Centro y Lima Este. Por lo que, al ubicarse cerca del centro histórico, financiero y en parte del centro comercial de la ciudad, la congestión generada tiene un impacto negativo muy alto. Idealmente se debería trabajar con un terminal que se encuentre en la capacidad de atender todas las rutas de Lima Este bajo un solo techo, además de tener un sistema intermodal que lo conecte con el resto de la ciudad.

El Terminal Terrestre Yerbateros, es el punto de ingreso y salida en dirección a la sierra central más concurrido. Está ubicado de manera ventajosa pues se encuentra directamente conectado a la Carretera Central, por donde se realizan la mayoría de los viajes interprovinciales de pasajeros y carga. Predominan los viajes a la sierra central pero no se limitan a estos, ya que también está conectado de manera secundaria a las carreteras Circunvalación y Evitamiento, que también abastecen las rutas Norte y Sur. Este terminal no cumple con la infraestructura necesaria; se encuentra en condiciones precarias, desaprovechando el área a su disposición y congestionando innecesariamente la Carretera Central y demás vías que lo rodean. Sin embargo, con una buena intervención en su infraestructura, flujos, capacidad y diseño, se podrá aprovechar su ubicación estratégica y actual popularidad, para implementar un único terminal en la zona de Lima Este.

El Terminal Terrestre Yerbateros se ubica en una zona en la que abundan las vías rápidas y es un punto de convergencia de cuatro distritos: San Luis, El Agustino, La Victoria y el Cercado de Lima. Esto, sumado al caótico funcionamiento del terminal, hace que se trate de un área fuertemente fragmentada y altamente congestionada ya que no se encuentra integrada a ningún sistema de transporte público masivo a nivel metropolitano, haciendo que predomine el flujo de pasajeros mediante transporte público informal y transporte privado. La ausencia de espacio público para recrear, infraestructura para peatones y la abundancia de calles con poca actividad por su carácter industrial son características que contribuyen al deterioro de la zona, al igual que la contaminación ambiental, auditiva y visual generada por la mala gestión vehicular. Como consecuencia, la zona carece de un entorno urbano adecuado que afecta la calidad de vida de sus vecinos y genera un gran sentimiento de inseguridad ciudadana. 
Todos los argumentos previamente expuestos justifican la implementación de un nuevo terminal terrestre para Lima Este que permita recuperar la zona, buscando mejorar el servicio de transporte terrestre interprovincial y la calidad de vida de los Limeños. Por estos motivos, será necesario mejorar la infraestructura del terminal para poder organizar los flujos de buses, atender la demanda de pasajeros $\mathrm{y}$, finalmente, generar un punto intermodal que no solo atienda al terminal mismo, sino también la zona intervenida. Así se lograría aportar un servicio de calidad a los viajeros, se reduciría la congestión vial generada por este medio de transporte en diversas zonas de la ciudad y se organizaría el transporte público y privado en el área.

Finalmente, será necesario mitigar el impacto negativo que trae consigo un terminal terrestre de esta envergadura, a través de un diseño enfocado hacia el peatón, que aporte espacio público y permita solucionar los problemas del entorno urbano, reduciendo el sentimiento de inseguridad ciudadana y revalorizando la zona.

\subsection{Planteamiento del problema}

\subsubsection{Problema general}

La problemática nace con la existencia de un terminal terrestre mal implementado y carente de infraestructura, en una zona en la cual debería ubicarse un único terminal terrestre que logre agrupar todas las rutas correspondientes a Lima Este, organizarlas y ofrecer un servicio de calidad al usuario. El terminal actual genera deficiencias en el transporte interprovincial y en la calidad del servicio, pero cuenta con una ubicación estratégica, por lo que se propone la modificación y ampliación de este, aprovechando su popularidad y concurrencia. Por este motivo, el nuevo terminal deberá lidiar con un entorno urbano deteriorado y desarticulado, en el que predomina la mala gestión vehicular, la ausencia de espacio público, la deficiente infraestructura para el peatón y una fuerte contaminación ambiental, auditiva y visual.

Con estas consideraciones en mente se plantea la siguiente interrogante:

¿Es posible implementar un nuevo Terminal Terrestre en Yerbateros, que además de mejorar la calidad del servicio de transporte interprovincial y ordenar una gestión vehicular deficiente, recupere el espacio público para el ciudadano en un área conflictiva, colapsada por el caos vehicular y carente de calidad de vida, regenerando 
así el entorno urbano y mitigando la presencia de un proyecto de infraestructura de gran escala?

\subsubsection{Problemas específicos}

- ¿Por qué las mejoras obtenidas de un diseño intermodal que tome en cuenta los sistemas de transporte público masivo, son beneficiosas para un terminal terrestre?

- ¿Por qué es necesaria la combinación de un terminal terrestre con un espacio público para la regeneración de la zona a intervenir?

- ¿Es posible que un proyecto de infraestructura con un diseño de vanguardia logre revalorizar una zona y generar orgullo en el vecindario circundante, además de demostrar la preocupación y presencia por parte del estado?

\subsection{Objetivos}

\subsubsection{Objetivo general}

Elaborar una investigación en torno al transporte terrestre interprovincial que llega y sale de Lima, que nos permita diseñar un terminal con la capacidad de descongestionar la zona intervenida, mediante el agrupamiento de empresas transportistas y el ordenamiento de sus flujos vehiculares. Además, comprender sus necesidades básicas para garantizar el buen funcionamiento del terminal y su activación mediante la implementación de características intermodales y usos complementarios. Finalmente, buscará analizar las condicionantes y problemáticas de la zona para comprender la posibilidad de regeneración y beneficios que brindaría un diseño enfocado hacia el peatón mediante la implementación de espacio público.

\subsubsection{Objetivos específicos}

- Contextualizar la situación del actual Terminal Terrestre de Yerbateros y la zona en la cual se ubica y estudiar los conceptos relacionados al transporte terrestre a nivel metropolitano e interprovincial haciendo énfasis en la problemática de la congestión vehicular, para implementar correctamente estrategias de la intermodalidad. 
- Analizar la zona de estudio y su carencia de espacio público para luego estudiar los conceptos vinculados a una mejor calidad de vida en la ciudad y así determinar en qué aspectos aportaría la implementación de un espacio público.

- Estudiar teorías y casos de proyectos de infraestructura ubicados en zonas degradadas, para comprender cómo ciertas características y estrategias de diseño pueden mejorar el impacto que tendrá en la zona.

\subsection{Supuestos básicos de investigación}

\subsubsection{Del terminal terrestre}

Si se diseña un terminal de buses con las dimensiones, flujos e infraestructura adecuada para centralizar todas las rutas de Lima Este en un solo lugar, contemplando aspectos intermodales y considerando al peatón como principal usuario, se podrá mejorar la calidad del servicio ofrecido, corrigiendo la mala gestión vehicular y reduciendo la insatisfacción del usuario.

\subsubsection{Del terminal terrestre como regenerador urbano}

Si se diseña un terminal de buses enfocado en el peatón, mediante la implementación de espacio público como eje central del proyecto para generar un nodo activador, se podrá mejorar la calidad del entorno urbano y reducir la inseguridad ciudadana, convirtiendo un proyecto de infraestructura en un regenerador urbano.

\subsection{Alcances y Limitaciones}

\subsubsection{De la investigación}

\section{$\underline{\text { Alcances }}$}

- Se buscará la historia de la zona de estudio, del Terminal Terrestre de Yerbateros y del transporte en el Perú desde su fundación hasta el presente, así como teorías y conceptos relacionado al transporte y movilidad en el mundo.

- Se desarrollará un estudio de la situación actual de Lima Centro, específicamente la zona limítrofe entre el Cercado de Lima, El Agustino, La Victoria y San Luis, siendo éste último el distrito donde se ubica el proyecto. Adicionalmente se estudiarán las vías rápidas que atraviesan la zona: Carretera Central, Circunvalación y Evitamiento. 
- Se analizarán las teorías relacionadas al diseño e impacto del espacio público en la ciudad, al igual que diversos conceptos aplicados alrededor del mundo para la regeneración urbana y la mejora de zonas olvidadas.

- Se buscarán normativas y lineamientos de diversas fuentes para completar los reglamentos nacionales sobre terminales terrestres, haciendo énfasis en el pre dimensionamiento de áreas y en el programa arquitectónico requerido.

- Se buscarán y analizarán referentes con diversas cualidades para un mejor entendimiento de todas las variables, resaltando sus principales características y verificando su posible incorporación en el proyecto.

- El análisis del terreno de estudio se hará con las variables dadas por la universidad.

\section{$\underline{\text { Limitaciones }}$}

- No se indagará en el estudio de otros medios de transporte interprovincial, como ferrovías o aerolíneas.

- Para el estudio estadístico de la zona en la actualidad no se realizarán levantamientos propios. En su lugar se utilizará la información disponible en los levantamientos del INEI, IPSOS y otras fuentes.

- Debido a la falta de datos específicos e informalidad existente entre las empresas de transporte, no se podrá trabajar con base de datos exacta, ya que estos datos pueden variar dependiendo de la fuente consultada y del estudio realizado. Para calcular la demanda se utilizó un estudio del año 2003 y se proyectó al 2035 según el crecimiento poblacional de Lima. Se sabe que existen otros factores que pueden modificar este cálculo, pero al no ser conocidos no se tomaron en cuenta.

- Por la envergadura del proyecto y el tiempo disponible, no se realizará un estudio de suelo, ni estudios de impacto vial e impacto ambiental. En su lugar se desarrollarán láminas sobre la zona de estudio.

- No se pretende modificar ni establecer nuevas rutas de transporte.

- No se realizará un análisis de posibles terrenos, ya que se trata de una expansión y remodelación de un terminal existente.

- No se contemplará el proceso ni la metodología de expropiación de terrenos. 


\subsubsection{Del proyecto}

$\underline{\text { Alcances }}$

- Se trabajará con el Reglamento Nacional de Edificaciones y las ordenanzas municipales vigentes.

- Se trabajará con la información disponible de los estudios preliminares sobre la línea 2 del metro de Lima.

- Se trabajará con los parámetros municipales correspondientes al lote \#10 perteneciente a la empresa de transportes El Pino, ubicado dentro del terreno a intervenir.

- Se buscará diseñar un terminal que considere las características de su entorno y se conecte a la red metropolitana de transporte público masivo. Sin embargo, aunque el impacto del proyecto abarque una zona mayor, la intervención arquitectónica se limitará al interior del terreno establecido.

- Para el pre dimensionamiento de las áreas del terminal se utilizarán los cálculos de diseño expuestos en el marco teórico.

- El proyecto se retirará cuatro metros a lo largo del frente del terreno que limita con la carretera central dejando un carril adicional para evitar conflictos con planes futuros de expansión vial.

- Cuando se hable de infraestructura vial se referirá a las vías de circulación vehicular dentro del proyecto para buses interprovinciales y a las bahías urbanas. Adicionalmente, no se especificarán las reglas de transito ni señalética aplicadas a la infraestructura vial.

- El terminal terrestre abarcará tanto el transporte de pasajeros como de encomiendas.

\section{$\underline{\text { Limitaciones }}$}

- Debido a la necesidad de tener un parámetro inamovible sobre el cual comenzar a diseñar se tomará los datos obtenidos en el estudio de demanda como única alternativa, estos luego serán utilizados al hallar la hora punta para el cálculo de capacidad y el posterior dimensionamiento de áreas.

- Por la envergadura del proyecto y el tiempo disponible, solo se desarrollará a nivel de anteproyecto. 
- Por la envergadura del proyecto y el tiempo disponible se presentarán esquemas generales de especialidades (estructuras, eléctricas, sanitarias y mecánicas).

- El proyecto no se plantea como una estación intermodal, pero adoptará ciertas características necesarias para su funcionamiento.

- No se desarrollarán los impactos específicos que tendrá el proyecto en las edificaciones ubicadas fuera de su terreno.

- Los costos generales del proyecto y el presupuesto se realizarán con ratios de construcción, no con un listado de partidas ni costos unitarios.

- Por la falta de información disponible, en el cálculo de ingresos y egresos para el flujo de caja no se considerarán los costos operativos del terminal.

\subsection{Diseño de la Investigación}

La investigación será principalmente de tipo descriptivo, pues empezará por analizar un proyecto existente y la zona en la que se emplaza. Para esto, analizaremos fuentes secundarias de carácter cuantitativo (INEI, MTC, MINCETUR, empresas de buses, etc.) sobre el actual Terminal Terrestre de Yerbateros, como, por ejemplo: cantidad de buses, número de pasajeros, horarios, etcétera y niveles socio económicos de la población, densidad poblacional de la zona, población económicamente activa, entre otros.

Con los valores recopilados buscaremos predecir tendencias y preferencias para poder aplicarlas de manera coherente en el diseño del proyecto arquitectónico.

La investigación también tendrá un carácter teórico - conceptual de manera secundaria. Esto se dará mediante el estudio de teorías y conceptos sobre diversos temas relacionados al transporte y el espacio público. También se recopilará información de otros proyectos de la misma naturaleza, contrastando los resultados con los conceptos y teorías previamente estudiados. De esta manera, se tendrá acceso a mayor cantidad y calidad de información, la cual servirá de ejemplo para mejorar la calidad de nuestra propuesta. 


\subsection{Metodología}

\subsubsection{Forma de consulta y recopilación de la información}

Para el desarrollo de la investigación será importante investigar el transporte terrestre en Lima e indagar en su historia, configuración y situación actual. Para esto, se recopilarán datos cuantitativos, planes urbanos, información histórica, etc. En otras etapas de la investigación se tocarán temas más teóricos, conceptuales e incluso normativos, para los cuales se consultarán ciertos autores, referentes existentes, normativas locales y del extranjero. Toda esta información será recopilada de libros, bases de datos estadísticos, reglamentos nacionales y extranjeros, documentos, revistas y libros digitales, páginas web de entidades municipales y de oficinas de arquitectura, entre otros. Se buscará esta información en bibliotecas, libros propios, tesis de grado de diversas universidades e Internet. De igual forma se tendrá que hacer levantamientos propios, mediante fotografías y conteos, para poder analizar la zona de estudio.

\subsubsection{Forma de análisis de la información}

Para analizar la información recopilada será necesario revisarla, leerla, analizarla, hacer resúmenes para sintetizar ideas principales, al igual que cuadros comparativos, listas clasificatorias y esquemas. De esta manera, se podrán desarrollar los diversos capítulos, láminas de análisis, fichas y estrategias de diseño.

\subsubsection{Forma de presentación de la información}

Para presentar la información previamente procesada, se elaborarán tablas comparativas, líneas de tiempo, flujogramas, esquemas, láminas y fichas, además del texto desarrollado a lo largo de toda la investigación. Este se estructurará en forma de capítulos con subcapítulos respetando el estilo de citación y referencias de APA. La información del proyecto será representada en planos de arquitectura mediante plantas, cortes, elevaciones y detalles. En algunos casos habrá esquemas de flujos y de especialidades para complementar el proyecto, al igual que 3D’s y maquetas. 


\section{CAPÍTULO II: MARCO REFERENCIAL}

\subsection{Del Transporte a la Movilidad}

\subsubsection{Introducción a la movilidad}

Según la Comisión Europea, un $40 \%$ del CO2 y $70 \%$ de otros contaminantes producidos en el área de transporte son atribuidos a la movilidad urbana. Además, la congestión vehicular en la Unión Europea suele ubicarse dentro y en los alrededores de zonas urbanas y resulta en un costo de 100 billones de Euros al año, lo que equivale al $1 \%$ del PBI de Europa (European Comission, 2015).

Adicionalmente, se puede decir que la movilidad es una pieza importante para la urbanización. Según la ONU Habitat ${ }^{1}$, en un solo día del 2005 se realizaron 7.5 billones de viajes en ciudades a nivel mundial y calcula que para el 2050, el número de pasajeros-kilómetros que se estimaron en el año 2000, se triplicaría o cuadruplicaría si es que la infraestructura y los precios lo permiten.

Sin embargo, del nivel de movilidad que se da en todo el mundo, aún existen grandes dificultades de acceso a lugares, servicios, etc. Esto se debe al crecimiento horizontal de muchas ciudades y un modelo en el que los viajes entre zona de trabajo, colegios, ocio, comercio y vivienda cada vez se vuelven más largos. En muchos lugares, la inversión en viajes representa un tercio de los gastos del usuario y en otros trae problemáticas de exclusión social: en África existen zonas en las que el 70\% de los viajes se realizan a pie. Por lo tanto, para muchos los diversos sistemas de transporte aún son inaccesibles, ya sean privados o públicos, y/o están en malas condiciones, generando problemas de inseguridad (UNO Habitat, 2012).

Los problemas relacionados a la movilidad en los estratos con menos recursos son sumamente altos, pues resultan en una especie de círculo vicioso. Al no poder acceder a un buen sistema de transporte, resulta complicado o imposible acceder a servicios básicos como educación, vivienda y empleo. Esto reduce sus posibilidades de

\footnotetext{
${ }^{1}$ La rama Habitat de la Organización de las Naciones Unidas [ONU] busca atender problemas relacionados a los Asentamientos Humanos. El objetivo de esta organización es promover ciudades y pueblos con conciencia ambiental y sostenible, además de buscar proporcionar una vivienda digna.
} 
conseguir oportunidades para salir adelante, manteniéndolos segregados social y espacialmente.

Parte de la problemática es la manera en la que se gestiona, pues en algunos casos no se ha establecido un sistema de transporte integrado, a lo que se suma la burocracia que se genera en muchos municipios que no trabajan de forma integral, originando que el transporte sea altamente ineficiente y sumamente costoso.

Lamentablemente, la tendencia en muchas ciudades cuando hay problemas de movilidad y accesos, es ensanchar la infraestructura existente con la ampliación de autopistas y la generación de pasos a desnivel o túneles, que por lo general solo benefician al usuario del automóvil, produciendo más congestión.

"So far, the standard response to addressing urban mobility issues typically has been to increase infrastructure, mostly for cars, such as building more roads, highways, flyovers, or tunnels. Unfortunately, these developments engender a vicious circle: more infrastructure stimulates urban sprawl because access to peripheral urban areas is eased, increasing the use of cars which, in turn, calls for further infrastructure development, and so on." (UNO Habitat, 2012)

La movilidad no solo se trata de los servicios y la infraestructura del transporte. Debe ser incluida en un contexto de urbanismo, donde se planifica la ciudad, con la finalidad de erradicar barreras sociales, económicas y físicas.

Una de las soluciones al problema de la movilidad es la proyección de ciudades compactas con usos mixtos, para evitar el desplazamiento innecesario. Es sumamente importante prestarle atención a la accesibilidad y la conectividad en conjunto y no por separado (UNO Habitat, 2012). De manera breve y puntual: el ciudadano debería poder suplir todas sus necesidades reduciendo en lo posible su desplazamiento a un mínimo.

También, es de suma importancia contemplar las cualidades intermodales de los sistemas de transporte, que permitan al usuario desplazarse mediante diversas modalidades, haciendo cualquier punto de la ciudad más accesible. Esto, con la finalidad de cubrir un área más extensa de manera eficiente. 
Claramente, nada es posible sin un buen gobierno y una buena gestión pública, que facilite la transformación de la planificación urbana. Para esto, es importante la coordinación entre diversas jurisdicciones y la auditoría por parte de una entidad superior o externa, que esté a cargo de la planificación integral. Es importante el trabajo en equipo y contemplar el sistema de transporte como una gran red unificada, evitando mayores costos de infraestructura y de pasajes.

\subsubsection{Los enfoques de la movilidad en el tiempo}

"Reconocer que la movilidad urbana es un derecho ha sido una gran conquista social; entender que 'movilidad' $y$ 'transporte' no significan lo mismo es una consecuencia de esa conquista . . ." (Herce, 2009, p. 12)

Durante muchos años se ha contemplado el transporte y su infraestructura como la solución a una demanda que crece con la expansión urbana.

La ingeniería civil o de transporte ha considerado el análisis de la demanda como un enfoque importante durante muchos años, partiendo en los años 30 con la configuración del CIAM (Congresos Internacionales de Arquitectura Moderna). En estos, se estudiaba y contemplaba la ciudad mediante la separación de usos (zonas de comercio, de ocio, de trabajo y de residencia) y también se entendía el automóvil como elemento fundamental para la movilidad dentro de las ciudades, adquiriendo una gran importancia en el diseño de estas, tal como lo dice Manuel Herce, “. . . hasta el extremo de proponer soluciones formales de la ciudad que giraban en torno al espacio del automóvil ..." (Herce, 2009).

Entre 1910 y 1930 se construyen un gran número de autopistas en Estados Unidos, como resultado de una expansión urbanística en grandes ciudades como Nueva York. De igual manera, en los años 20 se construyen las primeras autopistas en Alemania, conocidas como “Autobahn” y luego en 1940 “Turnpike” en Pennsylvania. 
De esta forma, se crea un nuevo modelo de ciudad, segregada por usos y expansiva sobre el territorio. Al introducir las autopistas como una nueva infraestructura de transporte, se vuelve necesaria la disciplina que busca predecir el tráfico para luego poder fijar una capacidad específica de la vía o sustentar la ampliación de esta. Esta disciplina surge en 1944, en conjunto con la Ley norteamericana de Ayuda Federal a las Autopistas. Luego, se publica el primer manual sobre autopistas, "Highway Capacity Manual" en 1950 en Cleveland. A continuación, surge la terminología inglesa de "commuting", que se refiere al viaje pendular que se realizaba entre zona residencial y zona de trabajo. A medida que van avanzando las tecnologías, la predicción del tráfico se vuelve cada vez más fácil y accesible a nivel mundial, convirtiéndose en una disciplina internacional.

La gran desventaja es que toda esta evolución se da principalmente entorno al uso del automóvil y por lo tanto se concibe de una manera que hoy categorizamos como insostenible: se buscaba ampliar la infraestructura y las redes, aumentando su capacidad, llevando a la dispersión de manera horizontal y extensa de la ciudad, en vez de optar por una manera más compacta. Por consecuencia, el mayor desplazamiento de los automóviles genera un mayor consumo de energía, en su mayoría no renovable.

Como se mencionó anteriormente, la manera tradicional de suplir con infraestructura a una ciudad, es partiendo del análisis de demanda: se analiza una actividad en algún punto de la ciudad, se entiende que esta genera una serie de relaciones y finalmente, analizando estas con diversas metodologías y estimando un pronóstico a futuro, se propone la modificación, implementación o ampliación de aquella infraestructura. Lamentablemente, este enfoque, al simplemente buscar satisfacer una demanda existente, dispone de recursos como si fueran infinitos.

Como resultado, surge una ciudad que está repartida e incluso fragmentada de manera funcional, generando áreas con un uso de suelo específico como ciudades dormitorio, centros de trabajo; lo cual en efecto multiplica los viajes realizados y congestiona las entradas y salidas de estos diferentes centros.

Según Herce (2009), la planificación de la movilidad debería tomar un rumbo similar al de suministro de agua y energía, que se basa en que la disponibilidad del recurso determinará la planificación. Es decir, revertir la línea de pensamiento: primero considerar la infraestructura y sus capacidades, luego entender las actividades y sus 
relaciones con la finalidad de reducir costos energéticos, contaminación ambiental y gestionar "el espacio" sin dejar zonas marginadas o desatendidas. Este enfoque "de oferta" se está aplicando en la actualidad en aquellos países que buscan cambiar su modelo de hacer ciudad.

"El enfoque denominado "de oferta” supone entender que la localización de las actividades, y el modo y la cuantía en que manifiesten en el futuro sus interrelaciones, dependen de la forma y organización que se dé a las redes de infraestructuras, e incluso de su gestión, porque de ella puede depender el funcionamiento del sistema.” (Herce, 2009, p. 97)

La gran problemática con el cambio de modelo, es la resistencia por parte de la administración. Esta suele mantenerse con el enfoque antiguo, que responde a una demanda existente, proponiendo la ampliación de vías, entre otros. A esto se le debe agregar la problemática generada por la sociedad misma, que exige la ampliación de carriles y extensión de infraestructura vial, pues ya es casi un tema cultural considerar que esa es la única solución al problema del transporte. Esto es lo que sucede actualmente en la ciudad de Lima, en la que la población, en una gran mayoría, demanda la ampliación de las vías de transporte porque es la única solución que conocen. En muchas ocasiones, el gobierno municipal y regional responde a esta exigencia del ciudadano para mantener su aprobación alta y no asumir riesgos desconocidos. Sin embargo, el municipio debería ser aquella entidad capacitada integralmente para indicar al ciudadano cuál es efectivamente el mejor camino a seguir. Aquello que el ciudadano exige no es siempre lo que la ciudad necesita (M. Alegre, comunicación personal, 2015).

La privatización del transporte colectivo es otro tema latente en ciudades de América Latina, ya que se termina utilizando un sistema mixto entre concesiones del gobierno y empresas privadas donde predomina la informalidad. La privatización de tareas públicas no es el problema, pues en la teoría, la entidad pública debe hacerse responsable de la planificación y la organización del sistema, cediendo la gestión al privado. Sin embargo, esto no se aplica en la práctica, dejando a las cooperativas, 
empresas y sindicatos funcionar como entes afiliados o asociación de transportadores (Montezuma, 2003).

"La actual metrópolis semicompacta se caracteriza por el déficit de infraestructuras de transporte, el aumento explosivo del automóvil y el funcionamiento deficiente del transporte colectivo. Los precarios sistemas de organización y gestión... ( (son producto) de la incapacidad de la administración pública para organizar, controlar o dirigir el transporte . . .” (Montezuma, 2003, pp. 185-186)

En el nuevo enfoque de movilidad de Manuel Herce, se entiende que las redes son el motivo de existencia del espacio, pues al conectar puntos de manera eficiente, logra sustentar el espacio generando la aparición de actividades. Es decir, el territorio se concibe de manera dinámica, gracias a la red vial compleja que refuerza algunos puntos con mayor conectividad.

“Las redes están generadas por la existencia de relaciones entre los puntos, pero la característica reticular esencial es que las relaciones se expresan a través de flujos . . que se manifiestan materialmente a través de las infraestructuras físicas de las redes. . . . La noción de red - asociada a una visión de la ciudad como un sistema estable de actividades relacionadas entre sí de forma que su comportamiento global depende de esas relaciones - ha sido una constante en el planeamiento y en el dimensionado de las redes de infraestructuras desde los años 1960.” (Herce, 2009, p. 53)

Tomando todo esto en cuenta, es importante que las políticas de inversión consideren que no solo se trata de una infraestructura de transporte, sino que también repercuten en la organización del espacio, dándoles cualidades de centralidad o marginalidad. Es decir, tienen en sus manos la capacidad de revitalizar o degradar los espacios en términos económicos y sociales. 
La siguiente tabla resume las principales diferencias entre los conceptos de transporte y movilidad y su evolución en el tiempo.

Tabla 1: Evolución del concepto de transporte vs. movilidad

\begin{tabular}{|c|c|}
\hline \multicolumn{2}{|c|}{ Transporte vs Movilidad: } \\
\hline Pasado & Actualidad y planes a futuro \\
\hline $\begin{array}{l}\text { Enfoque para la planificación de vías y ciudad: Demanda -> } \\
\text { Acción | Esto quiere decir que se analizan las actividades } \\
\text { existentes y sus relaciones para luego proponer la infraestructura } \\
\text { nueva o las ampliaciones. }\end{array}$ & $\begin{array}{l}\text { Enfoque para la planificación de vías y ciudad: Oferta -> Acción } \\
\text { Esto quiere decir que primero se considera la infraestructura vial } \\
\text { existente y sus capacidades para luego determinar la } \\
\text { planificación. }\end{array}$ \\
\hline $\begin{array}{l}\text { Categorizaciones para la planificación del trans porte: Viajes "por } \\
\text { obligación" y "viajes no obligados". Dentro de este último se } \\
\text { incluían actividades como realizar compras, dejar hijos en la } \\
\text { escuela, etc. }\end{array}$ & $\begin{array}{l}\text { Categorizaciones para la planificación del transporte: No deben } \\
\text { ser categroizadas ni jerarquizadas, ya que no existen tareas más } \\
\text { importantes que otras. Cualquiera actividad tiene gran } \\
\text { importancia para las relaciones e interacciones que se deben dar } \\
\text { en una ciudad }\end{array}$ \\
\hline $\begin{array}{l}\text { Automovil es vis to como elemento principal del transporte: se } \\
\text { prioriza su uso, las vias, estacionamientos, etc. Antes que } \\
\text { cualquier otro medio. }\end{array}$ & $\begin{array}{l}\text { Automovil pasa a ser el menos prioritario: antes que este figuran } \\
\text { los peatones, ciclistas, transporte público masivo, transporte de } \\
\text { carga y finalmente el auto particular. Se prioriza el espacio } \\
\text { peatonal, la pacificación de las calles, reductores de velocidad, } \\
\text { zonas si acceso automovilístico, etc. }\end{array}$ \\
\hline $\begin{array}{l}\text { Se hablaba del transporte y la movilidad como temas similares, } \\
\text { relacionados a lo mis mo }\end{array}$ & $\begin{array}{l}\text { Se habla del transporte de manera diferenciada de la movilidad, } \\
\text { ya que la segunda abarca las maneras más autónomas para } \\
\text { desplazarse además de contemplar el gasto energético y la } \\
\text { recuperación del costo invertido }\end{array}$ \\
\hline
\end{tabular}

Fuente: Manuel Herce (2009) y Ricardo Montezuma (2003)

Elaboración propia

\subsubsection{Cambiando la manera de hacer ciudad}

Cada vez más el cambio de pensamiento que está surgiendo busca evitar la exclusión social de las personas, tomando en cuenta todas las maneras de desplazarse al igual que los motivos para esto. De igual manera, se contempla la flexibilidad, el acceso y el costo. Una crítica al modelo tradicional de contemplar la movilidad, es que reaccionan a un síntoma, en vez de buscar las causas y por consecuencia predomina el automóvil, dejando de lado el pensamiento de ahorro energético y reducción de emisiones contaminantes.

Al inicio del capítulo, se menciona que existe una diferencia entre los conceptos de movilidad y transporte, al igual que en las tendencias a lo largo del tiempo y cómo han ido evolucionando. Cuando uno habla de transporte, implica el dispendio de energía y la búsqueda de una estrategia que recupere el costo invertido, pero cuando se 
habla de movilidad, incluye hasta las formas más autónomas de desplazamiento, como el ciclismo o movilizarse a pie. Este tema lo profundizaremos en el Marco Teórico ${ }^{2}$.

Parte de esta nueva tendencia de ver la ciudad y la planificación del transporte, descarta la metodología con la que se estudiaba el transporte anteriormente. Hoy no basta con contemplar los motivos de viaje ${ }^{3}$ y el medio que se utiliza, pues se considera que la jerarquización de tareas no contempla la igualdad socio-cultural en la ciudad. Hoy en día se entiende que la jerarquización de tareas no debe existir pues la interacción a nivel ciudad es igual de importante:

“. . . la ciudad se caracteriza por ser el lugar por excelencia de la relación social; pero, además, porque la realización de la mayoría de las necesidades derivadas de ese hecho depende del tratamiento que se dé al espacio público, al espacio de todos." (Herce, 2009, p. 11)

Además, hay un tema socio-económico que se debe contemplar al hablar de los desplazamientos dentro de la ciudad:

"El número de desplazamientos producidos en una ciudad depende de muchos factores, pero principalmente de la complejidad de las relaciones humanas, que aumentan con el progreso económico y social y con el acceso a la información por parte de los ciudadanos." (Herce, 2009, p. 29)

Es decir, el número de viajes dependerá del estrato social, ocupación y definitivamente la cultura, por lo que solo se puede estimar, para el mundo occidental un promedio de 3-3.5 viajes al día por persona (Herce, 2009).

\footnotetext{
${ }^{2}$ Ver capítulo 3.2: Sobre la intermodalidad.

${ }^{3}$ Anteriormente los motivos de viaje se categorizaban bajo dos grupos: viajes por obligación (es decir trabajo o educación) y viajes no obligados (por ocio o recreación). Dentro de la categoría "por obligación" no se contemplaban muchas actividades como llevar los niños al colegio, hacer compras, etc. que son igual de cotidianas y necesarias que otras.
} 
Al comparar el número de viajes dentro de la ciudad 40 años atrás con la actualidad, se entiende que ya no existen picos definidos y el número de viajes se extiende a lo largo del día, de una manera más homogénea (ver Figura 1). Esto está relacionado a todos los factores previamente mencionados, factores humanos que no se controlan y que además han cambiado según época, cultura etc. Por ejemplo, en épocas pasadas, los horarios de trabajo eran más "tradicionales" y estandarizados. Hoy en día vivimos en una sociedad tan distinta, en la que los horarios de trabajo varían según modalidad de empleo como por ejemplo el freelance ${ }^{4}$. Esto hace que los desplazamientos sean cada vez más difíciles de estimar y proyectar.

Figura 1: Comparación de la distribución del transito

Evolución desde 1977 de la distribución del tránsito a lo largo del día, según motivos.
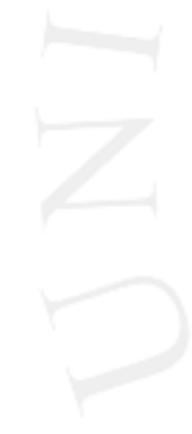

Años 70 's
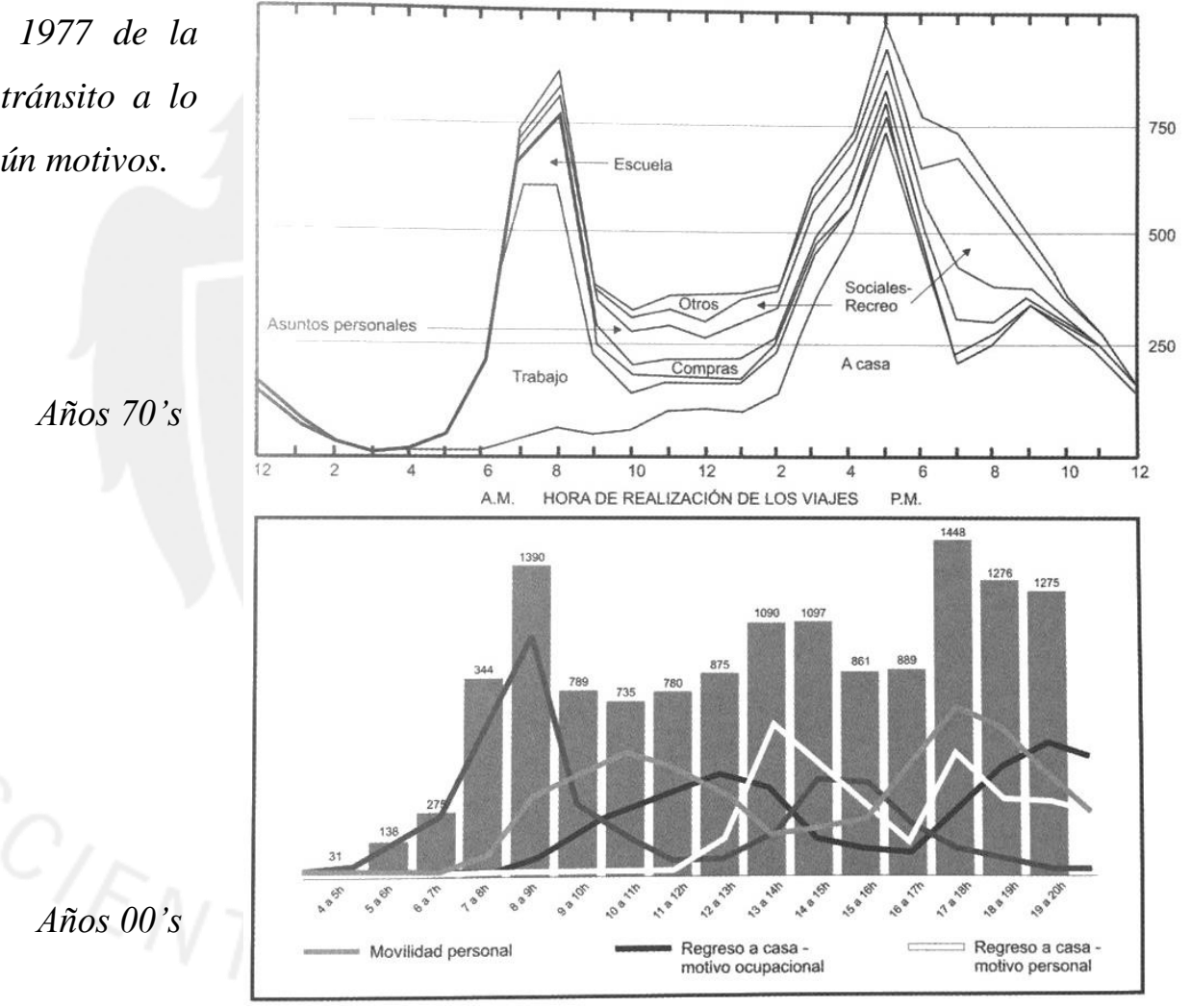

Fuente: Manuel Herce (2009, p. 33)

4 "Persona que trabaja independientemente en cualquier actividad” (RAE, 2017). 
Hoy en día, la movilidad también contempla aspectos de espacio urbano, minimización del consumo energético, entre otros y busca facilitar el intercambio de información y relaciones.

A la vez se debe priorizar viajes a pie, en bicicleta, transporte público masivo, sin dejar de lado la necesidad de conexión social. Para alcanzar un modelo que cumpla con estas características, es importante gestionar los usos de suelo y la oferta de transporte. Esto en sí no es novedoso, sin embargo, su enfoque sí lo es.

"Por eso el plan de movilidad es, antes de nada, un instrumento de reflexión sobre la ordenación urbana y sobre el crecimiento de la ciudad; y por eso la mayor parte de sus determinaciones tienen que ser físicas, tienen que afectar al acondicionamiento del espacio público urbano puesto al servicio de un modelo de movilidad." (Herce, 2009, p. 125)

La pacificación de las calles es otro concepto a estudiar, este tiene como finalidad la reducción de la velocidad e incluso la reducción de la presencia de automóviles en ciertas zonas de la ciudad. Es decir, lo que se busca es generar un ambiente seguro para el peatón u otros medios como la bicicleta. Para esto hay diferentes técnicas o maneras de realizarlo: pasos elevados para peatón, dificultar la circulación del automóvil a través de una calle con curvas u obstáculos, etc.

También, es importante contemplar la presencia de estacionamientos para automóviles, regularlos y reducirlos. Se acepta la presencia de estacionamientos en su origen, es decir en la vivienda, así como en estaciones intermodales donde se facilite el cambio de modalidad de transporte. Sin embargo, es importante considerar la reducción de estacionamientos en las calles de la ciudad con la finalidad de ampliar el espacio del peatón, ciclista u otros.

Herce discrepa con muchos profesionales y asegura que la reducción del número de estacionamientos por edificio de vivienda es inútil, pues el usuario al fin y al cabo va a ingeniarse la manera para guardar su carro ya sea en playas de estacionamiento o en espacios de la calle. La reducción del uso del automóvil no debería darse mediante la restricción de facilidades, si es que no se contempla un sistema alternativo que facilite 
el transporte, sino que finalmente el usuario opte voluntariamente por ese medio alternativo. Además, lo que se busca es que el desplazamiento con el automóvil sea minoritario, pero para eso es necesario tener "puntos de acopio", de manera que sea fácil dejar el automóvil y optar por un sistema de transporte eficiente e integrado.

Es preciso diferenciar el automóvil para uso privado de aquel que sirve como suministro para las diferentes funciones de la ciudad. Aquellos medios que buscan entregar víveres, encomiendas o incluso la limpieza, deben ser regulados teniendo cuidado en no exceder las limitaciones de ingreso o circulación por la ciudad, pues podría afectar el desempeño económico y comercial de ésta.

"Potenciar el uso del transporte colectivo es el verdadero desafio de la movilidad urbana y constituye, por tanto, el asunto que ha de concentrar más esfuerzos en las políticas de fomento de una movilidad sostenible. De hecho, el objetivo fundamental de un plan de movilidad urbana es conseguir que la gente vuelva a caminar para desplazamientos cortos y use el transporte colectivo para desplazamientos más largos.” (Herce, 2009, p. 198)

Lograr motivar al ciudadano a caminar más es cuestión de habilitar la infraestructura para el peatón, aplicando la pacificación ${ }^{5}$ de las calles y reduciendo la inseguridad con respecto a automóviles. También se trata de trabajar caminos agradables con posibilidad de otras actividades.

Por otro lado, implementar el transporte colectivo es de mayor complicación ya que implica costos más altos, inversiones de largo plazo y por supuesto la incomodidad de las obras durante un período de tiempo.

El transporte público abarca varias modalidades: ferrocarril, metro, tranvía, autobús intermunicipal, autobús urbano, microbús de barrio, funiculares, ascensores o escaleras mecánicas, taxis de diversos tipos, etc.

\footnotetext{
${ }^{5}$ La pacificación de las calles tiene como finalidad la reducción de la velocidad e incluso la reducción de la presencia de automóviles en ciertas zonas de la ciudad.
} 
El transporte también incluye los autobuses regionales que en algunas ciudades son un rezago del pasado, pero a pesar de eso son la única opción de transporte regional o interprovincial. Por otro lado, diversas ciudades ya cuentan con líneas de ferrovías para atender esa demanda.

Pero incluso en aquellas ciudades que cuentan con trenes regionales, el transporte terrestre en bus se está popularizando por diversos motivos. El más importante es el precio. En Alemania, la "Deutsche Bahn" es la línea de trenes regionales que llega a cada rincón del país. Durante muchos años era la única opción para ir de una ciudad a otra en transporte público. Los precios no eran baratos, pero eran asequibles y con tratos especiales para estudiantes, menores de edad y adultos mayores. Hoy, con la introducción de empresas de buses que realizan viajes entre ciudades, la "Deutsche Bahn" no puede competir. Los buses ofrecen una comodidad similar y la diferencia de precio es significativa. La única desventaja de viajar en bus es la duración; más larga, y en ciertas zonas menos desarrolladas la seguridad; al estar en una autopista, los riesgos son más altos que en un tren.

Cabe mencionar que algunas metrópolis siempre tuvieron una gran presencia de transporte regional en buses, como por ejemplo en la ciudad de Nueva York en 1939, en la cual la congestión vehicular se enfatizaba con la presencia de buses que abastecían viajes regionales. Múltiples empresas de buses contaban con terminales en diferentes partes de la ciudad, por lo que los buses circulaban por varias partes de ésta, generando tráfico innecesario.

En el caso de Nueva York, esta problemática fue atendida por la entidad a cargo de infraestructura de terminales y transporte de EEUU: "Port Authority", en este caso específico el "Port Authority of New York and New Jersey". Se negoció con las empresas privadas y se implementó un terminal terrestre central junto con un acceso directo desde una vía rápida, para reducir la circulación y presencia de estos en la ciudad (Port Authority of NY \& NJ, s.f.).

En otros casos, como la ciudad de Lima y otras ciudades en todo el mundo, el ordenamiento de terminales nunca sucedió. Dependiendo de la configuración de la ciudad, esto se convierte en un problema, ya que en varias ocasiones se trata de terminales ubicados en el centro de la ciudad, cuyo acceso es mediante calles angostas y/o antiguas. 
Según Manuel Herce, los terminales se deben estructurar de manera racional con una buena jerarquía clara en la movilidad: “. . . el autobús interurbano debe llegar a estaciones terminales donde se ha de garantizar una buena transferencia a otros modos de desplazamiento, entre los que es prioritario el autobús de la red urbana." (Herce, 2009, p. 206).

El encuentro intermodal entre estos debe tomar en cuenta la buena/fácil conexión tanto a nivel "sistema" como física, tomando en cuenta al peatón, ciclista y las tarifas correspondientes. También es importante la posibilidad de estacionar autos privados, incentivando y facilitando el cambio de modalidad de transporte.

Se podría concluir enfatizando en la necesidad de estructurar y gestar un plan, tomando en cuenta los efectos de una acción sobre la otra y sus consecuencias.

“La gestión de programas y actuaciones tendentes a garantizar el ejercicio de ese derecho a todas las personas es una tarea de la Administración pública, hoy en día exigida en todas las sociedades democráticas como un imperativo que se ha ido acrecentando aceleradamente en los tiempos recientes. Ha contribuido a ello una conjunción del hartazgo colectivo respecto al tiempo y la molestia asociados a los desplazamientos urbanos, con la mayor conciencia sobre los costes ecológicos y energéticos que conlleva el modelo imperante de atención a la movilidad de personas y mercancías." (Herce, 2009, p. 51)

\subsection{El transporte terrestre en el Perú}

En el Perú, el transporte terrestre ha tenido que superar una serie de barreras físicas desde sus inicios. La geografía tan diversa del país hace dificultoso el viaje en cualquiera de las direcciones. La costa, con extensos desiertos y salpicada de valles además de un literal ondulante lleno de acantilados, no es la más complicada, razón por la cual la capital del virreinato del Perú, la actual ciudad de Lima, decidió fundarse en la costa central. En la sierra, una cordillera de montañas hostiles y condiciones climáticas difíciles limitan drásticamente las posibilidades de atravesar el país de este a oeste y viceversa. Finalmente, la selva, una Amazonía densa y constantemente interrumpida por ríos, con abundantes lluvias e inundaciones posee un territorio 
mutante y cambiante de acuerdo a las condiciones geográficas de las estaciones por lo que hace terriblemente difícil una planificación del transporte.

Sin embargo, estas condiciones no eran limitaciones en la época del imperio incaico. Todo obstáculo tenía una manera de ser superado, ya sea mediante terraplenes, escaleras de piedra o puentes colgantes de soga y fibra vegetal. En la costa y en la sierra, los caminos eran indicados con postes y las rutas estaban preparadas para ser utilizadas por personas o llamas (Paz Navarro, Tuesta Serrano, Graziani Torres, \& Reginaldo Medina, 2010). Estos "Caminos reales" o "Qhapaq Ñan” (Coronado Díaz, 2012) eran rutas que tenían como propósito controlar, conectar y ayudar a la administración de los pueblos dominados durante el incanato, además de servir para el paso de los chasquis o mensajeros quienes mantenían informado al inca de lo que sucedía en los cuatro suyos. Lograron desafiar la geografía complicada, generando peldaños con piedras cuando se volvía muy empinado o atravesando cuencas y cañones con puentes tejidos en soga. Estos puentes se convertían en responsabilidad de la comunidad aledaña, siendo su deber mantenerlas en buen estado y hacer las reparaciones necesarias. El transporte de carga se realizaba sobre la espalda de hombres o sobre llamas, pero en vista que la llama tenía mayor capacidad de carga, muchos caminos estaban diseñados especialmente para esta. Las llamas soportaban una carga máxima de $20 \mathrm{~kg}$, por lo que se limitaba al transporte de carga, mas no de pasajeros. Además, se trata de animales bastante lentos que solo cubren unos 15 a $20 \mathrm{~km}$ al día. Sin embargo, unos ocho hombres podrían hacerse cargo de aproximadamente 100 llamas. A lo largo de los caminos existían los tambos ${ }^{6}$ que eran ubicados a una distancia correspondiente a un día de viaje (Coronado Díaz, 2012).

Con la llegada de los españoles, se introduce el caballo y la mula. Con esto se amplían las posibilidades de carga y poco a poco se van introduciendo diferentes tipos de carretas, ya sea para transportar minerales de la sierra, a la costa o transportar pasajeros. Los diferentes tipos de transporte de pasajeros variaban según el estrato social, su propósito y distancia. Los caballos servían para viajes más cortos y las carretas eran utilizadas cuando se trataba de viajes más largos. Durante la época de la

\footnotetext{
${ }^{6}$ Posada o tienda rural ubicada a lo largo de un camino, que sirve para atender a viajeros. Tiene orígenes en la época del imperio incaico donde se utilizaba principalmente para atender al Inca, chasquis y en ocasiones para cumplir propósitos militares y administrativos.
} 
colonia, debido a las dimensiones de las ciudades, no se gestionaba un sistema de transporte público definido. Se solía caminar, andar en caballo o incluso en carrozas cuando se trataba de familias nobles o adineradas. En esta misma época aparece el “palanquín”, una silla con cobertor que servía como medio de transporte principalmente para mujeres y era jalado por dos o cuatro sirvientes. Cuando se trataba del transporte de carga de larga distancia, el medio favorito era la carreta. Ensamblada con madera, cuero, ruedas de dos metros de diámetro, una zona de carga y otra para el "piloto", era jalada por 4 o 6 bueyes. Como transporte de carga también se utilizaban las mulas, sobre todo cuando se trataba de caminos dificultosos principalmente en la sierra (Paz Navarro, Tuesta Serrano, Graziani Torres, \& Reginaldo Medina, 2010).

\subsubsection{La historia del transporte terrestre en Lima}

En 1556 en la Ciudad de los Reyes que más tarde se conoció como Lima, se impuso la primera norma con preocupación medio ambiental, donde se especificaba que el transporte de carga y pasajeros se debería restringir a ciertas rutas. Otras no estarían habilitadas ya que las carretas malograrían las acequias que solían ir a lo largo de los caminos. Esto se debía a que el peso excesivo de estas eventualmente rompería el talud de contención de los caminos, lo que bloquearía las acequias.

Para 1851, el primer ferrocarril había llegado a Lima, conectando el Puerto del Callao con el Cercado de Lima y para 1908 ya se utilizaban 15 rutas. Hubo varios proyectos para conectar puntos importantes de provincia mediante ferrovías, sin embargo, la mayoría no fueron construidos por diversos motivos. Las ferrovías en Lima funcionaban con caballos y eran denominadas como "tracción a sangre". Luego fueron reemplazadas por energía eléctrica y en 1965 son suspendidas de manera definitiva, pues el costo competitivo de la gasolina hacía más rentable la implementación de buses (Coronado Díaz, 2012).

Para entonces habían surgido las primeras empresas de transporte terrestre de pasajeros en bus: “Agencia Ñapo", "Estación Sol”, "Empresa Bernales”, "Empresa América", "Empresa de Transportes Mendoza", etc. Sus destinos incluían Trujillo, Huaraz, Casma e Ica, entre otros. Anteriormente, en 1920, se había promulgado la ley No4113: Ley de Conscripción Vial o también conocida como "la mita republicana". Esta forzaba a todos los hombres entre 18 y 60 años a trabajar en la construcción de las 
carreteras, caso contrario recibirían multas. Sin embargo, se crearon excepciones, exonerando a diferentes profesionales, personas con ciertas nacionalidades o pertenecientes a diversos grupos. La ley tuvo constantes irregularidades y en efecto no culminó ninguna carretera en los primeros 8 años de trabajo y finalmente, la ley fue derogada en 1929 (Coronado Díaz, 2012).

Durante el gobierno de Leguía se implementaron aproximadamente 18,000 km de carretera que abastecían el norte, sur e incluso alcanzaban zonas centrales y de la Amazonía.

Es importante contemplar el proceso normativo relacionado a los terminales terrestres, ya que son el origen de la situación actual sumamente caótica. En 1941 se introduce la primera normativa relacionada directamente a los terminales terrestres interprovinciales. Esta permitía que las empresas transportistas operaran sin una infraestructura y se les autorizaba hacer uso de la vía pública. En esa época Lima no era una ciudad tan extensa y contaba con un parque automotor pequeño, además de 15 líneas de ferrovías, las cuales permitían a los ciudadanos desplazarse sin grandes problemas. Aún en 1946 la demanda de transporte interprovincial en buses era baja y competía con el cabotaje en vapores ${ }^{7}$. Además, se trataba de un medio de transporte principalmente para sectores más bajos, los cuales aún no representaban gran mayoría de la ciudad, por lo cual se consideró que el uso de la vía pública como zona de embarque y desembarque no sería un problema. La única condicionante impuesta por el gobierno central fue el registro del punto de partida y/o llegada (Flores Fernández, 2006).

Poco a poco, con el crecimiento de Lima, su parque automotor y la proliferación de las empresas de transporte interprovincial, la situación empieza a empeorar debido a la congestión generada por los terminales en plena vía pública. En vez de regular el uso de las vías, el gobierno central permite su "privatización” para uso de los terminales, con la condición de que se mudaran a calles menos transitadas. Para 1953 se prohíben las estaciones en avenidas principales por motivos de "estética de la ciudad".

\footnotetext{
${ }^{7}$ Cabotaje en vapores era el término utilizado para referirse al transporte de personas entre las diferentes ciudades de la costa por vía marina (Flores Fernández, 2006).
} 
A raíz del caos vehicular que aún prevalecía, el gobierno introduce una norma en 1955 con la intención aparente de ordenar y regular los terminales en la ciudad, y obliga a todas las empresas transportistas iniciar sus rutas en el terminal San Pablo ubicado en el distrito de La Victoria. Esta medida no es bien recibida por parte de las empresas transportistas ya que monopolizaría las rutas de transporte, yendo en contra del libre mercado. De igual forma es rechazada por los mismos usuarios, cuyos costos de movilidad aumentarían al tener que transportarse hasta La Victoria. Debido a la gran resistencia, a los dos años, el terminal San Pablo pasa de ser un terminal de origen/llegada a un simple puesto de control, reflejando así la falta de estudio y planificación por parte del gobierno central en sus tomas de decisiones. En 1957, las medidas implementadas por parte del gobierno central no hacen más que reflejar pasividad con respecto a los terminales e incluso incentivar las políticas incorrectas. Primero se convierte en un requisito registrar nada más que la ubicación de sus puntos de embarque y desembarque, sin aplicación de criterio o evaluación para ceder o retirar autorizaciones. Luego se incentiva aún más el uso de la vía pública como estación, al restringir la presencia de estacionamientos de autos particulares o paradas de buses urbanos en las zonas utilizadas por las empresas transportistas. Esta medida es un simple parche que busca cubrir los síntomas de una situación mal gestionada. Sin embargo, en 1975, el Ministerio de Transportes y Comunicaciones [MTC] introduce la primera norma bien encaminada, prohibiendo el uso de la vía pública como estación de buses interprovinciales. Lamentablemente, debido a la pasividad de las autoridades, hasta el día de hoy existen terminales en la vía pública. El gobierno central implementó medidas con la esperanza de incentivar a las empresas transportistas a salir de la vía pública, al exonerarlos de impuestos por la adquisición de inmuebles. Al poco tiempo se presentaron casos de mal uso en el que se adquirieron terrenos para otros fines, por lo que se empezó a sancionar a todo aquel que se aprovechara de este beneficio (Flores Fernández, 2006).

En 1979, después de 46 años (1933-1979), la tarea de administrar y regular los terminales terrestres interprovinciales pasa del gobierno central a manos de las municipalidades. Esta es una medida criticable, ya que cada terminal pasaría a responder al municipio que le corresponde según ubicación, perdiendo así la posibilidad de crear un sistema integral de terminales terrestres. A los pocos años, en una norma introducida en 1983, se publica por primera vez la definición textual de un terminal 
terrestre y qué debe tener para categorizar como tal. Sin embargo, esta medida no aplicaría a los terminales privados, sino solo a terminales estatales. Resultaría así inútil, ya que solo existía un terminal estatal en el Perú ubicado en Tacna.

Uno de los momentos contribuyentes al caos actual es la desregularización de todas las actividades económicas a inicios de los años 90. Las normas de los terminales terrestres no fueron una excepción, desapareciendo así todas las regulaciones sobre estos. Esto permitió la libre proliferación de múltiples empresas, hasta que dos años después se reintrodujeron algunas de las normas previas para controlar el caos. Así, en 1993 se introduce un nuevo reglamento en conjunto con el MTC: para poder establecer sus rutas, toda empresa transportista debía contar con un terminal terrestre autorizado por el MTC y cumplir con un análisis de impacto vial emitido por el gobierno regional. Sin embargo, ninguna de estas normas entró en vigencia, debido a que, en esa época, el transporte interprovincial y sus terminales no eran prioritarios para el gobierno central. Adicionalmente, se declaró en la nueva constitución de 1993, que el transporte terrestre interprovincial no se considera un servicio público y no sería obligación del gobierno brindarlo, motivo por el cual se cedería esta tarea al mercado privado, con, en algunos casos, subsidios por parte del estado. Todas estas normas llevaron a una situación en la que solo 35 terminales en toda la provincia de Lima contaban con el permiso adecuado del MTC, mientras que operaban 267 empresas transportistas. Esto deja suponer que un aproximado de 230 terminales operaban sin cumplir las normas básicas de funcionamiento. Es decir, sin autorización, infraestructura, análisis de impacto vial u otros servicios básicos (Flores Fernández, 2006).

En los últimos años PROINVERSION ha intervenido para buscar la colaboración entre entidades gubernamentales y el privado. Ha buscado incentivar la construcción de terminales por parte de los municipios, pero a la vez ha generado conflictos de interés, al obligar a las empresas privadas ya establecidas a utilizar el terminal estatal. Los operadores consideran que se trata de un modelo monopolizador encubierto, pues beneficia al único operador seleccionado por parte del municipio y no vela por el interés del usuario ya que restringe su derecho a elegir dentro del libre mercado. En algunos casos las municipalidades han operado con barreras burocráticas con la finalidad de obligar a empresas privadas a utilizar el terminal asignado. Esto ha llevado a múltiples empresas a denunciar a los municipios ante INDECOPI (Flores Fernández, 2006). 
El contexto de Lima entre 1990 y 2000 llevó al desarrollo de un programa dirigido por el Banco Interamericano de Desarrollo: Programa de Transporte Urbano de Lima Metropolitana - Subsistema Norte - Sur. El contexto era el de una ciudad que estaba mal estructurada en un sentido vial, con tránsito desordenado, alto congestionamiento, un viaje promedio de dos horas para aquellos con menores ingresos y un alto índice de contaminación ambiental. Esto generaba grandes pérdidas en horas hombre $\mathrm{y}$ en combustible que superaban los US\$ 50 millones al año (Banco Interamericano de Desarrollo; Banco Mundial, 2003).

Según el Banco Mundial (2003) las cifras estadísticas del período de 1990 - 2000 indicaban lo siguiente:

- Parque automotor se duplicó.

- Incremento de empresas de transporte colectivo de 150 a 441.

- Aumento de vehículos dedicados al servicio público de 10,500 a 47,000.

- Expansión de servicio de taxis de 10,000 automóviles a 191,000.

Se observaba una notable sobreoferta que tenía como consecuencia el deterioro acelerado de los vehículos ya que no cumplían con la cuota requerida para realizar el mantenimiento adecuado y la actualización de los servicios. Considerando que una buena porción del parque automotor tenía una antigüedad mayor a 20 años, la contaminación ambiental se incrementó, afectando tanto el medio ambiente, como la salud pública del Limeño. Adicionalmente se ocasionaban mayores accidentes de tránsito, especialmente en el servicio público que resultaron en un promedio de tres muertes al día. Para entonces, el transporte público de Lima, se ubicada entre los peores de América Latina y afectaba principalmente a los sectores de menores recursos. En comparación con otros países de América Latina, los precios, entre S/.0.90 y S/.1.60, eran altos considerando las malas condiciones de viaje (Banco Interamericano de Desarrollo; Banco Mundial, 2003).

La informalidad también fue un problema serio desde entonces, con aproximadamente un $30 \%$ de vehículos sin registrar y operando en rutas sin autorización. Pero no solo los informales generan un problema; el sistema formal también era y continúa siendo, altamente deficiente, ya que el manejo de las 
concesiones se da de manera impersonal y desregularizada. Los problemas que se generan con un sistema en el que no se cuenta con un trato directo entre los concesionarios, los empresarios y los choferes, son varios, pero el más grave de todos es la ausencia de personas que asuman responsabilidad. Adicionalmente, la configuración del sistema de prestación de servicios, lleva a que los choferes busquen la maximización de sus horas de trabajo, que combinado con la gran competencia en el mercado de transporte público, genera un comportamiento agresivo por parte de los choferes. Además, tienden a superar la jornada laboral, trabajando hasta 16 horas corridas. Incluso un $60 \%$ de los choferes provenían de otros sectores laborales, reduciendo las posibilidades de un buen desempeño "por falta de constancia".

Las regulaciones no colaboraban, en el sentido que estaba permitido que cualquier operador ingrese al sistema, poniendo sus propias rutas y tarifas. Claramente esto favorecía la fuerte competencia y por lo tanto contribuía al mal servicio y caos en la ciudad. Eventualmente se introdujo la "Ley Orgánica de Municipalidades" que delegaba responsabilidad a todos los gobiernos locales para la fiscalización y regulación adecuada.

En el 2002 se crea el Proyecto Especial PROTRANSPORTE, que buscaba generar un Sistema Integrado de Transporte Urbano. Parte de este proyecto fue la recuperación de información con respecto al usuario, específicamente perteneciente a la población pobre y muy pobre, sus motivos de viajes y su satisfacción, teniendo los siguientes resultados (Banco Interamericano de Desarrollo; Banco Mundial, 2003):

- $54 \%$ de los viajes son por trabajo y $22 \%$ por compras.

- Considerados como principales problemas: $40 \%$ tiempo del traslado, $35 \%$ incomodidad y $14 \%$ mal servicio.

- $60 \%$ está dispuesto a pagar más.

- El medio preferido es la "combi" por su rapidez, a pesar de la incomodidad e inseguridad.

Lamentablemente, hoy en día muchos de los problemas identificados entre 1990 y el 2000, aún prevalecen y requieren especial atención por parte de las entidades gubernamentales. 


\subsubsection{Gestión del transporte interprovincial de pasajeros}

\subsubsection{Entidades gubernamentales}

La primera intención de crear un ente regulador de las carreteras y la comunicación del país es realizada por el Congreso de la República en 1896, cuando se introduce el Ministerio de Fomento y Obras Públicas. Este estuvo a cargo de muchas labores que hoy se reparten entre diversos ministerios, entre ellos el tema del transporte. Además, veló por impulsar políticas que favorecieran la modernización e integración del país con proyectos de infraestructura de carreteras, ferrocarriles, caminos, puentes, etc. Durante el gobierno de Leguía, en los años 20, se implementaron varias obras de infraestructura vial y ferroviaria en el país, como caminos de penetración y carreteras troncales. Para la segunda mitad del siglo XX se trabajaba en base a una Plan Vial elaborado por el Ministerio de Fomento, que había implementado la creación de arbitrios o impuestos adicionales sobre ciertos productos, además del peaje, para luego financiar el mantenimiento y la construcción de la infraestructura vial del país. En 1968, durante el gobierno de Juan Velasco Alvarado, se disuelve el Ministerio de Fomento y Obras Públicas y se establece el Ministerio de Transportes y Comunicaciones, encargado de "dirigir, desarrollar, regular e inspeccionar las actividades de construcción, conservación y uso de vías terrestres, acuáticas, aéreas, los servicios de correos y telecomunicaciones; y regular y coordinar el tránsito vehicular." (Ministerio de Transportes y Comunicaciones [MTC], s.f.).

\section{Ministerio de Transportes y Comunicaciones [MTC]}

La red vial del país está a cargo del Ministerio de Transportes y Comunicaciones (MTC), órgano del Poder Ejecutivo y responsable del desarrollo de los sistemas de transporte, la infraestructura de las comunicaciones y telecomunicaciones del Perú. El MTC funciona como director y promotor de los sistemas de carreteras, ferrovías, tráfico aéreo y marítimo, con la finalidad de prever una integración nacional. También se encarga de supervisar las diversas vías que le incumben, entre ellas, todo aquello relacionado a autos, camiones, trenes, barcos y aviones. Debe ya sea ejecutar o promover las iniciativas que busquen construir nuevas carreteras y sistemas de transporte público. Las obras del MTC contribuyen al desarrollo socio-económico ya que mejoran la accesibilidad dentro del país y por lo tanto facilitan el comercio y 
generan mayores oportunidades (Ministerio de Transportes y Comunicaciones [MTC], 2010) .

En la actualidad, muchas de las obras de construcción y/o mantenimiento son delegadas a empresas privadas mediante concesiones o Asociaciones Público Privadas [APP]. Por otro lado, el MTC delega la inscripción de las vías del país al Registro Nacional de Carreteras [RENAC], el cual lleva un registro de sus respectivas longitudes y otras características.

\section{Dirección General de Transporte Terrestre}

El MTC tiene una serie de sub-áreas a cargo de diferentes planes. Entre estos se encuentra la "Dirección General de Transporte Terrestre", que se encarga de regular el transporte terrestre y autorizar la prestación de servicios de tránsito por carretera y otros. Este regula las políticas de los servicios de transporte terrestre de personas y mercancías, otorga autorizaciones para prestar servicios y trata muchos temas más como la seguridad vial, la educación con respecto a esta, licencias de conducir, etc.

\section{Provías Nacional}

El MTC cuenta con un programa llamado "Provías Nacional", creado en el 2002 con la finalidad de ejecutar, mejorar, rehabilitar y mantener la Red Vial Nacional, así como de la gestión y control de los recursos económicos que se utilizan para este medio. Con el objetivo final de brindar un servicio más eficiente, no solo se le otorga una autonomía técnica y administrativa, sino también financiera por parte del estado. Es por este motivo que absorbió una serie de programas como el Programa de Rehabilitación de Transportes , Proyecto Especial Rehabilitación Infraestructura de Transportes y del Sistema Nacional de Mantenimiento de Carreteras (Ministerio de Transportes y Comunicaciones [MTC], 2010).

\section{Consejo Nacional de Seguridad Vial}

El MTC también es parte del Consejo Nacional de Seguridad Vial [CNSV], entidad que busca mejorar las condiciones de la seguridad vial a través de la "defensa de la vida humana y la consolidación de una cultura de respeto por las normas de convivencia social" (Ministerio de Transportes y Comunicaciones [MTC], 2017). El principal 
objetivo del CNSV es la reducción de los índices de siniestralidad vehicular, por este motivo funciona como entidad dialogadora y conciliadora entre todas las partes involucradas en esta materia, además de promover, asesorar y vigilar cualquier iniciativa privada o pública que tenga injerencia en la seguridad vial.

\section{$\underline{\text { Superintendencia de Transporte Terrestre de Personas, Carga y Mercancías }}$}

Otra rama del MTC es la Superintendencia de Transportes Terrestre de Personas, Carga y Mercancías [SUTRAN], esta entidad tiene la función de promover el cumplimiento y la supervisión de las normas sobre el transporte y el tránsito terrestre. Asimismo, se encarga de regular y realizar las inspecciones, certificaciones y verificaciones necesarias, así como aplicar las respectivas sanciones (Superintendencia de Transporte Terrestre de Personas, Carga y Mercancías [SUTRAN], 2017).

\section{Protransporte}

El MTC en conjunto con la MML trabaja con el Instituto Metropolitano Protransporte de Lima, quien administra la vía del Metropolitano y la posible implementación de otros cinco corredores complementarios. Este último tiene la labor de educar sobre el uso del transporte público, fomentando su uso y asegurando su correcto funcionamiento. En este sentido, Protransporte también tiene que garantizar que todo el transporte público administrado por ellos este enfocado hacia el beneficio de los ciudadanos, siendo económicamente, financieramente y ecológicamente sostenible. Finalmente también debe promover la inversión pública y privada en proyectos estratégicos de infraestructura urbana (Protransporte, s.f.).

\section{Otras entidades}

Otras entidades gubernamentales relacionadas al transporte interprovincial de buses son aquellas que se encargan de velar por el desarrollo y bienestar de la infraestructura vial de Lima. Por ejemplo, EMAPE es la empresa municipal que se encarga de la construcción, remodelación y conservación de las vías administradas por la MML, también realiza obras con proyecciones sociales y recuperación de espacio público (Empresa Municipal Administradora de Peaje de Lima [EMAPE], s.f.). De igual forma, la concesionaria Rutas de Lima es la encargada de construir y administrar algunas de 
las infraestructuras viales de la ciudad, la cual cuenta con más 100 kilómetros construidos, entre las rutas norte, sur y centro (Rutas de Lima, s.f.). Finalmente, el ente regulador OSITRAN vela por la supervisión, regulación y fiscalización de actividades o servicios que involucran la infraestructura del transporte, además de la resolución de posibles controversias y reclamos (Organismo Supervisor de la Inversión en Infraestructura de Transporte de Uso Público [OSITRAN], s.f.).

\subsubsection{Estructura y categoría de vías}

Hoy contamos con la carretera Panamericana que cruza el país desde Tumbes hasta Tacna. Con una longitud de $2,661 \mathrm{~km}$, se trata de la vía más importante del Perú, que inicia en el ' $\mathrm{Km}$ 0" precisamente en el cruce de la Carretera Central con la vía Evitamiento. La red vial del país se conforma por carreteras longitudinales, de penetración y de enlace. Como mencionado previamente, son muchas las entidades a cargo de las vías, pero en su mayoría son asignadas a Provías o a través de concesiones a empresas privadas. Según un estudio realizado por la Asociación Automotriz del Perú (Coronado Díaz, 2012), las vías del país están repartidas según su pavimentación:

- Carreteras asfaltadas: $11,016 \mathrm{~km}(14 \%)$.

- Carreteras afirmadas: $18,098 \mathrm{~km}(23 \%)$.

- Carreteras sin afirmado: $14,163 \mathrm{~km}(18 \%)$.

- Trochas: $35,409 \mathrm{~km}(45 \%)$.

Como se observa en la siguiente tabla, las redes se categorizan bajo Nacional, Departamental y Vecinal, y también se organizan según la superficie de rodadura; pavimentada o sin pavimentar, en cuyo caso se clasifica bajo afirmada o sin afirmar. 
Tabla 2: Sistema Nacional de Carreteras del Perú

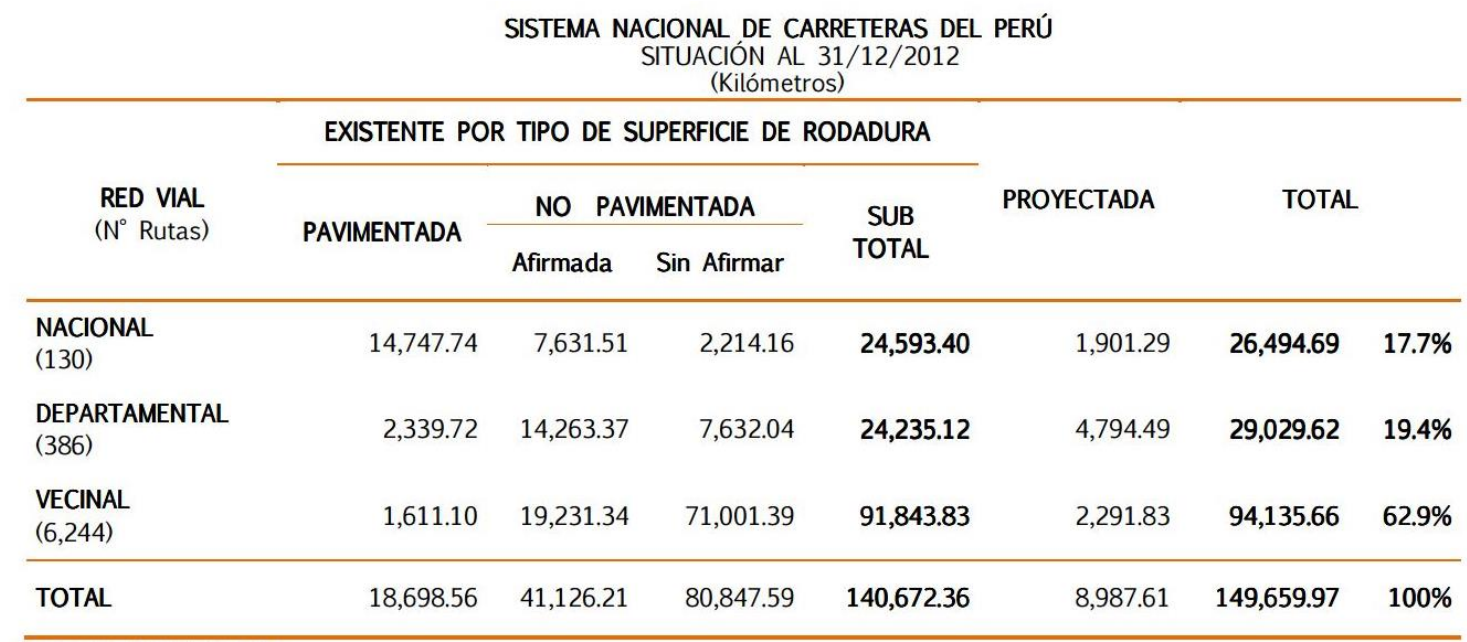

Fuente: Ministerio de Transportes y Comunicaciones (2012)

También se clasifican bajo Red vial internacional (Carretera Panamericana, Interoceánica y la Carretera Marginal de la Selva), Red vial Nacional conformada por ejes longitudinales como la Carretera Panamericana Norte y Sur, Longitudinal de la Sierra Norte, etc. Adicionalmente se cuenta con carreteras transversales como por ejemplo la Carretera Central o la Ruta Interoceánica Perú-Brasil. Finalmente, la categoría de Red vial regional se restringe a rutas de solo una región específica (MTC, 2007). En el caso de la Carretera Panamericana, vía principal del país, se trata de una carretera que conecta 10 departamentos. Al pasar por Lima, parte de esta vía rápida es denominada "Evitamiento" y se va tejiendo con otras vías de gran importancia a nivel metropolitano, como lo son la avenida Javier Prado y la Circunvalación. Considerando que se trata de una vía de categoría internacional, que conecta con Ecuador y Chile, es importante mantener una velocidad mínima, para no obstruir su fluidez. Por este motivo es de suma importancia estudiar los ingresos y salidas para evitar generar cuellos de botella ${ }^{8}$.

\subsubsection{Situación actual de los terminales de Lima}

Lima, único punto de llegada y salida internacional del Perú, es paso obligado para todos los turistas y ciudadanos peruanos que entran o salen del país. Al no existir una red ferroviaria en funcionamiento, el tránsito de pasajeros a nivel nacional queda

\footnotetext{
8 “Estrechamiento que hace más lento el paso por algún lugar” (RAE, 2014).
} 
reducido al único aeropuerto operativo de Lima el A.I. Jorge Chávez o a los múltiples terminales terrestres que se encuentran esparcidos por la ciudad. El primero transporta a más de 15 millones de personas al año (Lima Airport Partners, 2015), mientras que en el transporte terrestre se registró la llegada de más de 28 millones de pasajeros a Lima en viajes interprovinciales durante el mismo período de tiempo (Instituto Nacional de Estadística e Informática, 2013). En el mismo año se registraron una migración de 3’480,000 personas.

El termino migración se refiere específicamente al “. . . desplazamiento de la población que origina un cambio de lugar de residencia" (Instituto Nacional de Estadística e Informática, 2014). De estos más de 3 millones de personas, 368,500 vinieron de Junín, 163,700 de Huánuco, 139,500 de Huancavelica y 97,500 de Pasco, es decir más de 700,000 personas de la sierra central.

Al llegar de la sierra, uno ingresa por la Carretera Central y una vez en Lima, son múltiples los terminales a los que uno puede llegar. Empresas de Transportes Flores Hermanos, Transportes Línea, Turismo Civa, Expreso Cruz del Sur, Soyuz, etc. son las primeras empresas que figuran en el ranking del 2008 según la revista CASER (Grupo Maximixe, 2010). La mayoría cuenta con terminales terrestres privados en diferentes zonas de Lima, teniendo que adentrarse con grandes buses a diferentes partes de la ciudad, generando congestión innecesaria en muchos casos. Una gran mayoría para o pasa por el Terminal Terrestre de Yerbateros, que está ubicado en San Luis directamente vinculado a la Carretera Central. Sin embargo, este tampoco evita la congestión vehicular, pues carece de una infraestructura adecuada y de un plan integrado con las vías alimentadoras de la zona. Es importante hacer énfasis en la informalidad existente en este medio: "De acuerdo con el Consejo Nacional de Transporte Terrestre [CNTT], más del 50\% del transporte interprovincial de pasajeros . . . en el país operan informalmente” (Antúnez, 2014). Las problemáticas que trae consigo son por un lado el incumplimiento de normas de seguridad, como por ejemplo el descanso reglamentario, y por otro lado la abundancia de terminales terrestres no reglamentados en distritos incapaces de soportar la carga vehicular, como es el caso del Cercado de Lima.

Según un diagnóstico técnico realizado por el Ministerio de Transportes y Comunicaciones [MTC] en el 2009 había 115 terminales terrestres interprovinciales 
autorizados para su funcionamiento a nivel nacional. Estos están distribuidos en 21 regiones, siendo Lima la que mayor número tiene con un total de 55 terminales (48\%), seguido por Lambayeque con 10 (8.7\%) y luego Apurímac y Piura con 5 terminales respectivamente $(4.3 \%)$. Pero también se menciona la existencia de un gran número de terminales informales de diferentes tamaños y escalas, que operan abierta $\mathrm{y}$ públicamente sin ninguna autorización o regulación.

"Lo anterior refleja, no sólo una atomización de la infraestructura de terminales terrestres de pasajeros en las ciudades, sino también un bajo nivel de fiscalización del servicio, ya que el hecho de tener dispersos por toda la ciudad los terminales, resulta en difícil labor de control y auditoría a los mismos por parte de los organismos encargados de estas tareas." (Ministerio de Comercio Exterior y Turismo [MINCETUR]; Unión Europea [UE], 2009, p. 19)

En el caso específico de Lima, en el 2009 el Ministerio de Comercio Exterior y Turismo [MINCETUR] con el apoyo de la Unión Europea realizó un informe sobre la situación de los terminales terrestres, donde se analizaron 25 de los 55 terminales formales existentes. Estos en su mayoría se localizan en la parte central de la ciudad, donde $88 \%$ se encuentran en un radio de $3.5 \mathrm{~km}$ del centro histórico. Tan solo en el distrito de La Victoria se pueden encontrar 34 terminales de los autorizados para la provincia de Lima (Izquierdo Quispe, 2012). 
Figura 2: Ubicación de terminales terrestres en Lima

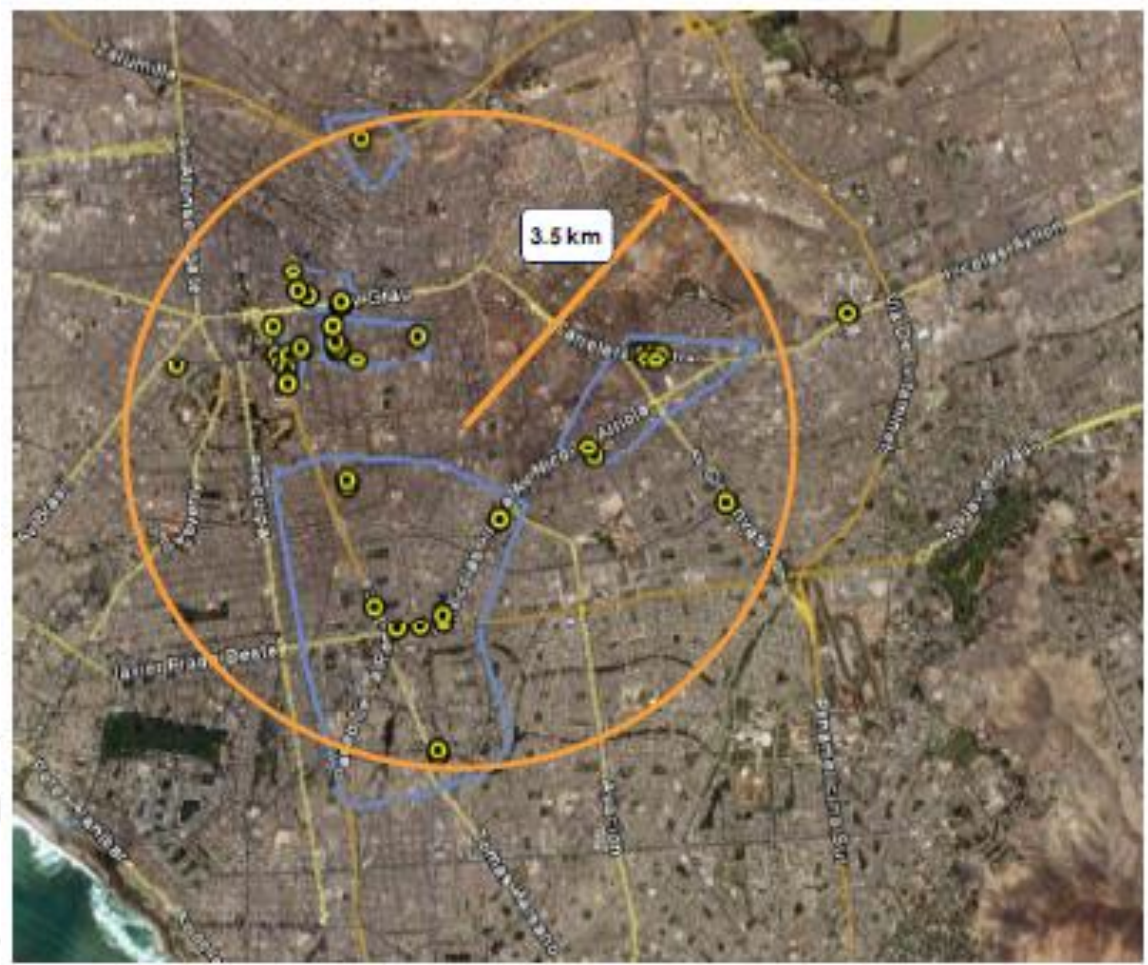

Fuente: Ministerio de Comercio Exterior y Turismo; Unión Europea (2009, p. 34)

En los casos analizados se determinó que los terminales siempre eran propiedad de una empresa privada de transporte y no se evidenció ninguna iniciativa que provenga del Gobierno Central, ni tampoco de una asociación público - privada [APP]. Por esto la operatividad y funcionalidad quedan a cargo de empresas privadas, las cuales son dueñas de la infraestructura del terminal y muchas veces prestan sus instalaciones para que otras empresas hagan uso de ellas.

Es importante precisar que en el $64 \%$ de los terminales analizados solo opera una empresa de transporte. Es decir, la relación es de una empresa transportista por cada terminal. En un $12 \%$ de los terminales analizados, se da una relación de cuatro empresas transportistas por terminal y solamente se pueden presenciar más de 15 empresas transportistas en dos terminales. Por lo tanto, solo en un $36 \%$ de los terminales analizados operan más empresas dentro de un único terminal (Ministerio de Comercio Exterior y Turismo [MINCETUR]; Unión Europea [UE], 2009, pp. 32-38). 
Tabla 3: Número de terminales según cantidad de empresas

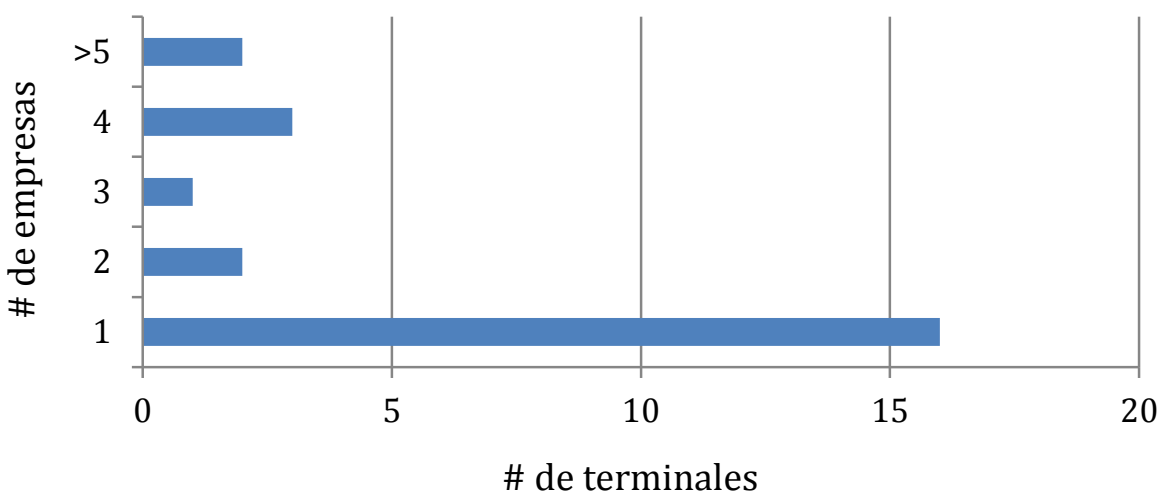

Fuente: Ministerio de Comercio Exterior y Turismo; Unión Europea (2009)

Elaboración propia

En cuanto a la infraestructura, es importante mencionar que el $40 \%$ de los terminales tienen un área relativamente pequeña entre $2,000 \mathrm{~m}^{2}$ y $5999 \mathrm{~m}^{2}$, mientras que solo el $24 \%$ tiene áreas más adecuadas para el tamaño requerido por un terminal terrestre, las que oscilan entre $6,000 \mathrm{~m}^{2}$ y $9,500 \mathrm{~m}^{2}$.

Tabla 4: Distribución de terminales según área construida

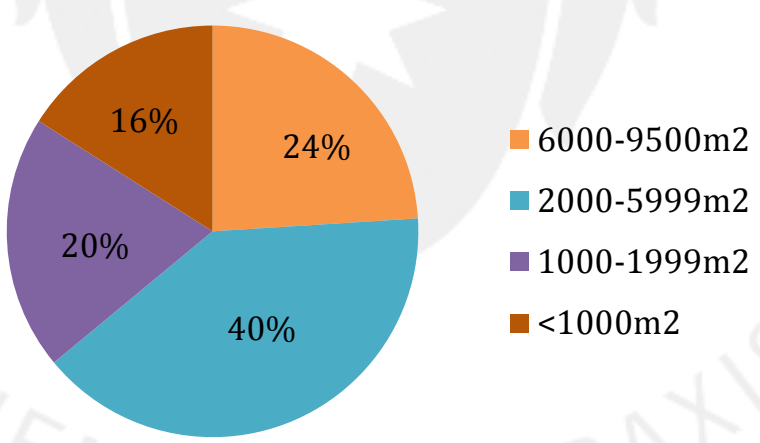

Fuente: Ministerio de Comercio Exterior y Turismo; Unión Europea (2009)

Elaboración propia

Del primer grupo, los terminales con áreas construidas entre $6,000 \mathrm{~m}^{2}$ y $9,500 \mathrm{~m}^{2}$, es importante resaltar que su área construida es en promedio $18 \%$, mientras que en los terrenos que son más pequeños como el segundo grupo, es de $32 \%$. En los terminales con terrenos menores a $1,000 \mathrm{~m}^{2}$ llega a ser casi $50 \%$ de área construida (Ministerio de Comercio Exterior y Turismo [MINCETUR]; Unión Europea [UE], 2009, p. 22). 
Cuando se analizaron los espacios interiores ${ }^{9}$ de los terminales se pudo determinar que solo el $56 \%$ de estos tienen un área específica para las funciones administrativas. En el resto, las zonas están mezcladas con las de los pasajeros e incluso en algunos casos no existen en lo absoluto. Las áreas de espera en el 88\% de los casos, se encontraban en espacios abiertos y estaban compartidas con otras actividades como el lobby principal, las boleterías, los puestos de información para los pasajeros, el envío de encomiendas y las zonas de comercio. A esto se le suma que el mobiliario, como asientos o butacas, en la mayoría de los casos no era suficiente para satisfacer la demanda por lo que un número significativo de usuarios debe permanecer de pie.

Tampoco se pudo determinar la existencia de zonas exclusivas para el flujo de pasajeros, ya que la mayoría de terminales no son lo suficientemente grandes como para separar las zonas de recorrido de las de permanencia.

La venta de boletos siempre se realiza en los mismos espacios donde es la sala de espera, la circulación y el comercio. Además, solo uno de los 25 casos analizados contaba con un sistema electrónico para la atención al público, el resto funcionaba con el sistema tradicional de filas donde los pasajeros permanecen de pie todo el tiempo, lo cual resulta en una mayor congestión.

Un dato alarmante es que no se identificaron áreas destinadas para la atención de emergencias médicas o enfermerías en ninguno de los terminales terrestres. De igual importancia es el hecho que en un $64 \%$ de los casos el comercio realizado dentro del terminal se hacía de manera informal (Ministerio de Comercio Exterior y Turismo [MINCETUR]; Unión Europea [UE], 2009, pp. 23-27).

El análisis de las zonas exteriores, reveló que en un $85 \%$ de los terminales estudiados, el embarque y desembarque de pasajeros se realiza en lugares establecidos para ese fin, pero que en su gran mayoría ninguno estaba correctamente implementado para brindar la seguridad necesaria a los usuarios. En algunas ocasiones, este espacio de embarque y desembarque, es también el patio de maniobras de los autobuses. En cambio, solo en dos terminales se pudo apreciar que el abordaje y desembarque de los buses se realizaba directamente desde una puerta de embarque en el edificio del

\footnotetext{
9 Todas las áreas comprendidas dentro del edificio principal del terminal terrestre, sin tomar en cuenta construcciones temporales o ambulantes.
} 
terminal. En estos dos únicos casos las zonas de circulación de los buses no eran accesibles para los usuarios, brindándoles mayor seguridad.

Por otro lado, el envío de encomiendas y equipaje de carga se realiza el $88 \%$ de las veces en áreas exclusivas para esta actividad y solamente en el 12\% restante se hace directamente en la zona de embarque.

Por último, es importante resaltar que el $76 \%$ de los terminales no cuenta con una zona para el estacionamiento de vehículos o bahías longitudinales para transporte privado o taxis, por lo que tienen que ocupar la calle para dejar o recoger pasajeros (Ministerio de Comercio Exterior y Turismo [MINCETUR]; Unión Europea [UE], 2009, pp. 28-31).

En cuanto a la accesibilidad hacia los terminales; el mismo informe demuestra que la mayoría están ubicados sobre vías principales de la ciudad como la Av. Javier Prado, Paseo de la República y Nicolás Ayllón. En estos casos el acceso se realiza mediante puertas que dan directamente hacia las avenidas, lo que genera gran congestión para el tráfico, ya que ninguno contempla un diseño vial adecuado. Adicionalmente el $60 \%$ de los terminales solo cuenta con una única puerta que se utiliza como entrada y salida de los autobuses.

Retomando el tema del transporte, es importante mencionar la falta de intercambio modal, ya que solo el $20 \%$ tenía la posibilidad de tomar taxis desde un paradero ubicado en el terminal y solo en el $4 \%$ se podía acceder a un medio de transporte público masivo de manera formal.

Se puede concluir este análisis sobre la situación general de los terminales terrestres en Lima comprendiendo que existe un grave déficit de estándares en cuanto a la implementación y los servicios que estos deben prestar. Las operaciones no se realizan eficientemente y generan un impacto que degrada todas las zonas cercanas al terminal. Tampoco hay una fiscalización adecuada que ayude a regular o exija que se cumplan las normas, y es por ese motivo que la informalidad es tan grande en este sector.

El estado actual de los terminales es muy lamentable. Salvo muy pocas excepciones todos los terminales están en una situación crítica. Es necesario hacer una reestructuración del sistema para poder brindar un servicio eficiente y de calidad para sus usuarios. 


\subsubsection{Estrategias de ordenamiento para el transporte público e interprovincial de}

\section{Lima}

En el año 2003 se introduce el programa de Transporte Urbano de Lima Metropolitana, Subsistema Norte - Sur. Como mencionado en el informe desarrollado por el Banco Interamericano de Desarrollo en conjunto con el Banco Mundial (2003), su objetivo era mejorar la movilidad dentro de Lima, específicamente la de menores ingresos. Adicionalmente se buscaría reducir y optimizar costos que se invierten en la provisión y uso del transporte público en Lima en la actualidad. Este programa se desarrolló en base a información recolectada en el periodo de 1990 al 2000 y es lo que hoy conocemos como la Vía del Metropolitano.

Figura 3: Sistema Integrado de Transporte Urbano de Lima
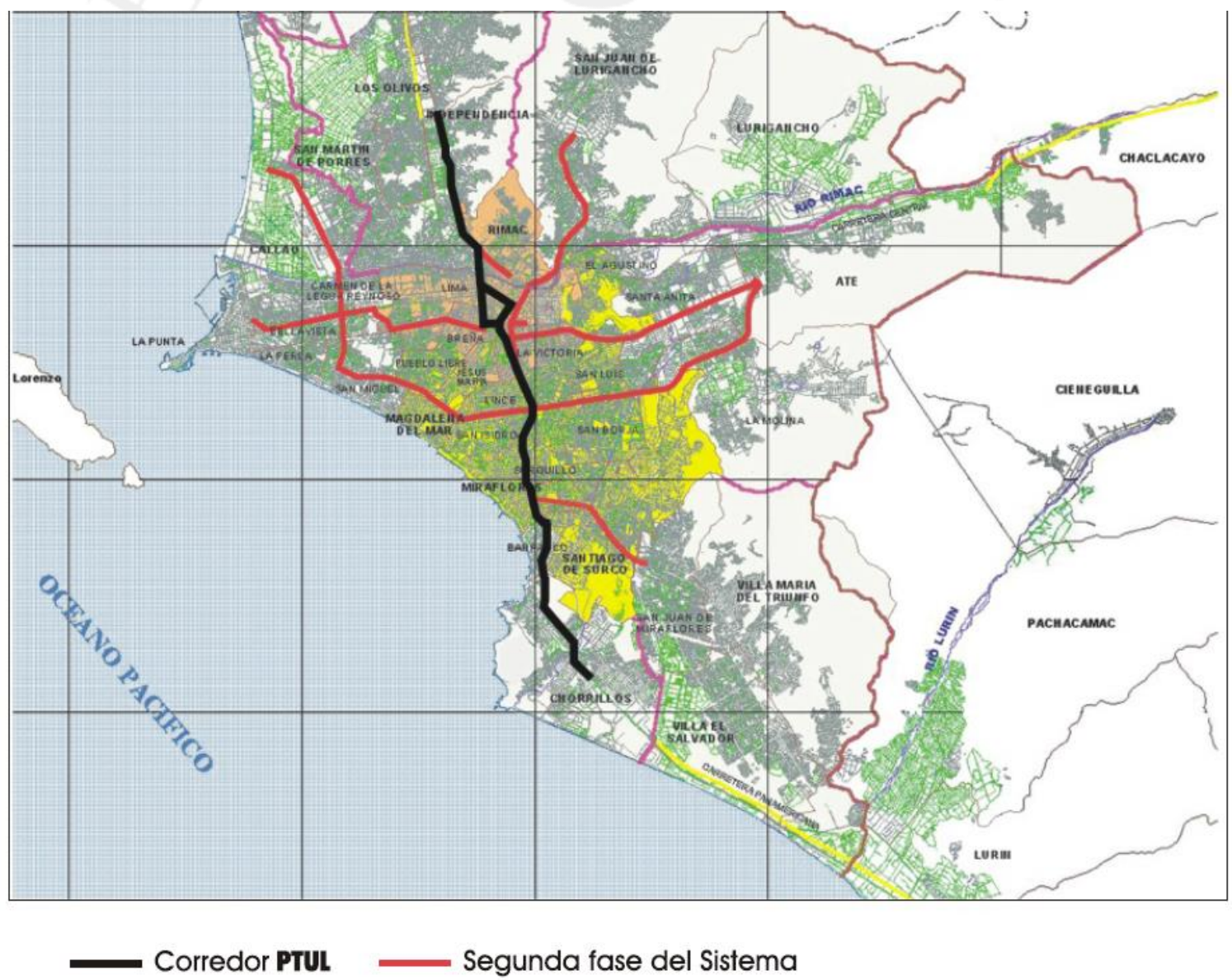
Segunda fase del Sistema

Fuente: Banco Interamericano de Desarrollo, Banco Mundial (2003, p. 6)

Se pretendió trabajar principalmente con la provisión de buses troncales que circularían en su propia vía, siendo más eficientes, confiables y seguros para el usuario 
y la ciudad. El enfoque, como mencionado, fue el de atender sobre todo a los sectores más pobres, para mejorar sus oportunidades de trabajo, tiempo de viaje, reducir accidentes y mejorar su accesibilidad dentro de la ciudad. Según la descripción del programa, el "sistema integrado de transporte urbano rápido masivo de Lima" buscaría trabajar líneas troncales independientes a las vías de la ciudad e interconectarlas en un sentido intermodal con ciclovías alimentadoras, entre otros. Principalmente enfocado en zonas de Lima, donde predominan habitantes con ingresos per cápita inferiores a US\$ 75 al mes, para su primera etapa pretende atender 630,000 pasajeros al día con una flota de 250 buses principales y 154 buses convencionales en las rutas alimentadoras. Se contempla la inclusión social, trabajando con sistemas de acceso para todo tipo de situaciones, ya sea mediante ascensores o paraderos a desnivel (Banco Interamericano de Desarrollo; Banco Mundial, 2003).

Los principales enfoques del programa fueron:

- Mejora de la movilidad y el ambiente urbano.

- Fortalecimiento institucional.

- Factibilidad sociopolítica.

- Estudios y supervisión.

Entre los beneficios de un programa de ordenamiento del transporte público como el propuesto, se encuentra la mejora general del ambiente urbano, la generación de mayores oportunidades para crear espacio público, la mejora de la seguridad ciudadana y sobretodo la mejor accesibilidad para los sectores más bajos que cuentan con menores recursos y que dependen de una buena accesibilidad para su desarrollo.

“Con la implementación del sistema de transporte masivo rápido se logrará una reducción significativa, si bien paulatina, en la obsoleta flota que hoy presta el servicio, una mejora cualitativa en la operación del transporte público, la disminución de los tiempos de viaje, la contaminación atmosférica y el nivel de ruido, una mejor circulación de peatones y ciclistas, la mejora de la seguridad vial y el descongestionamiento del tránsito en su zona de influencia." (Banco Interamericano de Desarrollo; Banco Mundial, 2003, p. 5) 
Por otro lado, los riesgos mencionados en el informe tratan la informalidad existente entre los operadores que se verán afectados por la reestructuración del sistema al igual que sus limitaciones para participar por falta de preparación. También se considera que la Municipalidad Metropolitana de Lima carece de ciertas capacidades para regular y fiscalizar de manera adecuada los servicios propuestos y la falta de conocimiento y experiencia en operaciones multilaterales.

Entre las soluciones propuestas para estos riesgos, se buscaría capacitar y preparar adecuadamente al personal involucrado de la Municipalidad Metropolitana de Lima, al igual que a muchos de los operadores informales que se vieron afectados, para la reinserción en el sistema con una mayor preparación, formalidad y por lo tanto generando una mejor oportunidad laboral (Banco Interamericano de Desarrollo; Banco Mundial, 2003).

Contemplando el transporte terrestre interprovincial y como mencionado en el recuento sobre la historia del transporte en el Perú y Lima, la necesidad de transportarse mediante buses dentro del país empieza a ser atendida en los años 40, con la creación de las primeras empresas de transporte interprovincial. Las rutas eran predominantemente costeras, pero a medida que las carreteras del país mejoraban y crecían fueron agregando nuevas rutas. Se puede asumir que no existió un plan que haya contemplado fundamentalmente el tema del transporte interprovincial, ya que este continuó creciendo de manera descontrolada y repartida por la capital. Sin una regulación o normativa que contemplara la ubicación de los terminales terrestres fuera del centro de la ciudad, estas crecerían en función a la demanda de mercado, ubicándose predominantemente en distritos del centro como el Cercado de Lima, La Victoria y otros. La mala gestión en un inicio y eventualmente la falta de normativas y regulación adecuada, permitiría la creación de "terminales en la calle" que no cuentan con instalaciones adecuadas que permiten a los pasajeros abordar el bus. En algunos casos existían las normas necesarias, pero por diversas situaciones políticas no entraban en vigencia. En otros casos la norma misma no era bien propuesta y a veces, las mismas autoridades eran muy pasivas al respecto.

"Actualmente la norma de zonificación veta la presencia de terminales terrestres en el centro de Lima, pero la pasividad de las autoridades de turno 
convierte en letra muerta el dispositivo, castigando con su desidia a las empresas que hicieron el esfuerzo económico de migrar a otras zonas de la ciudad y premiando con su inacción a las empresas infractoras que aún permanecen operando en la zona prohibida." (Flores Fernández, 2006, p. 72)

En el estudio realizado para el Plan Maestro de Transporte Urbano [PMTU] para el 2025, realizado en el 2005, se analiza la situación de los terminales de buses para transporte interprovincial. Se categorizan en dos grandes grupos, aquellos que tienen terminal y aquellos que no tienen, por lo tanto, operan directamente en las calles. De las empresas que si cuentan con terminales terrestres existen tres tipos o escalas: Gran escala cuando se trata de 20-25 andenes/espacios para buses, escala mediana cuando son 10 andenes y pequeña cuando se trata de 2-3. La problemática con respecto al número de terminales dispersos por la ciudad se presenta en el siguiente gráfico. Se puede apreciar que se concentran en dos distritos céntricos de Lima: el Cercado de Lima y La Victoria. Predominan los terminales que cuentan con un terreno para buses, pero igual se puede apreciar la existencia de varios "terminales" que funcionan en la calle (Agencia de Cooperación Internacional de Japón [JICA]; Consejo de Transporte de Lima y Callao; Ministerio de Transportes y Comunicaciones [MTC], 2005). 
Figura 4: Repartición de terminales según tipo

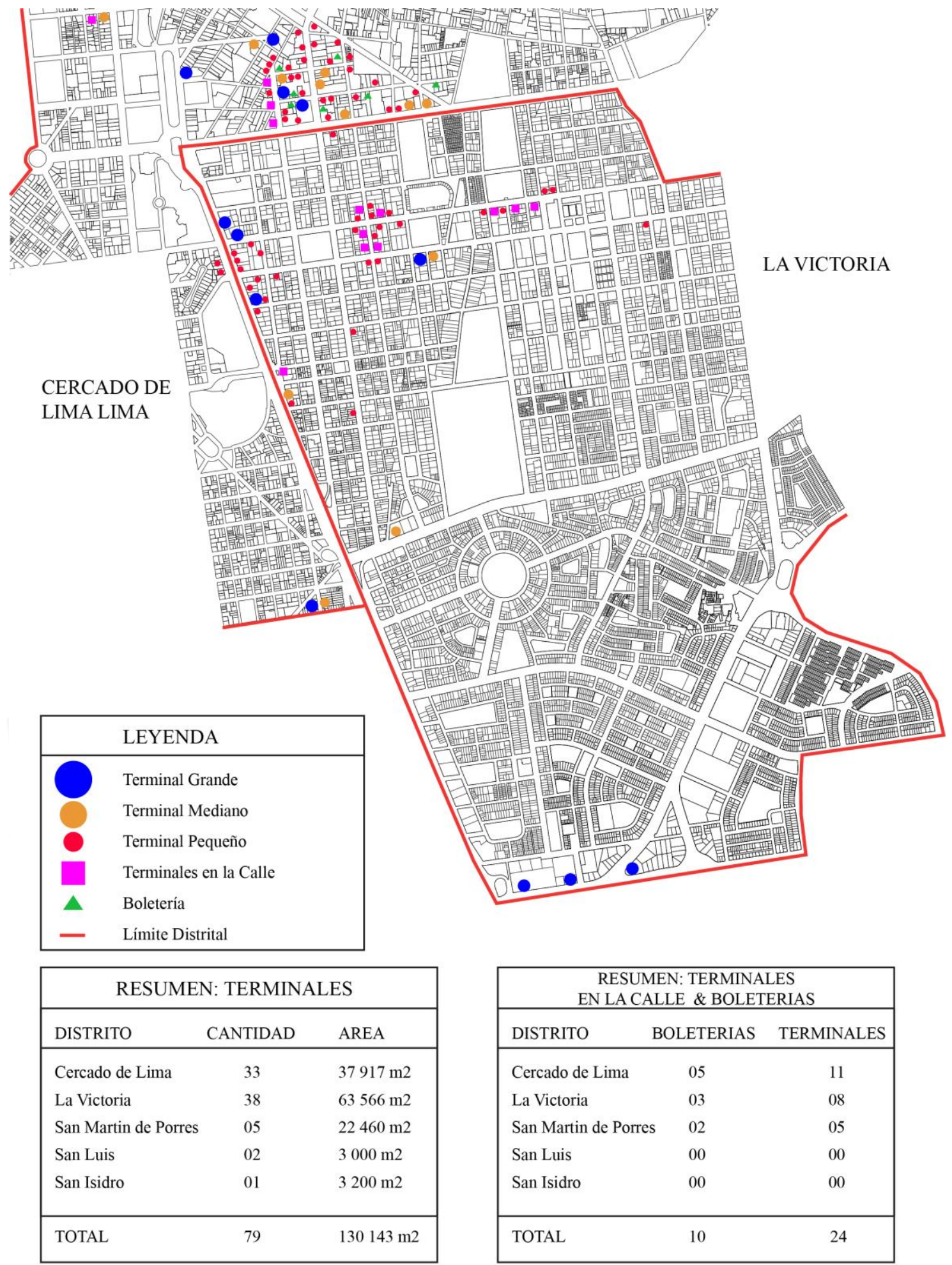

Fuente: Agencia de Cooperación Internacional de Japón; Consejo de Transporte de Lima y

Callao; Ministerio de Transportes y Comunicaciones (2005)

Adaptado de PMTU2025 
El PMTU para el 2025 sugiere que Lima deberá organizarse con 3 terminales de buses importantes, uno al norte de Lima, otro al sur y el último al este. Además, deberá funcionar de manera integrada con otros sistemas de transporte público. Proponen la aplicación de un sistema de "Buses Troncales" y rutas alimentadoras. El Bus Troncal trabajaría sobre una ruta especial con una mayor velocidad de operación, y este sería alimentado con buses convencionales y buses alimentadores.

Como se observa en la siguiente figura, también deberá estar integrado con un sistema de 4 líneas de trenes que ayudará a atender las zonas más lejanas de la ciudad.

Figura 5: Plan Maestro de Transporte Urbano 2025

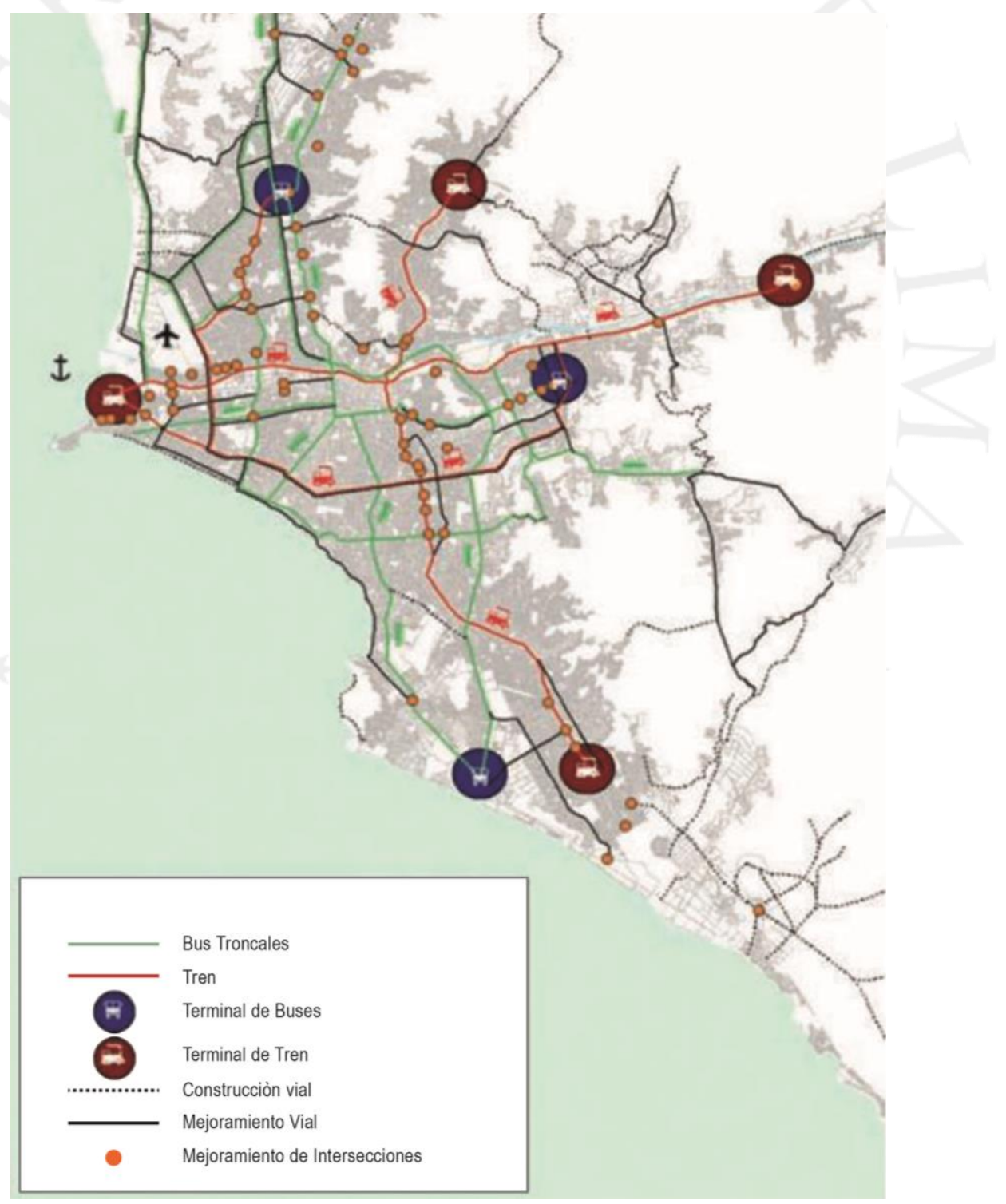

Fuente: Agencia de Cooperación Internacional de Japón; Consejo de Transporte de Lima y Callao; Ministerio de Transportes y Comunicaciones (2005) 
Esta sugerencia coincide con la propuesta del PLAM2035, que inicia su análisis con la misma aproximación: las empresas de transporte interprovincial dispersas por la ciudad, pero más de 10 años después (ver figura 6), lo cual nos indica la poca preocupación que ha tenido el gobierno con respecto a este tema.

Figura 6: Distribución de terminales terrestres en Lima

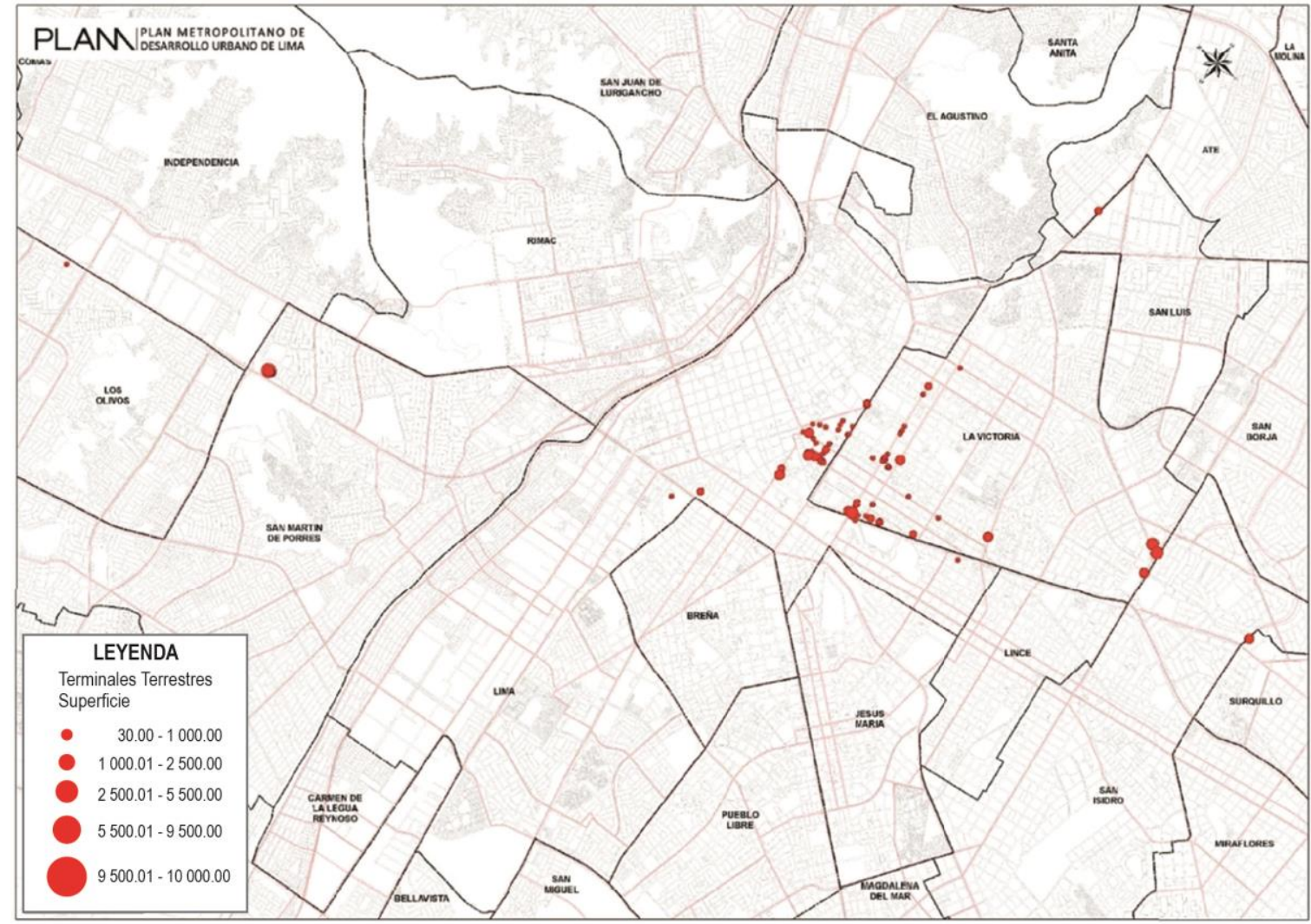

Fuente: Instituto Metropolitano de Planificación (2014)

Elaborado por el equipo del PLAM en base a SIRAD 2010

Para sustentar la existencia de tres terminales en Lima y no un gran terminal central, como sucede en otras ciudades, se analizan las vías rápidas de Lima al igual que el flujo de personas que ingresan y salen. En un estudio realizado en el 2003 por el grupo de consultoría TYPSA, se logró definir el número de viajes interprovinciales según ingreso y salida ya sea por el Norte, Este o Sur (ver figura 7). Considerando la expansión territorial que tiene Lima, no puede existir un solo terminal central que atienda toda la demanda, sobre todo por la posición geográfica en la que se puede definir claramente un ingreso y salida para el Norte, otro para el Sur y finalmente uno para el Este. Adicionalmente, la propuesta de ubicar un terminal en cada uno de estos 
puntos de ingreso o salida ayuda a mantener los buses interprovinciales en las afueras de la ciudad, evitando la congestión o posibles accidentes (Instituto Metropolitano de Planificación, 2014).

Figura 7: Movimiento de ingresos y salidas en Lima

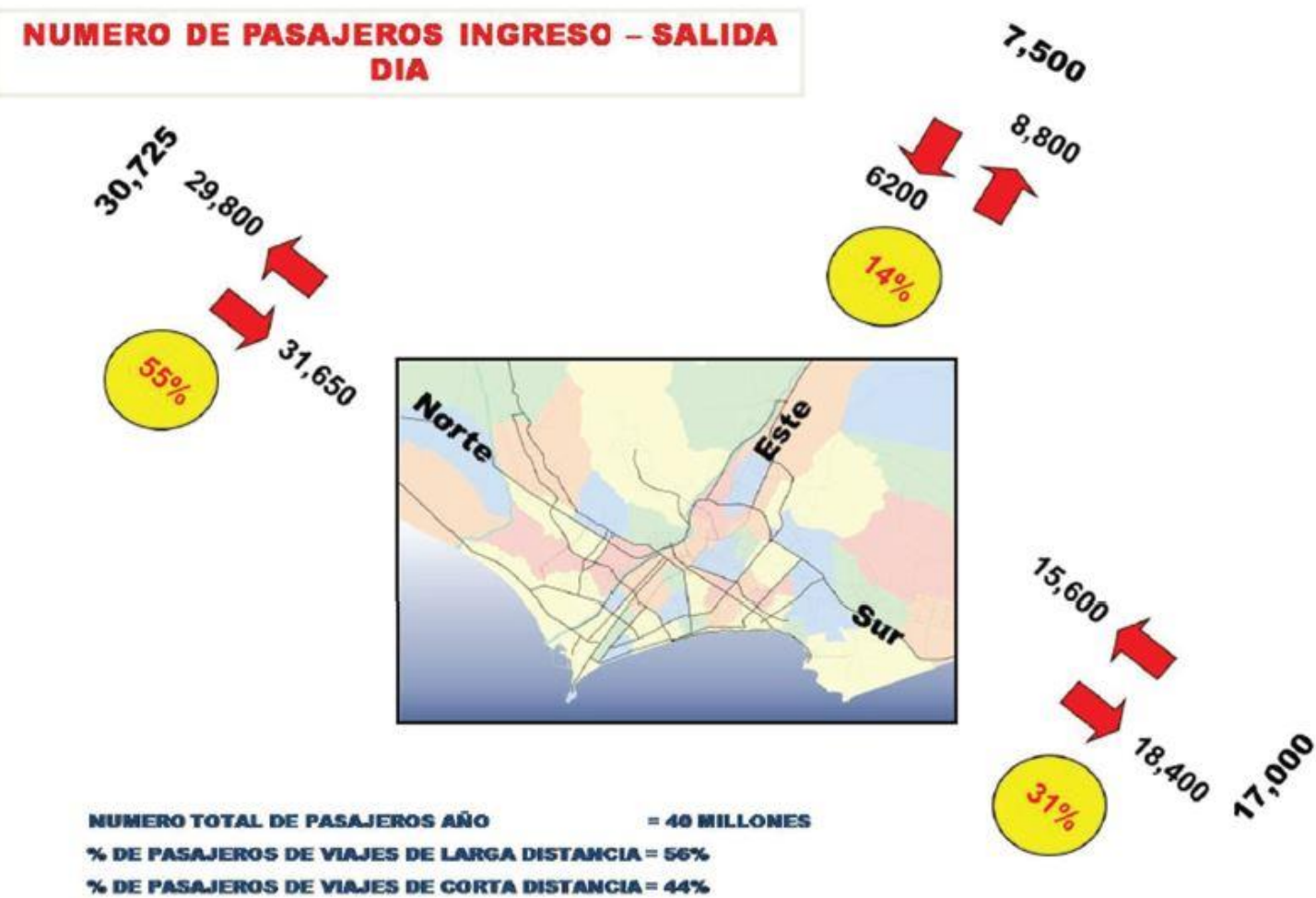

Fuente: Instituto Metropolitano de Planificación (2014)

Elaborado por el Grupo TYPSA, 2003

Es importante poder sustentar con una accesibilidad adecuada, los diferentes terminales en Lima. La propuesta del PLAM 2035, como mencionado anteriormente, busca distribuirlos según Norte, Este y Sur, pero considerando la conectividad con corredores complementarios y futuras líneas de metro, entre otros. Primero la ubicación con respecto a la vía principal del país: Panamericana Norte y Sur, y en el caso del terminal Este se debe contemplar la Carretera Central, que es la que alimenta la ruta Este. De esta manera, los distritos históricos de Lima que no cuentan con la infraestructura suficiente para atender el flujo de buses interprovinciales, no se ven afectados por terminales, ni por rutas de buses. 
El PLAM especifica una zona, más no un lugar específico para cada terminal, debido a que sería necesaria la adquisición de estudios técnicos y otros para poder establecer un terreno definido. Sin embargo, sí mencionan que, en base al estudio realizado por TYPSA (Instituto Metropolitano de Planificación, 2014), el terminal terrestre debería contar con un aproximado de 3 hectáreas para el desarrollo del proyecto.

Figura 8: Rutas de transporte y ubicación de terrapuertos según PLAM2035

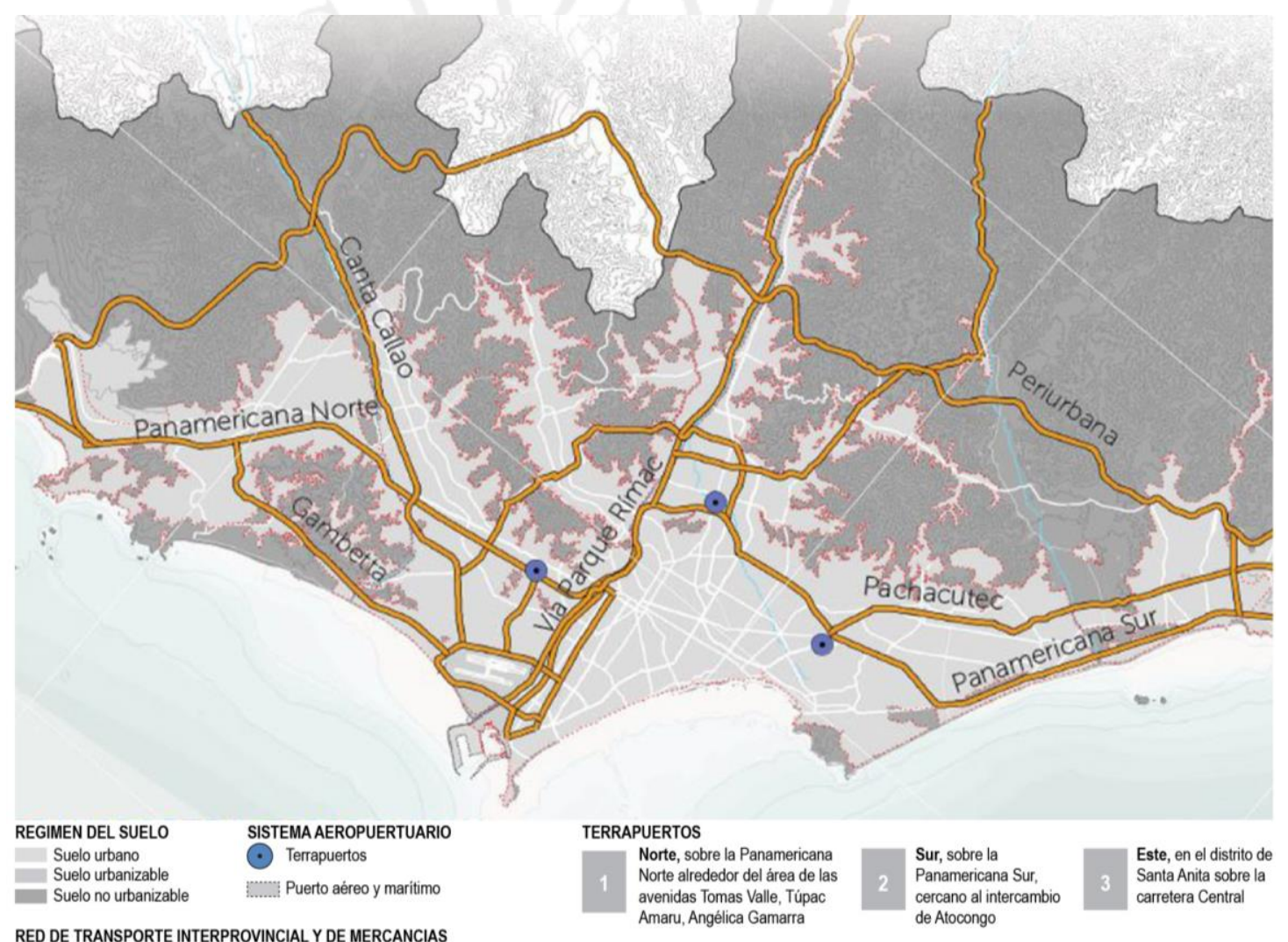

Fuente: Instituto Metropolitano de Planificación (2014)

La accesibilidad a esta distribución de terminales, el día de hoy, es bien limitada, considerando que solo existen dos rutas troncales de transporte público masivo: el Metropolitano y el tren eléctrico. El terminal de Lima Norte sí está conectado con la vía del Metropolitano, sin embargo, los terminales existentes en Lima Este y Lima Sur aún no tienen este tipo de conexión. Los planes realizados por el PLAM 2035 contemplan la realización de un sistema integral de líneas metropolitanas que permitirán una mayor accesibilidad a diferentes puntos de la ciudad. 
En el siguiente plano podemos observar diversas rutas, algunas ya existentes, y entre estas la línea 2 que atraviesa la ciudad de Oeste a Este. Adicionalmente se resaltan las áreas de influencia para cada línea.

Figura 9: Corredores y área de influencia según PLAM2035

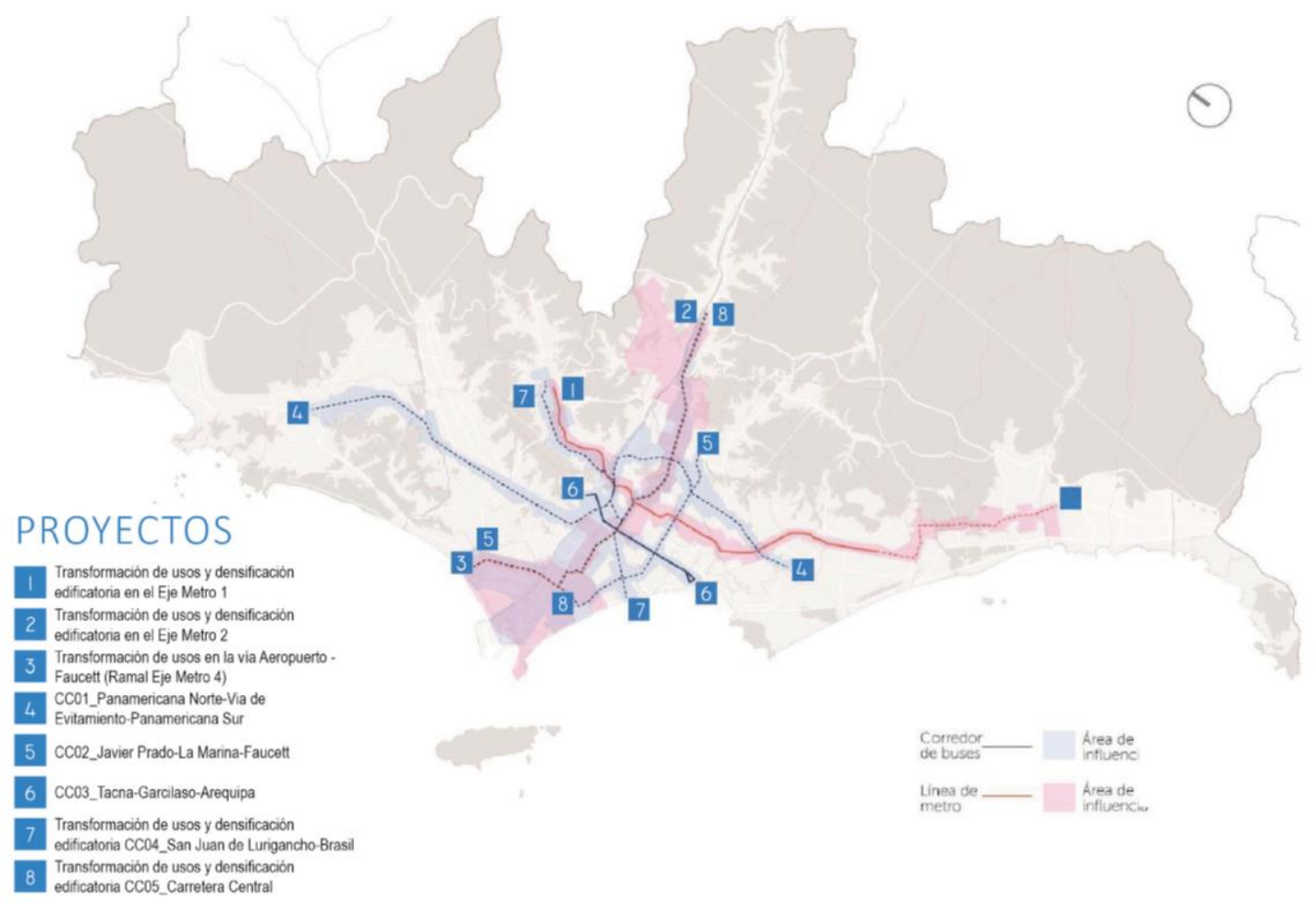

Fuente: Instituto Metropolitano de Planificación (2014)

Adaptado de PLAM Lima y Callao 2035

Las líneas 2 y 4 del futuro metro de Lima ya han sido evaluadas, procesadas y aprobadas, e incluso se han iniciado obras para una de ellas; la línea 2. El Grupo TYPSA menciona en su informe anual del 2014 la proyección de las líneas mencionadas. La concesión para el diseño y la construcción varía según el tramo escogido, y en el caso de la línea 2 es de 35 años con un presupuesto aproximado de 3,800 millones de euros. La línea 2 comprende $27 \mathrm{~km}$ de metro subterráneo, con 27 estaciones y conecta 13 distritos de Lima. Según las estimaciones, esta línea permitirá recorrer toda la sección transversal de Lima, desde Ate hasta el Callao, en 45 minutos (Grupo TYPSA, 2014). 
Junto con la implementación de la línea 2 del metro de Lima, el PLAM propone una serie de modificaciones en algunas zonas que va a impactar, las cuales se aprecian en la siguiente figura. Una de estas es el tramo de la Av. Nicolás Ayllón, extensión de la Carretera Central, entre Circunvalación y Evitamiento, en la cual predomina la "actividad industrial mono funcional" (Instituto Metropolitano de Planificación, 2014) que se caracteriza por tener lotes de grandes dimensiones. Esto es considerado una gran ventaja por el grupo de planificación, pues la industria que se ubica en los centros de las ciudades debe ser reubicada, lo cual dejaría una serie de lotes "cómodos" para intervenciones, cambio de zonificación, etc. Esta zona se verá beneficiada con las diversas estaciones del metro que reducirán los costos de transporte, aumentarán la accesibilidad y reducirán la congestión: al competir el metro, transporte masivo de mayor calidad y velocidad, con el transporte público pequeño se reducirá la presencia de estos en la zona, liberando la congestión usualmente ocasionada y reduciendo la contaminación ambiental y auditiva. Adicionalmente se buscará implementar diversas estrategias para la recuperación y activación de la zona. Entre estos la generación de un centro comercial y la recuperación del Río Surco, que a la vez se beneficiarán de una mejor infraestructura vial y peatonal gracias a las amplias avenidas.

Figura 10: Análisis de la zona según PLAM2035

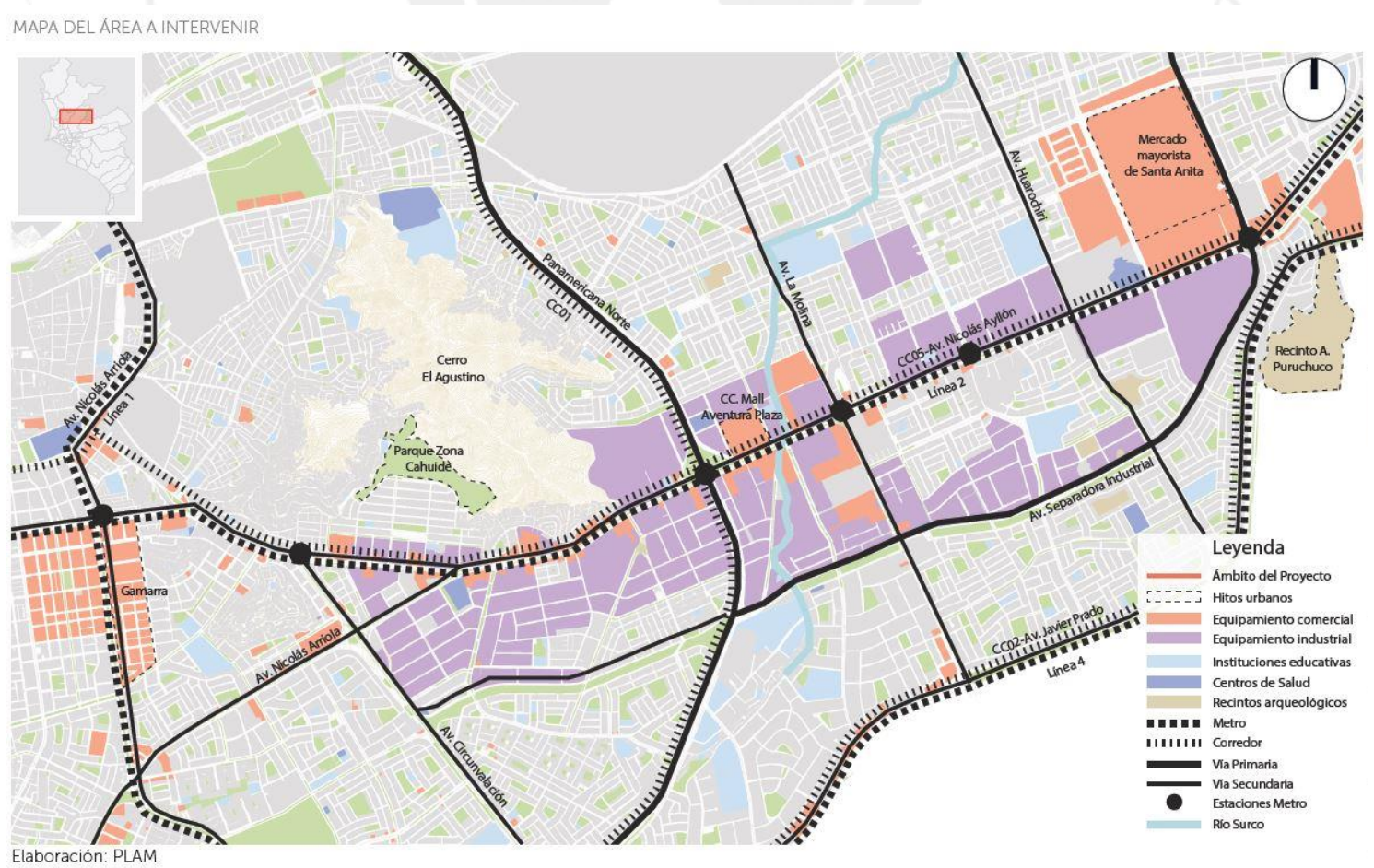

Fuente: Instituto Metropolitano de Planificación (2014) 
Como se observa en las figuras 9 y 10, las oportunidades en la zona son grandes y pueden tener un impacto positivo en sus alrededores; zonas que tienen alrededor de 50 años de antigüedad, pero que igual permanecen desatendidas y degradadas por el carácter actual de la zona.

El trabajo que realiza el grupo TYPSA para el MTC busca elaborar un modelo de transporte interurbano planificado y racional en un sentido técnico y económico que será desarrollado en el país en los próximos años, para el cual es necesaria la caracterización, cuantificación y el análisis de los flujos de pasajeros. Específicamente tendrá que recopilar y analizar información sobre los planes o estudios existentes en el sector de movilidad, las normativas y otros, al igual que realizar conteos para obtener los flujos de pasajeros y sus diversas características. Las encuestas formarán parte del estudio ya que ayudarán a caracterizar el motivo del viaje y lo que los pasajeros están dispuestos a pagar. Adicionalmente buscan comprender los motivos de los pasajeros al optar por el transporte interurbano informal, además de captar información sobre frecuencia de buses, velocidades, tiempos de viaje, etc.

Como mencionado, el objetivo es poder elaborar un modelo de transporte interurbano y proponer diferentes escenarios de modelación tanto a corto como a largo plazo (Grupo TYPSA, 2014).

\subsection{Zona de estudio: situación socio-cultural y económica}

\subsubsection{Lima: urbanismo inverso y la consolidación de Lima}

Las grandes oportunidades económicas que ha presentado la capital durante años, ha generado que muchas personas del interior del país decidan migrar a Lima buscando algún tipo de mejora económica y calidad de vida. Durante el gobierno de Leguía (1919-1930) se implementó una política que buscaba centralizar al país, mediante la industrialización. Se aplicó un modelo económico de industrialización por sustitución de importaciones, esto implicaba la fabricación de maquinarias y otros, generando una oportunidad de trabajo en Lima y por consecuencia, atrayendo una gran población en busca de oportunidades. Lima no se encontraba en la capacidad de recibir el número de migrantes, por lo que estos asumieron control de la situación, generando las primeras barriadas de la capital (Ludeña, 2002). 
Alrededor de 1940 el Censo Nacional de Población reveló que anualmente migraban más de 150 mil personas de las provincias a la capital, lo cual eventualmente llevó a la crisis de vivienda. Poco después se reubicó el Mercado Mayorista y Minorista, también conocido como la Parada, al pie del Cerro San Cosme. Esto tuvo como consecuencia la invasión del cerro por los mismos comerciantes y otros más (Matos Mar, 2011). Para 1946 ya estaban formadas las primeras barriadas informales: Cerro San Cosme y El Pino (Kapstein \& Aranda, 2014). Tan solo en 1956 las barriadas que se formaron en el Cerro San Cosme y el Agustino, alcanzaban una población de 13,536 pobladores. Desde entonces la inmigración se ha ido acentuando cada vez más, formando a través de los años los diversos barrios y distritos periféricos de la ciudad que hoy en día conforman los conos Norte, Sur y Este.

Los distritos más consolidados son aquellos que se encuentran más cerca al centro histórico ya que por su ubicación geográfica fueron los que acomodaron a los primeros migrantes, los cuales procedían de la sierra central del Perú. Es así como se forma en primera instancia La Victoria, donde llegaban los caminos que atravesaban los Andes, los que luego se convertirían en la Carretera Central. De este mismo modo con el pasar de los años se establecen El Agustino, Ate y San Luis.

Lima Este, el más antiguo y consolidado de los conos, es de esta forma la zona de la ciudad en la que vive la mayor cantidad de personas; llegando a tener dos millones y medio de personas, ósea poco más del $25 \%$ de la población total de la capital (Instituto Nacional de Estadística e Informática, 2014). Por su fuerte origen migratorio se sabe que más de la mitad de las cabezas de familia son procedentes del interior del país y el 75\% de la población restante tiene padres que no son limeños.

De igual manera es importante conocer los inicios de estos distritos, pues muchos fueron consolidados con el carácter de "barriada". Esto quiere decir que hay una temática de cultura y comunidad que viene desde los años 60's, al igual que una carencia de infraestructura y servicios básicos desde sus inicios.

San Cosme, la primera barriada oficial de Lima se caracteriza tanto por su conformación determinada y casi violenta como por las personas que la conforman que pertenecen a diversas capas sociales con diversos orígenes (Rodriguez \& Riofrío, 1972), y que por lo tanto influencia la zona de sus alrededores. De igual manera se dio con El Agustino y la invasión del cerro con el mismo nombre. El cerro el Pino tuvo un 
inicio similar y por lo tanto, se trata de una zona que comparte una serie de características de barriada (Matos Mar, 2011).

\subsubsection{Ubicación y contextualización de la zona de estudio}

El Terminal Terrestre de Yerbateros se ubica en el distrito de San Luis, rodeado por el cerro el Agustino, el Pino y no muy lejos el cerro San Cosme. Se encuentra en una zona cuyos inicios se dieron en forma de asentamientos y barriadas, y hasta el día de hoy carece de infraestructura básica, gestión de residuos, espacio público y tiene problemas de hacinamiento, entre otros. Será de gran importancia comprender los sucesos que llevan a la conformación de estos barrios, ya que a la vez definen el carácter de este y de sus pobladores. Servirá para comprender apreciaciones, valores, preferencias, temores y necesidades de los vecinos de la zona, lo cual nos permitirá una mejor aproximación para la regeneración urbana a plantear en el proyecto.

\subsubsection{La primera barriada de Lima: Cerro San Cosme}

La barriada del Cerro San Cosme se crea en 1946 debido a la falta de oportunidades para generar vivienda en la zona. Hasta ese mismo año el cerro había permanecido deshabitado, pues pertenecía a Luis y Alberto Cánepa, dueños de la hacienda "El Pino". Los invasores, principalmente trabajadores de los mercados de la zona, tenían la necesidad de conseguir una vivienda cerca de su zona de trabajo, por lo que en primera instancia se ubicaron en una de las avenidas cercanas con viviendas precarias. Diferentes grupos provenientes de diversas partes del país se fueron anexando a la pequeña invasión. Al poco tiempo ya habían ocupado una buena porción de terreno, tapando la acequia que pertenecía a la hacienda "El Pino". Poco después se hicieron las denuncias por parte de los hermanos Cánepa y fueron desalojados. El grupo se organizó y les propuso a los dueños de la hacienda comprar una parte de sus terrenos o alquilarlos, pero su propuesta fue rechazada (Matos Mar, 2011).

Eventualmente el grupo se organizó nuevamente para invadir de manera organizada una zona del Cerro San Cosme. Esta acción se realizó el 24 de Setiembre de 1946 y se instalaron 120 personas. La organización continuó, pues crearon una Asociación de Pobladores del Cerro San Cosme con una junta directiva y buscaron apoyo del estado. Adicionalmente acordaron que cualquier persona que necesitara una 
vivienda podría unirse a la barriada, por lo que poco a poco se generó un grupo suficientemente grande como para poder resistir a las autoridades. Eventualmente los hermanos Cánepa realizaron una denuncia ante los invasores por haberse apropiado de sus terrenos, pero las autoridades no pudieron desalojarlos sino se dedicaron a prevenir mayores invasiones. A pesar de esto, se dio una segunda invasión de otras 100 personas lo cual generó un motín en el cual falleció una persona. Este último evento desencadenó una protesta ante el gobierno que eventualmente terminó cediéndoles el derecho a utilizar el Cerro San Cosme (Matos Mar, 2011).

Es así que se formó la primera barriada de Lima, según Matos Mar, pues por primera vez se presentó una invasión organizada con carácter determinado y dispuesto a pelear por los terrenos deseados. Matos Mar considera que la actitud en la que se tomó el Cerro San Cosme es lo que hace tan definitivo el acto y, claramente después de ver el éxito que tuvieron, se convirtió en una tendencia dentro de Lima.

\subsubsection{La continuación de las barriadas: Cerro el Agustino}

El 15 de abril de 1947, tan solo 3 meses después de la ocupación del Cerro San Cosme, se dio la invasión del Cerro el Agustino, el cual está dividido en cuatro zonas con los nombres de San Pedro, Santa Clara de Bella Luz, El Agustino y Doña Isabel.

El cerro se encontraba rodeado por haciendas. Estas haciendas se subdividieron para ser arrendadas en parcelas más pequeñas a otras personas, principalmente de procedencia asiática. Estos también subarrendaban parcelas aún más pequeñas a diversas personas que trataban el suelo para tener productos agrícolas, pero que además instalaron viviendas encima.

Las invasiones en el cerro El Agustino se dieron de manera paulatina, una tras la otra, imitando los hechos sucedidos en el Cerro San Cosme. Sin embargo, se trataba de mayores dimensiones; 400 familias en algunos casos. Nuevamente la resistencia a la autoridad se dio debido a la actitud determinada de los invasores y los grandes números que hacían más dificultoso el proceso de desalojo (Matos Mar, 2011). 


\subsubsection{La urbanización de Lima Este}

Lima Este está conformado por nueve distritos: Lurigancho-Chosica, Chaclacayo, Ate, Cieneguilla, La Molina, San Juan de Lurigancho, Santa Anita, El Agustino y San Luis. Estos distritos ocupan un área aproximada de $810 \mathrm{~km}^{2}$ y su población, según el censo poblacional del 2010, es de más de 2 millones de habitantes. Aproximadamente un $70 \%$ de esta población vive en barrios populares que tuvieron sus orígenes en diversas barriadas como la de San Cosme (1946), El Agustino (1947), Huáscar (1976) y Huaycán (1984).

Tabla 5: Distritos de Lima Este

\begin{tabular}{|c|c|c|c|c|c|c|c|}
\hline \multirow{3}{*}{ No } & \multicolumn{7}{|c|}{$\begin{array}{l}\text { DISTRITOS DE LIMA ESTE: } \\
\text { FECHA DE CREACIONN, SUPERFICIE Y POBLACIÓN 1981, 1993, } 2007 \text { Y } 2010\end{array}$} \\
\hline & & Fecha de & Superficie & 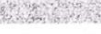 & Po & & \\
\hline & & creación & $(\mathrm{Km} 2)$ & 1981 & 1993 & 2007 & 2010 \\
\hline 1 & Ate & 4 agosto 1821 & 77.72 & 157,160 & 266,398 & 478,278 & 538,495 \\
\hline 2 & Chaclacayo & 24 abril 1940 & 39.5 & 33,553 & 35,994 & 41,110 & 42,982 \\
\hline 3 & Cieneguilla & 3 marzo 1970 & 240.33 & 4,566 & 8,993 & 26,725 & 33,382 \\
\hline 4 & El Agustino & 6 enero 1965 & 12.54 & 167,772 & 154,028 & 180,262 & 188,719 \\
\hline 5 & La Molina & 6 febrero 1962 & 65.7 & 14,776 & 78,235 & 132,498 & 148,738 \\
\hline 6 & Lurigancho-Chosica & 13 octubre 1894 & 236.47 & 62,478 & 100,240 & 169,359 & 189,974 \\
\hline 7 & San Juan de Lurigancho & 13 enero 1967 & 131.25 & 257,388 & 582,975 & 898,443 & 983,095 \\
\hline 8 & San Luis & 30 marzo 1968 & 3.49 & 57,824 & 48,909 & 54,634 & 57,175 \\
\hline 9 & Santa Anita & 25 octubre 1989 & 10.69 & - & 118,659 & 184,614 & 203,919 \\
\hline
\end{tabular}

Fuente: José Matos Mar (2011, p. 425)

Lima Este tiene una ubicación con una serie de beneficios, como lo son el Río Rímac y la Carretera Central como principal acceso de la sierra central del Perú a Lima, que además lo convierte en una de las zonas de Lima con mayor "familiaridad" con la sierra del Perú. Durante varios años del siglo XX, las riveras del Río Rímac servían para la recreación de la clase alta limeña, lo cual marcó la creación de varios clubes para recrear al igual que casas hacienda. 
De los nueve distritos, Ate es el más antiguo y fue fundado el 4 de agosto de 1821. Luego sigue Lurigancho - Chosica, Chaclacayo, La Molina, El Agustino, San Juan de Lurigancho, San Luis, Cieneguilla y finalmente Santa Anita (Matos Mar, 2011, pp. 425-457).

Ate originalmente estaba conformado por haciendas, y eventualmente cambió a ser centro de la industria textil desarrollando así un barrio obrero en su centro.

Santa Anita fue creada principalmente por el sector medio y aludía haber sido abandonada y dejada de lado por la constante preocupación de los municipios hacia las barriadas cercanas. Es conformada principalmente por empleados públicos, industria y uno de los núcleos comerciales más importantes de Lima: el óvalo Santa Anita.

El Agustino terminó de consolidar una buena parte de su conformación en los años 60 , después de haber pasado por el proceso de barriadas y apropiación de suelo mediante negociaciones con el estado y el privado. El distrito es oficialmente reconocido en 1965 y mantiene rasgos de sus diversos orígenes en los nombres de sus avenidas y urbanizaciones.

Lima Este es un importante centro de comercio para la economía de Lima, con la Carretera Central como eje para cientos de empresas de comercio, industria, restaurantes, fábricas, empresas de vehículos, etc. Además, es el punto de acceso de todos los productos de la sierra y selva central por lo que también cuenta con talleres de artesanos, fruteros, entre otros. Lamentablemente, en su mayoría se trata de un mercado informal, el cual es de vital importancia para el desarrollo económico de los pobladores de la zona.

Por otro lado, en los años 50, el 55\% de la población migrante se ubicaba en distritos del centro ya que los distritos periféricos eran principalmente rurales, como el caso de Ate que era rural en un $78 \%$. Esto fue cambiando desde la consolidación del Cerro San Cosme, llevando a la concentración de 253 barriadas en Lima Este: 124 barriadas en Ate, 12 en Santa Anita, 64 en el Agustino, 17 en Chaclacayo, 33 en Chosica y 3 en San Luis (Matos Mar, 2011, pp. 425-457). 


\subsubsection{Zona de estudio en la actualidad}

La influencia del terminal terrestre abarcará de forma directa las áreas circundantes en los distritos de San Luis, La Victoria, Ate Vitarte y El Agustino. Además, de forma secundaria, se esparcirá sobre distritos cercanos como el Cercado de Lima y la zona de Lima Este que es atravesada por el flujo de buses interprovinciales que circulan en la Carretera Central. Resulta importante analizar y entender la situación actual de la zona con el objetivo de responder de forma adecuada a las necesidades de este sector de la ciudad.

Haciendo un reconocimiento de la Zona Este de Lima, graficada en la siguiente figura, podemos comprender que se estructura a partir de la Carretera Central, la cual atraviesa de Este a Oeste y a su vez la separa en dos. Analizando la vía con mayor detenimiento se pueden reconocer diversos puntos de comercio incorporados a esta, razón por la cual sabemos que se trata de una zona con poder económico e influencia relativamente grande; la que aumenta paulatinamente conforme se acerca al Centro Histórico.

Figura 11: Nodos comerciales en zona de estudio

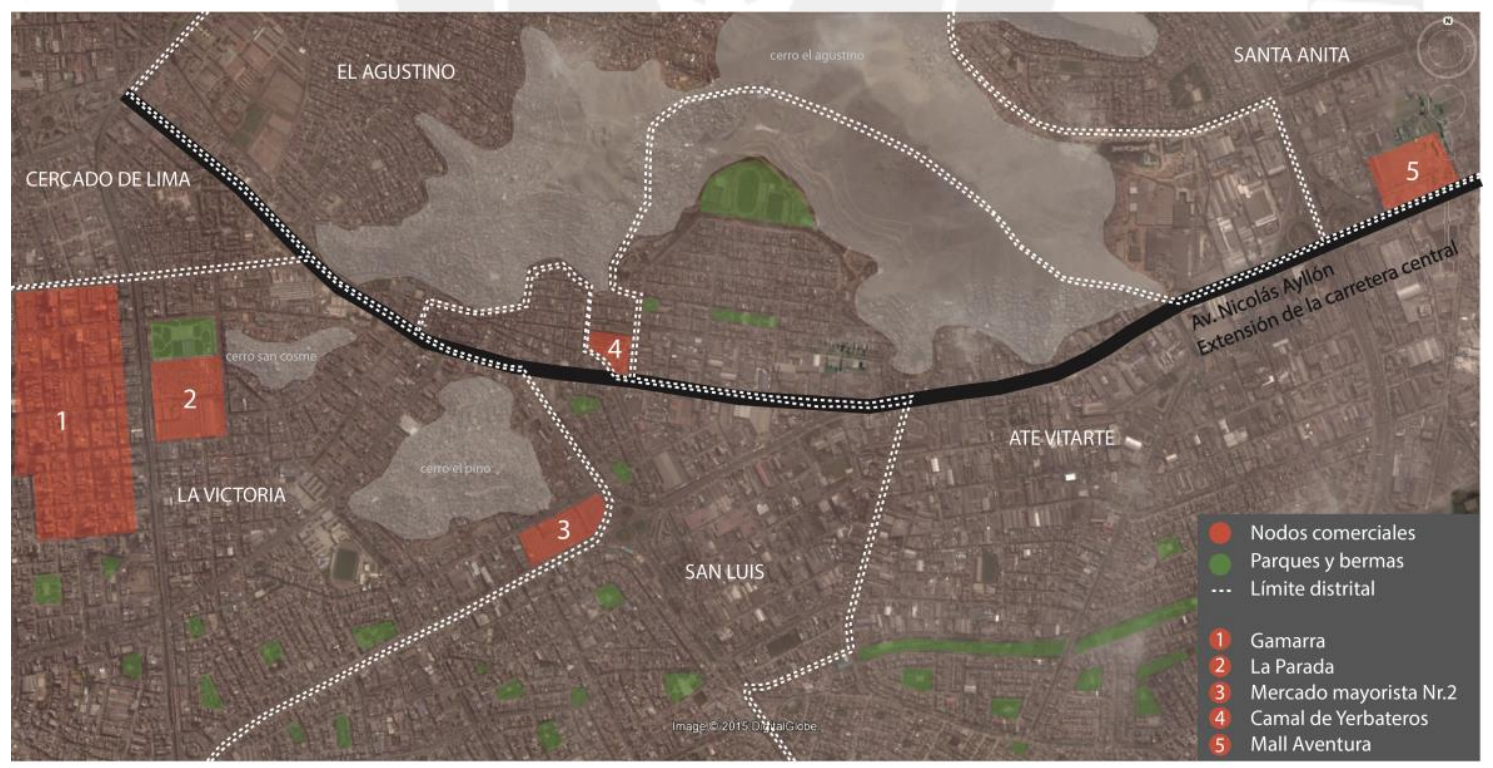

Fuente: Google Earth (2014)

Elaboración propia 


\section{Carácter Urbano}

Resulta de sumamente importante identificar los puntos comerciales de la zona como: el Gran Mercado Mayorista de Lima, el Mercado Mayorista Nr.2 de Frutas, el Camal de Yerbateros, Gamarra y la ex Parada, estos funcionan como lugar de acopio y venta para todos los productos provenientes, por medio de la Carretera Central, desde la sierra y selva central. Se trata de un encuentro previo a su repartición dentro de la metrópolis y sirve para separar las mercancías de acuerdo a sus diferentes rubros; productos agrícolas, ganadería, textiles, frutos, etc. Las ventajas generadas por el posicionamiento céntrico de estas vías respecto a Lima, se combinan con las vías de alimentación norte y sur (vía Evitamiento y Panamericana Sur y Norte) que se ubican cerca al centro histórico para abastecer a toda la ciudad con sus productos a un precio mucho menor. Esto se debe a que la provincia de Lima no genera la cantidad necesaria de productos agrícolas para su propia demanda y consumo, razón por la cual debe apoyarse en otras provincias para producirlos.

Este carácter de transporte y comercio viene de años atrás, siendo La Parada el motivo generador de las barriadas en el Cerro San Cosme y El Pino, en 1964. Características como estas, sumadas al actual sentido emprendedor de los residentes, le dan a la zona un potencial y capacidad de crecimiento muy favorable.

\section{Carácter demográfico}

La zona de estudio no solo se ubica en un nodo articulador de cuatro distritos, sino que además se encuentra en el límite entre Lima Este (2’506,449 hab.) y Lima Centro (729,854 hab.). Estas áreas geográficas son sumamente importantes para la ciudad ya que en ellas habitan más de un tercio de la población limeña (32.2\%). En Lima Este se ubican los dos distritos más poblados del Perú: San Juan de Lurigancho y Ate Vitarte (Ipsos, 2016). 
Tabla 6: Distritos en la zona de estudio

\begin{tabular}{|c|c|c|c|c|c|c|}
\hline & Distrito & Área & Habitantes & Hogares & Manzanas & Hogares/Mz \\
\hline \multirow{2}{*}{ Lima Este } & Ate Vitarte & $77.72 \mathrm{~km} 2$ & 649,348 & 138,231 & 5,891 & 23.5 \\
& El Agustino & $12.54 \mathrm{~km} 2$ & 191,738 & 48,352 & 1,427 & 33.9 \\
& La Victoria & $8.74 \mathrm{~km} 2$ & 168,189 & 60,118 & 1,026 & 58.6 \\
\cline { 2 - 8 } Lima Centro & San Luis & $3.49 \mathrm{~km} 2$ & 57,665 & 16,616 & 286 & 58.1
\end{tabular}

Fuente: Ipsos (2016)

Elaboración propia

Es importante resaltar que de los distritos sobre los que el terminal tiene una influencia directa, Ate Vitarte es el que presenta mayor cantidad de habitantes, pero debido a su gran tamaño es el que tiene la densidad de hogares más baja (ver tabla 6). De forma contraria, San Luis y La Victoria son los distritos con menos habitantes, pero al ubicarse más cerca al centro y ser más pequeños en área tienen casi el doble de densidad de hogares. Esta situación se explica si analizamos los tipos de vivienda en cada zona. En Lima Centro cerca de la mitad de todas las viviendas son casas independientes o quintas, dejando un $35 \%$ de edificios. Caso contrario en Lima Este más del $90 \%$ son casas independientes y menos del $10 \%$ son edificios, lo que genera una densidad mucho menor (Ipsos, 2016).

\section{Carácter social - económico}

En cuanto a la economía, el NSE C y D son los predominantes. Sin embargo, en el 2016 las empresas ubicadas en estos sectores representan cerca del $30 \%$ de todas las existentes en Lima, razón por la cual se ha registrado un ligero aumento de los NSE medios, sobretodo en Lima Centro. Es por este motivo que en los últimos años se ha registrado un aumento porcentual de hogares, pero una disminución de la población, lo que indica una mejora económica en las familias que permite una paulatina reducción del hacinamiento en las viviendas. 
Tabla 7: NSE en la zona de estudio

\begin{tabular}{|c|c|c|c|c|c|c|c|}
\hline \multirow{2}{*}{ Distrito } & \multicolumn{5}{|c|}{ \% de manzanas respecto a Lima Metropolitana } \\
\cline { 3 - 8 } & Total & NSE A & NSE B & NSE C & NSE D & NSE E \\
\hline \multirow{2}{*}{ Lima Este } & Ate Vitarte & $6.5 \%$ & $0.1 \%$ & $4.3 \%$ & $8.2 \%$ & $6.1 \%$ & $10.6 \%$ \\
& El Agustino & $1.9 \%$ & $0.0 \%$ & $0.2 \%$ & $1.7 \%$ & $1.9 \%$ & $2.9 \%$ \\
\cline { 2 - 8 } & La Victoria & $1.7 \%$ & $0.1 \%$ & $5.3 \%$ & $3.8 \%$ & $0.7 \%$ & $0.1 \%$ \\
\cline { 2 - 8 } & San Luis & $0.6 \%$ & $0.1 \%$ & $1.6 \%$ & $0.3 \%$ & $0.1 \%$ & $0.0 \%$ \\
\hline
\end{tabular}

Fuente: Ipsos (2016)

Elaboración propia

Como podemos ver en la tabla anterior los dos distritos de Lima Centro muestran un mayor número de manzanas del NSE B y $\mathrm{C}$, mientras que los distritos de Lima Este tienen mayor número de manzanas del NSE C, D y E. Esto se debe a que los primeros, son distritos que fueron consolidados en los años 40 y se integraron rápidamente a la ciudad. Por otro lado, los segundos se formaron a partir de barridas en los años 60 y aún se encuentran en una etapa de desarrollo.

Aun teniendo cierta predominancia de algunos NSE en los diferentes distritos, el ingreso promedio por familia no varía mucho entre las dos zonas. El ingreso promedio mensual por hogar en Lima Este es de S/. 3,211, mientras que en Lima Centro es de S/. 3460. De estos se gasta aproximadamente el $45 \%$ en alimentos y un $23 \%$ en servicios de uso básico como luz, agua y educación. Finalmente se gasta un $10 \%$ en diversión y cerca de 7\% tanto en salud como en transporte (Ipsos, 2016).

\section{Tenencia del terreno}

Una diferencia clave entre las dos zonas se observa si tomamos en cuenta el medio de adquisición de las viviendas. En ambas zonas se puede concluir que aproximadamente un $55 \%$ son propias y un $20 \%$ son cedidas por algún familiar o institución. La diferencia recae en las viviendas por invasión. En Lima Este cerca del 23\% de viviendas fueron obtenidas de este modo, sin embargo, en Lima Centro casi no existen. A diferencia del caso anterior los porcentajes de alquiler en Lima Centro llegan al 25\% mientras que en Lima Este no superan el 15\% (Ipsos, 2016).

Si nos enfocamos exclusivamente en el entorno inmediato al terminal terrestre de Yerbateros, podemos ver que casi todas las manzanas son de NSE C, con la 
excepción de las laderas de los cerros El Pino, San Cosme y El Agustino que por lo general son asentamientos humanos e invasiones del NSE D y E (ver figura 12).

Figura 12: Repartición de NSE en zona de estudio

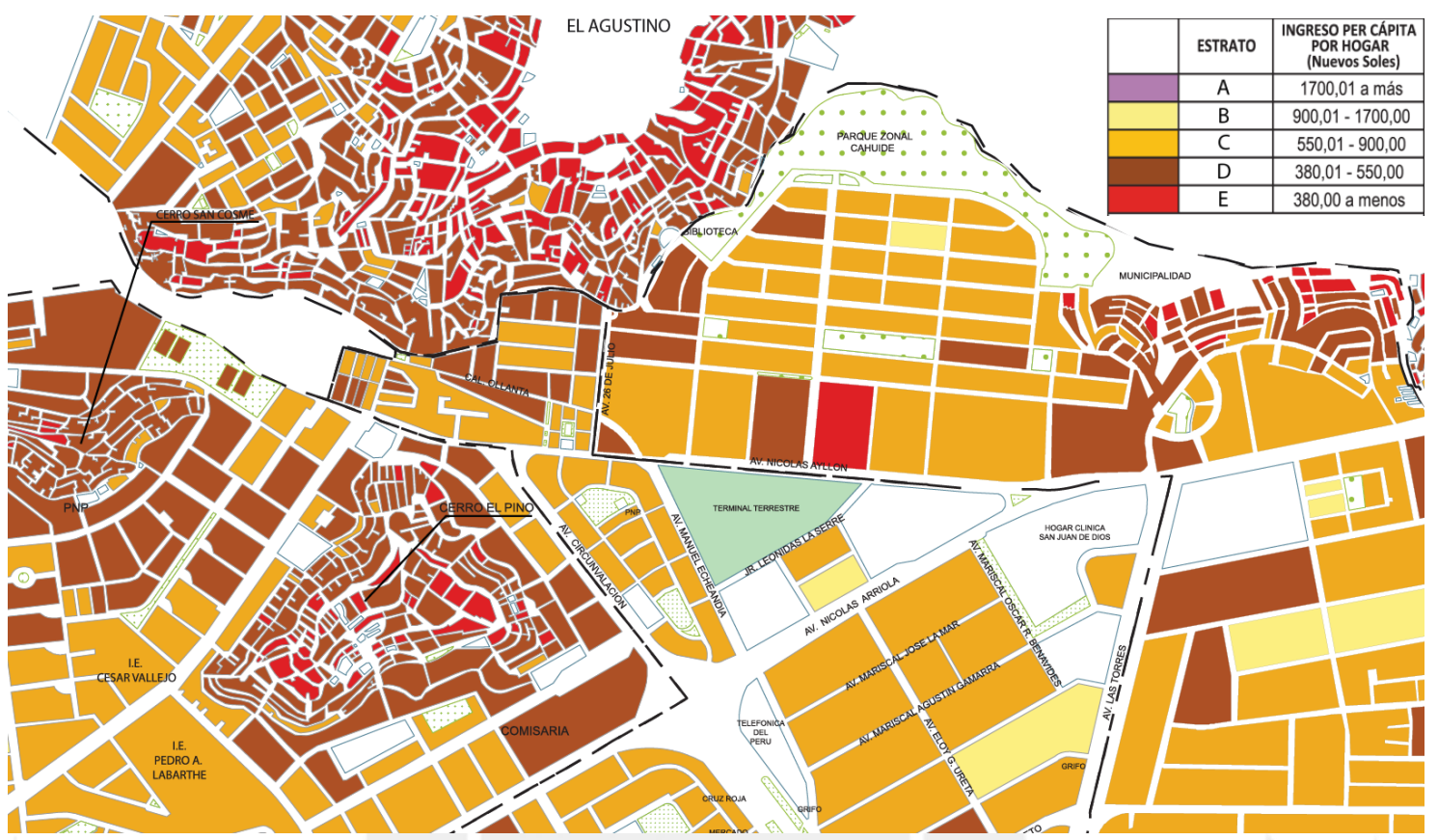

Fuente: Instituto Nacional de Estadística e Informática (2009)

Adaptado de Planos estratificados de Lima Metropolitana a nivel de manzana

\section{Nivel educativo}

Según el APEIM (2005) es importante resaltar que solo el 60\% de la población del NSE D ha culminado sus estudios secundarios, pero aun así un $60 \%$ de este sector cuenta con su propia empresa. Además, en su mayoría son propietarios de una vivienda de material noble revestido, aunque más de un tercio de estos hogares aún tiene techos provisionales. Casi el total de la población tiene acceso a luz eléctrica, pero solo la cuarta parte de ellos puede atenderse con el seguro social, mientras que el resto lo hace a través de servicios del estado. Más del $90 \%$ de los entrevistados compra sus alimentos en mercados cerca a sus casas, mientras que para la ropa la mayoría prefiere Gamarra.

La diferencia sustancial con el NSE C se puede apreciar en el nivel educativo, ya que en este último la mayoría completó los estudios secundarios y además dos tercios de la población ha terminado o se encuentra llevando una carrera técnica o 
universitaria. Respecto a los servicios de salud un $75 \%$ de la población cuenta con seguro Essalud. Si bien la compra de alimentos es mixta la gran mayoría prefiere comprar sus alimentos cerca de casa, pero no excluyen la compra en supermercados y admiten haber ido a comprar a uno de estos al menos una vez en los últimos 30 días. A diferencia con el NSE D, un tercio de la población compra su ropa en tiendas por departamentos (Asociación Peruana de Empresas de Investigación de Mercados [APEIM], 2014).

\section{Infraestructura y equipamiento}

Las empresas e instituciones que operan en la zona de estudio son muy importantes para mantener el progreso económico. Debemos resaltar el caso de Ate Vitarte, distrito en el cual funcionan más de 55\% de todas las empresas de Lima Este. De igual manera, La victoria posee cerca de $30 \%$ de las empresas de Lima Centro. Estos datos nos demuestran la importancia y el potencial económico que tiene la zona, los cuales tienen un gran impacto en el resto de la ciudad. Entre los principales rubros de empresas que realizan sus actividades se encuentran: las ventas al por mayor, los textiles y confecciones, los productos metálicos relacionados a minerales como el hierro, y la construcción (Ipsos, 2016).

Tabla 8: Número de empresas en la zona de estudio

\begin{tabular}{|c|c|c|c|c|}
\hline & Distrito & \# de empresas & \% respecto a la zona & Personas \\
\hline \multirow{2}{*}{ Lima Este } & Ate Vitarte & 568 & $55 \%$ & 91,546 \\
\cline { 2 - 6 } & El Agustino & 31 & $3 \%$ & 9,440 \\
\cline { 2 - 6 } Lima Centro & La Victoria & 421 & $29 \%$ & 75,602 \\
\cline { 2 - 6 } & San Luis & 160 & $11 \%$ & 12,959 \\
\hline
\end{tabular}

Fuente: Ipsos (2016)

Elaboración propia

El problema actual yace en la informalidad, la que aumenta la concentración de personas en ciertas áreas específicas y no permite el mejoramiento de la infraestructura ni de los servicios brindados. Esto se ve reflejado en los niveles socio-económicos de estas áreas que presentan un estancamiento en relación al creciente desarrollo del resto 
de la ciudad. Esto también se debe en muchos casos a la dificultad que se presenta en las vías de acceso; debido a la congestión vehicular y mal estado de las vías, por ende, a la lejanía en tiempo, mas no distancia, de los principales núcleos de desarrollo.

Si observamos con mayor detenimiento la zona cercana al terminal terrestre, comprendemos que se encuentra en la frontera de una zona netamente comercial e industrial con un área más residencial y de poca concentración de establecimientos comerciales. Las laderas de los cerros El Pino, San Cosme y El Agustino, resultan ser casi completamente residenciales.

Figura 13: Concentración de establecimientos comerciales

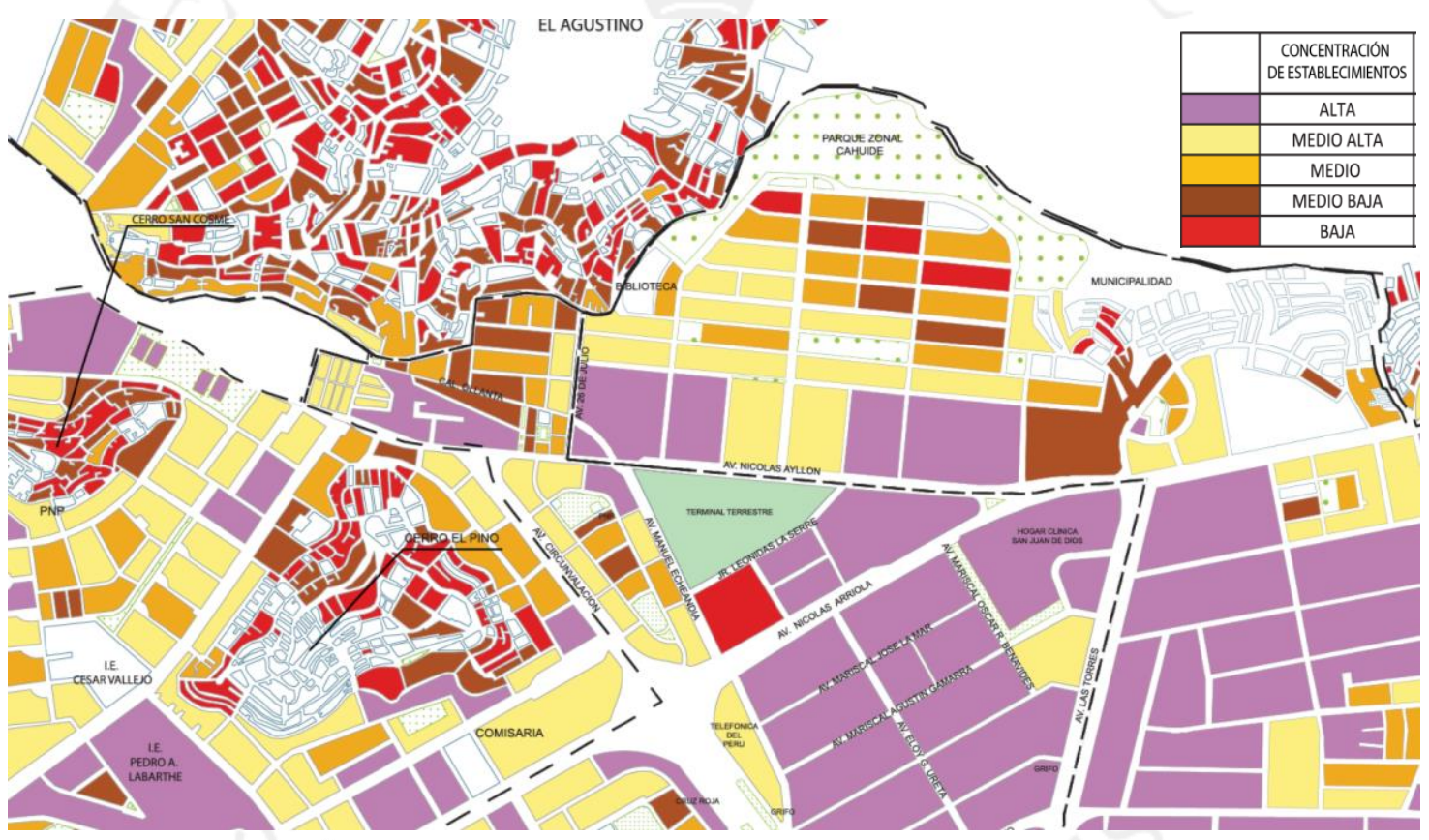

Fuente: Instituto Nacional de Estadística e Informática (2009)

Adaptado de Planos estratificados de Lima Metropolitana a nivel de manzana

Comprender las características, preferencias y conductas de los grupos humanos predominantes en la zona de estudio, es de vital importancia para resolver problemáticas relacionadas a la utilización del espacio público y también temas de violencia e inseguridad ciudadana. De igual manera es importante analizar la composición urbana del sector para poder proponer un proyecto de acorde a las necesidades reales y que responda a las actividades que allí se realizan. 


\subsubsection{El espacio público en la zona de estudio}

La palabra "espacio", según la Real Academia Española (RAE, 2014), se define de diversas maneras; "Parte que ocupa cada objeto sensible”, "capacidad de terreno, sitio o lugar", "distancia entre dos cuerpos", entre otros. Es decir, se refiere a un lugar y a un individuo. "Público" quiere decir ". . . contrapuesto a privado”, "perteneciente o relativo a todo el pueblo", "común del pueblo o ciudad”, por lo que nos olvidamos del individualismo y pensamos de manera colectiva. "Espacio público" es aquel sitio o lugar que pertenece a todo el pueblo.

Según el informe del 2014 del observatorio Lima Como Vamos (Lima Cómo Vamos, 2014), en Lima Este y en Lima Centro el nivel de insatisfacción con respecto al espacio público de la ciudad se promedia en un $26 \%$. Un $50 \%$ no se considera insatisfecho ni satisfecho y se consideran satisfechos un 23\%. Estos datos nos revelan la falta de interés con respecto al espacio público o la ignorancia hacia los beneficios que este puede aportar a la calidad de vida.

Por otro lado, se analiza la opinión del ciudadano con respecto a la privatización del espacio en la ciudad, mediante rejas o tranqueras. El $44.9 \%$ considera que tienen derecho a poner rejas si los vecinos se ponen de acuerdo. Sin embargo, un $52.6 \%$ considera que no deberían existir este tipo de restricciones. Este último pensamiento predomina en los sectores A/B. En general, al no comprender la importancia del espacio público, al ciudadano ya no le importa privatizar la calle.

El tema de la privatización del espacio público nos refleja el sentimiento de inseguridad hacia la ciudad, es decir el nivel de desconfianza que tiene el limeño hacia el resto. Esto tiene raíces en épocas pasadas donde el terrorismo estaba presente en cualquier parte de la ciudad y probablemente también en el hecho de que Lima es una ciudad conformada por migrantes donde no existe una verdadera identidad colectiva.

El problema del espacio público en Lima está estrechamente relacionado con la inseguridad ciudadana y el sentimiento de pertenencia y comunidad. Este pensamiento corresponde a todos los estratos socioeconómicos. El mismo informe nos muestra que el limeño considera que solo un $7.3 \%$ cuida de estos espacios públicos, según el $54 \%$ de los limeños encuestados. A la vez, un $82 \%$ considera que la inseguridad ciudadana es el principal problema que afecta la calidad de vida. 
Estos problemas se ven potencializados en zonas periféricas y barriadas de Lima. Una característica común es la densidad poblacional no por altura de edificación, sino por el hacinamiento y la falta de espacio público. Por consecuencia los índices de delincuencia y drogadicción son más elevados que en el resto de la ciudad, pues los adolescentes carecen de un espacio adecuado para recrear. Por ejemplo, en el caso específico de La Victoria, el principal problema que identifican los vecinos como perjudicial para su barrio es la delincuencia y drogadicción, además de la falta de limpieza pública y la inseguridad ciudadana. Vale recalcar que consideran más graves estos problemas que la pobreza, la falta de empleo y la deficiencia de los servicios básicos (Instituto Nacional de Estadística e Informática, 2015).

De las muchas variables que contribuyen a mejorar la zona, el número de áreas verdes $^{10}$ con las que cuenta el distrito contribuye notablemente en la seguridad de los ciudadanos. Este factor toma mayor importancia ya que según los estudios realizados, entre $50 \%$ y $60 \%$ de los habitantes de este sector de la ciudad suelen salir a caminar o encontrase con amigos fuera de casa en su tiempo libre. Resulta interesante ver que los distritos con mayor porcentaje de área verde sufren relativamente menos delitos que el resto. Claro está que este no es el único factor que contribuye a tener un distrito más seguro, pero sin duda es un factor clave. Si tomamos en cuenta los datos de la zona, San Luis cuenta con un $26 \%$ de áreas verdes con respecto al área construida y registra la menor cantidad de delitos. Por otro lado, Ate Vitarte (2\%), El Agustino (5\%) y La Victoria (6\%) son algunos de los distritos que cuentan con mayor número de delitos (INEI, 2014).

Cuando hablamos de delitos también es necesario considerar los servicios que brinda la municipalidad para reducir la criminalidad. Según la población de Lima Centro el 52\% asegura que existe vigilancia en su barrio, a diferencia de Lima Este donde solo $38 \%$ afirma lo mismo respecto a su barrio. Estos datos resultan ciertos cuando los comparamos con la cantidad de habitantes por cada serenazgo presente en el distrito: Ate Vitarte (1 cada 1938 habitantes), El Agustino (1 cada 1260 habitantes), La Victoria (1 cada 672 habitantes) y San Luis (1 cada 224 habitantes) (Ministerio del Interior, 2015).

\footnotetext{
${ }^{10} \mathrm{El}$ área verde por distrito corresponde a la sumatoria de las áreas de plazas, parques, bermas, alamedas, jardines y óvalos.
} 
Figura 14: Mapa de denuncias por comisión de delitos

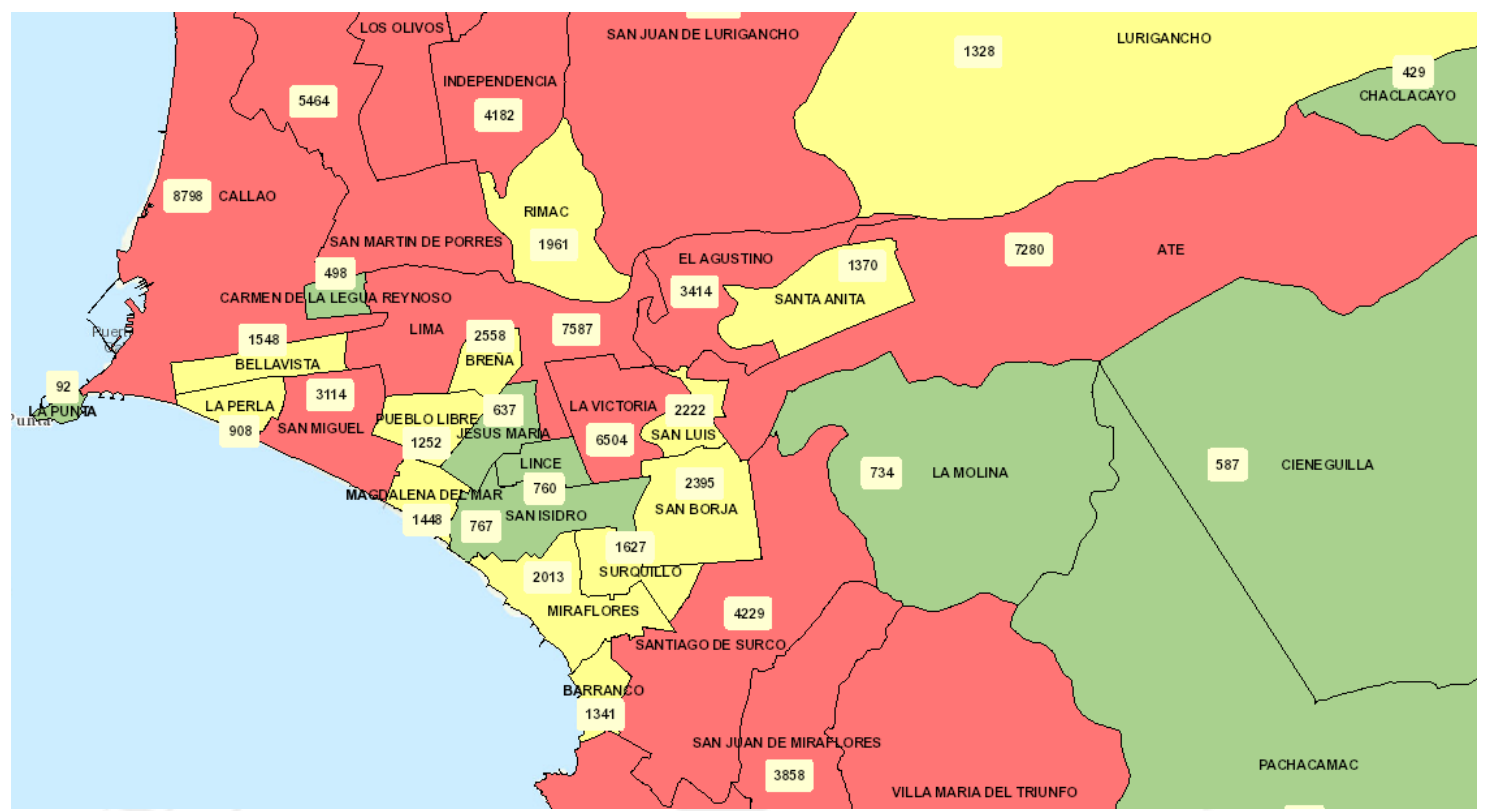

Fuente: Ministerio del Interior (2015)

Las estadísticas muestran que Lima Este es una de las zonas más inseguras, donde el 36\% de las personas afirman haber sido víctima de algún hecho delictivo. En los mismos estudios, Lima Centro registró en promedio $3 \%$ menos que el resto de áreas. Por más que sean cifras bastante elevadas todas las áreas estudiadas presentaron una reducción de $10 \%$ en hechos delictivos durante los últimos 5 años. Sin embargo, la percepción de inseguridad por parte de los ciudadanos sigue siendo elevada, donde casi el $90 \%$ de la población cree que puede ser víctima de algún hecho que atente contra su seguridad en los próximos doce meses (INEI, 2016).

\subsubsection{Línea del tiempo}

A continuación, se presenta una línea de tiempo que resume todos los hitos importantes del marco referencial ${ }^{11}$.

\footnotetext{
${ }^{11}$ Ver Línea del tiempo (ficha 1), ubicada en página 70.
} 



\subsection{Conclusiones Parciales}

La urbanización es un fenómeno que mueve millones de personas, genera dinámicas sumamente complejas en el territorio y afecta sus alrededores debido a su rápida expansión. Este desarrollo urbano no muestra indicios de estar reduciéndose, sino todo lo contrario; el incremento es constante y casi exponencial. Sin soluciones y estrategias de diseño urbano, este crecimiento se vuelve cada vez más insostenible, afectando el medio ambiente y la vida de los habitantes. Es por este motivo que la movilidad y el transporte son piezas fundamentales para un proceso de urbanización sostenible en el tiempo, por lo que no se puede subestimar el impacto que tienen estos conceptos en el diseño de ciudades y por consecuencia en el mundo. Es así que consideramos necesaria su inclusión en el diseño del terminal terrestre, motivo por el cual se determinó una ubicación para el terminal que estuviera interconectada con el resto de la ciudad, sin necesidad de incorporar infraestructura vial adicional. De igual manera, entender que por más que se trate de un proyecto para buses interprovinciales, será de vital importancia priorizar al peatón, permitiendo su fácil y libre desplazamiento de un medio de transporte al siguiente, convirtiendo el terminal en una infraestructura completamente inclusiva e intermodal.

Otro motivo para la inclusión de aspectos intermodales en el proyecto, es la mejora en la calidad de vida de los habitantes a través de la modernización del sistema de transporte urbano. En la actualidad, la mala gestión vehicular en los países en vías de desarrollo hace que el desplazamiento dentro de muchas ciudades aún gire en torno al automóvil, a pesar de haberse comprobado que es altamente ineficiente e insostenible. Como se menciona en el capítulo ${ }^{12}$, una de sus principales consecuencias es la generación de caos vehicular, por lo que su reducción será un punto importante para el terminal, ya que no solo representa un ahorro de capital monetario para la ciudad, sino que también repercute en la salud de los pobladores. Asimismo, puede solucionar problemas de marginalidad y exclusión social ya que facilita la accesibilidad hacia los servicios básicos.

Por estos motivos, el terminal terrestre de Yerbateros deberá cumplir con la intermodalidad que una metrópolis requiere; no debe solamente recibir los viajes regionales e interprovinciales, sino también funcionar como nodo articulador con la

\footnotetext{
${ }^{12}$ Ver capítulo 2.1 Del Transporte a la Movilidad.
} 
ciudad, conectándose con líneas de transporte público masivo e incentivando el uso de estas ante el uso del auto particular. Así, funcionará como un conector entre viajes regionales y viajes urbanos, permitiendo un fácil desplazamiento de usuarios.

Al estudiar el transporte actual y su historia en el Perú, comprendemos que las situaciones previamente mencionadas son características de nuestra realidad. Esto se debe a una serie de factores que van desde la complicada geografía del país, hasta el crecimiento masivo de las ciudades en los últimos años, que por consecuencia desbordan la capacidad de los municipios para gestionar el transporte. Esto no se restringe a la movilidad urbana, sino también abarca el transporte terrestre interprovincial. Al considerar la demanda existente, no es un tema que se pueda dejar desatendido, y menos, al estar en manos de muchas empresas informales. La demanda es muy alta y las opciones limitadas. Adicionalmente, el desorden normativo ha dejado en manos del mercado privado la administración del transporte terrestre interprovincial, por lo que juntar las empresas en un solo terminal será una iniciativa que dependerá del sector privado.

Las estrategias de ordenamiento territorial con respecto al transporte público e interprovincial son conocidas y concuerdan entre los diversos planes de desarrollo que Lima ha tenido. El consenso es claro: debe existir un terminal norte, un terminal este y uno sur que atiendan los diversos flujos de ingreso y salida a la ciudad. Por lo tanto, el terminal deberá agrupar las diferentes rutas para organizar el tráfico y aportar a la descongestión de la ciudad, reduciendo el número de estaciones de buses interprovinciales repartidas por esta y por lo tanto la congestión generada en zonas de la ciudad que no pueden soportar esa carga. Esto incluso trae consigo una mejora en la calidad de vida de los habitantes, pues al reducir la congestión vehicular, también se reducirá la contaminación ambiental y auditiva.

De igual manera se reducirá la informalidad del transporte interprovincial, ya que, al generar una alternativa bien implementada los usuarios optarán por esta. Esto se debe a que en la actualidad la infraestructura de terminales terrestres en Lima es muy precaria $^{13}$ y los usuarios desean un servicio adecuado. De esta manera se planteará un terminal terrestre con todos los servicios básicos y complementarios necesarios para el sentimiento de bienestar y seguridad del usuario, al igual que todos los requisitos de

\footnotetext{
${ }^{13}$ Ver capítulo 2.2.3 Situación actual de los terminales de Lima.
} 
seguridad en la infraestructura para los buses, garantizando una mejora significativa en la calidad del servicio del transporte interprovincial.

Finalmente, es importante considerar el aspecto socio-cultural de la zona. Con una historia de consolidación a través de barriadas, se trata de una cultura de migrantes que han logrado consolidarse de tal manera que hoy forman parte de la clase emergente. Sin embargo, con el pasar de los años, las costumbres y tradiciones de sus habitantes se han perdido, convirtiéndose en una sociedad con una cultura sumamente mixta, joven y posiblemente con falta de identidad. Asimismo, dado que la consolidación que tuvieron no fue planificada, su infraestructura urbana es muy deficiente, lo que no les permitió desarrollar un sentido de identidad y apropiación, haciendo que no perciban el espacio público como algo esencial para mejorar su calidad de vida y por consecuencia no muestran mucho interés al respecto. Una problemática derivada de la falta de espacio público es la inseguridad ciudadana. Por lo tanto, al combinar este problema con el desorden vehicular de la zona, el fuerte hacinamiento en las viviendas, la contaminación ambiental y la falta de consideración hacia el peatón, la calidad de vida de sus habitantes se degrada significativamente. Por estos motivos el terminal no solo tendrá que atender problemas de movilidad y transporte, sino también sociales. Es así que se deberá considerar la implementación de espacio público, que permita crear un nodo activador en la zona, trayendo diversas actividades y flujos de vecinos, usuarios y transeúntes, creando la actividad necesaria para reducir la inseguridad ciudadana en las calles cercanas. Además, tendrá que incorporar usos y espacios que permitan a los vecinos apropiarse e identificarse con el proyecto, para una mejor integración y aceptación por parte de este. 


\section{CAPÍTULO III: MARCO TEÓRICO}

\subsection{Glosario de Terminología}

\subsubsection{Terminal Terrestre}

Según el Reglamento Nacional de Administración de Transporte [RNAT], publicado en el Decreto supremo 017-2009/MTC, la definición de un Terminal Terrestre es la siguiente: “Artículo 3.75: Terminales Terrestres: Infraestructura complementaria del transporte terrestre, de propiedad pública o privada, destinada a prestar servicios al transporte de personas o mercancías, de ámbito nacional, regional y provincial." (Ministerio de Transportes y Comunicaciones [MTC], 2009).

En este mismo documento se precisa en el artículo 33.2 que cualquier empresa transportista deberá contar con un terminal terrestre para recibir la autorización adecuada de funcionamiento. Define que esta infraestructura deberá contar como mínimo con “. . . oficinas administrativas, terminales terrestres habilitados en el origen y en el destino de cada una de sus rutas, terminales terrestres o estaciones de ruta en las escalas comerciales y talleres de mantenimiento propios o de terceros." (Ministerio de Transportes y Comunicaciones [MTC], 2009).

Los terminales terrestres son obras arquitectónicas con su función principal centrada en ordenar el transporte de pasajeros y mercancías, facilitando el control de los horarios y además agrupando en una sola edificación las diferentes empresas transportistas.

Estas edificaciones, indispensables para el sistema de transporte terrestre, necesariamente deben contar con instalaciones y equipamiento para el embarque desembarque de pasajeros y carga, además de prever en la medida de lo posible la implementación de actividades complementarias para brindar comodidad, accesibilidad, seguridad e higiene a sus usuarios.

Por lo general están ubicadas en zonas estratégicas, conectadas a las principales redes del transporte vial con el objetivo de distribuir rápidamente los grandes volúmenes de pasajeros y vehículos que circulan diariamente por ellas. En este sentido 
también deben prever las facilidades para la implementación de la intermodalidad con otros medios de transporte urbano, facilitando el acceso a todos los usuarios.

Finalmente funcionan de forma complementaria como un punto de encuentro e interacción para un gran número de usuarios; por lo que, en la mayoría de casos, toman las características y ocupan el lugar de los espacios públicos.

\subsubsection{Autobuses}

Un autobús es un vehículo motorizado cuya función es transportar múltiples pasajeros. Los tamaños y capacidades de estos varían significativamente según su función específica, ya que existen buses urbanos y buses interurbanos o regionales.

Los buses urbanos suelen ser de un solo nivel, salvo en algunas ciudades o en casos de buses turísticos, los que cuentan con dos niveles. En algunas ciudades se utilizan autobuses articulados, los cuales buscan albergar una mayor cantidad de pasajeros. Estos son de mayor longitud, motivo por el cual requieren una articulación adicional para maniobrar dentro de la ciudad.

En ciudades en vías de desarrollo, los buses urbanos suelen ser muy variados en sus dimensiones y capacidades. Entre las opciones modernas más recurrentes están los sistemas de buses con carriles independientes. Este sistema de transporte masivo es una alternativa menos costosa que la construcción de un sistema de metro.

Una de las características principales de un bus urbano es la gran facilidad para el flujo de ingreso y salida de los pasajeros. Además, cuentan con menor cantidad de asientos y un mayor número de pasamanos y sujetadores, permitiendo así más personas de pie. Estas características facilitan, agilizan y maximizan el transporte de pasajeros, adaptándose al tipo de viaje realizado dentro de una urbe, donde se busca mover grandes cantidades de pasajeros en distancias cortas.

Es importante resaltar que, en muchas ciudades del mundo, los buses pueden ser eléctricos, ya que las distancias que recorren no son tan largas como las de los buses interurbanos. A diferencia de los autos eléctricos, los buses tienen una autonomía más corta, razón por la cual tienen que recargar más seguido. En una ciudad esto es realizable, pero para un bus interurbano esta opción no es viable. 
Las dimensiones de un bus urbano varían según marca y modelo. En promedio tienen 12 metros de largo y 3.5 metros de alto.

Figura 15: Dimensiones Bus Urbano
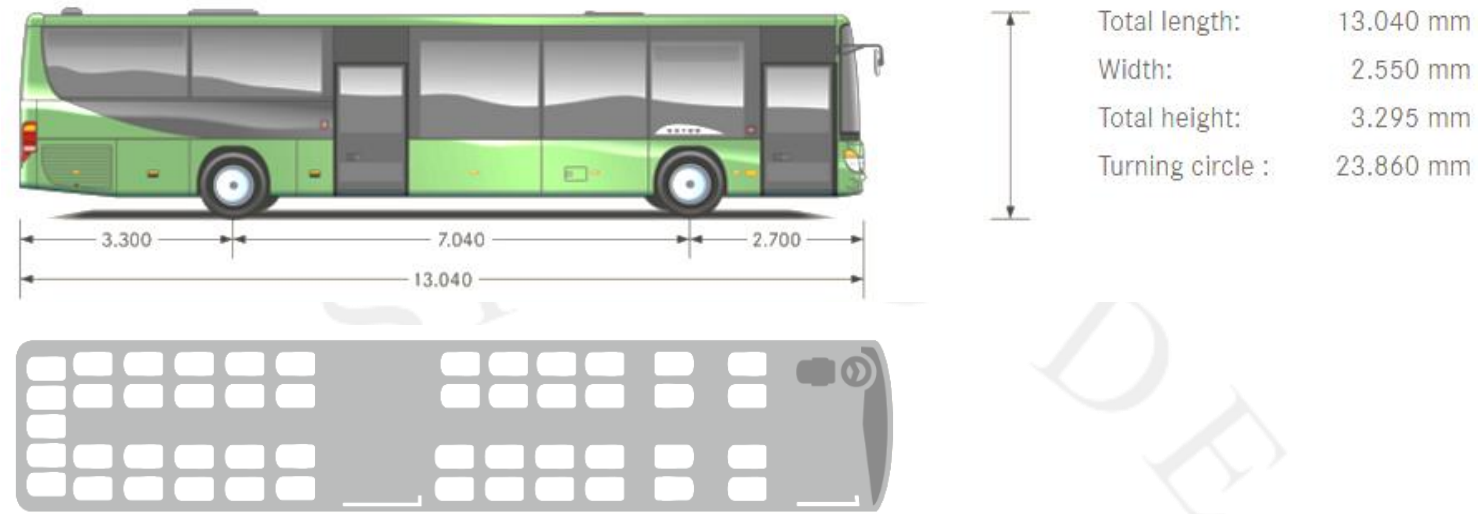

Fuente: Setra (2017)

Obtenido de https://www.setra.de/en/vehicles/multiclass/h-ul-models/s-416-ul.html

En el caso de buses interurbanos, las características son otras. Para empezar, se implementan butacas reclinables para mayor comodidad de los usuarios, también se maximiza el número de asientos, ya que no está permitido hacer viajes interurbanos de pie, es por esto que en muchos casos los buses cuentan con doble cabina. Por último, a diferencia de un bus urbano, el nivel de los asientos en un bus interurbano se ubica a mayor altura, ya que cuenta con una bodega de equipajes.

Las dimensiones de un bus interurbano varían según marca y modelo. En promedio tienen 14 metros de largo y 4 metros de alto, llegando hasta 4.20 metros en algunos casos. 
Figura 16: Dimensiones Bus Interurbano
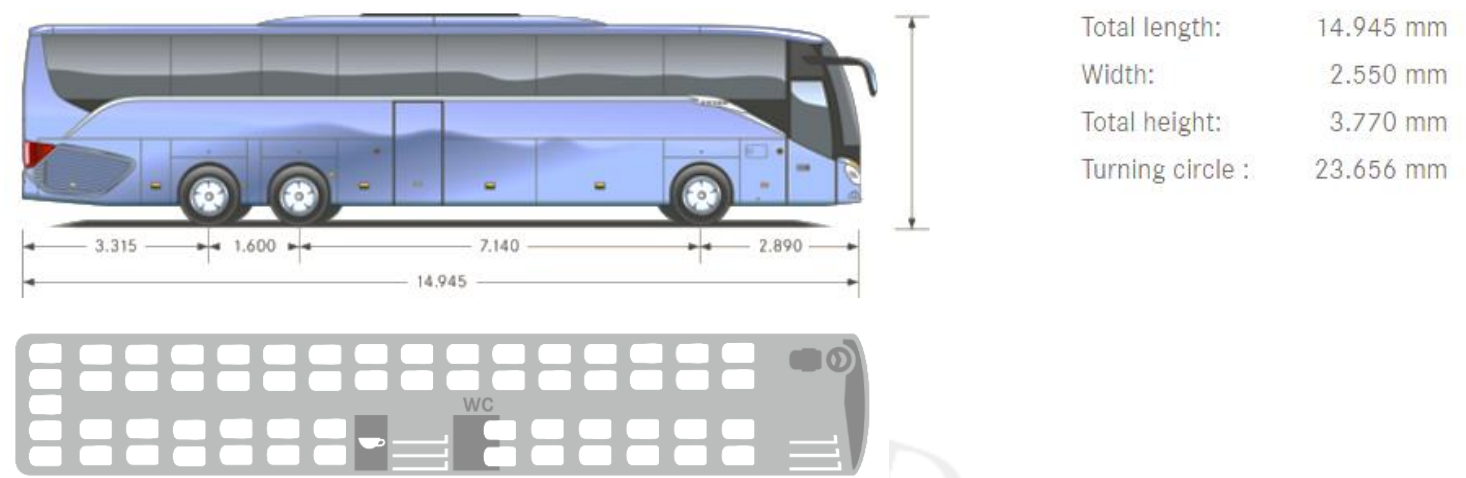

Fuente: Setra (2017)

Obtenido de https://www.setra.de/en/vehicles/comfortclass/hd-models/s-519-hd.html

\subsubsection{Intermodalidad}

La "intermodalidad" es un término utilizado principalmente en el ámbito de transporte. Cuando se habla del transporte de carga, es una pieza vital de la logística en el desplazamiento de un producto, ya que contempla diversos medios para llegar a su destino; ferrovía, barcos, aviones y camiones. Similar es el entendimiento de la intermodalidad cuando se habla de transporte de pasajeros, ya sea en un ámbito urbano o interurbano.

El prefijo "inter" quiere decir "entre" o "en medio", por lo cual "intermodalidad" se traduce como "entre medios (de transporte)" que hace alusión no solo al hecho de utilizar diversos medios para el desplazamiento, sino también al momento de intercambio.

La intermodalidad categoriza cuán fácil es moverse o desplazarse dentro de la ciudad utilizando medios alternos, observando los puntos en los cuales se cambia el medio de transporte y también la tarifa para el desplazamiento continuo. De esta manera, una estación intermodal congrega varias estaciones ya sea de bus, tren, metro, automóvil, ciclovía, etc. e incorpora la posibilidad de combinar varios tramos de una sola ruta bajo una tarifa.

\subsubsection{Barriadas}

Según la Real Academia Española, la barriada es un "barrio marginal, generalmente de construcciones pobres y precarias" (RAE, 2017). Con esta definición las "barriadas" 
no se diferencian mucho de lo que sería un asentamiento humano. Sin embargo, una barriada tiene una serie de características que la diferencian. Matos Mar enfatiza que la barriada se caracteriza, no solo por sus condiciones de habitabilidad sino por el medio con el que se consiguió crear el barrio.

Gustavo Riofrío enfatiza que las barriadas están compuestas por una mezcla diversa de capas sociales y orígenes.

Según Matos Mar, la definición de lo que es una "barriada" se dio con la invasión en el Cerro San Cosme. Con este hito se marcó un "nuevo modelo de crecimiento urbano" (Matos Mar, 2011, p. 87), que se propagó por el país, como movimientos organizados que buscaban invadir de manera planificada una propiedad privada. Como bien lo define Matos Mar, tenía un estilo “contestatario, bullente y emprendedor que combina organización, invasión, conflicto, asociación y actividades comunitarias” (Matos Mar, 2011, p. 88). Citando a Riofrío, “. . . la barriada responde a la necesidad de tener un lugar donde residir en la ciudad de amplios sectores urbanos. Dado que no se tiene otra posibilidad de obtenerlo salvo a través de la invasión de tierras . . ." (Rodriguez \& Riofrío, 1972).

\subsubsection{Sostenibilidad}

La Real Academia Española define la palabra "sostenible" de la siguiente forma: "Especialmente en ecología y economía, que se puede mantener durante largo tiempo sin agotar los recursos o causar grave daño al medioambiente” (RAE, 2017).

La sostenibilidad como tal, es definida por la Comisión Mundial del Medio Ambiente y del Desarrollo [CMMAD] en 1998 como:

“. . . el desarrollo que satisface las necesidades de la generación presente sin comprometer la capacidad de las generaciones futuras para satisfacer sus propias necesidades. . . El desarrollo sostenible requiere la satisfacción de las necesidades básicas de todos y extiende a todos la oportunidad de satisfacer sus aspiraciones a una vida mejor" (Macedo, 2005) 
Beatriz Macedo, de la Oficina Regional de Educación para América Latina y el Caribe [UNESCO] explica en su texto "El concepto de sostenibilidad" cómo es que la sostenibilidad como la entendemos hoy no es un término con algún origen ancestral ni nato, sino se trata de un significado que se origina netamente en el presente, desde el reconocimiento que nuestro planeta es finito y la humanidad no está considerando eso al explotarlo sin medidas de control: “. . . ese conocimiento es nuevo: la idea de insostenibilidad del actual desarrollo es reciente y ha constituido una gran sorpresa para la mayoría." (Macedo, 2005, p. 57). Además, considera que se trata de un concepto con poco avance, debido a que las consecuencias y desventajas del consumo incontrolado de los recursos de nuestro planeta se han empezado a mostrar recién en los últimos años de manera cada vez más notoria. Este aprendizaje lento también se debe a la mejora en la calidad de vida de ciertos poblados en el mundo en las últimas décadas, llevando a creer lo contrario de nuestro progreso. Macedo cita a Mayor Zaragoza de manera muy acertada:

“. . . la preocupación, surgida recientemente, por la preservación de nuestro planeta es indicio de una auténtica revolución de las mentalidades: aparecida en apenas una o dos generaciones, esta metamorfosis cultural, científica y social rompe con una larga tradición de indiferencia, por no decir hostilidad." (Macedo, 2005, p. 58)

Macedo entiende que la sostenibilidad, a la que se refiere como "desarrollo sostenible", se limita precisamente a la diferenciación entre "desarrollo" y "crecimiento". Es decir, el "desarrollo sostenible" no concibe el crecimiento dentro de sus opciones, pues significa un incremento o la "incorporación de mayor cantidad de energía (y) materiales" (Macedo, 2005, p. 58) en un mundo claramente finito. Pero en vez, enfatiza que sí es posible el desarrollo, trayendo así la mejora cualitativa para todo poblador sin importar su nivel socioeconómico ni estrato social.

Finalmente, la definición del desarrollo sostenible bajo el entendimiento de Ramón Folch (1998) resume la verdadera naturaleza de este concepto: "El desarrollo sostenible no es ninguna teoría, y mucho menos una verdad revelada . . . sino la 
expresión de un deseo razonable, de una necesidad imperiosa: la de avanzar progresando, no la de moverse derrapando" (Macedo, 2005, p. 59).

\subsubsection{Seguridad Ciudadana}

Se considera seguridad ciudadana a la acción integrada entre el estado y la ciudadanía para asegurar su convivencia tranquila, la eliminación de la violencia y la utilización de los espacios o vías públicas de forma pacífica. El Plan distrital de seguridad ciudadana de Santiago de Surco (2007) agrega: "La Seguridad Ciudadana es una situación social, donde predomina la sensación de confianza, entendiéndosela como ausencia de riesgos y daños a la integridad física y psicológica . . .". Asimismo, se puede definir a la inseguridad ciudadana como el sentimiento de vulnerabilidad ante la posibilidad de ser víctima de un acto delincuencial sin necesariamente haber sido victimado, el cual es trasmitido por contagio colectivo (Municipalidad de Santiago de Surco, 2007).

Es a partir de estas definiciones que se puede determinar la principal causa de la inseguridad ciudadana, identificándola como la cantidad de delitos que ocurren o se cree que ocurren en un determinado lugar. Existen tres condicionantes para que se realice un acto delictivo, en primer lugar, un autor motivado, seguido de una víctima potencial y finalmente un espacio favorable. Las primeras dos condicionantes son difíciles de controlar, ya que nunca se sabe la identidad de un posible criminal, ni la de una posible víctima, por lo que sería inviable proteger o monitorear a todas las personas. Para controlar estos factores, existen leyes que protegen a las personas y castigan a los criminales con el objetivo de reducir los índices de criminalidad, pero aun así resultan imposibles de erradicar ya que en Lima existen altos niveles de pobreza y muchas personas recurren a este tipo de comportamientos como forma de vida.

La última condicionante, un espacio favorable, está relacionada a la falta de vigilancia y la percepción de abandono, factores que facilitan la realización de actos delictivos. Este punto se puede controlar con un trabajo conjunto entre el estado y la comunidad. El primero es el encargado de evitar espacios favorables para la delincuencia y mientras que los segundos se encargan de mantenerlos. Es importante hacer énfasis en que la percepción de inseguridad está estrechamente relacionada con el ornato de las ciudades, es decir que el mal estado de las vías o veredas, la falta de 
iluminación y el aspecto desmejorado de las edificaciones en general, ya que pueden condicionar el entorno social y volverlo más vulnerable a la delincuencia.

Finalmente, es necesario mencionar que en Lima se publica un informe anual sobre seguridad ciudadana y su situación actual desde el 2010, el cual no ha registrado un cambio sustancial en las tendencias analizadas. En la actualidad, el tema de la inseguridad ciudadana sigue siendo muy recurrente con un sentimiento predominante ya que las encuestas revelan que el $68 \%$ de los limeños se siente desprotegido, percibiendo un aumento en la delincuencia y una amenaza constante para su vida cotidiana (Lima cómo vamos, 2016). También es importante recalcar que los crímenes más comunes y recurrentes son los que generan mayor sentimiento de inseguridad como robos al paso, los que muchas veces son situacionales y no premeditados, a diferencia de crímenes más violentos o peligrosos que ocurren esporádicamente.

\subsubsection{Calidad de vida}

Resulta difícil definir la "calidad de vida", debido a los múltiples factores que la influencian y componen. Se encuentra estrechamente ligada al entendimiento de "bienestar" el cual es definido por la Real Academia Española como "Conjunto de las cosas necesarias para vivir bien" o "vida holgada o abastecida de cuanto conduce a pasarlo bien y con tranquilidad” (RAE, 2017). Asimismo, la definición para calidad de vida aparece bajo "calidad" y es la siguiente: "Conjunto de condiciones que contribuyen a hacer la vida agradable, digna y valiosa" (RAE, 2017). Se puede interpretar que la calidad de vida tiene que ver con un conjunto de servicios o adquisiciones que permiten a uno llevar una vida sana, duradera y tranquila. En el artículo "La Noción de la calidad de vida y su medición”, Carolina Salas y María Garzón estudian un enfoque de 1993 en el cual los conceptos que definen la calidad de vida se subdividen en Sociales, Psicológicos, Ecológicos y Enfoques cualitativos. El enfoque social abarca temas como la salud, el bienestar social, la amistad, el estándar de vida, la educación, seguridad pública, ocio, vecindario, vivienda, etc. (Salas \& Carzón, 2013). Se entiende entonces que la calidad de vida está estrechamente relacionada con las condiciones de vida, bienestar tanto a nivel de salud física y mental, como bienestar dentro de una comunidad y la composición de esta misma, al igual que su infraestructura. Por lo tanto, es importante contemplar factores como la contaminación auditivita, visual, ambiental, calidad y/o cantidad de espacio público, seguridad 
ciudadana y transporte. Vale enfatizar que el contexto social, económico y cultural del individuo marcarán expectativas que definirán la medición de su calidad de vida.

\subsubsection{Beneficios sociales de la arquitectura}

Cuando se habla de beneficios sociales en la arquitectura nos referimos a todos los factores derivados al diseño que generan un cambio positivo o representan una mejora en un servicio para la sociedad. Toda obra arquitectónica tiene un impacto en su entorno, el cual puede variar según la escala y el uso. Por lo general, en proyectos de infraestructura es donde se pueden apreciar una mayor cantidad de beneficios sociales, ya que están directamente relacionados a las necesidades de los usuarios y son obras de tal envergadura que su radio de influencia va más allá de sus límites urbanos.

Por lo general el primer impacto es visual y está relacionado con la estética del edificio, la cual puede ser positiva o negativa, y generará preguntas, cuestionamiento y discusiones. Los usuarios que circulen a diario en la zona serán testigos de su construcción e implementación, por lo que estarán constantemente afectados por el impacto que este tenga en su entorno, si este resulta ser positivo generará un sentimiento de apropiación que luego se convertirá en una fortaleza del proyecto (Arkiplus, 2011).

El segundo impacto está conformado por todas las variables externas al proyecto que se verán mejoradas gracias a la implementación de este. Por lo que resulta ser mucho más importante que el primero, ya que sus variables son cuantificables y representan un ahorro económico para la sociedad. Como se verá más adelante en el capítulo de viabilidad, el estado puede aceptar realizar una inversión a cambio de un retorno económico por ahorros sociales ${ }^{14}$. Entre los valores más importantes que se toman en cuenta se encuentran la reducción de la contaminación ambiental, la reducción de la congestión vial, la reducción de accidentes vehiculares, la absorción de $\mathrm{CO} 2$, la generación de empleo y la revalorización de la zona aledaña.

\footnotetext{
${ }^{14}$ Ver capítulo 7.3.3: Retorno de la inversión.
} 


\subsection{Sobre la intermodalidad}

Según el PLAM2035, Lima debe contar con tres terminales terrestres: uno en la zona norte, otro en la zona sur y el último en la zona este. Considerando que la sugerencia es implementar tres terminales para una ciudad con más de 9 millones de habitantes, se sobreentiende que la escala de cada uno de estos terminales deberá corresponder a la magnitud de cada salida/entrada a la ciudad. Si se contempla a nivel macro, se trata de tres portales de ingreso y salida a la ciudad de Lima, que por consecuencia deben contar con la conectividad correspondiente hacia el resto de la ciudad. Para comprender esta conectividad es importante entender conceptos como el de la movilidad, incluidos sus alcances y limitaciones dentro de un plan urbano. Esto, finalmente, permitirá la correcta inserción y conexión de un terminal terrestre con su entorno, tanto inmediato como lejano.

\subsubsection{Conceptos de la movilidad}

Cuando hablamos de movilidad, entramos al área de flujos, urbanismo e incluso estructuras sociales. Para empezar, existen una serie de terminologías que se deben definir antes de profundizar en la "movilidad" y la diferencia con el "transporte". La "movilidad" se refiere a personas, bienes o información y su capacidad de acceder o apropiarse de un espacio "socio-geográfico". A diferencia del transporte, abarca tanto estructura como cultura y se entiende que el efecto que esta podrá tener en términos socio-espaciales podrá ser completamente diferente según su contexto. Cuando hablemos de movilidad, entenderemos que abarca la accesibilidad, los conocimientos necesarios para aprovecharla y su desenvolvimiento frente al medio (Brand, 2012).

La accesibilidad es un término importante al hablar de movilidad, pues clasifica la facilidad con la que se puede llegar de un lugar a otro, utilizando la red de transporte existente. De igual manera, la intermodalidad es un factor que se debe contemplar. Este definirá la facilidad con la que uno puede desplazarse por la ciudad utilizando diversos medios de transporte a lo largo del recorrido. Así uno puede iniciar su camino con una bicicleta, hasta una estación en la cual la deposita, toma una línea del metro o bus y luego continúa caminando (Fundación Transitemos; Asociación Cruzada Vial; Asociación de Representantes Automotrices del Perú; EMBARQ Andino; Libélula; Lima Cómo Vamos; Luz Ámbar; Pontificia Universidad Católica del Perú; Swiss Contact, 2013). 
La movilidad comprende el movimiento de bienes, personas, dinero e incluso información, aplicando la constante búsqueda de menos costos y mayores velocidades. Es decir, aplicado al urbanismo, es la constante de búsqueda de mejoras en la infraestructura de transporte, reduciendo la congestión vehicular, implementando tecnologías no contaminantes y promocionando el transporte público o medios no mecanizados como son la bicicleta y la caminata.

Según Urry (2007) el movimiento y los flujos son organizadores de la vida social, pues no solo se trata de flujos físicos, sino también virtuales. Es decir, se trata de un organizador social y espacial (Brand, 2012).

En el informe "Movilidad, Transporte y Acceso: Una renovación aplicada al ordenamiento territorial" la investigadora Andrea Gutiérrez (2010), discute la diferenciación e incluso indaga más allá del clásico espectro contemplado por el urbanismo. La nueva mirada a estos temas, define el transporte como un componente material de la movilidad en un sentido técnico, pues entiende temas como la accesibilidad. La movilidad es definida de manera mucho más amplia, que no se limita al movimiento en el espacio, sino le agrega la movilidad de bienes, personas e información. Incluso abarca bienes inmateriales como lo son la tecnología, el capital o las ideas.

Como bien se resume en el artículo una idea de Ascher (2005): “La movilidad es un derecho de las personas que trasciende la eficiencia de llegar de un lugar a otro en el menor tiempo y al menor costo posible, e incumbe el disfrutar de la experiencia de moverse." (Gutiérrez, 2010).

Por otro lado, según Lussault (2005) la movilidad sirve para gestionar la acción en el territorio mediante la aplicación de, por ejemplo, el transporte.

“. . . la movilidad es una herramienta para articular el territorio y también para su (re)composición y la de los espacios de vida. Esto incumbe a la conectividad, asociada a la materialidad; y también a la sociabilidad, asociada a la cohesión, la integración y la identidad. Así concebida, la movilidad es resultante de la distribución territorial de infraestructuras y servicios de transporte, tanto como de aspectos personales enmarcados en lo familiar, vecinal, y social." (Gutiérrez, 2010) 
En resumen, cuando hablamos del transporte nos limitamos a la relación de oferta y demanda trabajando con datos cuantitativos y cualitativos de las infraestructuras y los desplazamientos de vehículos motorizados. La movilidad, por otro lado, contempla más aspectos: edad, género, categoría social y laboral. Además, considera los medios de transporte y desplazamientos por persona al día, con la finalidad de entender sus motivos. Busca entender problemas de accesibilidad que por lo general son más frecuentes en usuarios marginados en periferias de la ciudad. Es decir, la movilidad no solo contempla los desplazamientos, sino también al usuario y su entorno.

Figura 17: Pirámide de prioridades en movilidad - Evolución

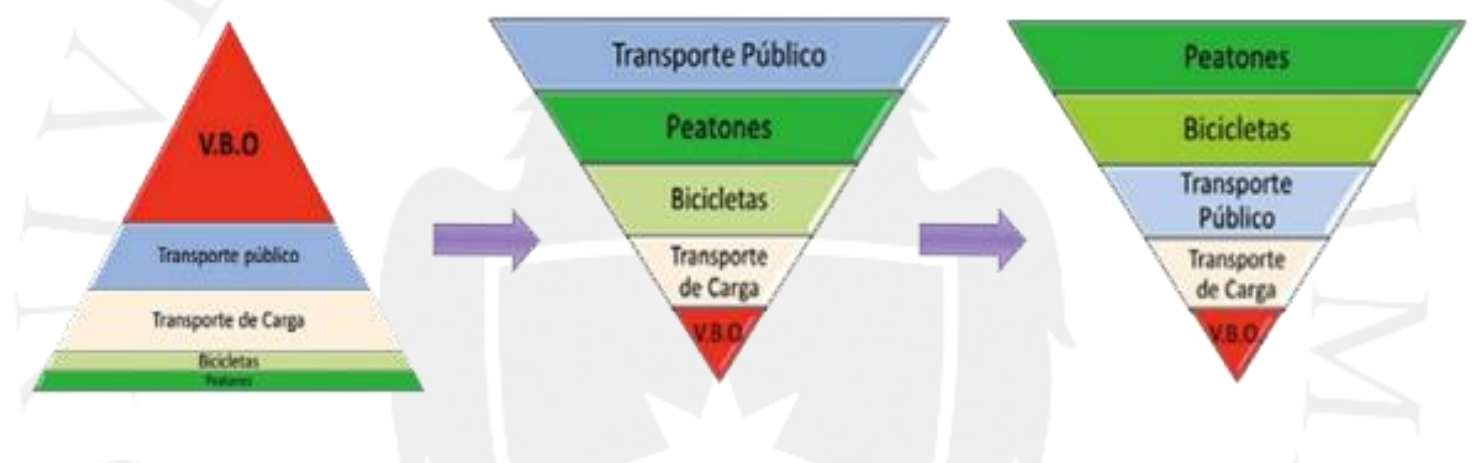

Nota: (De izquierda a derecha) Jerarquía actual, jerarquía estratégica de transición, jerarquía de la movilidad sostenible. VBO = Vehículos Motorizados de Baja Ocupación, autos privados.

Fuente: Fundación Transitemos; Asociación Cruzada Vial; Asociación de Representantes Automotrices del Perú; EMBARQ Andino; Libélula; Lima Cómo Vamos; Luz Ámbar; Pontificia Universidad Católica del Perú; Swiss Contact (2013)

Al estudiar la movilidad y por lo tanto el transporte surgen esquemas como aquella graficada en la figura 17. Esta "Pirámide Ideal” establece las prioridades según inclusión social, equidad, salud, medio ambiente y economía.

La pirámide aplica una lógica simple: del más vulnerable y menos contaminante, al más protegido, que puede ocasionar mayor daño o contaminación. Prioriza al peatón, pues lo beneficios de este para el planeta y la sociedad son abundantes, ya que no contaminan, utilizan poco espacio urbano y además interactúan. Es importante no dejar de lado a aquellos en silla de ruedas, con bastones, andadores o coches de bebés, entre otros. 
La siguiente prioridad la tiene el ciclista, pues se trata de un medio de transporte sumamente económico ya que no requiere ningún combustible, es flexible, no contamina, no congestiona e incluso promueve la actividad física que como consecuencia beneficia la salud del usuario. Luego continúa el transporte público masivo que debe apuntar a un nivel de eficiencia alto: es decir, movilizar un gran número de pasajeros utilizando la menor cantidad de energía para desplazarse. Incluye trenes, tranvías, metros, Buses Rápidos de Transporte Público [BRT], entre otros. Aquí también se incluyen los taxis, que a pesar de no poder transportar un gran número de pasajeros si cumplen con la disponibilidad inmediata en la ciudad. A continuación, el transporte de carga motorizado, refiriéndose no a los que transporten grandes volúmenes a puntos de acopio de la ciudad, sino los que abastecen negocios dentro de esta para satisfacer las necesidades del ciudadano.

Finalmente, los $\mathrm{VBO}^{15}$ por su cualidad privada. Abarca tanto automóviles como motocicletas. Ocupa un determinado espacio, pero no optimiza, ya que es privado. Además, demanda grandes inversiones de infraestructura, beneficiando a pocos.

El punto intermedio de evolución de la pirámide, es para aquellas ciudades que cuentan con grandes infraestructuras para automóviles, de manera que la transición hacia una mejor jerarquía sea gradual, cediéndole temporalmente el espacio al transporte público y a la vez buscando la implementación para los más vulnerables (Fundación Transitemos; Asociación Cruzada Vial; Asociación de Representantes Automotrices del Perú; EMBARQ Andino; Libélula; Lima Cómo Vamos; Luz Ámbar; Pontificia Universidad Católica del Perú; Swiss Contact, 2013).

\subsection{Sobre el espacio público}

El corazón de una ciudad es el espacio público. Todos los espacios restantes entre los edificios, sean una calle, plaza, parque, puente u otros, son lugares que serán utilizados por el ciudadano en múltiples formas. Es por este motivo que el diseño del espacio público es sumamente complejo y amplio. Implica entender todos los posibles usuarios que transitarán por este y aquello que los motiva a pasar por ahí. Implica además entender porque algunos espacios funcionan de manera óptima, mientras que otros se convierten en focos de delincuencia o abandono. Por este nivel de complejidad es vital

\footnotetext{
${ }^{15}$ Vehículos Motorizados de Baja Ocupación, por ejemplo: autos privados.
} 
comprender las principales teorías sobre el espacio público, pues nos permitirán identificar sus problemas: ¿Se utiliza? ¿Se ignora? ¿Se vandaliza? ¿Se trata de un espacio residual o un espacio diseñado? ¿Aporta al vecindario o genera inconveniencias? También nos ayudarán a identificar aquello que sí funciona de manera exitosa y el porqué.

El Terminal Terrestre de Yerbateros se encuentra en una zona con serias deficiencias de espacio público, lo cual repercute en la calidad de vida del usuario y del transeúnte que utiliza el terminal o atraviesa la zona. Sin embargo, son en muchos casos, acciones pequeñas o gestos simples que pueden lograr la mejora del espacio público. Para saber identificar los errores y aplicar las correcciones, se estudiarán conceptos del espacio público de Jan Gehl y Jane Jacobs, dos expertos en el tema. A través de la aplicación de sus teorías podremos integrar el proyecto mediante acciones pequeñas que lo harán parte del sitio y evitaremos la generación de un proyecto con características de un elefante blanco ${ }^{16}$.

\subsubsection{Teorías de Jan Gehl}

Hablar de espacio público es hablar de la ciudad en general. Como dice Enrique Peñalosa ${ }^{17}$ en el prólogo del libro "La humanización del espacio urbano": "Si la ciudad es el lugar de encuentro por excelencia, más que cualquier otra cosa, la ciudad es su espacio público peatonal" 18 (Gehl, 2006, p. 6).

Para comprender su significado es necesario entender, antes que nada, que el espacio público puede ser todo: este cambia junto al contexto, la escala con la que se

16 “Un “Elefante Blanco” es una obra pública de construcción, mantenimiento o instalación de un bien inmueble, la cual tiene un impacto negativo para la comunidad debido a que ha sido abandonada o está inconclusa, sus costos superan los beneficios de su funcionamiento, no es utilizada, o su uso es diferente para aquel que fue creada." (Presidencia de la República de Colombia, 2016).

${ }^{17}$ Ex alcalde de Bogotá (1998-2000), estudió economía e historia en la universidad de Duke y realizó su maestría en administración pública en París, Francia. Durante su alcaldía tuvo un fuerte enfoque hacia la movilidad, realizando ciclovías, caminos peatonales y su obra principal el “Transmilenio". En la campaña electoral se aproximó al ciudadano al recorrer las calles a pie, usar el transporte público y buscar contacto personal. (Peñalosa, 2015).

${ }^{18}$ El prólogo del libro La humanización del espacio urbano, es escrito por el ex Alcalde de Bogotá, Enrique Peñaloza. 
mira y el punto de vista de quien lo analiza. En una casa el espacio de uso común; la sala y la cocina, es el espacio público para los miembros de esa familia. En el barrio; la calle y el parque, son el espacio público para los integrantes de esa comunidad. De esta misma forma en una ciudad; la vía y la plaza principal son los espacios públicos para los ciudadanos. Uno no excluye al otro y todos existen a la misma vez, pero cada individuo solo los percibe uno a uno, conforme se desplaza y atraviesa los umbrales entre las diferentes escalas.

Hablar de cada uno de ellos sería muy extenso y no viene al caso de nuestra investigación, es por eso que nos vamos a enfocar en la escala pertinente para nuestra tesis: la ciudad. "La cantidad y la calidad del espacio público peatonal determinan la calidad urbanística de una ciudad" (Gehl, 2006, p. 7).

Todas las personas, por lo general, tienen una necesidad de contacto. Esto solo se puede dar de manera natural en el espacio público, y es por esto que resulta tan importante entender que la satisfacción de un ciudadano está muy ligada a la ciudad en la que vive, viéndose la mayoría de veces fuera de su alcance encontrar soluciones ya que se escapan de su rango de acción. Para comprender qué tan buena es la calidad del entorno físico, existen tres factores a analizar, estos miden que tipo de actividades se realizan en el espacio público y por ende como lo perciben sus principales usuarios, los ciudadanos. La primera actividad son las acciones necesarias, seguida por las acciones opcionales y por últimos las actividades sociales.

Las acciones necesarias suceden siempre, sin importar la calidad del entorno urbano. Esto se debe a que los ciudadanos están más o menos obligados a realizarlas; es el caso de ir a hacer las compras, ir al trabajo o ir a la escuela. Las actividades opcionales por otro lado dependen completamente de la calidad y la percepción que tiene el usuario de su espacio público, ya que son las acciones voluntarias que realiza cada uno fuera de los espacios privados; dar un paseo o hacer ejercicio fuera de casa, son algunos ejemplos de actividades que uno elige realizar y que son completamente proporcionales al grado de satisfacción que se tiene con el entorno urbano. El último punto son las actividades sociales o resultantes. Estas también están vinculadas y son en cierta medida proporcionales a la calidad del espacio público de la ciudad, ya que son todas las interacciones imprevistas que suceden como resultado de las relaciones con 
otras personas durante el desarrollo de las dos primeras actividades. Es decir, relacionarte con vecinos o conocidos cuando te encuentras con ellos en la calle.

En el caso de los dos últimos tipos de acciones, estas son determinantes para evaluar el espacio público, porque cuando este no es satisfactorio, solo se realizan las actividades estrictamente necesarias. Por consiguiente, las actividades opcionales y resultantes tienden a durar muy poco tiempo ya que se prefiere regresar rápido a casa.

Paralelamente a la necesidad de contacto, existe la necesidad de estímulo. Esta última se caracteriza por la experiencia de estar con otras personas, recibir estímulos externos y variaciones sensoriales; los que se presentan únicamente de esta forma, en contraposición a la monotonía de ver edificios y objetos inanimados constantemente. Es por esta razón que Jan Gehl dice:

"Donde quiera que haya gente (en los edificios, los barrios, lo centros urbanos, las zonas de recreo, etcétera) por lo general es cierto que las personas y las actividades humanas atraen a otras personas. La gente se siente atraída por la gente" (Gehl, 2006, p. 31)

Es por esta razón que resulta tan importante activar los espacios públicos de la ciudad, ya que si estos funcionan de manera adecuada la gente va a ocuparlos de forma automática. Una calle peatonal, un parque o una plaza nunca tendrán dos sensaciones iguales. Es por esto que con las características físicas correctas las personas siempre estarán naturalmente dispuestas a utilizarlas, gracias a su necesidad de nuevos estímulos sensoriales.

De igual forma, en la que un buen o mal planteamiento arquitectónico del espacio urbano puede afectar de manera significativa en el desarrollo de actividades beneficiosas para los ciudadanos, un mal planteamiento urbanístico o vial tiene la misma capacidad. Las vías para automóviles son necesarias para el funcionamiento de la ciudad, pero se les debe prestar mucha importancia cuando se las relaciona con el espacio del ciudadano de a pie. Estos tienen gran capacidad de influir en la percepción de las personas de su entorno aledaño. La velocidad de circulación de un vehículo motorizado $(60 \mathrm{~km} / \mathrm{h})$ es mucho mayor a la que las personas están fisiológicamente 
adaptadas $(5-15 \mathrm{~km} / \mathrm{h})$, y es por esto que no son compatibles en el mismo entorno inmediato y se dificulta tremendamente la interacción entre peatones y autos. Ninguno de los dos está en las capacidades de percibir cualidades del otro. Calles con poco, regular o mucho tráfico tendrán definitivamente un uso peatonal diferente, razón por lo que las relaciones interpersonales se desarrollarán diversamente en cada uno de los casos, siendo las calles con mayor tráfico las que registrarán menos interacciones entre los peatones.

Nuestros sentidos juegan un papel muy determinante cuando se habla de relaciones interpersonales. Si estos son contemplados o no en el diseño de un espacio público, se verá afectada definitivamente nuestra forma de comportarnos. Por ejemplo, la vista está diseñada para ver planos horizontales, casi $180^{\circ}$, y no verticales. Nos resulta mucho más fácil percibir e interactuar con elementos en un solo nivel; como una calle de cien metros de largo con tiendas consecutivas, que con elementos en varios niveles; una variación de más de tres metros es suficiente para que pasen desapercibidos en nuestro rango visual. De la misma forma, espacios muy pequeños donde las interacciones entre desconocidos ocurren en distancias muy cortas resultarían incomodos y espacios muy grandes, a su vez, harán que no se produzcan relaciones en absoluto, ya que casi no habría interacción entre las personas.

Jan Gehl identifica cinco medios a través de los cuales el arquitecto y el urbanista pueden inhibir o fomentar el contacto entre las personas, trabajando con los sentidos más importantes para la interacción: la vista y el oído. 
Figura 18: Cinco formas de controlar el contacto

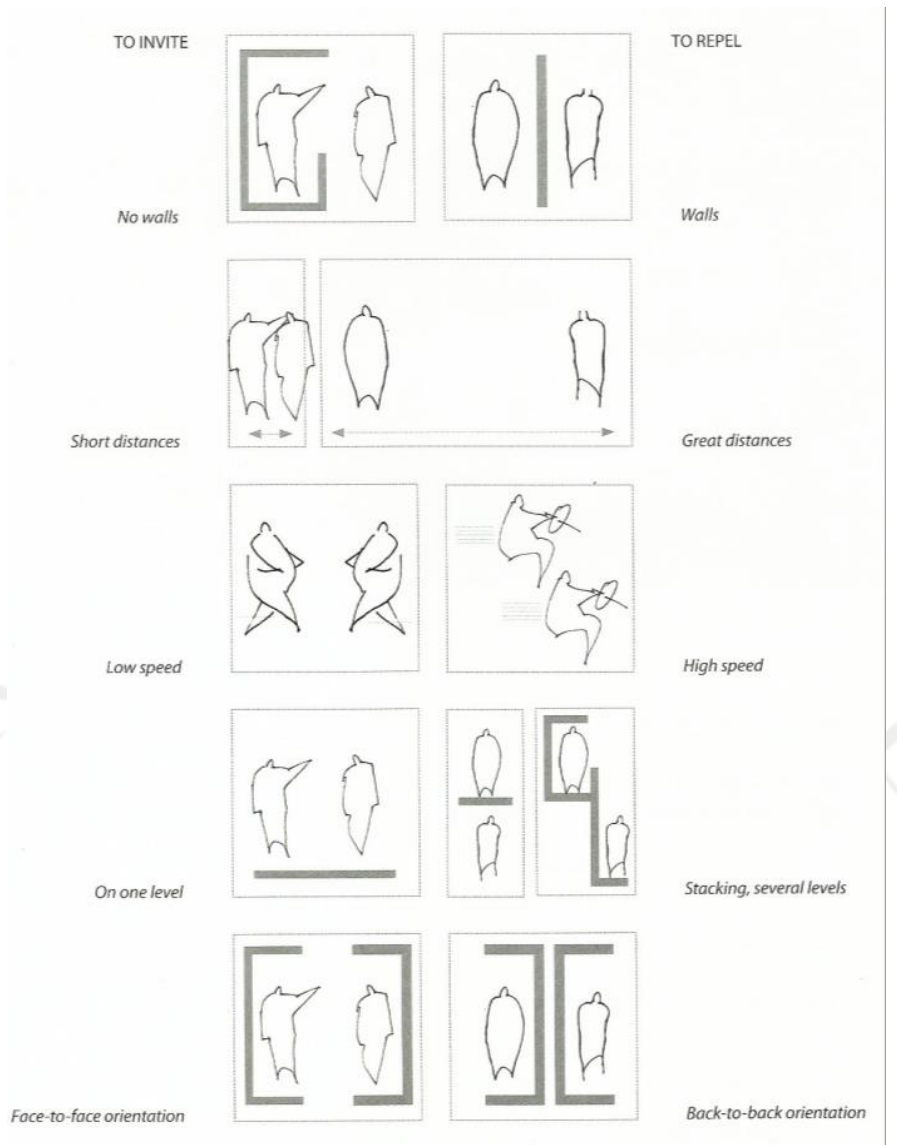

Fuente: Jan Gehl (2010, p. 237)

Las diversas situaciones graficadas en la figura 18 son acciones que son correctas dependiendo de lo que se quiere lograr. Inhibir el contacto no es necesariamente malo. Básicamente son formas de interactuar entre el entorno físico y los usuarios, que tienen como resultado agrupar a las personas o integrar, abrir y atraer las actividades que estas realizan. Si se desea, por el contrario, también pueden dispersar, segregar, cerrar o repeler tanto a las actividades como a los individuos que las realizan.

Además de fomentar el contacto entre personas es necesario que cuando se busque crear espacios para la gente se contemplen temas como las actividades que se puedan realizar optativamente allí. Es aquí donde el carácter y el contenido de la vida exterior cobra importancia. 
"Que las personas y los acontecimientos se agrupen en el tiempo y en el espacio es un requisito para que pase algo, pero es más importante qué actividades se pueden desarrollar. No basta con crear espacios que permitan a la gente ir y venir. También debe haber condiciones favorables para deambular y entretenerse en esos espacios . . .” (Gehl, 2006, p. 143)

Existen tres acciones indispensables que deben ocurrir para que un espacio público este correctamente adecuado para su uso: poder caminar libremente dentro de él, poder estar de pie sin estorbar al resto y por último poder sentarse para descansar o pasar el tiempo.

La primera es completamente necesaria para siquiera considerar el espacio exterior como público. Caminar es ante todo un tipo de transporte, que brinda la posibilidad de estar presente en un entorno urbano. Poder caminar libremente y sin interferencias es un requisito indispensable. Las diferencias de nivel pueden en cierto grado influir en el comportamiento de las personas, es deseable evitarlas, y muchas veces llevan a la modificación de una ruta preestablecida solo por el hecho de no tener que bajar o subir niveles. El espacio resulta mucho más amigable con los peatones cuando se utilizan rampas o subidas progresivas en vez de escaleras prolongadas.

Estar de pie es una actividad intermedia entre caminar y estar sentado. Es en realidad el primer contacto real entre el usuario y el lugar donde se encuentra, ya que aquí se le permite por primera vez la posibilidad de levantar la cabeza, dejar de preocuparse por donde está caminando y ver lo que le rodea. Muchas veces la actividad solo toma unos segundos antes que el usuario prosiga con su camino, pero otras veces es muy importante porque determina si éste se quedará o no de manera prolongada en aquel lugar. Si el espacio cumple con sus expectativas es muy probable que la persona decida quedarse, si hay donde hacerlo. Tener la posibilidad de estar resguardado del flujo peatonal constante, protección del clima o tener una visual sobre alguna actividad interesante suelen ser algunas de las principales características necesarias para que esta actividad se desarrolle.

El mejor atributo que puede tener un espacio público, es la capacidad de brindarle a su usuario un lugar donde sentarse, es aquí donde se producen las estancias largas, las que permiten la interacción prolongada entre personas, por lo que se activa 
de manera considerable toda la zona pública. De esta manera aparecen ciertas actividades que solo se pueden presenciar en estas condiciones y no en ninguna de sus etapas precedentes: leer el periódico, jugar ajedrez o dar de comer a las palomas. Son las acciones prolongadas las más efectivas para aplicar la idea de que "si está pasando algo, la tendencia es que se incorporen más personas y acontecimientos" (Gehl, 2006, p. 83).

Poder ver, oír y hablar con facilidad son algunas características necesarias en cualquiera de las acciones descritas previamente. Por ejemplo, cuando se habla de zonas para sentarse es importante tener en cuenta la teoría de los bordes, la cual dice que las personas tienden a colocarse en lugares donde se sienten más seguros, es decir protegiendo sus puntos ciegos y teniendo una visual de la mayor área posible del espacio en el que se encuentran.

El espacio público bien desarrollado no solo beneficia a los ciudadanos que transitan o viven por ahí, también es de vital importancia cuando se habla de comunidad. Según Jan Gehl (2006) "la vida entre los edificios, es el fruto del número y duración de cada uno de los acontecimientos (que alli ocurren)” (p. 87). Cuando estos no se dan, se presenta un fenómeno bastante negativo en el cual "la vida exterior se reduce drásticamente ya que las actividades no pueden estimularse y apoyarse mutuamente” (p. 85). Es aquí donde surgen problemas relacionados a la desintegración de los espacios públicos, por ende, el gradual abandono de la calle y es de esperarse entonces el aumento del vandalismo y la delincuencia. Cuando estos dos elementos "llegan a ser un problema, todo el mundo se mantiene alejado de las calles, y con razón. Se ha completado el círculo vicioso” (p. 87).

Este efecto negativo es ampliamente estudiado por Jane Jacobs, quien profundiza mucho sobre la relación que existe entre el grado de seguridad que proporciona la calle y el nivel de actividad que allí se presenta. Si existe un considerable número de sucesos relevantes e interesantes en una calle, por consiguiente, habrá muchas personas prestando atención a lo que allí sucede. Es así como se crea esta "vigilancia natural de la calle", donde los vecinos son los encargados de advertir si algo anda mal, cuidando todos en conjunto de la propia comunidad. 


\subsubsection{Teorías de Jane Jacobs}

El libro "Muerte y vida de las grandes ciudades" de Jane Jacobs (2011), como ella misma lo describe, es un ataque contra el urbanismo y la reconstrucción urbana de los años cincuenta. Tenía como intención presentar los nuevos principios urbanos según los cuales debían regirse las ciudades. La principal virtud de este análisis es su enfoque desde el punto de vista del ciudadano, con ejemplos tangibles que ilustran el diverso impacto que puede tener una buena o mala arquitectura y gestión de ciudad. Estos planteamientos serán de gran importancia al momento de trabajar el terminal terrestre como un regenerador urbano, ya que nuestra intervención busca recuperar en parte una zona degradada. Como bien dice Jacobs (2011): "Por muy diferentes que sean entre sí vías férreas, muelles, campus, grandes autopistas, aparcamientos y parques, también tienen mucho en común, al menos en lo que se refiere a su tendencia a existir en medio de vecindades moribundas y decadentes" (p. 294). Es por este motivo que nos interesa comprender cada situación urbana y sus soluciones, con el fin de evitar condiciones que no sean favorables para la viabilidad en el tiempo de nuestro proyecto.

Para propósito de nuestra investigación son de gran importancia las tres primeras partes de este libro: "La peculiar naturaleza de las ciudades", "Las condiciones para la diversidad urbana" y "Fuerzas de decadencia y fuerzas de regeneración". En cada una de estas partes se disecciona la ciudad con el objetivo de visualizar y analizar características específicas, dando ejemplos positivos y negativos que nos ayuden a entender el porqué de cada condición urbana. Al igual que para nuestra investigación, las ideas aquí presentadas son de vital importancia para el urbanismo actual y también son el cimiento de muchos pensamientos arquitectónicos vigentes hoy en día.

En primera instancia se habla sobre el uso de las aceras y los parques, enfatizando su importancia a la hora de definir el carácter de un barrio o zona. El enfoque se da a partir de un punto clave: la seguridad.

Según Jacobs, la seguridad es el factor principal al momento de analizar una zona de la ciudad. Pero no solo el hecho especifico de si la zona es segura o no, sino la impresión que trasmite a los usuarios, haciendo que estos transiten por ella o caso contrario que la eviten. "Por muy modestos, casuales y dispersos que parezcan, los contactos en las aceras son la calderilla a partir de la que crece la riqueza en la vida pública de la ciudad" (Jacobs, 2011, p. 100). 
Tanto en las aceras como en los parques el mejor guardián, a diferencia de lo que muchos creen, no es la policía; sino el ciudadano mismo. Esto se debe a que no existen suficientes policías que puedan estar presentes en cada lugar de la ciudad, sin embargo, siempre habrá personas. Es aquí donde cobra fuerza la idea de comunidad, donde a todas horas hay muchos "ojos" mirando y si ocurre algo fuera de lo común rápidamente se corre la voz de alarma. Un barrio debe valerse tanto de la gente que habita allí como de los que vienen de afuera, para lograr este objetivo. La seguridad debe ser constante y uniforme en las calles y en los puntos de encuentro, es decir no deben existir zonas desatendidas. Se debe evitar el uso de la vigilancia alquilada, porteros y guardianes, para suplir la falta de "ojos". Esta es una tarea de la que se pueden encargar los mismos usuarios, sin un costo adicional.

Tomando esta cualidad como el principio básico para la seguridad se pueden establecer tres características necesarias, con el fin de velar por el bienestar de una zona. La primera es una característica urbana: una clara demarcación entre lo privado y lo público, dejando en claro por donde puede transitar o recrear un usuario sin molestar a los residentes del lugar. El segundo es un aspecto que afecta principalmente a la arquitectura: la orientación y visuales de los edificios debe favorecer para que los usuarios permanentes tengan la capacidad de estar en contacto con la calle, esto con el objetivo de aumentar los ojos vigilantes. Por último, la tercera característica está relacionada exclusivamente con el uso del suelo: ya que la intención es que las aceras y los parques estén constantemente utilizados por usuarios, lo que se logra con un comercio variado que los atraiga voluntariamente durante todo el día.

En lo que concierne al comercio, se debe resaltar la importancia de usos mixtos, que congreguen diferentes grupos de personas, generando una diversidad de horarios que mantengan la actividad en las calles y parques, evitando así las horas muertas. Es necesario evitar la competencia, tanto en locales comerciales como en espacios públicos: parques y plazas. Si todos ofrecen lo mismo la gente se dispersará, generando zonas vacías. En el caso de estos últimos, se debe generar un uso especializado dentro de cada uno que lo diferencie del resto: deporte, cine, espectáculos, música, piscina, etc. Los usos específicos que involucran elementos de la localidad, tienen que ser aprovechados para la generación de comunidad. 
Es importante atraer usuarios, pero tan importante como esto es mantener un control sobre ellos. Las tiendas son el lugar por excelencia donde se van a presentar los contactos y es aquí donde se tiene que trabajar también la inclusión social. Es preferible una diversidad de pequeñas tiendas locales que una grande multinacional, ya que las tiendas pequeñas darán trabajo a la gente de la zona y aumentarán los "ojos" vigilantes. Por lo general estas tienen un contacto constante con la calle y están atentas a lo que sucede allí. De forma contraria, las tiendas de gran tamaño, trabajan hacia el interior y no les interesa lo que sucede afuera, cortando esta interacción tan importante para la seguridad.

Otro factor que contribuye a la seguridad es la presencia de niños. Cuando estos están en las calles o patios de juego, atraen las miradas de los adultos con mayor facilidad que cuando no están presentes. La eficacia de su presencia recae en que no tienen horas predeterminadas para estar en la calle, por lo que están allí todo el día. Es por esta razón que resulta importante incorporar espacios para ellos: estos lugares deben ser interesantes y accesibles, fuera del paso de los transeúntes y deben tener sombra para protegerlos del sol. Si se quiere que las interacciones entre los niños se den de manera espontánea en las aceras, estas no deben tener menos de 9 metros de ancho ya que el tránsito peatonal los desanimaría de cualquier intercambio. Caso contrario, si las interacciones han de darse en los parques es recomendable que estos cuenten con un punto central que sea interesante: un "clímax" del recorrido. Esto se logra con cambios de niveles, diversidad de vegetación, aperturas y visuales; todo con el objetivo de enriquecer el lugar y crear un vínculo con los usuarios.

"Si el conjunto se capta de un vistazo, como un buen póster, y si todos los sitios del parque son exactamente iguales, y si el usuario se siente más o menos igual en un sitio que en otro cualquiera de ese parque, entonces éste ofrece pocos estímulos para todos estos usos y emociones. No habrá muchas razones para volver" (Jacobs, 2011, p. 134)

Conforme se siguen desarrollando las ideas, se hace énfasis también en la importancia del ciudadano a la hora de activar las zonas degradadas y se profundiza en los factores claves para la generación de diversidad. Es decir, las herramientas 
necesarias que debe tener un barrio para mantener una comunidad activa durante todo el día, que a su vez se encargará de brindar seguridad.

Un lastre en la activación de muchas áreas es la zonificación, ya que no toma en cuenta la escala de uso y permite la monotonía: "Se suprime innecesariamente la diversidad" (Jacobs, 2011, p. 272).

Los espacios públicos dependen de la vitalidad de los alrededores, por lo que, en zonas deprimidas sin ningún magnetismo no pueden triunfar. Es aquí donde Jane Jacobs da algunas ideas importantes que sirven para enriquecer la vida urbana.

"En las áreas grises las salpicaduras de usos no residenciales no hacen bien y pueden dañar porque estas áreas no están equipadas para manejar a desconocidos (o para protegerlos) . . . En distritos animados donde se ha catalizado una abundante diversidad, estos usos no dañan. Al contrario, son necesarios, bien por su directa contribución a la seguridad, el contacto público y los usos divergentes, o porque ayudan a mantener otra diversidad con esos efectos" (Jacobs, 2011, p. 266)

Primero habla de la necesidad de combinar diferentes usos: tener funciones primarias y secundarias en un mismo lugar. Las primeras para atraer gente a la zona por una razón específica: oficinas, educación, vivienda, comercio básico y ocio. La principal función de estas es congregar gente. Si se crean usos que ocupan un gran espacio físico, pero solo atraen a un grupo muy pequeño de usuarios, harán poco o nada para contribuir a la animación y diversidad. Las funciones secundarias, como el comercio complementario, sirven para atender las necesidades momentáneas de los usuarios mientras realizan otras actividades. Su función es entretener y retener a los usuarios, evitando que se vayan o dispersen rápidamente luego de haber realizado sus actividades primarias. El comercio ambulatorio es muy importante para mantener grandes zonas abiertas como parques o plazas activadas. La mezcla de actividades permite horarios variados, juntando áreas de uso permanente con áreas de uso esporádico. Es importante mencionar que, al crear nuevos usos, no se debe desplazar los existentes, si se destruye un uso primario se debe reemplazar con un uso similar, para no afectar a los usuarios. 
En segundo lugar, se habla sobre la necesidad de tener manzanas pequeñas con calles cortas, con el objetivo de evitar que se generen largos recorridos y áreas muertas. Las manzanas pequeñas aumentan la riqueza y diversidad del barrio ya que permiten el uso de diferentes rutas para llegar a un mismo lugar, lo que propicia la creación de pequeños comercios. Además, se resalta la importancia de los edificios antiguos, ya que estos sirven para dar inicio a nuevos locales comerciales que necesitan reducir costos y también dan diversidad de clases sociales a un barrio, cualidad que es indispensable si se quiere un barrio constantemente activo.

En tercer lugar, es necesario reducir el número de vehículos en las vías, pero no suprimirlo del todo. Esto se obtiene manteniendo al transporte pesado alejado de la gente, ósea en las autopistas donde pueden fluir rápidamente. El transporte liviano se controla con la implementación de un buen sistema de transporte público que desanime al usuario de usar el vehículo particular. Las calles más transitadas deben ser peatonalizadas para dinamizar el comercio y las actividades en la acera. Las vías peatonalizadas tienen que ser de un solo nivel, con puntos de atracción en el centro de estas para fomentar su uso: como bancas y sombra.

Por último, es importante crear un hito que identifique y defina la zona. Este no solo sirve para ubicar a la zona dentro de la ciudad, sino que además crea un vínculo con los habitantes y usuarios del lugar, el cual se transmite al resto de la ciudad. La trascendencia de estos recae en que afirma explícita y visualmente que el lugar es funcionalmente importante. Como dice Jacobs (1992), los hitos son “anunciadores y dignificadores de la diversidad" (p. 423). Los hitos son necesarios para colocar un área dentro del mapa mental de los ciudadanos, pero tampoco se debe abusar de su uso. Muchos hitos en una única área solo generaran competencia, restándose importancia entre sí, evitando que alguno destaque. Lo más importante es que el hito sea el ápice de una vida urbana bien establecida funcionando como eje estructurador. "Una interrupción visual atrae la atención por sí misma y su personalidad particular determina mucho la impresión de la escena en conjunto. Si es banal, vacua o simplemente confusa, mejor que no exista” (p. 422).

Estas pautas son principalmente aplicables a zonas degradadas que se quieren recuperar, ya que tienen las herramientas necesarias para atraer y retener gente, revitalizando el lugar. Que una recuperación urbana sea exitosa no depende de cuantos 
usuarios hay en un lugar determinado sino de cuantos realmente quieren estar ahí por motivación propia. "Que una rehabilitación tenga éxito implica que haya gente suficiente con apego a su barrio para decidir quedarse en él; y también implica que les sea práctico quedarse” (Jacobs, 2011, p. 323).

Estas teorías se complementan con las estudiadas previamente de Jan Gehl. Las teorías de este último nos dan las pautas a seguir para diseñar espacios públicos pensados para quien los usa desde el punto de vista físico y de interacción con otros usuarios. Por otro lado, las teorías de Jane Jacobs nos dan el conocimiento necesario que nos permitirá activar constantemente estos espacios, garantizando un uso intenso que le brinde seguridad y vitalidad.

\subsection{Sobre la regeneración urbana}

La regeneración urbana se puede dar mediante un sinfín de herramientas. Estas pueden variar en inversión de tiempo y dinero, como también pueden diferenciarse por su escala o por el tipo de intervención. Pero a pesar de toda esta gran variedad, tienen un objetivo común: la recuperación de una zona que ha sido degradada en cualquier aspecto: apariencia, seguridad, infraestructura, etc. Pero se debe especificar que al hablar de una regeneración urbana se está haciendo énfasis en el espacio compartido, que finalmente le pertenece a cada ciudadano en igual proporción. Por lo tanto, es vital identificar sus usuarios, el tipo de vecindario, las actividades que se realizan y aquello que funciona y lo que no funciona.

Una vez identificado el o los problemas, se deberá buscar una solución para llevar a cabo la regeneración urbana. Conocer experiencias pasadas, que varían en inversión monetaria, como también en escala de intervención, es de gran importancia. De igual manera lo es, entender qué implica un proceso de consulta para un proyecto de mayor envergadura. El área que rodea el Terminal Terrestre Yerbateros, presenta múltiples problemas, como la ausencia de espacio público, el caos vehicular, contaminación visual, auditiva y ambiental, etc. Todos estos problemas generan un fuerte sentimiento de inseguridad, lo cual consecuentemente ahuyenta al usuario de muchas zonas y las deja desoladas. Las estrategias que se verán a continuación, servirán como herramientas para poder recuperar la calidad de vida de los habitantes e incentivar el uso de la zona a intervenir. 


\subsubsection{Teorías aplicadas para la recuperación de zonas degradadas}

\subsubsection{Urbanismo Social: Proyectos de infraestructura en barrios marginados}

En una columna de Gestión pública y desarrollo escrita por Juan José Arrué en enero del 2014, encontramos una cita del ex alcalde de Medellín y autor del "urbanismo social”, Sergio Fajardo ${ }^{19}$ : “. . . se apostó a repagarla (una deuda "histórica” hacia el pueblo) mediante la construcción de obras infraestructurales y arquitectónicas de alta calidad y fuerte impacto estético. Bajo la consigna de "lo más bello para los más humildes"... ." (pp. G1-G5).

Esta es la estrategia que se está empleando en Medellín, con la búsqueda de regenerar espacios de la ciudad y darle calidad de vida a sus habitantes, mediante el redireccionamiento de inversiones públicas hacia zonas marginales. Los proyectos que se realizan son articulados principalmente como PUI's (Proyecto Urbano Integral) y funcionan en zonas marginales, segregadas, con violencia y pobreza, como un instrumento de planeación e intervención física. Estos son proyectos de infraestructura y equipamiento urbano, llevados a cabo con la participación o consulta ciudadana.

"El "urbanismo social". . . se basa en el direccionamiento de grandes inversiones públicas en proyectos urbanísticos puntuales hacia los sectores populares de la ciudad. . . . Se trata de una gama de proyectos, estructurados inicialmente alrededor de los Metrocables y articulados espacialmente mediante los denominados Proyectos Urbanos Integrales (PUIs), ahora extendidos a otros sectores de la ciudad, que incluyen equipamientos educativos y culturales, y mejoras habitacionales y del espacio público (Alcaldía de Medellín, 2010)" (Brand, 2012, p. 41)

\footnotetext{
${ }^{19}$ Exalcalde de Medellín (período del 2004-2007) y postulante a la presidencia de Colombia para el 2010, es un matemático graduado de la Universidad de Wisconsin-Madison en EEUU, que terminó involucrándose en la política. Es conocido por no tener una ideología política, además de la buena administración durante su alcaldía en Medellín. Logró reducir significativamente los índices de criminalidad, implementó buenas políticas de inclusión social y gestionó eficientemente las inversiones, por lo que recibió diversos premios de reconocimiento (Villa Moya, 2013).
} 
Los Metrocables, teleféricos que funcionan como sistema de transporte urbano para llegar a las zonas más lejanas y altas de la ciudad, son un ejemplo del urbanismo social, pues la gestión del proyecto mantuvo una comunicación y participación estrecha con la comunidad de la zona. Otro ejemplo es un proyecto de vivienda que también se realizó en las periferias de Medellín, que se gestó y desarrolló mediante un proceso participativo de una escala mediana. Adicionalmente, los proyectos de ParquesBibliotecas tenían la característica de urbanismo social, al querer afirmar la presencia del estado en lugares marginados (Brand, 2009).

Una estrategia importante para poder realizar estos proyectos bajo un concepto de "Urbanismo Social", fue la transformación de los equipos de trabajo que integraban diferentes sectores del municipio, como la re-estructuración interna de la Empresa de Desarrollo Urbano [EDU] (Echeverri \& Orsini, 2012). Otro aspecto bastante importante es el medio de financiamiento, empezando por optimizar la manera en la que el proyecto se desarrolla, para reducir costos prolongados en el tiempo, que además deberían ser financiados por entidades gubernamentales. Esto es, para generar sentido de pertenencia no solo con la comunidad, sino también con otras entidades gubernamentales.

Claro está, que el urbanismo social no busca solamente la participación de la comunidad local en el proyecto. También se le llama así, por su carácter que apunta a "liderar una transformación profunda", aportando con espacios públicos de calidad y proyectos de infraestructura que empoderen al ciudadano. Aparte de los aspectos ya mencionados, el urbanismo social le da bastante importancia a la estética y al acabado del proyecto. Estos aspectos, junto con el simbolismo que tienen en la zona, terminan de reforzar y materializar la idea de "inclusión social" (Brand, 2009, p. 4).

Algunos debaten la eficacia de estas acciones, pues hay que mencionar todo aquello que no anda bien. El mismo co-autor del libro Movilidad Urbana y Pobreza, Peter Brand dice:

"Muchos fenómenos económicos y urbanos van en su contra: una ciudad socialmente cada vez más desigual y espacialmente segregada, altos niveles de pobreza, una creciente crisis de vivienda social, desempleo estructural, alarmantes niveles de informalidad y degradación del trabajo, y oportunidades 
restringidas para los jóvenes. Si se suma a este panorama la reaparición de bandas delincuenciales relacionadas con procesos incompletos de reinserción de grupos armados, el tráfico y consumo de drogas, el control delincuencial de barrios, etc., entonces los desafios siguen siendo grandes” (Brand, 2012, p. 44)

Habla además sobre las intenciones que se reflejan en el lema de la alcaldía de Alonso Salazar (2008-2011): "Medellín solidaria y competitiva", pues cómo combinar la competitividad junto con la solidaridad en una sociedad con tantas problemáticas. Ahí yace el intento constante del urbanismo social de mantener las dos lógicas y volverlas compatibles.

\subsubsection{Metodologías para la regeneración de espacios degradados}

Existen múltiples metodologías para regenerar barrios en mal estado, pero primero es importante entender qué tipo de problemáticas se generan en estos espacios degradados y averiguar si es que existen factores específicos que se pueden trabajar. Los factores pueden ser varios, como por ejemplo la apariencia del barrio, la falta de espacio público e incluso el nivel socioeconómico que predomina en este. Es importante reconocer que a veces, intervenciones de menor escala y presupuesto pueden llegar a tener un impacto positivo mucho mayor, por lo que es de suma importancia reconocer la situación del barrio, antes de definir una intervención específica.

En un artículo llamado "Broken Windows" publicado en la revista Atlantic Monthly, los autores James Q. Wilson y George L. Kelling (1982) hablan sobre la seguridad ciudadana en un barrio de Nueva Jersey y cómo la percepción de seguridad puede ser influenciada por factores tan simples como el aspecto del vecindario.

Cuentan sobre la implementación de una nueva política de seguridad en los años 70 en Newark, Nueva Jersey. Parte de esta nueva política era la inclusión de policías a pie que patrullaran los diferentes vecindarios con la finalidad de reducir los crímenes. Se debatió intensamente y se puso en duda la efectividad que podrían tener patrulleros a pie, ya que sin duda estaban más expuestos, cubrían un área más reducida y tenían menos control de las situaciones. Se estimó que los índices de criminalidad no bajarían 
y luego se realizó un estudio que lo confirmó. Sin embargo, la percepción de seguridad en esos vecindarios si mejoró significativamente.

La explicación es que el miedo de los ciudadanos no se limita a la posibilidad de un ataque violento, sino también a pequeños fastidios generados por borrachos, drogadictos o pandillas. La presencia de los policías ayudó a mantener situaciones en orden, reduciendo este tipo de incomodidades o encuentros en las calles, y por consecuencia llevó a un sentimiento de bienestar mayor, mejorando el vecindario. Con esto surge la idea de que el desorden y la criminalidad están estrechamente relacionadas. Para ilustrar esto utilizan otro ejemplo en el que se analiza un edificio con una ventana rota. Sin importar el barrio en el que se encuentre, ya sea bueno, malo, rico o pobre, siempre va a dar la impresión de deterioro, desorden, abandono y ausencia de autoridad, llevando a la automática repetición del acto, rompiendo aún más ventanas.

En 1969, el psicólogo Philip Zimbardo, decidió poner a prueba la misma teoría, colocando un auto con el capó abierto en el "Bronx", un barrio de bajos ingresos conocido por su nivel de criminalidad, y otro con las mismas características en Palo alto, un barrio mucho más adinerado y más seguro.

Dentro de las primeras 24 horas, el auto en el Bronx ya había sido desmantelado e incluso vandalizado. La gente que fue partícipe era de todo porte, pues incluso gente bien vestida, madres, padres e hijos fueron parte de este proceso.

Por otro lado, en Palo Alto no se tocó el auto por más de una semana, hasta que el mismo psicólogo decidió dañarlo. Esto fue el inicio para el desbando de incluso la gente más rica, pues vandalizaron el auto en cuestión de horas.

El resultado de estos experimentos demuestra que cualquier tipo de propiedad desatendida (o que parezca estar desatendida) tiene una probabilidad muy alta de ser vandalizada, sin importar su entorno. De igual manera demuestra que cualquier tipo de persona, bajo determinadas circunstancias puede terminar rompiendo las reglas a las que normalmente se atiene. Cuando se trate de un barrio donde sea casi "normal" la presencia de propiedades abandonadas, al igual que los robos, vandalismo y la anonimidad entre la gente, estas acciones se darán con mayor facilidad. Algo que refuerza esta situación es la experiencia del barrio, en la que, en situaciones pasadas de algún tipo de rompimiento de normas, no hubiera nadie que se preocupe y nadie que sancione. 
Por otro lado, en barrios más tranquilos, como era el caso de Palo Alto, las personas se acostumbran a creer que las cosas tienen dueños y que estos se preocupan por sus propiedades. Además, también están acostumbrados a que una mala conducta suele ser fuertemente sancionada (Wilson \& Kelling, 1982).

Pero como mencionado previamente, este experimento demuestra que el vandalismo se puede dar donde sea, ya que el único catalizador necesario es que el vecindario o algún objeto en este tenga un aspecto de deterioro y que alguien rompa las "barreras" o reglas de la comunidad. Con estas nos referimos al sentido de respeto mutuo y obligación civil. Una vez que se rompen, se entiende que hay desinterés y que nadie se preocupará, y esto se ve aún más reforzado cuando las malas acciones no se sancionan.

\section{$\underline{\text { Rio de Janeiro: Vila Cruzeiro }}$}

Jeroen Koolhaas y Dre Urhahn, son unos artistas holandeses que se unieron en el 2005 bajo el nombre de Haas\&Hahn para realizar una serie de intervenciones con murales de arte. Inicialmente se realizaban en las favelas de Rio de Janeiro, específicamente en "Vila Cruzeiro". Hoy en día ya son reconocidos a nivel internacional y reciben encargos de varias ciudades. Ya han trabajado en Venezuela, EEUU, Haití, Brasil, etc.

En el 2007 decidieron realizar su primer mural. Pintaron las fachadas de tres casas, creando un mural con fondo azul de un niño volando una cometa. 
Figura 19: Boy with kite

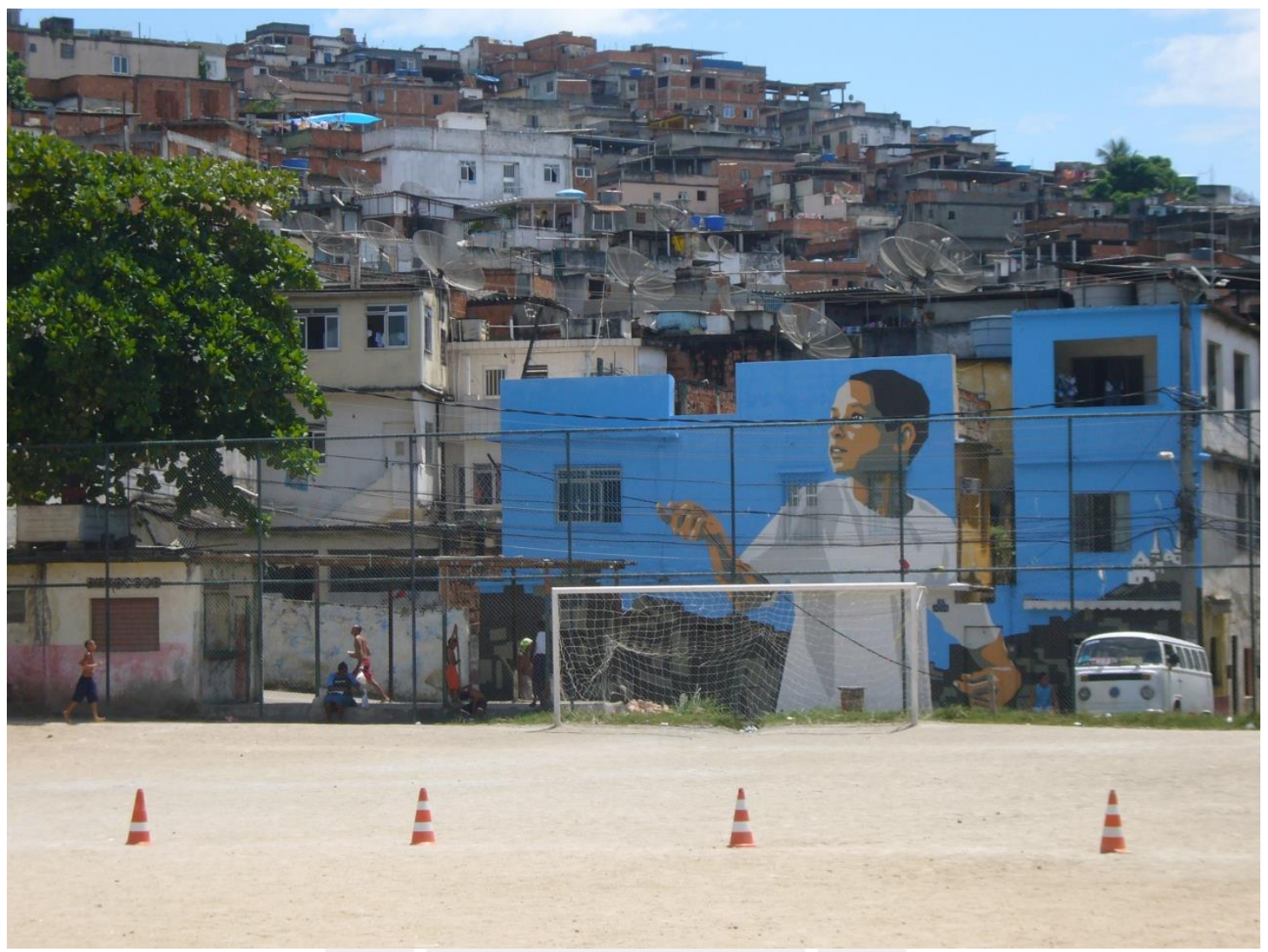

Fuente: Haas \& Hahn (s.f.)

Obtenido de http://www.favelapainting.com/

Con esta primera experiencia descubrieron una serie de cosas. Primero, la importancia de consultar con el barrio y conocer su cultura, pues al pintar las casas de azul, muchos estaban descontentos ya que este era el color de las estaciones de policía. Fue importante tomarlo en cuenta debido a la relación y antecedentes existentes entre el barrio y la policía. Luego, al tratarse de un mural que requería cierta imaginación para completar la imagen, la comunidad quedó frustrada, pues la supuesta cometa que volaba el niño del mural no se ubicaba en el mural. Finalmente decidieron agregarlo en otra casa y el barrio quedó satisfecho. Luego decidieron emprender un proyecto un poco más ambicioso, que se realizaría en un camino de escaleras, cuyos alrededores habían sido bañados en concreto para evitar deslizamientos de tierra. Para este proyecto invitaron a un artista especializado en pinturas japonesas, para desarrollar un "macro mural" de un río con peces (ver figura 20). Al descubrir las dificultades del proyecto y el tiempo que les tomaría realizarlo, terminaron mudándose al barrio a vivir con una familia que los acogió. Esto les permitió conocer mejor a la gente. 
Figura 20: Rio Cruzeiro

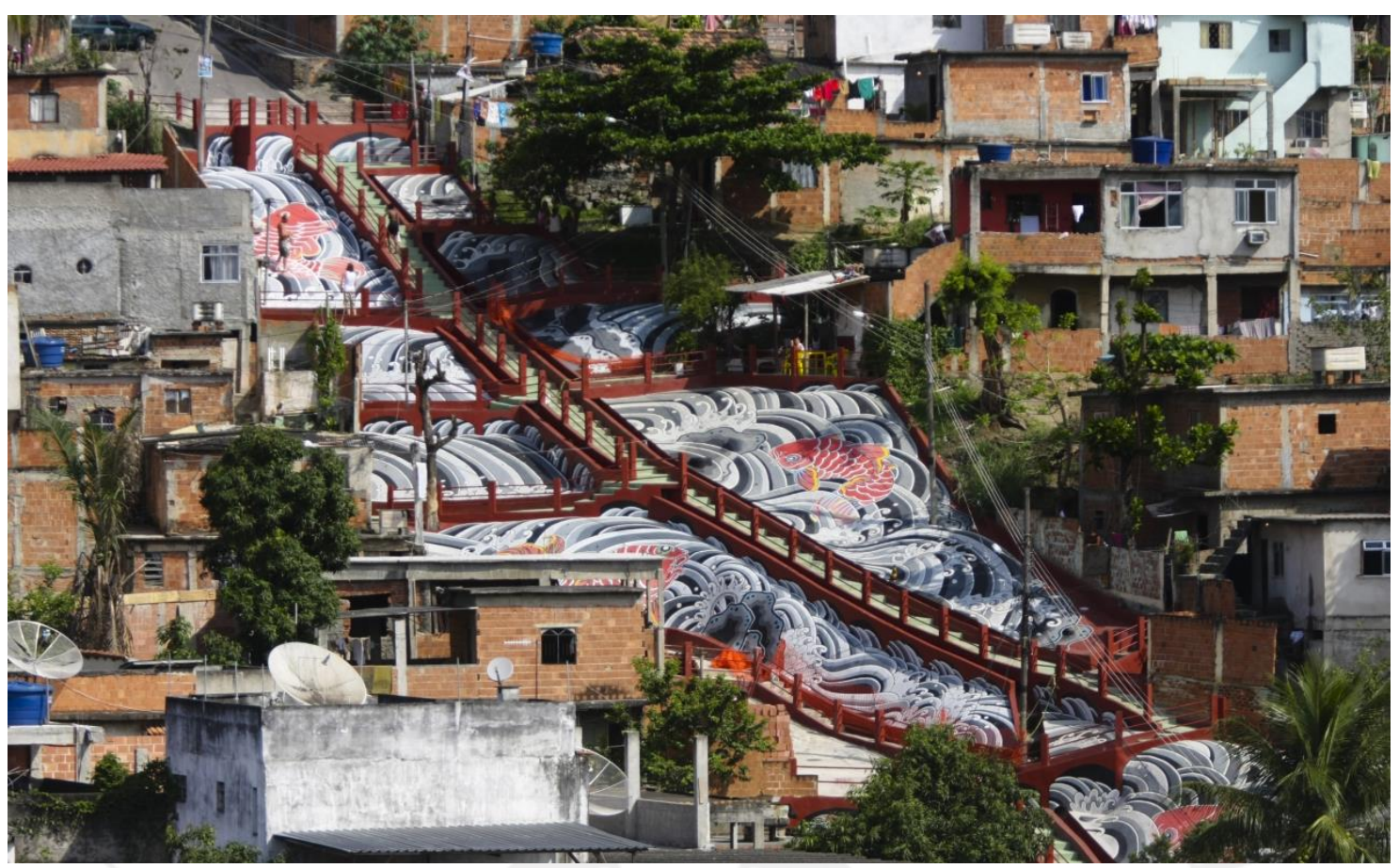

Fuente: Haas \& Hahn (s.f.)

Obtenido de http://www.favelapainting.com/

De este proyecto aprendieron la importancia de la simpleza del diseño, pues cuando se trata de un proyecto muy complejo, el cual solo pueden ejecutar profesionales, se pierde el sentido de trabajo comunitario. Por otro lado, cuando son figuras geométricas simples, todo aquel interesado en participar, puede hacerlo. Es por esto que su siguiente proyecto, Praca Cantao realizado en el 2010, se ejecutó en un periodo no mayor a un mes con la participación del barrio, ya que decidieron enfocarse en un diseño simple, ejecutable, pero sumamente colorido. Así convirtieron las fachadas que daban a una pequeña plaza, en un gran mural de colores. 


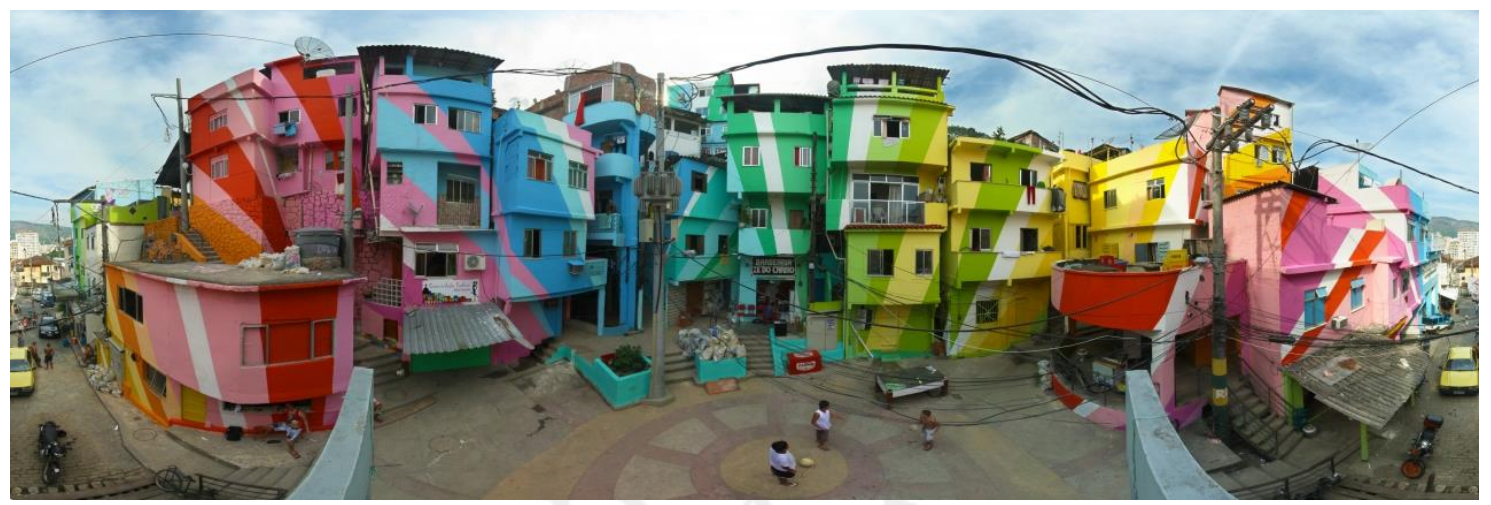

Fuente: Haas \& Hahn (s.f.)

Obtenido de http://www.favelapainting.com/

Este proyecto fue ejecutado en conjunto con un grupo local de 25 jóvenes llamado "Tudo de cor para você", que se ha encargado, junto con la comunidad, de continuar el desarrollo del proyecto con la participación de aproximadamente 800 personas. El impacto del proyecto se aprecia en lo estético y en la manera de convivir y compartir (Koolhaas \& Urhahn, 2014).

\section{Ciudad de México: Pachuca}

La organización "Germen Colectivo" busca activar y regenerar espacios públicos mediante la aplicación de grafitis, murales, documentación audiovisual, etc. Buscan "reinterpretar" la identidad del ciudadano y fortalecerla. Uno de los objetivos es el de generar un sentido de pertenencia, orgullo y de convivencia en conjunto, además de fomentar la participación de la comunidad para integrar a los jóvenes del barrio. Fue fundada en el 2012 y ya han desarrollado una serie de proyectos; los XVI juegos panamericanos en Guadalajara, Centro de Arte y cultura Circo Volador A.C., H. Ayuntamiento de Culiacán Sinaloa, Bibliotecas Públicas Faro del saber, etc.

Comprenden que el espacio público es el núcleo de vida de la sociedad y buscan la aplicación de colores y texturas con la finalidad de motivar, entusiasmar y fortalecer a las comunidades intervenidas.

"El respeto al espacio público es la esencia para transformarlo, de esta manera, el paisaje urbano vierte millones de posibilidades de interacción e innovación artística, por esto nosotros optamos por entender el espacio público 
como el escenario de la interacción social cotidiana que debe cumplir funciones educativas, potencializadoras, materiales y tangibles, donde el fin sea satisfacer las necesidades de desarrollo colectivo más allá de lo individual y económico . . - queremos refuncionalizar el espacio público haciéndolo más útil para quienes lo habitan, un lugar que eduque, motive, ayude, aporte y germine una nueva relación de los ciudadanos con su entorno y las expresiones que ahí convergen" (Germen Colectivo, 2012)

Consideran que la participación del ciudadano es vital para la apropiación del espacio y la intervención, además de integrar y cultivar el trabajo en equipo dentro de la comunidad. De igual manera estos trabajos se deberían llevar a cabo con instituciones municipales públicas y privadas para establecer y trabajar una relación.

Uno de los proyectos de Germen Colectivo, es el de un "macro mural" en el barrio de Palmita en Pachuca, que se puede apreciar en la siguiente figura. El proyecto es lanzado en el 2012 como un programa de prevención social, con el apoyo de México nos Mueve la Paz, el Ayuntamiento de Pachuca y la Secretaría de Gobernación [SEGOB]. Conocido por ser uno de los barrios más violentos en el estado de Hidalgo, tiene altos índices de criminalidad, pandillaje y consumo de drogas, además de ser un barrio sumamente humilde (Hernandez, 2015).

Los miembros del colectivo trabajaron durante 14 meses junto a 20 personas contratadas y ayuda de la comunidad. Empezaron pintando con base blanca las 200 casas de 452 familias del barrio, para luego aplicar los colores vivos que transformarían el barrio Palmitas en el "primer barrio mágico", como lo dice el director de proyecto Enrique Gómez (Comex, 2015). Los colores lavanda, verde limón, naranja y otros le quitarán el aspecto triste y venido abajo. Según dice Enrique Gómez, cada color representa el alma del vecindario, mientras que el diseño del mural, con su forma de ondas y curvas, hace homenaje al viento, ya que la zona también es conocida como "la bella airosa". 
Figura 22: Barrio La Palmita, Pachuca

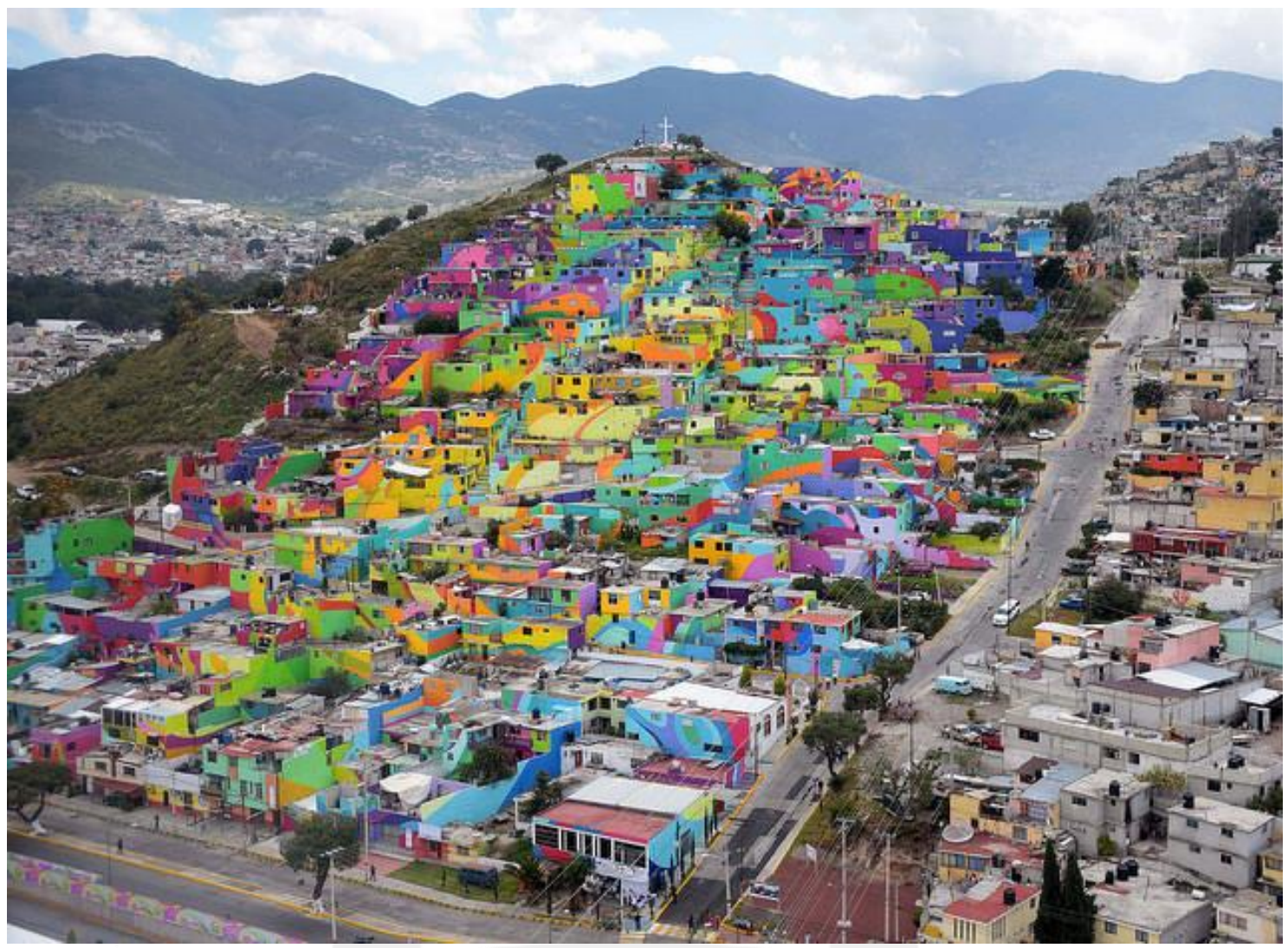

Fuente: Presidencia de la República Mexicana (2015)

Obtenido de https://www.flickr.com/photos/presidenciamx/albums/72157657962958196

El mismo director del proyecto fue parte de pandillas, pero cambió su estilo de vida con el arte y este tipo de proyectos. Admite estar sorprendido con el cambio de actitud de la comunidad y las ganas que tienen de convertir su barrio en uno más seguro. Todo esto gracias a una intervención artística.

El primer paso fue convencer al barrio entero. Era necesario conseguir autorización de cada propietario para luego empezar a pintar de blanco. Esta primera acción no fue solo por practicidad, sino también como un acto simbólico para indicar al pueblo la igualdad y horizontalidad entre todos. Se utilizaron 20,000 litros de pintura para cubrir un área de 20,000m² (Associated Press in Pachuca, 2015).

Según la jefa de planeamiento de Pachuca, Ana Estefanía García, el proyecto costó unos US\$ 310,000 y redujo la criminalidad en un 35\% desde que se inició el proyecto en el 2012. Esto se debe a la participación comunitaria entre el gobierno con la localidad y los vecinos mismos. Al trabajar en conjunto, las diversas pandillas empezaron a intercambiar y reconocer intereses comunes como el bienestar de su 
comunidad. Como en cualquier proyecto, existen aquellos descontentos con la iniciativa, pues consideran que no va a hacer una diferencia. El testimonio de un poblador de la localidad es clave para comprender el otro lado del proyecto; Adante López originalmente se opuso a dar permiso para pintar su casa, sin embargo, luego cedió. Su opinión al respecto revela poco convencimiento: "Las cámaras son el objeto principal que ha reducido la violencia. Un ladrón permanece ladrón, sin importar el color de las paredes" (Estibal, 2015). Por otro lado, un trabajador de la zona indica que se siente muy a gusto al ver su barrio con tanto color y en sí, el proyecto ha tenido un recibimiento tan positivo que se está considerando la misma acción para un barrio cercano: Cubitos (López, 2015).

"tu aqui en palmitas puedes ver un cambio físico muy importante, pero eso no es lo más importante que ha pasado en palmitas, obviamente eso es lo más bonito y lo más visible, pero lo más importante que ha pasado en palmitas, y eso es lo que busca un programa de prevención, es el cambio en la dinámica de la gente, el cambio en la dinámica de violencia” (Hernandez, 2015).

\subsubsection{Conceptos de la Acupuntura Urbana y Urban Upgrading}

Como procesos regeneradores también es de nuestro interés entender la "Acupuntura Urbana". Entendiendo el concepto de Acupuntura Urbana como un proceso de intervenciones de escala pequeña para transformar el entorno urbano de la zona, comprendemos que puede servir como una estrategia de aproximación para regenerar espacios.

Se trata de un concepto que combina el diseño urbano con la acupuntura, medicina tradicional de China. Consiste en seleccionar, dentro de los barrios marginales, las zonas con mayor potencial de recuperarse y estratégicamente intervenir allí, generando un efecto contagioso en sus alrededores (Casagrande, s.f.).

Este concepto, desarrollado por un arquitecto y urbanista de Barcelona; Manuel de Solas Morales, entiende la ciudad como un organismo vivo. Así como la acupuntura libera estrés del cuerpo, la Acupuntura Urbana libera estrés del contexto urbano. Esta idea se continuó desarrollando por otros arquitectos, urbanistas y teóricos, entre ellos el 
ex alcalde de Curitiba Jaime Lerner, quién cree firmemente en la reacción en cadena que puede desatar un proyecto bien ubicado y diseñado. Enfatiza que antes de realizar proyectos masivos de renovación urbana, se debe dar importancia a aquellos proyectos más focalizados y desarrollados con la comunidad, que pueden impactar de manera positiva sus alrededores y que abren espacio para mayores mejoras. Estos pueden tener un mejor resultado sobre todo en países que se encuentran en vías de desarrollo, por lo que da como ejemplo la colocación de un museo en una zona degradada, como un primer paso hacia la mejora del vecindario (Stgo, 2009).

"Boiled down to a simple statement, "urban acupuncture" means focusing on small, subtle, bottom-up interventions that harness and direct community energy in positive ways to heal urban blight and improve the cityscape. It is meant as an alternative to large, top-down, mega-interventions that typically require heavy investments of municipal funds (which many cities at the moment simply don't have) and the navigation of yards of bureaucratic red tape" (Casagrande, s.f.).

Al analizar la "acupuntura urbana" no podemos dejar de lado conceptos como “Urban Upgrading” o "Slum Upgrading”. Estos son conceptos o más bien procesos por los cuales se lleva a cabo la mejora de una zona gradualmente. Esto consiste en poco a poco ir integrando el barrio marginal en el tejido urbano, formalizando paso a paso e implementando mejoras a la comunidad. Este concepto es opuesto al de la modernización en la que se reubicaba una población marginal en un complejo de viviendas multifamiliares. Slum Upgrading no solo busca la mejora de servicios básicos como instalaciones sanitarias y eléctricas, sino busca activar la economía y actividad social e institucional de la zona. Empezando por formalizar la vivienda de los usuarios y legalizarla, se les atribuye un sentimiento de propiedad y pertenencia. Además, es importante activar el sentimiento de comunidad, implementando espacios públicos, calles y caminos apropiados e incluso acceso a educación y salud. El propósito final es lograr que el usuario se identifique con el programa para auto-gestionarlo y apoyar el proyecto (The World Bank Group, 2001). 


\subsection{Lineamientos y normas básicas para un terminal terrestre}

Cualquier tipo de estación o terminal juega un papel importante en el desarrollo, como conector de las comunidades y sus redes existentes, tanto en escala local como regional. Estas redes normalmente consisten de sistemas intermodales que responden a la premisa básica de transportar gente y bienes, siendo nodos para la movilidad de la ciudad que van desde el transporte peatonal y ciclista al sistema vial de buses y automóviles.

Propiamente dicho, un terminal terrestre es un edificio que sirve como punto inicial o final de largos recorridos en buses, atendiendo las necesidades de los usuarios antes y después de subirse y bajarse de los autobuses. El terminal también alberga el equipamiento necesario para almacenar, dar mantenimiento y combustible a las unidades que dependen de este.

Tiene como función principal centralizar todas las oficinas, despachos y movimientos de buses interurbanos de la ciudad. Centralizar los servicios en un solo punto facilita el control de horarios y la distribución de rutas, además de permitir una fiscalización eficiente de las empresas, lo que mejora la seguridad y la calidad del servicio (Vidal, 2013).

Al diseñar un terminal terrestre se trabaja con una complejidad espacial muy elaborada, ya que se deben tener en consideración muchos factores que moldearán la arquitectura. Las relaciones espaciales de los ambientes, la logística de los buses, los flujos y los tiempos de espera de los pasajeros son algunos de los principales factores a tomar en cuenta.

Para entender qué zonas o ambientes son necesarios y en qué orden se deben ubicar, hemos estudiado diferentes fuentes, algunas de las cuales con realidades similares a la nuestra como el caso de Colombia, Chile y México. Sin embargo, también hemos tomado en cuenta informes y estudios realizados en Estados Unidos, Japón y la Unión Europea. Por más que se trate de realidades distintas, los estudios resultan muy interesantes de comprender y podrían ser aplicados en ciertos puntos clave del proyecto. 


\subsubsection{Requerimientos previos}

Cuando se piensa en el diseño de un terminal terrestre que atiende la demanda de todo un sector del país, tenemos que tener en cuenta que nuestros principales competidores serán otros medios de transporte como los aviones y los vehículos particulares que cubren esas rutas. Es por este motivo que tanto la infraestructura como el servicio que se ofrecerá deberán ser sumamente atractivos. La principal ventaja de un terminal radica en el bajo precio de los pasajes sin afectar la calidad del servicio. Esto se debe a que la competencia generada entre las diferentes empresas transportistas se rige bajo estrictas normas de seguridad e higiene, que protegen la integridad de los usuarios (Escala, 1974).

Uno de los factores que se debe tomar en cuenta desde el inicio del proyecto es la ubicación e intermodalidad del terminal. Este se puede localizar en un área densamente urbana si cuenta con una vía de acceso independiente. Sin embargo, lo ideal sería que se ubique a las afueras de la ciudad, siendo también accesible desde una vía arterial. Se deberán establecer conexiones intermodales que no generen tráfico para llegar al centro de la ciudad y viceversa, como: bicicletas, metro, autobuses y taxis. En este tipo de infraestructura, la implementación de estacionamientos para autos privados no es la más primordial ya que una estación mueve grandes cantidades de personas por lo que requiere un tránsito fluido y no estacional de los vehículos. Si es posible debería además tener un sistema masivo de conexión directa hacia el aeropuerto o la estación de trenes más cercana. Para su correcto funcionamiento es de sumo interés no congestionar el sistema vial existente, creando vías exclusivas para el transporte público y privado.

Generalmente se cuenta con un espacio abierto al ingreso que sirve como punto de encuentro y distribución antes de ingresar a la zona de la boletería o de embarque. Aquí también deberán estar implementadas algunas áreas con vegetación que funcionen como colchones de aislamiento para evitar generar molestias en los residentes de las zonas aledañas. La plaza de ingreso debe beneficiar tanto al terminal como a la comunidad circundante (Vidal, 2013, pp. 16-22).

Para el diseño del edificio del terminal y el dimensionamiento de sus áreas internas se deben de obtener una serie de datos indispensables. La Enciclopedia de arquitectura Plazola (Plazola Cisneros, 1995) señala cuales son las variables que se necesitan conocer y que influirán de forma considerable en el proyecto: 
- Número de pasajeros transportados por día y su proyección a futuro.

- Número de corridas diarias y su proyección a futuro.

- Capacidad de salas de espera.

- Número de empresas que utilizarán el terminal.

- Dimensiones de los autobuses que albergará.

- Número de andenes necesarios.

- Zonas de servicios auxiliares para autobuses.

- Modulación del terminal y posibilidad de expansión.

- Elementos estructurales.

El diseño de las áreas internas y operacionales del terminal deberá respetar una serie de lineamientos y recomendaciones internacionales que aseguran el correcto funcionamiento o dimensionamiento de estas zonas. Se debe recalcar que no se trata de normas sino de sugerencias realizadas por diferentes institutos como la IATA $^{20}$ y $\mathrm{JICA}^{21}$, que se encargan de estudiar precisamente este tipo de instalaciones, por lo que su aplicación es necesaria para evitar futuros problemas.

\subsubsection{Consideraciones generales de diseño}

Según el Urban Rail Transit Design Manual (Vidal, 2013), el diseño general de un terminal terrestre está definido por algunos conceptos guías que se deberían respetar para asegurar su buen funcionamiento. Estos parámetros definen una serie de consideraciones que se deben tomar en cuenta, marcan de antemano las pautas más importantes e introducen tendencias que son muy valoradas hoy en día.

${ }^{20}$ International Air Transport Association: es una organización internacional con base en Canadá. Es representante de 265 aerolíneas, es decir 83\% del total de tráfico aéreo en el mundo. Esta institución se encarga de desarrollar políticas y reglamentaciones para su correcto funcionamiento, promoviendo la seguridad y confianza de este medio de transporte (International Air Transport Association, 2016).

${ }^{21}$ Japan International Cooperation Agency: es una entidad independiente que asiste al gobierno japonés, que además se especializa en el desarrollo económico y social a través de cooperaciones internacionales. Tiene un gran número de programas que se centran en la seguridad humana, realizando estudios con el objetivo de mejorar las condiciones de trabajo (Japan International Cooperation Agency, 2016). 
Este manual habla específicamente sobre el diseño de estaciones para trenes, pero los conceptos son aplicables también en estaciones de buses. Es por su gran flexibilidad y vigencia que hemos decidido usarlas como base general para el desarrollo de nuestra investigación. Los puntos que no son tratados en este manual los completaremos utilizando información obtenida de la Enciclopedia de arquitectura Plazola (Plazola Cisneros, 1995) y la revista Escala (Escala, 1974).

\subsubsection{Arquitectura: Lineamientos guía}

El Urban Rail Transit Design Manual (Vidal, 2013) considera que la construcción de una estación exitosa dependerá de la implementación de seis principios guía, los cuales abarcan todas las áreas pertinentes al proyecto: la integración con el entorno, accesibilidad a través de diferentes medios de transporte, simplicidad funcional, seguridad de los usuarios, creación de una identidad con la comunidad y la implementación del arte en el diseño.

El primer parámetro que se debe tomar en cuenta es la integración con su entorno inmediato, es decir el contexto en cual se encuentra. Se debe partir desde la respuesta natural a los elementos que lo rodean, empezando por el clima. La arquitectura deberá proveer protección del medio ambiente como lluvia, sol y viento. Pero a su vez tiene que ser sensible respecto a los valores culturales de la zona, proporcionando facilidades para sus usuarios, pero también para los residentes de la comunidad. La incorporación de pequeños comercios compatibles alrededor de la estación, que provean al público de facilidades para su vida cotidiana, no solo ayudará en la aceptación del proyecto, sino que además pueden ser una importante fuente económica. También es importante tener en cuenta la integración cultural, pues se puede mejorar a través de la creación de plazas abiertas, donde se creen nodos dinámicos.

Finalmente, todo tipo de estación termina siendo, la mayoría de veces, un hito para la comunidad, razón por la cual resultan siendo el lugar ideal para implementar conceptos arquitectónicos que relacionen al usuario con su entorno y los inviten a usar este medio de transporte. 
Lo segundo a estudiar es la intermodalidad. El punto clave en este tema es dar la posibilidad a un amplio número de personas para que sean capaces de llegar fácilmente hasta la estación utilizando diferentes medios de transporte.

En este rubro existe una escala de importancia, siendo los peatones y los ciclistas los más importantes, seguidos por el transporte público masivo, luego el transporte particular temporal y por último el transporte particular permanente.

Los peatones deben recibir la mayor atención por parte del diseño arquitectónico. Esto se debe a que es su principal fuente de usuarios, ya que cualquier usuario que llegue mediante otro medio de transporte deberá cambiar al transporte peatonal antes de poder ingresar a la estación. Una buena red de caminos peatonales, bien integrada y no fragmentada, motivará a más personas a utilizar este medio de transporte aliviando el tránsito vehicular y mejorando la percepción del terminal como un espacio público.

Las distancias caminables no deben exceder los 500 metros de recorrido y deberán unir las plazas con los sistemas de recolección de pasajeros como el Metro o la red estatal de buses. El transporte intermodal es de suma importancia ya que permite la rápida conexión con diferentes puntos de la ciudad y facilita el traslado de gran cantidad de pasajeros.

La circulación peatonal en su mayoría deberá ser a nivel de la calle evitando desniveles. También es importante que esté separada del transporte motorizado y que en las zonas donde la gente se va a congregar se implementen elementos que den sombra y protejan del clima.

En cuanto al transporte vehicular particular existen dos tipos. Los de corta estadía solo tienen la función de recoger y dejar pasajeros, con no más de 15 minutos de espera. Los de larga estadía son aquellos vehículos estacionados permanentemente durante la duración de todo el viaje del usuario. Idealmente los servicios de taxi deberán tener su propia vía para no congestionar el flujo de otros vehículos que dejen y recojan pasajeros.

En este tercer punto, es importante tener en cuenta la claridad y la facilidad de uso que presenta el terminal. Es decir, qué tan amigable es con el usuario, permitiendo realizar sus actividades sin mayores dificultades ni contratiempos. 
El diseño de los componentes que integran el complejo, deberán estar organizados de forma lógica, logrando que el usuario promedio pueda realizar cualquier actividad sin problema: llegar a la estación, encontrar los baños, comprar los boletos y abordar su medio de transporte. Esta lógica también se aplica para los pasajeros que desembarcan, los que deberán además recoger su equipaje sin mayores dificultades.

Uno de los componentes más importantes para el éxito de un proyecto de esta envergadura, es su seguridad. La percepción de los usuarios sobre este último, determina si el proyecto es un éxito o un fracaso. La premisa de mayor importancia en este aspecto, es que el diseño arquitectónico genere una tendencia hacia la reducción de los accidentes o actos criminales, sin la necesidad de recurrir a elementos adicionales de seguridad.

Existen tres temas esenciales para tener en cuenta al momento de realizar la propuesta arquitectónica, los cuales pueden mejorar la precepción de la gente hacia el edificio.

El primero es el control de los accesos; esto implica guiar físicamente al usuario, localizando los puntos de encuentro en zonas centrales y con fácil acceso hacia cualquier punto de la estación. Además, se debe integrar con recorridos bien definidos y delimitados, que permitan un claro entendimiento del funcionamiento del terminal.

La segunda recomendación es la vigilancia pasiva; la que se logra colocando las actividades y por lo tanto a la gente, en un determinado modo que permita una conexión visual de todos los puntos de la estación, retomando la idea previamente estudiada por Jane Jacobs, sobre los ciudadanos como principales guardianes naturales ${ }^{22}$.

El tercer punto es poder transmitir a los usuarios la idea que hay gente encargada de cuidar y mantener el lugar. El arte en las paredes, el diseño interior y de los jardines, los tratamientos de suelo, la iluminación y el mantenimiento general de todos los servicios; son algunos de los aspectos más valorados a la hora de expresar pertenencia, los cuales trasmiten un mensaje de seguridad.

La cantidad de personas que transitan diariamente por un terminal y la importancia que tiene como punto de encuentro o de referencia hacen que pueda representar un icono de orgullo y de identidad para una zona específica de la ciudad. El

\footnotetext{
${ }^{22}$ Ver capítulo 3.3.2: Teorías de Jane Jacobs.
} 
carácter cívico que representa, puede llegar a tener un radio de influencia muy amplio entre las comunidades cercanas, motivo por el cual se debe crear un vínculo especial con las personas que lo utilizan diariamente.

Uno de los métodos más eficientes para lograrlo es a través del arte. La gran cantidad de áreas de espera, plazas, zonas de encuentro y zonas comerciales son en la mayoría de casos un gran lienzo en blanco, el que puede ser fácilmente utilizado como área de exposición. Los usuarios que transitan diariamente por el terminal son una audiencia de flujo constante, que en la mayoría de casos tienen que realizar esperas prolongadas. Es por eso que resulta tan beneficioso integrar las dos actividades, ya que esta interacción momentánea crea vínculos emocionales entre los usuarios y la comunidad. Estas teorías fueron estudiadas en el capítulo sobre las metodologías para regenerar un espacio de la ciudad ${ }^{23}$. Es además una forma de promover la cultura local y de exponerla a gente que por lo general no vería este tipo de elementos en su día a día.

Como elemento final de esta lista aparece el arte en el diseño arquitectónico. Este debe ser utilizado como un catalizador para promover la integración del proyecto con la comunidad, además de mejorar la experiencia de viaje de cualquier usuario y de ser posible servir como una ventana para la ciudad.

\subsubsection{Esquema básico de funcionamiento}

Todas las personas que entran a un terminal terrestre se convierten en pasajeros oficiales en el instante que ingresan a la zona de llegada. Pueden arribar a través de diferentes medios de transporte, pero siempre van a tener que pasar por esta instancia para poder proceder a las siguientes etapas: las instalaciones para los pasajeros y las zonas de embarque. Estos tres elementos principales dan vida y articulan todas las funciones complementarias de un terminal terrestre, siendo así el eje básico para su diseño.

La zona de llegada es el primer contacto que experimenta cualquier usuario con la estación en sí, es por esto que resulta primordial analizar cuáles son los medios de transporte utilizados para dirigirse al terminal. También determinará el tamaño y

\footnotetext{
${ }^{23}$ Ver capítulo 3.4.1.2: Metodologías para la regeneración de espacios degradados.
} 
jerarquía que tendrá cada una de las áreas destinadas a recibir y despachar pasajeros, siendo el peatón quien tiene la preferencia sobre el resto, seguido por el transporte público y finalmente el privado. El hall o zona de llegada está anexada a la plaza de ingreso, lugar donde pueden reunirse o descansar los usuarios antes de ingresar al edificio del terminal. Adicionalmente, en esta zona se deben implementar módulos de información al usuario y baños públicos.

La segunda y tercera zona que se deben estudiar son las instalaciones para los viajeros. Se encuentran en los espacios interiores del terminal, pero solo son accesibles para todos los usuarios hasta cierto punto. Las instalaciones para los pasajeros están compuestas de un área de transición donde se puede comprar los boletos, dejar las encomiendas, esperar a que alguien llegue o comprar comida. En general, todas las actividades que se pueden dar en un espacio público cerrado y adicionalmente las actividades necesarias para el funcionamiento de una estación de bus.

Para acceder a la tercera área, la zona de embarque, se tiene que pasar primero por un control de seguridad, ya que esta zona es de acceso restringido únicamente para los pasajeros. El área de embarque tiene como principales características: tener zonas de espera para los pasajeros y andenes para que los buses interprovinciales se puedan estacionar correctamente y de manera ordenada mientras esperan su hora de embarque. Adicionalmente se debe prever la instalación de implementos para el uso diario de los pasajeros como máquinas expendedoras de comida, teléfonos públicos, bebederos, kioscos, oficinas de información para turistas, bancas y tachos.

Figura 23: Esquema de funcionamiento

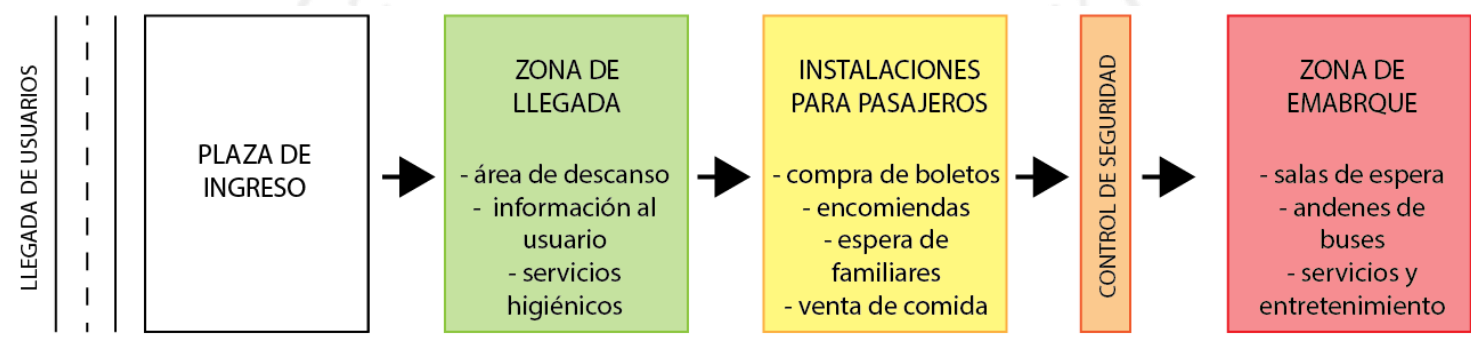

Fuente: Luis Vidal (2013)

Elaboración propia

Un elemento arquitectónico de gran importancia que está presente en todos los terminales terrestres es la cubierta. Normalmente se utilizan sistemas estructurales 
complejos debido a las grandes luces a cubrir. Estos elementos son primordiales porque pueden imprimir un carácter importante en la arquitectura y en la estética del proyecto. Hoy en día también es necesario incluir algunos elementos medio ambientales en estas grandes superficies, como son los paneles solares para la producción de energía y la ventilación natural o la iluminación diurna para el ahorro energético (Vidal, 2013, pp. 24-40).

\subsubsection{Programa requerido}

Para el diseño de un terminal terrestre el PLAM 2035 (Instituto Metropolitano de Planificación, 2014) contempla una serie de espacios obligatorios que se deben tomar en cuenta para su construcción en Lima. Estos espacios presentados por el IMP los hemos contrastado con el programa propuesto en la Enciclopedia de arquitectura Plazola (Plazola Cisneros, 1995), con el objetivo obtener un programa más completo. No todas las zonas aquí presentadas para el programa del terminal son requerimientos obligatorios y de igual forma hay espacios que son necesarios, pero no se mencionan, asimismo para su fácil comprensión han sido dividas de acuerdo a sus usos.

Conexión urbana:

- Plaza de acceso.

- Estacionamiento para bicicletas (opcional).

- Área de circulación para transporte público, taxis y vehículos particulares.

- Zona de intercambio modal de transporte público.

- Zona de intercambio modal de taxis.

- Zona de intercambio modal de vehículos particulares.

- Zona de parqueo momentáneo para taxis.

- Bahías de ascenso y descenso de pasajeros hacia transporte público, taxis y vehículos privados.

- Estacionamiento para vehículos particulares.

Zona pública:

- Áreas verdes, libres y de esparcimiento.

- Pórticos de entrada y salida de la estación (opcional). 
- Vestíbulo de entrada y salida.

- Concesiones y establecimientos comerciales externos.

Servicios al usuario:

- Vestíbulo general.

- Áreas de circulación peatonal desde el vestíbulo general al resto del terminal.

- Módulo de información y orientación al usuario.

- Mostradores de empresas transportistas.

- Recepción, entrega y reclamo de equipaje.

- Oficina de envío y recojo de encomiendas.

- Cabinas de internet y locutorio telefónico.

- Oficina de correo.

- Capilla (opcional).

- Tópico o área de atención médica.

- Oficina de la policía nacional del Perú.

- Guarda de objetos personales y mostrador de objetos perdidos.

- Servicios higiénicos para hombres, mujeres y discapacitados.

- Establecimientos comerciales.

- Restaurantes:

- Vestíbulo de ingreso.

- Mostradores y cajas de pago.

- Área de comensales.

- Servicios higiénicos para hombres, mujeres y discapacitados.

- Cocina.

- Área de lavado.

- Área de almacén y refrigeración.

- Zona de recepción de proveedores.

- Cuarto de basura.

- Control de seguridad y verificación de boletos para el ingreso a las salas de espera.

- Salas de espera.

- Andenes de ascenso y descenso de pasajeros. 
Servicios para operadores de autobuses:

- Vestíbulo.

- Sala de descanso para choferes.

- Zona de alimentación para choferes.

- Servicios higiénicos para hombres, mujeres y discapacitados.

- Vestidores, duchas y casilleros.

- Dormitorios (opcional).

Oficinas de empresas transportistas:

- Vestíbulo de distribución.

- Recepción para clientes.

- Sala de espera.

- Sala de reuniones.

- Oficinas:

- Gerente administrativo.

- Jefe de servicios y personal (opcional).

- Jefe de tránsito (opcional).

- Jefe de taquillas (opcional).

- Jefe de envíos y equipaje (opcional).

- Oficinas administrativas.

- Archivo.

- Servicios higiénicos para hombres, mujeres y discapacitados.

Administración del terminal:

- Recepción y atención al público.

- Sala de espera.

- Sala de reuniones.

- Oficina del gerente.

- Oficinas administrativas.

- Sala de control de llegadas, salidas y tránsito de autobuses.

- Sala control y seguridad.

- Sala de sonido y comunicación interna.

- Archivo. 
- Servicios higiénicos para hombres, mujeres y discapacitados.

Zona de autobuses:

- Garita de control de ingreso al patio de maniobras.

- Patio de maniobras.

- Estacionamientos temporales y permanentes de autobuses.

- Área de carga y descarga de mercancías para proveedores.

- Zonas de mantenimiento para vehículos de transporte:

- Oficina de jefe de mantenimiento.

- Taller para reparaciones.

- Estacionamiento de autobuses para reparaciones.

- Zona de pintura (opcional).

- Zona de lavado.

- Zona de abastecimiento de combustible (opcional).

- Almacén.

- Depósito de desechos y cuarto de basura.

- Servicios higiénicos para hombres, mujeres y discapacitados.

Servicios generales:

- Mantenimiento del terminal y depósito.

- Sala de máquinas para sistema de aire acondicionado y ventilación.

- Sala de bombas de agua y sistema contra incendio.

- Subestación eléctrica.

- Grupo electrógeno (opcional).

- Cisternas.

\subsubsection{Valores y fórmulas para la estimación de áreas}

El principal factor que se deberá tener en cuenta para la factibilidad de un terminal terrestre será el cumplimiento de las áreas mínimas y estándares para cada zona. Como se mencionó al inicio de este capítulo, para poder establecer ciertas áreas mínimas primero se deben obtener una serie de datos, principalmente la demanda de pasajeros y la cantidad de buses que deberán partir y llegar. Con estos datos se calcularán todos los 
puntos críticos del terminal como el número de andenes, el número de mostradores, los tamaños para las zonas de espera, el ancho de los corredores y el tamaño de los vestíbulos, entre otros.

Para el cálculo de la demanda diaria de pasajeros se utilizaron los datos sobre ingresos y salidas de viajes interprovinciales en Lima Este de TYPSA 2003 publicado en el Plan Regional de Desarrollo Concertado de Lima (Municipalidad Metropolitana de Lima, 2012), datos que luego fueron contrastados con el índice de crecimiento de Lima del INEI (Insituto Nacional de Estadística e Informática, 2014). Con la comparación de estas dos fuentes se pudo calcular la demanda diaria estimada de usuarios para el 2035, como indicado en la siguiente tabla.

Tabla 9: Estimación de pasajeros

\begin{tabular}{|c|c|c|c|c|c|c|}
\hline & \multicolumn{5}{|c|}{ Número de pasajeros estimados por día } & \\
& 2003 & 2010 & 2015 & 2020 & 2025 & 2035 \\
\hline $\begin{array}{c}\text { Crecimiento } \\
\begin{array}{c}\text { Ingreso a } \\
\text { Lima Este }\end{array}\end{array}$ & - & $2.35 \%$ & $1.30 \%$ & $1.10 \%$ & $0.90 \%$ & $0.70 \%$ \\
$\begin{array}{c}\text { Salida de } \\
\text { Lima Este }\end{array}$ & 8,167 & 6,312 & 6,394 & 6,462 & 6,520 & 6,618 \\
\hline Total & 14,913 & 15,263 & 15,461 & 15,631 & 15,771 & 16,008 \\
\hline
\end{tabular}

Fuente: Municipalidad Metropolitana de Lima (2012) e Insituto Nacional de Estadística e Informática (2014)

Elaboración propia

Una vez establecida la demanda diaria de pasajeros, se tendrá que determinar el volumen de pasajeros en hora pico, ya que este valor será el utilizado en el dimensionamiento de áreas. Debido a la informalidad existente en el transporte interprovincial de Lima Este, existe un déficit de estudios sobre los flujos diarios de pasajeros y buses, lo que dificulta un cálculo exacto de la hora pico. Es por este motivo que utilizaremos la tabla recomendada por la Federal Aviation Administration [FAA] ${ }^{24}$ que nos permite realizar este cálculo en base al movimiento anual de usuarios. La tabla

\footnotetext{
${ }^{24}$ La FAA es una organización norteamericana que vela por la seguridad aeronáutica de Estados Unidos. Incluye la construcción y operación de los aeropuertos, el control de tráfico aéreo, la certificación de los profesionales y todos los aspectos relacionados a vuelos comerciales (U.S. Department of Transportation, 2017).
} 
10 es una adaptación de esta, que nos permitirá tener un mejor entendimiento de la fórmula, la cual trabaja con el término de "pasajeros en hora pico típica" 25 . Este valor se obtiene al multiplicar la cantidad anual de pasajeros, por un ratio establecido por la FAA, el cual llamaremos "ratio para cálculo de hora pico".

Tabla 10: Cálculo de hora pico

\begin{tabular}{|c|c|c|}
\hline $\begin{array}{c}\text { Volumen anual de } \\
\text { pasajeros }\end{array}$ & $\begin{array}{c}\text { Ratio para cálculo de hora } \\
\text { pico }\end{array}$ & $\begin{array}{c}\text { Pasajeros en hora pico } \\
\text { típica }\end{array}$ \\
\hline$<100,000$ & 0.00200 & $<200$ \\
$100,001-500,000$ & 0.00130 & $130-650$ \\
$500,001-1,000,000$ & 0.00080 & $400-800$ \\
$1,000,001-10,000,000$ & 0.00050 & $500-5,000$ \\
$10,000,001-20,000,000$ & 0.00045 & $4,500-9,000$ \\
$20,000,001-30,000,000$ & 0.00040 & $8,000-12,000$ \\
$>30,000,001$ & 0.00035 & $>10,500$ \\
\hline
\end{tabular}

Fuente: Norman Ashford, Saleh Mumayiz \& Paul Wright (2011, p. 429)

Adaptado de Airport Engineering

La complejidad de áreas requeridas en un terminal terrestre y la falta de normativas nacionales para este tipo de infraestructuras dificulta el dimensionamiento de áreas. Es por este motivo que para determinar las fórmulas y estándares que usaremos en nuestro proyecto nos basaremos en las recomendaciones realizadas por la Enciclopedia de arquitectura Plazola (Plazola Cisneros, 1995) y el informe de Dimensionado de Terminales de transporte público colectivo en Transantiago (Ministerio de Transportes y Telecomunicaciones, 2005). Este informe se utilizó al año siguiente como base para el estudio realizado en la planificación y construcción del Sistema Metropolitano de Transporte de Lima, publicado con el nombre de Estudio de Corredores Complementarios (Advanced Logistics Group, 2006). Ambas fuentes serán completadas con datos específicos obtenidos de la revista Escala (Escala, 1974), el manual desarrollado por la IATA: Airport development reference manual (IATA, 2004), el manual desarrollado por la JICA: Airport Terminal Building Planing (JICA DGCA, 1996) y el estudio realizado por la UE y el MTC sobre los terminales terrestres

\footnotetext{
25 Traducido del inglés "typical peak hour passenger".
} 
en Lima (Ministerio de Comercio Exterior y Turismo [MINCETUR]; Unión Europea [UE], 2009).

\subsubsection{Requerimientos del terreno}

El primer punto a tomar en cuenta es la superficie neta del terreno, es decir el área efectiva que se puede utilizar en la construcción del terminal, descontando los retiros municipales. Se debe incluir el edificio del terminal propiamente dicho con todos sus servicios complementarios, el área de mantenimiento y el patio de maniobras. Adicionalmente este último debe contar con un tratamiento de suelo especial y deberá encontrarse segregado del resto de áreas. Así como se indica en la siguiente tabla, los terminales se clasifican en diferentes categorías de acuerdo a la población diaria transportada y el área utilizada.

Tabla 11: Clasificación de los terminales

\begin{tabular}{|c|c|c|c|c|}
\hline \multirow{2}{*}{ Tipo } & \multicolumn{4}{|c|}{ Clasificación de los terminales } \\
\hline Población diaria & Número de & $\mathrm{m} 2$ construidos & m2 de terreno \\
\hline transportada & cajones & por cajón & Hasta 10000 \\
\hline TP -2 & Hasta 5000 & Hasta 15 & $50-150$ & $10000-25000$ \\
\hline TP -3 & $5000-18000$ & $16-30$ & $150-250$ & $25000-50000$ \\
\hline TP -4 & $18000-30000$ & $25-60$ & $250-350$ & Más de 50000 \\
\hline
\end{tabular}

Fuente: Alfredo Plazola Cisneros (1995)

Elaboración propia

Cuando consideramos el área total del terreno debemos tener en cuenta que se deberá dejar una franja verde arborizada en todo el perímetro con la función de mitigar el impacto del terminal en las zonas aledañas. Esta norma se debería implementar siempre que se tengan edificaciones colindantes, pero sobre todo cuando el terreno se encuentra en una zonificación donde se admite el uso residencial. El ancho de las franjas verdes será establecido según el área del terreno como indica la siguiente tabla: 
Tabla 12: Ancho de franja verde

\begin{tabular}{|c|c|}
\hline Categoría & Ancho mínimo \\
\hline $\mathrm{TP}-1$ & $2-4$ metros \\
$\mathrm{TP}-2$ & 6 metros \\
$\mathrm{TP}-3$ & \\
\hline $\mathrm{TP}-4$ & \\
\hline
\end{tabular}

Fuente: Advanced Logistics Group (2006)

Adaptado de Proyecto de corredores complementarios

En cuanto al emplazamiento del terminal es necesario considerar que tendrá un gran impacto en la infraestructura vial cercana, así como en las comunidades aledañas. Por este motivo es importante tomar en cuenta el uso de suelo establecido según la zonificación municipal, al igual que la clasificación de las rutas de acceso vehicular, ya que estos factores son determinantes para decidir si el emplazamiento del terreno es apto o no para su uso como terminal terrestre.

Tabla 13: Uso de suelo y vía de acceso

\begin{tabular}{|c|c|c|}
\hline Categoría & Tipo de uso del suelo & Vía de acceso \\
\hline $\mathrm{TP}-1$ & Infraestructura, actividades productivas & Local o mayor \\
\hline $\mathrm{TP}-2$ & Comercio o servicios & Colectora o mayor \\
\hline $\mathrm{TP}-3$ & Infraestructura, actividades productivas & Colectora o mayor \\
$\mathrm{TP}-4$ & Comercio o servicios & Arterial o mayor \\
\hline
\end{tabular}

Fuente: Advanced Logistics Group (2006)

Adaptado de Proyecto de corredores complementarios

En el caso del nuevo terminal terrestre de Yerbateros se consideró la demanda a futuro de los próximos 20 años llegando a 16,000 usuarios, lo que nos colocaría en el tipo de terminal TP - 2. El terreno del proyecto cuenta con un área de 50,000m², más del doble requerido por este tipo de terminales, lo que nos permitirá implementar sin problemas los perímetros verdes necesarios y además una serie de usos adicionales como espacios públicos y comercio. El tipo de zonificación es industrial que también permite el uso como infraestructura, asimismo se encuentra conectado directamente a la Carretera Central, vía arterial de Lima. La ubicación actual del terreno cumple con todas las especificaciones mínimas requeridas, lo que hace viable el proyecto. 
Finalmente, para asegurar la correcta inserción y factibilidad del proyecto en el sitio, sería necesaria la elaboración de un estudio de impacto vial y ambiental.

\subsubsection{Conexión urbana}

\section{Plaza de acceso}

Como ya lo hemos mencionado anteriormente, el medio de transporte más importante, pero a su vez uno de los más relegados, es el peatonal. Es considerado el medio de locomoción básico y se debe tener en cuenta que es el único que utilizarán los usuarios tras descender del transporte público o privado.

Para que la zona peatonal sea lo más amigable posible se necesita crear un ambiente que encaje con su entorno y haga que la estadía del peatón sea segura y agradable. Estos espacios consisten en una red de caminos interconectados entre sí y a la red urbana existente, además de generar nodos y plazas. También deberían agrupar a la gente y presentar las características necesarias para la implementación de servicios que animen el contexto inmediato. Es recomendable crear puntos focales de atracción cerca del ingreso al terminal o en la plaza pública anterior, con el objetivo de atraer la atención de la gente y darle vida al terminal mismo.

La plaza de acceso es uno de estos elementos principales ya que reúne a todos los usuarios antes de ingresar al terminal, sin importar el medio de transporte que utilicen. Además, permite que los usuarios se sienten, conversen, descansen y se entretengan sin sentir que están invadiendo una propiedad privada. Si estos espacios cuentan con un punto central resultan muy importantes ya que atraen la atención de los usuarios y los direcciona hacia el terminal. Para reforzar esta idea se deberá incluir comercio, lo que servirá como un estímulo adicional para animar la plaza.

Es necesario tener en cuenta la interacción entre los usuarios y otros medios de transporte como el automóvil, en cuyo caso se tiene que garantizar el bienestar del peatón. Para lograrlo se necesita implementar algunos métodos con tal de reducir la velocidad vial en los puntos críticos más cercanos al terminal. Un medio de transporte que se integra fácilmente al peatonal son los ciclistas, ya que ambos tienen características y requerimientos similares haciendo que sean altamente compatibles. Asimismo, es importante respetar dimensiones mínimas, tal como lo indicado en la siguiente tabla, velando siempre por la seguridad y comodidad del peatón. 
Tabla 14: Dimensiones mínimas para tránsito peatonal

\begin{tabular}{|c|c|}
\hline Instalación & Dimensión es tándar \\
\hline $\begin{array}{c}\text { Caminos peatonales } \\
\text { Cruces peatonales }\end{array}$ & $\begin{array}{r}\text { El ancho mínimo debe ser } 1.80 \mathrm{~m} \text { más un adicional de } 0.30 \mathrm{~m} \text { de } \\
\text { seguridad. }\end{array}$ \\
$\begin{array}{c}\text { El ancho mínimo es igual al requerido por los caminos peatonales } \\
\text { en todas las intersecciones. } \\
\text { peatones }\end{array}$ & $\begin{array}{r}\text { El ancho mínimo sin obstrucciones debe ser } 1.80 \mathrm{~m} \text {. En paraderos } \\
\text { con mas de } 3 \text { buses en fila se incrementará este ancho en } 0.60 \mathrm{~m} \\
\text { por cada unidad adicional. }\end{array}$ \\
Ciclovías & El ancho mínimo para un ciclovía de doble carril debe ser $2.40 \mathrm{~m}$. \\
\hline
\end{tabular}

Fuente: Washington Metropolitan Area Transit Authority (2008)

Adaptado de Station site and access planning manual

\section{Zonas de intercambio modal}

En Lima el transporte urbano mediante buses y combis suman el $63 \%$ de todos los viajes realizados diariamente (Lima Cómo Vamos, 2014). Es por esta razón que este medio de transporte es el segundo más importante a la hora de planificar un nodo con tanto flujo de personas como un terminal terrestre.

Como fue mencionado anteriormente existen dos tipos de zonas cuando se habla de embarque y desembarque de pasajeros; las estadías de corta y de larga duración. En el primer caso se debe diferenciar el transporte privado como carros y taxis, del público como micros y buses. Esto se sugiere mediante dos vías paralelas, cada una con su respectiva bahía, para no interferirse mutuamente en los flujos de personas, siendo la del transporte público la que se debe ubicar más cerca del terminal. Por recomendación general los cajones de estacionamiento deberán tener una separación de 2 metros entre sí para realizar maniobras, así como un ancho de 4 metros para el transporte urbano y 3.5 metros para taxis y vehículos particulares (Ministerio de Comercio Exterior y Turismo [MINCETUR]; Unión Europea [UE], 2009). En ambos casos se recomienda que las áreas de desembarque sean techadas, con asientos de espera y que respeten un ancho mínimo de acera, como lo recomendado en la tabla 15. Además, se debe evitar que los peatones tengan que cruzar las vías de los buses o carros y de ser necesario deberá ser a través de puentes peatonales.

Para las zonas con mayor tiempo de espera, se aconseja que estén ubicadas como máximo a 200 metros del ingreso a la estación y además se deje suficiente 
espacio para que por lo menos cuatro vehículos puedan estacionarse simultáneamente a esperar pasajeros sin obstruir la vía.

Tabla 15: Ancho de vereda en bahías urbanas

\begin{tabular}{|c|c|c|}
\hline $\begin{array}{c}\text { Número de buses } \\
\text { dispuestos en fila }\end{array}$ & $\begin{array}{c}\text { Ancho mínimo de acera sin } \\
\text { obstrucciones }\end{array}$ & $\begin{array}{c}\text { Ancho de acera } \\
\text { recomendado }\end{array}$ \\
\hline $1-2$ & $1.80 \mathrm{~m}$ & \\
\hline $3-4$ & $2.40 \mathrm{~m}$ & $4.00 \mathrm{~m}$ \\
\hline 5 & $3.00 \mathrm{~m}$ & \\
\hline 6 & $3.60 \mathrm{~m}$ & \\
\hline
\end{tabular}

Fuente: Washington Metropolitan Area Transit Authority (2008)

Adaptado de Station site and access planning manual

Por último, es mandatorio contar con vías especiales en caso de emergencia, por donde solo puedan circular ambulancias, bomberos o policías, sin tener que maniobrar evadiendo al resto de vehículos. De igual importancia es la presencia de accesos para discapacitados ya sea en las áreas exteriores como interiores. Entre lo requerido se encuentran las rampas, los ascensores, caminos guiados, textos informativos en braille y las señales o letreros con audio.

Bahías de ascenso y descenso de pasajeros

La IATA (2004) propone la siguiente fórmula para el cálculo de la longitud de la bahía de llegada y salida, de taxis y vehículos particulares. En terminales donde existe una única bahía de conexión urbana tanto para llegadas como salidas, se calcula en base a la cantidad de pasajeros en hora punta total. Cuando las bahías son independientes se deberá utilizar la hora punta correspondiente de llegada o salida para cada una de estas.

$$
\text { Longitud de bahía }=\left(\frac{a \times p \times l \times t}{60 \times n}\right)+(10 \%)
$$

$a=$ pasajeros en hora punta que utilizan la conexión urbana.

$p=$ proporción de pasajeros que usan el medio de transporte analizado $(0.3-0.5)$.

$l=$ longitud media por vehículo (12 - 14 metros).

$t$ = tiempo de permanencia de cada vehículo (1 - 1.5 minutos/vehículo $)$.

$n=$ media de pasajeros por vehículo (1.7 - 3 pasajeros). 


\section{Estacionamiento de vehículos particulares}

Se recomienda la implementación de estacionamientos privados en el terminal, permitiendo a los usuarios ir en un vehículo privado y recogerlo al retorno de su viaje. De esta misma forma se potencian las cualidades comerciales del proyecto, ya que permite que los usuarios usen las áreas públicas y comerciales sin necesidad de abordar un bus. Los estacionamientos pueden ser subterráneos o elevados en un edificio, pero se debe cuidar las dimensiones para evitar muros fuera de escala y grandes áreas vacías que incomoden a los usuarios.

Las zonas de estacionamiento se pueden ubicar frente al terminal o al lado de la plaza de acceso, pero cuidando de no encontrarse a más de $450 \mathrm{~m}$ de distancia de la puerta de ingreso a la estación. Como recomendación general, se considera un cajón de estacionamiento por cada $50 \mathrm{~m}^{2}$ construidos (Plazola Cisneros, 1995). En todo caso esta área no deberá ser menor al 30\% del área del patio de maniobras y deberá cumplir con los requerimientos mínimos establecidos para cada uso por el Reglamento Nacional de Edificaciones. Las dimensiones mínimas por cajón serán de $2.50 \mathrm{~m}$ de ancho por $5.00 \mathrm{~m}$ de largo.

\subsubsection{Servicios al usuario}

\section{$\underline{\text { Vestíbulo general o de salida }}$}

Esta es la primera zona del terminal a la que se accede cuando se proviene del área de conexiones urbanas. Aquí se albergan los mostradores de facturación, los que determinaran la composición y distribución interna del vestíbulo.

Según las fuentes mencionadas al inicio del capítulo, existen tres tipos diferentes de zonas de facturación. La primera es la facturación centralizada, donde los mostradores no están divididos por compañías transportistas, sino que están centralizados. En este caso la administración del terminal se encarga de recibir a todos los pasajeros y enviar los equipajes a una única zona de clasificación donde se distribuyen hacia los buses. La segunda es la facturación descentralizada, en la cual cada compañía tiene su propio mostrador y se encarga de movilizar el equipaje de sus clientes. Al ser un trato directo entre las empresas y los clientes se mejora la calidad del servicio. Por último, existe la facturación en puerta de embarque, donde todo el proceso 
ser realiza frente a esta, simplificando procesos como el movimiento de equipajes, pero aumentando el tiempo y el personal necesario, sobre todo en los chequeos de seguridad.

A menos que se trate de terminales muy pequeños y con poco flujo de personas, deberá existir un vestíbulo para el área de salidas y otro para el área de llegadas, y adicionalmente se puede implementar un tercero para la zona comercial. La IATA (2004) y la JICA (1996) definen la siguiente fórmula para el cálculo del área necesaria para el vestíbulo de salidas.

$$
\text { Área vestíbulo salidas }=(a \times y) \times[s \times(1+b)]
$$

$a=$ pasajeros de salida en hora punta.

$y=$ tiempo medio de ocupación, se sabe que en un momento crítico hay como máximo $50 \%$ de los pasajeros en hora punta (0.5).

$s=$ espacio recomendado por pasajero (1.5 - 2 metros cuadrados).

$b=$ número de acompañantes por pasajero, cambia dependiendo de cada cultura $(0.2-$

\section{5 personas).}

\section{Atención al usuario y mostradores de empresas transportistas}

En un lugar visible del vestíbulo de llegadas y otro en el de salidas, se implementará un mostrador como punto de información y orientación al usuario, que tendrá capacidad para 2 personas y un área de $6.00 \mathrm{~m}^{2}$ a $10.00 \mathrm{~m}^{2}$. Adicionalmente, el vestíbulo de llegada deberá contar con un centro de atención al usuario, y servirá para que los usuarios realicen reclamos o reporten algún tipo de incidente. El área mínima de esta oficina será de $15.00 \mathrm{~m}^{2}$ (Ministerio de Comercio Exterior y Turismo [MINCETUR]; Unión Europea [UE], 2009).

Los mostradores de las empresas transportistas se dispondrán a lo largo del vestíbulo de llegada sin interrumpir el tránsito de los pasajeros. Estos tendrán por lo menos 1.5 metros de ancho y una profundidad de 2.50 metros, además de ser acoplables por si algunas empresas necesitan más de uno. De ser posible se recomienda un conexión visual o audiovisual con el área de plataformas, con el objetivo de facilitar datos sobre los pasajeros. Cuando los mostradores funcionen también como oficina para las empresas transportistas estos no podrán tener un área menor a $15.00 \mathrm{~m}^{2}$. 
Para el cálculo del número de mostradores necesarios en un terminal terrestre hemos recurrido a la fórmula propuesta por la IATA (2004), graficada a continuación. De igual forma se obtuvo la fórmula para el cálculo del área de colas en la zona de mostradores. En este caso, las colas de los puntos de venta no deberán interrumpir bajo ningún motivo el tránsito de los pasajeros hacia las zonas de embarque.

$$
\text { Número de mostradores }=\left(\frac{a}{60} \times t\right)+(10 \%)
$$

$a=$ pasajeros de salida en hora punta.

$t$ = tiempo medio de atención a un pasajero (2 - 3.5 minutos/pasajero $)$.

$$
\text { Área de colas }=\left(\frac{1}{6} \times a \times s\right)+(10 \%)
$$

$a=$ pasajeros de salida en hora punta.

$s=$ espacio recomendado por pasajero $(1.5$ - 1.6 metros cuadrados $)$.

\section{Zona de equipaje y envío de encomiendas}

Existen tres formas de manejar la entrega de equipajes en un terminal terrestre. En la primera, el acopio de equipaje se hace a través de un punto centralizado que se encarga de distribuirlo hacia los andenes de embarque. En la segunda forma, el equipaje se entrega en el mismo mostrador de cada empresa, en cuyo caso la distribución del equipaje hacia los buses se hace más complicada. En la última opción, se entrega el equipaje directamente en el andén de embarque, lo que reduce el personal necesario, pero aumenta el tiempo de embarque y dificulta los chequeos de seguridad.

Los mostradores deberán contar con dos entradas para el equipaje, una a nivel de suelo para las maletas pesadas y otra por encima del mostrador para las más livianas. El transporte del equipaje desde los mostradores hasta los andenes se realizará mediante carritos o bandas transportadoras.

En todo terminal debe existir la posibilidad para que los usuarios guarden su equipaje dentro de este durante un tiempo determinado. Esto se puede realizar mediante la implementación de casilleros o de un cuarto especial para guardado, el cual tendrá un 
área mínima de $12.00 \mathrm{~m}^{2}$. Además, debe haber un depósito para equipajes no reclamados.

La zona de encomiendas se puede ubicar dentro vestíbulo de llegadas o en un área anexa, dependiendo de la demanda existente. El área podrá ser entre $20 \mathrm{~m}^{2}$ y $36.00 \mathrm{~m}^{2}$ (Plazola Cisneros, 1995). Esta zona deberá contar con una zona para la atención al público y otra para el almacenaje de las encomiendas. Al igual que la zona de entrega de equipajes, deberá estar conectada con la de andenes mediante carritos o bandas transportadoras.

$\underline{\text { Servicios complementarios al usuario y locales comerciales }}$

Una variedad de servicios complementarios para los usuarios mejorará el nivel brindado por el terminal. Existe una serie de instalaciones básicas que se deben incluir, es el caso del mobiliario como bancas, bebederos y basureros. Estos se deberán ubicar en el perímetro de las áreas utilizadas por los pasajeros para facilitar el libre tránsito. Adicionalmente se instalarán en puntos clave como en las zonas cercanas a los ingresos, kioscos y las salas de espera.

Es obligatorio contar con un servicio médico, el cual se deberá ubicar en una zona céntrica y con acceso tanto a las áreas públicas como operacionales, además de contar con un fácil acceso desde el exterior. Contará al menos con una sala de espera y un cuarto privado para atender a los usuarios. Se recomienda un local con $20 \mathrm{~m}^{2}$ como mínimo (Plazola Cisneros, 1995).

También se sugiere la implementación de otros servicios complementarios como: cabinas de internet, un locutorio telefónico, una oficina de correo, una oficina para la policía nacional del Perú, una farmacia, una capilla, sucursales bancarias y locales comerciales.

Estos servicios complementarios se distribuirán a lo largo de los vestíbulos de llegada y salida, así como en las salas de espera y las circulaciones entre zonas. Se debe evitar que estos se ubiquen de forma contigua a los mostradores de las empresas transportistas en el vestíbulo de llegadas, con el objetivo de evitar mayor congestión en las áreas de colas. El área recomendada para estos locales será de $10.00 \mathrm{~m}^{2}$ como mínimo y un máximo de $40.00 \mathrm{~m}^{2}$ (Ministerio de Comercio Exterior y Turismo [MINCETUR]; Unión Europea [UE], 2009). 
Para las áreas comerciales se debe considerar un andén de carga específico para proveedores, el cual deberá ser accesible desde el patio de maniobras. Los recorridos de suministros y basura de las áreas comerciales no pueden interferir con las rutas de los pasajeros. Cada local deberá además contar con un área de almacenamiento. Es necesario prever las instalaciones adicionales de gas, agua, electricidad, electromecánicas y contra incendio para las zonas comerciales en el proyecto del terminal para que estas no afecten la arquitectura.

La zona de restaurantes o patio de comidas se calcula con una demanda máxima del $30 \%$ de la capacidad de las salas de espera, asignando un rango de $1.50 \mathrm{~m}^{2}$ a $2.00 \mathrm{~m}^{2}$ por comensal.

Adicionalmente, se deberá contemplar la implementación de servicios higiénicos según las reglamentaciones establecidas por el RNE. La dotación para patio de comidas será como se especifica en las siguientes tablas.

Para empleados:

Tabla 16: Dotación de servicios - Patio de comidas I

\begin{tabular}{|c|c|c|}
\hline Según el núme ro de empleados & Hombres & Muje res \\
\hline De 1 a 5 empleados & \multicolumn{2}{|c|}{ 1L, 1U, 1I } \\
\hline De 6 a 20 empleados & 1L, 1U, 1I & $1 \mathrm{~L}, 1 \mathrm{I}$ \\
\hline De 21 a 60 empleados & 2L, 2U, 2I & 2L, 2I \\
\hline De 61 a 150 empleados & 3L, 3U, 3I & 3L, 3I \\
Cada 100 empleados adicionales & $1 \mathrm{~L}, 1 \mathrm{U}, 1 \mathrm{I}$ & $1 \mathrm{~L}, 1 \mathrm{I}$ \\
\hline \multicolumn{2}{|c|}{$\mathrm{L}=$ lavatorio, $\mathrm{U}=$ urinario, $\mathrm{I}=$ inodoro } \\
\hline
\end{tabular}

Fuente: Ministerio de Vivienda, Construcción y Saneamiento (2006) Adaptado de Reglamento Nacional de Edificaciones 
Para clientes:

Tabla 17: Dotación de servicios - Patio de comidas II

\begin{tabular}{|c|c|c|}
\hline Según el número de clientes & Hombres & Muje res \\
\hline De 1 a 16 clientes & \multicolumn{2}{|c|}{ No requiere } \\
De 17 a 50 clientes & $1 \mathrm{~L}, 1 \mathrm{U}, 1 \mathrm{I}$ & $1 \mathrm{~L}, 1 \mathrm{I}$ \\
De 51 a 100 clientes & 2L, 2U, 2I & 2L, 2I \\
\hline Cada 150 clientes adicionales & $1 \mathrm{~L}, 1 \mathrm{U}, 1 \mathrm{I}$ & $1 \mathrm{~L}, 1 \mathrm{I}$ \\
\hline \multicolumn{2}{|c|}{$\mathrm{L}=$ lavatorio, $\mathrm{U}=$ urinario, $\mathrm{I}=$ inodoro } \\
\hline
\end{tabular}

Fuente: Ministerio de Vivienda, Construcción y Saneamiento (2006)

Adaptado de Reglamento Nacional de Edificaciones

\section{Control de seguridad}

Antes de abordar los buses todos los usuarios deben pasar por un control de seguridad con magnetómetro, y el equipaje pasará por rayos $\mathrm{X}$ y registro manual. Es por este motivo que se recomienda un control de seguridad centralizado antes de pasar a las salas de embarque. Si el control de seguridad es descentralizado y se realiza en cada sala de embarque individualmente se desperdicia espacio, tiempo, personal y se necesita un mayor número de máquinas de rayos $\mathrm{X}$.

El cálculo de la cantidad de máquinas de rayos $\mathrm{X}$ necesarias para un control de seguridad centralizado se realiza mediante la siguiente fórmula propuesta por la IATA (2004).

$$
\text { Número de máquinas }=\frac{a}{p} \times u
$$

$a=$ pasajeros de salida en hora punta.

$p=$ unidades por hora punta que es capaz de procesar el aparato (450 - 600 unidades/hora).

$u=$ número de equipajes por pasajero ( $1-2$ equipajes $).$ 


\section{$\underline{\text { Salas de espera o embarque }}$}

Se debe considerar la implementación de un vestíbulo previo a las salas de embarque, con el objetivo de recibir y distribuir a todos los pasajeros que ya pasaron por el control de seguridad, pero que aún no tienen una sala de embarque especifica. Esta zona estará equipada con servicios complementarios y comercio, además de contar con pantallas informativas para dirigir a los usuarios.

Se debe implementar al menos una sala VIP para los usuarios que deseen tener un trato más personalizado, la cual estará conectada directamente al vestíbulo previo.

Las salas de espera tienen un acceso directo a sus respectivas plataformas de embarque. Para la zona de espera se sugiere una altura mínima de 3.50 metros. También se recomienda que la separación mínima entre butacas sea de $1.50 \mathrm{~m}$, para que las personas dejen sus pertenencias sin obstruir el paso. Como norma general, estas salas tendrán un área mínima de $20 \mathrm{~m}^{2}$ por andén (Plazola Cisneros, 1995). Adicionalmente y de ser posible, se sugiere una ventilación e iluminación natural eficaz.

Para el dimensionamiento óptimo de las áreas de espera se utilizará la fórmula desarrollada por la IATA (2004) y la JICA (1996), ya que ésta toma en cuenta el porcentaje promedio de personas sentadas $(60 \%)$ y paradas $(40 \%)$ en la sala de espera, para evitar sobre dimensionamientos.

Área de espera $=m \times c \times[(0.6 \times a s)+(0.4 \times a p)]$

$m=$ número máximo de asientos en el autobús más grande que utilizará el terminal. $c=$ factor de ocupación del autobús (0.8).

as = área recomendada por pasajero sentado (1.5 metros cuadrados).

$a p=$ área recomendada por pasajero parado (0.8 metros cuadrados).

Adicionalmente, se deberá contemplar la implementación de servicios higiénicos según las reglamentaciones establecidas por el RNE. La dotación para salas de espera será como se especifica en la siguiente tabla. 
Tabla 18: Dotación de servicios - Salas de espera

\begin{tabular}{|c|c|c|}
\hline Según el número de personas & Hombres & Muje res \\
\hline De 0 a 100 personas & 1L, 1U, 1I & 1L, 1I \\
\hline De 101 a 200 personas & 2L, 2U, 2I & 2L, 2I \\
\hline De 201 a 500 personas & 3L, 3U, 3I & 3L, 3I \\
Cada 300 personas adicionales & $1 \mathrm{~L}, 1 \mathrm{U}, 1 \mathrm{I}$ & $1 \mathrm{~L}, 1 \mathrm{I}$ \\
\hline \multicolumn{2}{|c|}{$\mathrm{L}=$ lavatorio, $\mathrm{U}=$ urinario, $\mathrm{I}=$ inodoro } \\
\hline
\end{tabular}

Fuente: Ministerio de Vivienda, Construcción y Saneamiento (2006)

Adaptado de Reglamento Nacional de Edificaciones

\section{Plataforma de embarque y desembarque}

Las plataformas son la zona de conexión entre el terminal terrestre y los buses. Se trata de un área que debe conectarse con las salas de embarque o desembarque, según sea necesario. Ambas zonas siempre deben estar separadas, y la circulación no debe interferir entre ellas. Las plataformas estarán localizadas más cerca a la entrada del terminal que otras zonas como depósitos y talleres.

Cuando se trate de plataformas de embarque, se colocará un puesto de seguridad para controlar los boletos de los usuarios. El tiempo promedio que demora un autobús en embarcar completamente es de 15 a 30 minutos y en temporada alta el tiempo se puede disminuir hasta 15 minutos por unidad.

Entre el edificio del terminal y los andenes de los buses debe existir una acera para que los usuarios puedan formar una cola o descender del bus sin problemas, esta zona tendrá 4.00 metros de ancho para atender a 10 plataformas consecutivas, más 2.00 metros libres adicionales para el flujo entre plataformas. En caso que las salas de espera se encuentren en otro nivel, las escaleras o ascensores no pueden ocupar parte de estos 6.00 metros, obteniendo un área libre de al menos $20.00 \mathrm{~m}^{2}$ por plataforma. La acera para el acceso de los pasajeros hacia la puerta del bus deberá tener 9.00 metros de largo y 1.20 metros de ancho como mínimo (Escala, 1974). Todas estas áreas peatonales tendrán una altura mínima de 15 centímetros sobre el nivel del patio de maniobras (ver figura 24).

Se colocará una baranda de seguridad para impedir que los usuarios accedan al estacionamiento del bus y evitar accidentes. Al final de cada plataforma se ubicarán dos topa llantas, para evitar que el autobús se estacione fuera de lugar. 
Estas zonas se encontrarán techadas para proteger a los usuarios del medio ambiente, la altura libre para la zona de buses será de 5.00 metros y deberá cubrir al menos un $75 \%$ de la longitud del bus. Si es necesaria la colocación de columnas en el área de las plataformas, deberán estar situadas como mínimo a 1.20 metros del borde del andén, sin obstruir la visual de los choferes (Ministerio de Comercio Exterior y Turismo [MINCETUR]; Unión Europea [UE], 2009).

Figura 24: Consideraciones para el diseño de Bahías

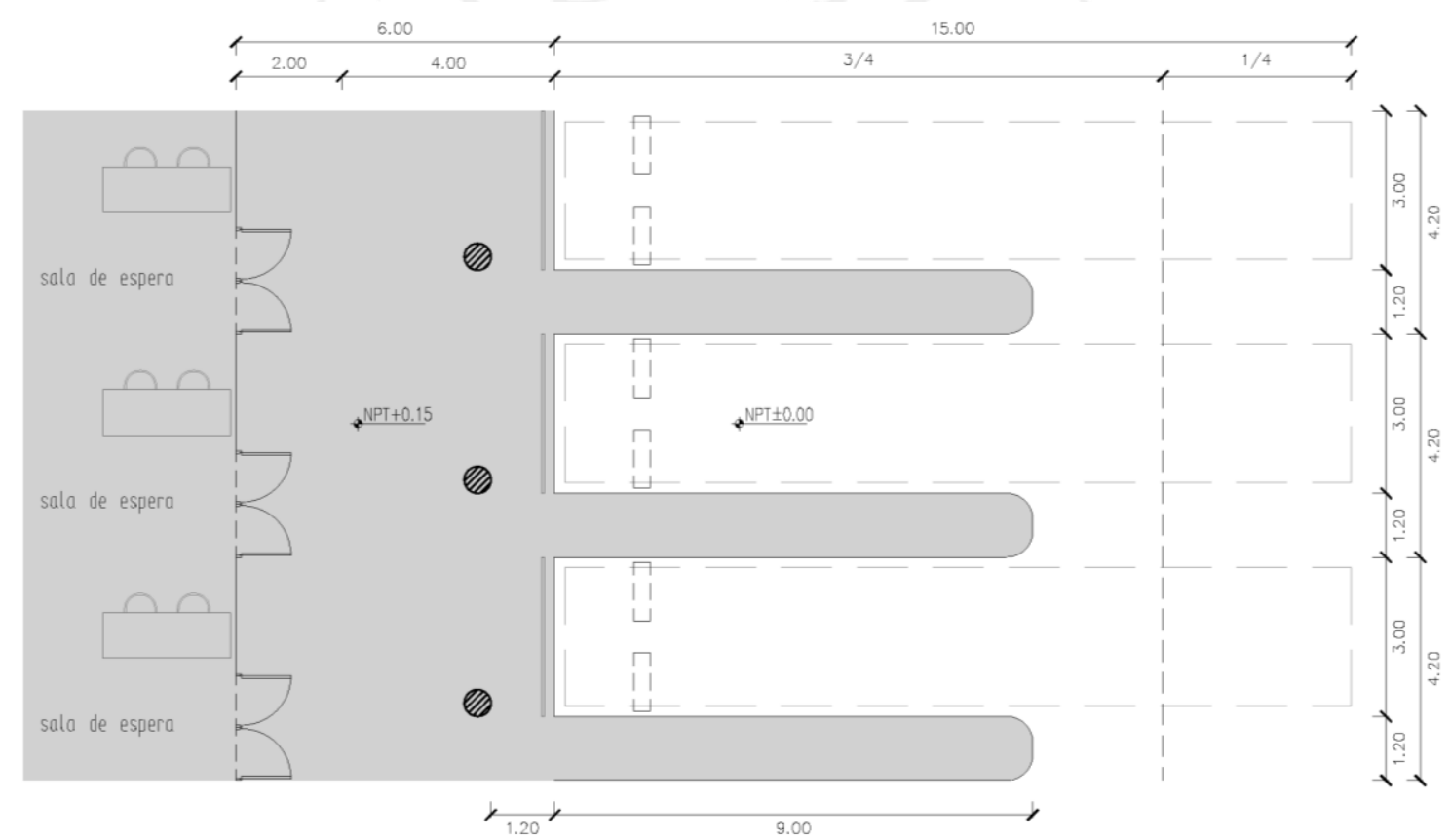

Fuente: Escala (1974) y Ministerio de Comercio Exterior y Turismo; Unión Europea (2009)

Elaboración propia

Las plataformas de estacionamiento tendrán un ancho mínimo de 3.00 metros y un largo de 15.00 metros. Adicionalmente, se dejarán 4.00 metros libres adicionales para maniobras del bus. Estas plataformas pueden tener diferentes inclinaciones dependiendo de la configuración del terminal, las medidas aproximadas de cada inclinación de estacionamiento son como se describen en la Tabla 19, para mayor comodidad se recomienda el estacionamiento en 60 o 90 grados. Para el cálculo del número de andenes, se recomienda uno por cada 6 buses en hora punta. 
Tabla 19: Inclinación de plataformas

\begin{tabular}{|c|c|c|c|c|}
\hline \multicolumn{5}{|c|}{ Inclinación de plataformas } \\
\hline & $30^{\circ}$ & $45^{\circ}$ & $60^{\circ}$ & $90^{\circ}$ \\
\hline Ancho & $8.00 \mathrm{~m}$ & $5.65 \mathrm{~m}$ & $4.60 \mathrm{~m}$ & $4.00 \mathrm{~m}$ \\
\hline Profundidad & $18.50 \mathrm{~m}$ & $24.50 \mathrm{~m}$ & $30.50 \mathrm{~m}$ & $36.50 \mathrm{~m}$ \\
\hline Área neta por bus & $148.00 \mathrm{~m}$ & $138.40 \mathrm{~m}$ & $140.30 \mathrm{~m}$ & $146.00 \mathrm{~m}$ \\
\hline
\end{tabular}

Fuente: Escala (1974)

Adaptado de Revista Escala $n^{\circ} 63$

Las mismas normas se aplican para la plataforma de carga, utilizada por los proveedores de los locales comerciales, con la única diferencia que esta se ubicará en una zona independiente del terminal, sin acceso al público.

\section{Zona para el recojo de equipaje}

Una vez que los pasajeros han descendido de los buses, se dirigirán hacia la zona de recojo de equipaje. Todo el equipaje se movilizará mediante fajas transportadoras y se recogerá en los hipódromos de entrega ${ }^{26}$. La IATA (2004) propone una fórmula para el cálculo del área requerida en la zona de recojo de equipaje y otra para el numero de hipódromos necesarios. Adicionalmente, sabemos que el perímetro de cada hipódromo es de 30 - 40 metros y la separación mínima entre estos será de 9.00 metros.

$$
\text { Área de equipaje }=\left(\frac{d \times r \times g}{60}\right)+(10 \%)
$$

$d=$ pasajeros de llegada en hora punta.

$r$ = tiempo medio de ocupación por pasajero (30 minutos).

$g=$ espacio requerido por pasajero (1.5 metros cuadrados).

\footnotetext{
${ }^{26}$ Maquinaria que facilita el transporte y la entrega de equipaje a los pasajeros. En el Perú también es conocido como carrusel de equipaje.
} 


$$
\text { Número de hipódromos }=\frac{d \times q}{60 \times j}
$$

$d=$ pasajeros de llegada en hora punta.

$q$ = tiempo medio de ocupación de los hipódromos (10 minutos).

$j=$ media de pasajeros por autobús multiplicado por un factor de ocupación de 0.8 (52).

Vestíbulo de llegada

Como se mencionó al inicio del capítulo, deberá existir un vestíbulo para el área de llegadas. En esta zona los usuarios que descienden del bus podrán descansar antes de salir del terminal o encontrar algunos servicios necesarios como teléfonos, información, reclamos y alquiler de autos. La IATA (2004) propone una fórmula para el cálculo de esta zona, graficada a continuación, y se deberá tomar en cuenta la cultura del lugar al momento de determinar el número de acompañantes que recibirá cada pasajero.

$$
\text { Área vestíbulo llegadas }=s \times\left(\frac{w \times d}{60}+\frac{z \times d \times b}{60}\right)+(10 \%)
$$

$d=$ pasajeros de llegada en hora punta.

$w$ = tiempo medio de ocupación por pasajero (15 minutos).

$z=$ tiempo medio de ocupación por visitante (30 minutos).

$s=$ espacio recomendado por pasajero (1.5 - 2 metros cuadrados).

$b=$ número de acompañantes por pasajero, cambia dependiendo de cada cultura (0.2 -

\section{5 personas).}

\subsubsection{Servicios para operadores de autobuses}

Para el caso de las zonas destinadas a los operadores de buses, las superficies mínimas requeridas estarán en función de la cantidad de buses que utilice el terminal, como se indica en la siguiente tabla. Estas deberán incluir áreas de descanso y alimentación para los conductores, así como servicios higiénicos y duchas. En algunos casos también se incluirá la administración. Si la zona administrativa se encuentra anexada, su área no podrá sobrepasar el $35 \%$. 
Tabla 20: Servicios al operador

\begin{tabular}{|c|c|c|}
\hline Flota diaria de buses (F) & $\begin{array}{c}\text { Superficie mínima } \\
\text { destinada a servicios }\end{array}$ & $\begin{array}{c}\text { Dotación mínima de } \\
\text { servicios }\end{array}$ \\
\hline Hasta 10 & $25 \mathrm{~m} 2$ & \multirow{3}{*}{$\begin{array}{l}\text { Sala multiusos, oficina y } \\
\text { servicios higiénicos }\end{array}$} \\
\hline 11 a 25 & $17+\mathrm{F} \times 0.8 \mathrm{~m} 2$ & \\
\hline 26 a 50 & $24+F \times 0.52 \mathrm{~m} 2$ & \\
\hline 51 a 100 & $30+\mathrm{F} \times 0.4 \mathrm{~m} 2$ & \multirow{4}{*}{$\begin{array}{l}\text { Sala de alimentación, sala } \\
\text { de descanso, sala } \\
\text { multiusos, oficinas y } \\
\text { servicios higiénicos }\end{array}$} \\
\hline 101 a 200 & $35+\mathrm{F} \times 0.35 \mathrm{~m} 2$ & \\
\hline 201 a 400 & $50+\mathrm{F} \times 0.275 \mathrm{~m} 2$ & \\
\hline Más de 401 & $80+\mathrm{F} \times 0.2 \mathrm{~m} 2$ & \\
\hline
\end{tabular}

Fuente: Advanced Logistics Group (2006)

Adaptado de Proyecto de corredores complementarios

La zona de servicios al operador es para uso exclusivo de los choferes de autobuses. Aquí podrán alimentarse, descansar y dormir antes de su siguiente viaje. Esta área se organiza a partir de un vestíbulo privado, que cuenta con un control al ingreso. El control se realizará mediante una oficina de seguridad de al menos $12.00 \mathrm{~m}^{2}$, que permitirá la identificación de cada chofer y la realización de un control de alcoholemia.

En terminales grandes y con flujo constante de buses, se recomienda la implementación de dormitorios. De esta forma se permitirá que los choferes puedan cumplir con sus rutas sin poner en riesgo la vida de los pasajeros. Se sugiere que los dormitorios tengan como máximo 3 camas por habitación y no deberán tener un área mayor a $20.00 \mathrm{~m}^{2}$ (Plazola Cisneros, 1995).

El espacio principal e imprescindible es la sala de descanso para los choferes. Esta debería contar con un espacio para comer y una sala de juegos, y en la medida de lo posible, se deberá situar al aire libre.

\subsubsection{Oficinas de empresas transportistas}

Cada compañía transportista deberá contar con sus respectivas oficinas administrativas. Dependiendo del tamaño de la empresa y su administración interna, las oficinas pueden ser solo para la administración diaria de los buses o también de uso permanente.

Cuando las oficinas sean para la administración diaria, se sugiere que se ubiquen en la parte posterior o superior de sus respectivos puntos de venta de boletos. En el caso de oficinas permanentes se recomienda una planta libre para que cada empresa pueda 
organizar los espacios internos a su gusto, además de contar con un área de espera para los usuarios. Estas oficinas deberán estar conectadas al resto del terminal y se recomienda que se encuentren anexadas o comunicadas a los mostradores de venta de boletos. El área de las oficinas de cada empresa debe ser entre $8.00 \mathrm{~m}^{2}$ y $20.00 \mathrm{~m}^{2}$ (Ministerio de Comercio Exterior y Turismo [MINCETUR]; Unión Europea [UE], 2009).

\subsubsection{Administración del terminal}

La zona reservada para la administración del terminal está compuesta por una serie de oficinas que se encargan de administrar las partes esenciales para el correcto funcionamiento del terminal terrestre. Se trata esencialmente de la torre de control, es decir los encargados de monitorear y ordenar el flujo de buses en el patio de maniobras. Adicionalmente, se ubican en esta zona la oficina de comunicación interna y la de seguridad. Es preferible que estas oficinas tengan visibilidad completa y directa sobre las plataformas de estacionamiento y el patio de maniobras, con la posibilidad de tener un acceso rápido.

Asimismo, se deberá contar con una oficina en el vestíbulo general, para la atención al público.

Se deberá contemplar la implementación de servicios higiénicos según las reglamentaciones establecidas por el RNE. La dotación para zonas administrativas será como se especifica en la siguiente tabla.

Tabla 21: Dotación de servicios - Zona administrativa

\begin{tabular}{|c|c|c|}
\hline Según el número de empleados & Hombres & \multirow{2}{*}{ Mujeres } \\
\hline De 1 a 6 empleados & \multicolumn{2}{|c|}{ 1L, 1U, 1I } \\
\hline De 7 a 20 empleados & 1L, 1U, 1I & 1L, 1I \\
\hline De 21 a 60 empleados & 2L, 2U, 2I & 2L, 2I \\
\hline De 61 a 150 empleados & 3L, 3U, 3I & 3L, 3I \\
\hline Cada 60 empleados adicionales & 1L, 1U, 1I & 1L, 1I \\
\hline \multicolumn{3}{|c|}{$\mathrm{L}=$ lavatorio, $\mathrm{U}=$ urinario, I = inodoro } \\
\hline
\end{tabular}

Fuente: Ministerio de Vivienda, Construcción y Saneamiento (2006)

Adaptado de Reglamento Nacional de Edificaciones 


\subsubsection{Zona de autobuses}

Patio de maniobras

Es el área destinada a la circulación de autobuses, zona de maniobras y el estacionamiento de estos. Deberá estar conectada a las plataformas de acceso y descenso, a la zona de estacionamiento temporal y a los servicios de mantenimiento. Las vías de acceso hacia el patio de maniobras deberán ser privadas y ubicarse dentro del terminal, con el objetivo de no congestionar las vías de la ciudad. Si estas vías son de un solo carril, se recomienda que tengan un ancho $5.50 \mathrm{~m}$ y si se tiene dos carriles o más serán de $3.50 \mathrm{~m}$ por lado. Además, se colocará una acera de $1.20 \mathrm{~m}$ al borde, protegida por un desnivel de 15 centímetros de alto. Para las curvas se utilizará un radio de giro interno de $8.50 \mathrm{~m}$ y uno externo de 15.00m (Plazola Cisneros, 1995). Para el correcto y preciso diseño de las vías de buses se utiliza la aplicación "Vehicle Tracking" ${ }^{\prime 27}$ de AutoCAD. Por último, la pendiente máxima en el área de circulación será de 6\%. Se deben evitar los cruces peatonales en las vías de circulación y de ser necesario se utilizarán barreras físicas que eviten que personas no autorizadas caminen por estas áreas. Adicionalmente, al ingreso del terminal se colocará una caseta de control para el acceso al patio de maniobras que deberá tener control visual de los buses que circulan en el terminal y del área de estacionamientos.

Una vez dentro del terminal, se debe garantizar el tránsito fluido de los buses a través de un buen diseño de flujos. La circulación se realizará en una sola dirección, en sentido anti horario y no debe haber otro tipo de vehículos en esta zona. Finalmente, se sugiere que exista un ingreso y salida alterno, para evitar contratiempos en hora punta.

El área mínima para el estacionamiento, maniobra y circulación de autobuses se determina a partir de las siguientes fórmulas, las que fueron tomadas del manual de diseño de los terminales de Santiago de Chile (Ministerio de Transportes y Telecomunicaciones, 2005).

\footnotetext{
27 “Vehicle Tracking” de AutoCAD es un programa con el cual se puede calcular el radio de giro de diferentes vehículos, simulando el paso de los buses, calculando la trayectoria de sus llantas y sus esquinas, evitando así posibles colisiones.
} 
Área de andenes y maniobras $=0.1 \times k \times i \times v \times f e$

$k=$ flota diaria de buses.

$i=$ largo del autobús más grande en servicio (15 metros).

$v=$ ancho recomendado para andenes (4.5 metros).

$f e=$ factor de estacionamiento.

El factor de estacionamiento, es un número relacionado al largo de los vehículos y el ángulo con el cual se estacionen en relación a la vía de acceso, como se muestra en la siguiente tabla.

Tabla 22: Factor de estacionamiento

\begin{tabular}{|c|c|c|c|c|}
\hline \multirow{2}{*}{ Ángulo } & \multicolumn{4}{|c|}{ Largo de buses (L) } \\
\cline { 2 - 5 } & $\mathrm{L}<9 \mathrm{~m}$ & $9 \mathrm{~m}<\mathrm{L}<14 \mathrm{~m}$ & $14 \mathrm{~m}<\mathrm{L}<16 \mathrm{~m}$ & $\mathrm{~L}>16 \mathrm{~m}$ \\
\hline $0^{\circ}$ & 1.1 & 1.14 & 1.11 & 1.07 \\
\hline $45^{\circ}$ & 1.45 & 1.53 & 1.47 & 1.42 \\
\hline $90^{\circ}$ & 2.12 & 2.03 & 1.86 & 1.76 \\
\hline
\end{tabular}

Fuente: Advanced Logistics Group (2006)

Adaptado de Proyecto de corredores complementarios

La separación mínima que debe existir entre las plataformas y el fondo del patio de maniobras es de 3 autobuses estacionados, es decir el primero en el andén y los otros dos en el área de maniobras. Esta zona deberá ser lo más plana posible, únicamente con pequeñas pendientes de $2 \%$ para canalizar el agua de lluvias.

Los siguientes ejemplos de estacionamientos son referencias de 1974 y 1995. Son guías para el diseño de los estacionamientos, mas no se trata de normas. El paso de los años, el mercado y la tecnología han llevado a un diseño de buses más grandes y radios de giro más cerrados, motivo por el cual estas medidas ya no aplican el día de hoy. Como mencionado anteriormente, en el diseño del terminal hemos utilizado la aplicación de AutoCAD “Vehicle Tracking” para el cálculo acertado de los radios de giro y zonas de maniobra. 
Ejemplos de tipos de estacionamiento:

- Estacionamiento en 90 grados:

Figura 25: Estacionamiento en $90^{\circ}$

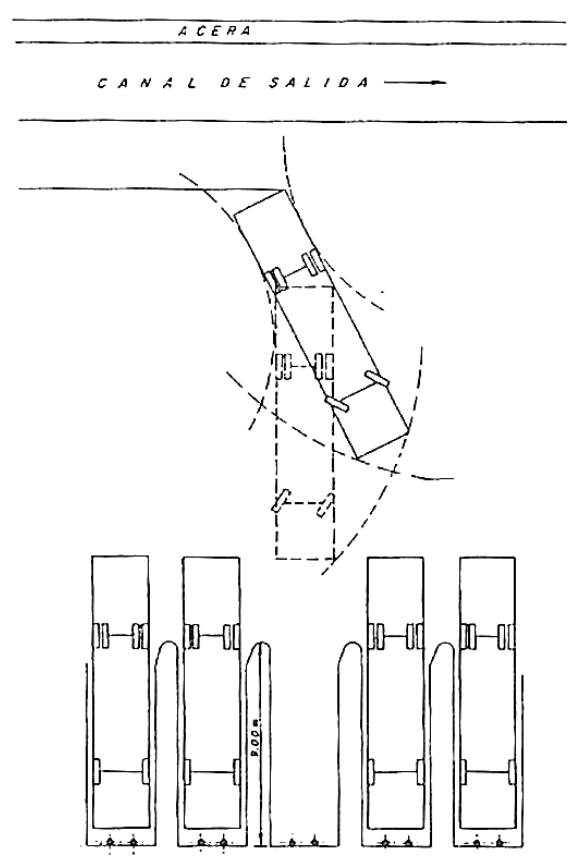

Fuente: Escala (1974, p. 6)

Adaptado de Terminales de Transporte

- Estacionamiento en 60 grados:

Figura 26: Estacionamiento en $60^{\circ}$

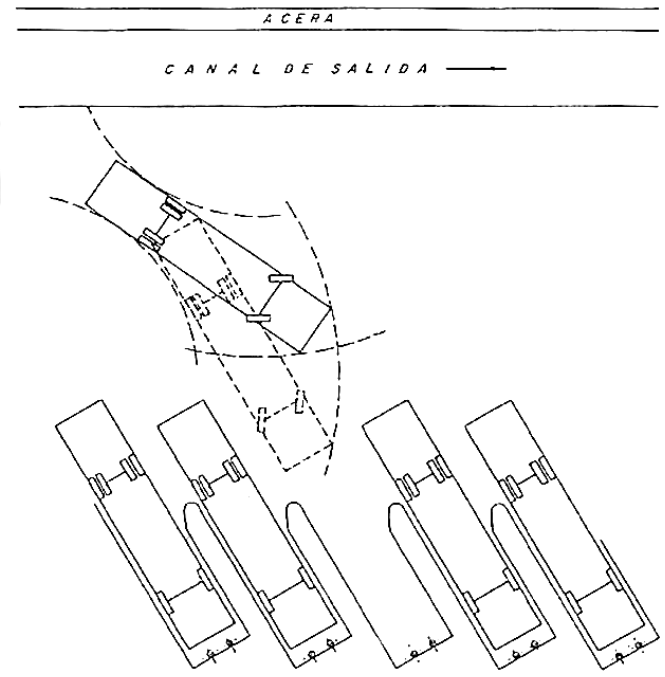

Fuente: Escala (1974, p. 6)

Adaptado de Terminales de Transporte 
- Estacionamiento en 45 grados:

Figura 27: Estacionamiento en $45^{\circ}$

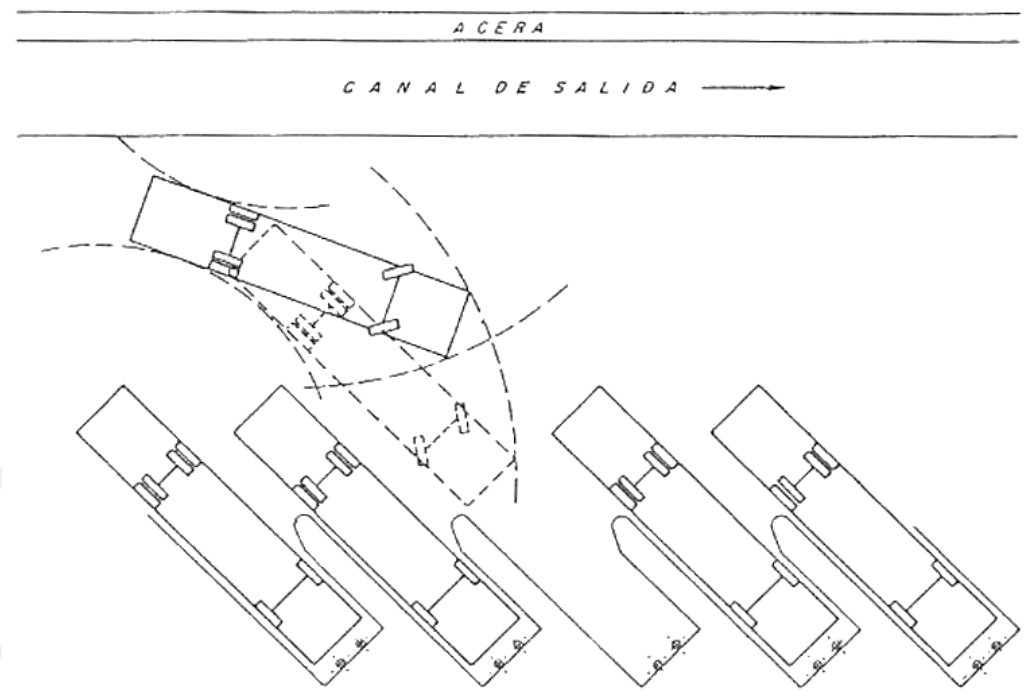

Fuente: Escala (1974, p. 6)

Adaptado de Terminales de Transporte

- Estacionamiento en 30 grados:

Figura 28: Estacionamiento en $30^{\circ}$

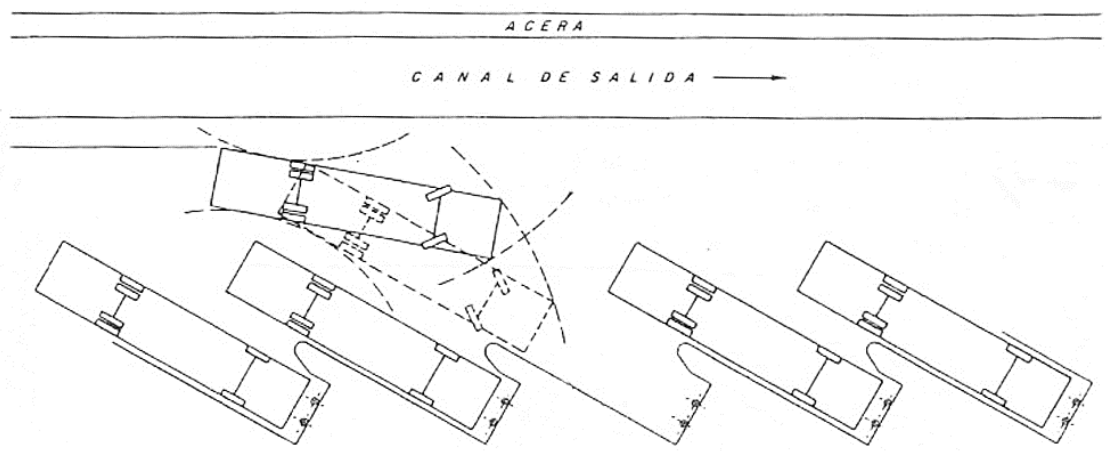

Fuente: Escala (1974, p. 6)

Adaptado de Terminales de Transporte 


\section{Estacionamiento de buses}

En todo terminal existen dos tipos de estacionamientos: el temporal donde la espera es solo operacional y el permanente o nocturno con largos tiempos de espera. Estas zonas siguen las mismas reglas que las de las plataformas de ascenso y descenso, solo que no se incluyen las bahías y las separaciones, ya que únicamente se marcan con delimitaciones en el pavimento. Se puede utilizar la fórmula propuesta en el manual de diseño de los terminales de Santiago de Chile (Ministerio de Transportes y Telecomunicaciones, 2005), para estimar el área requerida.

\section{Área de estacionamientos $=k^{1} \times i \times v$}

$k^{l}=$ flota de buses en hora punta.

$i=$ largo del autobús más grande en servicio (15 metros).

$v=$ ancho recomendado para estacionamientos (4 metros).

Se debe tratar de centralizar todas las áreas que utilicen autobuses en una única zona y de no ser posible los estacionamientos permanentes pueden situarse fuera del edificio del terminal, pero necesitan estar perfectamente conectados. En terminales grandes, para evitar retrasos, se recomienda que cada empresa cuente con sus propios estacionamientos temporales. Los estacionamientos que se encuentren dentro del área del terminal no pueden interferir con el movimiento de los vehículos en operación.

\section{Zonas de servicio para vehículos de transporte}

Debemos considerar las áreas necesarias para las actividades complementarias al transporte, es decir todos los servicios relacionados al mantenimiento de los autobuses como: lavado, pintado, reparación y abastecimiento de combustible. Esto implica ventajas operacionales y económicas para las empresas transportistas. Si el terminal se encuentra en una zonificación residencial, las actividades de mantenimiento deben desarrollarse en un recinto cerrado, para no generar molestias a los vecinos. Cuando las instalaciones son pequeñas, esta zona se puede ubicar fuera del terreno en una propiedad anexa. En ningún tipo de terminal, esta área deberá ser menor al $4 \%$ del área total del terreno, el área máxima se determinará de acuerdo a la categoría del terminal. 
Tabla 23: Actividades complementarias

\begin{tabular}{|c|c|}
\hline Categoría & $\begin{array}{c}\text { Porcentaje máximo de la superficie del terreno } \\
\text { destinado a actividades complementarias }\end{array}$ \\
\hline TP -1 & $15 \%$ \\
TP -2 & $25 \%$ \\
TP -3 & \\
TP -4 & \\
\hline
\end{tabular}

Fuente: Advanced Logistics Group (2006)

Adaptado de Proyecto de corredores complementarios

Se deberá implementar una caseta de control para los trabajadores, la que contará con vestidores, duchas y sanitarios. Adicionalmente, se implementará una oficina para el jefe de taller, la cual tendrá visibilidad sobre todas las zonas del taller. Se estima que la cantidad de trabajadores para un terminal mediano es de 20 a 25 empleados.

La zona del taller mecánico deberá tener $70.00 \mathrm{~m}^{2}$ como mínimo, sin incluir las bahías de estacionamiento para buses. De forma anexa al taller, se ubicarán los almacenes para el equipo y las herramientas de uso diario, así como el almacén de repuestos con un área máxima de $60.00 \mathrm{~m}^{2}$ (Plazola Cisneros, 1995). El área de lavado debe ser independiente al resto del terminal, debe estar nivelada y el agua sucia drenará a una cámara des-engrasadora.

Adicionalmente, se deberá contemplar la implementación de servicios higiénicos según las reglamentaciones establecidas por el RNE. La dotación para talleres será como se especifica en la siguiente tabla.

Tabla 24: Dotación de servicios - Zona de talleres

\begin{tabular}{|c|c|c|}
\hline Según el núme ro de empleados & Hombres & Muje res \\
\hline De 1 a 15 empleados & 1L, 1U, 1I & 1L, 1I \\
\hline De 16 a 50 empleados & 2L, 2U, 2I & 2L, 2I \\
\hline De 51 a 100 empleados & 3L, 3U, 3I & 3L, 3I \\
\hline De 101 a 200 empleados & 4L, 4U, 4I & 4L, 4I \\
\hline Cada 100 empleados adicionales & $1 \mathrm{~L}, 1 \mathrm{U}, 1 \mathrm{I}$ & $1 \mathrm{~L}, 1 \mathrm{I}$ \\
\hline \multicolumn{2}{|c|}{$\mathrm{L}=$ lavatorio, $\mathrm{U}=$ urinario, I = inodoro } \\
\hline
\end{tabular}

Fuente: Ministerio de Vivienda, Construcción y Saneamiento (2006)

Adaptado de Reglamento Nacional de Edificaciones 
Finalmente, el área de almacenamiento y expendio de combustible atenderá exclusivamente a los vehículos del terminal y se ubicará en un lugar que no interfiera con los movimientos de los buses. Son necesarias de 2 a 4 bombas de gasolina, además de servicios de aire y agua a presión. Los tanques de almacenamiento pueden ser subterráneos o ubicarse en un edificio anexo separado al menos 6 metros de las circulaciones vehiculares. Adicionalmente se tendrá que respetar una distancia mínima de 3 metros desde el borde interior de la vereda más cercana, al igual que una altura mínima de techado para las islas de abastecimiento de 3.90 metros. No podrá estar a menos de 25 metros de la subestación ni a 20 metros de la Carretera Central.

Para el dimensionamiento de los tanques de combustible utilizaremos la fórmula establecida por la Enciclopedia de arquitectura Plazola (1995).

\section{Volumen de tanques de gasolina $=\{[c b \times(f l \times 0.2)]+(50 \%)\} \times a b$}

$f l=$ flota de autobuses diaria .

$c b=$ consumo de gasolina por autobús (400 litros).

$a b=$ días que tarda el terminal en abastecerse de combustible.

\subsubsection{Servicios generales}

Se debe contar con un área para la limpieza y el mantenimiento del terminal, así como la zona para almacenar los suministros y elementos necesarios para su funcionamiento. Todos los desperdicios del terminal se depositarán en el cuarto de basura, el que debe estar aislado de las demás zonas y contar con un fácil acceso para su disposición final.

Adicionalmente, se contará con un cuarto de máquinas para albergar la subestación eléctrica, el grupo electrógeno, el cuarto de bombas y las cisternas. El tamaño de esta zona varía de acuerdo a las dimensiones del edificio que atiende, pero generalmente rodea los $60.00 \mathrm{~m}^{2}$ (Plazola Cisneros, 1995). De preferencia se debe ubicar en un edificio anexo perfectamente ventilado y con conexión al patio de maniobras. El grupo electrógeno debe atender los ascensores, las escaleras automáticas, la ventilación, las bombas de agua, las bombas contra incendio e iluminación en las zonas públicas: salas de espera, corredores y áreas de operación. 


\subsection{Conclusiones Parciales}

\subsubsection{De la intermodalidad}

La movilidad es un tema que se toca en las ciudades cuando se habla de cualquier tipo de desplazamiento. Este término abarca la accesibilidad, refiriéndose a la facilidad con la que se pueden usar los servicios básicos de la ciudad, además de prever la repercusión que el transporte puede tener en el espacio, en la cultura y en sus dinámicas. Es por esto que se encuentra estrechamente vinculado con la intermodalidad, concepto que nos permite entender y categorizar cuán fácil es moverse o desplazarse dentro de una ciudad utilizando diversos medios.

Al analizar estos términos podemos determinar tres factores que se deben considerar al momento de desarrollar un terminal terrestre: la optimización del espacio, la reducción del tiempo y el ahorro monetario. Aplicando estos factores a nuestra investigación comprendemos que el terminal terrestre fomentará la optimización del espacio, ya que promoverá el transporte masivo de pasajeros y creará la posibilidad de ofrecer una variedad de rutas de transporte y servicios complementarios bajo un mismo techo. La reducción de tiempo es un elemento determinante en la factibilidad de este proyecto, ya que se puede materializar como ahorro de horas laborales perdidas, es decir costo monetario. El hecho de implementar el terminal terrestre, reducirá las horas perdidas en el tráfico pues se acortarán las distancias que los buses deberán recorrer dentro de la ciudad. Adicionalmente, la intermodalidad obtenida al integrar el metro, los buses urbanos, los taxis y los buses interprovinciales en un solo lugar, reducirá también el tiempo de desplazamiento requerido en la actualidad para interconectar estos medios de transporte. Asimismo, cuando se habla exclusivamente de ahorro monetario directo, la implementación del terminal terrestre cumplirá un papel decisivo, ya que permitirá centralizar y compartir ciertos servicios que representan un gasto operativo importante para todas las empresas transportistas.

Finalmente, en el diseño del terminal se implementará la intermodalidad de medios de transporte, siendo el peatón quién reciba la mayor importancia. De igual forma, se buscará mitigar los efectos negativos generados por este tipo de transporte para hacerlo más amigable con el entorno y sostenible en el tiempo. 


\subsubsection{Del espacio público}

Las funciones que se desarrollan dentro de un terminal terrestre traen consigo una aglomeración constante de usuarios. Por este motivo se deberá plantear un espacio público con la capacidad de recibir este flujo de personas y a su vez funcionar como un nexo conector con la zona circundante. Esta función adicional mitigará el impacto que el proyecto pueda tener y buscará activar el entorno para la creación de comunidad, mediante la inclusión de los ciudadanos en el proyecto.

Por lo tanto, para que esto funcione, el espacio debe considerar diversos factores de diseño con el objetivo de ser utilizado y evitar generar zonas muertas sin uso. Un espacio público sin activación, no solo es un desperdicio de recursos, sino que es perjudicial para el vecindario, pues permite la creación de nuevas actividades delincuenciales. Se debe partir de la premisa que este sirve para la libre interacción entre todos los usuarios, por lo que no se podrá controlar las actividades que allí se desarrollen, pero sí direccionarlas mediante el diseño. Se buscará la mejora de la calidad de vida, a través de espacios que incentiven el desarrollo de actividades físicas, además de la inclusión de zonas verdes y árboles que mejorarán la calidad del ambiente. Mientras más actividades opcionales y voluntarias se lleven a cabo allí, más alto es su valor para la comunidad.

La sensación de seguridad es uno de los factores determinantes para activar un espacio público y las zonas aledañas. Esta sensación no la pueden transmitir ni los guardianes ni la policía, sino la misma comunidad que utiliza los espacios. El concepto de vigilancia pasiva se logrará con la implementación de un espacio público ameno al que los usuarios se sientan invitados a utilizar, el cual se deberá complementar con comercio constante y variado durante todo el día, prefiriendo una variedad de tiendas locales pequeñas, antes que una grande multinacional, ya que aportarán una mayor diversidad. Al momento de diseñar se incorporarán espacios de recorrido y permanencia para usuarios de todas las edades tomando en cuenta sus diferentes cualidades.

Como hemos mencionado anteriormente, el principal usuario del terminal será el peatón, por lo que el diseño del espacio público estará centrado en su satisfacción. Las teorías de Jan Gehl nos permiten comprender su importancia y cómo aplicar ciertas estrategias para mejorar el proyecto. En nuestro caso, al tratarse de un punto de 
convergencia de múltiples medios de transporte y tener un público variado debemos considerar las diferentes características fisiológicas de los usuarios priorizando la accesibilidad y reduciendo su relación directa con los vehículos motorizados.

Cuando todos los factores mencionados previamente se contemplen en el diseño del terminal, se creará un espacio donde los ciudadanos serán beneficiados de manera significativa, sean o no usuarios directos del lugar. De esta manera el proyecto de infraestructura no solo resolverá el problema específico para el que fue planteado, sino que también contribuirá a mejorar la calidad de vida de la zona haciéndolo sostenible en el tiempo. Este enfoque hacia el ciudadano tiene la capacidad de influir drásticamente en su valoración como proyecto, lo que resultará de vital importancia cuando se busque formas de financiamiento que involucren al estado.

\subsubsection{De la regeneración urbana}

Cuando se hable de proyectos de infraestructura tan grandes que afectarán indudablemente su entorno urbano, se deberá considerar la regeneración y recuperación del área circundante como parte del planteamiento base, con el objetivo de aportar mejoras a los habitantes de la zona. Con este objetivo en mente, se estudiaron diferentes metodologías de regeneración urbana, las que pueden variar según la problemática a la que se enfrentan.

El urbanismo social, desarrollado e implementado en Medellín se caracteriza por tener grandes inversiones monetarias en infraestructura, las que se realizan en los sectores más marginados y degradados, con la consigna de tener un fuerte impacto estético. El objetivo de estas intervenciones es recuperar zonas deprimidas de la ciudad y trasmitir un sentimiento de inclusión social y de igualdad entre todos los ciudadanos. Al tratarse de una realidad similar creemos que la aplicación del urbanismo social en Lima es factible, por este motivo para el terminal terrestre se propondrá una arquitectura innovadora que destaque y se convierta en un elemento único. Esto no significa que el proyecto puede ser un despilfarro de dinero, por lo que es de suma importancia su buena gestión y la optimización de recursos.

Asimismo, para tratar el tema de la delincuencia, se estudiaron algunos casos de barrios marginales, como lo son las favelas de Brasil o las barriadas de México, donde existe una falta de sentido de comunidad y vida en las calles, por miedo a la 
delincuencia. En estos casos, se trabajó la regeneración urbana a través del arte, con murales que generaron un cambio estético en el barrio, el cual no solo reactivó las calles y revalorizó la zona, sino que generó un cambio de ánimo en los pobladores. En el diseño del terminal terrestre buscaremos implementar estas metodologías en las áreas públicas mediante la inclusión de muros reservados para el arte, talleres vecinales de participación y contemplando la posibilidad de incluir en su programa guarderías o nidos que permitan la inclusión de niños y padres de familia en la infraestructura.

En conclusión, el objetivo final es empoderar al ciudadano, generando un sentido de pertenencia y trasmitiendo una sensación de bienestar que se pueda irradiar hacia las zonas aledañas. Estas acciones no solo mejorarán el aspecto de la zona, reduciendo la apariencia de deterioro y por consecuencia los actos criminales, sino que también abrirán campo a la interacción entre vecinos. Así se creará un nuevo sentimiento colectivo de comunidad, que por consecuencia generará un mayor interés por parte de los vecinos para cuidar su vecindario y sancionar a aquellos que no lo hacen.

\subsubsection{De los lineamientos y normas básicas para un terminal terrestre}

Al no existir normativas ni publicaciones nacionales sobre terminales terrestres, resulta muy complicado determinar cuál es la infraestructura básica que se necesita. Por este motivo hemos analizado diversas fuentes extranjeras para crear, a través de una comparación muy detallada, un manual propio que recoge las principales ideas de cada una.

Lo primero que se consideró fueron los lineamientos básicos, es decir los datos que se refieren a conceptos generales, como el funcionamiento de las áreas públicas y de conexión urbana, así como la distribución de áreas internas y su interrelación para una mejor operatividad. De forma similar a los estudios sobre el espacio público y las metodologías de regeneración, los lineamientos hacen mucho énfasis en la relación e inclusión de la comunidad en el proyecto. Por este motivo se estudiará el entorno urbano para poder crear un emplazamiento adecuado que respete a la comunidad. Luego se buscará forjar una identidad con esta, lo cual se podrá lograr con la creación de un hito del que se sientan orgullosos. Este último punto se puede potenciar tomando 
en cuenta elementos de su cultura pasada o contemporánea e implementándolos en el diseño como un elemento representativo.

Para el funcionamiento correcto y articulado del terminal, se tendrán en cuenta los flujos de usuarios respetando una simplicidad funcional, la que implica una secuencia lógica en las zonas internas para que sean fáciles de utilizar. Para el dimensionamiento especifico de estas zonas es necesario realizar un estudio cuidadoso de la demanda. Esta se calculó en base a una proyección a futuro, con el objetivo de establecer una posibilidad de crecimiento y asegurar la durabilidad del proyecto en el tiempo. Una vez realizado este cálculo, se determinó el programa con la ayuda de la Enciclopedia de arquitectura Plazola y los cálculos desarrollados por el Airport development reference manual para determinar las áreas y medidas mínimas de cada espacio. Como fue mencionado en el desarrollo del capítulo, estos cálculos son solamente referenciales y serán tomados como un posible ejemplo a seguir. Sin embargo, serán nuestro punto de partida, lo que simplificará el proceso de dimensionamiento y asegurará que respetemos un estándar internacional. 


\section{CAPÍTULO IV: MARCO OPERATIVO}

Para comprender mejor las características de un terminal terrestre se optó por estudiar siete referentes en diversas ciudades del mundo. Los primeros tres, el terminal de Yerbateros, Cruz del Sur y Plaza Lima Norte, se enfocan en la realidad nacional, mientras que los siguientes dos, el de Guayaquil y el de México, nos dan una perspectiva que corresponde a América Latina. Finalmente se verán dos terminales, uno en Nueva York y otro en Múnich, para comprender realidades de países pertenecientes al primer mundo.

Para el análisis de estos siete referentes será necesario prestar atención a las siguientes variables. Primero la ubicación y conectividad del terminal dentro de la ciudad y su nivel de intermodalidad. Es decir, a qué tipo de vías vehiculares se conecta, que medios de transporte público lo abastecen y qué tan fácil es el intercambio de un medio al siguiente para el peatón. Luego será importante analizar los servicios complementarios que se ofrecen, así como la existencia de espacio público. En este análisis se podrá comprender que servicios son indispensables para el usuario de un terminal terrestre, cuáles atraen grandes masas de personas y cómo esto repercute en el terminal. De igual forma es importante comprender si es que apuesta por la implementación de espacio público e identificar qué beneficios les trae. Finalmente se revisará que sistema estructural utilizan y su capacidad de crecimiento. Es decir, evaluar que experiencias han tenido con respecto al crecimiento de la demanda; si se proyectó un crecimiento a futuro y si se consideró dentro del dimensionamiento.

Adicional a los referentes de terminales terrestres estudiaremos dos casos de espacio público, permitiéndonos ver sus estrategias para activarlo, diseñarlo e integrarlo en su entorno.

Para finalizar se verán dos referentes de sistemas constructivos de cubiertas que nos permitirán ver tanto soluciones para cubrir grandes áreas, como la permeabilidad que estas pueden tener. 


\subsection{Referentes nacionales}

\subsubsection{Terminal Terrestre Yerbateros, Perú}

Durante los últimos 50 años la demanda de transporte terrestre interprovincial hacia la Sierra y Selva central ha sido absorbida en su mayoría por los terminales terrestres informales ubicados a lo largo de la carretera central. Cuando hablamos de transporte terrestre informal hacemos referencia al servicio paralelo al sector formal; son empresas que se han constituido como sociedades comerciales, pero no cumplen con los estándares establecidos y además incluyen a los conocidos buses-camión ${ }^{28}$ que no cuentan con las medidas de seguridad necesarias para el transporte de personas. Este servicio por lo general está orientado a los usuarios con menores ingresos económicos y funcionan de acuerdo al sistema de oferta y demanda, creando un mercado con precios fluctuantes e impredecibles.

En las zonas próximas a la carretera central se crearon una serie de aglomeraciones con establecimientos que brindan estos servicios. Uno de los puntos donde se establecieron en mayor cantidad fue la zona denominada Yerbateros, debido a su proximidad con el centro histórico de la ciudad, los mercados mayoristas y el camal. La zona se caracteriza por tener aproximadamente un conjunto de siete terminales independientes, aglomerados en tres manzanas contiguas; sin embargo, el terminal principal y de mayor tamaño se construyó de manera formal en 1996 bajo el nombre de Terminal Terrestre Molina, pero rápidamente adoptó el nombre de la zona como propio.

Este terminal agrupa 25 pequeñas empresas. La mayoría de estas son informales y envían diariamente de 40 a 60 buses hacia diversas ciudades ubicadas en la sierra y selva. Los destinos principales son ciudades ubicadas al este de Lima como Huancayo, La Merced, Tarma y Pucallpa; llegando a un volumen diario de 3,600 personas (Centro de Investigación y Desarrollo de Tecnología, 2010).

El terminal está dividido en tres partes principales. Primero el edificio donde se ubican las boleterías de las diferentes empresas, una sala de espera común y una cafetería. En segundo lugar, se encuentra el patio de maniobras y embarque (ver figura

\footnotetext{
${ }^{28}$ Es un autobús fabricado artesanalmente sobre el chasis de un camión. Esto lo hace menos flexible y reduce su resistencia, siendo así más propenso a sufrir accidentes. Debido a su uso frecuente en países latinoamericanos, incluido el Perú, el MTC introdujo el Decreto Supremo N 006-2006, que prohíbe la operación y construcción de estos vehículos (Buses y Camiones, s.f.).
} 
30), el cual no tiene ninguna infraestructura para delimitar las áreas de estas dos funciones. Por último, hay un área pequeña de estacionamiento particular y taxis.

Se debe recalcar que al terminal se accede directamente desde la carretera central pero no cuenta con ninguna bahía o pista auxiliar para evitar que se congestione esta vía con el ingreso o salida de los buses. Así mismo existe un gran número de comercio ambulatorio y de transporte informal mediante taxis-colectivos que se ubican a las afueras del terminal, los que contribuyen con la congestión vial. Por último, se comprobó que el terminal de Yerbateros no se encuentra integrado a ningún sistema formal de transporte público masivo (Ministerio de Comercio Exterior y Turismo [MINCETUR]; Unión Europea [UE], 2009).

Figura 29: Patio de maniobras - Terminal Terrestre Yerbateros

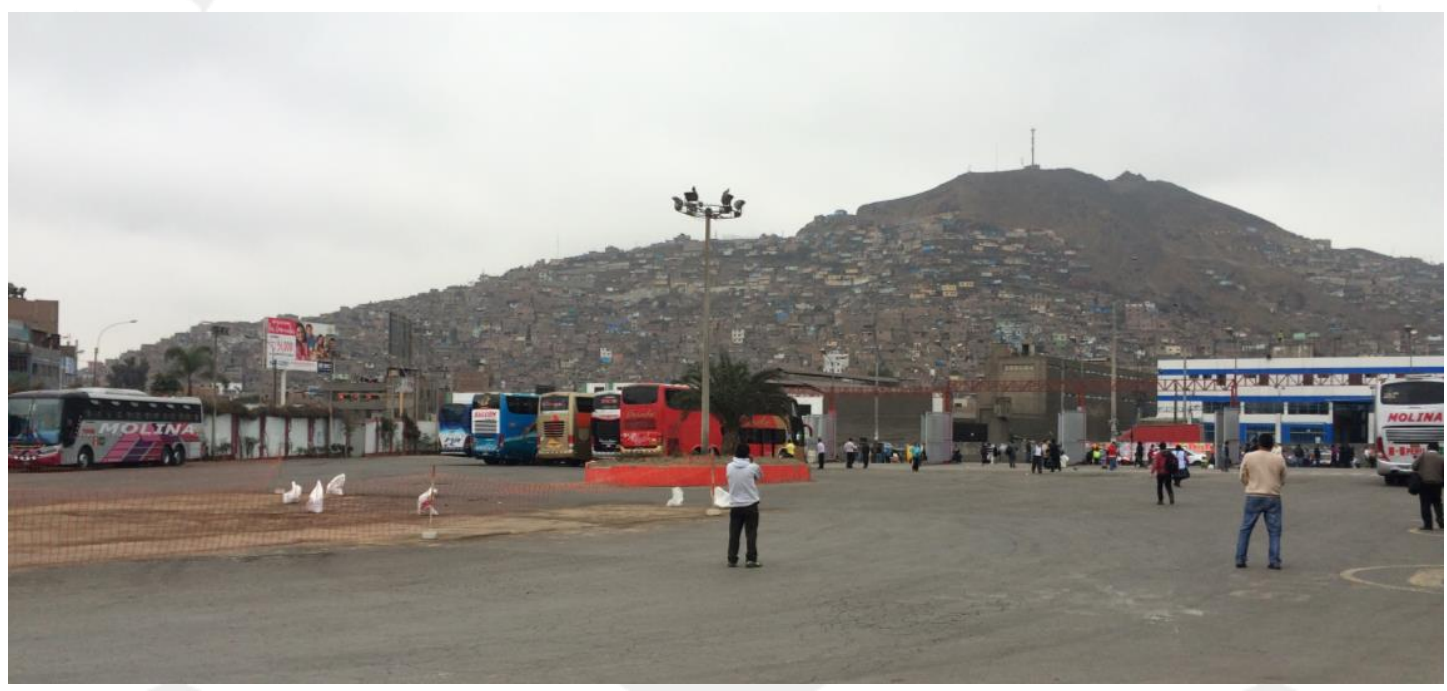

Elaboración propia

En una encuesta realizada por el Centro de Investigación y Desarrollo de la USIL en el 2010, en la que se midió la percepción de los usuarios hacia la situación actual del terminal, se revelaron niveles de inseguridad muy altos y una gran deficiencia en el servicio brindado.

En este informe se determinó que el $93 \%$ de los viajeros del terminal de Yerbateros considera que la zona en la que se ubica es "Peligrosa" o "Muy Peligrosa". Además, consideran que el mayor problema que tiene el terminal son los asaltos (67\%) y las continuas estafas hacia los pasajeros $(27 \%)$. 
En cuanto al servicio recibido, el $30 \%$ considera que la calidad del servicio es deficiente y el $60 \%$ cree que es regular. Coincidentemente el $90 \%$ de los usuarios estaría dispuesto a pagar más por un servicio mejor. Por otro lado, también opinan que hay un déficit de buses ya que mucha gente está obligada a viajar de pie por el escaso número de buses que parten al día.

Un dato esperanzador es el obtenido cuando se les preguntó porque utilizaban este terminal informal, donde el $45 \%$ respondió que era el único que conocían para llegar a su destino. Esto indica que sí estarían dispuestos a probar otras alternativas formales si se les diera la posibilidad (Centro de Investigación y Desarrollo de Tecnología, 2010). 

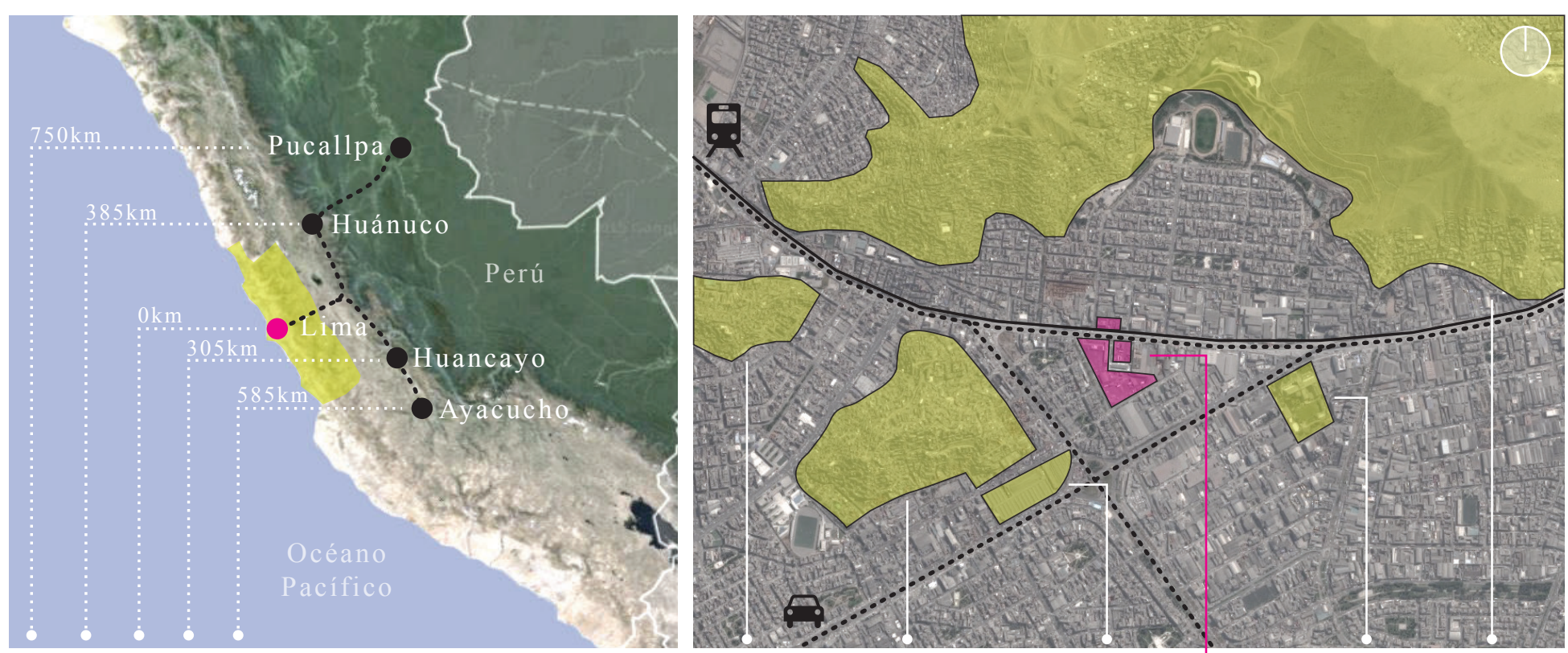

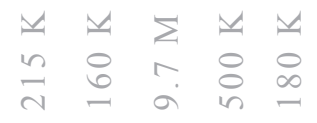
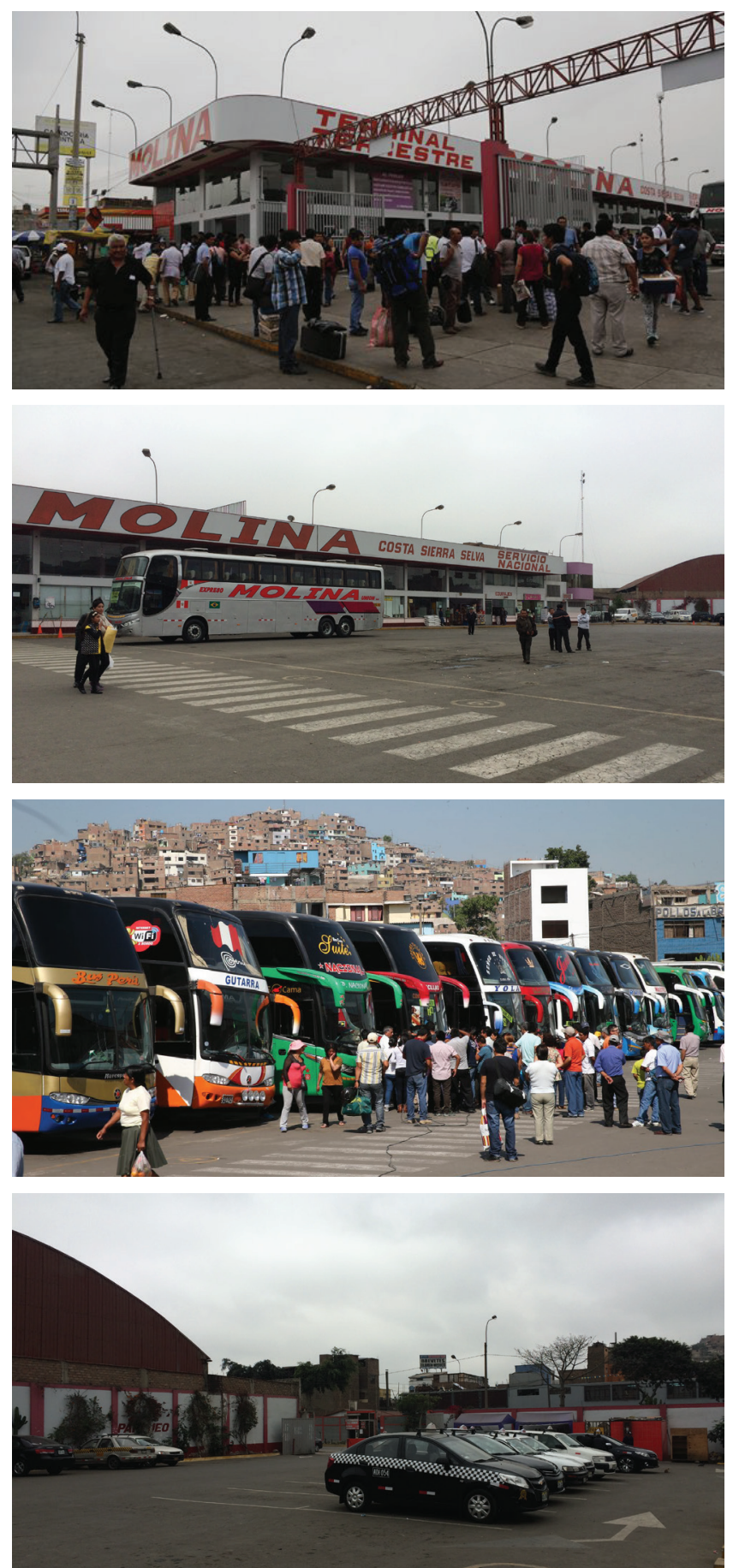

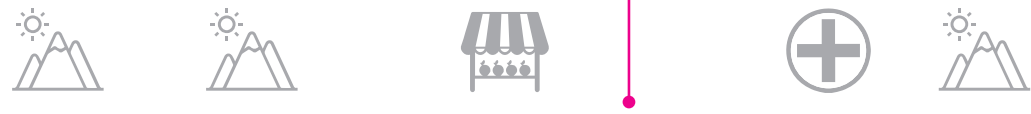

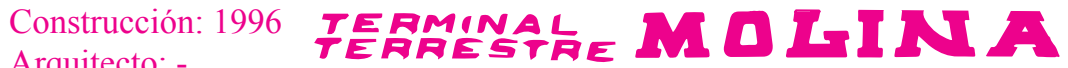
Programa
P Parking

Administración

Ri Gasolina ヘึก SSHH

U S o

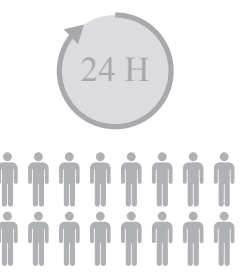

3600 usuarios

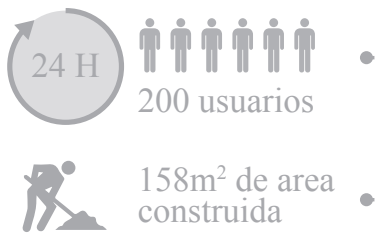

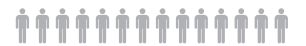

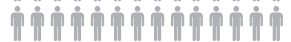

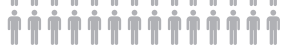
1340000 usuarios
Nond

18 andenes*

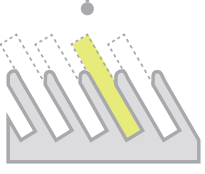

Esquema de funcionamiento: sección transversal

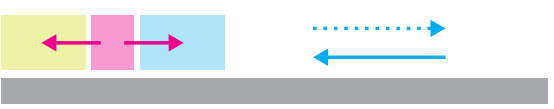

$\longrightarrow$ Ingreso buses

Nucleo circulación

$\longrightarrow$ Flujo peatones $\square \quad$ Embarque + desembarque 


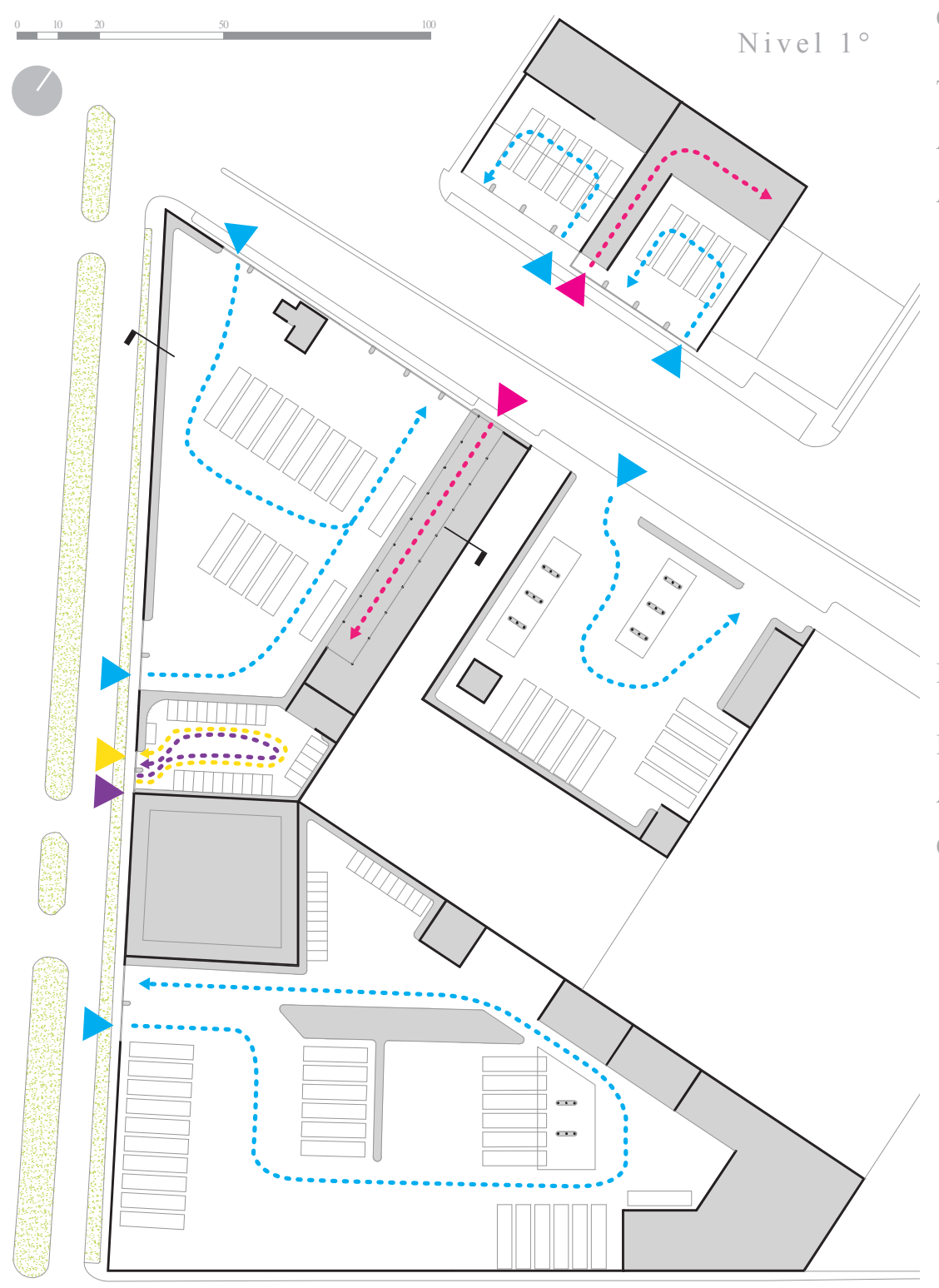

$\triangle$ Ingreso buses

Ingreso taxis

- Ingreso peatones

- Ingreso autos particulares

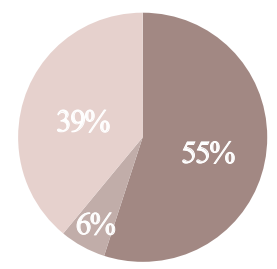

Composición del terminal

Terminal Yerbateros: $12106 \mathrm{~m}^{2}$

Terminal Molina: $8764 \mathrm{~m}^{2}$

Terminal Salazar: $1770 \mathrm{~m}^{2}$

Terminal Raraz: $1572 \mathrm{~m}^{2}$

Servicios complementarios: $18992 \mathrm{~m}^{2}$

E.T. El Pino: $14264 \mathrm{~m}^{2}$

E.S. Primax: $4727 \mathrm{~m}^{2}$
Ocupación del terreno

Terreno: $12106 \mathrm{~m}^{2}$

Area ocupada: $2630 \mathrm{~m}^{2}$

Area libre: $9476 \mathrm{~m}^{2}$

$22 \%$

$78 \%$

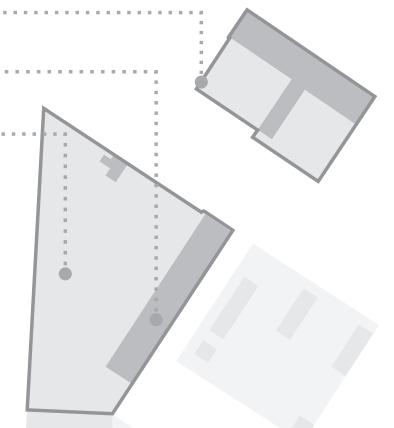

Repartición del terreno: 1 nivel

Patio de manoibras: $7820 \mathrm{~m}^{2}$

Area construida: $2835 \mathrm{~m}^{2}$

Conexión urbana: $1450 \mathrm{~m}^{2}$

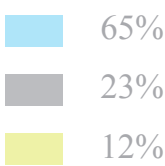

Intermodalidad

Area construida
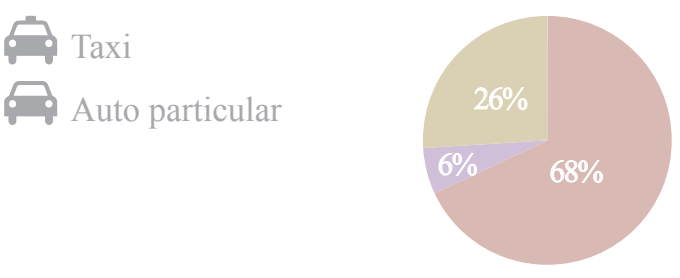

- Comercio + administración

Embarque + desembarque

Circulación

Zona de buses

Estacionamientos Circulación Andenes

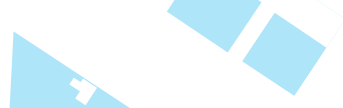

Mantenimiento

Estación de servicio 


\section{Ubicación}

Se encuentra en una zona beneficiosa, por su cercanía al centro histórico de la ciudad, la cual es al mismo tiempo una ubicación parcialmente periférica. Esto evita que ciertas rutas de buses interprovinciales ingresen a zonas más congestionadas de la capital, aspecto importante para un terminal terrestre actual. A pesar de encontrarse en una zona externa al centro, se vincula mediante vías arteriales que conectan con diferentes partes de la urbe. A futuro contará con una conexión a la línea 2 del metro de Lima, la cual le permitirá acceder a otros sectores de esta sin complicaciones. Por otro lado, los problemas que presenta el terminal, están directamente relacionados a sus flujos vehiculares y a las conexiones que lo vinculan con las vías que lo rodean, generando un gran congestionamiento en una de las avenidas más importantes de la ciudad.

\section{Intermodalidad}

En la actualidad no se encuentra vinculado a ningún sistema de transporte masivo, por lo que no se puede considerar como un terminal intermodal, sobretodo, considerando que para categorizar como tal se requiere de cierta facilidad e infraestructura para el cambio de medios de transporte. Este terminal presenta un nivel de caos vehicular muy intenso, también presente en su conectividad con otros medios de transporte. A este llegan taxis, colectivos, buses y micros que buscan recoger pasajeros que se dirigen a múltiples destinos. Por la pobre infraestructura con la que cuenta el terminal, es decir la ausencia de bahías para la recepción de diversos medios de transporte, el recojo de pasajeros se convierte en una tarea sumamente caótica que entorpece el flujo vehicular de las vías aledañas. En la actualidad se está construyendo el metro de Lima, el cual contará con una estación frente al terminal. Esto permitirá reducir parcialmente la cantidad de empresas de transporte que circulan por la zona, pero requerirá de mayor intervención para aliviar el caos vehicular. Un factor positivo es que sí cuenta con estacionamientos en la parte posterior del terreno, al cual acceden vehículos particulares y taxis.

\section{$\underline{\text { Servicios complementarios }}$}

El edificio del terminal cuenta con pocos servicios complementarios. Se trata de un hall longitudinal que abarca los puestos de atención de diferentes empresas, un par de 
oficinas, una cafetería y servicios higiénicos. Aparte cuenta con una capilla, la cual resulta ser un elemento importante considerando la cultura fuertemente religiosa en el Perú. Uno de los frentes del terminal, mira a una calle que cuenta con varios restaurantes de escala pequeña, además de múltiples puestos de comida en carretilla que se ubican en las calles que lo rodean. El mismo terminal cuenta con pequeños quioscos en ciertas zonas del patio de maniobras, que venden productos comestibles al paso. En general, los servicios complementarios de este terminal son sumamente básicos, se encuentran en estado precario y se han generado de manera aleatoria. Esto se debe al fuerte carácter espontáneo e informal de la zona.

\section{Espacio público}

No cuenta con ningún tipo de espacio público, más que las veredas que lo rodean. El mismo hall que alberga todos los usos complementarios del terminal, tiene un número reducido de butacas para la espera de los pasajeros. Cuando estas se llenan, las personas se acomodan en las zonas que encuentran disponibles repartidas por el patio de maniobras y los linderos del terminal. Esto representa un serio problema, no solo por la ausencia de espacios para recrear, sino también por la poca seriedad con la que se utiliza el patio de maniobras, zona que idealmente debería estar aislada del público general. Este es un tema serio a tratar, ya que es ahí donde se generan muchos problemas de delincuencia, informalidad y degradación de la calidad de vida del habitante y el usuario.

\section{$\underline{\text { Sistema constructivo }}$}

Carece de múltiples consideraciones y se resume en un solo volumen de doble altura. Su construcción es en albañilería y concreto y no utiliza el segundo nivel, más que una zona como mezzanine. El patio de maniobras no cuenta con ningún tipo de cobertura, dejando a los pasajeros y buses completamente expuestos a la intemperie.

\section{$\underline{\text { Crecimiento }}$}

El terminal de Yerbateros surge originalmente como el Terminal Terrestre Molina. Se creó de manera improvisada y sin planeamiento a futuro, por lo que no cuenta con ningún plan para su expansión. En la actualidad presenta problemas de 
dimensionamiento en diversos aspectos. Para empezar, la zona de espera se ubica en el mismo hall que todos los demás servicios y además carece de suficientes butacas para los pasajeros. Estos ya se ven desplazados a otros sectores del terminal para poder esperar su viaje.

\subsubsection{Terminal Terrestre Plaza Lima Norte, Perú}

Una batalla que se lleva a cabo en Lima desde hace muchos años es la que involucra a las empresas formales e informales de buses. Al norte de la ciudad se encuentra Fiori, el terminal informal más antiguo de Lima y durante mucho tiempo el punto más usado como conexión con la región Norte del país. El principal problema con este tipo de transporte informal, además de la precariedad del servicio y la falta de seguridad, es el precio fluctuante de los pasajes debido a la oferta y la demanda, llegando en algunas ocasiones hasta triplicar los precios originales. Esto se debe a que no existe un ente regulador que se encargue de supervisar y regular este servicio. Un problema derivado que trae consigo la falta de supervisión en Fiori es la contaminación del medio ambiente.

Ya en 1996 se trató de solucionar parcialmente el problema de informalidad en Fiori con la construcción de un pequeño terminal central perteneciente a la Universidad de Ingeniería [PETROUNI] de donde parten catorce empresas, pero el terminal informal siguió en funcionamiento con cerca de 60 buses diarios, lo que mueve un volumen aproximado de 4,900 usuarios.

El nivel de inseguridad por parte de los usuarios era muy alto. El 80\% consideraba la zona "Peligrosa" o "Muy Peligrosa" y el 60\% creía que los asaltos eran el principal problema a solucionar, antes que invertir en la seguridad del transporte. Así mismo la insatisfacción con los servicios brindados era muy alta ya que el $30 \%$ la consideraba deficiente y más del $50 \%$ pensaba que la organización del terminal era mala (Centro de investigación y desarrollo de tecnología [CIDT], 2010).

En los últimos años el descontento creado en los usuarios por este tipo de situaciones y la mejora económica ha llevado a muchos de ellos a considerar otras opciones más seguras de transporte, entre estas la de utilizar empresas formales que cumplan con ciertas normativas de seguridad y calidad. Según la encuesta realizada en 2009 el 73\% de los usuarios del terminal informal estaban dispuestos a pagar más por 
un mejor servicio. Por este motivo y luego de una ardua batalla legal y mediática en contra de las empresas informales, en el año 2009 se inició la construcción del Gran Terminal Plaza Lima Norte, con la función de agrupar y supervisar a las diversas empresas que deseen brindar servicios de transporte, asegurando que se respeten todas las medidas de seguridad y normas impuestas por Defensa Civil y el Ministerio de Transportes y Comunicaciones [MTC].

Bajo la tutela del grupo Wong y del grupo brasilero de gestión Socicam el arquitecto Carlos Chinen proyectó un Terminal con capacidad para transportar a un millón de personas al mes. Construido en un terreno de 35,000 metros ${ }^{2}$, la estación se integra también con el centro comercial Plaza Lima Norte para abastecer a los usuarios de una gran cantidad de servicios a poca distancia de su punto de partida y llegada (Gran Terminal Terrestre Plaza Lima Norte, s.f.).

Entre los principales servicios que se ofrece a los usuarios del nuevo terminal se encuentra la implementación de salas de espera privadas, zonas para el descanso de los conductores, un corredor con locales comerciales y de comida, una sala de conferencias multiusos, zonas exclusivas para el envío de encomiendas sin ingresar al área de embarque, atención las 24 horas del día, precios fijos todo el año, servicio de vigilancia constante y una rápida conexión con el aeropuerto Jorge Chávez de diez minutos.

Con un acceso directo a tres de las vías más transitadas de la capital como son la Panamericana Norte, la avenida Alfonso Ugarte y la avenida Tomas Valle; el terminal resulta muy accesible para todos sus usuarios y también permite la rápida salida de los buses fuera de la ciudad. 
Figura 30: Ingreso de buses - Terminal Terrestre Plaza Lima Norte

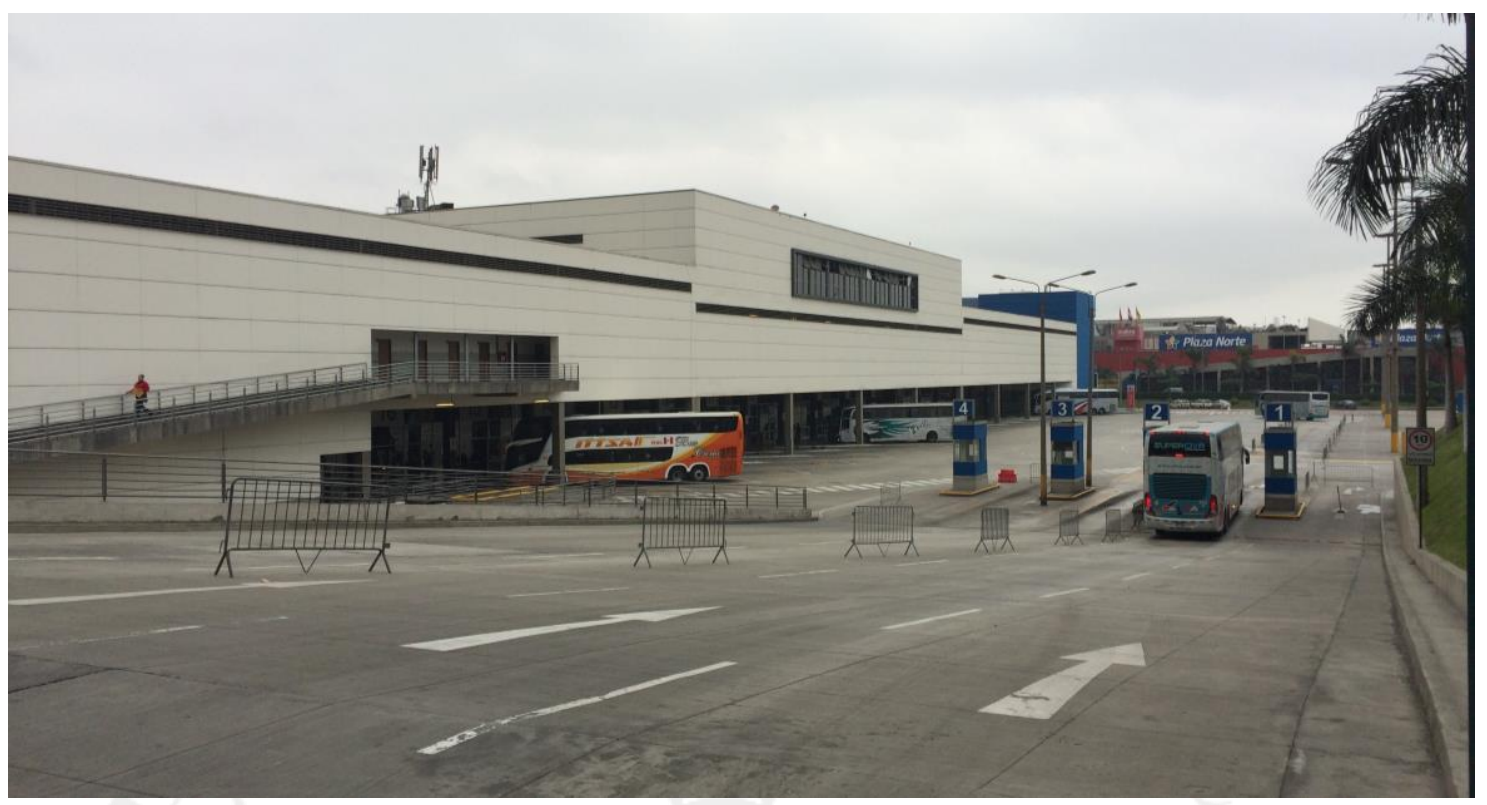

Elaboración propia

El proyecto se compone de un edificio de tres pisos, de los cuales uno se ubica bajo el nivel de la calle, albergando las salas de espera y de embarque. Estas solo son accesibles a través de una zona de seguridad que se encarga de revisar el equipaje y de asegurarse que todas las personas cuenten con un ticket de embarque. En el nivel medio y desde el cual se accede al edificio del terminal, se ubican las oficinas y boleterías de todas las empresas de transporte, la zona de envío de encomiendas, los locales comerciales y el área de comidas. Por último, en el nivel superior se encuentran los servicios higiénicos y un salón multiusos.

El terminal cuenta con bahías para taxis y estacionamientos privados dentro de sus instalaciones, pero no cuenta con una conexión propia con algún medio de transporte masivo. La más cercana es la estación de buses urbanos del metropolitano, que se ubica a una cuadra de distancia en la avenida Tomás Valle. 


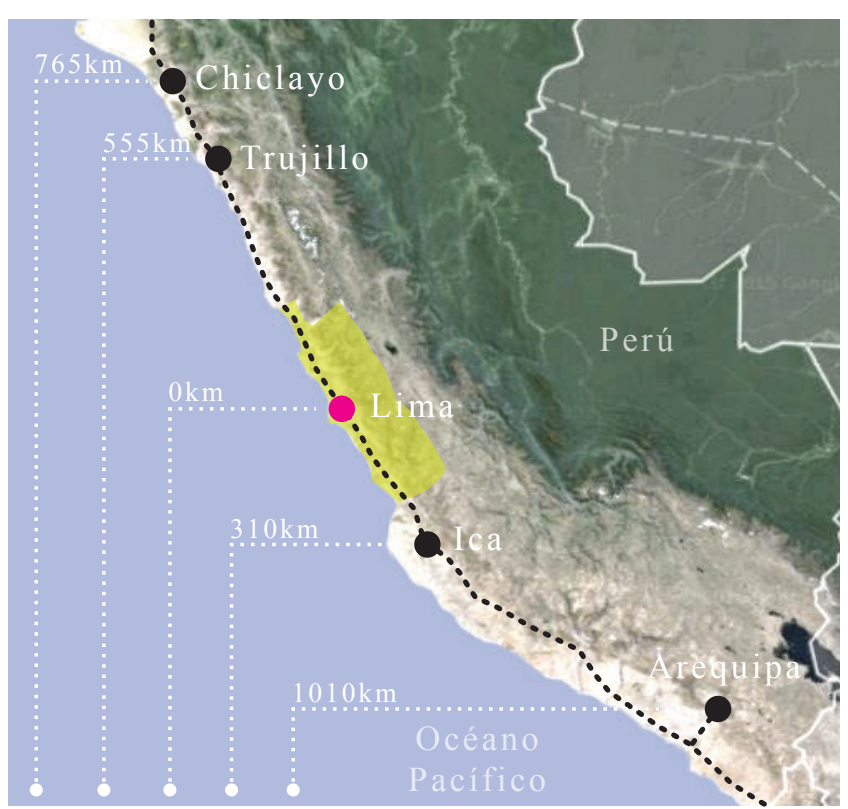

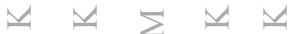

ㅇำ
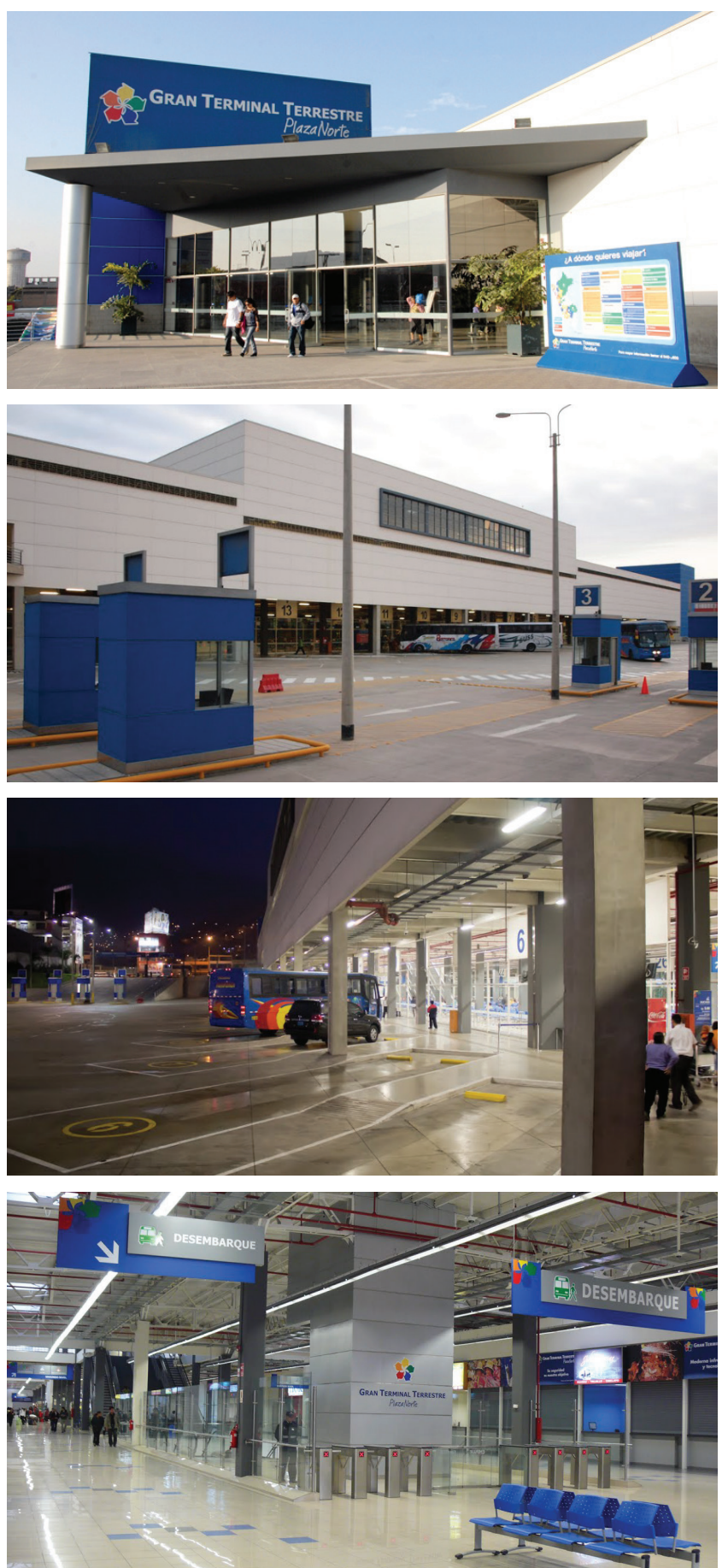

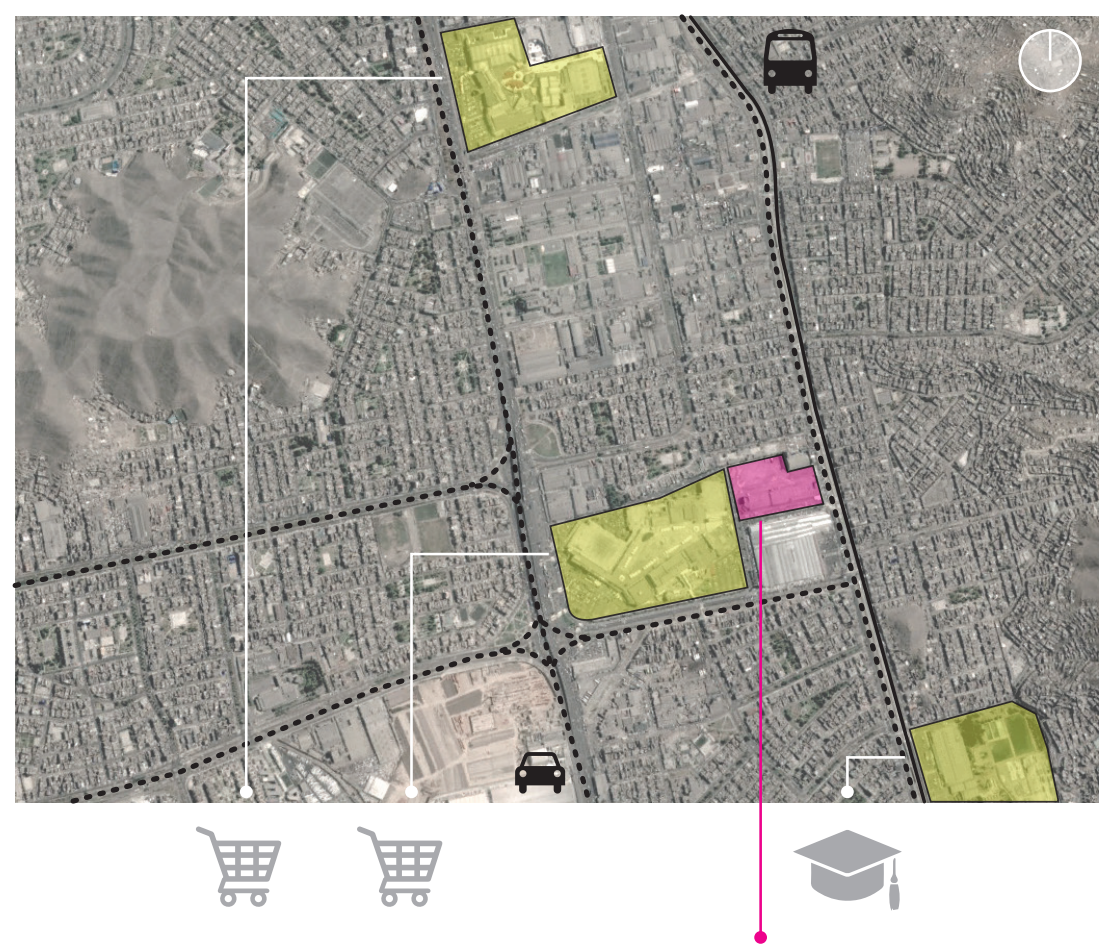

Construcción: 2009

Arquitecto: Carlos Chinen

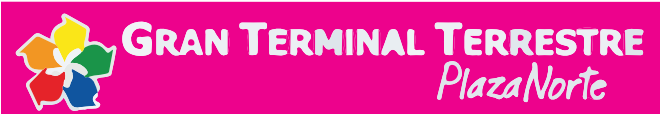

Programa

P Parking

P Farmacia

III Bancos

(1) Encomiendas

USO

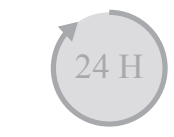

กำกำกำกำ

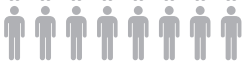

35000 usuarios

(24) $\begin{gathered}\text { 巾n 巾 } \\ 921 \text { usuarios }\end{gathered}$

I. $532 \mathrm{~m}^{2}$ de area
重 Venta de pasajes

Westaurantes

@ Cabinas Internet

Administración

TY Mantenimiento

冈ิ $\mathrm{NSHH}$

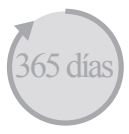

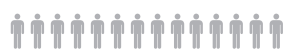

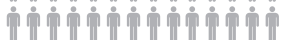

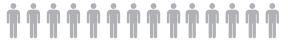

12775000 usuarios

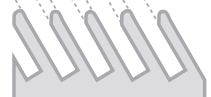

38 andenes

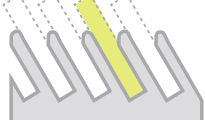

por cada andén

Esquema de funcionamiento: sección transversal

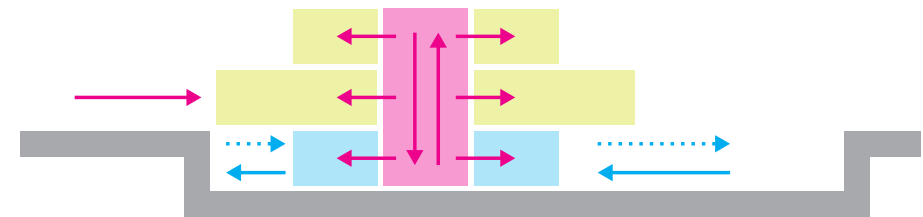

$\longrightarrow$ Ingreso buses $\quad$ Nucleo circulación

$\ldots$ Salida buses Zona comercial

$\longrightarrow$ Flujo peatones $\square \quad$ Embarque + desembarque 

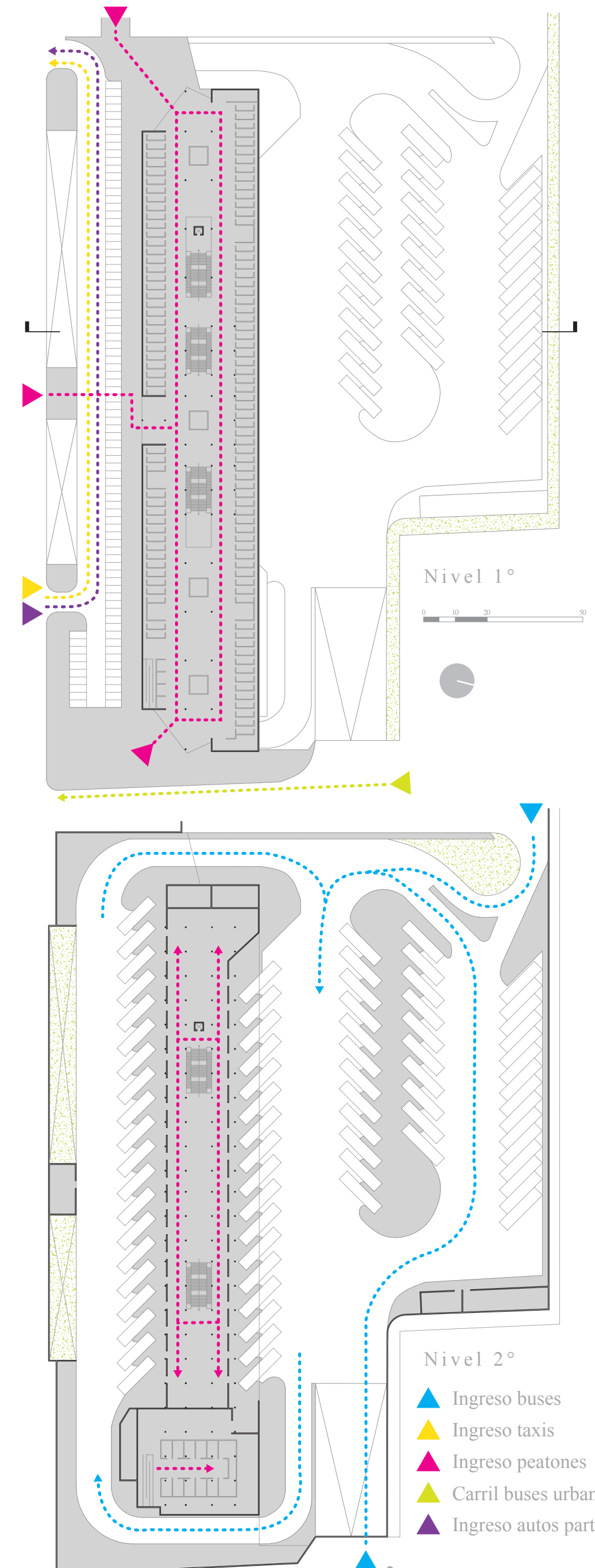

Ocupación del terreno

Terreno: $33475 \mathrm{~m}^{2}$

Area ocupada: $7696 \mathrm{~m}^{2}$

Area libre: $25779 \mathrm{~m}^{2}$
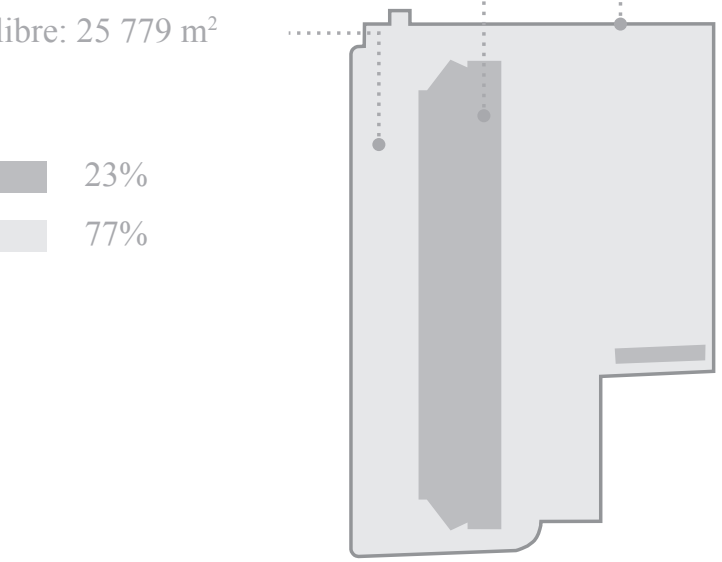

Repartición del proyecto: 3 niveles

Area del proyecto: $50480 \mathrm{~m}^{2}$

Patio de maniobras: $19450 \mathrm{~m}^{2}$

Area construida: $20225 \mathrm{~m}^{2}$

Conexión urbana: $8081 \mathrm{~m}^{2}$
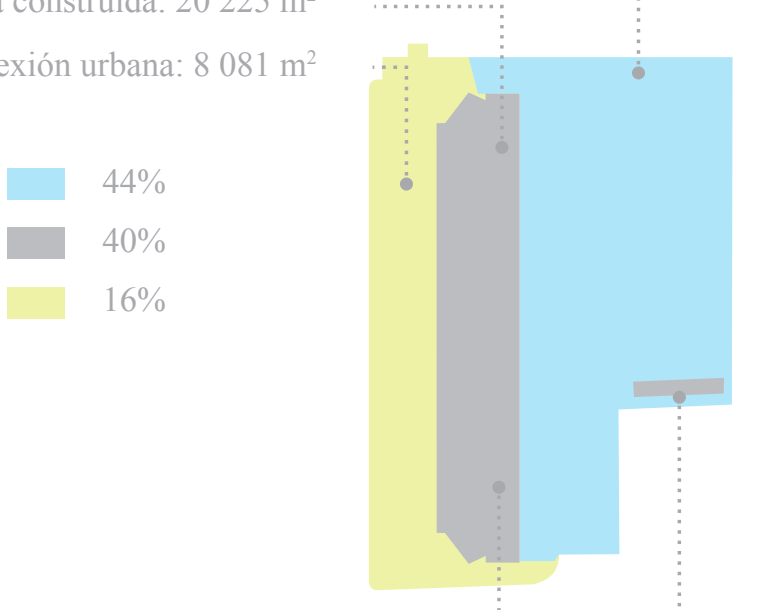

Intermodalidad

Area construida
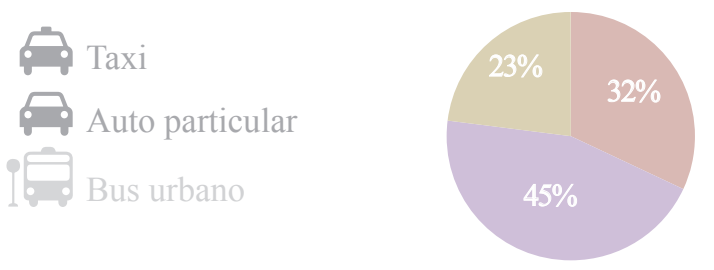

Comercio + administración

Embarque + desembarque

Circulación

$\mathrm{Nive} 12^{\circ}$

Zona de buses

- Ingreso buses

Ingreso taxis

Mantenimiento

- Ingreso peatones

- Carril buses urbanos

Estacionamientos

Circulación

- Ingreso autos particulares Andenes 


\section{Ubicación}

En relación a la ciudad, se encuentra en una zona cercana al centro y densamente poblada, pero de fácil acceso. Esto se debe a que se ubica a un lado de la Panamericana Norte, carretera principal de la ciudad. Sin embargo, el ingreso al terminal se realiza por una vía adyacente y de carácter secundario, lo que evita problemas de congestionamiento en la carretera.

\section{$\underline{\text { Intermodalidad }}$}

No cuenta con la infraestructura adecuada para su conexión intermodal con sistemas de transporte urbano masivo. Su principal conexión es la estación de buses metropolitanos que se ubica a pocos metros de distancia de la puerta de ingreso, a la cual se accede cruzando una calle. Esta ruta es importante ya que la conecta con el resto de la ciudad en dirección norte y sur. De forma paralela, también funciona el sistema de transporte público informal en la misma ruta. Por otro lado, sí cuenta con una bahía de corta duración para el ascenso y descenso de pasajeros hacia vehículos particulares. De igual forma, dispone de un sistema de taxis permanente y un estacionamiento para vehículos privados.

\section{$\underline{\text { Servicios complementarios }}$}

Se organiza alrededor de un corredor central, el cual cuenta con una serie de servicios complementarios distribuidos a lo largo del edificio. Entre estos, destaca el área de restaurantes ubicada a un extremo, la cual cuenta con una zona de mesas para comodidad de los usuarios. Adicionalmente, dispone de un área abierta con locales comerciales alquilados, que por lo general funcionan como mercado artesanal. En el tercer nivel del edificio se ubica un centro de convenciones que se alquila para eventos especiales y conferencias. En el caso especial de este terminal, su cercanía con el centro comercial Plaza Lima Norte resulta ventajosa ya que se encuentran vinculados mediante un sistema de puentes peatonales, lo que permite el libre tránsito de los usuarios entre ambas edificaciones. 


\section{Espacio público}

El terminal no cuenta con ningún espacio público, ya que se encuentra completamente enrejado. Sin embargo, si tiene áreas con características de espacio público dentro de sus linderos, los cuales no son accesibles para el uso de los peatones en horas donde este no se encuentra en funcionamiento. Durante las horas de atención, su principal lugar de carácter público es la pequeña plaza previa al ingreso. Además, cuenta con la zona de boleterías y patio de comidas, los cuales se ubican cerca al ingreso principal y funcionan a modo de centro comercial. Durante el día, los locales comerciales exteriores también cuentan con un mayor flujo de personas, funcionando como una extensión de la zona comercial.

\section{$\underline{\text { Sistema estructural }}$}

La zona de buses y patio de maniobras no tienen ninguna cobertura, pero el edificio del terminal cuenta con dos tecnologías diferentes para el techado de diversas áreas importantes. La primera de estas tecnologías es la utilizada en el área de embarque, donde se ubican los andenes de ascenso de pasajeros. Esta zona se encuentra por debajo del edificio del terminal. Debido al gran peso que carga y a las grandes luces libres que se deben cubrir, se utiliza una estructura metálica robusta (vigas en I) con losa colaborante de concreto y metal. La segunda cobertura es mucho más ligera y es la utilizada para la cubierta de la nave central del terminal. En esta zona se recurre a una estructura metálica ligera de cerchas con una cobertura de calamina metálica.

\section{$\underline{\text { Crecimiento }}$}

Su construcción se realizó para reemplazar a los terminales informales existentes en la zona norte. En la actualidad no funciona al máximo de su capacidad, pero el número de usuarios movilizados se irá incrementando paulatinamente hasta llegar a un tope de 1 millón de personas al mes.

\subsubsection{Terminal Terrestre Cruz del Sur, Perú}

Un rubro que viene creciendo y adquiriendo mayor fuerza en Lima durante los últimos años es el transporte interprovincial de pasajeros de manera formal. Como se mencionó anteriormente, existen 55 terminales de este tipo en la ciudad que buscan cubrir la 
demanda. Una característica importante sobre estos es que solo dos funcionan como una central y agrupan a un número considerable de empresas en su interior, el Gran Terminal Terrestre Plaza Lima Norte y el Terminal Terrestre Molina de Yerbateros. El resto son terminales independientes, donde no operan más de cinco empresas, y se encuentran esparcidos por las diversas zonas de la ciudad (Ministerio de Comercio Exterior y Turismo [MINCETUR]; Unión Europea [UE], 2009).

El terminal terrestre de Cruz del Sur se crea bajo esta misma lógica y funciona como terminal para una única empresa de transporte, ubicándose en el cruce de dos avenidas arteriales del área metropolitana de Lima, la avenida Javier Prado y la avenida Nicolás Arriola. Es una de las empresas más reconocidas del rubro con más de 55 años de experiencia en el transporte nacional y además una de las únicas que incorpora en su servicio los destinos internacionales. La construcción se realizó en 1997 a partir del proyecto realizado por el estudio de arquitectura "Tarii Wasi", a cargo de los arquitectos Tatiana Gonzales y Ricardo Flórez, luego de ganar un concurso nacional para el diseño del anteproyecto.

Figura 31: Terminal Terrestre Cruz del Sur

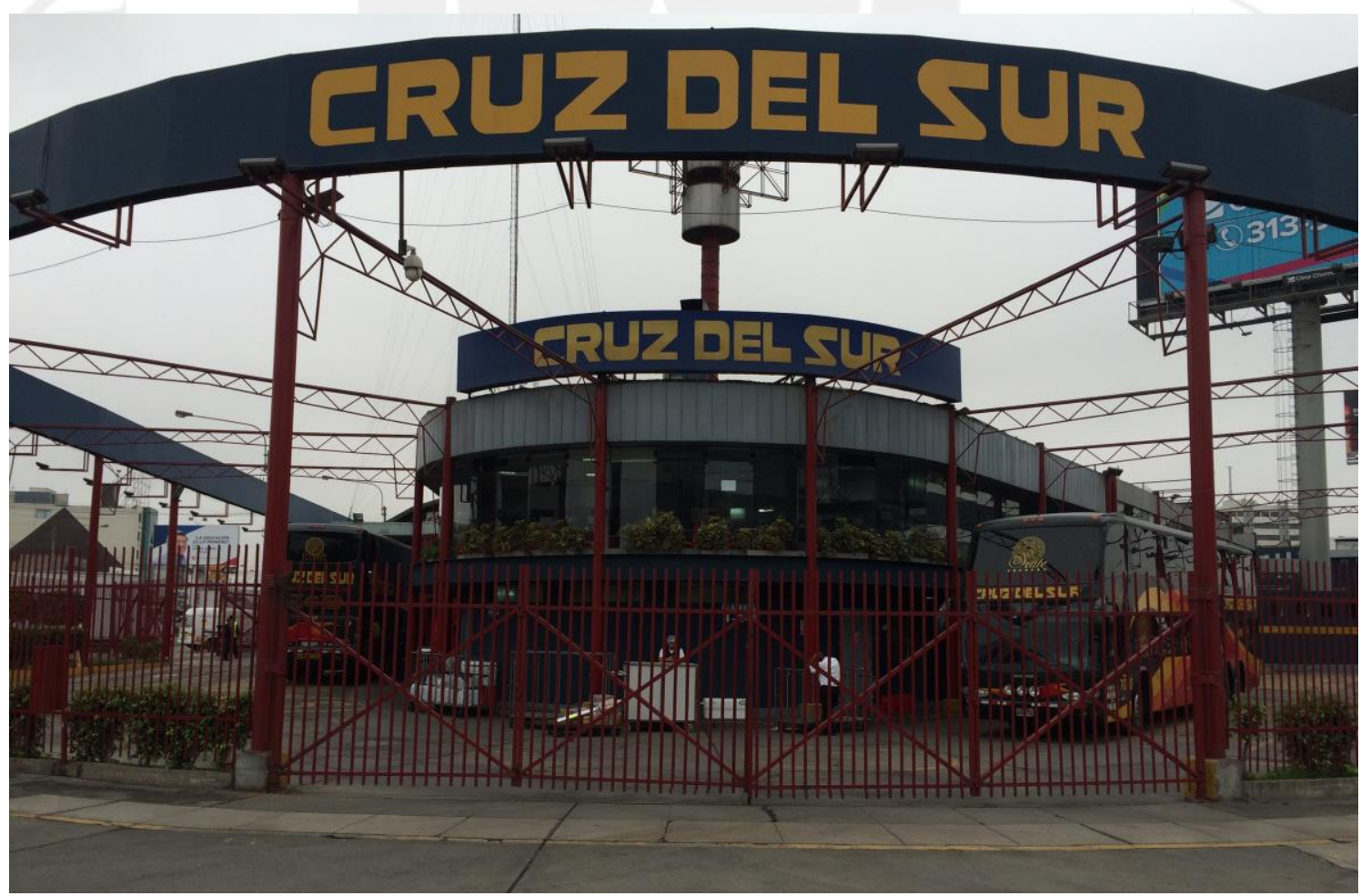

Elaboración propia 
La propuesta para la creación del terminal fue integrar los espacios interiores con los exteriores a través de transparencias y espacios virtuales. Como se aprecia en la figura anterior, esto se logró proponiendo el circuito de maniobra para los buses en el área perimetral del proyecto y colocando el edificio como un elemento central que funciona como un gran mirador (Tarii Wasi, 1999, pp. 88-93).

Una de las principales características del terminal es la incorporación de un patio de maniobras para los buses a manera de bahía lo que permite un acceso fácil y rápido que no congestiona las vías de acceso. También cuenta con un área interna destinada a taxis y estacionamiento privado para mayor comodidad de los usuarios. En el segundo nivel cuenta con una cafetería y sala de espera que por la morfología del terreno funciona como mirador hacia la ciudad. La zona de encomiendas se realiza mediante un edificio adyacente que funciona de forma independiente a la zona de pasajeros.

El terminal funciona las 24 horas del día y cuenta con tres puertas de embarque, las que están debidamente implementadas con una sala de espera y un mostrador para el control de los pasajeros. 

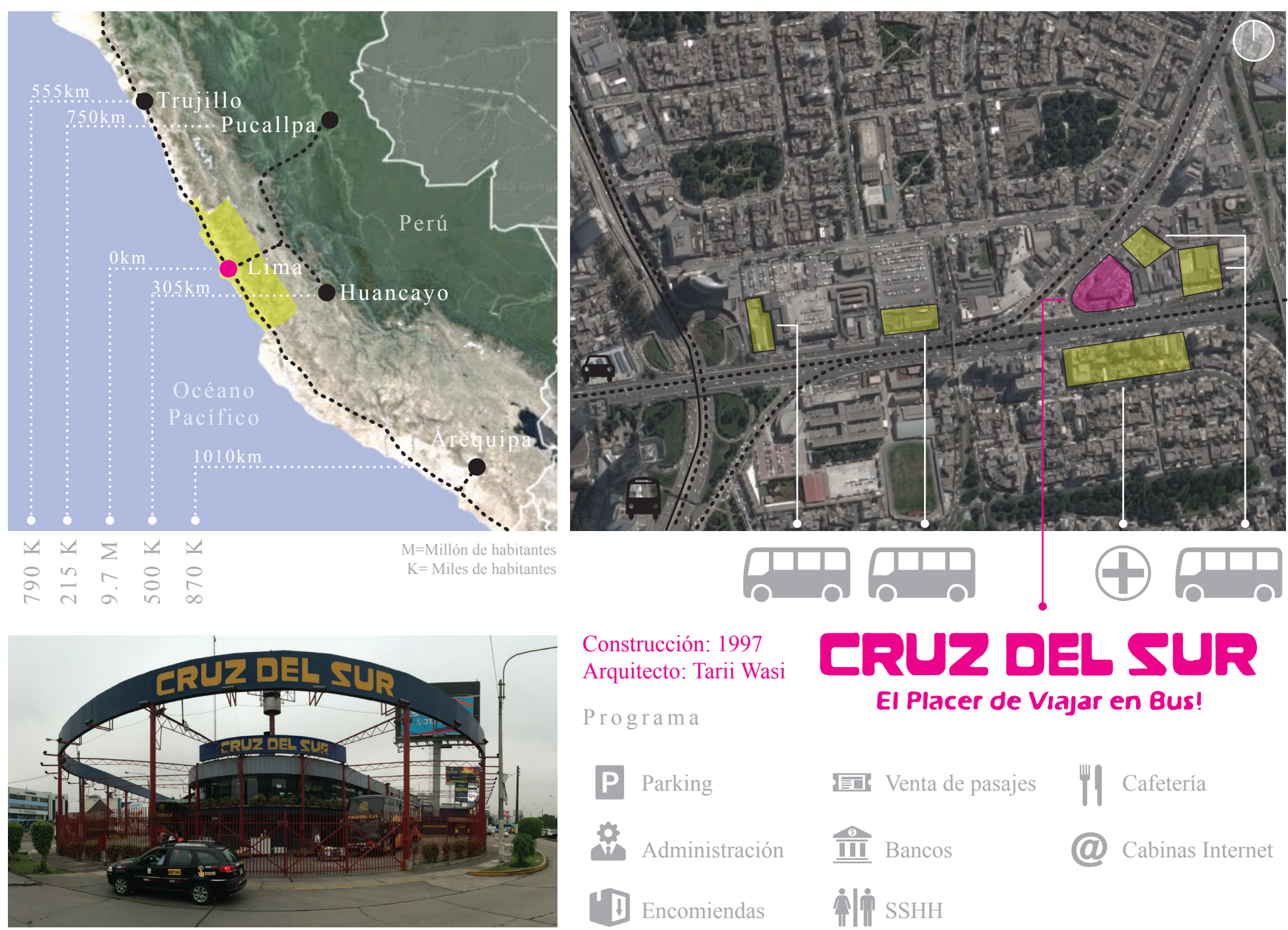

Construcción: 1997

Arquitecto: Tarii Wasi

Programa

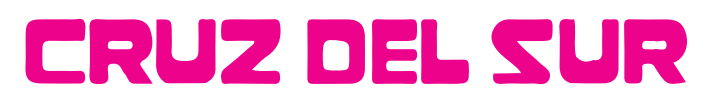

El Placer de Viajar en Bus!

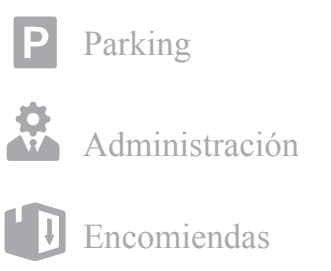

重 Venta de pasajes

W Cafetería

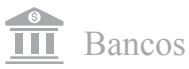

(a) Cabinas Internet

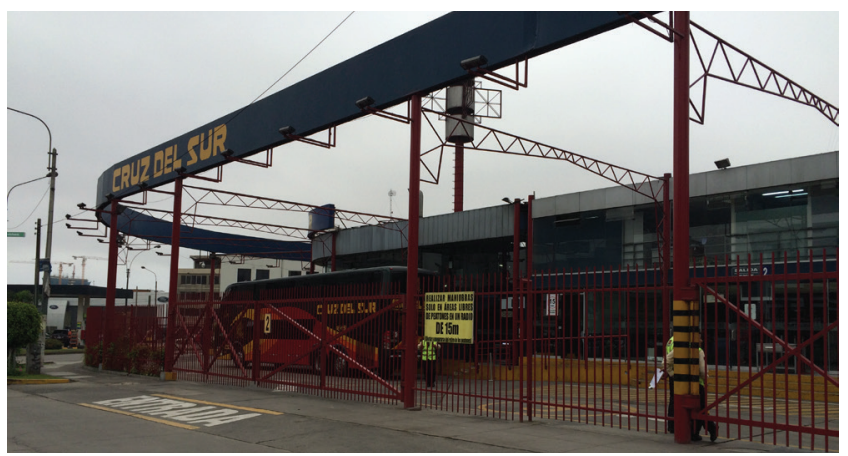

U S O

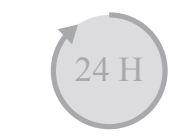

ヘิ๊ $\mathrm{inSHH}$
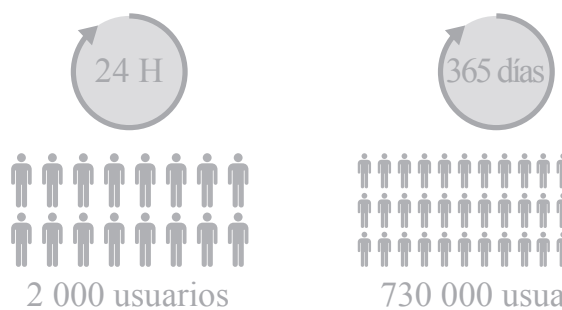

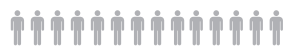

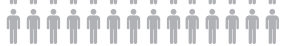

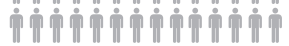

730000 usuarios

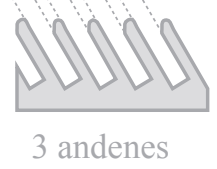

(24 H)

$523 \mathrm{~m}^{2}$ de area
construida

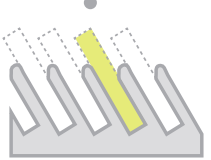
53

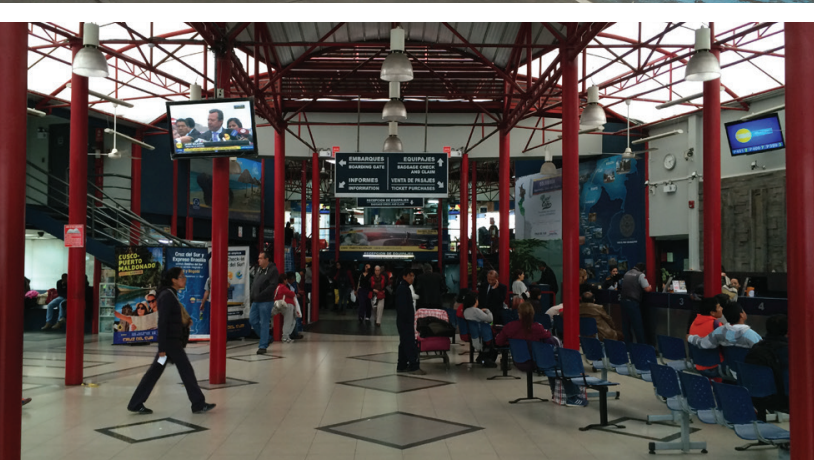

Esquema de funcionamiento: sección transversal

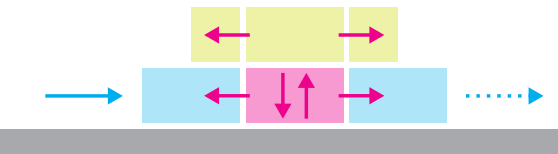

$\begin{array}{lll}\longrightarrow & \text { Ingreso buses } & \text { Nucleo circulación } \\ \longrightarrow & \text { Salida buses } & \text { Zona comercial } \\ \longrightarrow & \text { Flujo peatones } & \text { Embarque }+ \text { desem }\end{array}$ 


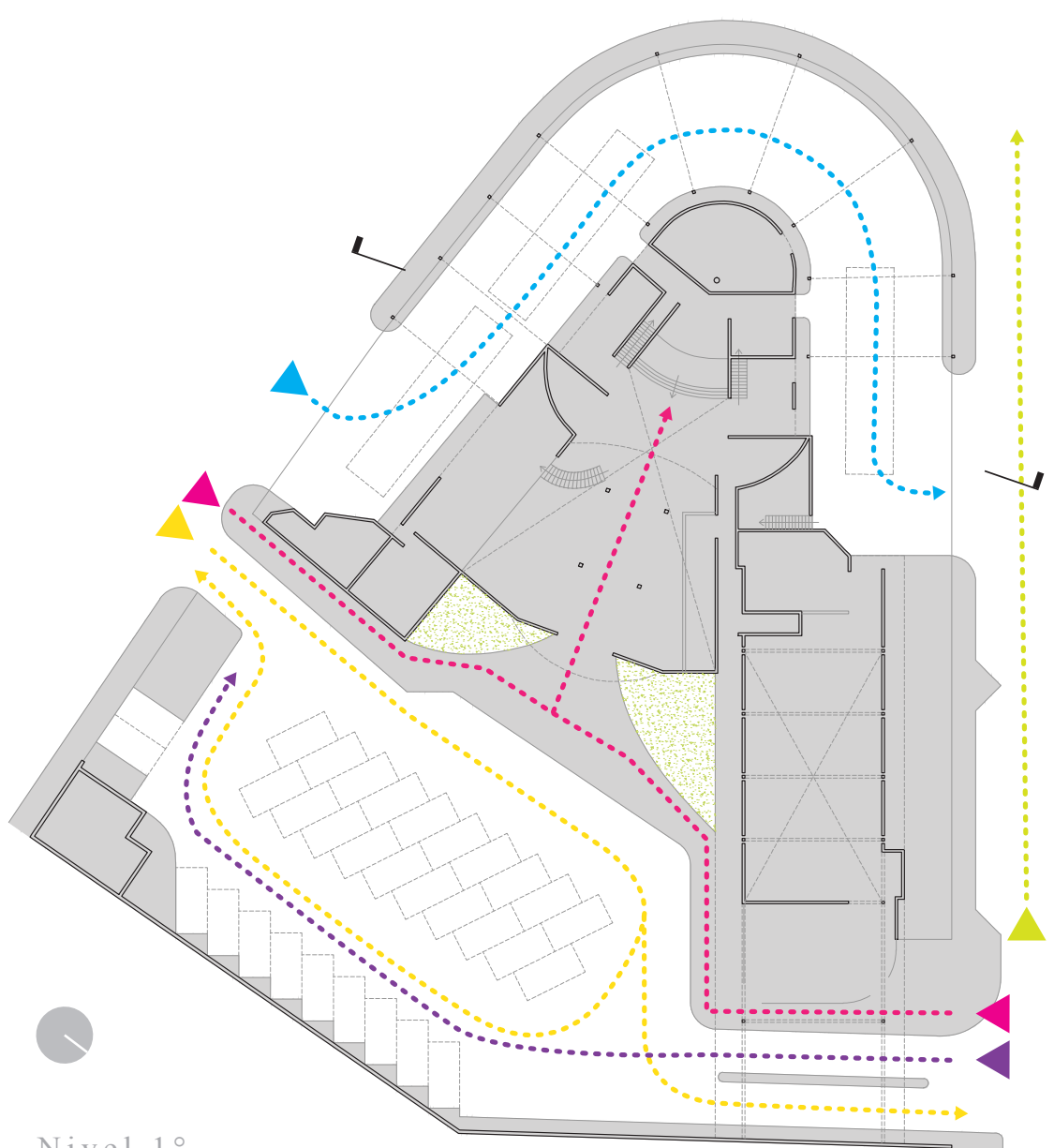

Nive $11^{\circ}$
Ocupación del terreno

Terreno: $4400 \mathrm{~m}^{2}$

Area ocupada: $1160 \mathrm{~m}^{2}$

Area libre: $3240 \mathrm{~m}^{2}$

$26 \%$

$74 \%$

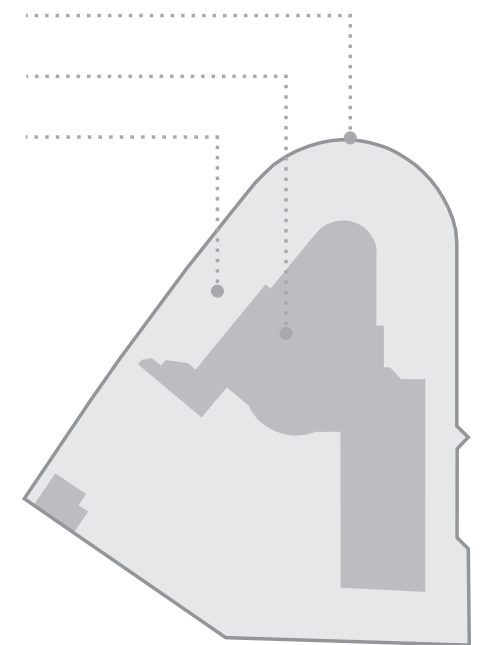

Repartición del proyecto: 2 niveles

Area del proyecto: $4806 \mathrm{~m}^{2}$

Patio de maniobras: $1027 \mathrm{~m}^{2}$

Area construida: $1566 \mathrm{~m}^{2}$

Conexión urbana: $2213 \mathrm{~m}^{2}$

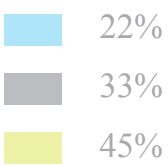

Intermodalidad

Area construida
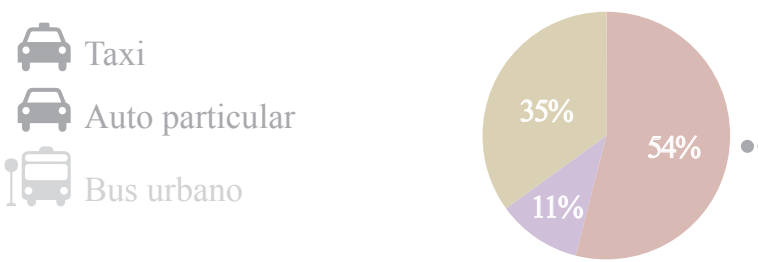

Comercio + administración

Embarque + desembarque

Circulación

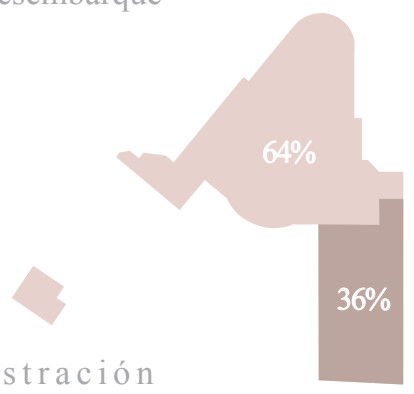

Comercio y administración

Encomiendas

Nive $12^{\circ}$

Administración del terminal Comercio 


\section{Ubicación}

No es la más adecuada para un terminal terrestre, ya que se encuentra inmersa en el centro de la ciudad, muy cerca al centro financiero. A pesar de ubicarse en un carril auxiliar para evitar la congestión, su principal ruta de acceso es una vía arterial de la ciudad con graves problemas de tráfico vehicular. Por este motivo los buses tienen que prever las horas punta para evitar los atascos. En lo que respecta a la infraestructura del terminal, su diseño contempla un carril exclusivo para el ingreso de buses separándolos del tránsito de otros vehículos.

\section{Intermodalidad}

No cuenta con ningún espacio para la conexión con el sistema de transporte urbano masivo. Sin embargo, gracias a su ubicación tan céntrica, la parada de buses más cercana se encuentra a una cuadra de distancia, mientras que la estación más cercana es la del sistema de transporte metropolitano y se ubica a cinco cuadras. Dentro del terreno, cuenta únicamente con un área reservada para el servicio de taxis y otra para estacionamientos particulares de corta estadía. Se puede concluir, que la falta de intermodalidad se debe en parte al bajo flujo de usuarios que tiene, ya que solo atiende a una empresa de transporte.

\section{$\underline{\text { Servicios complementarios }}$}

El único espacio comercial con el que cuenta el terminal es la zona ubicada en el segundo nivel, en la que existe un locutorio y cabina telefónica, además de una cafetería que también funciona como mirador hacia la ciudad y sala de espera. A pesar de esta falta de servicios complementarios, es uno de los únicos terminales que tiene con un edificio exclusivo para el servicio de encomiendas, lo que agiliza el proceso de atención.

\section{Espacio público}

Debido a su reducido tamaño no cuenta con ningún espacio público. Sin embargo, posee una pequeña plaza al ingreso de la estación que sirve como recibimiento para sus usuarios, pero se restringe al horario de funcionamiento del terminal. Sin embargo, la 
gran aglomeración de pasajeros durante ciertas horas del día hace que los usuarios tengan que esperar fuera del terminal hasta el momento de abordar su bus.

\section{$\underline{\text { Sistema estructural }}$}

Si se observa el terminal desde las coberturas, este se divide en dos zonas. La primera es la utilizada por el área de atención al usuario y salas de espera, las que cuentan con una estructura metálica y recubrimiento ligero en calamina. La segunda zona identificable es la de los buses, la cual tiene una cercha virtual de acero, pero sin recubrimiento alguno.

\section{$\underline{\text { Crecimiento }}$}

El espacio reducido de terreno con el que cuenta el terminal no permitió una proyección a futuro, más que la separación de una porción del terreno para posibles expansiones. Esta se ha utilizado para agregar estacionamientos. El diseño original contemplaba únicamente la implementación de dos salas de embarque con sus respectivas zonas de espera. Al aumentar la demanda, en los últimos 15 años, se adicionó una tercera sala de embarque, reduciendo así las zonas de espera. Actualmente, también funciona las 24 horas del día, para poder cumplir con la demanda existente.

\subsection{Referentes en América Latina: realidades similares}

\subsubsection{Terminal Terrestre de Guayaquil, Ecuador}

La ciudad de Guayaquil, con más de 3 millones de habitantes, es la ciudad más grande de Ecuador. Una ciudad costera, atravesada por dos ríos de gran importancia (río Guayas y río Daule), que cuenta con una extensión territorial de $345 \mathrm{~km}^{2}$ y un clima bastante tenue.

En 1985 se construye el terminal terrestre "Dr. Jaime Roldós Aguilera”, pero tan solo dos años después ya se encontraba en abandono uno de los niveles. En total, la edificación antigua permaneció abandonada por unos 18 años. Para el 2002, el edificio se encontraba en mal estado, con daños estructurales, problemas funcionales e incluso niveles completamente desocupados. Adicionalmente tenía problemas para integrarse a las redes existentes. 
Finalmente se decide crear una entidad que se encargara de recuperar el terminal: "Fundación Terminal Terrestre". Es una fundación sin fines de lucro que fue creada en el 2002, para hacerse responsable de la transformación, ampliación, administración y mantenimiento del terminal (Pico Cedeño, 2009).

Al asumir la responsabilidad sobre este terminal, lanzan un concurso por invitación a diversos estudios de arquitectura en América Latina. El objetivo era la renovación del existente y la implementación de un edificio multifuncional, además de adecuar características intermodales. Durante el período de renovación se creó el "Terminal provisional de Guayaquil" ubicado en un terreno aledaño, para poder utilizar espacio de estacionamiento, pero trasladar la atención al cliente a un espacio más seguro.

El terminal provisional se inauguró el 11 de noviembre del 2005 y se previó unos 18 meses de construcción y funcionamiento a la vez. El pronóstico para la terminación de la construcción sería al cabo de dos años, en el 2007.

El nuevo terminal terrestre "Dr. Jaime Roldós Aguilera", que supuso una inversión de US\$ 50 millones, esta estratégicamente ubicado entre dos avenidas importantes, al costado de la línea de metro y el aeropuerto de Guayaquil. Con un pronóstico de 42 millones de usuarios al año (120,000 al día), se buscó, entre otros, reorganizar los flujos vehiculares para reducir la congestión en las calles y para generar un espacio agradable exterior para los peatones y usuarios. Se tomó en cuenta cada medio de transporte que pudiera ingresar al terminal, como autos particulares, camiones, autos de servicio, ómnibus urbano (que cuenta con una estación en el terminal), taxis, etc. Para los peatones se diseña una plaza de llegada sin interferencias de vehículos y resguardada de las avenidas por un límite de vegetación del lugar. 
Figura 32: Terminal Terrestre de Guayaquil

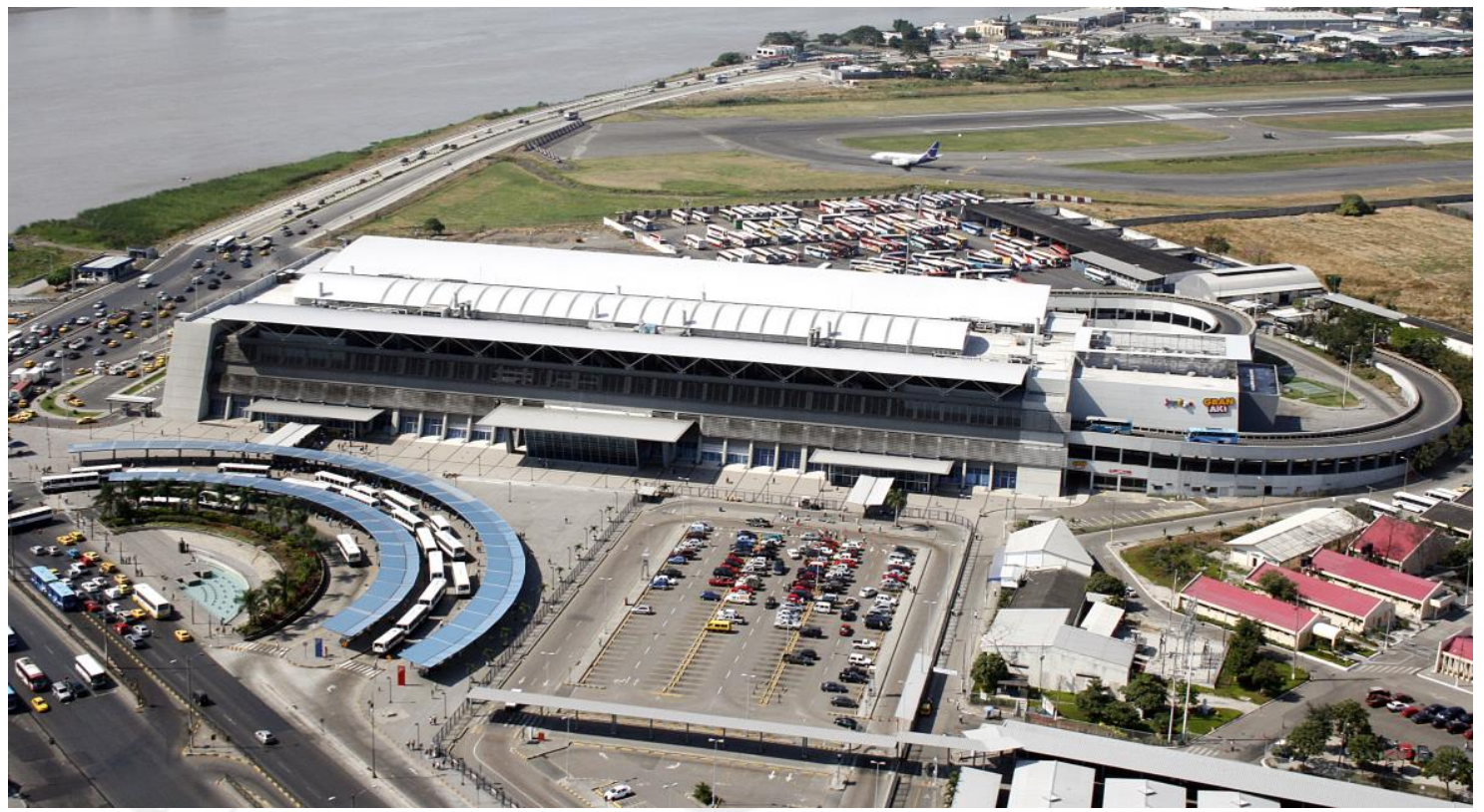

Fuente: Municipio de Guayaquil (2015)

Obtenido de http://www.guayaquilesmidestino.com/es/descubre-guayaquil/como-llegar/terminalterrestre-jaime-roldos-aguilera

Con respecto al diseño arquitectónico "Se plantea un lenguaje contemporáneo y dinámico, que con pocos recursos logra una imagen claramente identificable y contundente." (Gómez Platero Arquitectos, s.f.). Es importante tomar en cuenta las cubiertas realizadas en "chapa", un tipo de calamina galvanizada, ya que resultan prácticas por su ligereza, fácil reemplazo y mantenimiento. Esto permite que la estructura que soporta la cubierta sea de una estructura metálica ligera. El metal se sigue implementando en el cerramiento de la fachada, pero como parasoles.

Para obtener una buena iluminación interior, se mantiene un corredor central que sirve para la circulación principal, pero que además, al tratarse de una triple altura no obstruye la luz que ingresa desde el techo.

El terminal cuenta con un nivel subterráneo que sirve como depósito y área técnica, pero además se está considerando una conexión subterránea con el terminal marítimo del río Raule que podría convertirse en una conexión muy transitada por pasajeros y el traslado de encomiendas. El primer nivel abastece varias funciones, desde atención a los pasajeros, estacionamiento vehicular, zona comercial y gastronómica y andenes de llegada para la descarga de pasajeros. El edificio cuenta con un tipo de piso 
técnico habilitado con pasarelas para servir y mantener las subestaciones y equipos de aire acondicionado que ahí se ubican. Luego en los siguientes niveles se distribuyen los locales comerciales y andenes para buses y pasajeros.

Se toma en cuenta la separación de encomiendas y pasajeros, para evitar que los flujos se crucen, al igual que una zona especial para la espera de los autobuses mismos. 

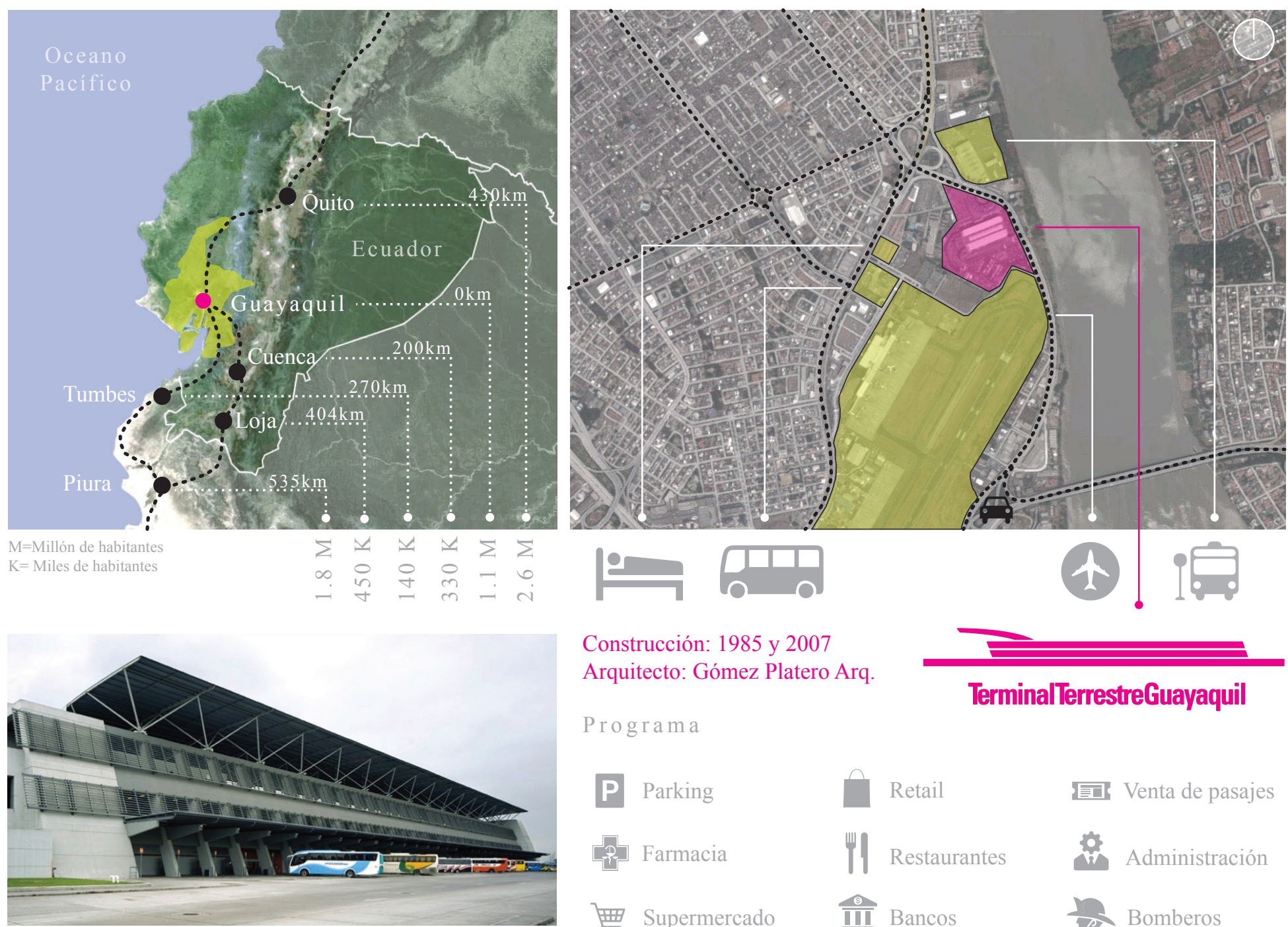

Construcción: 1985 y 2007

Arquitecto: Gómez Platero Arq.

Programa

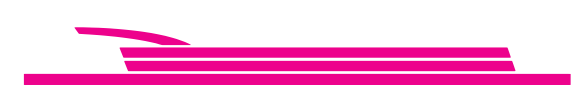

TerminalTerrestreGuayaquil
P Parking

[7 Farmacia

典 Supermercado

Tด Mantenimiento Us o

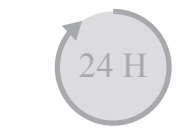

部部部部

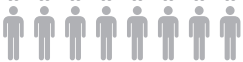

120000 usuarios

(24 H)

area construida

重 Venta de pasajes

Retail

III Bancos

(1)
Administración

Bomberos

ஸे门 SSHH
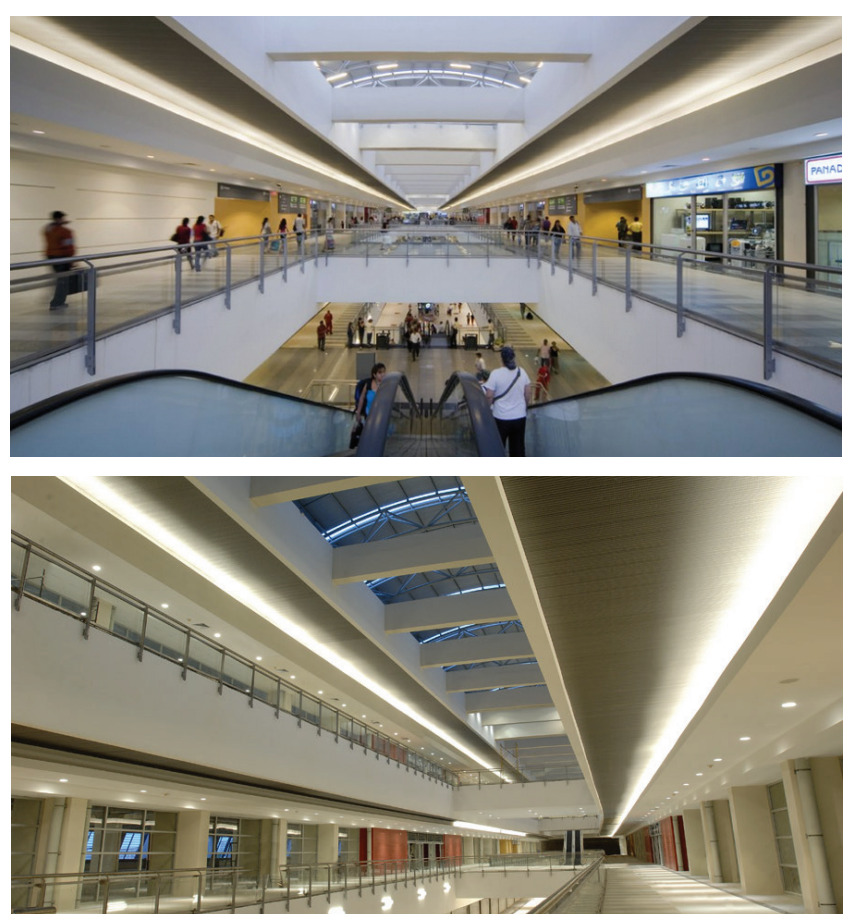

Esquema de funcionamiento: sección longitudinal

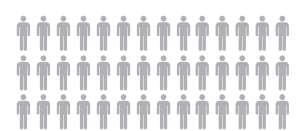

42000000 usuarios

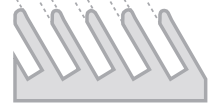

112 andenes

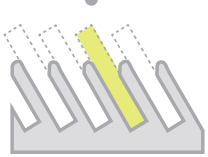

por cada andén

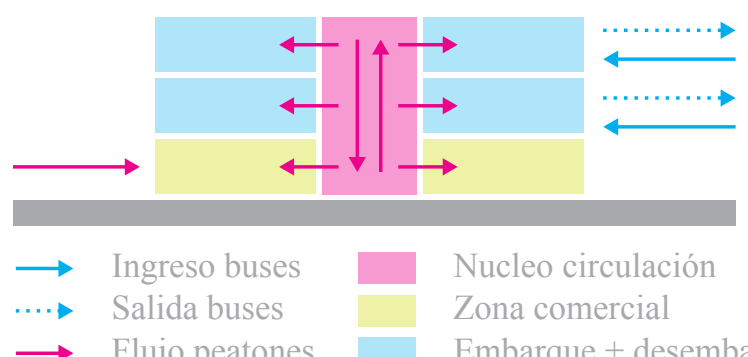

$\longrightarrow$ Flujo peatones $\longrightarrow$ Embarque + desembarque 
Ocupación del terreno

Terreno: $166605 \mathrm{~m}^{2}$

Area ocupada: $33095 \mathrm{~m}^{2}$

Area libre: $133510 \mathrm{~m}^{2}$

$20 \%$

$80 \%$

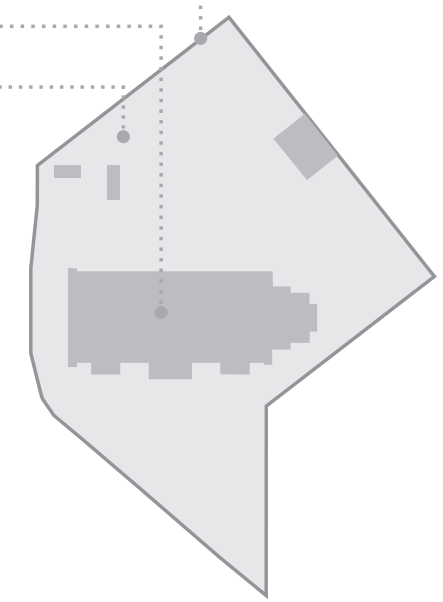

Repartición del proyecto: 3 niveles

Area del proyecto: $221599 \mathrm{~m}^{2}$

Patio de maniobras: $83552 \mathrm{~m}^{2}$

Area construida: $88089 \mathrm{~m}^{2}$

Conexión urbana: $49958 \mathrm{~m}^{2}$

Ingreso buses

Ingreso taxis

$\triangle$ Ingreso peatones

Ingreso buses urbanos

- Ingreso autos particulares

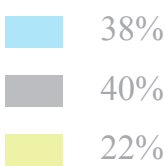

$8 \%$

$0 \%$

$22 \%$

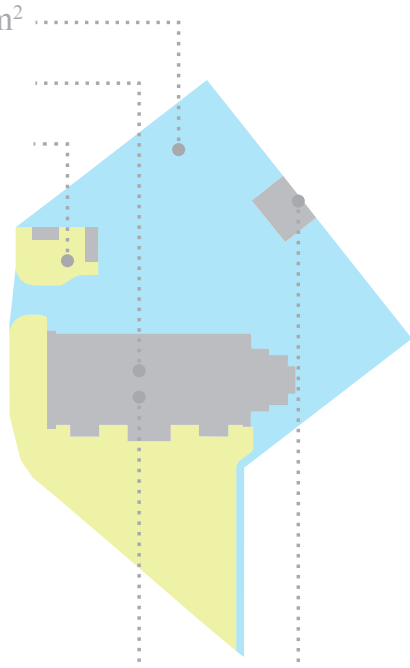

Nivel $2^{\circ}$

Intermodalidad

Area construida

Bus urbano

?ि Taxi

Auto particular

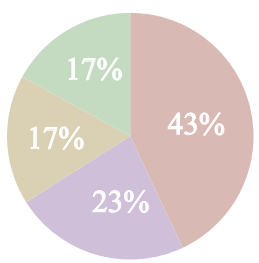

Comercio + administración

Embarque + desembarque

Circulación

Nive $13^{\circ}$
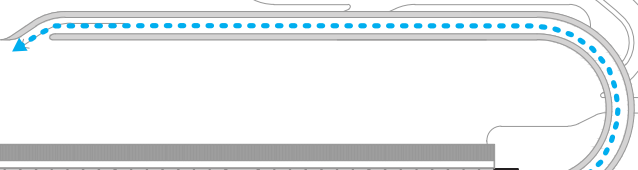

Otros + áreas verdes

Zona de buses

Mantenimiento

Estacionamientos

Circulación exterior

Circulación interior

Andenes 


\section{Ubicación}

Se ubica al margen del río Guayas al norte de la ciudad, conectado a varios puntos de gran importancia. Por un lado, colinda con el aeropuerto JJ Olmedo, lo cual es muy beneficioso, pues permite conectar vuelos nacionales e internacionales con rutas de buses interprovinciales y también internacionales sin grandes movilizaciones por la ciudad. Además, puede conectar fácilmente con vías arteriales y una carretera, permitiéndolo realizar sus rutas sin entorpecer el flujo vehicular dentro de la zona urbana. Cruzando la calle se conecta con la Metrovía, el cual es un sistema integrado de transporte masivo urbano. Cuenta con la infraestructura necesaria para evitar congestionamiento causado por buses, taxis, carros particulares y buses metropolitanos.

\section{$\underline{\text { Intermodalidad }}$}

Este aspecto está bien planteado, ya que contempla casi todos los medios de transporte necesarios. La mayor prioridad se la da al peatón, quien puede acceder el terminal sin tener que cruzar estacionamientos ni bahías. Por otro lado, cuenta con bahías especialmente para taxis, otra para buses metropolitanos y un ingreso diferenciado para autos particulares. A futuro se planea conectar un túnel peatonal con el puerto marítimo. Un gran punto a favor es su cercanía al aeropuerto JJ Olmedo, que a pesar de no estar conectado directamente de manera peatonal, alivia significativamente el desplazamiento para muchos viajeros. Además, aún cuenta con la posibilidad de generar una conexión directa si así lo desasen.

\section{$\underline{\text { Servicios complementarios }}$}

Desde su remodelación en el 2007 ha sido equipado como un centro comercial, abarcando hasta $25,000 \mathrm{~m}^{2}$ repartidos en una galería en el primer nivel con 267 tiendas, restaurantes y un supermercado. Esto significa que el terminal cuenta con múltiples servicios complementarios para el viajero, aliviando sus necesidades sin grandes desplazamientos ni pérdidas de tiempo. Otro factor importante a considerar es que una infraestructura con ese nivel de equipamiento comercial contará con un flujo constante de consumidores, sean o no viajeros. De esta manera se evitan espacios en desuso o abandono del terminal. 


\section{Espacio público}

La cantidad y calidad de espacio público en este terminal dependerá de lo que uno considera como tal. En algunos países, se considera que los centros comerciales son un buen reemplazo para el espacio público. Esto se da principalmente en realidades latinoamericanas, donde es común la ausencia de espacios abiertos en la ciudad, al igual que la inseguridad ciudadana que hace que el usuario se sienta inseguro si no se percibe algún tipo de sistema de seguridad. Sin embargo, un centro comercial no permite el libre uso por parte de las personas, pues se trata de un espacio privado para el uso público bajo horarios restringidos. El terminal de Guayaquil es el clásico ejemplo donde un centro comercial reemplaza las características que debería tener un espacio público. Este cuenta con galerías comerciales, las cuales se utilizan para comprar, pero también como paseo. El único espacio público auténtico que tiene, es el espacio previo al ingreso del terminal, que funciona como el recibimiento de peatones y se consolida como una pequeña plaza.

\section{Sistema estructural}

Se trata de una construcción principalmente de concreto armado, con cubiertas de calamina galvanizada en el último nivel. Esta se caracteriza por su ligereza, fácil reemplazo y mantenimiento, lo cual también permite que la estructura que la soporta sea metálica. El recorrido central, con una triple altura, aprovecha la iluminación cenital con una modulación que evita la sobreexposición. Al incluir los andenes dentro de la edificación, en el segundo y tercer nivel, la cubierta se simplifica, ya que no se trata de grandes patios de maniobra que requieren cubiertas complicadas. La estructura principal sí se compone de elementos estructurales en concreto, para soportar las cargas del segundo y tercer nivel. La cantidad de apertura que se trabajó en estos niveles también es importante, pues permite la ventilación natural en los ambientes de andenerías. Los laterales de la edificación cuentan con parasoles metálicos para regular el ingreso de luz.

\section{Crecimiento}

Este terminal se puso a prueba en su primera versión. Aquel terminal se construyó en 1985, para dos años después empezar a evidenciar un gran desuso. Por 18 años 
permanece abandonado hasta que se culmina la remodelación en el 2007. Para esta versión se optó por la inclusión de un centro comercial para mantener una activación constante, incluso en temporadas bajas donde disminuyen los viajes en buses. En este también se amplió la capacidad y se buscó generar un terminal intermodal. A través de estas estrategias se busca un nivel de conectividad e intermodalidad que permite el constante y fácil flujo de usuarios, evitando otro posible abandono a futuro.

\subsubsection{Terminal de Autobuses de Pasajeros de Oriente, México}

En México el transporte interurbano y urbano, durante años, estuvo inmerso en un caos debido a la desorganización que existía. Era necesario adecuar y desarrollar de manera integral su infraestructura vial a las necesidades del país. Con ese motivo se crea en 1973 el Programa Nacional de Regularización del Autotransporte.

La intervención de este programa en México DF fue fundamental y cambió radicalmente el sistema existente. Tuvo como principal función agrupar a los 127 terminales terrestres que estaban dispersos por toda la ciudad en cuatro centrales: norte, sur, poniente y oriente. Entre ellos el más importante fue el Terminal de Autobuses de Pasajeros de Oriente [TAPO], debido a su particular arquitectura y su ubicación relativamente céntrica, ya que se encuentra exactamente a la mitad de camino entre el Aeropuerto Internacional Benito Juárez y el Centro Histórico.

En esta estación se agruparon 18 compañías transportistas en un terreno de $90,000 \mathrm{~m}^{2}$, alimentando las rutas a nivel nacional e internacional de norte y sur. Es además uno de los 20 terminales más grandes del mundo. Hoy en día se encuentra completamente inmerso en el casco urbano de la ciudad, pero está conectado con las principales rutas viales que atraviesan la ciudad, además de colindar directamente con el sistema de transporte colectivo [METRO].

El TAPO fue obra del arquitecto Juan José Díaz Infante y se terminó su construcción en 1979. Inicialmente fue planeado para albergar a 80,000 personas al día, pero se superó rápidamente llegando en el 2005 a tener 185,000 personas y se estima que en la actualidad es atravesada por 500,000 personas al día durante temporada alta. (Ministerio de Comercio Exterior y Turismo [MINCETUR]; Unión Europea [UE], 2009, p. 57). Entre las características arquitectónicas principales se encuentra su planta circular donde destaca la gran cúpula, la cual es más grande que la de San Pedro en 
Roma, llegando a los 62 metros de diámetro y 25 metros de altura. En el centro de la cúpula hay un óculo de 16 metros debido a que todas las vigas que forman parte del techado no pueden converger en un solo punto, por lo que se utiliza un anillo de compresión. Estas vigas son pretensadas y tienen forma curva con una sección en T variable. El techado de la cúpula se realizó mediante planchas curvas de plástico, realizadas especialmente para este proyecto. Además, se utilizó una estructura temporal para soportar 600 toneladas de peso que tienen las vigas hasta que el anillo de compresión estuviera listo.

Figura 33: Terminal Terrestre México

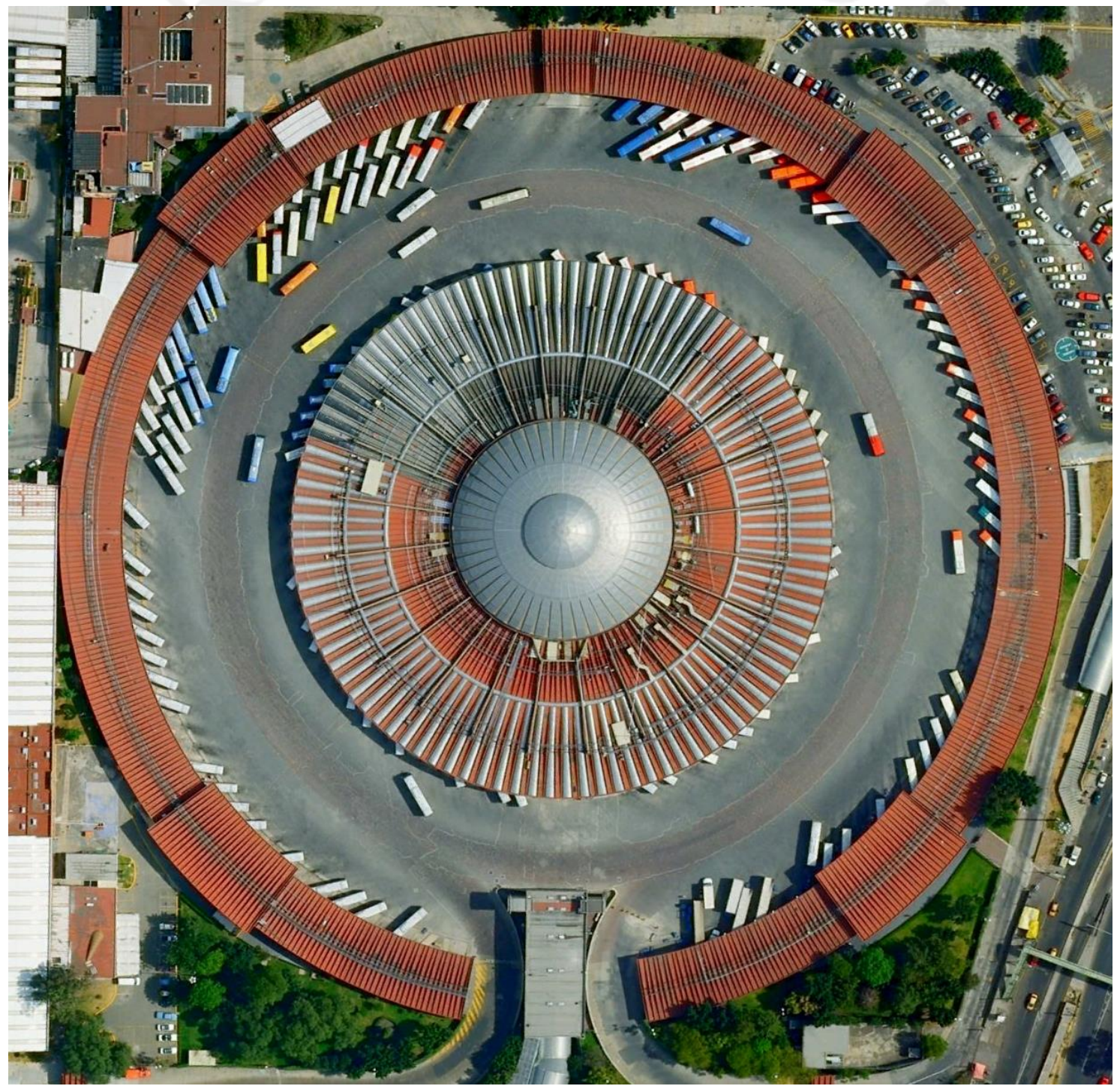

Fuente: Daily Overview (2015)

Obtenido de http://dailyoverview.tumblr.com/post/114153031284/the-terminal-de-autobuses-depasajeros-de-oriente 
El terminal se organiza de forma radial, alrededor del edificio central con la cúpula. En este se encuentran los restaurantes y el área de salidas. Alrededor del edificio se ubica el patio de maniobras y parqueo de buses. El edificio exterior del terminal está conformado por un anillo de un nivel y cuatro edificios de dos. En este se ubica toda la zona de llegadas y administrativa; el primer piso es para el uso público, mientras que el segundo está reservado para los trabajadores y conductores.

El ingreso de pasajeros a la zona de salidas se realiza mediante dos túneles peatonales que pasan por debajo del patio de maniobras, los cuales se ubican en los dos ingresos. Al primero se accede desde la conexión con el Metro y buses urbanos, mientras que al otro se accede desde el estacionamiento de vehículos particulares y taxis.

El gran terreno colindante al terminal es propiedad de ADO y funciona como zona de mantenimiento y oficinas administrativas, que se conectan con el TAPO mediante una vía interna. (Terminal de Autobuses de Pasajeros de Oriente, 2007). 

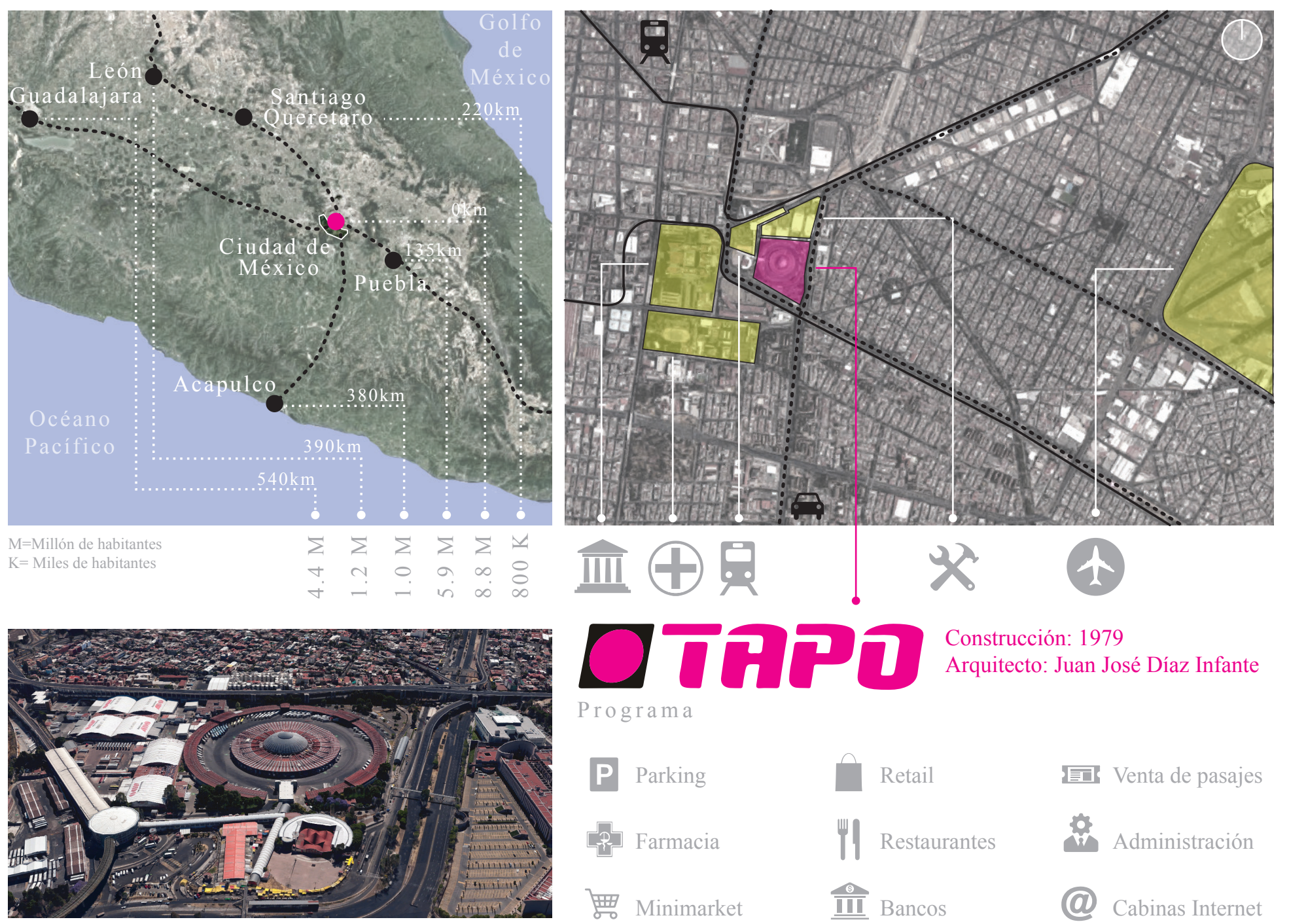

Construcción: 1979

$\sum \sum \sum \sum \Sigma 凶$

Programa

P Parking

Farmacia

典 Minimarket

Ţ Mantenimiento

U s o
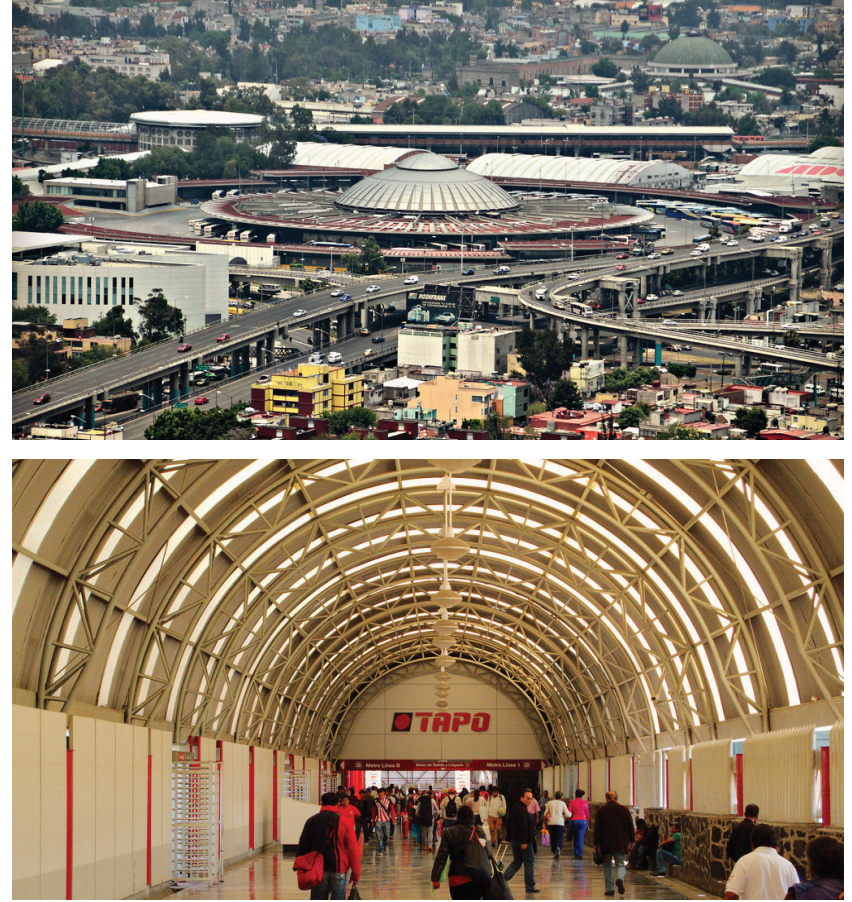

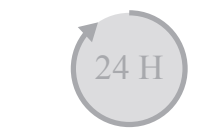

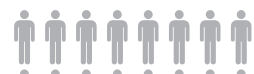

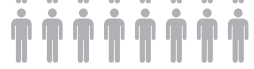

185000 usuarios

(24 H)

Construida
Venta de pasajes

II Restaurantes

Administración

프 Bancos

@ Cabinas Internet

(1)

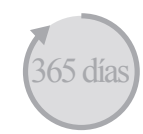

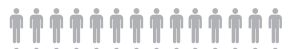

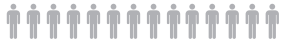

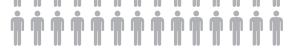

67500000 usuarios

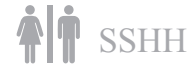

\section{HAIILIIIII}

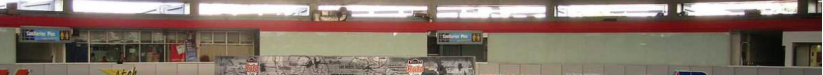

1 An

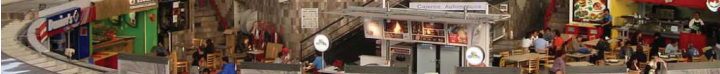
$\stackrel{\leftrightarrow}{\longrightarrow} \quad \stackrel{4 \ldots . .}{\longrightarrow} \quad \longleftarrow \quad \longrightarrow$ 


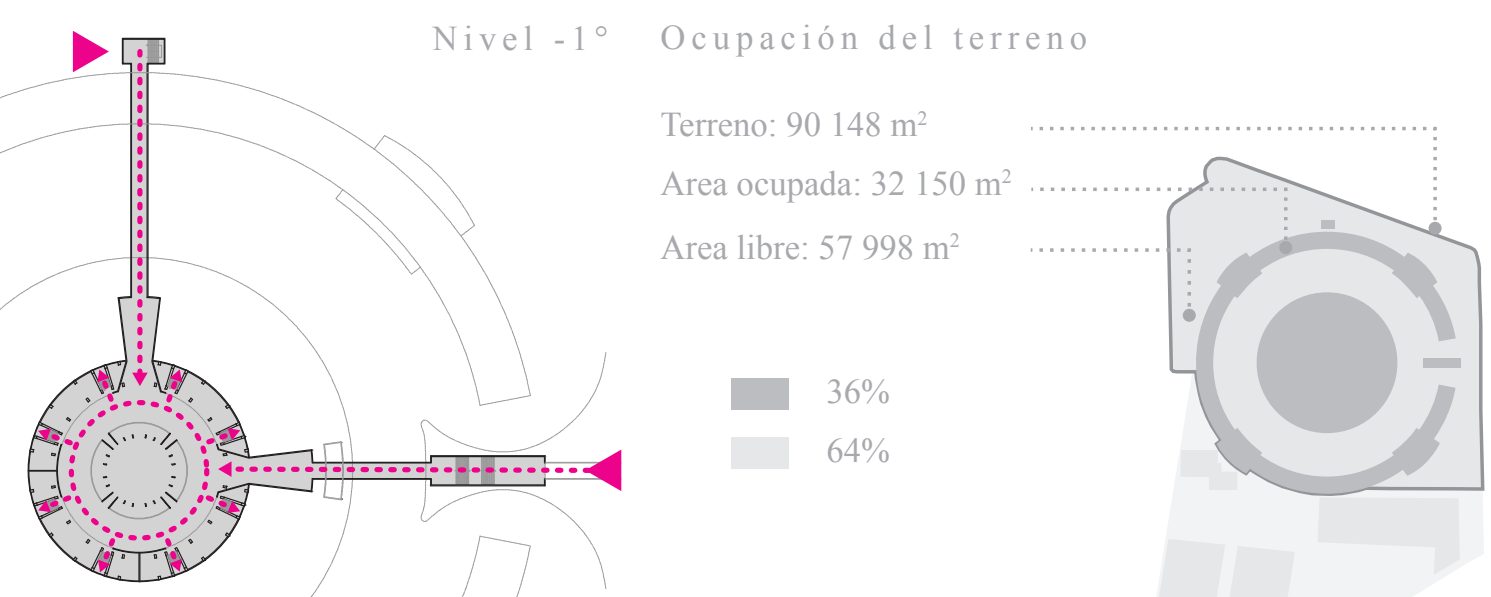

- Ingreso buses Ingreso taxis

$\Delta$ Ingreso peatones

Ingreso buses urbanos

- Ingreso autos particulares

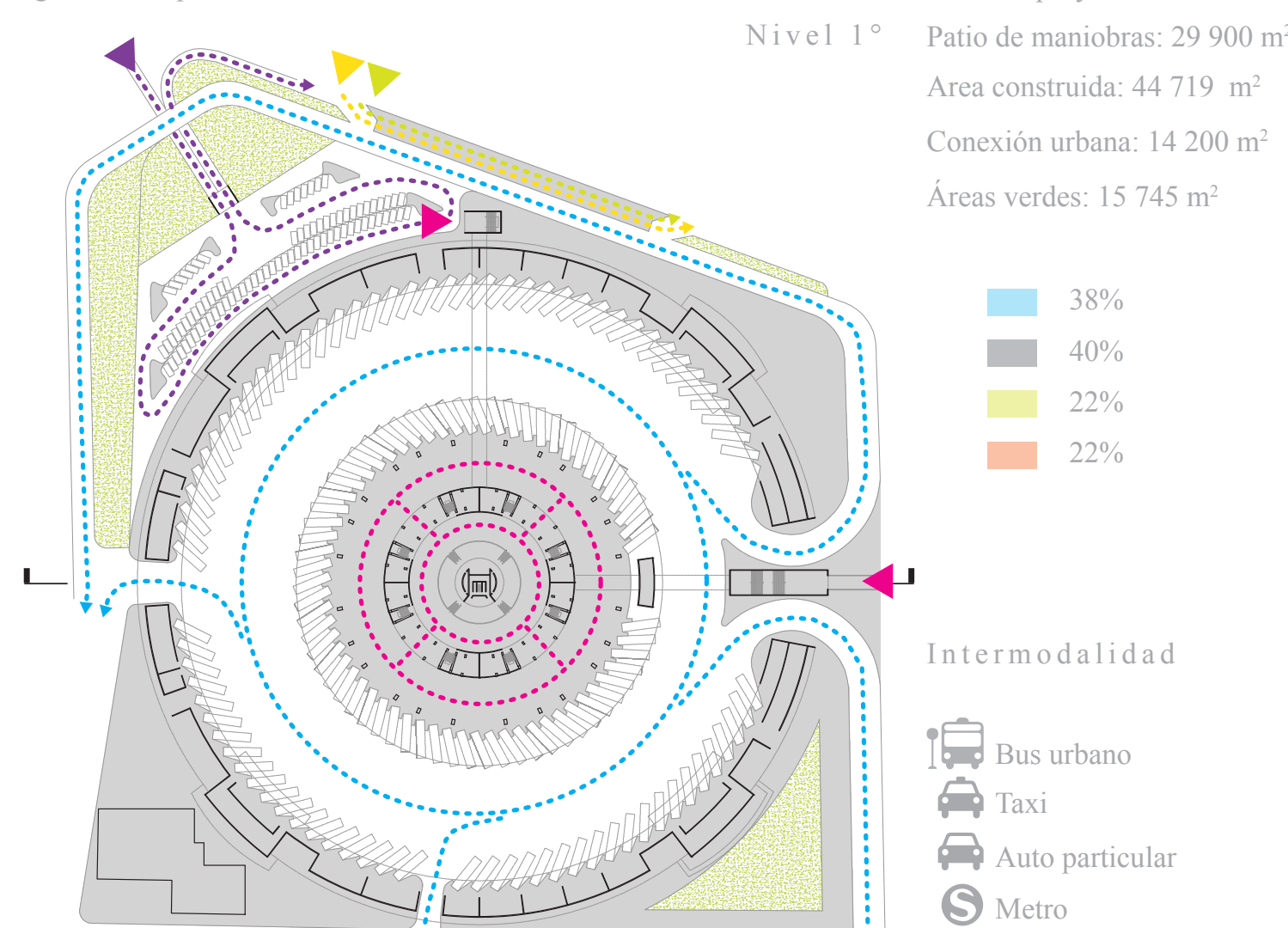

Repartición del proyecto: 3 niveles

Area del proyecto: $104565 \mathrm{~m}^{2}$

Area construida: $44719 \mathrm{~m}^{2}$

Conexión urbana: 14200 m²

Áreas verdes: $15745 \mathrm{~m}^{2}$

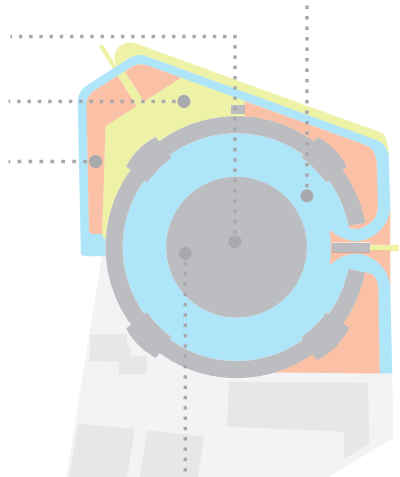

Area construida

Sus urbano

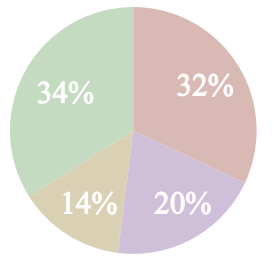

Comercio + administración

Embarque + desembarque

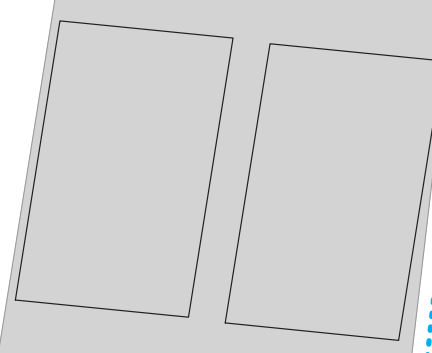

Circulación

Otros + coberturas

Composición del terminal

Terminal TAPO: $90148 \mathrm{~m}^{2}$

Servicios complementarios: $58329 \mathrm{~m}^{2}$

Mantenimiento + Oficinas ADO 


\section{Ubicación}

Inicialmente era periférica a la capital, pero con el paso de los años este quedó inmerso dentro de la urbe. Hoy en día se localiza a mitad de camino entre el centro histórico de la ciudad y el aeropuerto, lo que lo ubica en un punto céntrico y muy concurrido de la ciudad. Es por este motivo que se encuentra rodeado por tres avenidas principales. A pesar de encontrarse inmerso en la urbe, se encuentra bien articulado con las vías adyacentes y los sistemas de transporte masivo, evitando así grandes atascos. Sin embargo, al no contar con carriles exclusivos para llegar al terminal, sí debe prever la hora punta de tráfico en la ciudad, pues las vías arteriales podrán contar con congestión vehicular.

\section{$\underline{\text { Intermodalidad }}$}

El terminal cuenta con una serie de conexiones intermodales debido a su elevado número de usuarios. Si se analizan los sistemas de transporte masivo, el diseño contempló su integración con la estación San Lázaro del metro subterráneo de la ciudad, además de contar con una conexión adicional al sistema de trenes. También tiene una vía auxiliar para el servicio de buses urbanos, con una amplia zona de bahías. Tanto los vehículos privados como taxis tienen una vía diferenciada para el embarque y desembarque de pasajeros, fuera de las avenidas principales lo que evita la congestión en esta zona. Además, se cuenta con estacionamientos permanentes para los vehículos particulares. Finalmente, al encontrarse rodeado por dos avenidas muy concurridas en sus dos frentes principales, el terminal cuenta con una serie de puentes peatonales que sirven de crucero para el intenso tránsito de peatones. El comercio ambulatorio que existe en esta zona, obliga a los usuarios a movilizarse a través de túneles exclusivos para ingresar al terminal.

\section{$\underline{\text { Servicios complementarios }}$}

Se encuentran distribuidos dentro de la zona de salidas, bajo la cúpula central. En total se ofrecen 29 restaurantes para los usuarios, además de una serie de instalaciones comerciales como bancos, locutorios, cabinas de internet y tiendas de suvenires. De los terminales analizados es el único que cuenta con una zona exclusiva para los choferes, así como una zona para realizar el servicio de reparación de buses, las cuales se 
encuentran ubicadas en una serie de edificios independientes a los que se accede directamente desde el patio de maniobras.

\section{Espacio público}

No cuenta con un espacio público propiamente diseñado, ya que todas las aceras y zonas exteriores se encuentran atiborradas de comercio ambulatorio y efímero. Entre el área de conexión con el metro y la estación de trenes parten dos túneles que tienen la función de direccionar y llevar a los usuarios directamente hasta el terminal terrestre, evitando que salgan a la calle.

Dentro del terminal, la zona del patio de comidas funciona como espacio público interno, ya que cuenta con una zona de espera equipada con mesas y sillas para albergar a los usuarios, pero se limita su uso al horario de funcionamiento del terminal.

\section{$\underline{\text { Sistema estructural }}$}

La principal cobertura del terminal terrestre es el área central que se encuentra bajo una gran cúpula de 60 metros de diámetro, que tiene vigas curvas de concreto y una serie de paneles de plástico a manera de cerramiento. Estos cerramientos son transparentes permitiendo el ingreso de luz natural durante las horas de día. El edificio exterior y que delimita el patio de maniobras es de estructura tradicional en concreto, mientras que la zona de maniobras para los buses esta al aire libre. Los andenes de salida se encuentran cubiertos por un volado de vigas de concreto con cobertura transparente al igual que la cúpula central.

\section{$\underline{\text { Crecimiento }}$}

La estructura original no se ha modificado desde su construcción hace más de 35 años, pero la cantidad de buses que parten desde ahí se ha triplicado y en temporada alta es más de 6 veces su volumen original. 


\subsection{Referentes en países desarrollados}

\subsubsection{Terminal Terrestre de Nueva York, EEUU}

Según un artículo del New York Times en 1970, existían dos tipos de usuarios que atendían el terminal terrestre de buses en Nueva York: "Algunos esperan el bus. Otros esperan la muerte” 29 (Flegenheimer, 2013).

El terminal terrestre de Nueva York, Port Authority Bus Terminal, ha pasado por una serie de transformaciones desde los años 40 .

En 1939 habían 8 diversas empresas y sus respectivos terminales repartidos por Manhattan, agudizando la problemática en la ciudad de Nueva York con respecto al número de buses regionales que circulaban por esta. En 1946 el alcalde promueve una ley que prohíbe la proliferación de terminales independientes, y a la vez solicita al "Port Authority of New York and New Jersey" ${ }^{30}$ promover la implementación de un solo terminal terrestre que congregue las diversas empresas. El 27 de enero de 1949 se inicia la construcción del terminal central, con 9,000 toneladas de acero, más de 2 millones de ladrillos y una inversión de US\$ 24 millones, para ser inaugurado el 15 de diciembre de 1950. Diez años después, en 1960 se decide ampliar el terminal, agregándole tres pisos encima de la estructura original para albergar 1,000 estacionamientos más.

\footnotetext{
${ }^{29}$ Traducido del inglés: "Some are waiting for buses. Others are waiting for death"

${ }^{30}$ En 1921 el estado de Nueva York y el estado de Nueva Jersey se unifican para crear el "Port Authority of New York and New Jersey” con la finalidad de unificar todas las coordinaciones y gestión de los diversos puertos y terminales de la zona. Las consecuencias de una mala coordinación de la "CiudadPuerto" traía problemas relacionados a la vivienda, aumentaban los costos de vida y empeoraba la situación económica.
} 
Figura 34: Terminal Terrestre de Buses en Nueva York entre 1950 y 1960

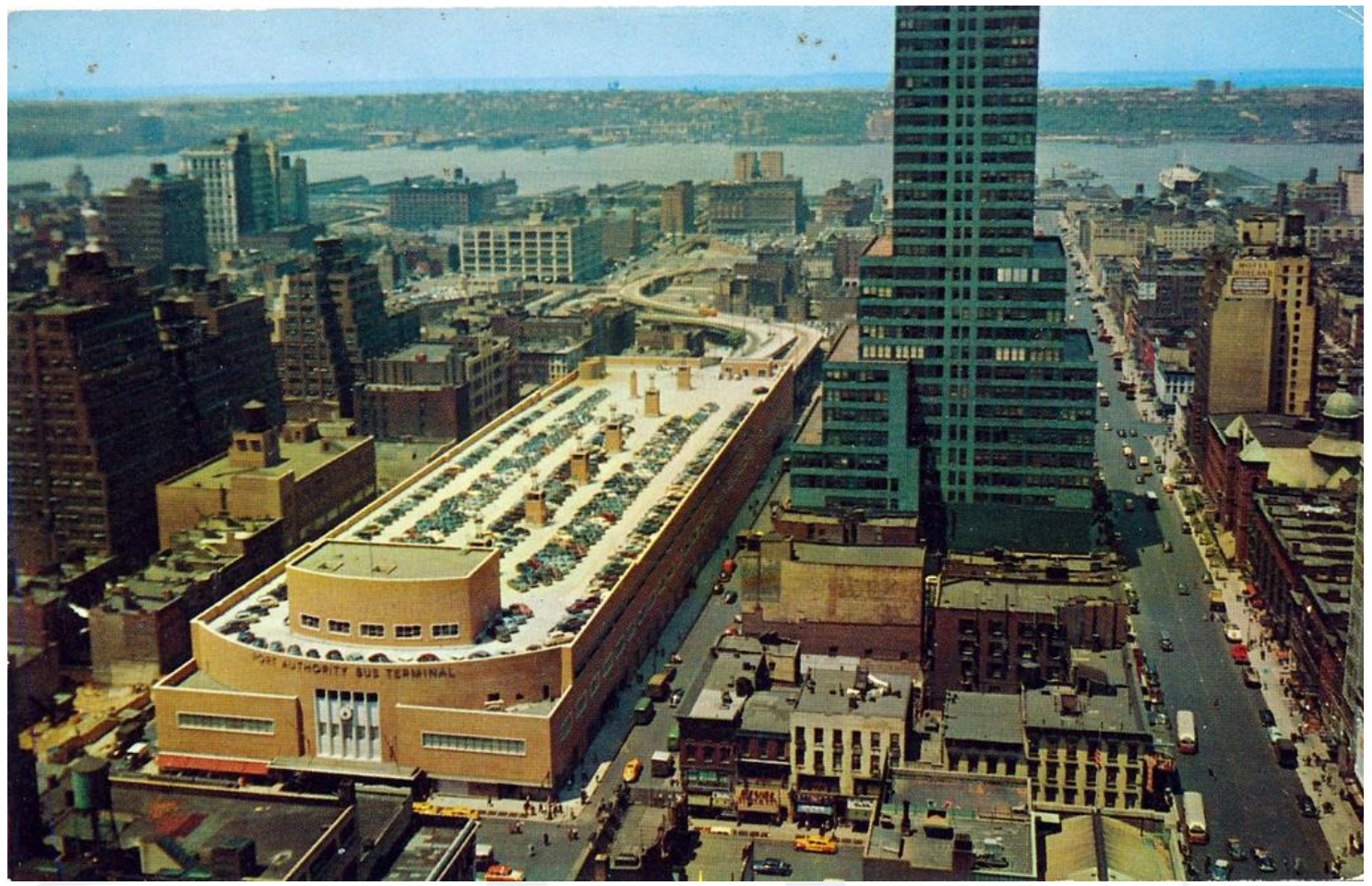

Fuente: SkyscraperPage.com (s.f.)

Obtenido de http://forum.skyscraperpage.com/showthread.php?t=160480

En el año 1966 se registraron 2.5 millones de buses y aproximadamente 69 millones de pasajeros utilizando el terminal. Sin embargo, cuatro años después en 1970, el tráfico y la congestión ocasionada por la gran demanda de buses llegó a su límite, por lo que el "Port Authority" decidió implementar una vía exclusiva para buses permitiéndoles atravesar la ciudad de manera más rápida, terminando en una conexión directa, como se aprecia en la siguiente figura. Esto aliviaría el tiempo de ingreso y salida de la ciudad, al igual que reduciría la congestión en las calles de Manhattan.

Entre los 70's y 80's sucedieron una serie de eventos, que eventualmente le generaron una mala reputación al terminal. Primero, el poder económico del ciudadano promedio se elevó, incrementando el uso de viajes aéreos en vez de terrestres. Eso redujo el número de usuarios en el terminal dejándolo con vacíos que se prestarían para actos criminales o para ser ocupados por vagabundos. Adicionalmente se redujo el número de automóviles que acudirían al estacionamiento ubicado en el techo del terminal. Al quedar desolado se prestaba para prostitución y violaciones (McCormick, 2014). 
A medida que la zona aledaña, conocida como el distrito de teatro o "Broadway", iba mejorando su reputación y atraía cada vez más visitantes, se decidió mejorar la atención del terminal y su seguridad. Una de las primeras acciones, fue la de reubicar a todos los vagabundos de la zona en refugios y reforzar la seguridad del terminal. Luego se buscó trabajar con una ONG "Project for Public Spaces" para mejorar ingresos y flujos, entre otros (Port Authority of NY \& NJ, s.f.).

A inicios de los años 80, se decide ampliar la capacidad del terminal en un 50\% para atender la demanda, agregando 52 plataformas de buses y un centro comercial de 70 tiendas a un extremo del complejo. Esto, en conjunto con las acciones previas, serviría para reducir la inseguridad y la criminalidad.

Figura 35: Terminal Terrestre de Buses en Nueva York hoy

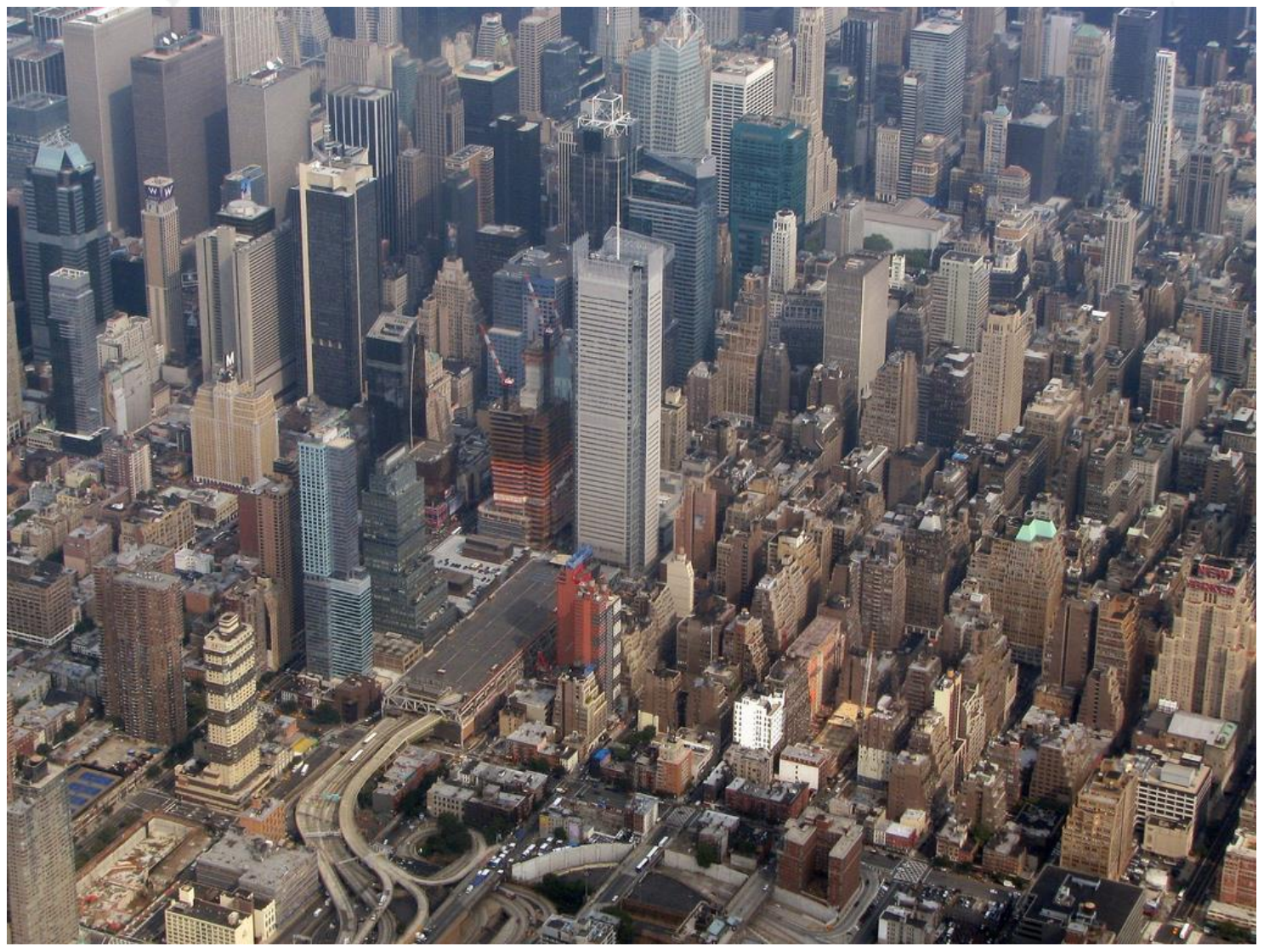

Fuente: SkyscraperPage.com (s.f.)

Obtenido de http://forum.skyscraperpage.com/showthread.php?t=160480

Según la página web de la administración (Port Authority of New York and New Jersey), en el 2014 se registraron 66 millones de pasajeros de buses en el terminal. 
Además, en ese mismo año se asignó un presupuesto de aproximadamente US\$ 90 millones para renovar el terminal y mejorar su rendimiento, ya que actualmente trabaja por encima de sus capacidades. Al ser un punto intermodal, que se conecta con el sistema de metro de la ciudad, recibe automóviles privados, taxis, etc. Es sumamente transitado, con aproximadamente 230,000 pasajeros al día y con una proyección de 35$51 \%$ de incremento para el 2040. Actualmente tiene serias dificultades para atender los picos, generando retrasos en los horarios de los buses e insatisfacción en el usuario.

Adicionalmente se estima que la estructura antigua del terminal no debe ser usada por más de 15-25 años, ya que se han empezado a encontrar puntos deteriorados. Esto tiene una serie de complicaciones: en la actualidad, el mantenimiento de las instalaciones es caro, precisamente por tratarse de materiales viejos, entre otros. Por otro lado, la rehabilitación de la estructura sería un reto ya que requeriría reestructuraciones completas del edificio, lo cual no permitiría el uso de las instalaciones durante las renovaciones (Port Authority of New York and New Jersey, s.f.). 


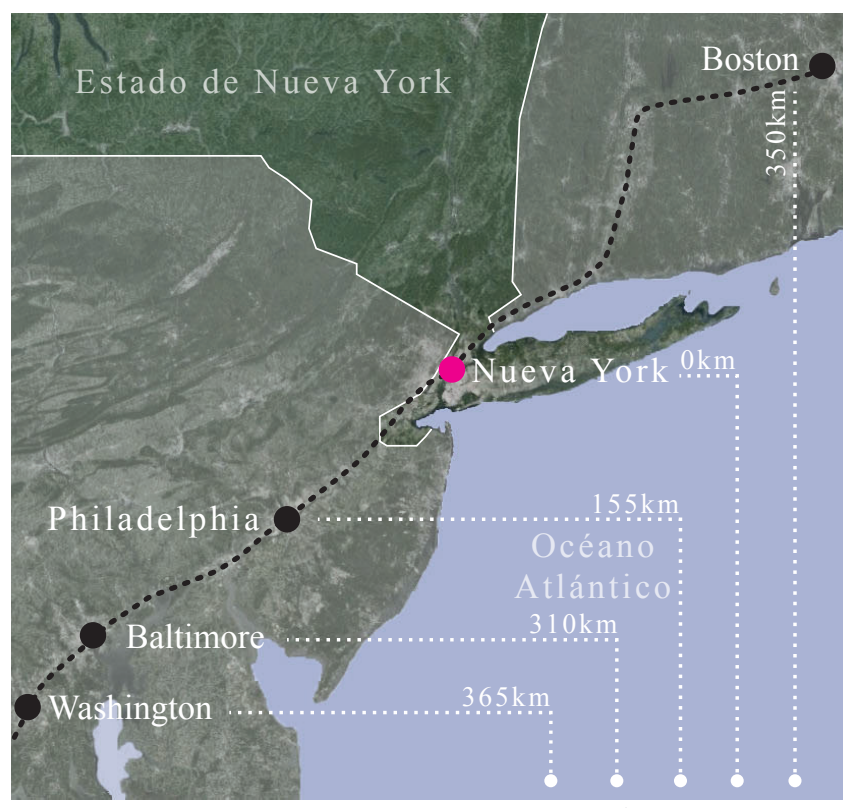

$\Sigma \Sigma \Sigma \Sigma \Sigma$
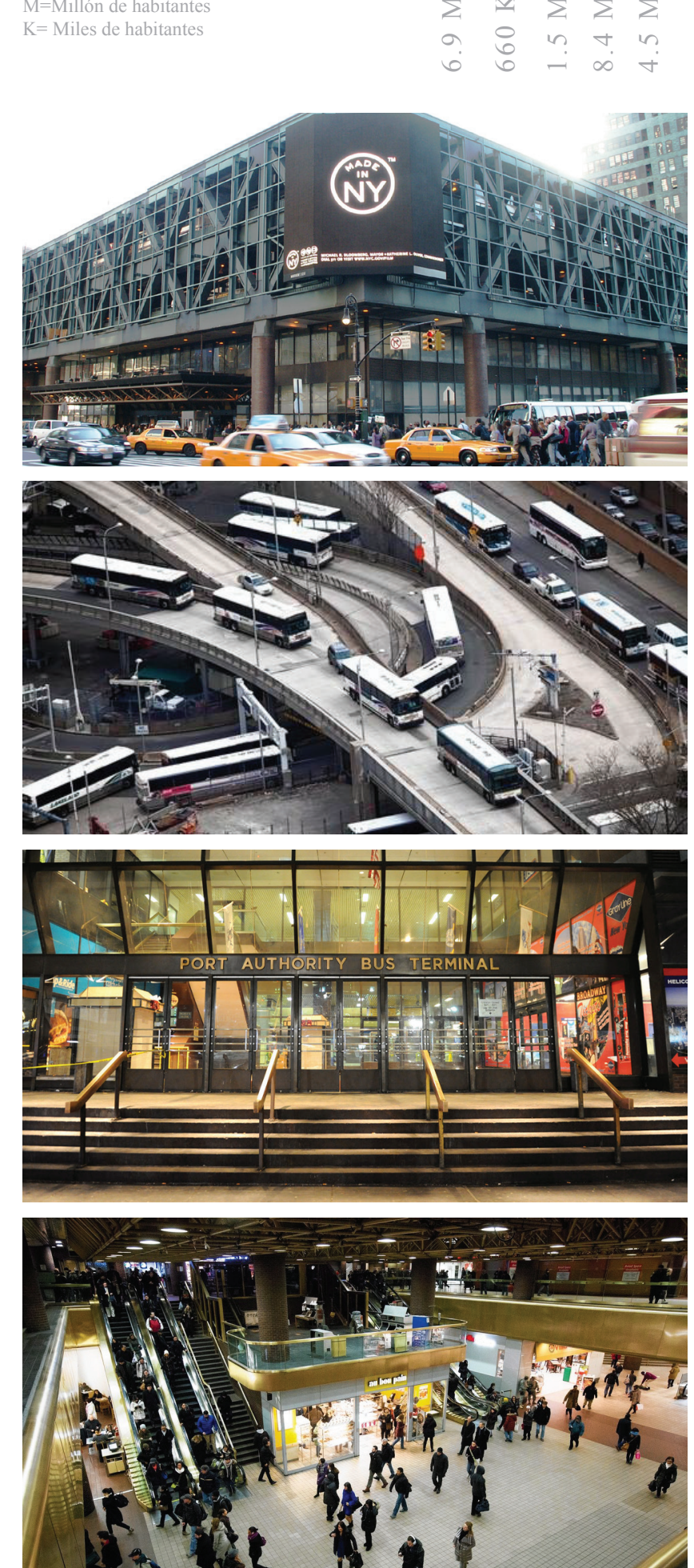

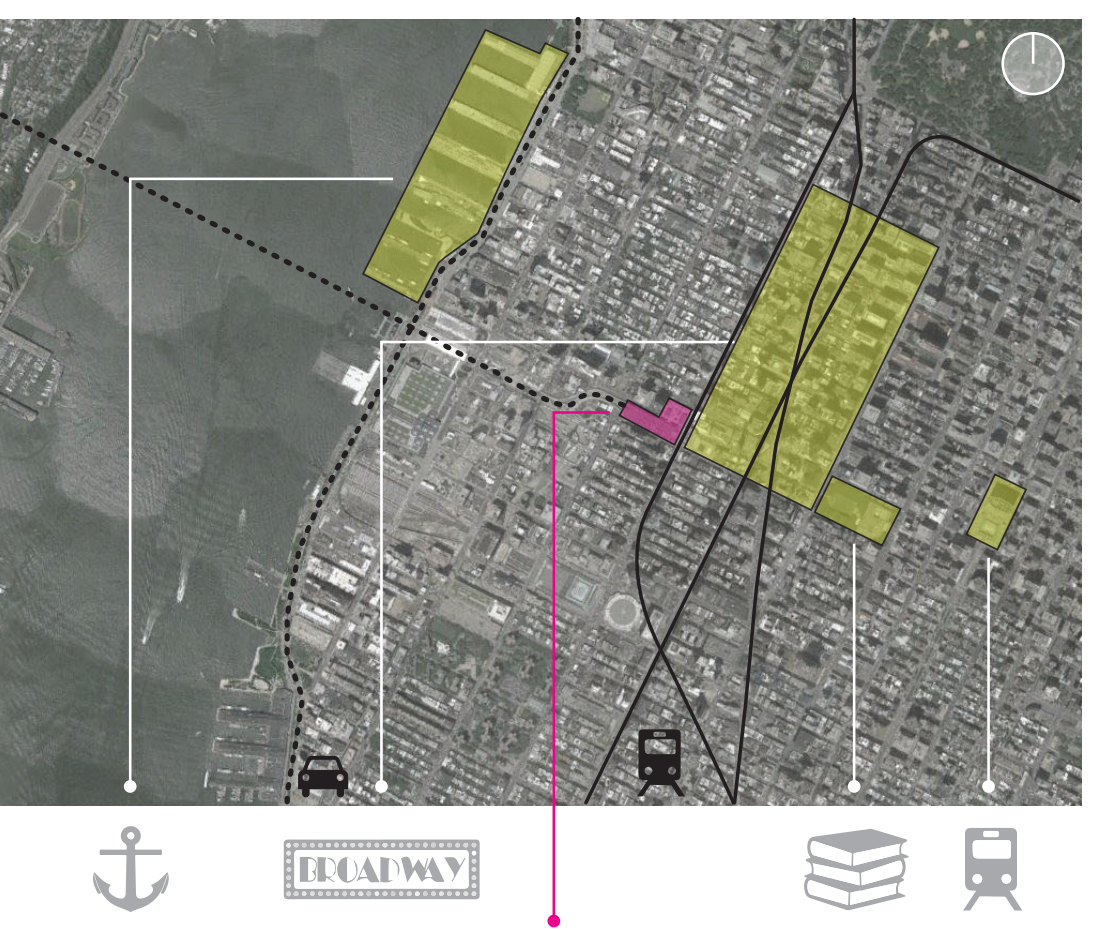

D1 Construcción: 1950,1963,1979, NYNJ Arquitecto: -

Programa
P Parking

Farmacia

带 Supermercado

$\therefore$ Bowling U s o

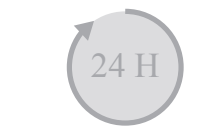

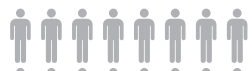

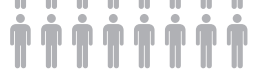
230000 usuarios
Retail

|W Restaurantes

프 Bancos

䍩 SSHH

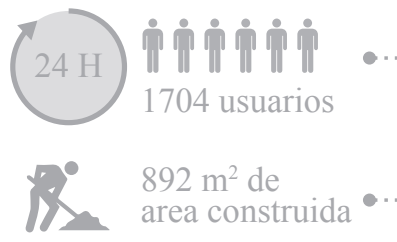

를
Administración

is Oficinas
Nondo

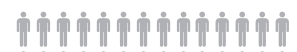

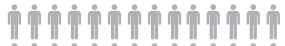

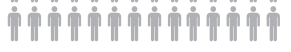
66000000 usuarios
135 andenes

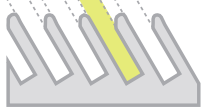

por cada andén

Esquema de funcionamiento: sección longitudinal

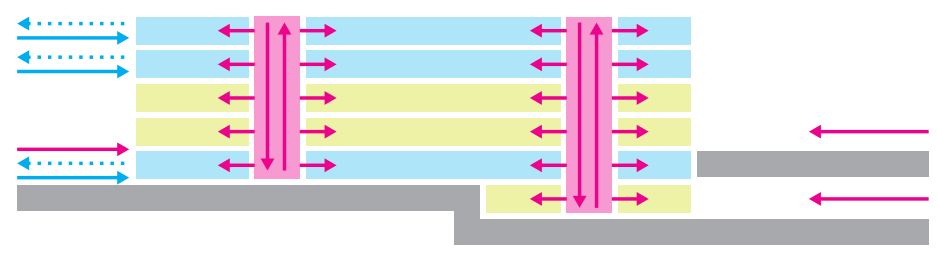

$\begin{array}{lll}\text { Nucleo circulación } & \longrightarrow & \text { Ingreso buses } \\ \text { Zona comercial } & \cdots & \text { Salida buses }\end{array}$ 
Nive $1-1^{\circ}$

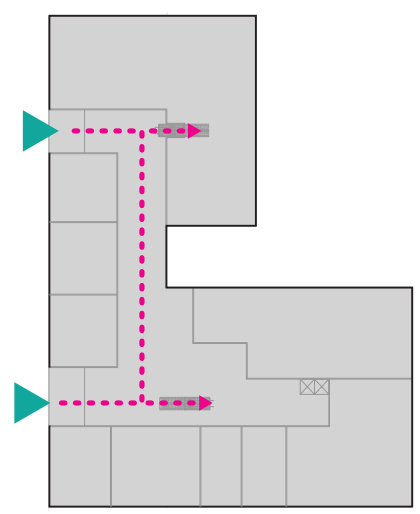

- Ingreso buses

- Ingreso peatones

- Conexión metro

- Carril buses urbanos

Carril taxis

- Carril ciclistas
Ocupación del terreno

Terreno: $22635 \mathrm{~m}^{2}$

Area ocupada: $22635 \mathrm{~m}^{2}$

Area libre: $0 \mathrm{~m}^{2}$

$100 \%$

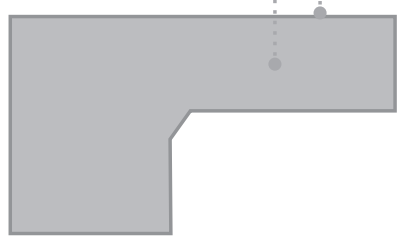

Repartición del proyecto: 6 niveles

Area del proyecto: $120391 \mathrm{~m}^{2}$

Patio de maniobras: $39502 \mathrm{~m}^{2}$

Usuario + Admin.: $78210 \mathrm{~m}^{2}$

Conexión urbana: $2678 \mathrm{~m}^{2}$

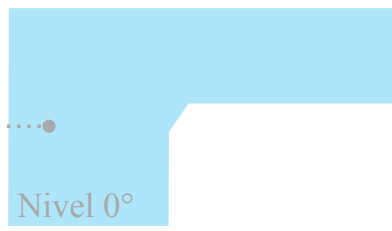

Nivel $1^{\circ}$
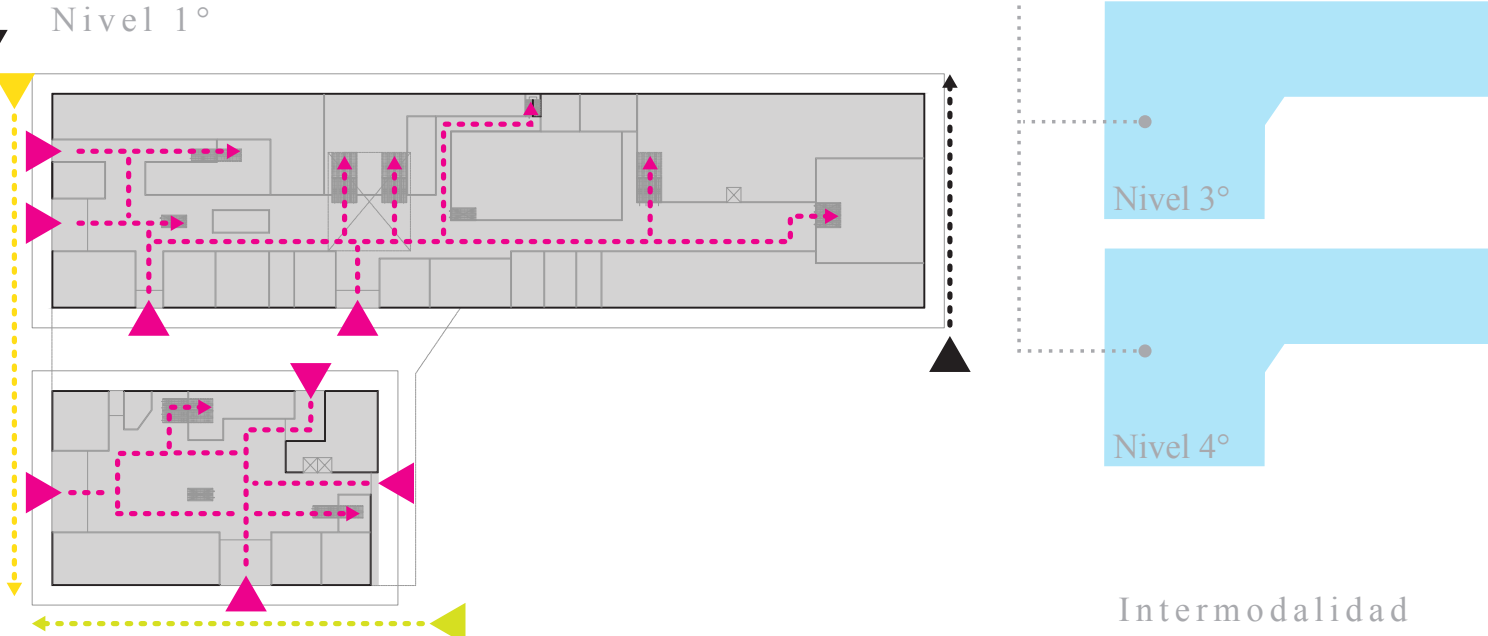

Intermodalidad

S Metro

A Auto particular

Pि Taxis

Buses urbanos

क하 Ciclovía
Area construida

Comercio +

Oficinas

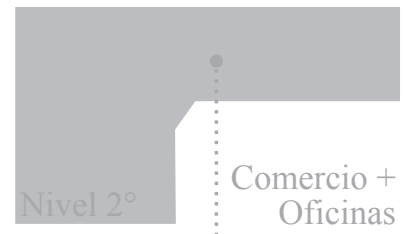

Oficinas

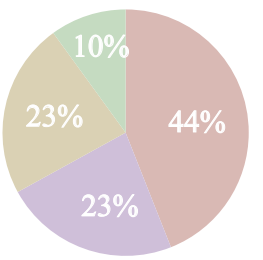

Comercio + administración

Embarque + desembarque

Circulación

Otros + áreas verdes

*Area construida no incluye cubierta: estacionamiento de autos particulares 


\section{Ubicación}

Este es un buen ejemplo para un terminal que se ubica en el centro de la ciudad sin congestionarla. Esto se da gracias a la vía arterial que lo articula con las afueras sin interrumpir ni ingresar a las calles de la metrópolis. Se trata de carriles exclusivos en el Lincoln Tunnel para el ingreso de autobuses a la isla de Manhattan, que desembocan casi directamente en el terminal. Esta situación es beneficiosa para el usuario, pues termina su viaje en un punto sumamente céntrico con múltiples posibilidades de conexiones, ya sea mediante líneas del metro, taxis, autos particulares u otros.

\section{Intermodalidad}

Se da principalmente mediante la conexión directa con dos líneas distintas del metro. Al encontrarse el desembarque de buses en los últimos niveles de la edificación, y la conexión con el metro en el nivel subterráneo, se trata de una conexión óptima ya que solo requiere movilizarse en sentido vertical. Esto también aplica para el usuario que busca llegar al estacionamiento de autos particulares, ubicado en la cubierta del edificio con 1,500 espacios disponibles. Los desplazamientos del usuario se reducen drásticamente gracias a esto. La conexión con el nivel de la calle también es igual de efectiva, pero es importante hacer énfasis en que la intermodalidad con respecto a los taxis no es óptima, pues no cuenta con las bahías necesarias. En uno de sus laterales cuenta con una parada de buses urbanos al igual que con múltiples estacionamientos de bicicletas de la ciudad. Desde esta parada parten buses al aeropuerto de Newark, aportando aún más a la intermodalidad del terminal.

\section{$\underline{\text { Servicios complementarios }}$}

Después de su remodelación en los años 80, se incorporó un centro comercial con 70 diferentes puestos de venta, restaurantes, comida al paso y otros. Esto se llevó a cabo con la intención de reactivar el terminal, que años antes había sido invadido por delincuencia y vagabundos. En la actualidad se trata tanto de una estación de buses como del metro, por lo que cuenta con actividad constante de pasajeros, así como también el gran porcentaje de usuarios que entran en busca de algún producto. Adicionalmente cuenta con una pista de bolos. También es importante resaltar que, al 
encontrarse en pleno Manhattan, está rodeado por diversos tipos de comercio y usos como oficinas, vivienda, entretenimiento y otros.

\section{Espacio público}

La infraestructura tiene un carácter público, en el sentido que las personas tienen la libertad de circular libremente por dentro de este. Sin embargo, no se encuentra particularmente preparado para la recreación libre que normalmente atiende un espacio público. Esto se debe a que se parece mucho a cualquier estación central de trenes subterráneo: edificaciones predominantemente cerradas, en las que las principales actividades son las de caminar o consumir productos al paso. Los únicos espacios para descansar o reducir el ritmo son restaurantes y cafeterías o salas de espera, las cuales son de acceso restringido. Los alrededores del terminal son calles sumamente transitadas y activas, que también carecen de espacios públicos para parar y descansar, creando un patrón para la zona, en la cual uno debe consumir para poder descansar.

\section{$\underline{\text { Sistema estructural }}$}

Fue construido con una estructura de acero con tabiques de ladrillos, luces cortas y poco contacto con el exterior. El terminal es, en sí, un común edificio de pocos niveles. Al albergar los andenes dentro de este mismo, la circulación de los buses se da dentro de la estructura existente, sin la necesidad de generar grandes patios de maniobra que requieren cubiertas complejas de estructurar. El estacionamiento temporal de buses se compone de varios terrenos de menor escala repartidos en los alrededores del terminal, que no cuentan con ningún tipo de cubierta ni protección a la intemperie.

\section{Crecimiento}

Ha sido remodelado tres veces, ampliando cada vez más su capacidad, inicialmente de autos particulares, zona de comercio y luego también de buses. En la actualidad se ha aprobado un presupuesto de 90 millones de dólares para una nueva ampliación, ya que está trabajando por encima de sus capacidades. 


\subsubsection{Terminal Terrestre de Múnich, Alemania}

La ciudad de Múnich, capital de la región de Bavaria, cuenta con aproximadamente 2.8 millones de habitantes y es la ciudad más grande y poblada de la región, además de ser la tercera ciudad más grande de Alemania (Bayerisches Landesamt für Statistik und Datenverarbeitung, 2014). Adicionalmente se trata de la ciudad más cara para vivir dentro de Alemania, teniendo que pagar más de 10 Euros por $\mathrm{m}^{2}$ por alquiler. Esto es $65 \%$ más alto que el promedio (Spiegel Online Wirtschaft, 2014). También se trata de una ciudad sumamente turística por su cultura, festividad y arquitectura. En el año 2009 se registró un ingreso de casi 5 millones de personas a la ciudad. De estas, aproximadamente un 50\% eran extranjeros (Landeshauptstadt München, 2011). Por otro lado, en el 2014 se registró que aproximadamente 13.4 millones de personas pasaron la noche en algún tipo de hotel, hostal o pensión (München: Das offizielle Stadtportal, 2014).

El 11 setiembre del 2009 se completa el "Terminal Central de Buses de Múnich" ${ }^{31}$, también conocido como ZOB. Con un programa mixto de oficinas, comercio, una discoteca en el sótano y 29 puertas de embarque, está preparado para recibir 160 buses al día, 50,000 buses al año y atiende líneas internacionales. Algunos de los destinos nacionales incluyen Berlín, Hamburgo y muchas otras ciudades, y destinos internacionales como Innsbruck, Praga o Zagreb (Muenchen: Das offizielle Stadtportal, s.f.). Ha sido diseñado contemplando la intermodalidad, permitiendo al usuario trasladarse fácilmente a la línea de "Tram", "SBahn” y la autopista.

Se trata de una estación transcurrida por 30,000 personas al día entre los múltiples usos que alberga. Con respecto al tránsito de personas que llegan mediante buses, está diseñado para recibir entre 8,000 y 10,000 personas al día y 2.5 millones de personas al año. La gestión del terminal ha sido delegada a la Cruz Roja de Bavaria y cobran una tarifa a cada bus que utiliza el terminal. Esto incentiva la puntualidad, pues mientras más se demore, más debe pagar.

El terminal ocupa un área aproximada de $25,000 \mathrm{~m}^{2}$ con 170 estacionamientos para autos privados, una zona comercial con 19 tiendas, 6 establecimientos gastronómicos y puestos de venta de pasajes de bus. El diseño, desarrollado por el estudio de arquitectura "Auer + Weber + Assoziierte”, contempla una planta libre que

\footnotetext{
${ }^{31}$ Traducido del alemán: "Zentraler Omnibusbahnhof München"
} 
sirve para la circulación y embarque de los buses, con diversas escaleras de acceso. Luego, en el segundo piso, se encuentra el área comercial y gastronómica, con diversas terrazas en el exterior para el usuario. En total cuenta con siete pisos, en los que se reparten los usos previamente mencionados, además de oficinas. La envoltura del edifico se estructura con aluminio y las conexiones con otros medios de transporte se dan de manera directa, mediante escaleras eléctricas, puentes y caminos. Además, cuenta con una plaza pública previa al ingreso (Zentraler Omnibusbahnhof München, s.f.).

Figura 36: Terminal Terrestre Múnich

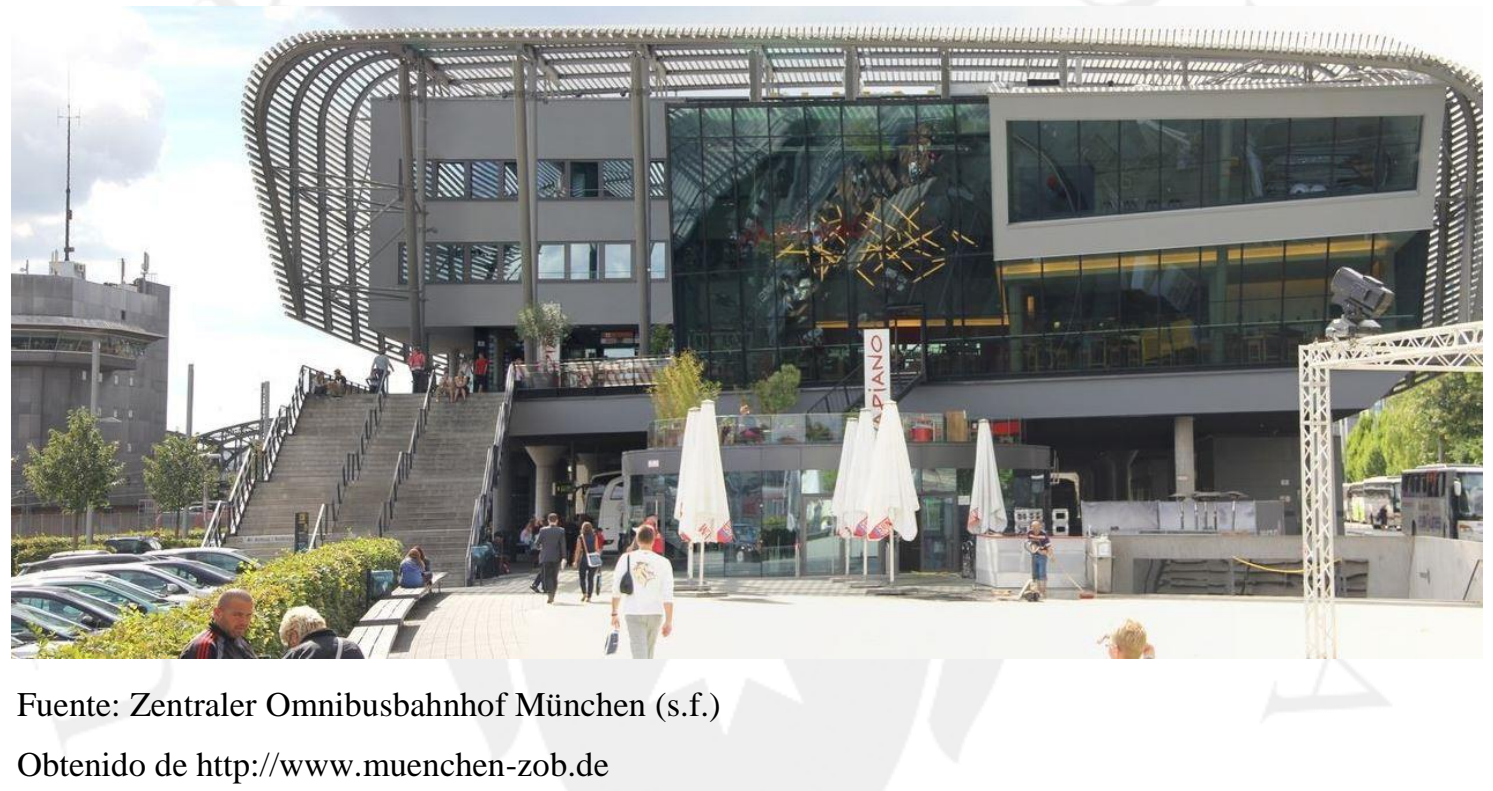



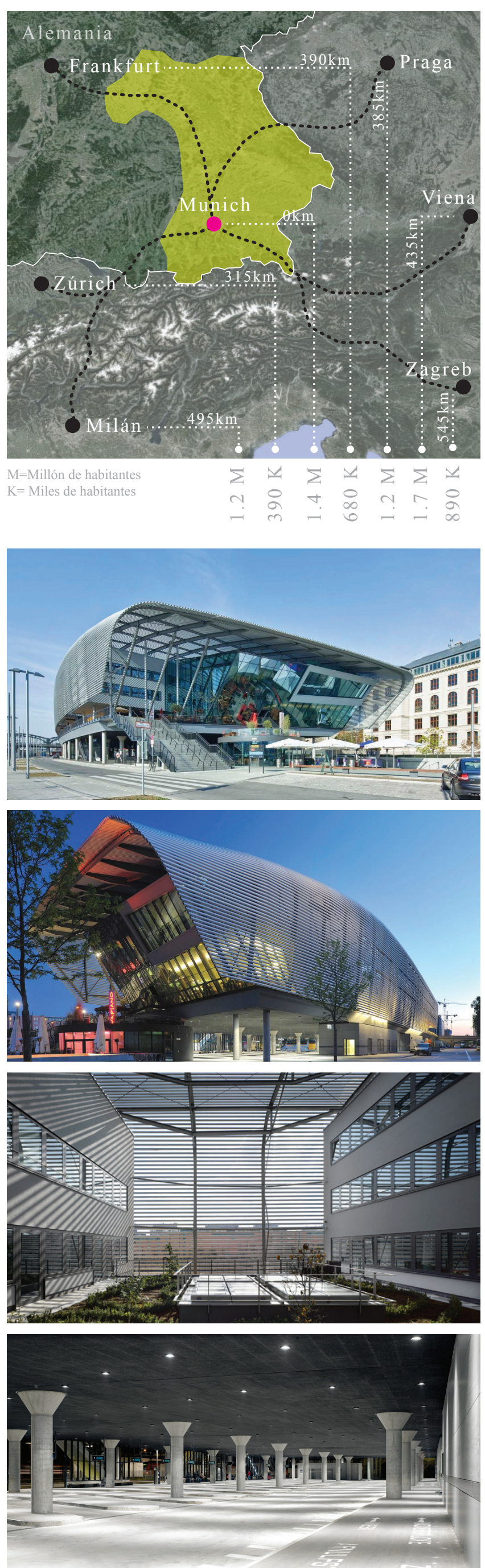

\section{Programa}

P Parking

$\left[\begin{array}{l}7 \\ 0\end{array}\right]$ Farmacia

曲 Supermercado

$£$ Discoteca

U s o

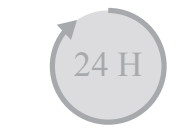

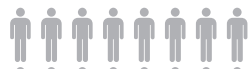

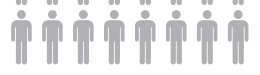

8000 usuarios

(24 H) ำ กำ กำ กำ

area construida
重 Venta de pasajes

W Restaurantes

Administración

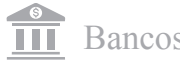

* Oficinas

ヘิ๊ $\mathrm{SSHH}$

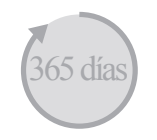

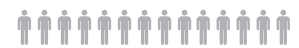

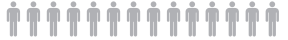

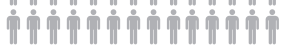

2500000 usuarios

MMll

29 andenes

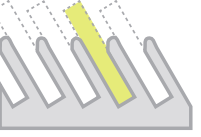

por cada andén

Esquema de funcionamiento: sección longitudinal

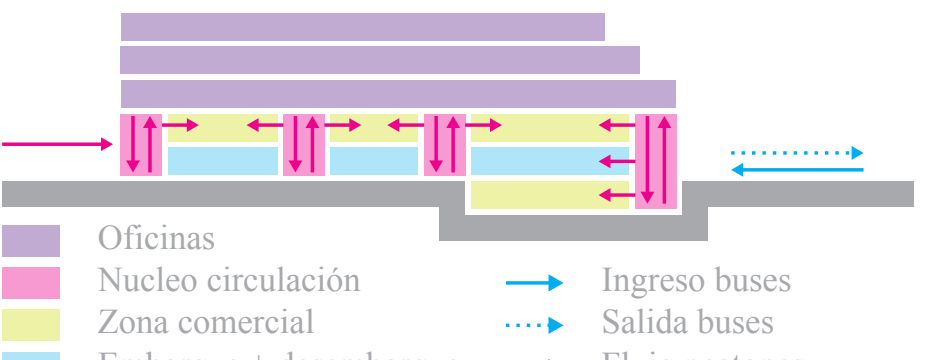




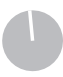

Nive $11^{\circ}$

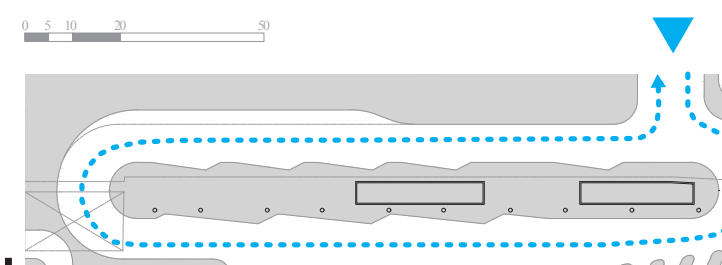

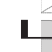

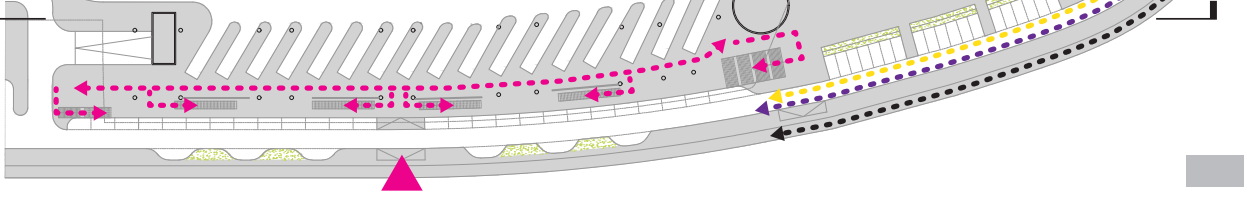

- Ingreso buses

Ingreso taxis

$\triangle$ Ingreso peatones

A Ingreso ciclistas
Ocupación del terreno

Terreno: $15139 \mathrm{~m}^{2}$

Area ocupada: $5207 \mathrm{~m}^{2}$

Area libre: $9931 \mathrm{~m}^{2}$

Repartición del proyecto: 6 niveles

Area del proyecto: $31473 \mathrm{~m}^{2}$

Nivel $2^{\circ}$

Patio de maniobras: $4273 \mathrm{~m}^{2}$

Area construida*: $20267 \mathrm{~m}^{2}$

Conexión urbana: $6933 \mathrm{~m}^{2}$

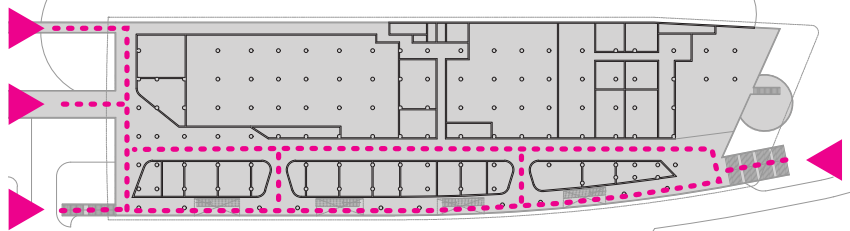

Nivel $3^{\circ}$

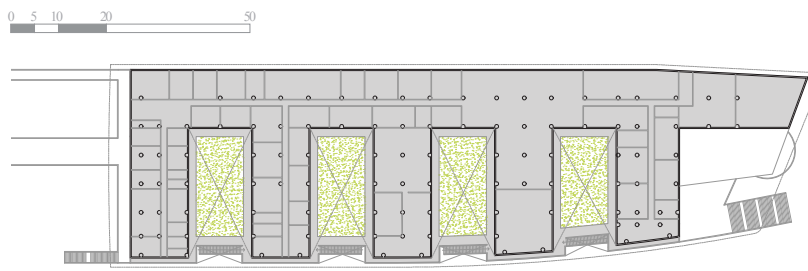

Nive $14^{\circ}$

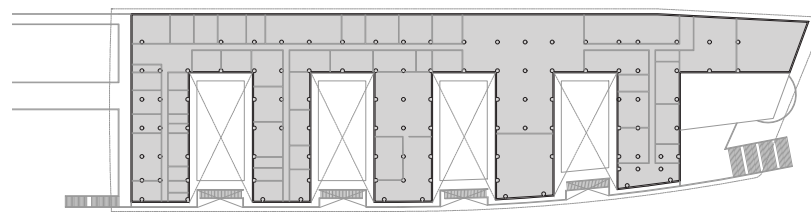

Nive $15^{\circ}$

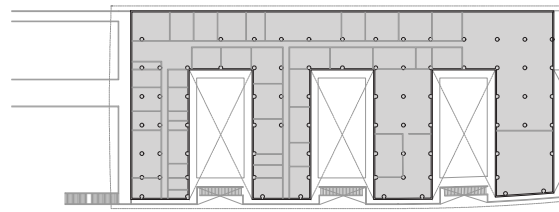

Oficinas

Area de oficinas: $11127 \mathrm{~m}^{2}$

* Area construida no incluye sótanos: estacionamiento de autos particulares ni discoteca 


\section{Ubicación}

Se encuentra en una zona relativamente céntrica de la ciudad, pero vinculada a una avenida principal que permite ingresar o salir fácilmente de la parte urbana. Su ubicación es ventajosa gracias a la fácil conexión con el sistema de trenes y tranvía. En la misma zona se encuentran múltiples hoteles, instituciones educativas y demás.

\section{$\underline{\text { Intermodalidad }}$}

Cuenta con una conexión directa al sistema de tranvías y a la estación de trenes de la ciudad. Se conecta al sistema de trenes mediante un puente y además incorpora estacionamientos particulares y una zona de recojo y desembarque de pasajeros para taxis y autos. La intermodalidad también se da en un ámbito peatonal al incluir sistemas de transporte más preferidos como lo son las bicicletas. La conectividad con todos estos medios es buena, pero se debe recalcar que la facilidad con la que uno pasa de un sistema al siguiente es menos directa, ya que son recorridos más extensos con elementos que dificultan la circulación, como lo son escaleras, puentes, etc.

\section{Servicios complementarios}

El edificio consta de seis niveles; el primero para el embarque y desembarque, el segundo para locales comerciales y los siguientes para funciones administrativas y oficinas. El segundo nivel se distribuye como un corredor, con ambos lados implementados con comercio, boleterías y diversos puntos de comida. En el sótano se incluyó una discoteca a la cual se accede desde la plaza pública del terminal.

\section{Espacio público}

En uno de los extremos del proyecto se ubica una plaza activada con un restaurante que aprovecha la explanada. Este funciona como un espacio previo al ingreso que se da mediante unas escaleras a la intemperie y que conecta el exterior con el interior comercial del proyecto. Además, se encuentran pequeños espacios de diversas dimensiones, para el uso del ciudadano. En el interior del edificio se genera un corredor comercial, espacio que podría considerarse de carácter público hasta que cierran los ingresos. Además, cuenta con una serie de patios internos que buscan cubrir la 
necesidad de los empleados que trabajan en las oficinas, abriendo un espacio de respiro y descanso de carácter semi-público.

\section{$\underline{\text { Sistema estructural }}$}

La piel que envuelve este terminal cumple funciones estéticas al igual que funcionales. Se trata de un elemento que envuelve el edificio en forma de costillar, para luego recibir una trama de tubos de aluminio en un sentido longitudinal. Este sirve, por sus laterales, como parasoles y en su totalidad como un elemento con características formales. Por lo demás, el edificio se estructura mediante un sistema tradicional de concreto armado con una planta libre para la fácil circulación de los buses.

\section{$\underline{\text { Crecimiento }}$}

Este terminal, al ser relativamente nuevo, operó durante un tiempo significativamente por debajo de sus capacidades. En los últimos años el número de usuarios se ha ido incrementando, pero sin llegar a su capacidad máxima. Es decir, cuenta con un margen para utilizar, antes de superar su capacidad de funcionamiento. 


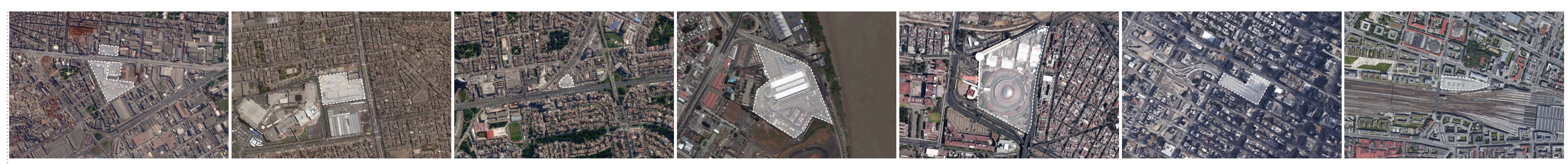

(

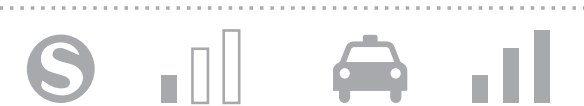
帛 ॥l
自 II
由.
(5) II คी
(5) II
帛
(5)
帛川
谓 II
嗢 , II
得 II
阳
自 II
Iram ı니
百 II
舅, II
㧢 II

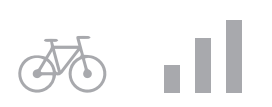

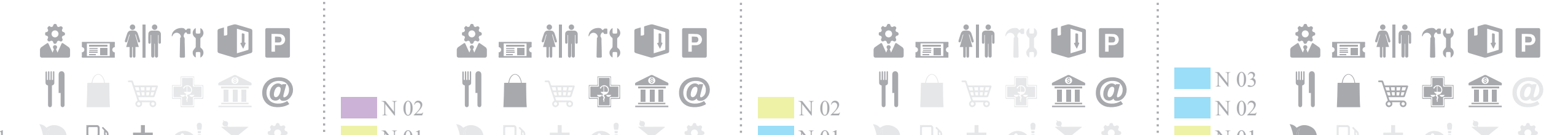
总国粗祝四口

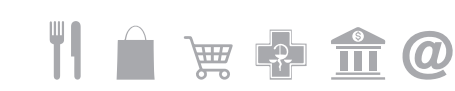

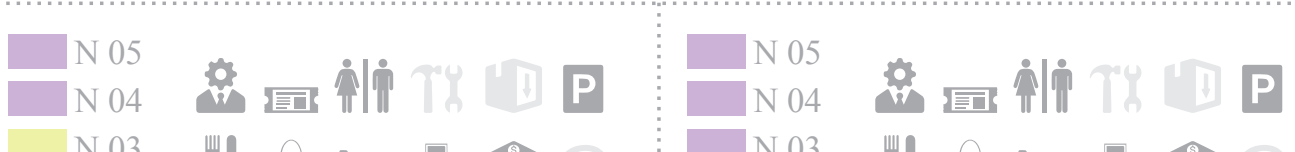 ${ }^{\mathrm{N}} \mathrm{N}$

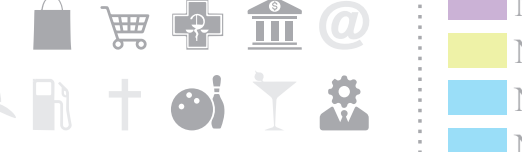

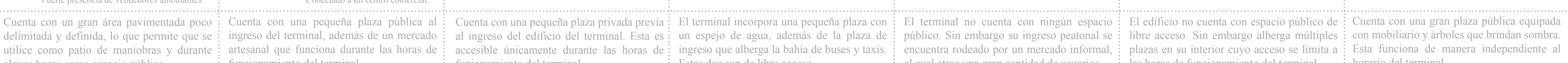
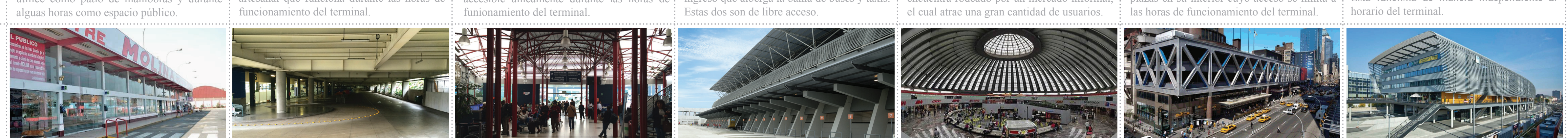

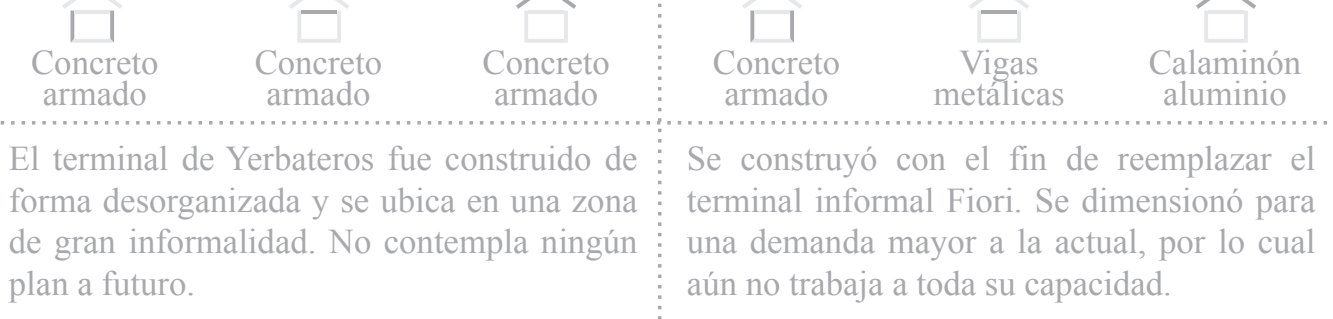

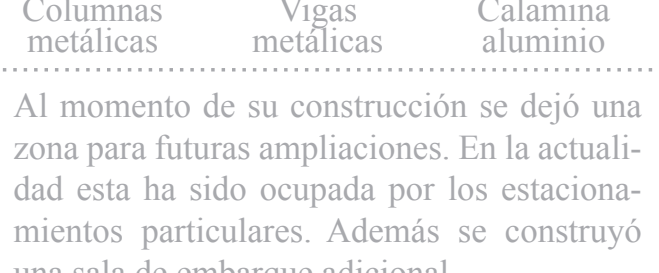

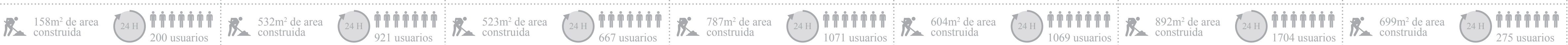




\subsection{Referentes de espacio público}

\subsubsection{Zhengzhou Vanke Central Plaza, China}

En el 2013, Locus Associates; un estudio de arquitectura en Hong Kong, recibe el encargo por parte del complejo de vivienda, comercio y oficinas "Zhengzhou Vanke" de diseñar un espacio público de $10,500 \mathrm{~m}^{2}$, que además se conectaría con los diversos equipamientos. Está pensado para diversas actividades con la finalidad de integrar a los vecinos y también al transeúnte común. Para esto fue vital considerar y entender al usuario de la zona, por lo que tuvieron que tomar en cuenta la diferencia entre la cultura occidental y la oriental, ya que en la occidental los encuentros casuales y la interacción entre desconocidos son bastante comunes. La cultura oriental por otro lado, especialmente la china es más introvertida, pero sí aprovechan la oportunidad para hacer taichí u otras actividades. El objetivo del proyecto fue la de implementar la plaza con la mayor cantidad de actividades, que pudieran atender una gama amplia de intereses, desde el más joven al más anciano. Se utilizaron palestras para niños, zona de patineta, juegos para niños, una pileta y muchos más, pero todos acompañados por espacios para descansar o sentarse, de manera que se cultive la observación de las actividades, o como lo mencionan los arquitectos "ver-y-ser-visto" 32 . Por otra zona se aplican espejos de agua y áreas verdes, creando una barrera/descanso natural entre la zona comercial y la zona recreativa.

\footnotetext{
32 Traducido del inglés: “see-and-be-seen” (Locus Associates, 2014).
} 
Figura 37: Espacio público - Zhengzhou Vanke Central Plaza

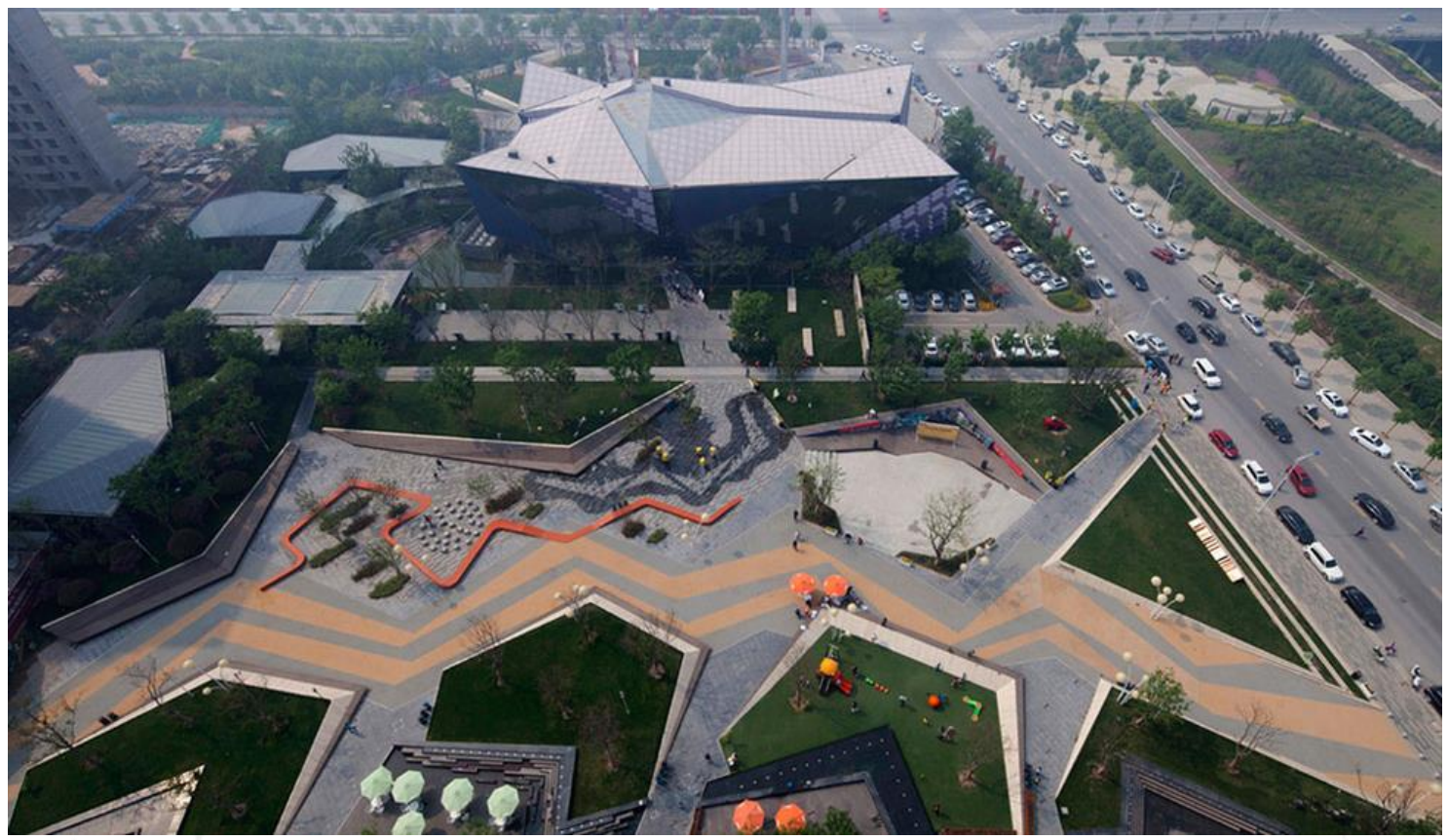

Fuente: Locus Associates (2014), fotografía de Béton Brut

Obtenido de http://www.locusassociates.com/project/zhengzhou-vanke-central-plaza/

El diseño considera una circulación perimetral además de conexiones intermedias y "atajos" para fomentar la fluidez del peatón y evitar circulaciones "anti naturales". También se trabajó cuidadosamente con los niveles de la topografía para generar algunas zonas de resguardo y otras que canalizaran el flujo de la gente. En conjunto con el agua, se crean diferentes calidades de espacios, tanto de juego como de aislamiento (Locus Associates, 2014). 


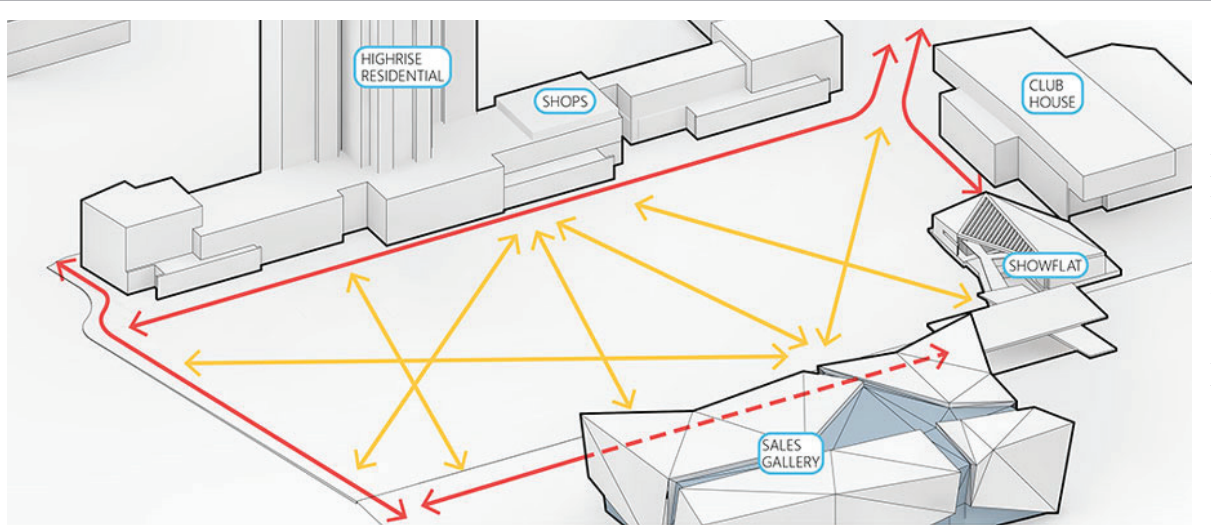

Circulación

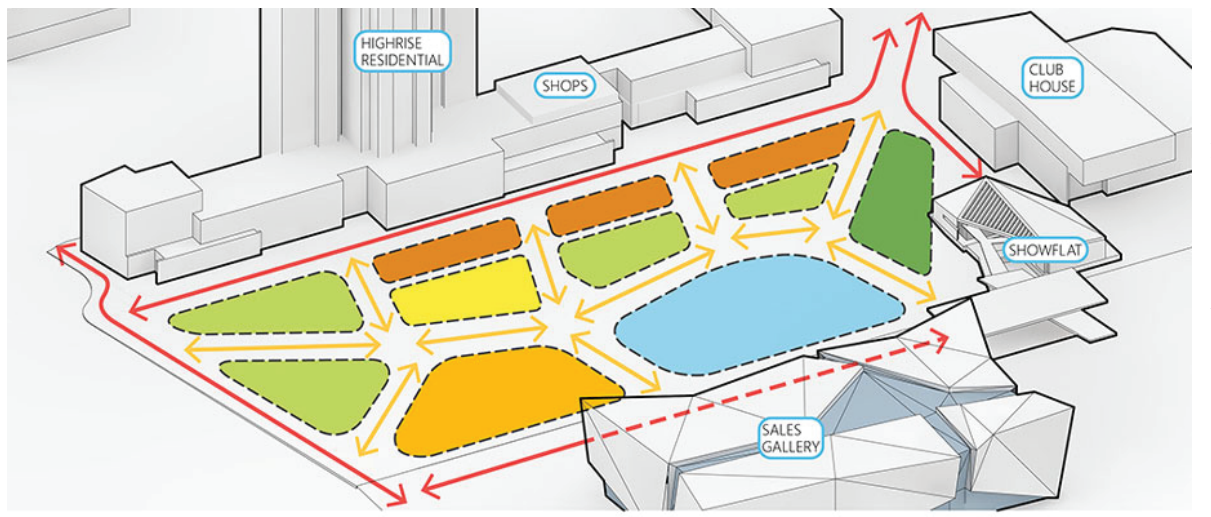

Programa

La plaza tiene como entorno uno de los puntos con mayor actividad comercial y económica de la zona, convirtiéndola en un punto de encuentro para una gran diversidad de usuarios. Por este motivo se decidió atender la mayor cantidad de intereses con un programa variado. Luego se juntó la distribución general del programa con la trama inicial de circulación, botando así una serie de espacios de diversas escalas, formas y usos.

GREen BUFfer

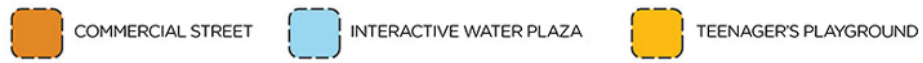

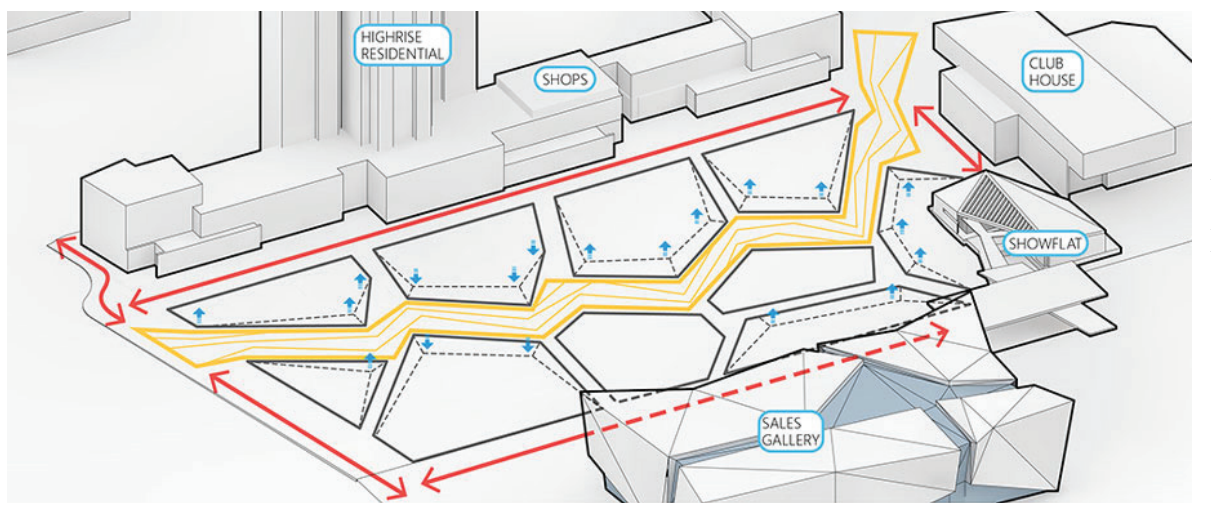

Topografía y forma

El diseño del camino principal se inspiró en la cultura local que cree en los flujos de energía y la buena armonía. Luego se trabajó la topografía para poder generar diferentes situaciones; en algunos casos se generan espacio resguardados, en otros se canaliza el flujo y también se trabaja con las visuales del espacio.

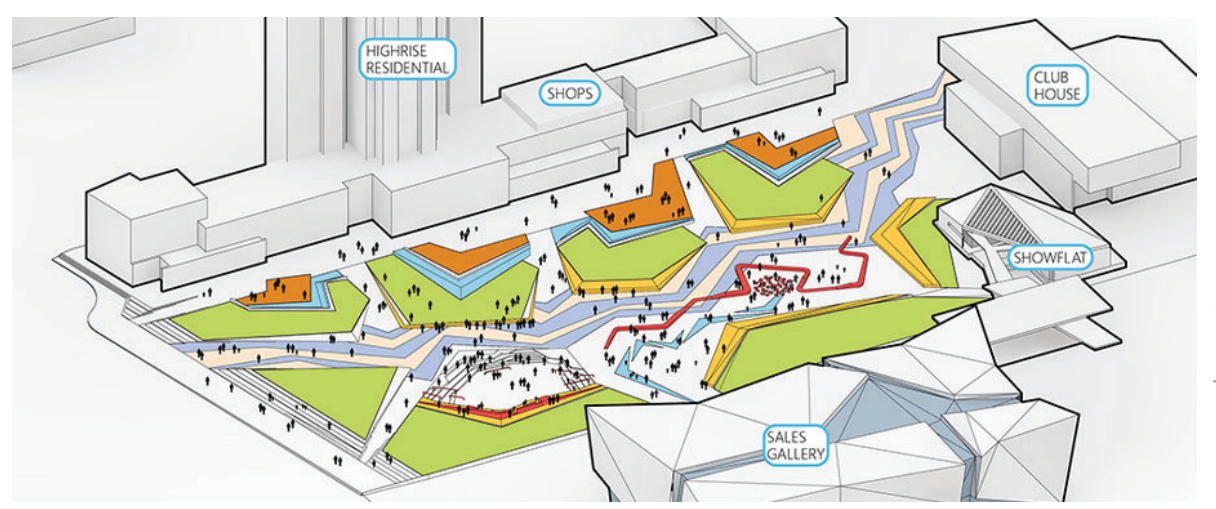

Agua y actividad

Para el diseño se utilizó el agua en diferentes formatos; espejos de agua, fuentes e incluso fuentes diseñadas para que los niños jueguen en ellas. Adicionalmente se diseñó el mobiliario de la plaza con múltiples usos y como conector de espacios; una banca puede servir como mesa y como plataforma de juego, etc
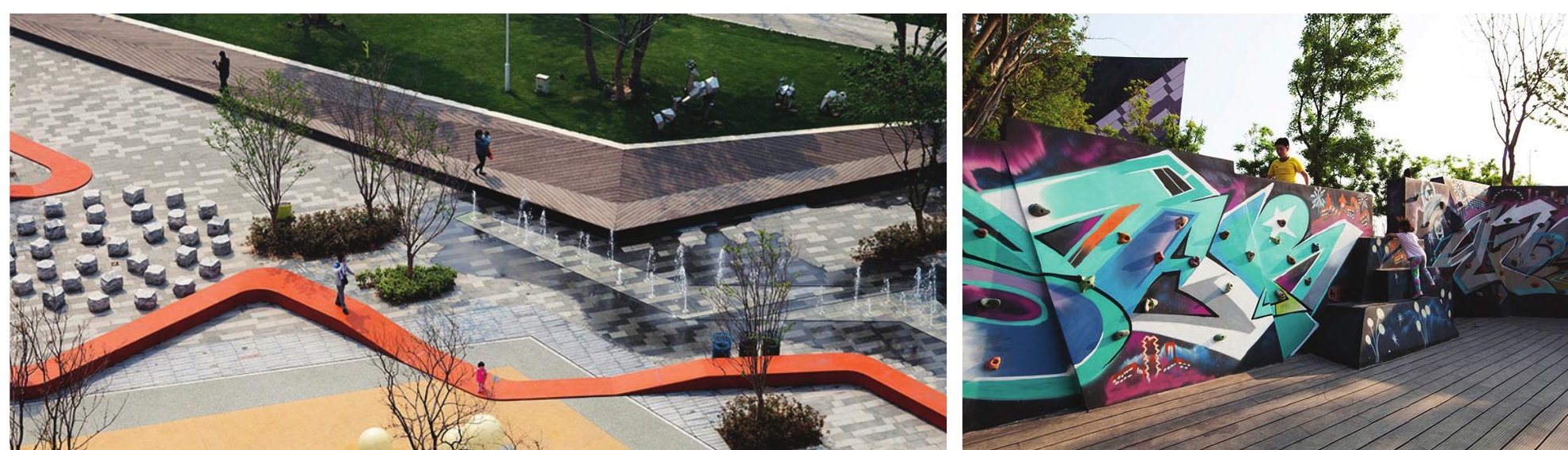


\subsubsection{High Line New York City, EE.UU.}

El "High Line" es un espacio público muy particular y probablemente único en el mundo. Se trata de un parque lineal elevado en medio de Manhattan que se serpentea entre los edificios con una serie de espacios de descanso y caminos para pasear.

La ciudad de Nueva York y en especial Manhattan ha mantenido durante muchos años varios puertos y puntos de industria en medio de la ciudad. En 1934 se permite el ingreso de trenes a la ciudad mediante una vía elevada, con la finalidad de mover cargamentos de industria y mercancías. Como se aprecia en la siguiente figura, se trataba de una estructura elevada a aproximadamente tres pisos de altura enteramente construida en fierro, que tenía como destino diversos hangares y puertos en la ciudad. Con el paso de los años la zonificación de Nueva York fue cambiando y poco a poco se fueron reduciendo los lugares industriales. Eventualmente, en 1980, el ferrocarril elevado que se serpenteaba por Manhattan, quedó en desuso y pasó al abandono.

Figura 38: High Line, Nueva York - Años 60's

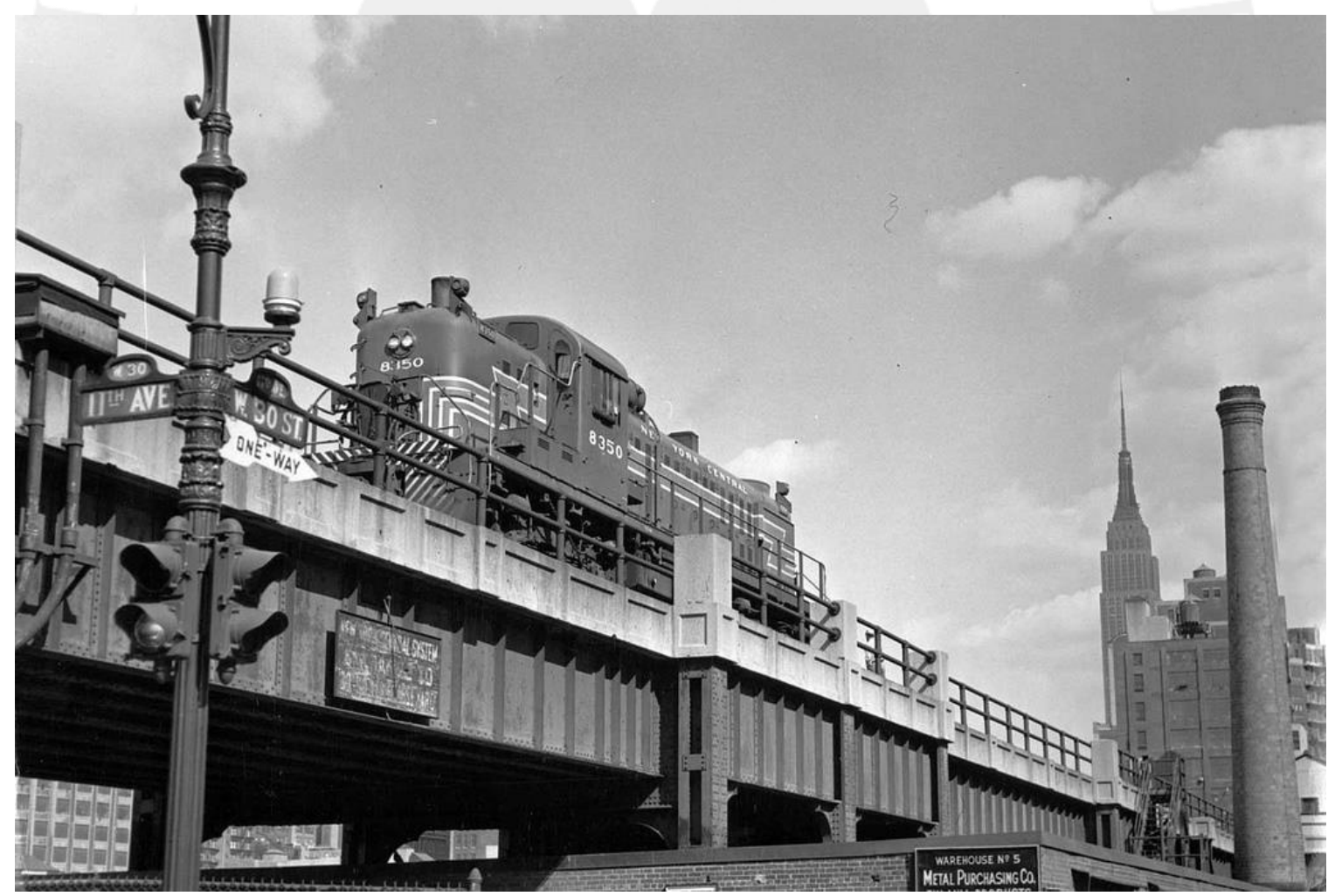

Fuente: Steve (2011)

Obtenida de https://www.flickr.com/photos/syscosteve/5476852481/ 
Los vecinos empezaron a menospreciar esta gran estructura abandonada en medio de sus vecindarios y eventualmente, en los años 90, diversos alcaldes y vecinos se organizaron para iniciar su demolición. Esta acción se encontró con una serie de problemas, como la de algunos activistas que no compartían esa actitud y preferían conservar la estructura. En 1999 dos residentes del vecindario, Joshua David y Robert Hammond, se organizan y fundan un grupo bajo el nombre de "Friends of the High Line" con la finalidad de velar por la preservación de la estructura para eventualmente convertirlo en un espacio público. Para el 2003 esta sugerencia se había aprobado y se inicia la planificación para un concurso abierto de ideas. Para setiembre del 2004 ya se había logrado congregar un equipo de trabajo conformado por James Corner Field Operations, un estudio de arquitectura paisajista, Diller Scofidio + Renfro y Piet Oudolf.

El 9 de junio del 2009 se inaugura la primera sección del nuevo espacio público elevado de Nueva York. Dos años después se inaugura el siguiente tramo y tres años después el siguiente.

El aspecto del "High Line" se inspiró en la previa existencia de diversas plantas que habían crecido en los antiguos y abandonados rieles del tren, con un aspecto desordenado en el cual la naturaleza había tomado control.

Figura 39: High Line en su estado natural y previo a la remodelación

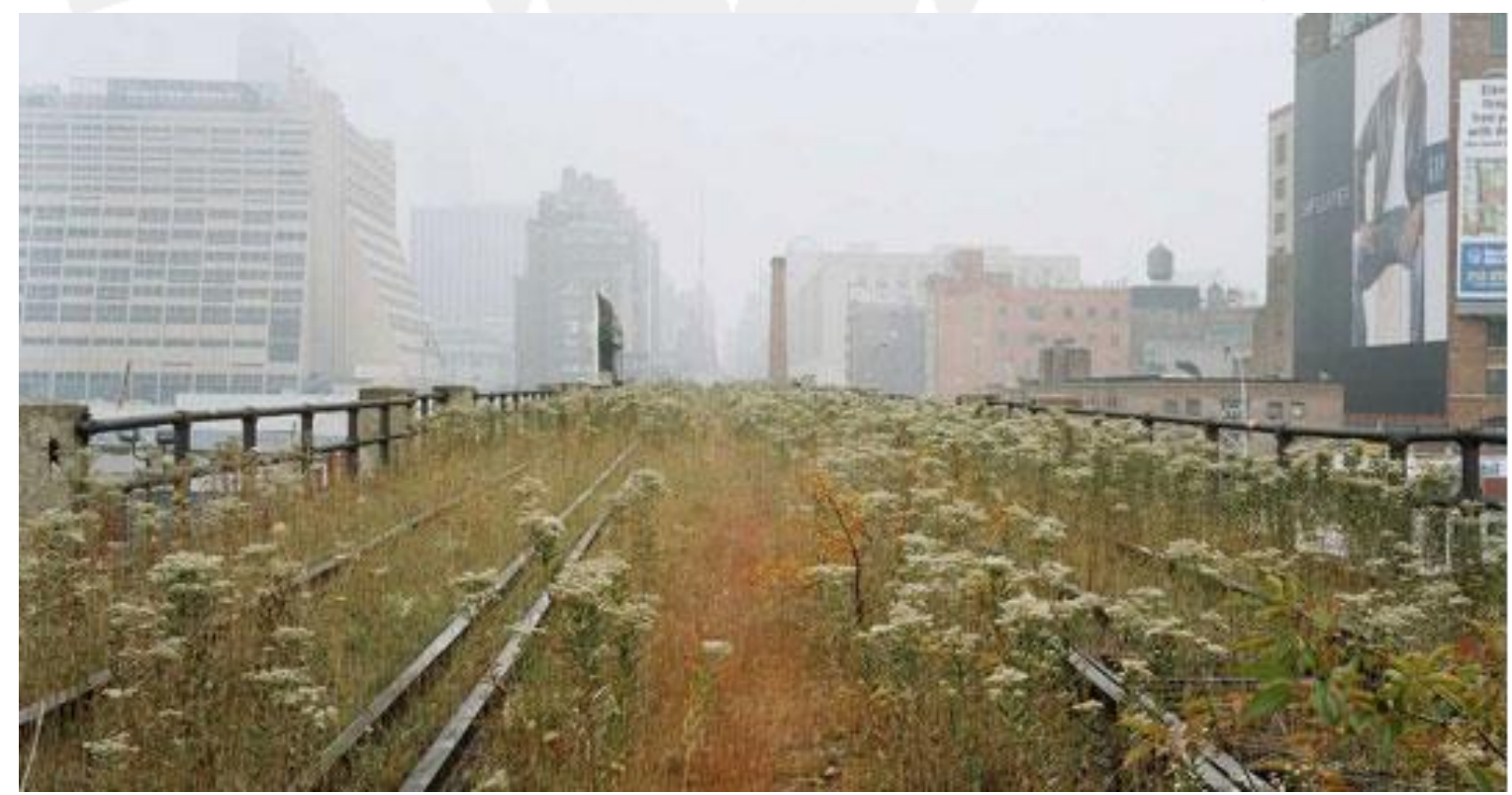

Fuente: Joel Sternfeld (2000)

Obtenida de http://www.cafleurebon.com/bond-no-9-high-line-the-scent-of-urban-renewal-for-new-yorkcity 
De esta manera se enfocaron en trabajar con plantas locales y de las temporadas correspondientes, ya que estas eran suficientemente resistentes al clima de la zona y por lo tanto fáciles de mantener. Debido a los diversos entornos del High Line, se encuentran diferentes situaciones o "microclimas" que permiten múltiples configuraciones con respecto a la vegetación. Cuando el High Line pasa entre edificios, se trata de una zona mejor resguardada, con menor viento y más sombra; esto favorece a un tipo de plantas. Por otras partes, donde la configuración es más abierta y con mayor exposición al sol y viento, nuevamente la oferta de vegetación cambia. Esto se analizó previamente y se decidió respetar y aprovechar el conocimiento adquirido para reducir el costo de mantenimiento. Siguiendo esta línea de pensamiento, la misma fundación recicla maleza para trabajar el compost mediante programas de voluntariado. Teniendo en mente la sostenibilidad del proyecto, era importante el fácil mantenimiento, pero también la memoria colectiva, motivo por el cual decidieron preservar los rieles del tren como parte del escenario.

Figura 40: Vista aérea del High Line

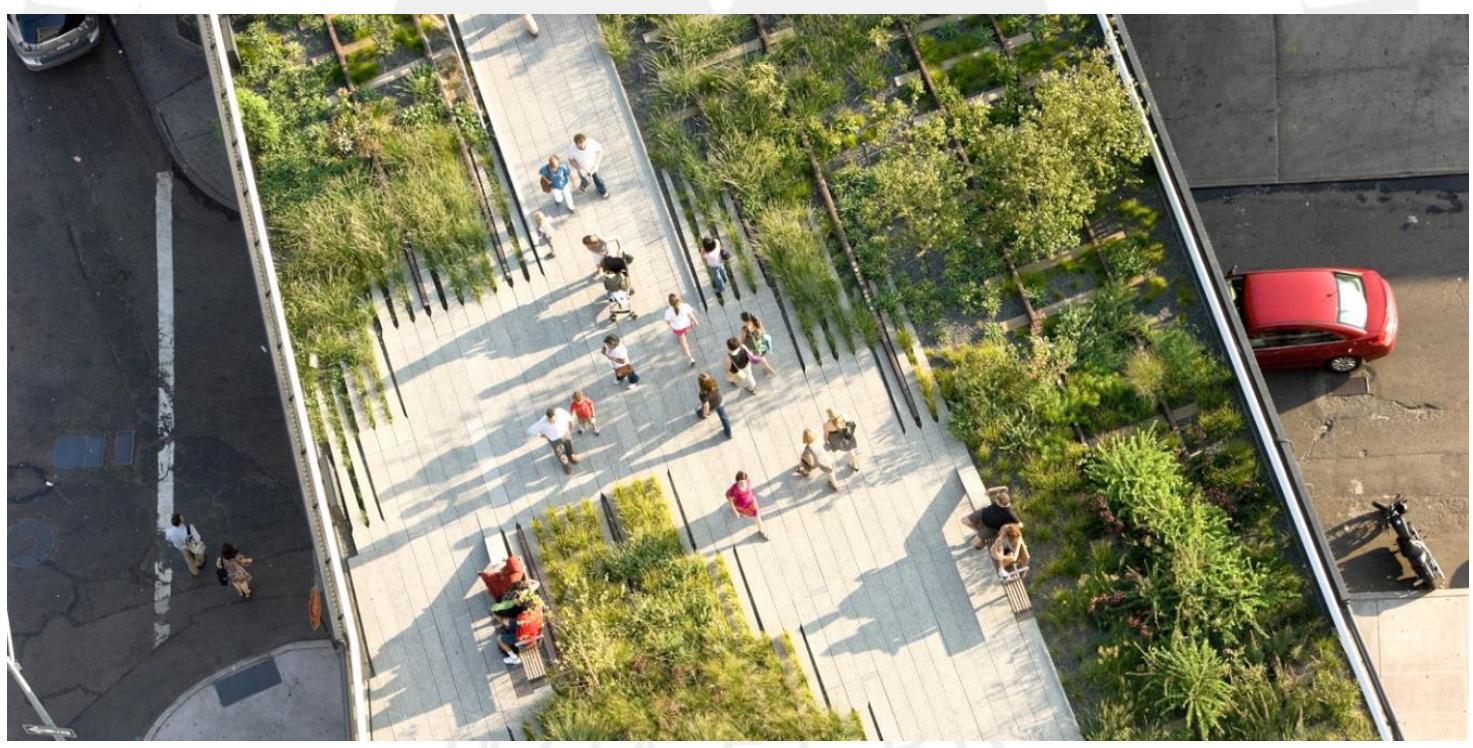

Fuente: Friends of the High Line (s.f.)

Obtenido de http://www.thehighline.org/about

Como se trata de una organización que trabaja en conjunto con el municipio de la ciudad, también se trabajan programas y actividades para mantener el interés de los ciudadanos, aportar en educación y mantener el lugar activado para el bienestar de la ciudad. Los programas varían entre educación, arte, eventos escolares (Friends of the High Line, s.f.). 

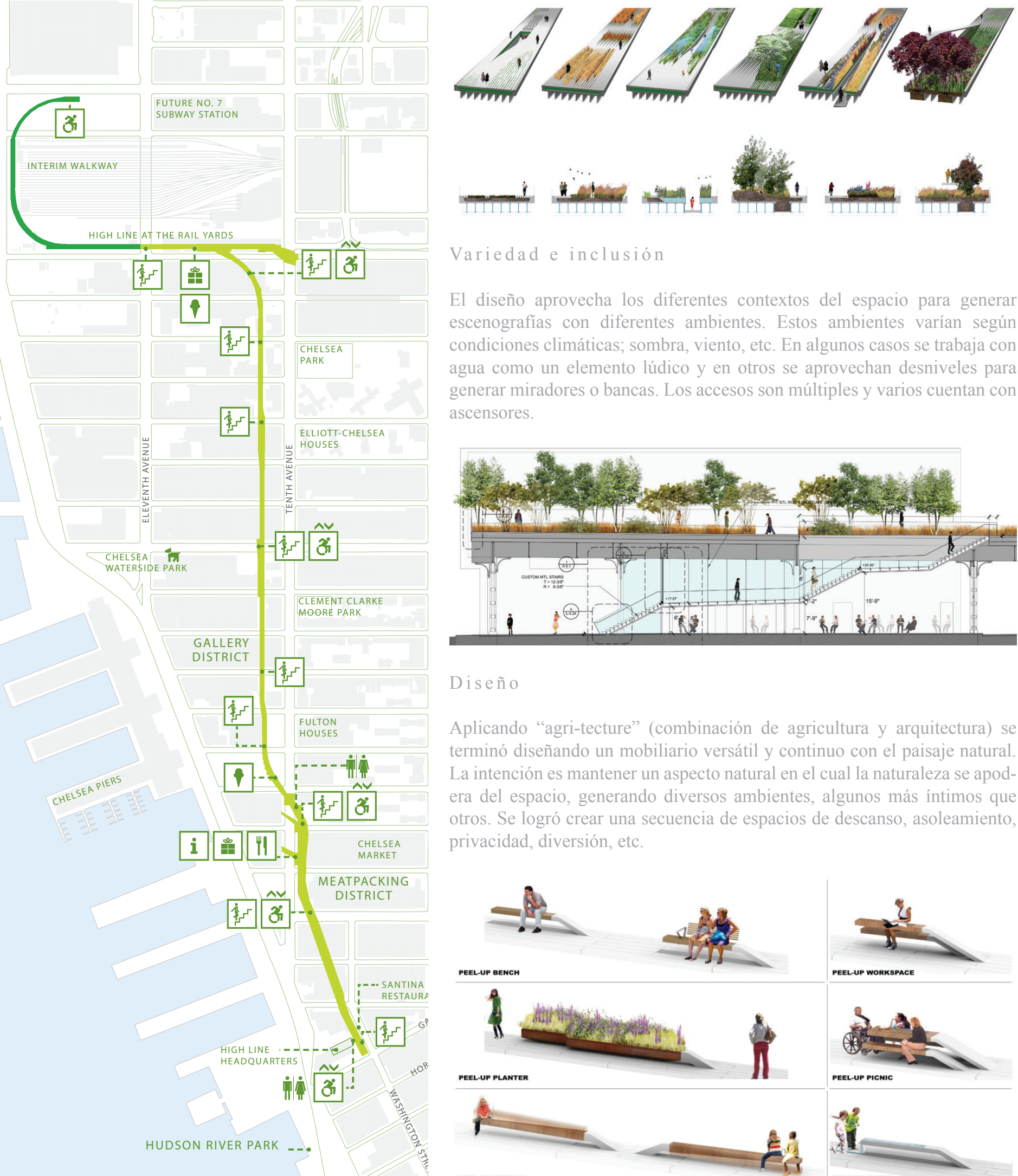

Variedad e inclusión

El diseño aprovecha los diferentes contextos del espacio para generar escenografías con diferentes ambientes. Estos ambientes varían según condiciones climáticas; sombra, viento, etc. En algunos casos se trabaja con agua como un elemento lúdico y en otros se aprovechan desniveles para generar miradores o bancas. Los accesos son múltiples y varios cuentan con ascensores.

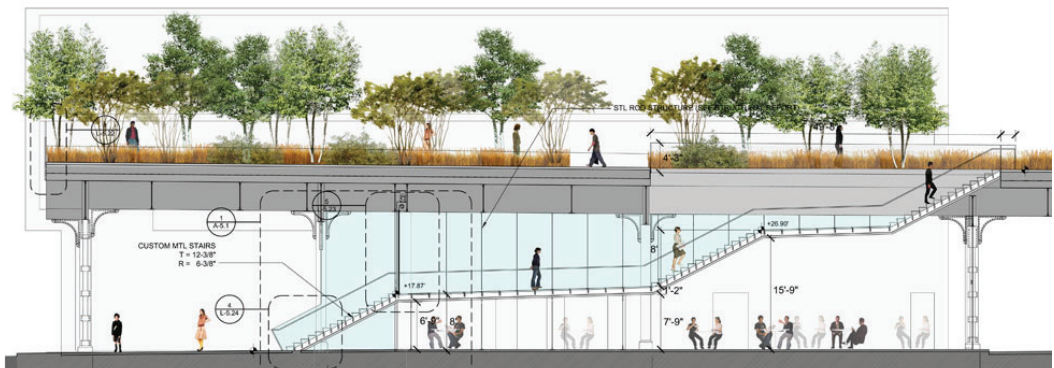

D is eño

Aplicando "agri-tecture" (combinación de agricultura y arquitectura) se terminó diseñando un mobiliario versátil y continuo con el paisaje natural La intención es mantener un aspecto natural en el cual la naturaleza se apodera del espacio, generando diversos ambientes, algunos más íntimos que otros. Se logró crear una secuencia de espacios de descanso, asoleamiento, privacidad, diversión, etc.
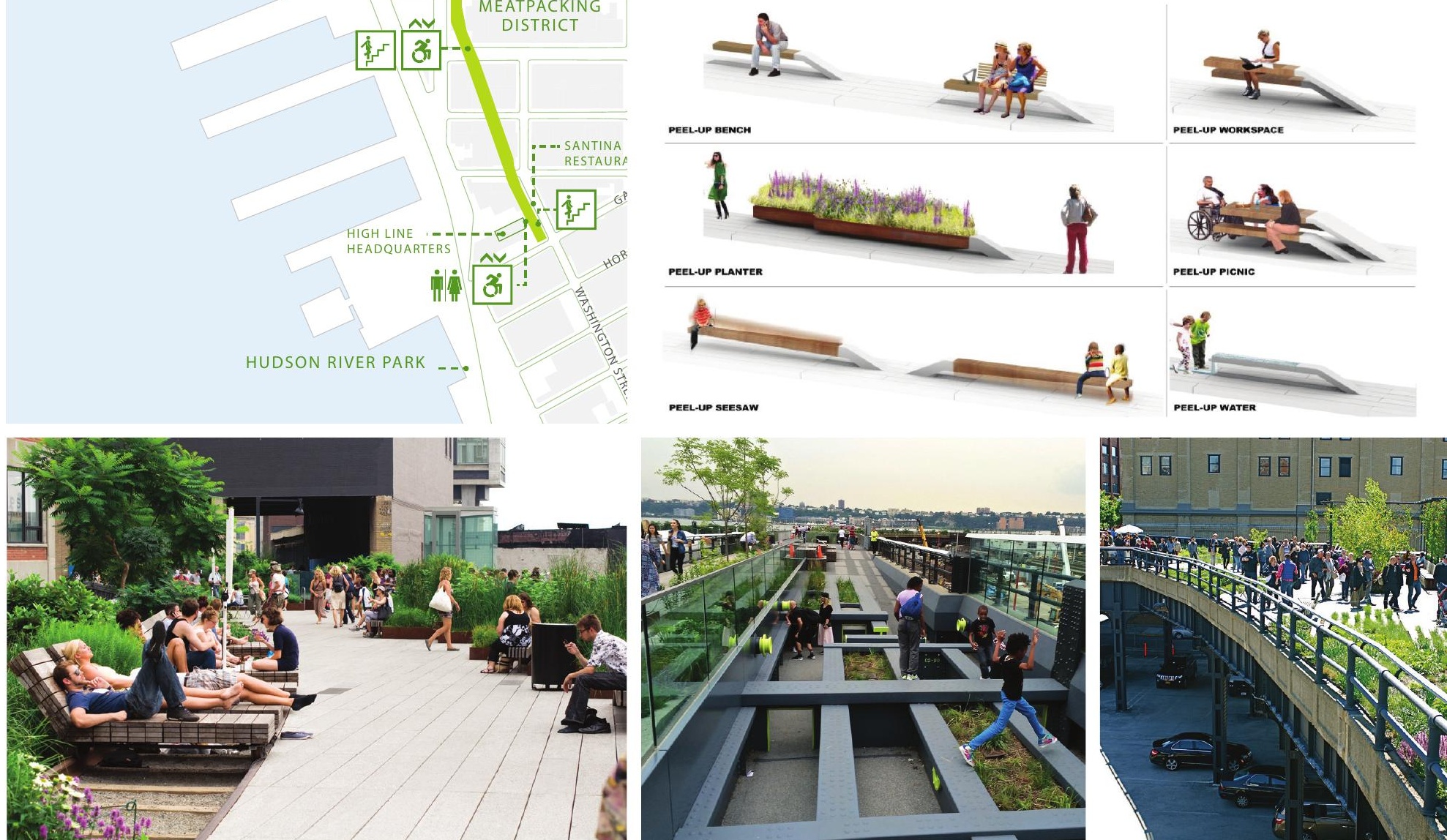


\subsection{Referentes de sistemas constructivos para techados}

\subsubsection{Campus Restaurant Ditzingen, Alemania}

Tras el pedido de Trumpf, empresa que se dedica al diseño y producción de maquinaria para industria, de elaborar un comedor para 2,000 empleados, los arquitectos Barkow Leibinger Architekten de Berlín se propusieron crear una cubierta innovadora y única.

La cubierta está compuesta de elementos hexagonales de madera con estructura metálica que cumplen diversas funciones como permitir el ingreso de luz, contener luminarias y absorber la resonancia mediante paneles acústicos.

Los diseñadores de la cubierta se inspiraron en dos elementos de la naturaleza: hojas y esponjas. Los resultados fueron dos características aplicadas a la cubierta: la compartimentación que respeta una jerarquía en su estructura, inspirándose en una hoja y la profundidad de la cubierta (espesor) como en una esponja.

Figura 41: Comedor en Ditzingen

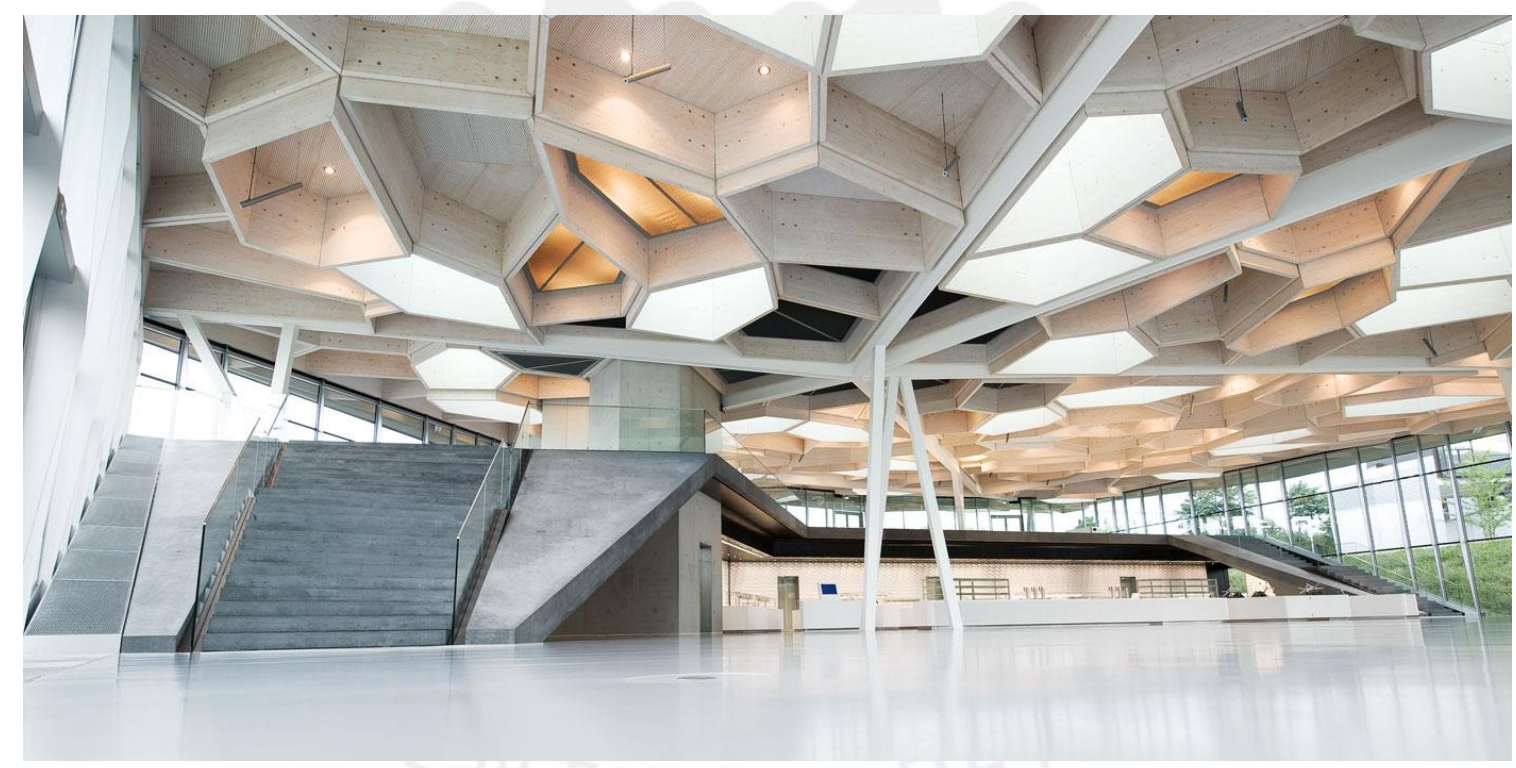

Fuente: Barkow Leibinge (s.f.)

Obtenido de http://www.barkowleibinger.com/img/projects/95/w/kan_project_1.jpg

Para realizar este diseño se utilizó acero y madera, siendo el primero el material para la estructura primaria y el segundo para la estructura secundaria además de funcionar como cerramiento. La cubierta pentagonal se subdivide en nueve triángulos de acero que se apoyan sobre nueve pilares del mismo material. Estos triángulos utilizan vigas de madera laminada para generar la estructura secundaria. El entramado 
que se inserta dentro de esta última estructura está compuesto por elementos que conectan a la estructura de acero. Esta subdivisión interna tiene tres diferentes espesores: $90 \mathrm{~cm}, 120 \mathrm{~cm}$ y $150 \mathrm{~cm}$. La unión en ángulo de las maderas es reforzada con una estructura metálica más fina. Las diversas conexiones en los nodos, reforzadas con láminas de acero, resultaron muy costosas. Por este motivo se les dio una mayor dimensión a los panales para reducir el número de nodos y por lo tanto también el costo. Al final se implementaron un total de 295 nodos conectores para cubrir un área de $5,400 \mathrm{~m}^{2}$.

El cliente solicitó que la cubierta tuviera una buena absorción sonora para mejorar la acústica del espacio. Para esto se utilizó una combinación específica: a las planchas de madera con huecos perforados se les agregó un absorbente acústico por la parte superior. Con respecto al tema lumínico, por un lado, se trabajaron paneles dedicados a la luz natural y por otro lado paneles que contendrían las luminarias. Aquellos que atienden la luz natural debían aprovechar al máximo la luz y además prevenir el deslumbramiento. Para esto se utilizó un acristalamiento con protección especial. Adicionalmente se ubicaron siempre acompañados con otro panal que tendría otro tratamiento de luz, esta vez artificial. Esta está especialmente diseñada con una celosía de aluminio y una luminaria específica. Con esta combinación se logra una transición tenue en el cambio de día a noche.

Para finalizar el trabajo se ubicaron todas las instalaciones necesarias por encima de la cubierta, respetando los ingresos de luz y otros. Se contempló mucho la "quinta fachada" ya que, al encontrarse hundido este edificio, se vería el techo desde las demás edificaciones. Desde el exterior la edificación adquiere un carácter especial, ya que se aprecia una franja con un espesor significativo, generado por la estructura interna de la cubierta (Detail, 2009). 

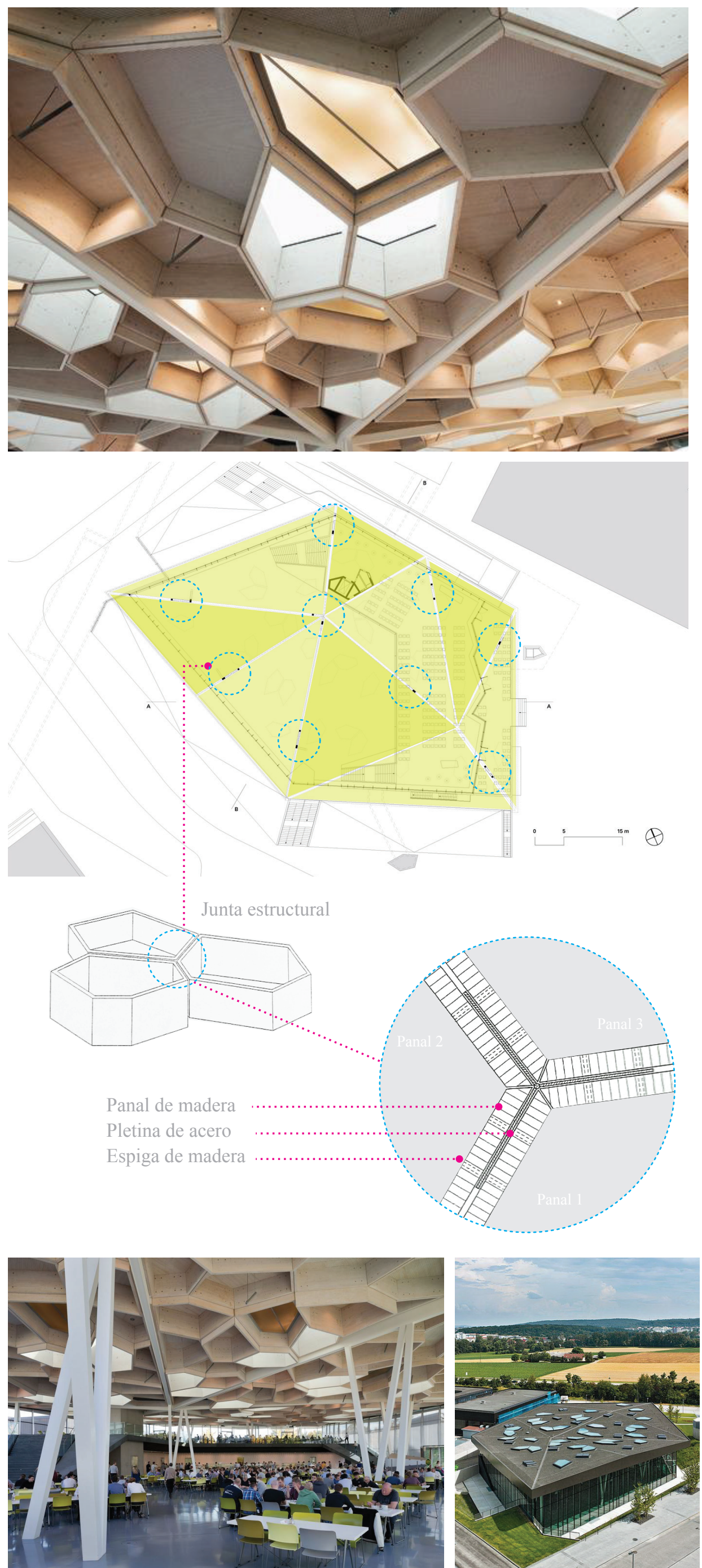

Panales

La cubierta se compone de cuatro panales con diversas profundidades.

El primero sirve para dejar entrar luz natural de forma cenital. El segundo tiene un panel reflector con una luminaria interna, recubierto con una fina celosía de aluminio y el tercero alberga una luminaria decorativa. El cuarto sirve como aislante acústico, compuesto por un material absorbente y un panel de madera perforada.

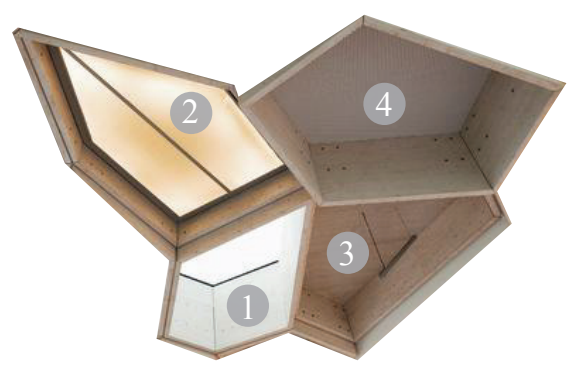

Estructura

La cubierta pentagonal se subdivide en nueve triángulos. Estos conforman la estructura principal y están enmarcados con vigas de acero rectangular hueco. Esta gran cubierta se apoya sobre nueve pilares de acero.

Iluminación artificial .....

Viga de acero

Luz natural

Luz artificial

Panal acústico

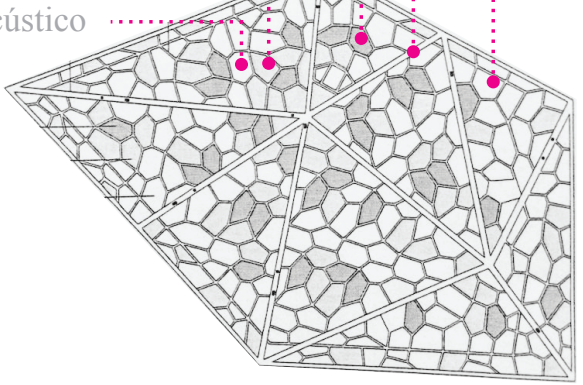

Ensamblaje

Las juntas estructurales de los panales de madera deben ser reforzadas con planchas de acero para ayudar a soportar las cargas y unirse entre si. Por el exterior se aprecia la viga laminada de madera y en el interior la pletina de acero. Estas dos se sujetan mediante una espiga de madera.

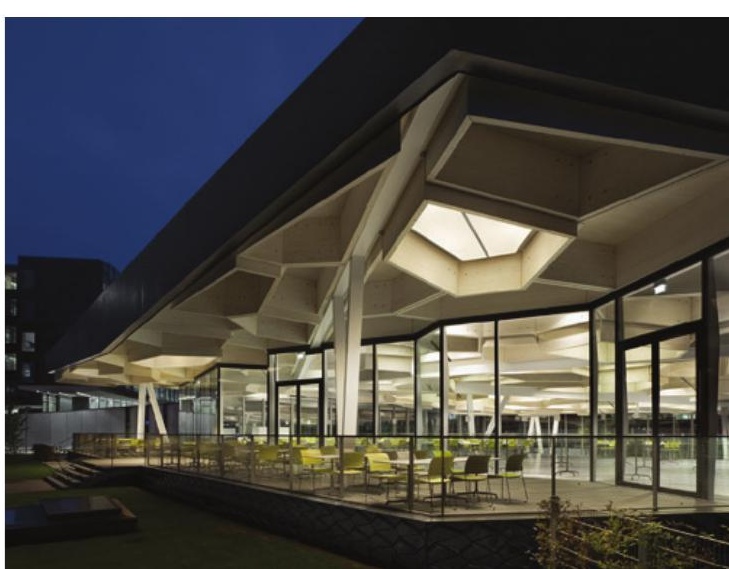




\subsubsection{Bodegas Protos de Peñafiel, España}

Bodegas Protos, una empresa viticultora, encarga al estudio de arquitectura Rogers Stirk Harbour + Partners diseñar sus nuevas instalaciones en Peñafiel, España. Para este proyecto diseñan una cubierta particular que busca imitar la tradición viticultora con un enfoque moderno. Parten de la curvatura de una catenaria invertida o una parabólica y optan por desarrollarla en madera (Rogers Stirk Harbour + Partners, s.f.).

Figura 42: Bodegas Proto

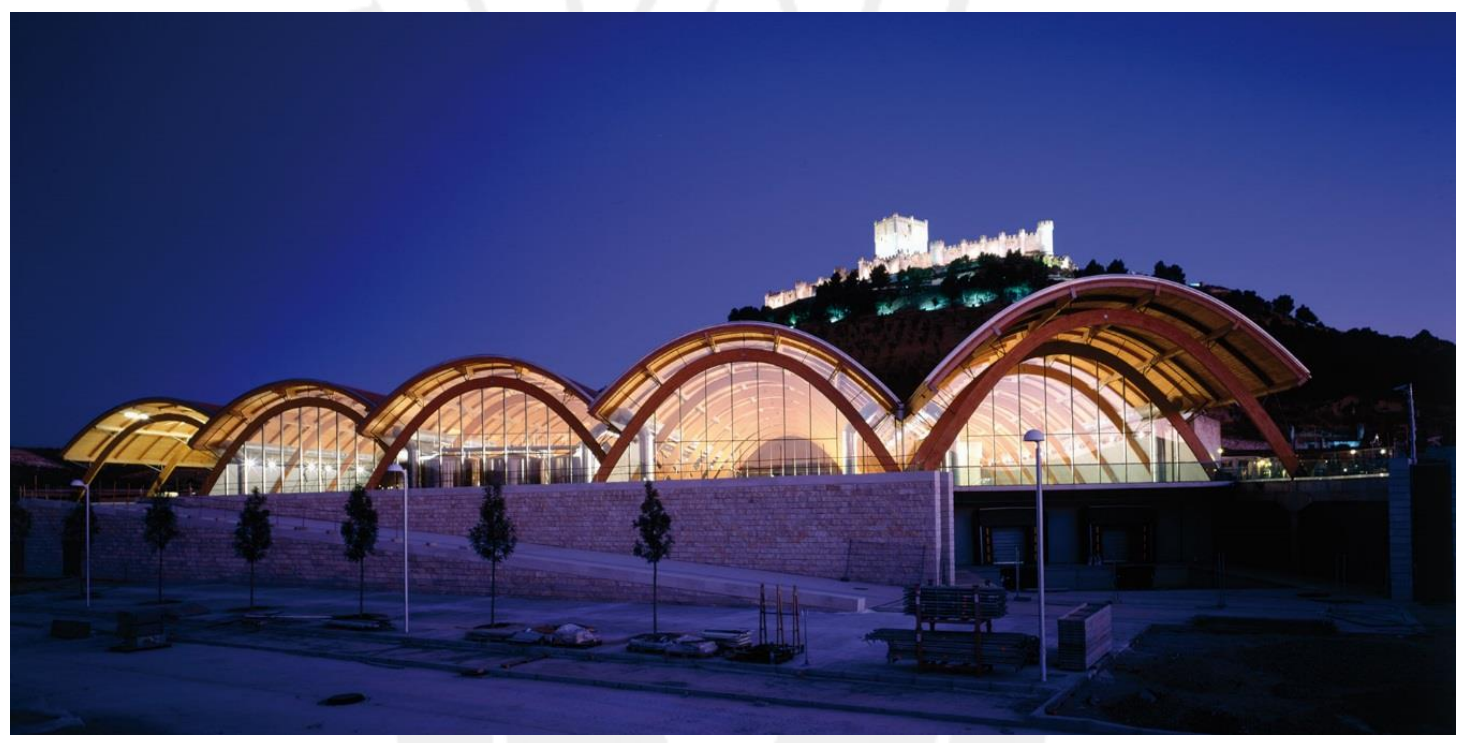

Fuente: Rogers Stirk Harbour + Partners (s.f.), fotografía de Katsuhisa Kida Obtenido de https://www.rsh-p.com/projects/bodegas-protos/

Todo el complejo consta de cinco grandes bóvedas que se apoyan sobre arcos de madera y han sido revestidas con cerámicos de formato grande en forma de piel flotante. Esto quiere decir que se creó una cámara de aire entre la cubierta y la piel exterior, reduciendo el efecto térmico en $4^{\circ} \mathrm{C}$. Esto permitió un ahorro de $10 \%$ en consumo energético, además de la protección pluvial. La preferencia por una estructura con forma parabólica ahorró los costos en materiales en un $30 \%$, ya que su geometría es altamente eficiente además de ser modular (Rogers Stirk Harbour + Partners, s.f.). 

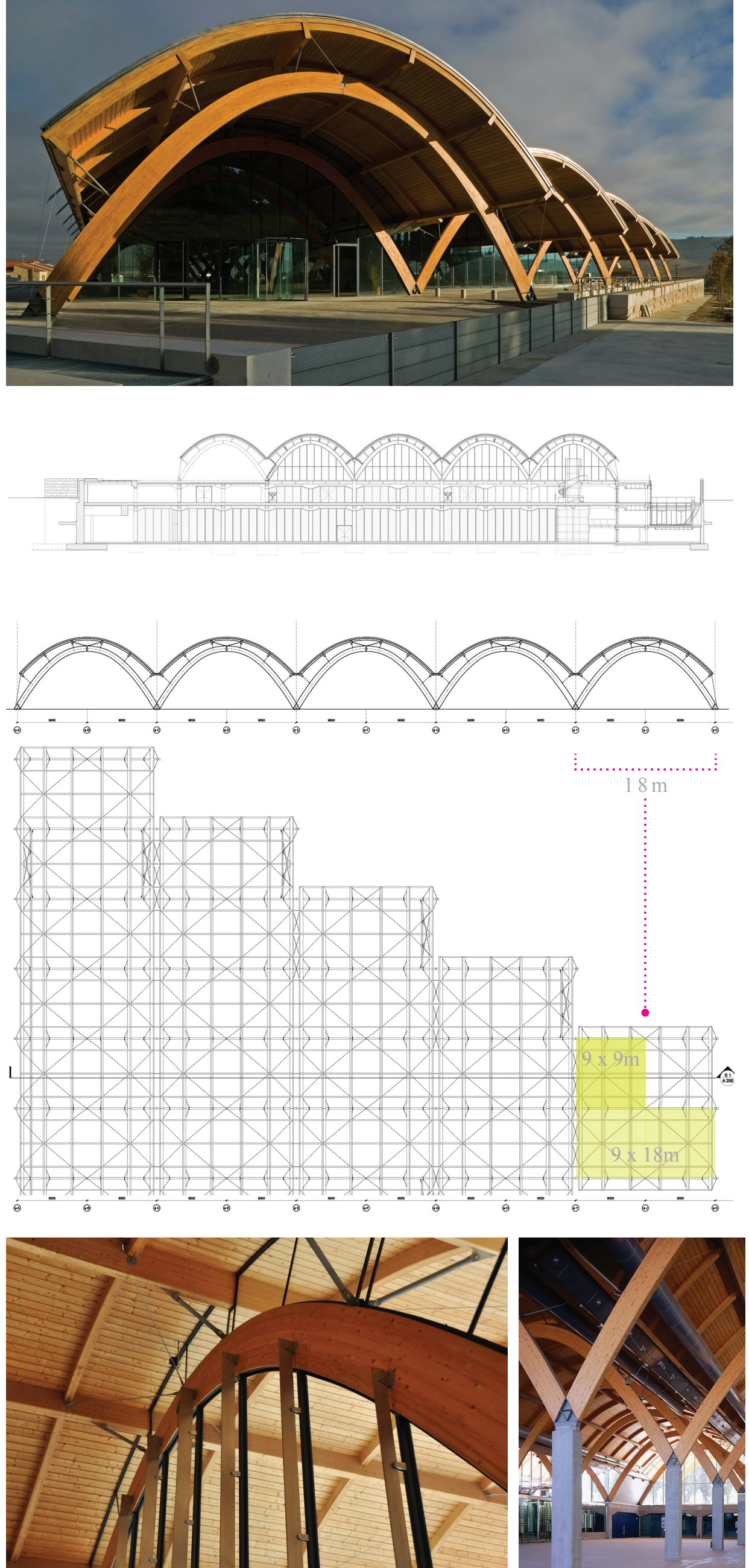

\section{Distribución}

El proyecto se distribuye en tres niveles: dos de estos son subterráneos y fueron pensados para almacenar los vinos, mientras que la producción del vino se da en el nivel 0 . Este es recubierto por grandes bóvedas estructurales de madera con recubrimiento de ladrillos de terracota. Como se trataba de una ampliación, fue de gran importancia la conexión entre la infraestructura antigua y la nueva, motivo por el cual se construyeron túneles que conectan los diversos edificios.

Estructura

Se optó por una estructura modular por su capacidad de soportar cargas sin grandes complicaciones. Estos elementos modulares se plantearon en forma de arcos parabólicos con luces de $18 \mathrm{~m}$. Los arcos estructurales fueron hechos en madera laminada y las uniones de acero. La base subterránea se realizó con elementos estructurales de concreto armado, en una grilla de $9 \mathrm{~m}$ x 9m, recibiendo así la carga de la cubierta y permitiendo una facil distribución para el almacenamiento de los vinos.

Estrategias pasivas y materiales

Debido a un presupuesto limitado, se optó por utilizar materiales de la zona, decisión que tendría un efecto positivo en la huella ambiental del edificio. La cubierta se reviste con ladrillos de terracota, un material muy característico de la región. Adicionalmente se utilizaron piedras de una cantera cercana, para aprovechar un material sin uso y su masa térmica. La madera es otro elemento característico de la zona, por lo cual se utilizó en múltiples revestimientos y elementos estructurales. La cubierta fue diseñada dejando un colchón de aire entre la madera y el recubrimiento de terracota, generando así un aislamiento térmico pasivo. En el último sótano se encuentra el almacén de vinos, ubicado ahi para aprovechar la masa térmica del suelo que lo rodea.

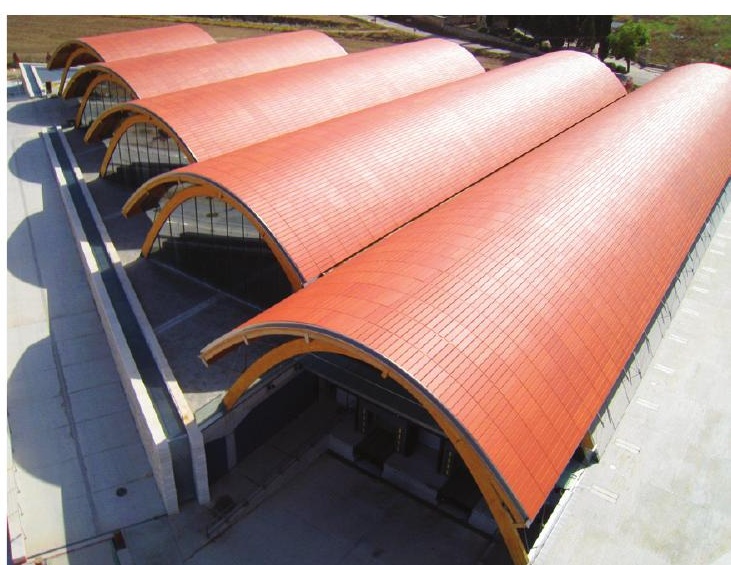




\subsection{Conclusiones Parciales}

En el análisis de referentes estudiamos siete terminales terrestres repartidos en diversas realidades; tres en Lima, dos a nivel latinoamericano y dos a nivel internacional. Al analizar la ubicación de todos estos, reconocemos que comparten situaciones similares. Algunos se encuentran en el centro de la ciudad y otros en las afueras, pero ninguno de los terminales tiene una ubicación periférica. Esto es así por un motivo bien simple: encontrarse cerca al centro de la urbe es ventajoso por sus múltiples conexiones de transporte público. Sin embargo, es importante enfatizar que todos cuentan, o buscan contar con algún tipo de vía arterial que les permita ingresar o salir sin utilizar calles o avenidas secundarias para no contribuir a la congestión vehicular ni tampoco verse afectados por esta. Es decir, la ubicación de un terminal terrestre podrá ser cercana al centro urbano, siempre y cuando cuente con la infraestructura vial correcta que permita su acceso sin congestionar las vías y que a la vez reduzca el tiempo de viaje de los pasajeros. En algunos casos, y sobre todo cuando no hay vías arteriales que llegan al centro urbano, se podrá utilizar una ubicación más externa, siempre y cuando se logre conectar con diversos medios de transporte público de la ciudad. Los referentes nos permiten comprender que no hay una regla estricta al respecto y que cada situación es distinta, con soluciones y estrategias para cada una. Es por esto que el terminal terrestre, al estar ubicado en un punto intermedio entre centro y periferia, tendrá que posicionarse estratégicamente para aprovechar las vías arteriales existentes y a la vez buscará conectarse a diversos medios de transporte público para garantizar su accesibilidad.

Considerando la ubicación que tendrá el terminal, es sumamente importante mencionar la intermodalidad de los terminales terrestres, ya que, sin este aspecto pueden quedar completamente obsoletos. Por lo general, cualquier terminal cuenta con bahías para buses urbanos, taxis, una zona para estacionamiento de vehículos particulares y según cada ciudad, conexiones con otros medios de transporte público masivo. Para aplicar el concepto de mejor manera, se debe comprender que priorizar al peatón y su fácil desplazamiento es el primer objetivo, seguido por los ciclistas, transporte público masivo y al final de la lista el vehículo particular. Por lo tanto, se tendrá que prestar especial cuidado a este punto, asegurando un flujo continuo, fácil e inclusivo, para evitar generar problemas de accesibilidad. Se tendrá que prever la implementación correcta de bahías para buses urbanos y taxis, además de accesos para autos particulares, pero se prestará especial atención a la conexión con la línea 2 del 
futuro metro de Lima. Estas características permitirán que el terminal se convierta en un punto conector entre viajes regionales y viajes urbanos en bus, metro, taxi y auto particular. Uno de los beneficios de crear un nodo conector como este es la generación de un flujo de personas constante, permitiendo activar el terminal en horas de poco uso.

Otra manera para mantener un flujo constante y activar el terminal es mediante la incorporación de servicios complementarios. Existen dos tipos de servicios para los usuarios, unos con la intención de mejorar el servicio de transporte y otros con el objetivo de ayudar a que la estadía del pasajero sea más placentera. Por lo general las actividades que están relacionadas a los servicios de transporte suelen ser planificadas y deben ubicarse dentro del terminal, como zonas exclusivas para choferes y servicios para el mantenimiento de buses. Estas actividades no generan un ingreso económico adicional para el terminal, pero mejoran significativamente el servicio ofrecido. El gran flujo de pasajeros y las prolongadas esperas que se realizan en los terminales terrestres, van de la mano con la implementación de diversos puntos de comercio para los usuarios a lo largo del terminal y en sus alrededores. Cuando estas zonas no han sido planificadas adecuadamente en el proyecto original, se crean espontáneamente y sin ningún tipo de supervisión, siendo el comercio informal su principal exponente. En terminales de mediana escala se suele implementar una actividad fuerte, es decir un único comercio importante, complementado por una serie de locales comerciales más pequeños. El objetivo de esto es mantener un flujo constante de usuarios, sean viajeros o no. Esta mezcla entre centro comercial y terminal terrestre no solo garantiza la constante activación de todos los espacios del terminal, sino que también es una importante fuente de ingresos económicos.

Considerando lo analizado, el terminal contará con los servicios básicos para la buena atención y experiencia del viajero, aparte de los mostradores de venta, módulos de atención y servicios higiénicos, los cuales son indispensables para el funcionamiento del terminal. También se implementarán servicios como una posta médica, oficina para la policía, farmacias, bancos y otros. Así se podrá generar un flujo, no solo de viajeros, sino de transeúntes en búsqueda de ciertos servicios. Sin embargo, también se buscará la implementación de algún servicio adicional con la intención de integrar a los vecinos en el uso del proyecto sin la necesidad de consumir. 
Con las estrategias mencionadas previamente, se logrará atraer un público más grande que requerirá de la implementación de espacio público. Buscando distribuir el flujo de viajeros, vecinos y transeúntes, será necesario crear zonas de esparcimiento para recrear y evitar la aglomeración de grandes masas de personas. En la mayoría de referentes se reconoce una tendencia que es característica de la actualidad; la implementación del centro comercial como espacio público. Si bien es cierto que las galerías comerciales generan grandes flujos y atraen mucha gente, no siempre atienden correctamente las necesidades del usuario y se encuentran condicionadas al consumo. Es por este motivo que, si bien estas zonas funcionan como un espacio público para el terminal, no aportan calidad de vida al entorno circundante, característica básica que deberían tener. Contemplando los análisis sobre el espacio público, el High Line de Nueva York y Zhengzhou Vanke Central Plaza en China, comprendemos la importancia de un buen espacio público y su diseño. En el caso de Nueva York queda clara la capacidad de revitalizar la ciudad y generar una nueva relación con esta. Por otro lado, en China, se aprecia la importancia de un espacio público diseñado para su público objetivo, demostrando que la más mínima alteración en el diseño puede marcar una diferencia en la interacción con el espacio. En ambos casos se aprecia la importancia de elementos lúdicos, la conexión con la naturaleza y sobretodo la libertad sobre la apropiación del espacio. Acciones como asolearse, descansar, conversar, almorzar, jugar y recrear en sí con absoluta libertad, son las que le dan las cualidades necesarias al espacio.

La continuidad espacial dentro de un terminal es fundamental para su diseño. Al igual que los patios de maniobras, estos espacios requieren coberturas especiales con la capacidad de tener grandes luces libres. Para lograr estos techados, la estructura metálica es la preferida debido a su ligereza, flexibilidad y fácil mantenimiento en el tiempo. Cuando se opta por luces más pequeñas, en los casos analizados se utiliza el clásico aporticado en concreto, a veces aplicando tipos de losas especiales que permiten mayores luces o menor número de columnas. Esta construcción tradicional, también puede mejorarse con la implementación de una piel o cubierta externa que la proteja del medio ambiente y le brinde una característica estética adicional, como sucede en algunos de los referentes. Otra tendencia es la de albergar una parte del patio de maniobras dentro del terminal mismo, aprovechando la estructura y su techado para no 
tener que cubrir grandes áreas de un solo nivel. En estos casos se logra optimizar tanto el espacio en el terreno, como las coberturas para generar sombra.

Al contemplar el análisis del sistema constructivo del comedor de la empresa Trumpf en Alemania, comprendemos que la cobertura puede aportar mucho más que una superficie elevada. La implementación de elementos luminosos al igual que tecnologías para la mejora acústica, es una acción ingeniosa que además puede resultar en una estética distintiva. De igual manera, los ahorros energéticos que puede traer un diseño de cobertura, como el caso de Bodegas Protos en España, pueden ser sumamente altos y beneficiosos para la edificación.

Se puede concluir que la cobertura debe ser más que un simple elemento protector de la intemperie, y debe buscar optimizar y perfeccionar la edificación en términos de sostenibilidad, estética y practicidad, sin la necesidad de comprometer su funcionalidad. Por estos motivos se propondrá una cubierta cuyo diseño permita el acondicionamiento pasivo del terminal para reducir costos de operación y funcionar como un referente en tecnología. Asimismo, se utilizarán materiales ligeros que permitan diseñar una cubierta con grandes luces y a la vez contribuir a una arquitectura icónica.

El crecimiento de la demanda es un tema difícil de estimar. Los terminales terrestres atienden un servicio fluctuante debido al comportamiento humano. Esta característica lleva a que se trate de un servicio que varía mucho según temporadas del año, ofertas en el mercado, crecimiento poblacional, desempeño económico y competencia con otros medios de transporte. Por lo tanto, se trata de un pronóstico difícil de realizar, motivo por el cual existen varios problemas al diseñar un terminal. En los casos estudiados, se presentan dos problemas principales: el terminal termina en desuso y pasa al abandono o colapsa por la gran demanda y termina trabajando por encima de sus capacidades. Algunos motivos para que termine en desuso son la introducción de aerolíneas con costos más bajos, la reintroducción de vías férreas o incluso crisis económicas en las que se viajaba menos. En estos casos, se comprobó que la activación mediante la incorporación de comercio resultaba sumamente efectiva. Por lo tanto, en sus respectivas remodelaciones se incluyeron galerías comerciales y usos complementarios, los cuales velarían por mantener un flujo constante de usuarios, activando el terminal. 
Todos estos ejemplos nos demuestran que el dimensionamiento debe hacerse con mercados estables, calculando crecimientos poblacionales y evaluando los posibles competidores. De igual forma demuestran que la combinación del terminal con otros establecimientos y usos ayudan a mantener un flujo constante, manteniéndolo activo. Es así que el terminal se dimensionará con un crecimiento estimado para el 2035 y con un balance de recreación y comercio para asegurar su uso constante. 


\section{CAPÍTULO V: MARCO CONTEXTUAL}

\subsection{Variables del lugar}

\subsubsection{Terreno}

La zona indicada en la siguiente imagen con el color rojo, es aquella propuesta dentro del PLAM2035 (Instituto Metropolitano de Planificación, 2014) de manera tentativa para la ubicación del terminal terrestre de Lima Este. Sin embargo, no se han realizado estudios que sustenten su ubicación específica. El terreno escogido para nuestra propuesta, indicado en color amarillo, es donde se ubica el actual Terminal Terrestre de Yerbateros o también conocido como Terminal Terrestre Molina. Hemos optado por renovar y ampliar el terminal existente, ya que consideramos que tiene una ubicación ventajosa, además de ser bastante conocido en el ámbito del transporte terrestre interprovincial. Por lo tanto, no será necesaria la comparación de diversos terrenos, sino la ampliación y adaptación de los terrenos colindantes.

Figura 43: Dos opciones para ubicar un terminal terrestre

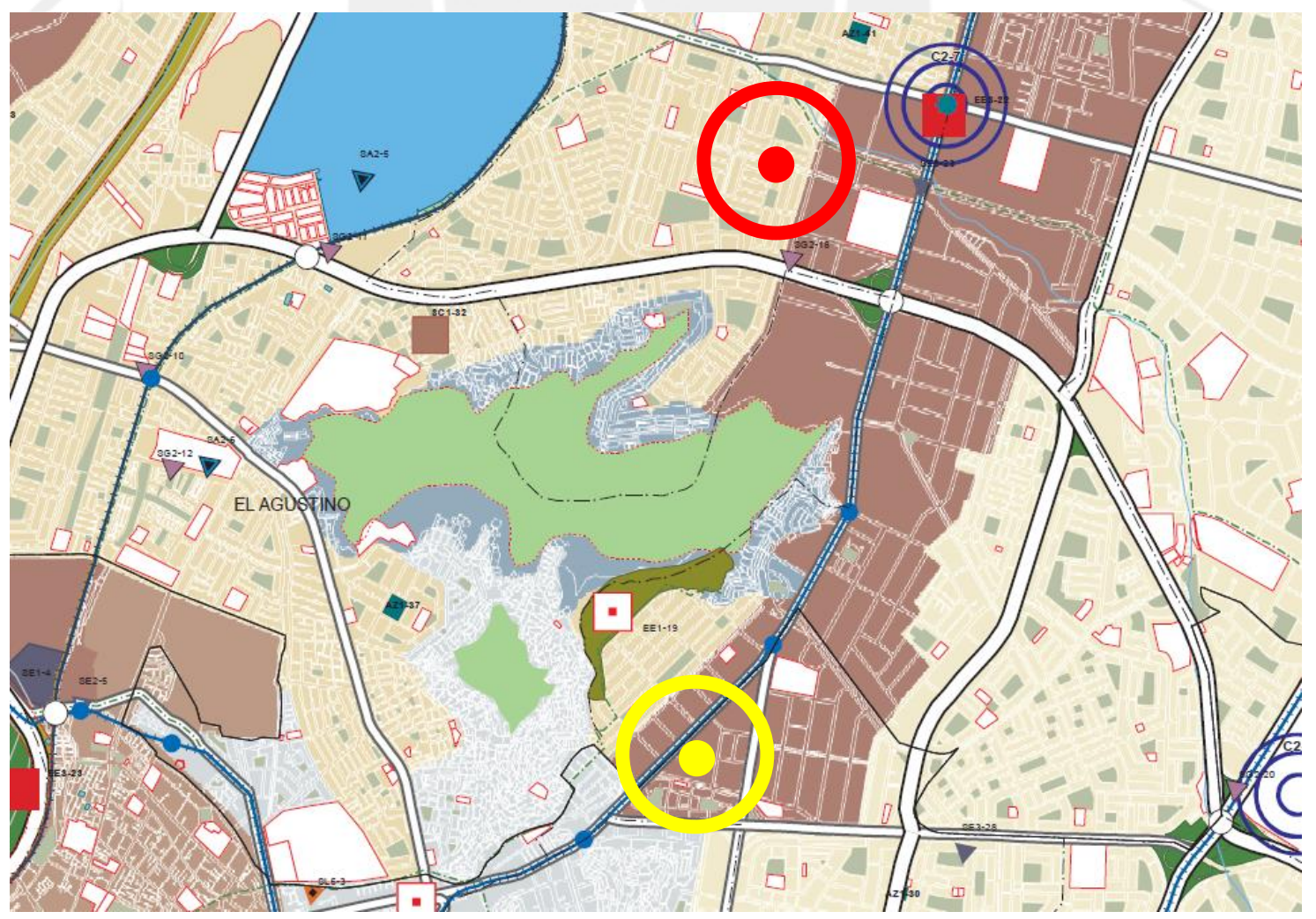

Fuente: Instituto Metropolitano de Planificación (2014).

Adaptado de PLAM Lima y Callao 2035 
La zona escogida para el nuevo Terminal Terrestre de Yerbateros es significativamente más grande que el actual terminal, pues también incluye los demás lotes que componen la manzana. En total son $52,523.24 \mathrm{~m}^{2}$ repartidos en siete diferentes lotes.

Actualmente los terrenos se encuentran ocupados por las siguientes empresas: Terminal Terrestre Molina, Maquinarias Nissan, Grifo Primax, Transportes El Pino S.A.C., GNV Derivados, Frigoríficos La Colonial y Almacén Halema / Marco Polo. La zona de estudio es de 201 hectáreas $\left(2^{\prime} 017,711 \mathrm{~m}^{2}\right)$ y será analizada bajo diversas variables dentro de este capítulo (ver lámina 1.1).

Figura 44: Terreno a analizar en zona de estudio

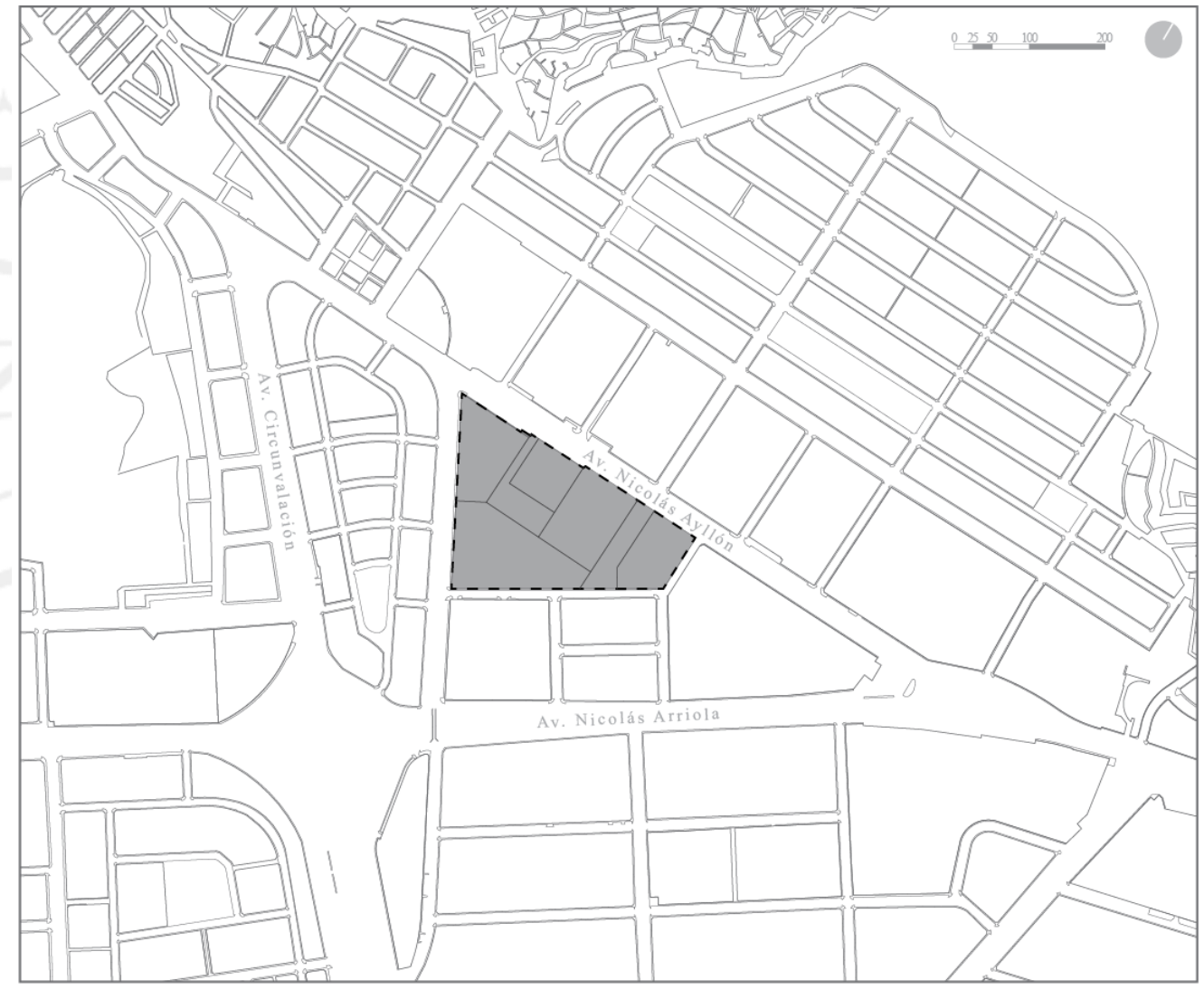

Elaboración propia 


\section{Figura 45: Parámetros urbanísticos}

" Afro de la Diversificación Praductiva y el fortalecimiento de la Educación "

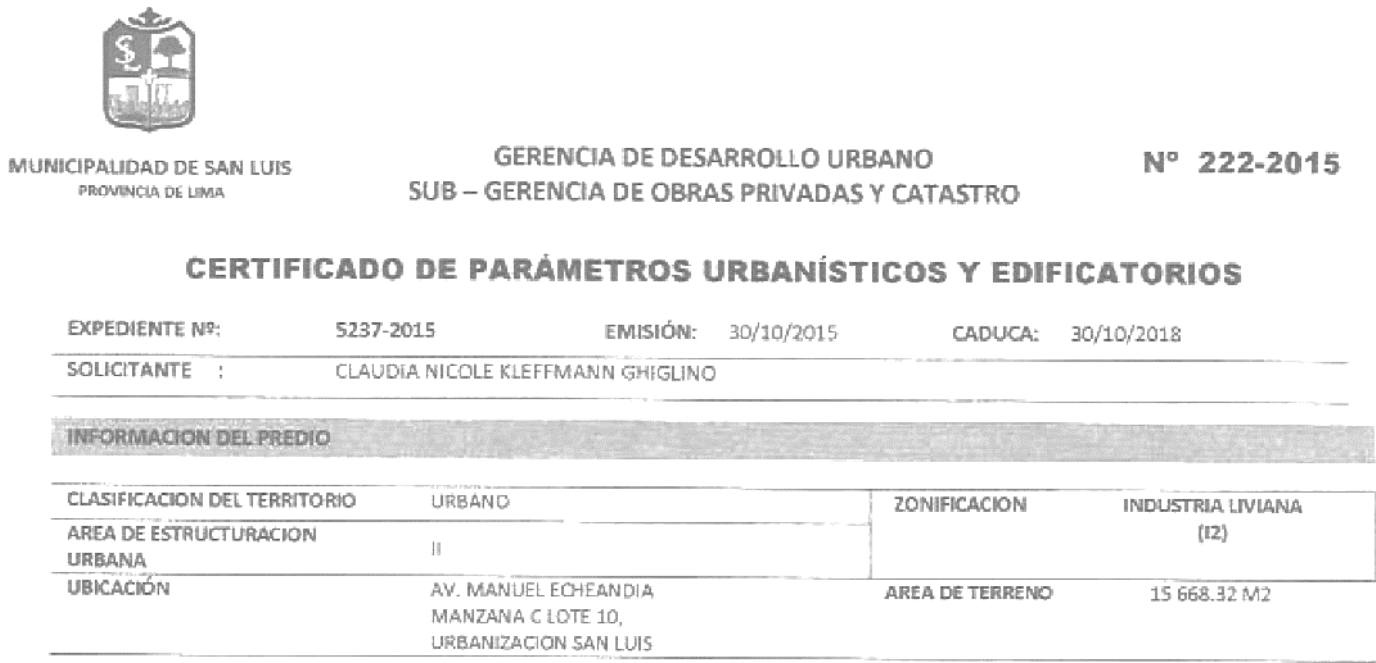

\begin{tabular}{|c|c|}
\hline USOS PERMISIBLES Y COMPATIBLES & $\begin{array}{l}\text { SEGÚN INDICE OE USOS PARA LA UBICACIÓN DE ACTIVIDADES URBANAS PARA LA } \\
\text { PROVINCIA DE LIMA, APROBADA MEDIANTE ORDENANZA N } 1015 \text {-MML } Y \text { PUBLICADA } \\
\text { CON FECHA 14/OS/O7. }\end{array}$ \\
\hline USO RESIDENGAL COMPATIBLE & (2) \\
\hline ALTURA DE EDIFICACÓN MÁXIMA & $\begin{array}{l}\text { SEGUN PROYECTO, } \\
\text { SEGÚN ENTORNO. }\end{array}$ \\
\hline ÁREA LBRE MINIMA & SEGÚN ACTIVIDADES ESPECIFICAS Y CONSIDERACIONES AMBIENTALES. \\
\hline RETIRO MINIMO FRONTAL & SIN RETIRO. \\
\hline ALINEAMIENTO DE FACHADA & $\begin{array}{l}15.50 \mathrm{M} \text { / AV, MANUEL ECHEANDIA IDISTANCIA MEDIDA ENTRE EL EIE DE LA VIA Y LA LINEA } \\
\text { DE EDUFCACION, SIN RETIROF. }\end{array}$ \\
\hline ESTACIONAMIENTO & PARA USO INDUSTRIA LIVIANA SE CONSIDERARA I CADA G PERSONAS EMPLEADAS ( 2 ). \\
\hline FRENTE MINIMO NORMATIVO & $20.00 \mathrm{M}$ \\
\hline ÁREA DE LOTE MÍNIMO NORMATIVO & $1000,00 \mathrm{M}^{2}$ \\
\hline
\end{tabular}

OBSERVACIONES :

1. DE ACUERDO AL DECRETO DE ALCAIDIA NN 003-2012-MDSL DE FECHA 16/03/2012.

2. EL REQUERIMIENTO DE ESTACIONAMIENTOS PARA ESTABLEOMIENTOS ESPECIALES SE REGUIRÁ POR LO SEÑALADO EN LAS ESPECIFICACIONES NORMATIVAS SEGÜN TIPO DE PROVECTO (REELLAMENTO NACIONAL DE EOIFICACIONES\}.

LOS ESTACIONAMIENTOSDEBEN SËR RESUELTOS DENTRO DEL ÁREA DEL LOTE.

BASE NORMATIVA:

ORDENANZA N 1OB2-MML- 11/10/2007

REGLAMENTO NACIONAL OE EDIFICACIONES

LEY NO 29090 Y SU MODIFICATORIA LEY 29899 Y DS CO3-2010

EL PRESEVITE CERTIFICADO NO AUTORIZA LA EJECUCIIÓN DE NINGŨN TIPO DE OBRA

PICIRO DE PAGO N 0000495971 FFCHA 26 DE QCTUBRE DI 2015

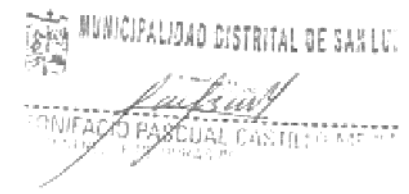

Av. Del Aire 1540 - Lirb. Vita Jardin - San Luis - Lima

Web: unwwimunisandis.pob.pe

Fuente: Municipalidad distrital de San Luis (2015) 
Tabla 25: Ordenanza $N^{\circ} 1015-M M L$

\begin{tabular}{|c|c|c|c|c|c|c|c|}
\hline \multirow{2}{*}{\multicolumn{8}{|c|}{$\begin{array}{l}\text { ÍNDICE DE USOS PARA LA UBICACIÓN DE ACTIVIDADES URBANAS } \\
\text { área de tratamiento normativo II }\end{array}$}} \\
\hline & & & & & & & \\
\hline & & $\mathrm{CV}$ & $\mathrm{CZ}$ & $\mathrm{CM}$ & $\mathrm{I}-1$ & $\mathrm{I}-2$ & $\mathrm{I}-2$ \\
\hline $60-2-1-03$ & Transporte interurbano & & & $\mathrm{X}$ & $\mathrm{X}$ & $\mathrm{X}$ & $\mathrm{X}$ \\
\hline $60-2-1-04$ & Transporte urbano & & & $\mathrm{X}$ & $\mathrm{X}$ & $\bar{X}$ & $\mathrm{X}$ \\
\hline $60-2-1-05$ & Transporte interprovincial & & & $\mathrm{R}$ & $\mathrm{R}$ & $\mathrm{R}$ & $\mathrm{R}$ \\
\hline $60-2-1-06$ & Transporte internacional & & & $\mathrm{R}$ & $\mathrm{R}$ & $\mathrm{R}$ & $\mathrm{R}$ \\
\hline $63-0-3-17$ & Terminales terrestres de pasajeros y carga & $\mathrm{E}$ & $\mathrm{E}$ & $\mathrm{E}$ & $\mathrm{E}$ & $\mathrm{E}$ & $\mathrm{E}$ \\
\hline \multicolumn{8}{|c|}{$\mathrm{X}=$ Ubicación conforme. } \\
\hline & 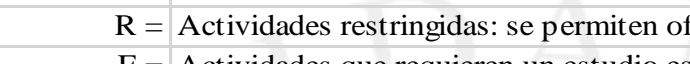 & IS C & $\mathrm{TCl}$ & $y a$ & & a. & \\
\hline
\end{tabular}

Fuente: Municipalidad Metropolitana de Lima (2007)

Elaboración propia

\subsubsection{Condiciones medio ambientales}

Se registran vientos suaves durante todo el año, provenientes del sur oeste. Estos cambian de dirección al encontrarse con los cerros el Pino y el Agustino. Su temperatura varía entre $15^{\circ} \mathrm{C}$ en invierno y $25^{\circ} \mathrm{C}$ en verano (Ministerio del Ambiente del Perú, 2016).

La topografía entre los cerros es bastante homogénea, llegando a tener una variación de dos metros de altura en $370 \mathrm{~m}$ de frente. El terreno está alineado al eje Oeste - Este, al igual que la Carretera Central, lo que le permite aprovechar al máximo las horas de sol. A pesar de encontrarse rodeado por cerros, estos son de baja altura, al igual que las edificaciones circundantes (1 a 2 niveles), por lo que, el terreno, no se encuentra en sombra durante ninguna época del año (ver lámina 2.1).

\subsubsection{Sistema de áreas libres}

El área verde en la zona de estudio se reparte entre un parque zonal, parques distritales y áreas verdes no accesibles. Todas estas juntas, representan tan solo un $10 \%$ de la zona de estudio. De este $10 \%$, el parque zonal abarca un $6.4 \%$ y las áreas verdes no accesibles, es decir las bermas en las vías, un $2 \%$. Por lo tanto, como áreas verdes utilizables, solo están los parques distritales que representan un 1.6\%. Sin embargo, solo un $0.5 \%$ de estos son de libre acceso, ya que el restante $1.1 \%$ corresponde a parques distritales enrejados por el municipio (ver lámina 3.1). 
Como se puede ver en la siguiente tabla, al comparar estos valores a la población en la zona de estudio, calculamos que el área verde por habitante es un aproximado de $7.9 \mathrm{~m}^{2}$. Según la Organización Mundial de la Salud, el valor adecuado debe ser de $9.2 \mathrm{~m}^{2}$ como mínimo, mientras que en otras ciudades este valor llega hasta $\operatorname{los} 27 \mathrm{~m}^{2} \mathrm{o}$ incluso $33 \mathrm{~m}^{2}$ de área verde por habitante. Por lo tanto, si se contempla el valor de $7.9 \mathrm{~m}^{2}$ de manera independiente, no es muy negativo. Sin embargo, si se considera que en su mayoría se trata de áreas verdes inaccesibles, que no fueron pensadas para el uso peatonal y que además están rodeadas por vías arteriales de alto tránsito, esta cifra pierde valor.

Tabla 26: Área verde por habitante

\begin{tabular}{|c|c|c|}
\hline ÁREA TOTAL ANALIZADA & $201.7 \mathrm{ha}$ & $100 \%$ \\
\hline Parque zonal Cahuide & $12.9 \mathrm{ha}$ & $6.4 \%$ \\
\hline Parques distritales enrejados & $2.1 \mathrm{ha}$ & $1.1 \%$ \\
\hline Áreas verdes no accesibles & $4.1 \mathrm{ha}$ & $2.0 \%$ \\
\hline Parques distritales de libre acceso & $1.1 \mathrm{ha}$ & $0.5 \%$ \\
\hline
\end{tabular}

\begin{tabular}{|c|c|c|}
\hline HAB. ÁREA ANALIZADA & 25,622 hab* $^{*}$ & \multirow{4}{*}{$\begin{array}{c}\text { Area } \\
\text { verde por } \\
\text { habitante } \\
7.9 \mathrm{~m}^{*}\end{array}$} \\
\hline Ate & 3,964 hab* $^{*}$ & \\
\hline El Agustino & 1,524 hab* $^{*}$ & \\
\hline La Victoria & 5,733 hab* $^{*}$ & \\
\hline San Luis & 14,401 hab* $^{*}$ & * aproximado \\
\hline
\end{tabular}

Elaboración propia

Lo positivo de las áreas verdes "no accesibles" en la zona de estudio es que funcionan como colchones aislantes en las vías más transitadas o como división de la zona industrial de la de viviendas. Estas se encuentran principalmente en la zona que pertenece a San Luis.

En el distrito de Ate se encuentra el parque zonal Cahuide, el cual funciona como área de recreación principal de toda la zona. El sector analizado del Agustino está conformado principalmente por asentamientos informales en el cerro, por lo que es la zona con menor cantidad de áreas verdes.

Los espacios de recreación en la zona se limitan a ocho parques vecinales. De estos solo uno, el parque General, tiene las dimensiones adecuadas para el vecindario en el que se emplaza y el resto son principalmente parques enrejados. 
Figura 46: Parques enrejados en la zona de estudio

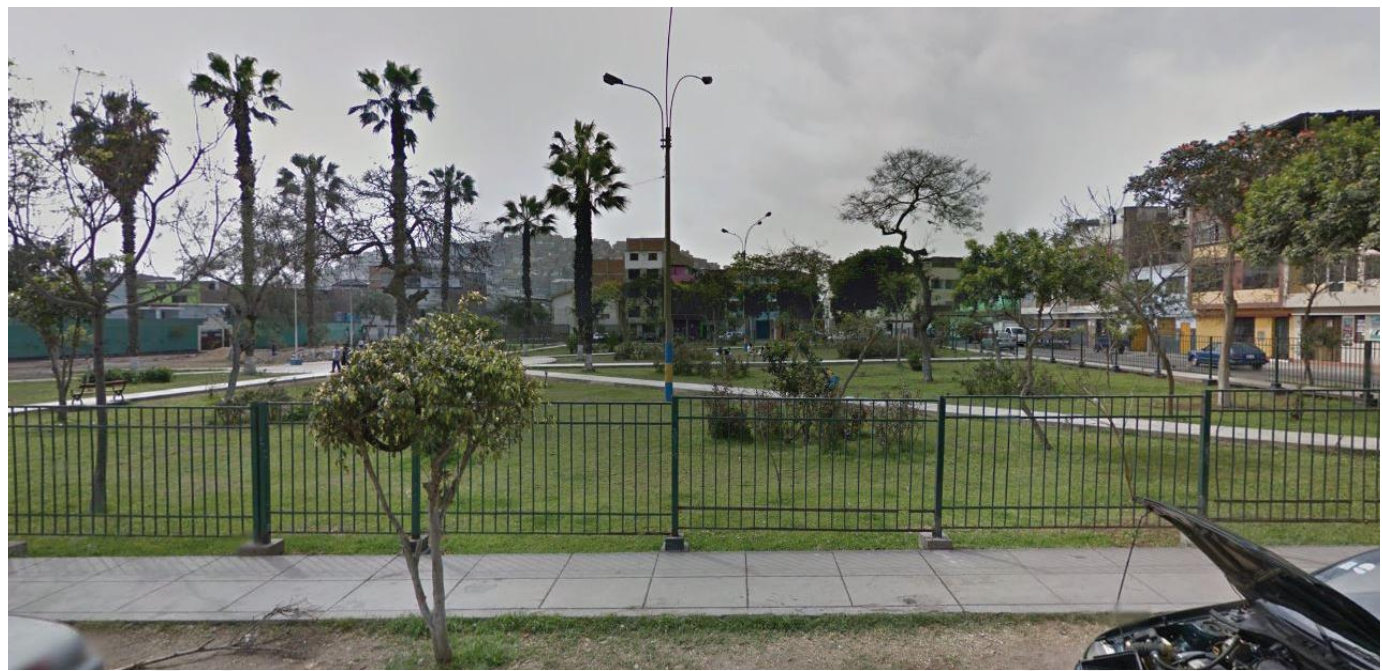

Fuente: Google Street View (2013)

Obtenido de https://goo.gl/FDoMHL

\subsubsection{Sistema de cuerpos edificados}

Se trata de una zona que se ha consolidado en los últimos 50 años, razón por la cual no cuenta con edificios de carácter histórico. Por otro lado, sí cuenta con elementos naturales de gran importancia, como lo son los cerros El Agustino y El Pino, símbolos de la apropiación territorial a través de la ocupación informal. Estos son hitos del perfil actual de la ciudad.

La mayoría de elementos de gran importancia se dan por su uso, ya que se trata de una zona sumamente dinámica y articuladora de la ciudad, donde se realizan múltiples transacciones comerciales diariamente. Un ejemplo de esto es el Camal de Yerbateros, conocido por varias generaciones, el cual tiene un impacto que va más allá de la zona colindante. Otros ejemplos según uso varían desde losas deportivas, a mercados, clínicas, comisarías, estaciones de servicio y terminales.

Se pueden identificar también grandes edificaciones industriales que fragmentan la zona debido a su gran tamaño y muros ciegos perimetrales. De estos hay múltiples en la zona de estudio, específicamente por su fuerte carácter industrial (ver lámina 4.1).

Es importante considerar que la forma de las diversas edificaciones o infraestructuras viales también tienen un rol importante en el carácter de la zona. Por ejemplo, el trébol de Circunvalación genera una fuerte barrera urbana para los peatones, tanto por su forma como por el constante tránsito vehicular. Otra barrera urbana es la 
misma carretera central. Aunque esta sí cuenta con cruceros peatonales en ciertas zonas, se trata de una vía fuertemente congestionada, que no ha sido pensada como una vía metropolitana.

Figura 47: Barrera urbana en la zona

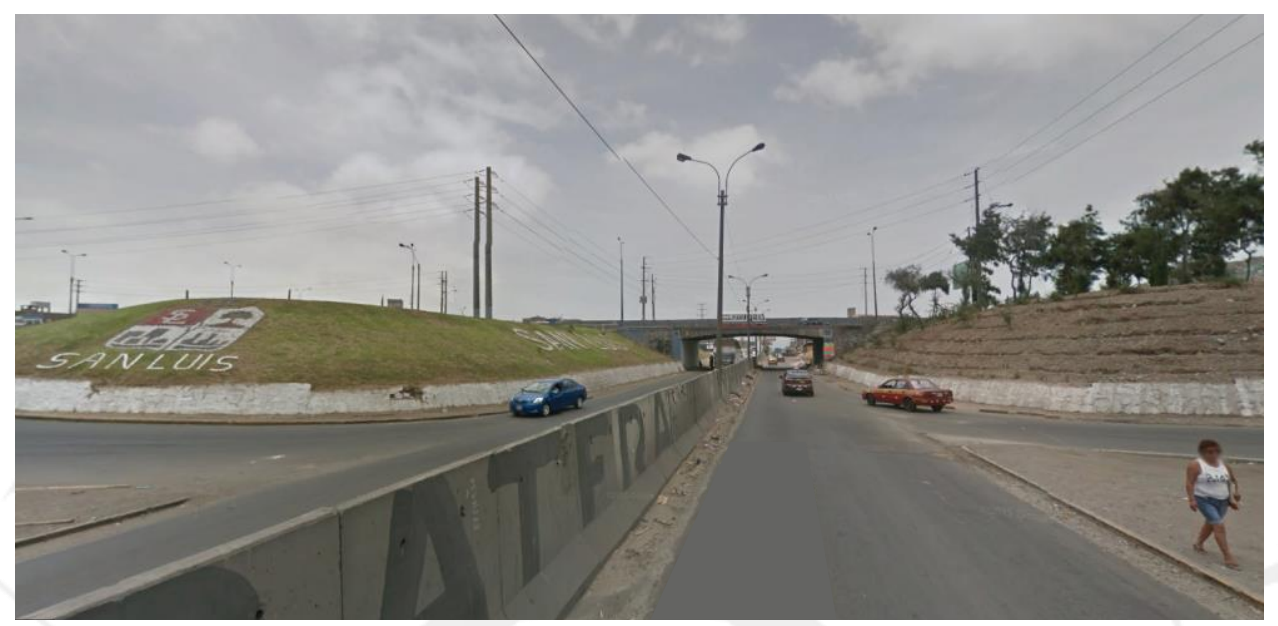

Fuente: Google Street View (2015)

Obtenido de https://goo.gl/7vRRRy

\subsubsection{Sistema de llenos y vacíos}

En este análisis se busca obtener la distribución de llenos y vacíos en la zona de estudio.

Es importante contemplar que dentro de "vacíos" se incluyen todas las vías, sean calles o arterias principales, al igual que parques y patios sin techar. Se debe tomar en cuenta debido a la presencia de múltiples avenidas de gran tamaño y una zona industrial muy extensa.

La distribución de llenos y vacíos es relativamente homogénea, siendo un 45\% vacío y un 55\% lleno. Al analizarlos se reconoce claramente la fragmentación de la zona en 6 a 8 piezas, generadas por las grandes vías que atraviesan en diversas direcciones. Adicionalmente se puede identificar la variedad de tramas presentes, algunas marcadas por la topografía y otras por el uso aplicado. En el caso de vivienda, la trama es sumamente tupida con vacíos pequeños y múltiples recovecos. La industria, por otro lado, trabaja lotes y cubiertas grandes, con algunos vacíos dependiendo del tipo de industria que se esté observando. En ambos casos la trama es ortogonal y las vías mantienen las mismas dimensiones. 
Las tramas ubicadas sobre los cerros están fuertemente marcadas por las curvas de la topografía. Se logra identificar ciertas vías, pero incluso estas pueden ser difíciles de diferenciar, debido al desorden. Los vacíos no siempre significarán una calle, pues podría tratarse de zonas muy empinadas que no pueden ser habitadas. Con respecto a los llenos, estos reflejan una mayor densidad que en el resto de la zona, pues no presentan vacíos más pequeños en su interior, como sí sucedía en otras zonas de vivienda (ver lámina 5.1).

\subsubsection{Bordes y Barrios}

La zona de estudio se encuentra fragmentada por dos tipos de bordes: naturales y artificiales. Los naturales, el cerro El Agustino y el cerro El Pino, funcionan como límites que encierran la zona. Estos límites pueden ser fuertes o leves, dependiendo de la topografía. En algunos casos es posible construir sobre el cerro, lo cual suaviza el borde natural, pero cuando la topografía es más agresiva se genera un límite más tajante. La presencia de los cerros tiene ventajas y desventajas. Por un lado, los barrios contenidos se ven resguardados de diversas condiciones climáticas y a la vez se pueden beneficiar con la topografía de la zona. Por otro lado, se aíslan del resto de la ciudad y también cuentan con suelos que dificultan o limitan la construcción.

Figura 48: Bordes naturales - El Agustino y El Pino
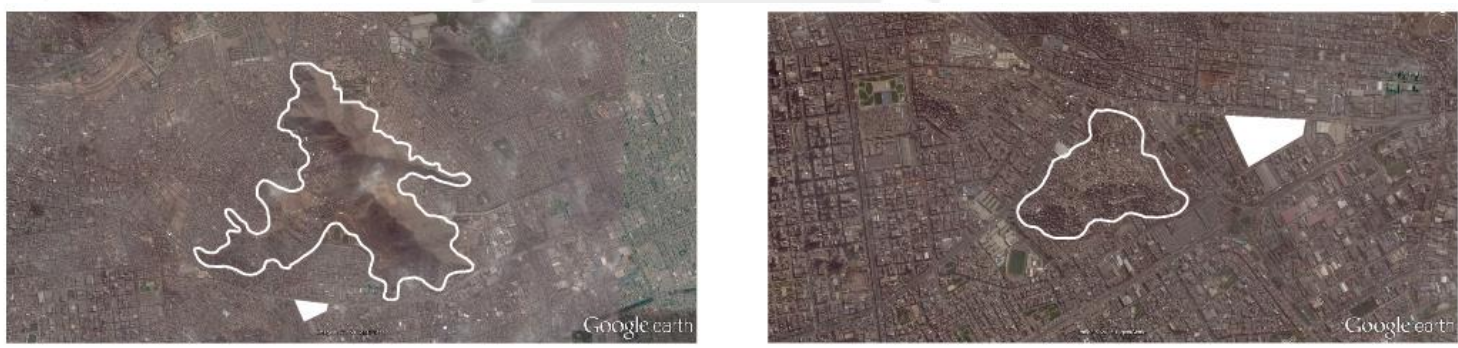

Fuente: Google Earth (2014)

Elaboración propia

Aparte de los bordes naturales hay bordes artificiales, como por ejemplo la Av. Nicolás Ayllón, Av. Nicolás Arriola y Circunvalación. Estas fragmentan la zona ya que se trata de avenidas sumamente grandes y difíciles de cruzar. La Av. Nicolás Ayllón (extensión de la Carretera Central) se convierte en un borde al contar con cuatro carriles por lado, en total ocho. Con divisiones de concreto, intercambios viales y esporádicos 
cruceros peatonales, genera un límite entre un barrio y el otro. La Av. Nicolás Arriola, al pasar por la zona de estudio, se convierte en un intercambio vial a desnivel creando una zanja. Por abajo circulan dos carriles por lado y en las partes superiores, nuevamente dos por lado. Estos bordes, a diferencia de los naturales, malogran la calidad de vida en la zona, por el fuerte tránsito vehicular, la contaminación ambiental, auditiva y visual.

Figura 49: Bordes artificiales - Sección de avenidas
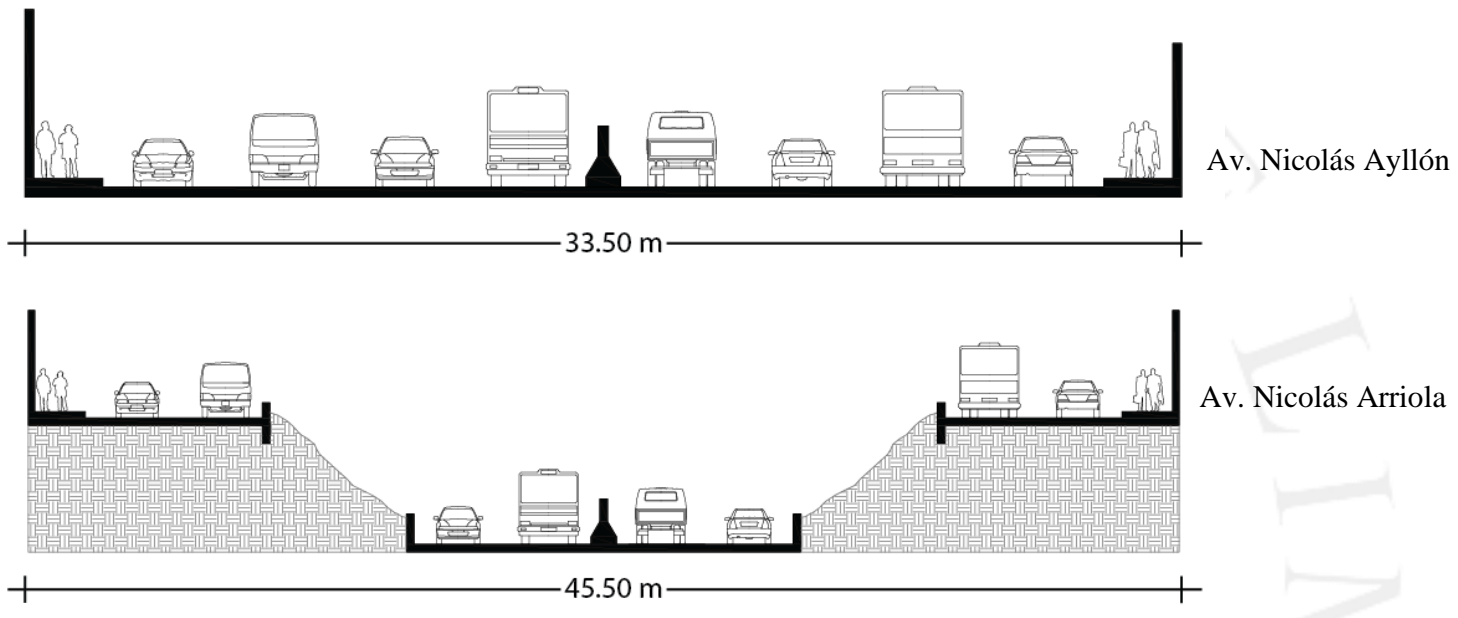

Elaboración propia

En la zona de estudio hay 12 diferentes barrios, generados por los bordes previamente mencionados, pero también por la configuración de las calles, la trama y la zonificación. Entre estos hay seis barrios residenciales, cuatro industriales y dos asentamientos humanos (ver lámina 6.1).

\subsubsection{Hitos, Nodos y Sendas}

La zona cuenta con nodos de diversas escalas y tipos. Algunos nodos son generados por comercio, mientras que otros por el flujo automovilístico.

Entre los nodos de comercio se encuentran el camal de Yerbateros, el Mercado 26 de Julio Ate Vitarte y CC. El Triunfo, el Mercado Mayorista Nr.2 de Frutas y el Terminal Terrestre de Yerbateros. Cada uno de estos tiene un gran impacto en el tránsito a sus alrededores por no contar con la infraestructura necesaria. Al tratarse de zonas informales que no son equipadas adecuadamente, terminan invadiendo las vías de 
la zona con estacionamientos informales, extensiones de los mercados, paraderos informales, etc.

El Terminal Terrestre de Yerbateros es particularmente caótico ya que, entre buses, colectivos y taxis, invaden la misma carretera central, generando una congestión vehicular innecesaria. Adicionalmente, los nodos comerciales se concentran en un solo sector de la zona de estudio convirtiéndolo en un área desordenada, pero a la vez práctico para aquel que busca realizar múltiples tareas.

Aparte de los nodos comerciales, hay tres nodos vehiculares que son las intersecciones entre las sendas principales de la zona: Av. Nicolás Ayllón con Av. Circunvalación, Av. Nicolás Ayllón con Av. Nicolás Arriola y el trébol de la Av. Circunvalación con la Av. Nicolás Arriola. El primero es importante por la actividad presente: paraderos, cruceros peatonales, venta de productos al paso, etc. Las siguientes intersecciones son nodos importantes por la presencia de intercambios viales que permiten cambiar la dirección de las rutas, y por lo tanto son fuertemente concurridos. Estos nodos son además intersecciones entre avenidas muy conocidas y sirven como puntos de referencia (ver lámina 7.1).

En la zona de estudio hay tres hitos de gran importancia y diversas escalas. El Parque Zonal Cahuide se encuentra en las faldas del Cerro El Agustino, hito principal de escala vecinal. A pesar de la intención original que el Parque Zonal funcione a nivel distrital o metropolitano, mantiene una escala vecinal debido a su ubicación y sus accesos. El cerro El Agustino es un hito de escala metropolitana y el cerro El Pino un hito de escala distrital.

Las sendas respetan una trama ortogonal delimitada por los bordes previamente definidos. Estas respetan la ortogonalidad hasta encontrarse con la topografía de los cerros, que las obliga a cambiar su morfología a una mucho más aleatoria y orgánica.

\subsubsection{Análisis de vías}

Las vías principales que rodean la zona de estudio, son vías de gran importancia a nivel metropolitano. Con tres vías arteriales; la avenida Aviación con el tren eléctrico, la avenida Nicolás Ayllón (extensión de la Carretera Central), la vía Evitamiento (Panamericana Norte) y dos vías principales; la avenida Nicolás Arriola y la avenida Circunvalación, se trata de una zona con múltiples opciones de conexión. 
La Av. Nicolás Arriola conecta la zona de estudio con la metrópolis, ya que desemboca en la Av. Javier Prado, una de las arterias principales de la ciudad. La Av. Circunvalación es otra alternativa para llegar a la Av. Javier Prado o para conectarse con la Panamericana Sur. La Av. Nicolás Ayllón funciona como extensión de la Carretera Central, arteria que conecta la sierra y selva central con la ciudad de Lima. Si se quiere conectar con el norte o sur del País, se puede utilizar la Av. Evitamiento, tramo entre la Panamericana Sur y la Panamericana Norte. Adicionalmente incorpora la vía del tren eléctrico y la futura línea 2 del metro de Lima. Estas son vitales para el desempeño de la zona, pues facilitarán la circulación y disminuirán el tiempo de desplazamiento para las personas (ver lámina 8.1).

Figura 50: Vías arteriales en la zona de estudio

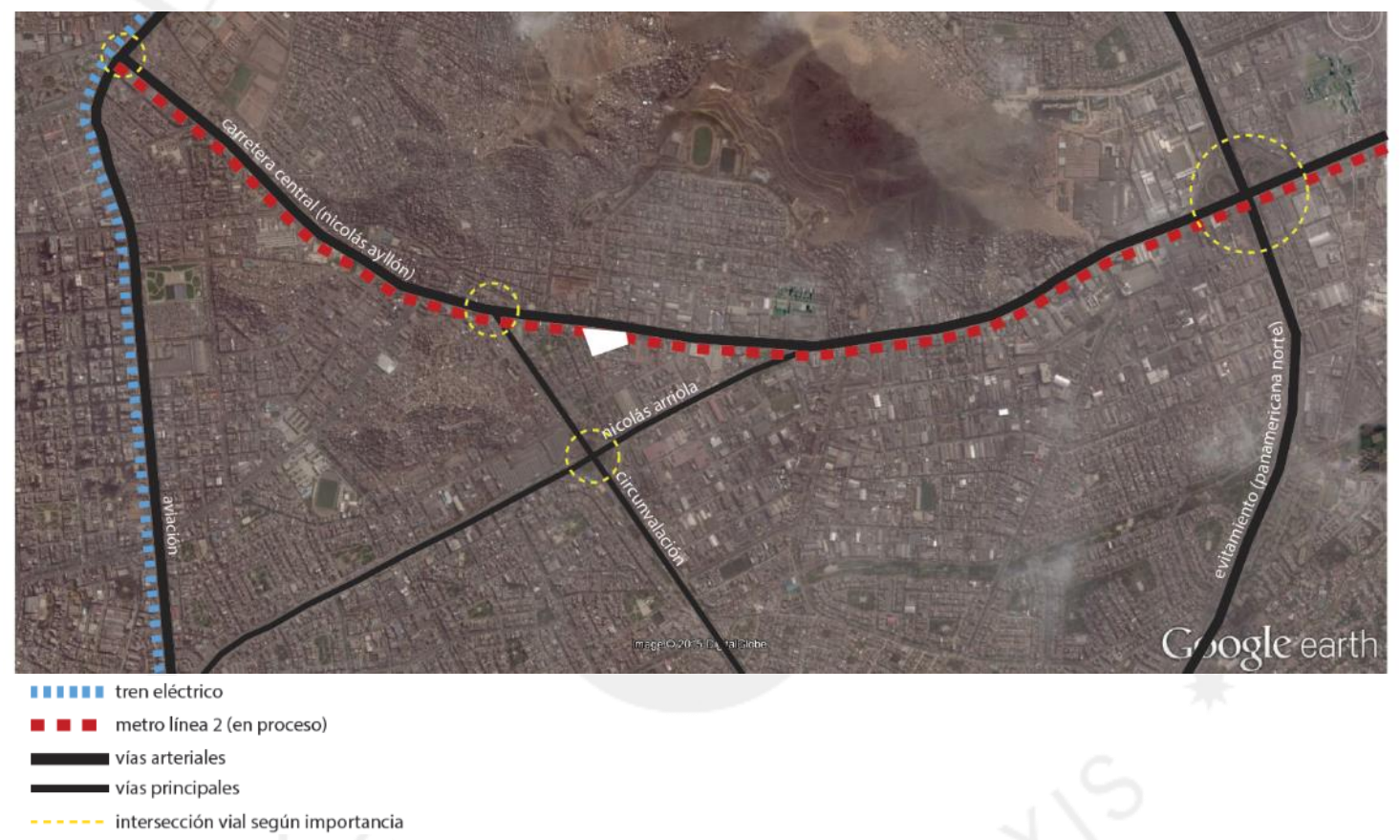

Fuente: Google Earth (2014)

Elaboración propia

\subsubsection{Flujo Vehicular}

El flujo vehicular en la zona de estudio es pesado y variado. Gran parte del flujo vehicular es definido por el tipo de transporte presenciado y en este caso se trata de una variedad de vehículos muy amplia. Al ser la carretera central una vía interprovincial, que además está rodeada por un alto porcentaje de barriadas e informalidad, se 
presentan muchos moto-taxis y carretillas que agudizan la congestión vial y aumentan las probabilidades de accidentes de tránsito. Debido al carácter de la zona, con múltiples terminales terrestres, también circula un gran número de buses interprovinciales, además del transporte urbano que se da mediante buses y micros. La competencia entre las múltiples empresas de buses genera, al igual que en el resto de Lima, una congestión vial muy alta con contaminación auditiva y visual, degradando la calidad de vida en la zona. A esto también contribuye el gran número de taxis y colectivos presentes.

Debido al carácter industrial del sector, existe una gran presencia de transporte de carga. Es además uno de los principales factores que ralentizan el flujo vehicular. También circulan camiones remolque que transportan todo tipo de bienes desde el puerto, además de camiones de carga interprovincial. Adicionalmente, debido a la cantidad de comercio barrial de la zona, se movilizan muchos camiones de carga chica, al igual que la versión informal: la carretilla. Claramente esto aumenta el riesgo para aquellos que transitan, pues no cumplen con las medidas de seguridad requeridas. Un problema adicional es el mal estado de los vehículos, por lo que generan un alto índice de contaminación ambiental.

Es importante resaltar que, a pesar de la gran presencia de vehículos pesados y transporte público desorganizado, la mayor cantidad de vehículos son los privados.

El terreno colinda, por el norte con la Av. Nicolás Ayllón, por el oeste con la Calle Manuel Echeandía y por el sudeste con la Av. Nicolás Arriola.

La calle Manuel Echeandía, es una calle poco transitada, mayormente utilizada como atajo para evitar el cruce de las avenidas Circunvalación y Nicolás Ayllón. La hora pico en esta calle se ubica al medio día, con mayor presencia del auto particular, luego camiones y finalmente buses y micros.

La Av. Nicolás Ayllón es la prolongación de la Carretera Central y es una de las vías más utilizadas para llegar al centro de Lima. En las mañanas existe un mayor flujo en dirección Lima centro, pero según los conteos y los gráficos, el momento con mayor circulación de vehículos es a las $12 \mathrm{pm}$. Sin embargo, esto no refleja la realidad, ya que el flujo más intenso se presenta a las 6 $\mathrm{pm}$. La diferencia es que, a esta hora, la congestión es tan fuerte, que ningún auto se mueve durante varios minutos. 
La Av. Nicolás Arriola sirve como conexión entre la Carretera Central y la Av. Javier Prado (centro financiero). El flujo de camiones y buses es constante todo el día, pero se registra un ligero aumento cuando disminuye el flujo de vehículos privados. En las mañanas, cuando las personas van a trabajar, el flujo predominante es hacia el centro financiero. En cambio, en las tardes cuando estos regresan, el flujo predominante es hacia la zona este (ver lámina 8.2).

\subsubsection{Flujo Peatonal}

En la zona se aprecia un flujo peatonal variado: trabajadores, amas de casa, estudiantes de colegio, ciclistas, vendedores de comida, carretilleros, entre otros. El flujo peatonal es fuertemente activado por motivos como trabajar o estudiar, al igual que por puntos de venta de periódico o comida. Estos últimos, se suelen ubicar alrededor de los paraderos de buses o taxis, cerca de las intersecciones viales. De esta manera, varias esquinas tienen un fuerte flujo de personas, algunas transeúntes y otras como consumidores.

Los cruceros peatonales sirven para conectar los diversos paraderos y usos de la zona, como es en el caso del Camal de Yerbateros. Existen tendencias según la hora de análisis: por ejemplo, en la mañana se incrementa el flujo peatonal pues todos salen a trabajar o a estudiar. Esto se repite en la tarde cuando todos regresan. Durante el día disminuye la intensidad, pero mantiene un nivel constante. Las calles secundarias suelen servir como atajos para llegar a diversos lugares, por lo que se mantiene un flujo leve.

Todas estas actividades suceden a pesar de las múltiples problemáticas en la zona. Los paraderos de buses y taxis suelen ubicarse arbitrariamente, respondiendo a la ubicación de la mayor cantidad de peatones, es decir, ahí donde se ubican los cruceros peatonales. Debido a la cantidad de buses y micros que transitan y compiten en las vías, estos terminan bloqueando los cruceros peatonales, impidiendo el paso organizado del peatón. Nuevamente, debido a la competencia entre múltiples empresas de transporte, estas se estacionan de manera desorganizada, inclusive en doble hilera, bloqueando el flujo vehicular y obligando al peatón a invadir la vía para subirse a un bus (ver lámina 8.3). 
Otro problema es la falta de respeto por parte del automóvil hacia el peatón, obviando su preferencia de cruce cuando el conductor busca girar en una intersección. Esto termina por impedir que el peatón cruce en el tiempo que tiene disponible y, por lo tanto, lleva a que no se respeten las luces peatonales y crucen cuando no deben, generando la posibilidad de un accidente.

\subsubsection{Entorno, lugares de interés}

Se trata de una zona que contempla una gran variedad de lugares de interés, sobre todo a nivel metropolitano. Esto se debe a sus importantes vías de acceso y su función como nodo conector con la sierra central del país a través de la carretera central.

Existe también, una gran cantidad de puntos de interés a nivel vecinal en la zona de viviendas consolidadas, pero una carencia de estos en la parte industrial.

Entre los lugares de interés de escala metropolitana se encuentra el actual Terminal de Yerbateros al igual que el Camal de Yerbateros, la Clínica San Juan de Dios y el Mercado $\mathrm{N}^{\circ} 2$ de frutas. Estos tienen un impacto relativamente grande por diversos motivos. Por ejemplo, la escala del equipamiento, el impacto visual, el nivel de popularidad tanto en generaciones nuevas como antiguas, la referencia a nivel metropolitano, etc. (ver lámina 9.1).

Los lugares de interés también pueden funcionar a una escala distrital, como lo son grifos, una tienda de productos de construcción y terminales terrestres de menor escala. Estos son puntos de interés para personas que transitan en la zona o el distrito ya que funcionan como puntos de orientación.

A nivel vecinal aumentan los puntos de referencia, ya que incluyen parques, escuelas, postas médicas, comisarías, etc. Estos son puntos relevantes para un peatón que transita por los diversos barrios.

En general, los lugares de interés se encuentran repartidos de manera homogénea en la zona de estudio, por lo que cuenta con gran potencial para ser un sector rico en actividades vecinales, intercambio y como eventual nodo articulador con suficientes equipamientos. 


\subsubsection{Zonificación}

La zonificación en la zona de estudio abarca múltiples usos. El sector perteneciente a San Luis está dedicado principalmente a industria liviana, mientras que el sector perteneciente a Ate se encuentra zonificado como industria liviana y vivienda taller. El Parque Zonal Cahuide, que abarca una gran área de la zona de estudio, es categorizado como Zona Recreativa Pública. En el resto de la zona de estudio predomina la Vivienda Taller, Residencia de Densidad Media, Comercio Zonal y Comercio Vecinal. Aquello que pertenece al cerro el Agustino es categorizado como Zona de Tratamiento Especial.

Toda la industria liviana presente en la zona de estudio alcanza un 32\% de esta, parecido a la vivienda taller que alcanza un $31 \%$. Las instituciones educativas son pocas y representan un $0.9 \%$ de la zona de estudio (Municipalidad de San Luis, 2015).

Figura 51: Zonificación en la zona de estudio
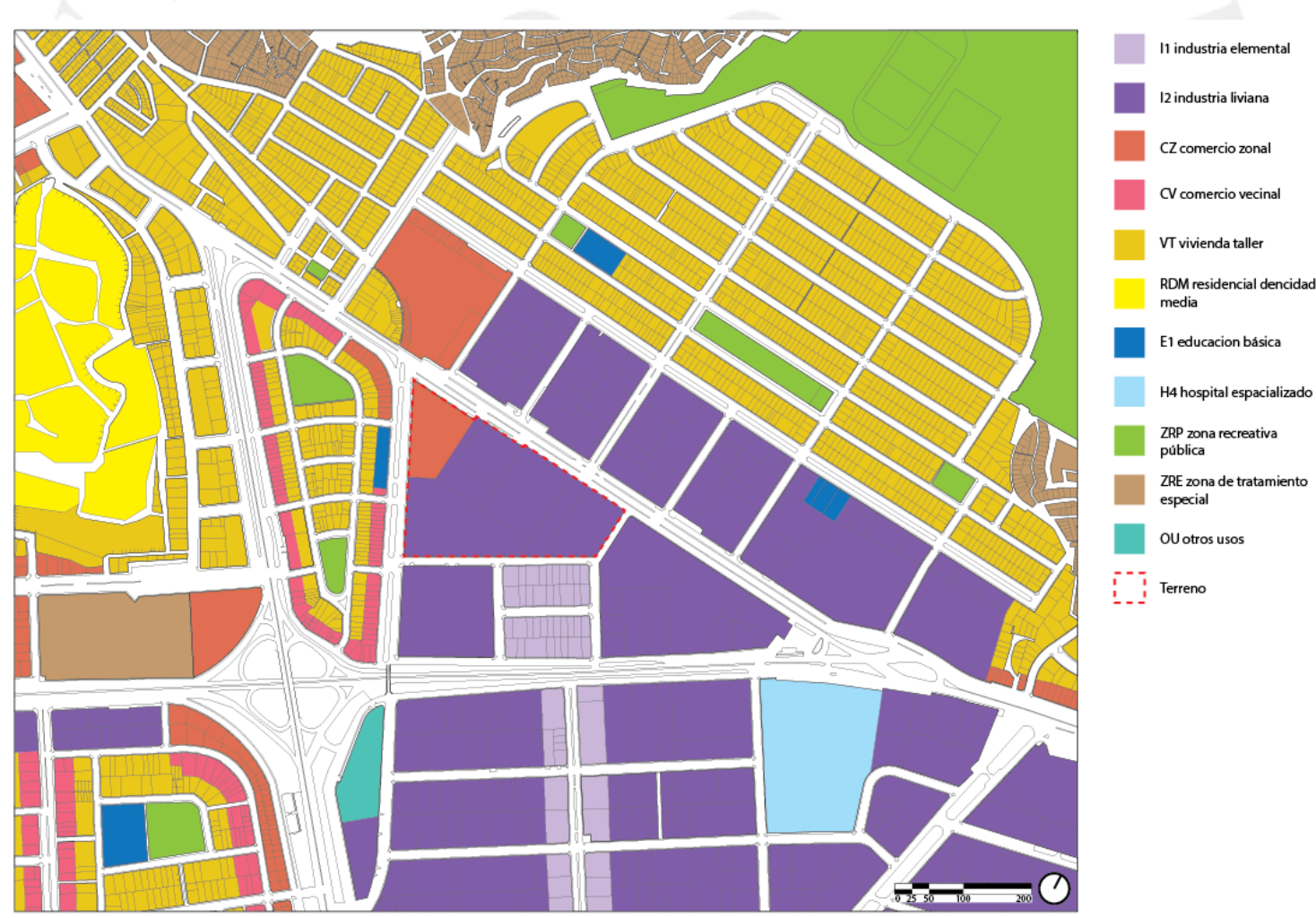

Fuente: Instituto Metropolitano de Planificación (2007)

Elaboración propia

Los lotes usados para industria liviana son significativamente más grandes que aquellos para la vivienda taller, ya que por normativa deben cumplir con un mínimo de $1,000 \mathrm{~m}^{2}$. Esto genera una diferencia sustancial en la espacialidad de las calles: en 
algunos casos con muros perimetrales de 3-4 metros de altura que recorren cuadras completas, y en otros con comercios esporádicos entre ingresos y salidas a viviendas o restaurantes.

El comercio, tanto zonal como vecinal, representa un $7.6 \%$ de la zona de estudio. Sin embargo, esto no considera el comercio presente en la vivienda taller, uno de los usos predominantes en la zona (ver lámina 10.1).

Uno de los sectores más consolidados, aparte del sector de Vivienda Taller ubicado frente al Parque Zonal Cahuide, es el cerro El Pino, cuya zonificación corresponde a Vivienda de Densidad Media.

Así mismo la menos consolidada y con zonificación de "tratamiento especial” es la zona del cerro El Agustino, ya que es una zona de alto riesgo en la cual no se permite la construcción de viviendas, sin embargo, esta igual se da de manera informal.

Otros sectores de la zona de estudio se podrían considerar como áreas de transición, ya que se están empezando a diferenciar las áreas de comercio de las residenciales. En estas mismas zonas, la tendencia es la de permitir diferentes tipos de comercio en los frentes de las manzanas que dan hacia las avenidas principales.

Tabla 27: Porcentaje de usos

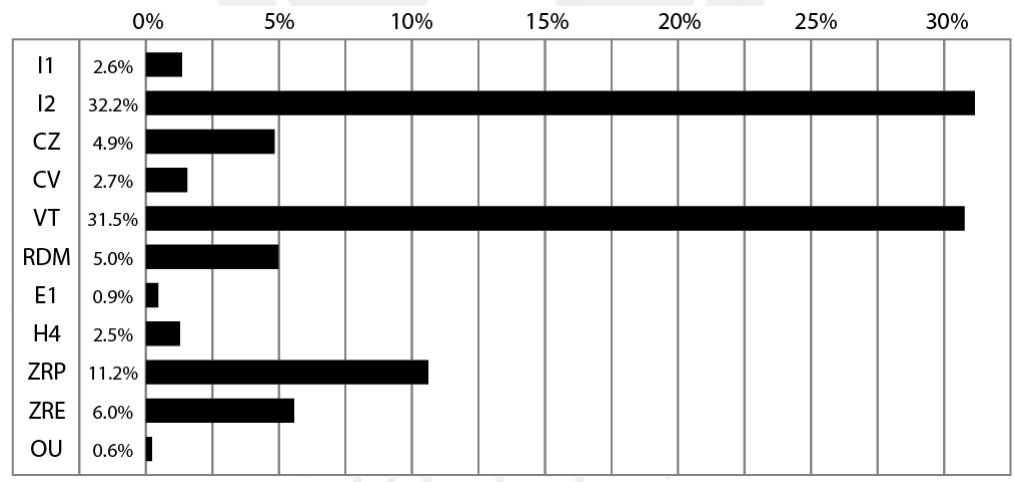

Elaboración propia

\subsubsection{Percepción}

La percepción en la zona se genera en base a una combinación de factores, como lo que uno ve, lo que oye y la calidad espacial del sitio. Estos pueden generar sentimientos de 
inseguridad, estrés, además de malestares físicos a través de la contaminación ambiental o auditiva.

La principal característica de la zona es su espacialidad efímera: mercados, calles y estacionamientos que definen espacios en constante cambio de acuerdo a las diferentes horas del día. La acumulación de basura y el precario estado de las edificaciones denotan una falta de interés por parte de los propietarios y de los diferentes municipios por su aspecto. Esto contribuye a la contaminación visual, al igual que zonas congestionadas por el fuerte tránsito vehicular. Lo mismo aplica a calles principalmente industriales, en las que se estacionan un gran número de camiones y que terminan cumpliendo la función de baño público. Se puede establecer claramente la Carretera Central y la vía Circunvalación como ejes principales de contaminación, tanto a nivel visual como auditivo. Todos estos factores, combinados con la ausencia de espacio público y por consecuencia peatones, son contribuyentes al sentimiento de inseguridad en la zona. Inclusive en aquellas calles o intersecciones en las que la presencia de peatones es constante y alta, la inseguridad prevalece, debido al gran desorden vehicular, el aspecto de deteriorado de los alrededores, la ausencia de vegetación y espacios de permanencia.

Figura 52: Contaminación visual y ambiental en la zona

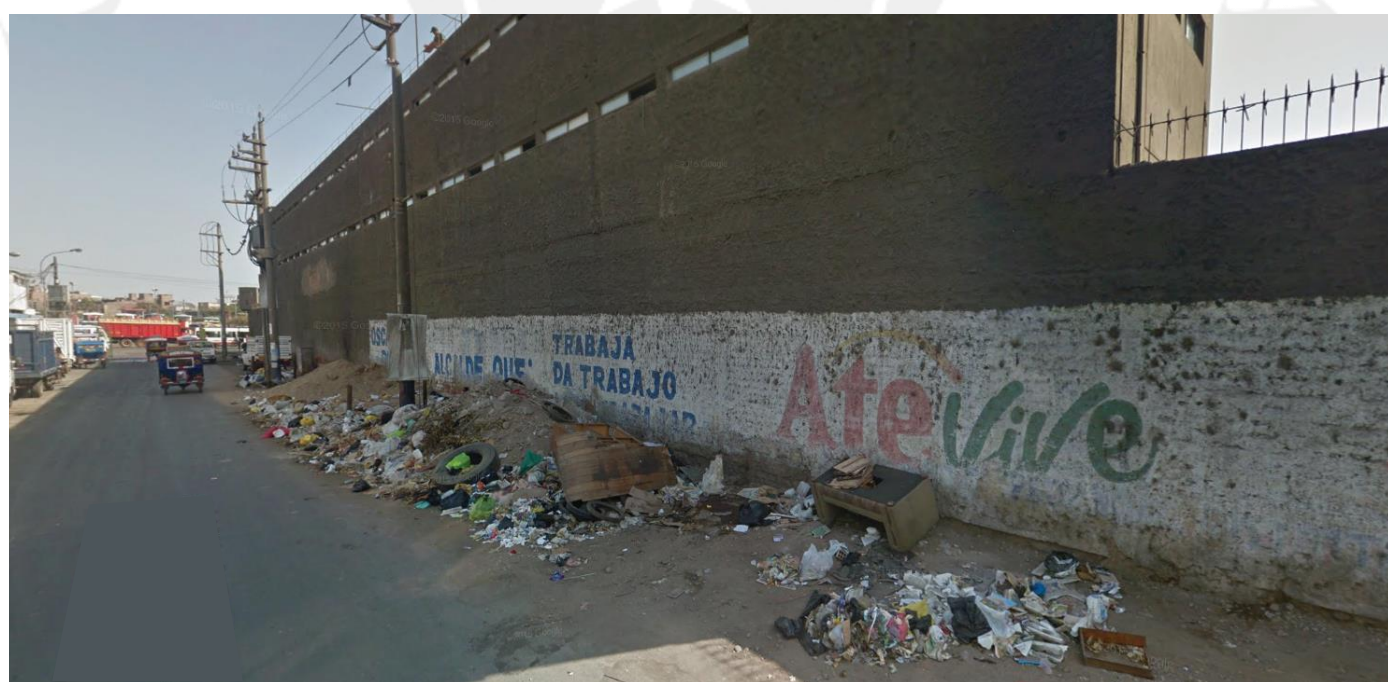

Fuente: Google Street View (2015)

Obtenido de https://goo.gl/uKNPvB 
Como espacialidad pobre se entienden las zonas industriales con muros ciegos a ambos lados de la vía, que crean callejones inseguros para los peatones, al igual que las grandes avenidas principales con intercambios viales que terminan degradando la experiencia peatonal, así como las calles sin veredas (ver lámina 11.1).

Al tratarse de una zona altamente industrial cuenta con vías relativamente anchas y edificaciones que no superan los dos pisos de altura. Esto permite visuales amplias, pero a la vez significa una sobreexposición a la intemperie, debido a la ausencia de árboles o elementos que generen sombra.

Entre las vistas más interesantes resalta el cerro El Pino y el cerro El Agustino, así como la visual que se presenta sobre la Carretera Central desde el bypass.

\subsubsection{Levantamiento fotográfico: Lote y entorno}

La manzana a trabajar está conformada y rodeada principalmente por uso industrial. Entre terminales, almacenes, grifos, talleres de pintura, talleres mecánicos, y otros, los muros perimetrales de la manzana son principalmente ciegos y de unos 3 a 4 metros de altura. Esto lleva a que se utilice fácilmente como estacionamiento informal de buses y camiones, al igual que de punto de acopio para desmonte y basura. El lado que da hacia la carretera central, también es utilizado para estacionamientos informales, obstaculizando partes de la carretera y dificultando el paso de peatones. La ausencia de veredas hace que transitar por ese frente sea sumamente riesgoso. El único frente más amigable con el ciudadano es el que da hacia la Av. Manuel Echeandía, pues no es muy alto ni continuamente ciego, cuenta con una vereda y algo de vegetación que aporta sombra.

En la zona hay dos usos predominantes: Vivienda-Comercio e Industria. En zonas de Vivienda-Comercio, la altura de edificación no supera los 4 niveles y en el caso de industria los muros son ciegos y de 3 a 4 metros de altura. Las calles cuentan con las dimensiones suficientes para implementar una vereda amplia y estacionamientos de autos, pero muchas carecen de este nivel de infraestructura (ver láminas 12.1-12.2). 


\subsubsection{Limitaciones}

Existen dos usos predominantes en la zona: industria y vivienda. La vivienda es categorizada como "vivienda taller" y comparte usos con comercio. Esta es la etapa previa a una urbanización más consolidada, en la que los usos se diferencian de manera más clara. El comercio de la vivienda taller aporta a la zona manteniéndola activa. Sin embargo, genera a la vez una alta competencia entre los comerciantes, que por consecuencia se ven obligados a bajar sus precios.

Por el lado de industria, se presentan problemas como la congestión vial generada por el tipo de vehículos necesarios para el transporte de carga. Al tratarse de muros perimetrales ciegos y de gran altura, que a la vez son utilizados como estacionamientos informales de buses y camiones, aumenta la inseguridad en las calles y se incrementan los puntos para desmonte de basura. En general la zonificación de industria degrada la zona por la poca calidad espacial entre sus linderos (ver lámina 13.1).

Debido a esta diferenciación de usos tan marcada, además de las vías arteriales de carácter metropolitano, la zona se ve automáticamente fragmentada en múltiples piezas. La problemática es que no se logra una integración adecuada al tejido urbano, se generan pequeños barrios aislados y sectores con problemas de inseguridad.

La calidad de vida es baja, en parte por las pocas áreas para recrear que se encuentran. Por partes hay más parques a nivel barrial, sin embargo, un alto porcentaje de estos se encuentran delimitados por una reja o muro, cuya consecuencia es el difícil acceso y uso del espacio. Por esto, los parques quedan en desuso y no cumplen con su objetivo inicial de mejorar la calidad de vida de los usuarios. Otro factor que empeora la calidad de vida, es el nivel de tugurización y hacinamiento presente. Este afecta la habitabilidad ya que, por falta de accesos bien implementados, no cuenta con servicios básicos. La mala accesibilidad, al hacer más difícil el recojo de basura, genera botaderos que malogran el aspecto, contaminan y son posibles focos de enfermedades. Finalmente, una zona tugurizada que además se ubica en un cerro, está expuesta a posibles derrumbes por la mala calidad de la construcción. 


\subsubsection{Potencialidades}

Una de las principales potencialidades de la zona es su ubicación céntrica. Colinda con tres distritos, La Victoria, El Agustino y Ate, y cuenta con la infraestructura necesaria para conectarse de manera inmediata con Lima Este (a través de la Av. Nicolás Ayllón), Lima Sur (a través de la Av. Circunvalación o Av. Evitamiento) o Lima Centro (continuando la Av. Nicolás Ayllón o Nicolás Arriola).

Si bien la calidad de vida no es muy buena, cuenta con las herramientas y el potencial necesario para recuperarse. Una de estas es la presencia de varios parques en la zona, los cuales se pueden intervenir para la generación de espacios públicos. Por otro lado, existe una cultura barrial suficientemente fuerte como para que se consoliden barrios a pesar de la fuerte fragmentación y la existencia de bordes de grandes dimensiones. Adicionalmente, el comercio metropolitano funciona como activador del espacio, atrayendo un constante público peatonal y generando micro comercio en las zonas aledañas (ver lámina 14.1).

La presencia de hitos urbanos también es de gran importancia, ya que le da un sentido de identidad y pertenencia al usuario. De esta manera adquieren un sentido de apropiación y resulta más fácil un proceso de participación ciudadana. Los hitos también funcionan como puntos de referencia.

\subsubsection{Población}

La población de San Luis se reparte casi homogéneamente entre población femenina y masculina, siendo las mujeres mayoría por una ligera diferencia. Adicionalmente se trata de una población predominantemente joven, cuya mayoría es el grupo de 20 a 24 años, tanto en hombres como en mujeres. Los grupos de edad entre 45 y 50 disminuyen drásticamente, pero esto no quiere decir que no exista población del adulto mayor. El grupo de 65 años a más tiene una fuerte presencia, que incluso compite con los rangos de edad de 20-30 años. Esto se ve reflejado en el análisis de la Población Económicamente Activa, pues al contar con un porcentaje tan alto de adulto mayor, se reduce el porcentaje de personas en capacidad de trabajar.

Sin embargo, dentro de la PEA, el porcentaje de personas desocupadas es mínimo. De aquellos excluidos del PEA, predominan las mujeres mayores a 65 años y 
niñas menores a 14. En el caso de los hombres son menos adultos mayores los que no participan, pero si un buen porcentaje de niños menores a 14 años (ver lámina 15.1).

La principal actividad económica de la zona está relacionada al comercio de repuestos para autos, reparaciones, talleres, etc. y luego sigue el comercio al por menor, industria, almacenes y otros. Estas actividades marcan el carácter industrial y poco amigable con el usuario de la zona (Ipsos, 2015).

\subsubsection{Vulnerabilidad}

La vulnerabilidad se evalúa respecto al daño que puede sufrir la zona de estudio en caso de un sismo. Existen cuatro variables que la determinan: la densidad, el estado de conservación, la altura edificada y los materiales de construcción.

En el caso de un sismo, la mayor parte de la zona estudiada se encuentra sobre suelo con regular - buena resistencia. Sin embargo, el cerro El Agustino y las áreas que lo rodean se categorizan bajo "Suelo de pésima resistencia", haciendo que la vulnerabilidad en esa zona sea la más alta. Esto también aplica al cerro el Pino, que es categorizado con una vulnerabilidad "Muy Alta" frente a un sismo (ver lámina 16.1).

Las zonas aledañas a los cerros y las que se emplazan sobre estos, están conformadas por barriadas que nunca fueron reguladas. En estas predomina la informalidad, la tugurización y un estado de conservación muy pobre. Debido a esto, se trata de barrios muy vulnerables en el eventual caso de un sismo, ya que podrían colapsar muy fácilmente. Otro factor que aumenta el nivel de riesgo es la altura edificada, sobretodo bajo las circunstancias especificadas, ya que son precisamente estos barrios que cuentan con mayor altura edificada, llegando hasta tres niveles (Municipalidad metropolitana de Lima, 2012).

El resto de la zona a estudiar tiene niveles más bajos de vulnerabilidad sísmica, pero sigue presentando niveles de riesgo. A pesar de eso, es mucho menos complicada, ya que también es menos densa, utilizan sistemas constructivos más resistentes, la altura edificada no supera dos niveles de altura y se encuentra bien consolidada con un buen estado de conservación. 
Análisis del terreno para el desarrollo del Terminal Terrestre de Yerbateros

\begin{tabular}{|c|c|c|c|}
\hline Distrito: & Área del terreno: & Área analizada: & Actualidad: \\
\hline San Luis & $\begin{array}{l}52523.2 \mathrm{~m}^{2} \\
5.2 \text { hectáreas } \\
54701.5 \mathrm{~m}^{2} \\
\text { con bahías de buses, } \\
\text { taxis y autos } \\
\text { particulares }\end{array}$ & $\begin{array}{l}2^{\prime} 017,711 \mathrm{~m} 2 \\
201 \text { hectáreas }\end{array}$ & $\begin{array}{l}\text { (1) Terminal Terrestre Molina } \\
\text { (2) Maquinarias Nissan } \\
\text { (3) Grifo Primax } \\
\text { (4) Transportes El Pino S.A.C. } \\
\text { (5) GNV Derivados } \\
\text { (6) Frigoríficos La Colonial } \\
\text { (7) Almacén Halema / Marco Polo }\end{array}$ \\
\hline
\end{tabular}

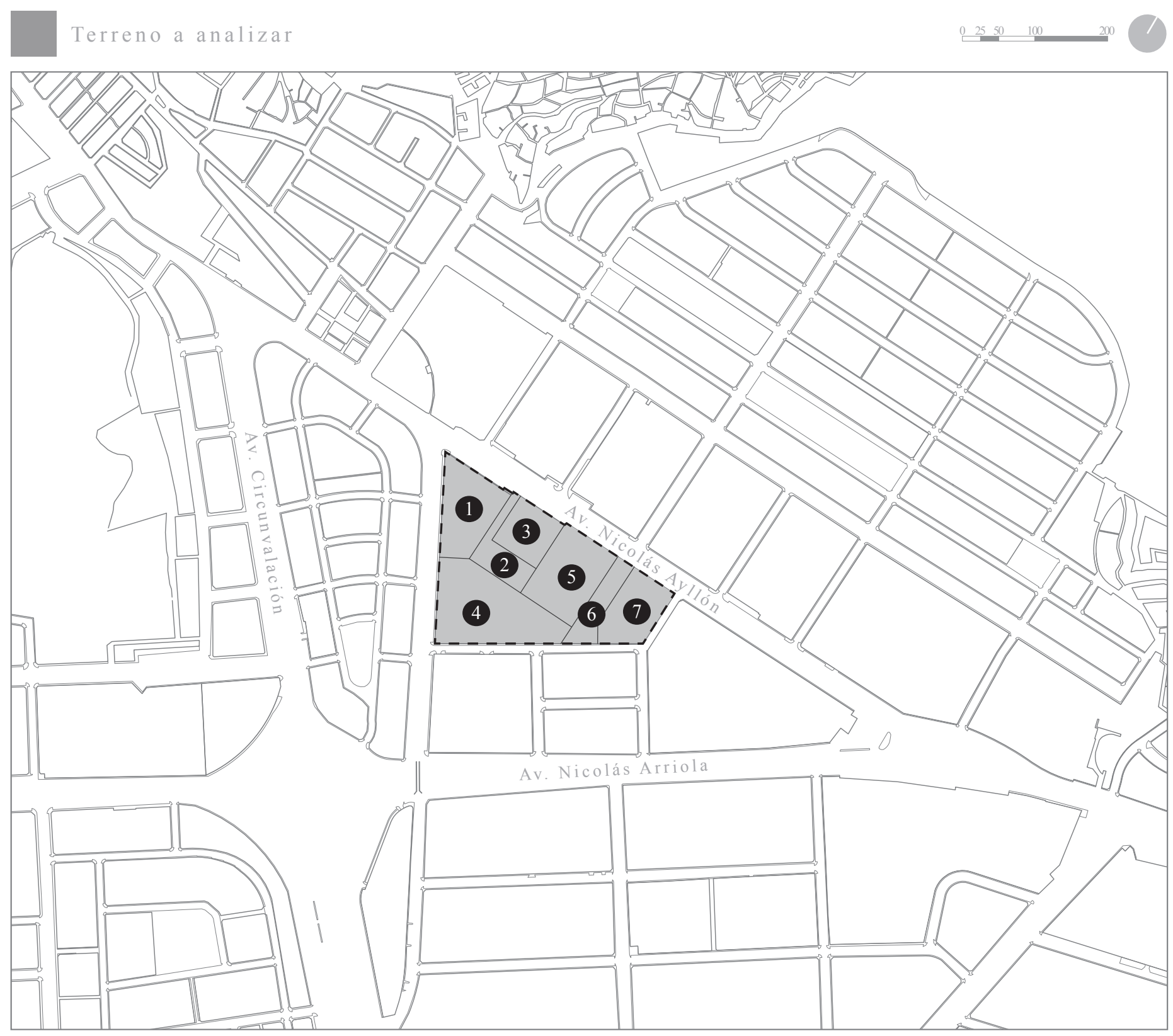




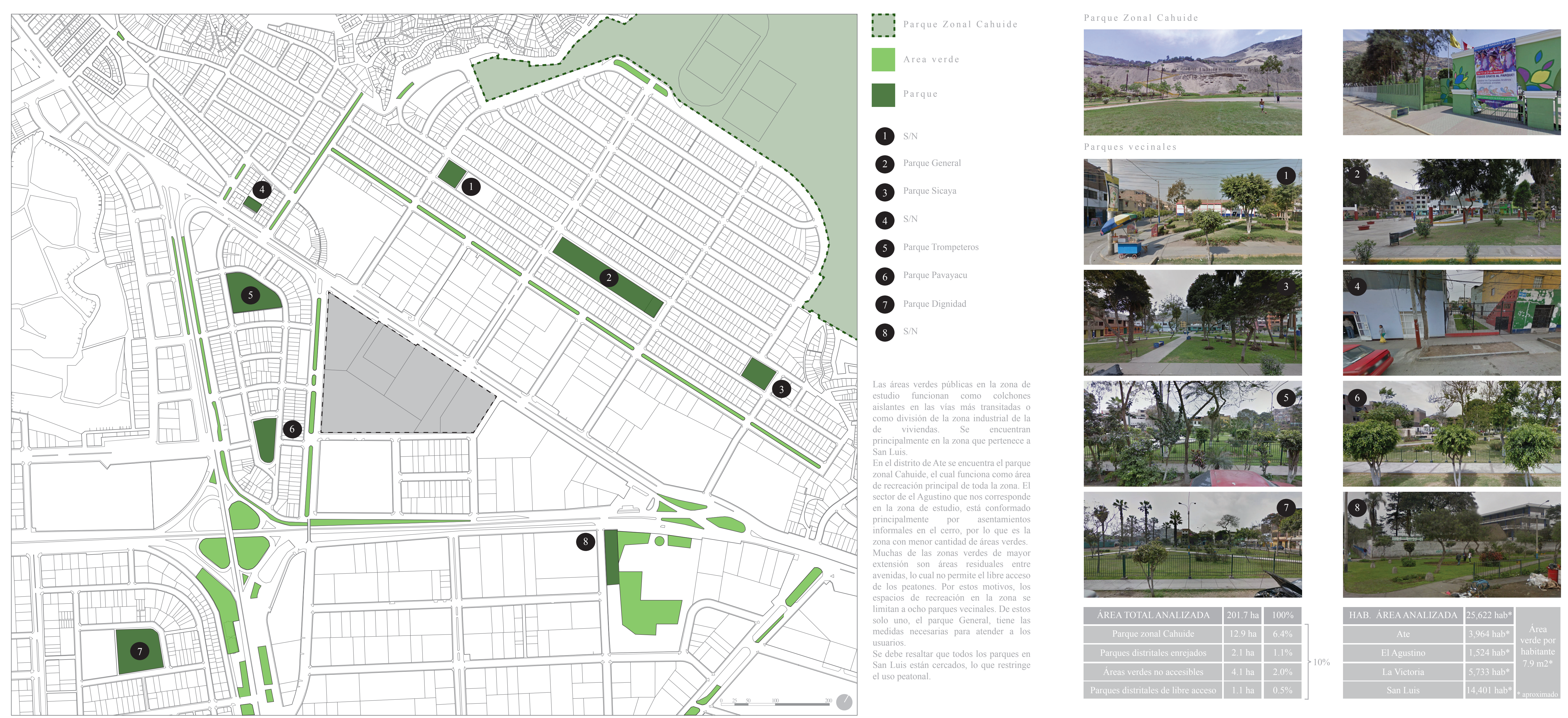


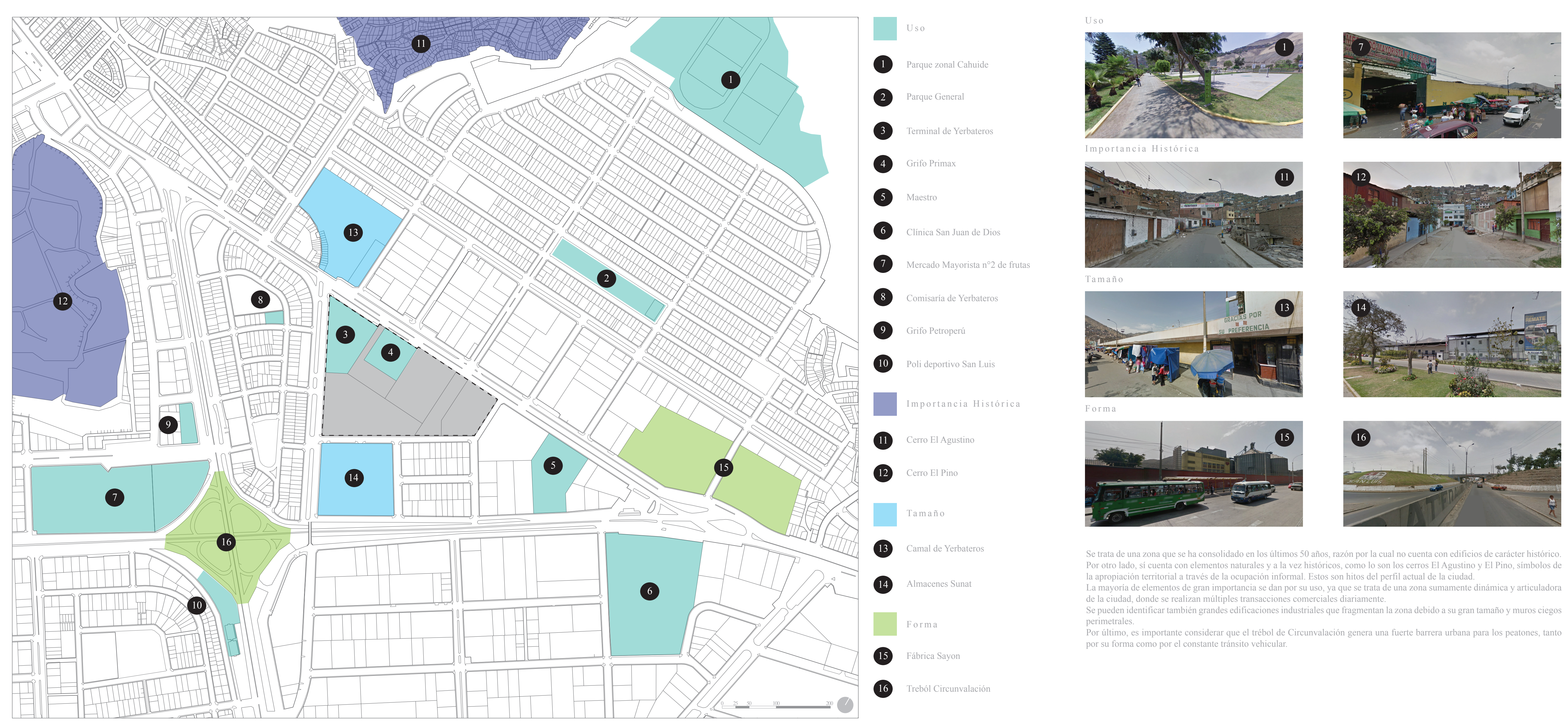




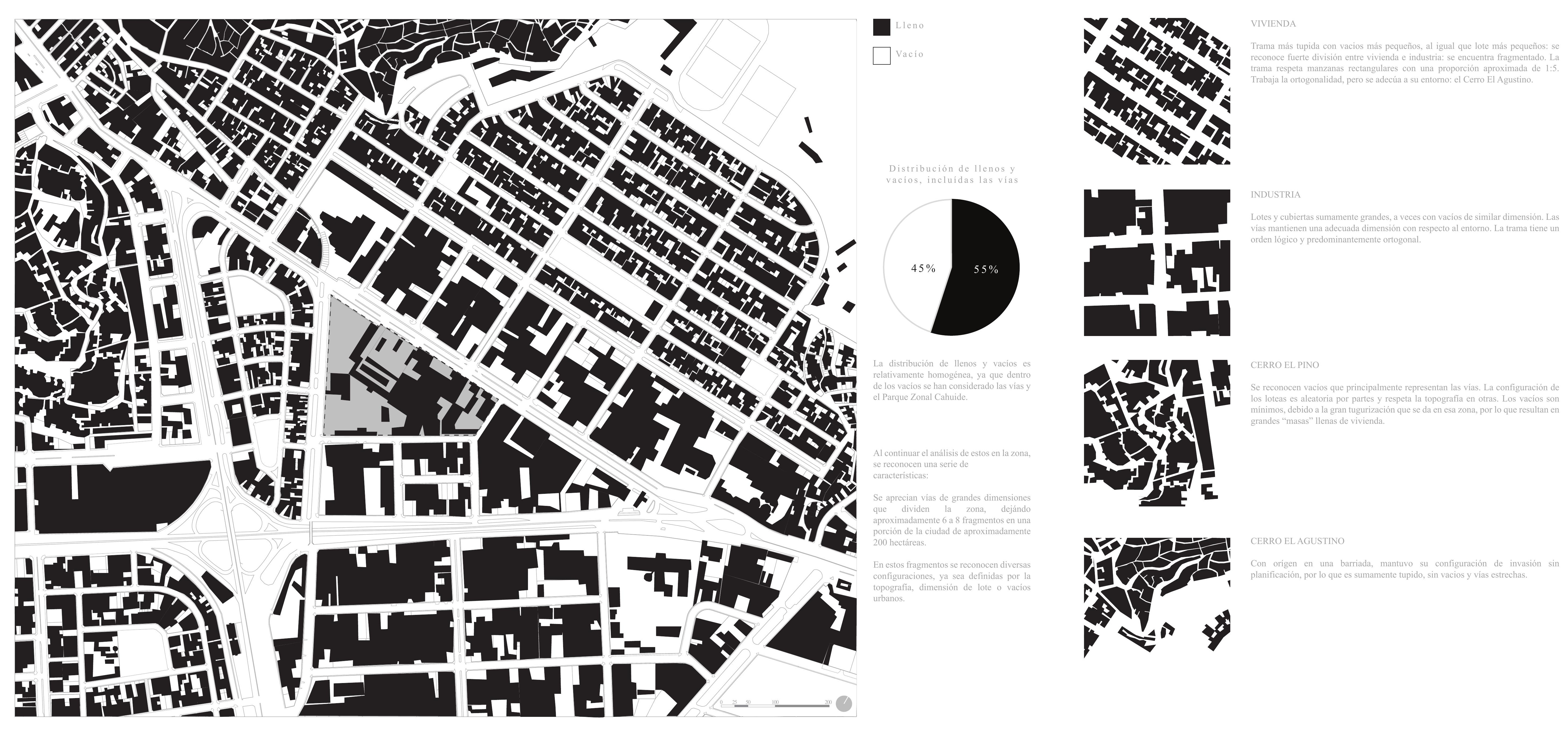




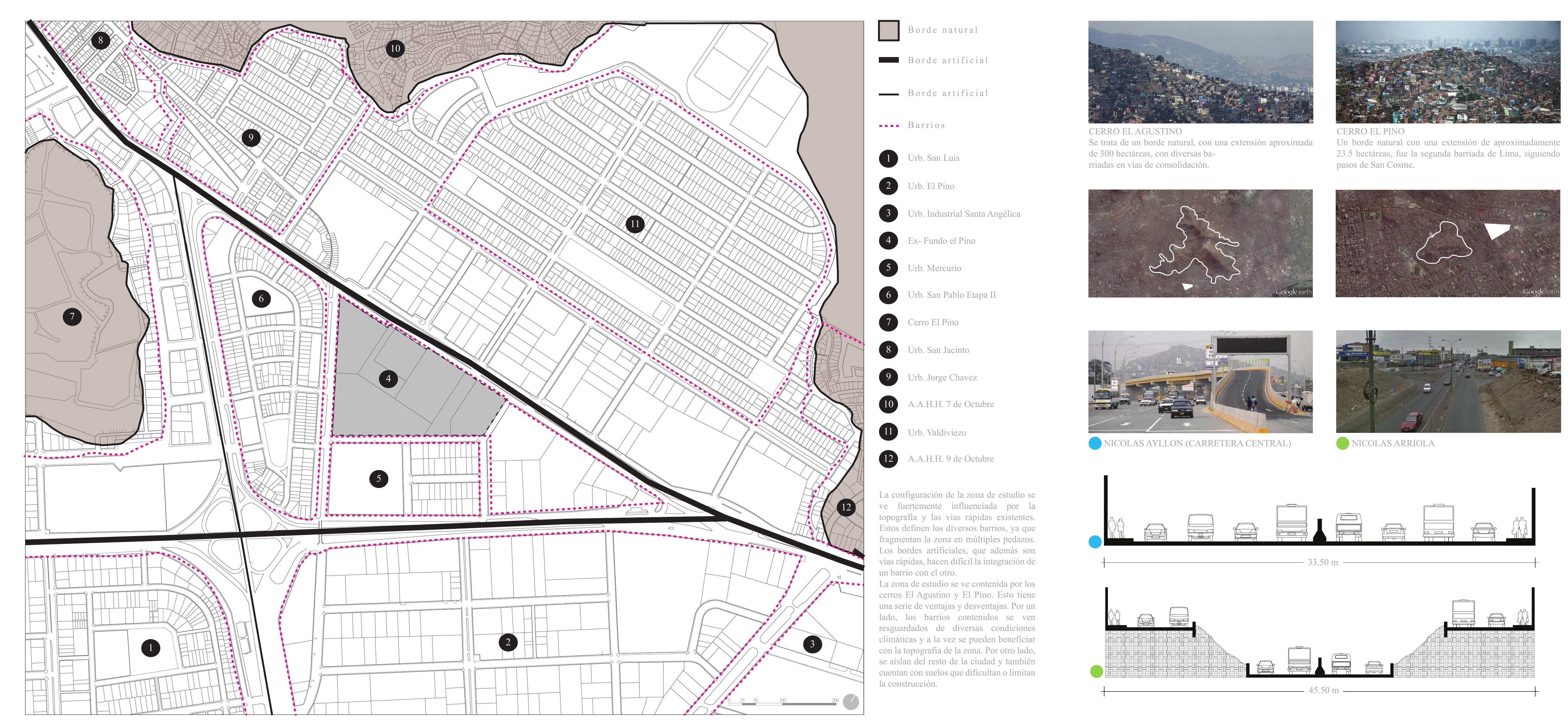



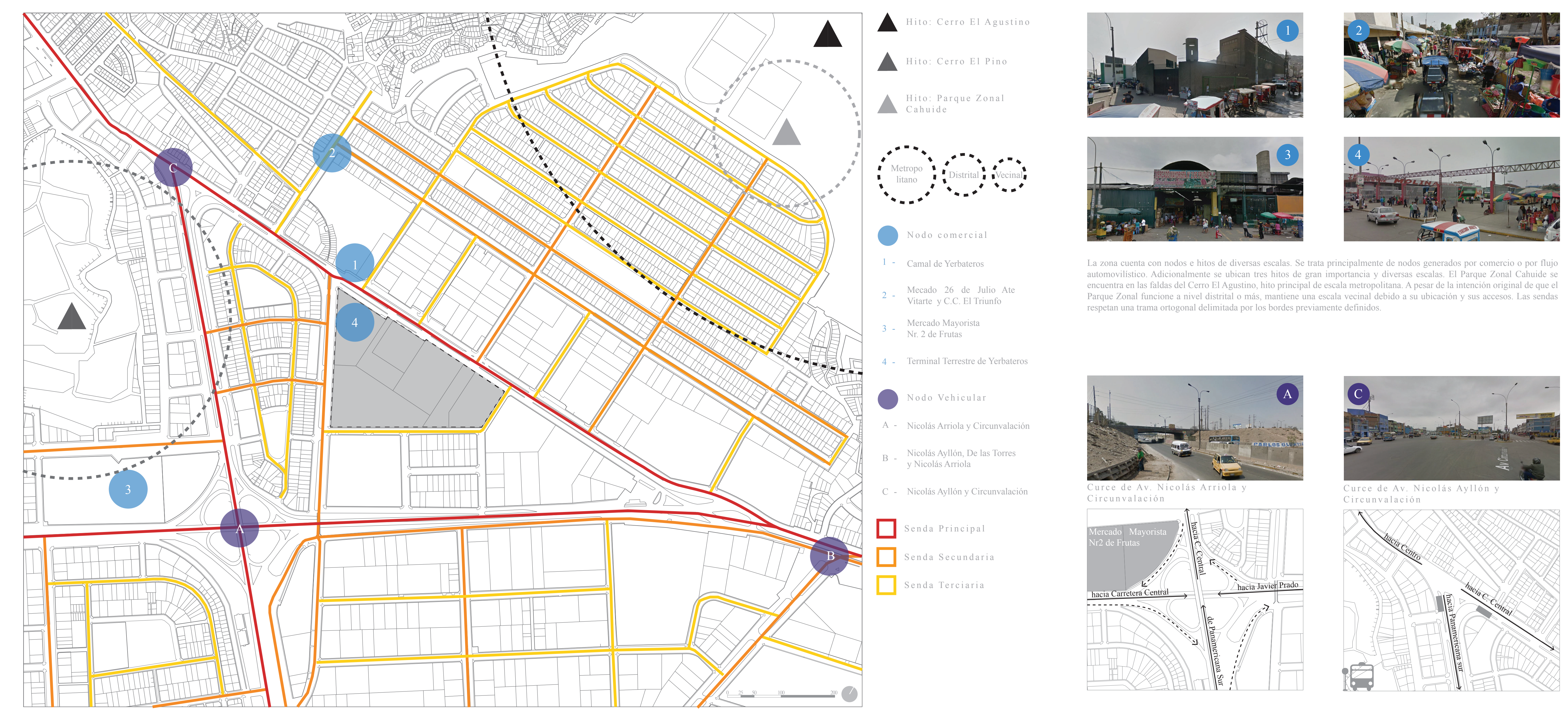

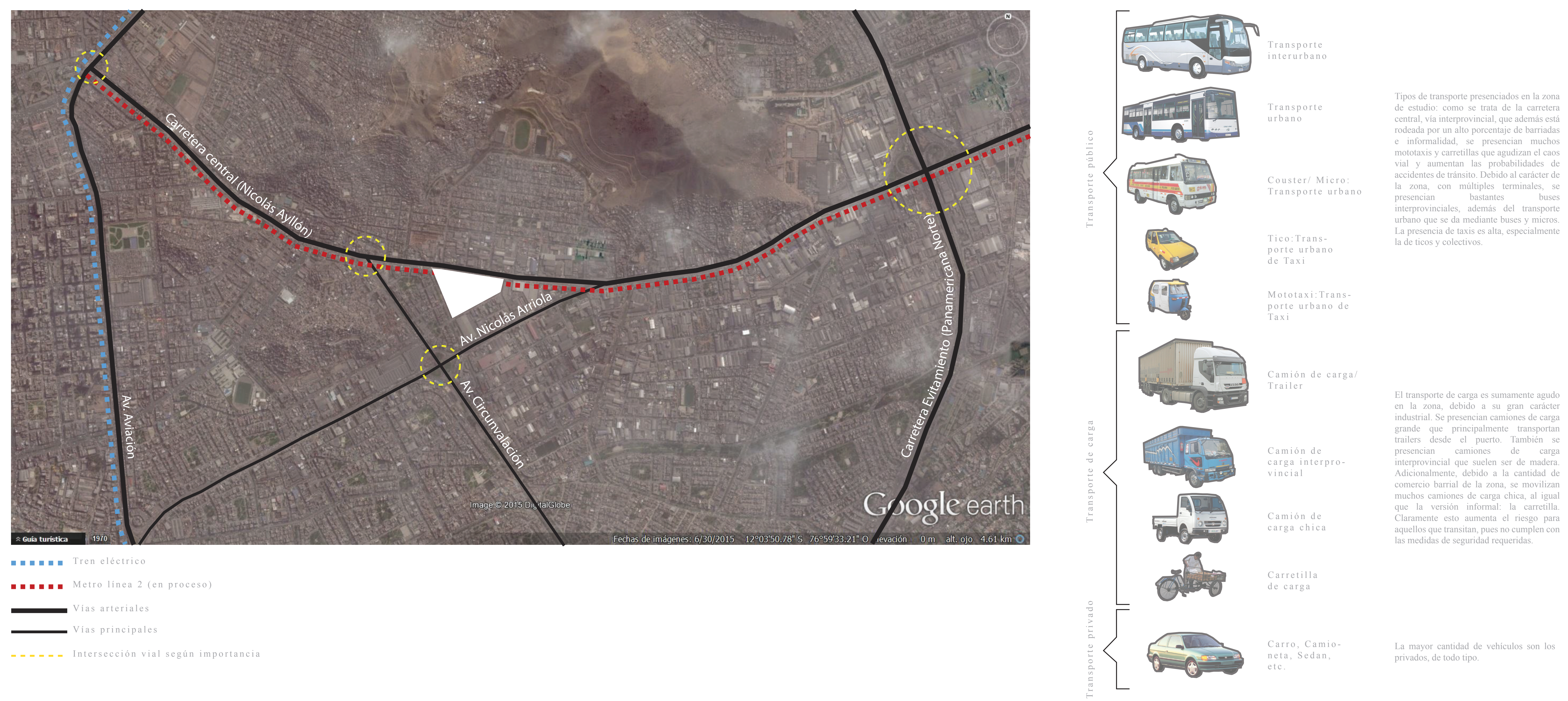

...... Metro línea 2 (en proceso)

$\square_{\text {Vias arteriales }}$ Vinincipale 


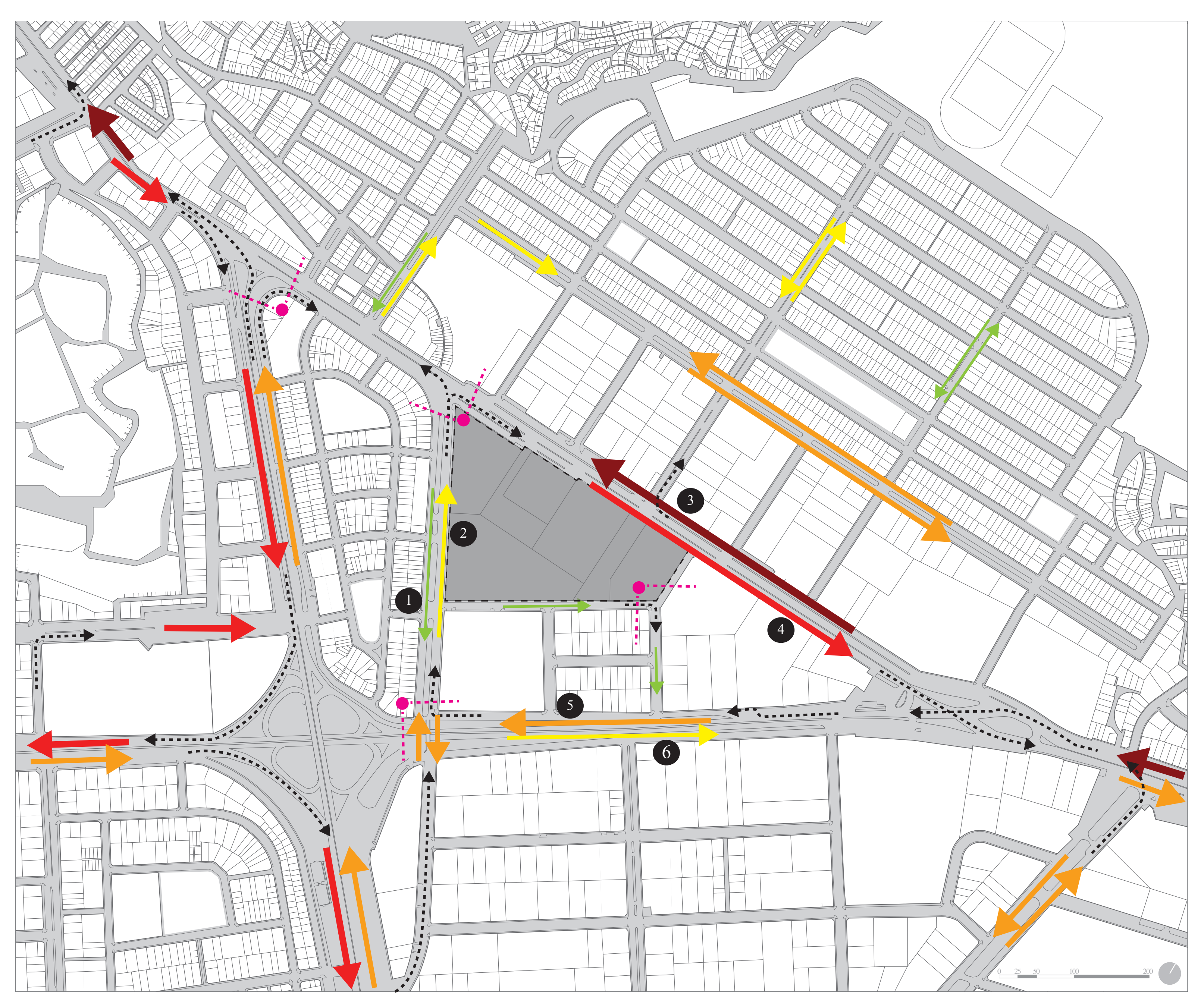

(1)

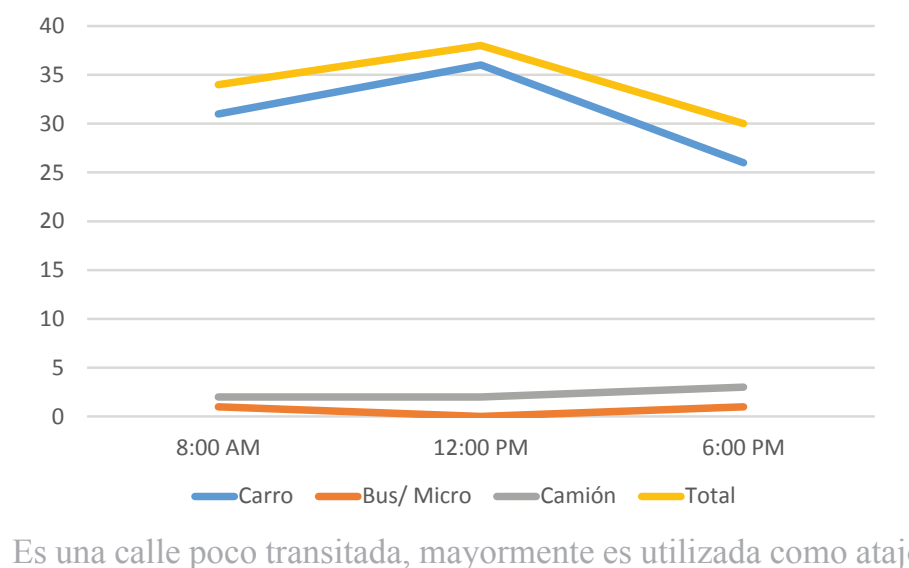

2

$\because \quad$ Esquinas

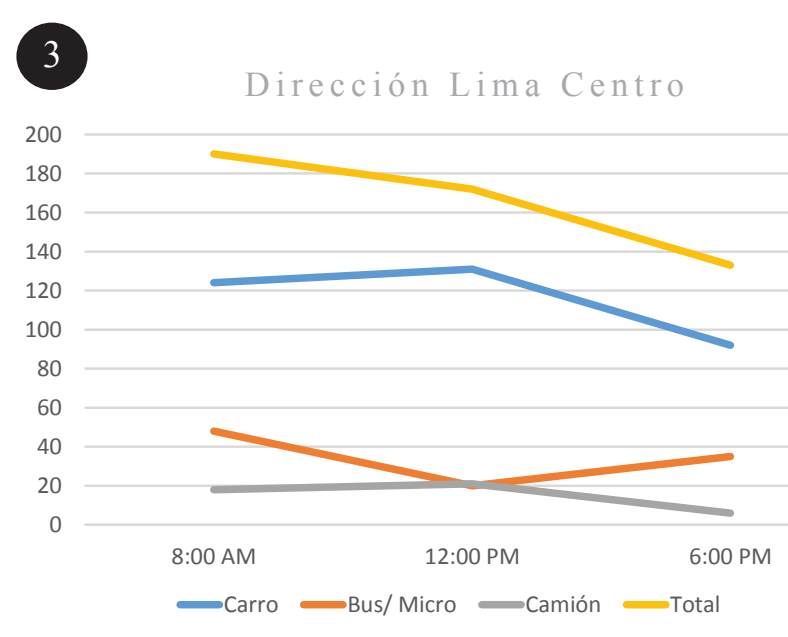

4

Esta prolo
existe un $m$ megn

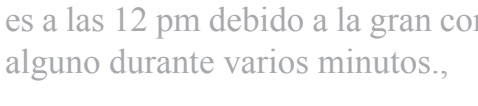

(5)

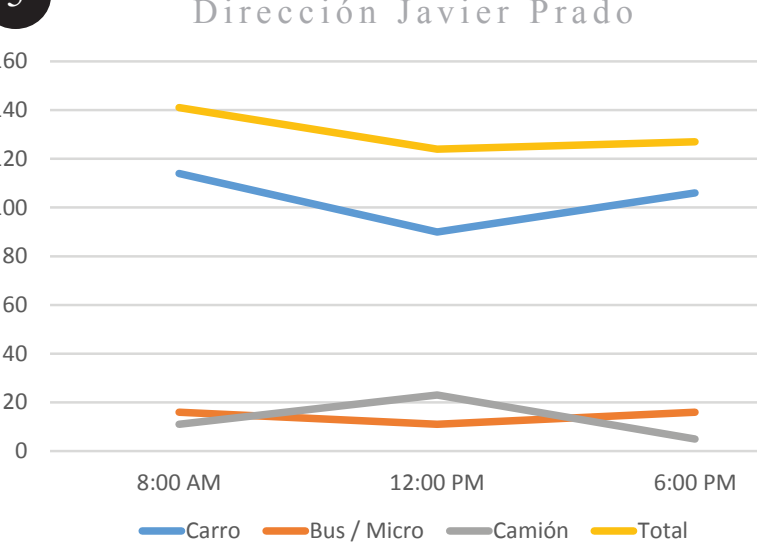

6 

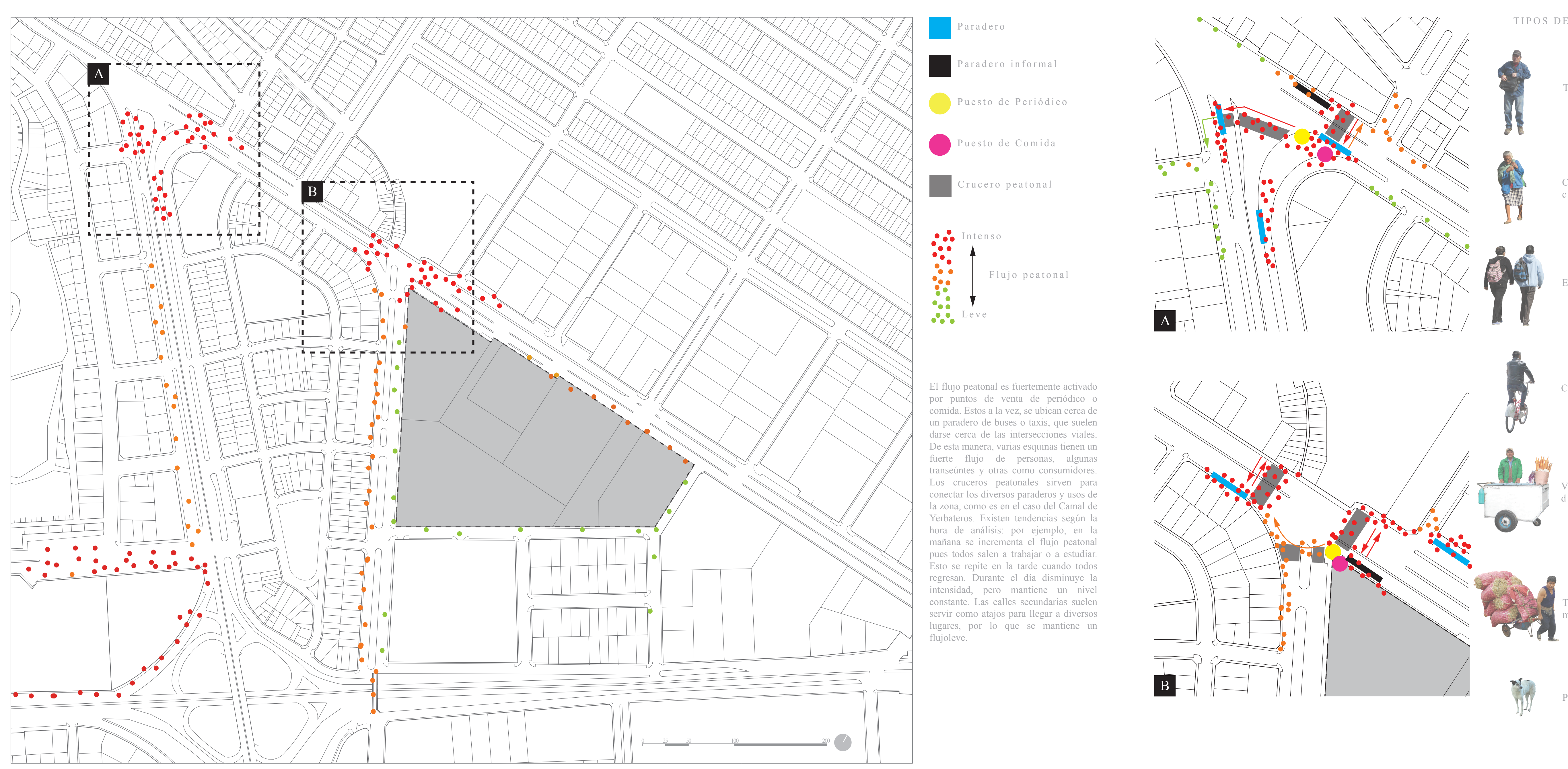


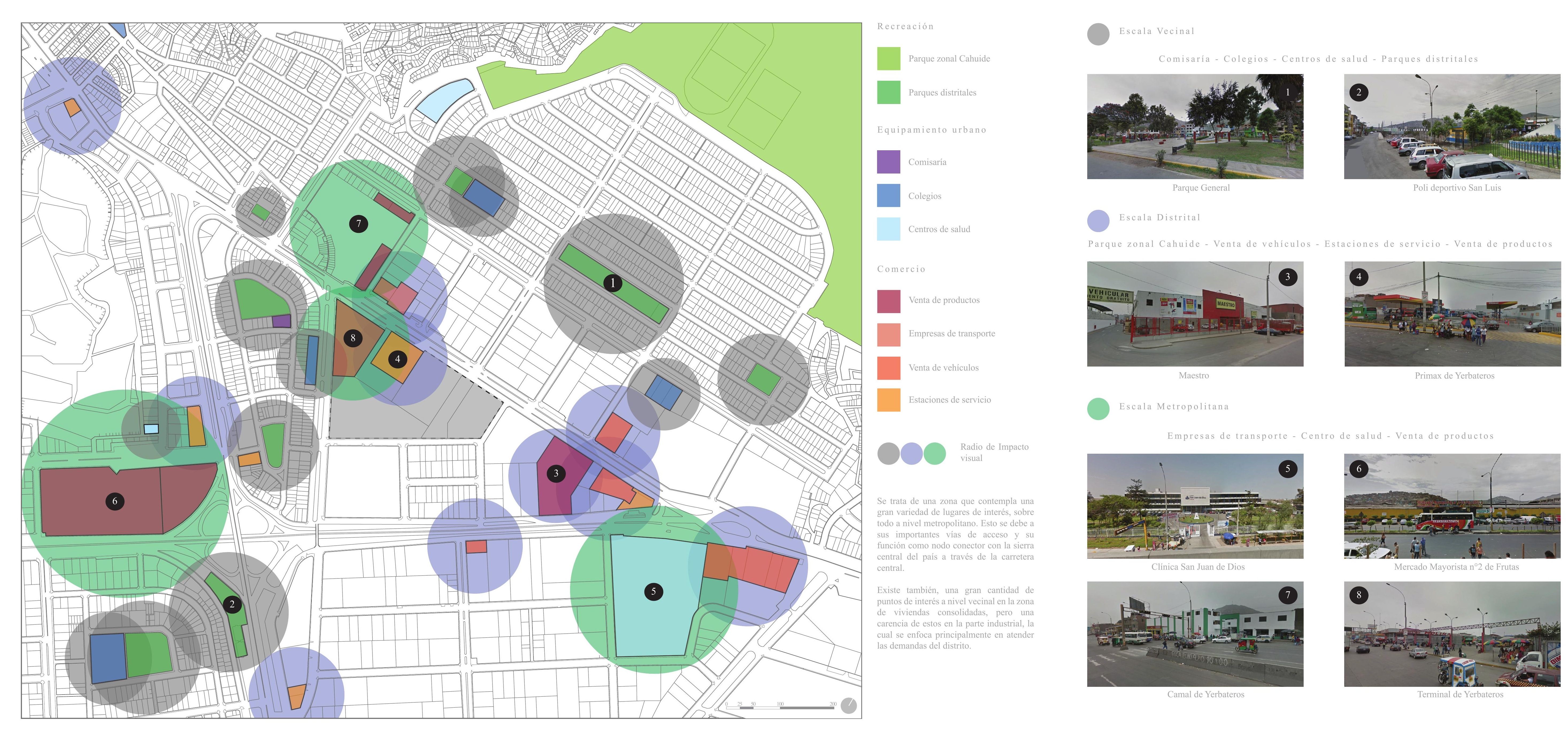




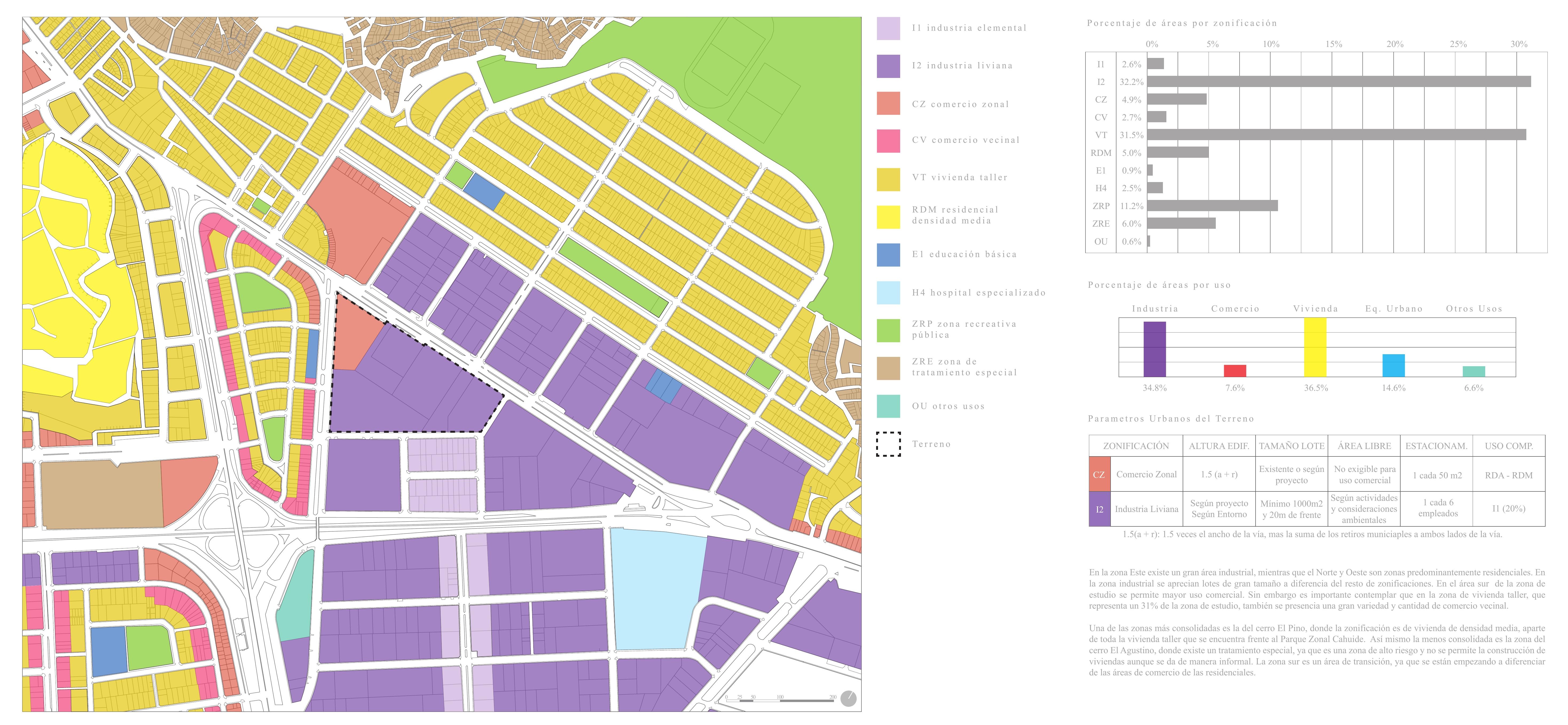



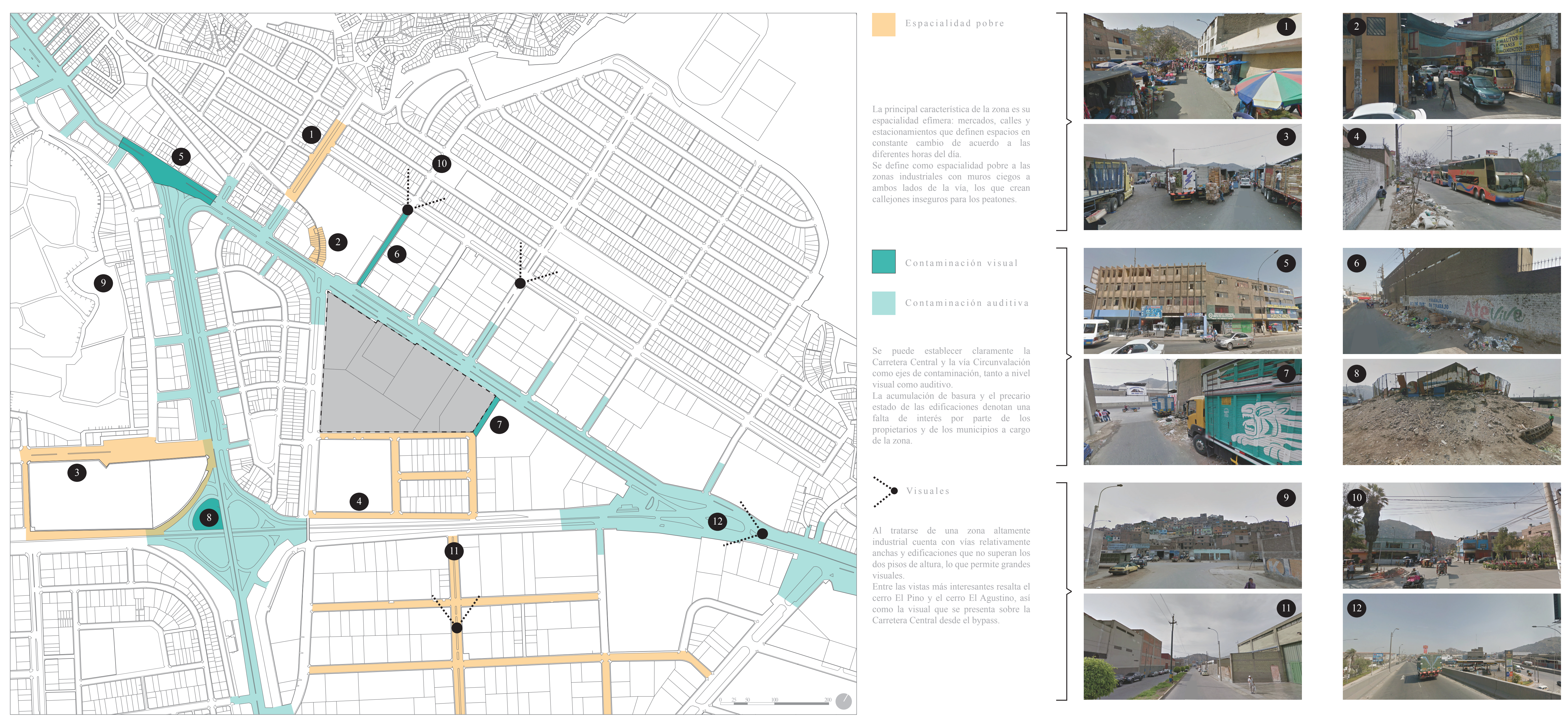


\section{mester}

C.

Codin - the

Det Hit

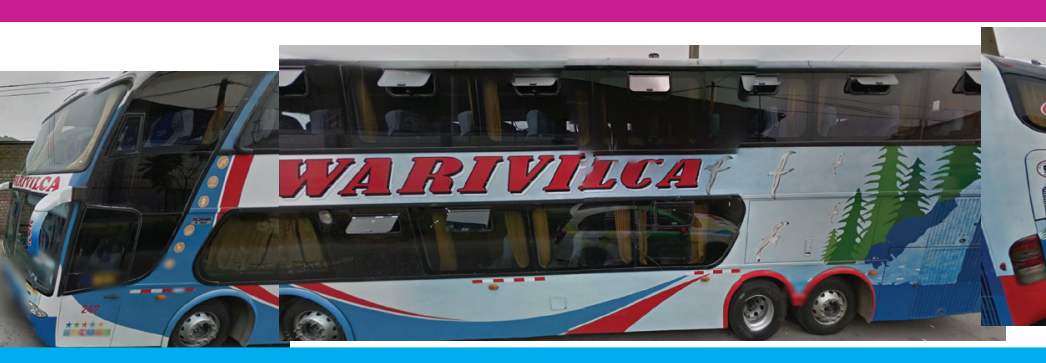
tey

\section{3}

$-12=-\infty$ and

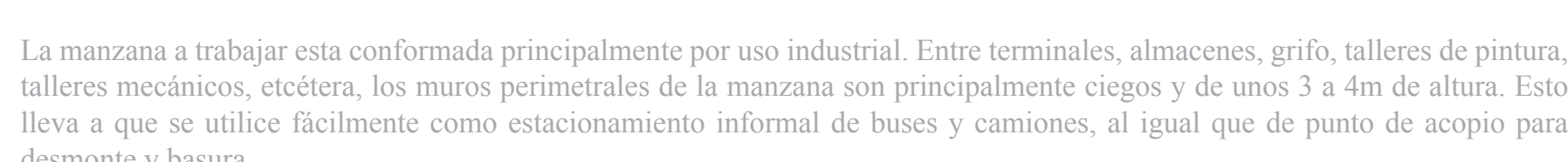

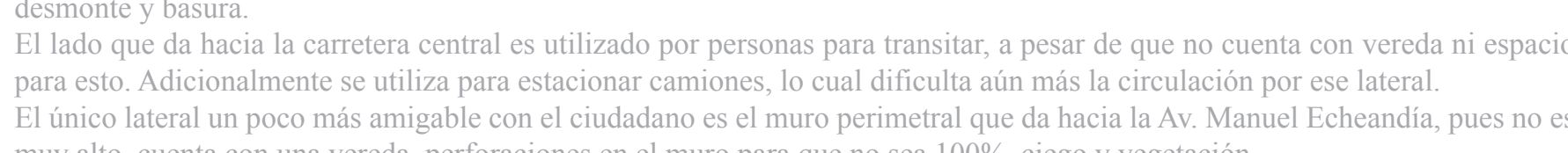

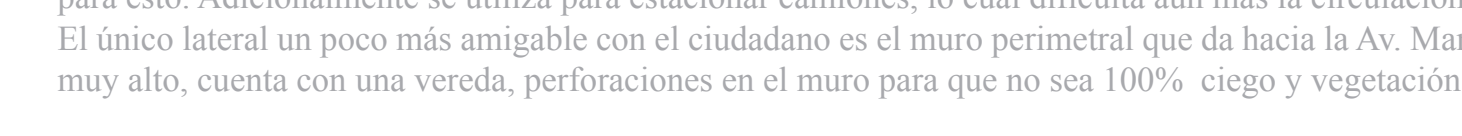




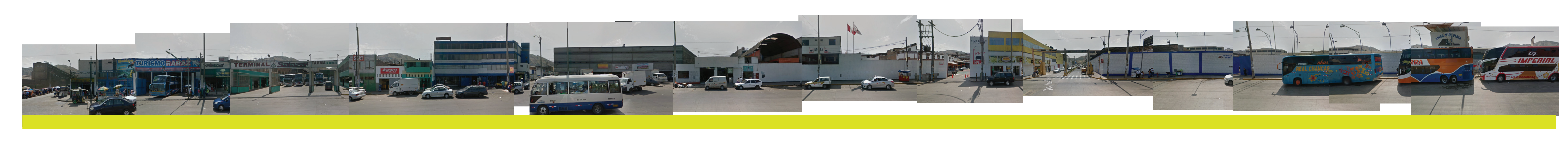
rra

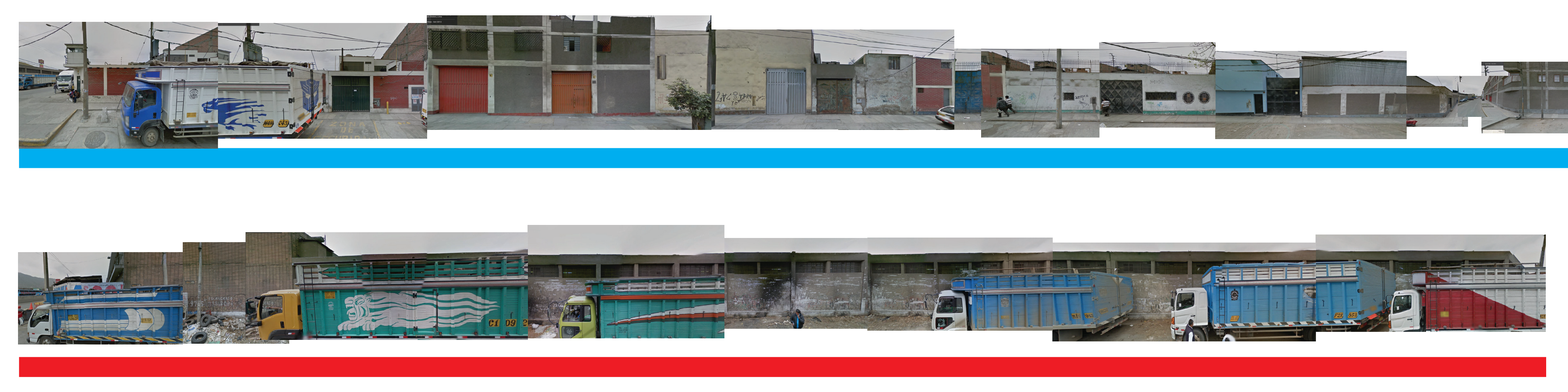

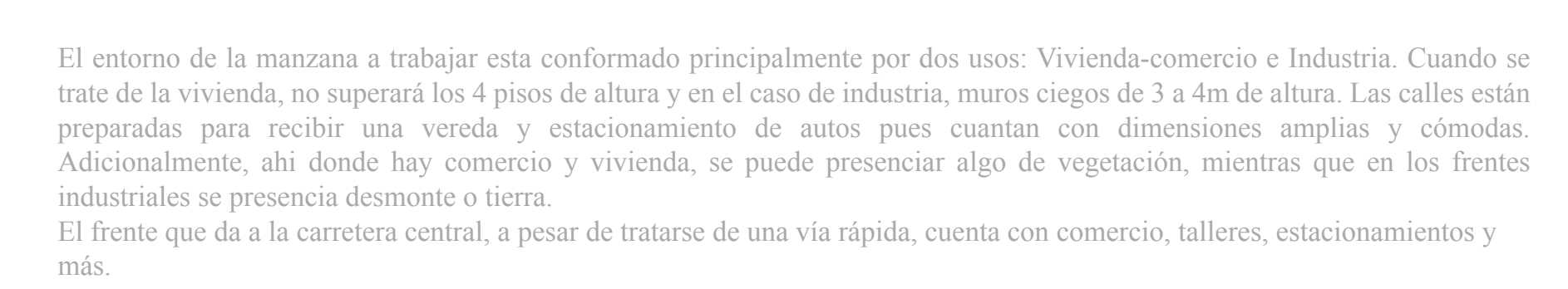



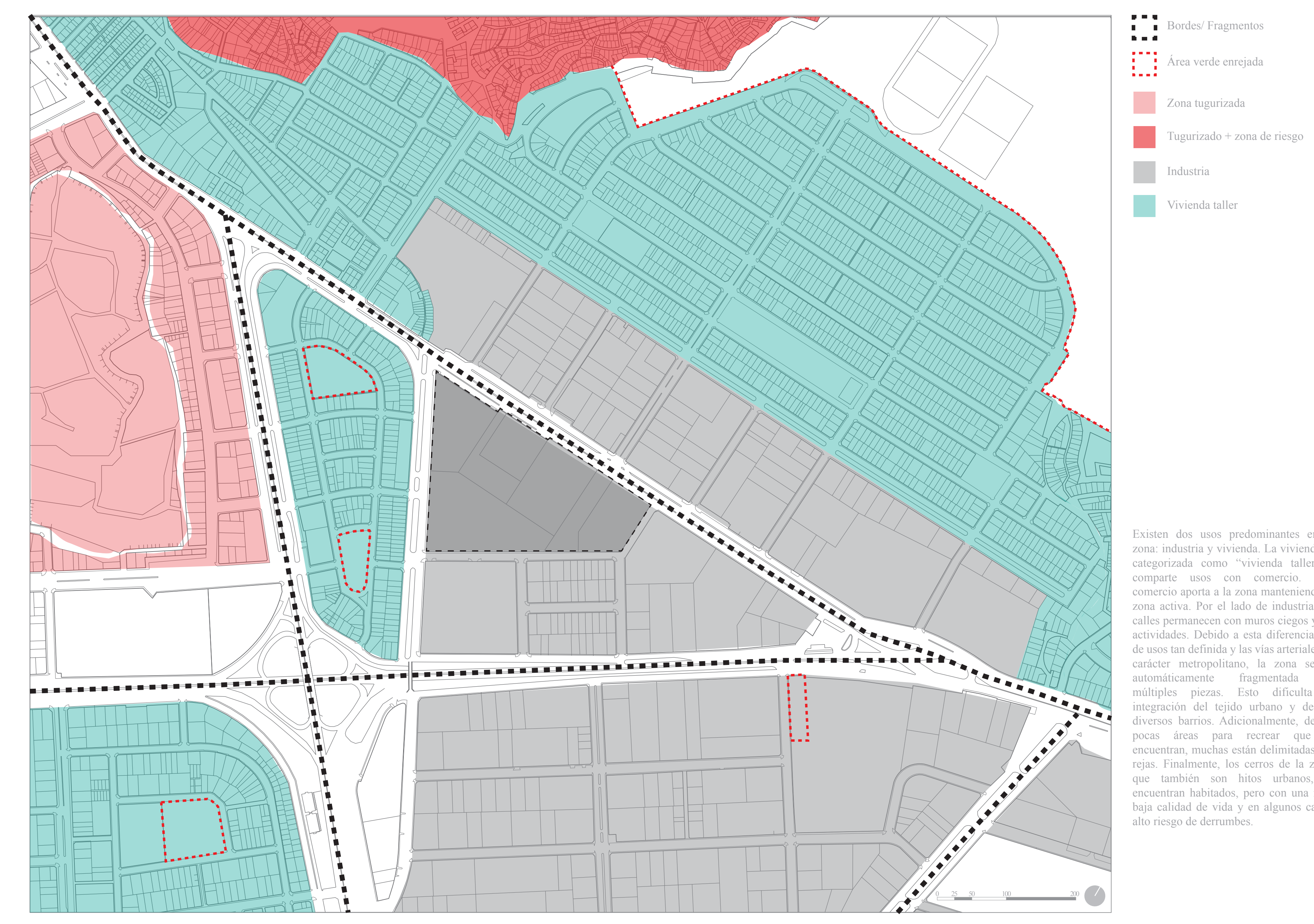

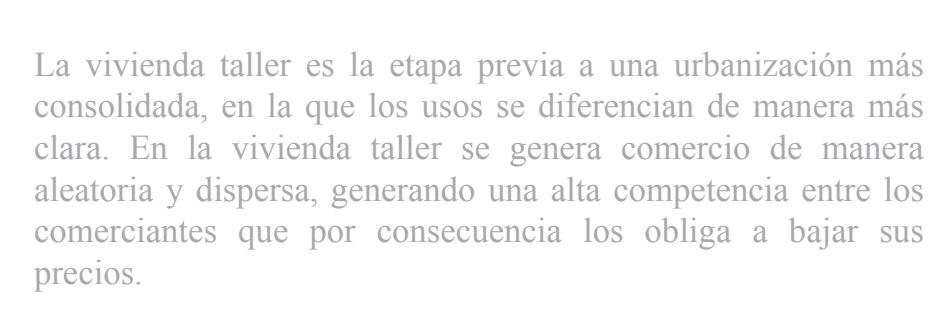

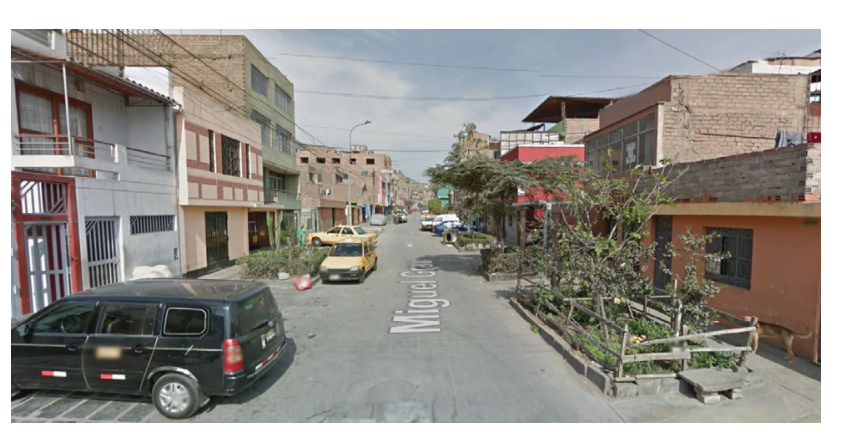

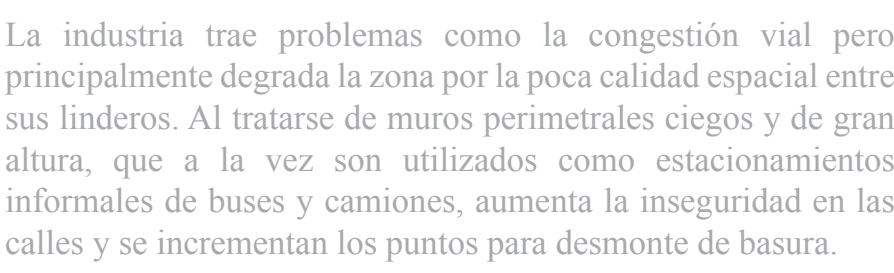

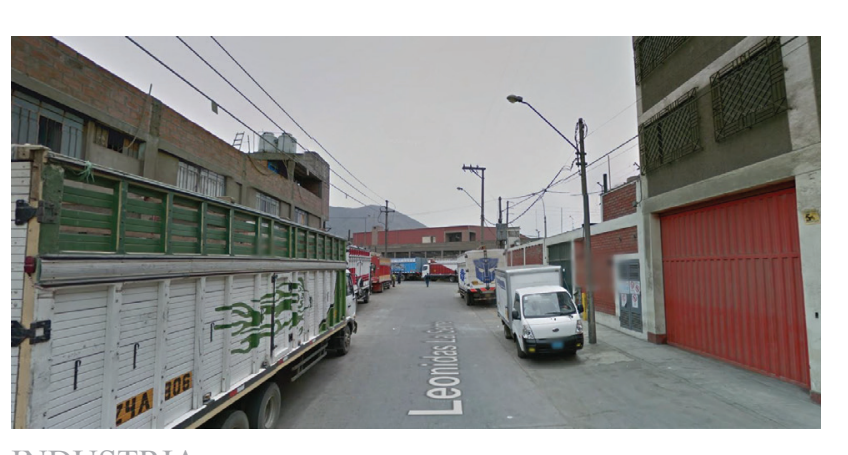

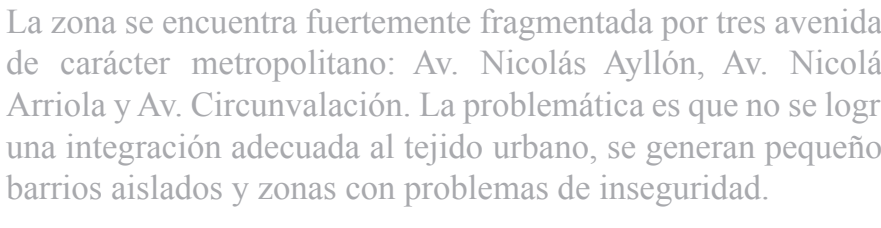

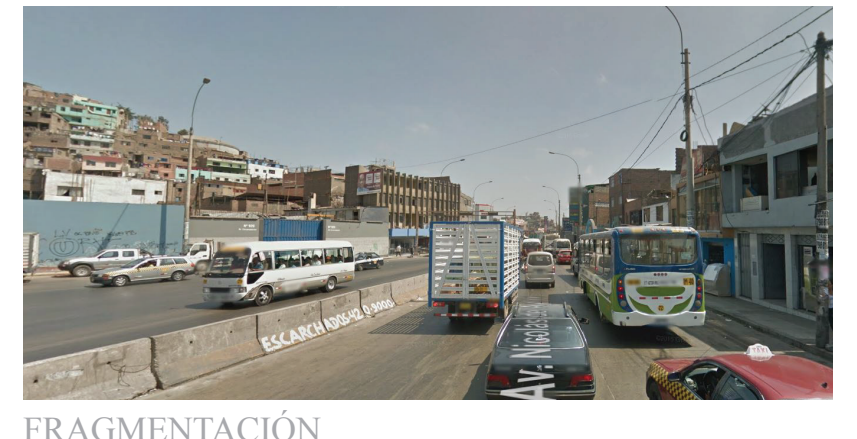

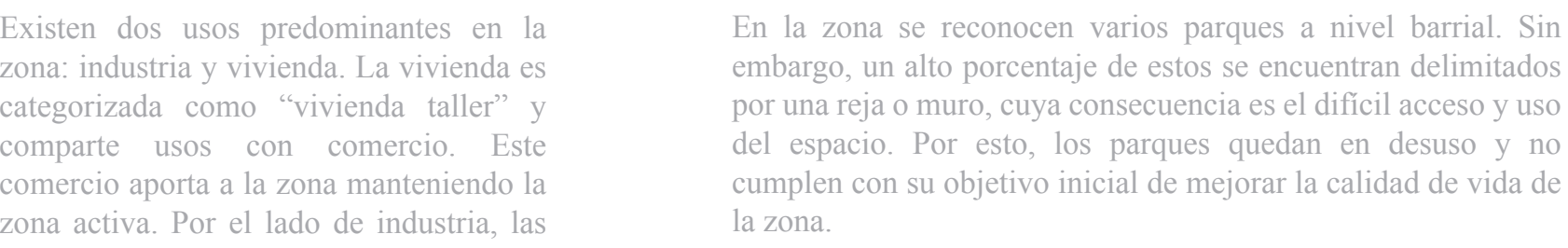

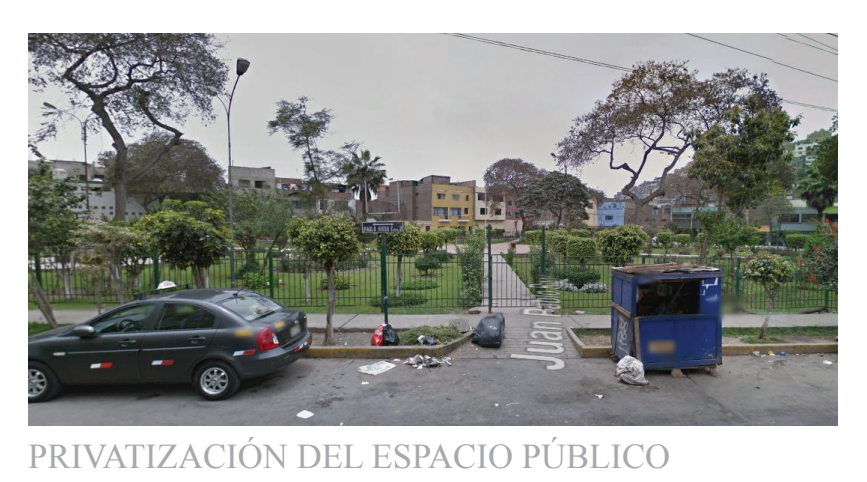

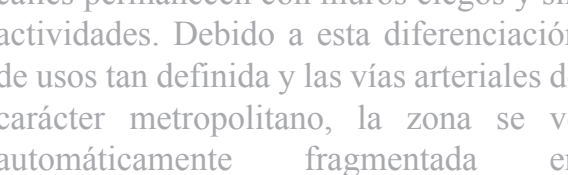

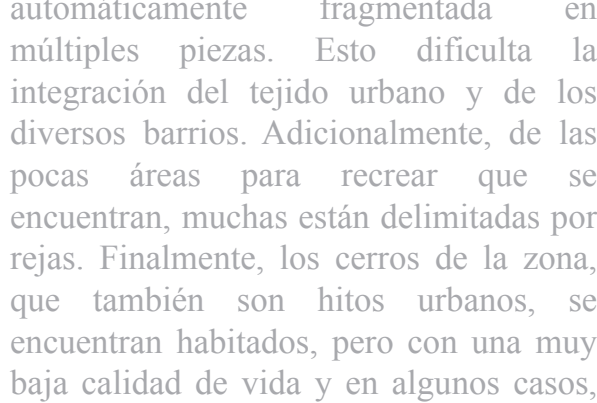

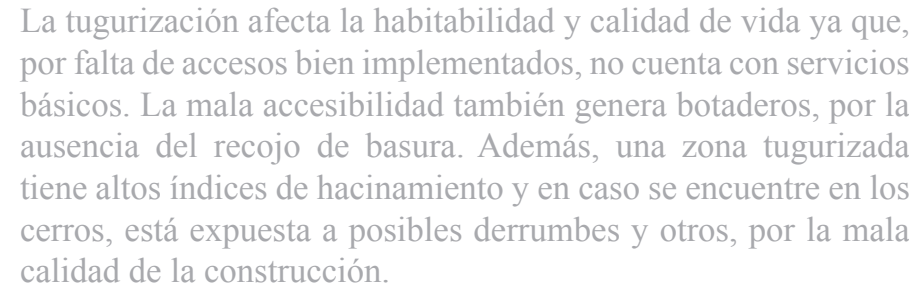

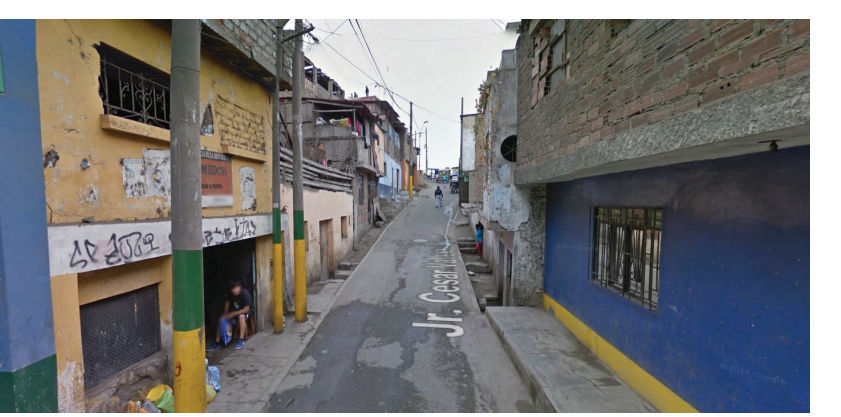




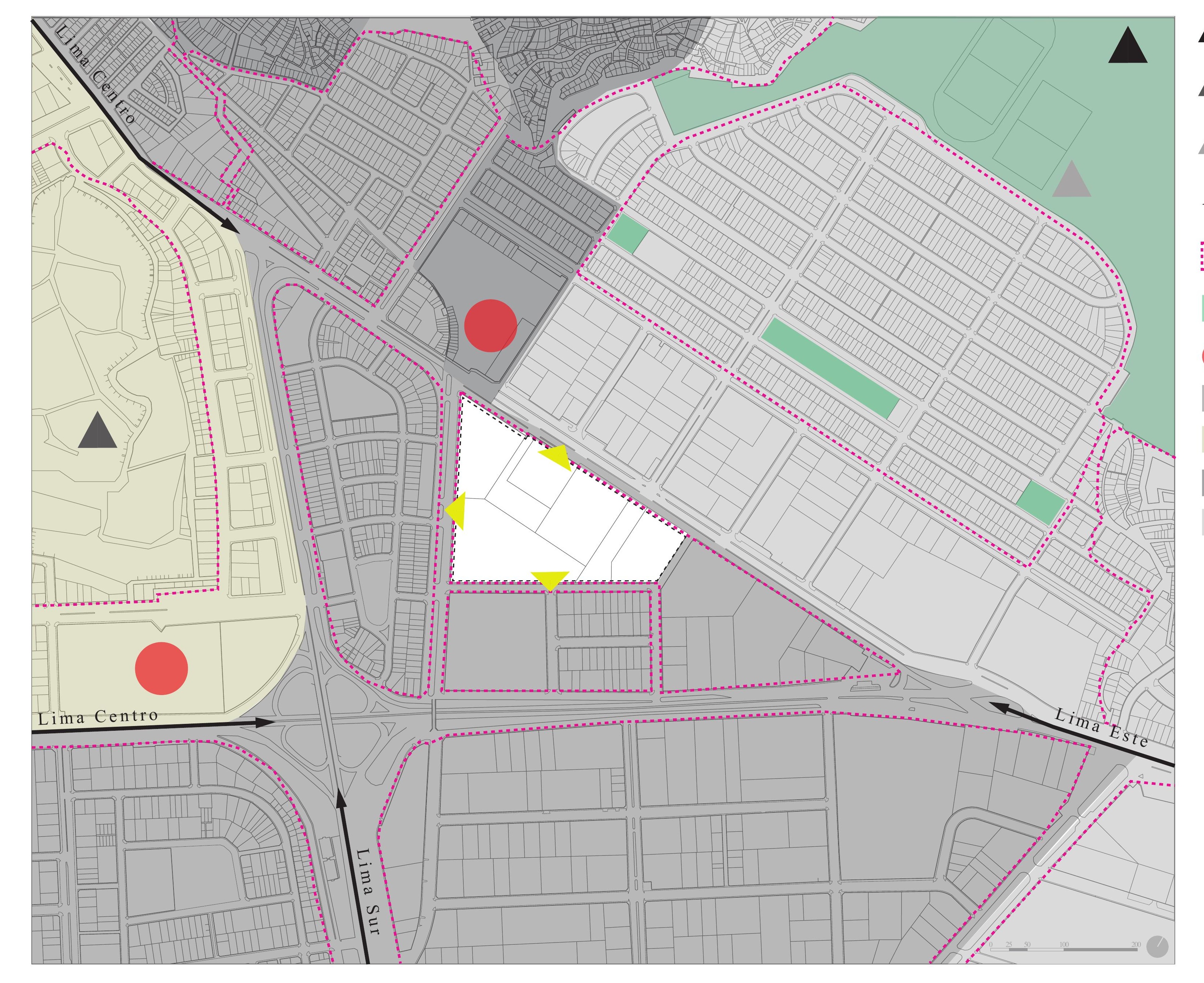

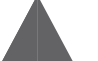

Aito: Paraue Zonal

$\leftarrow$

:...:

Areas verdes preparadas

O

西

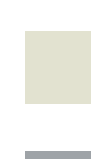

(1)

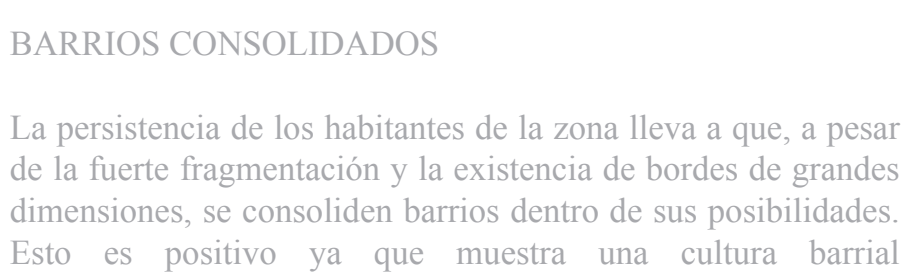

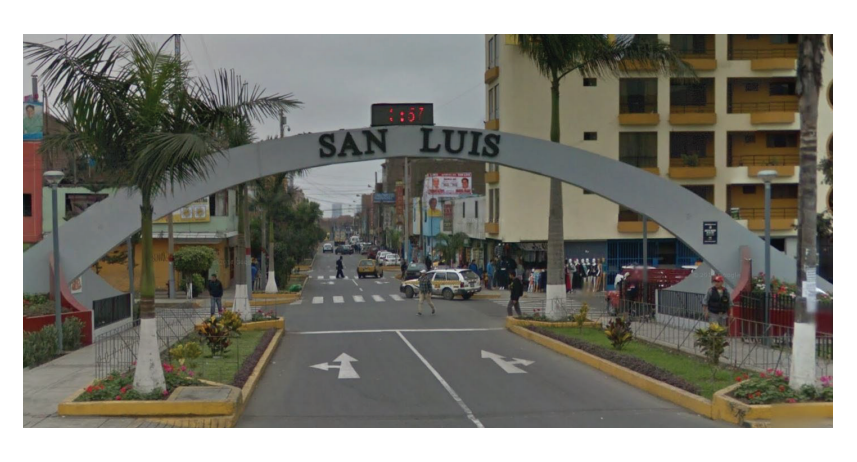

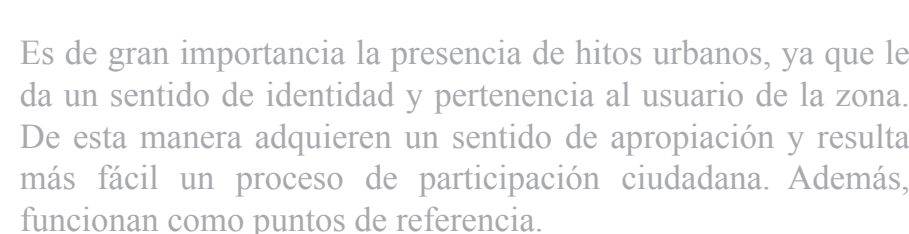

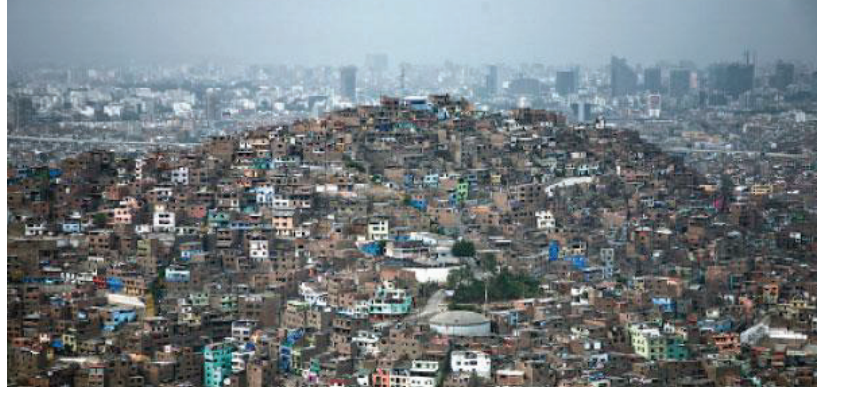

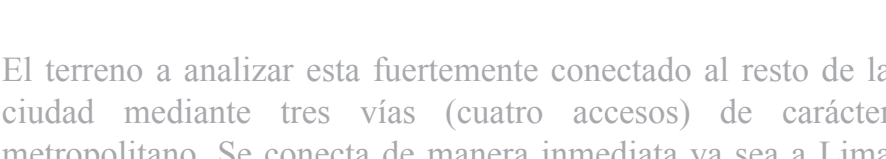

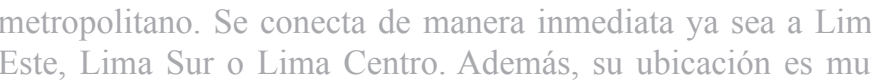

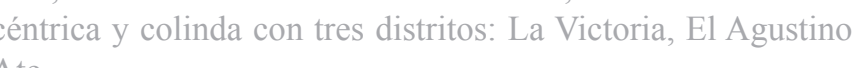

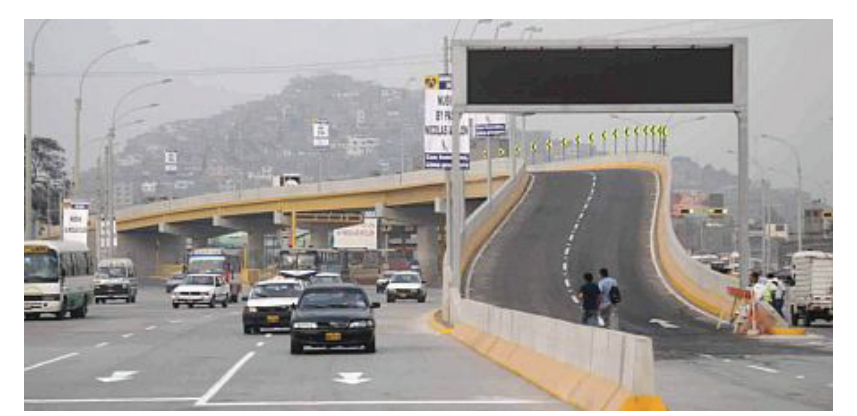

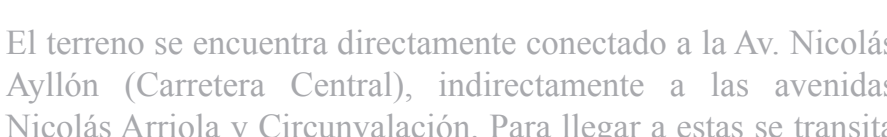

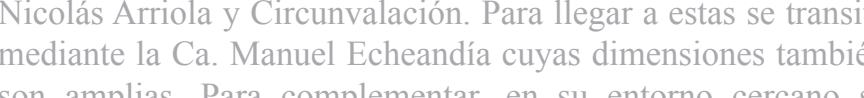

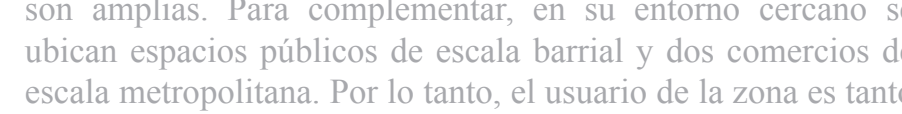

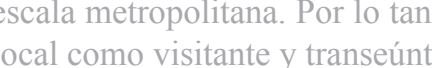

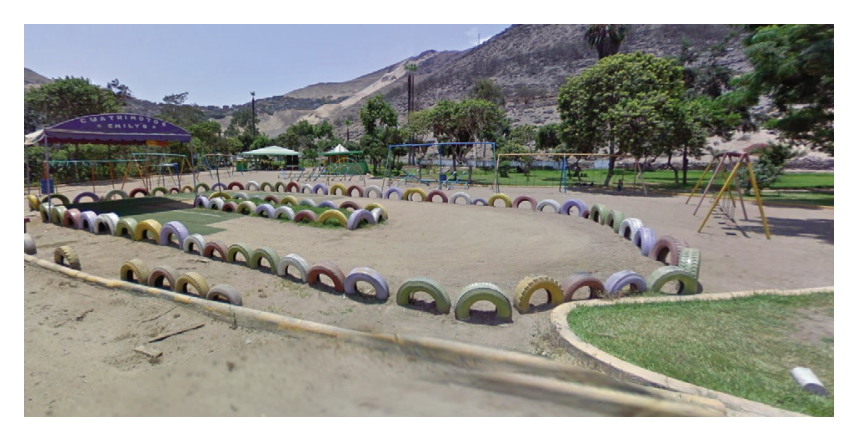




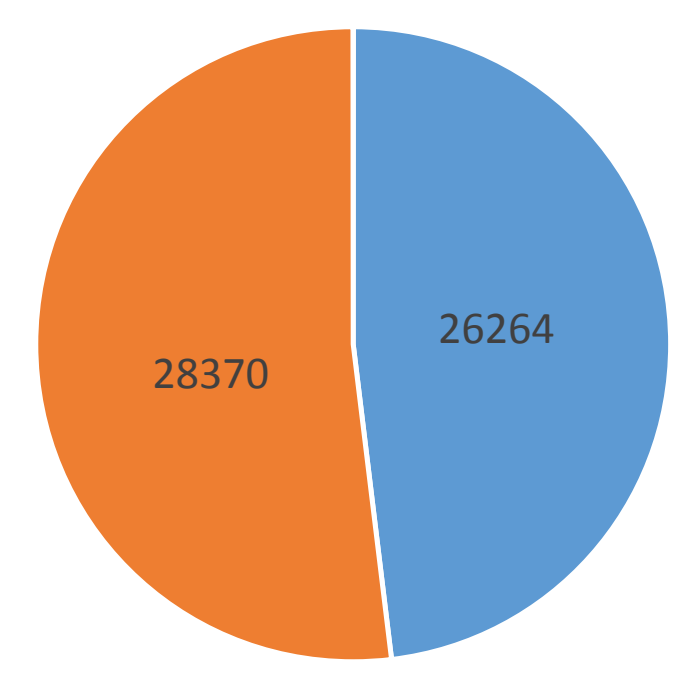

- Hombres $\square$ Mujeres

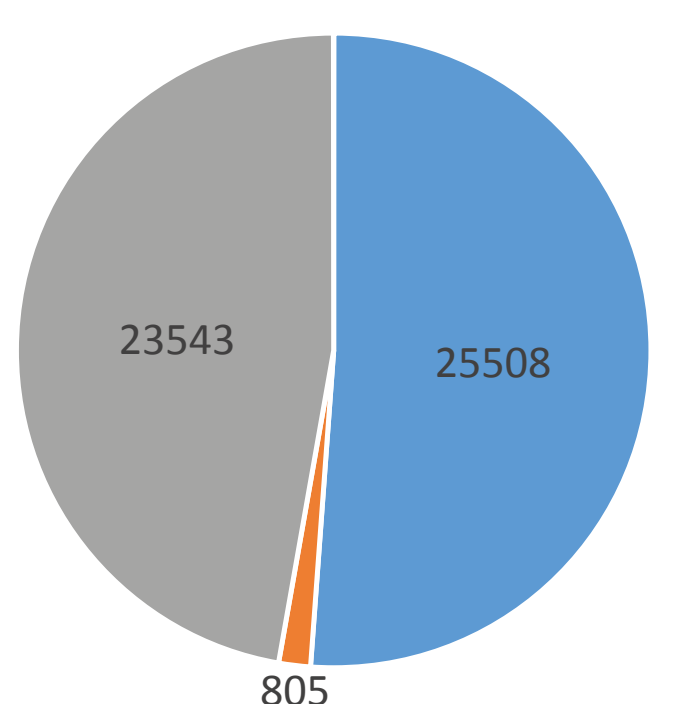

Ocupada $\square$ Desocupads: $\backsim$ No PEA
CONDICION DE ACTIVIDAD ECONOMICA: MUJERES

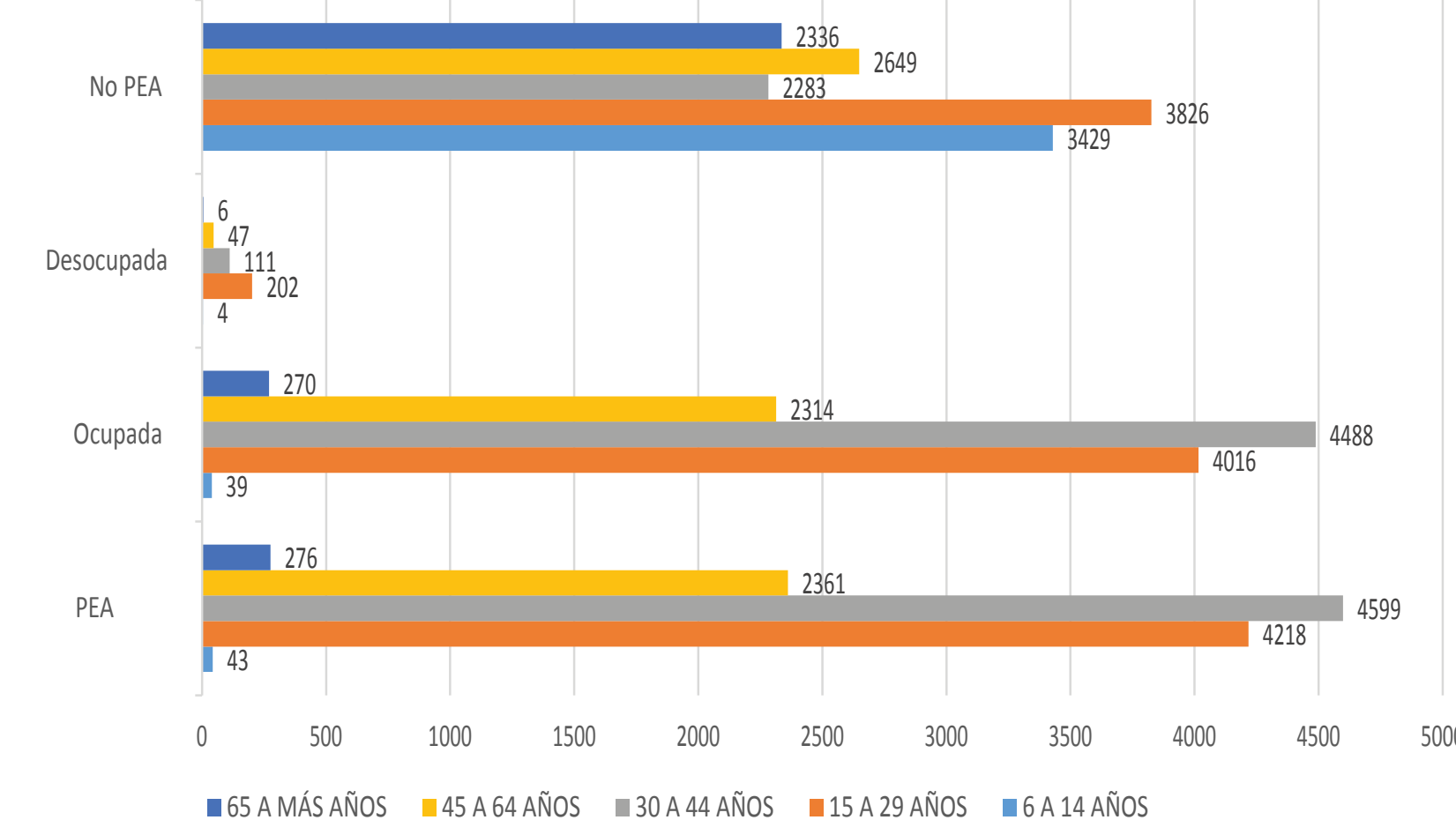

CONDICION DE ACTIVIDAD ECONOMICA: HOMBRES

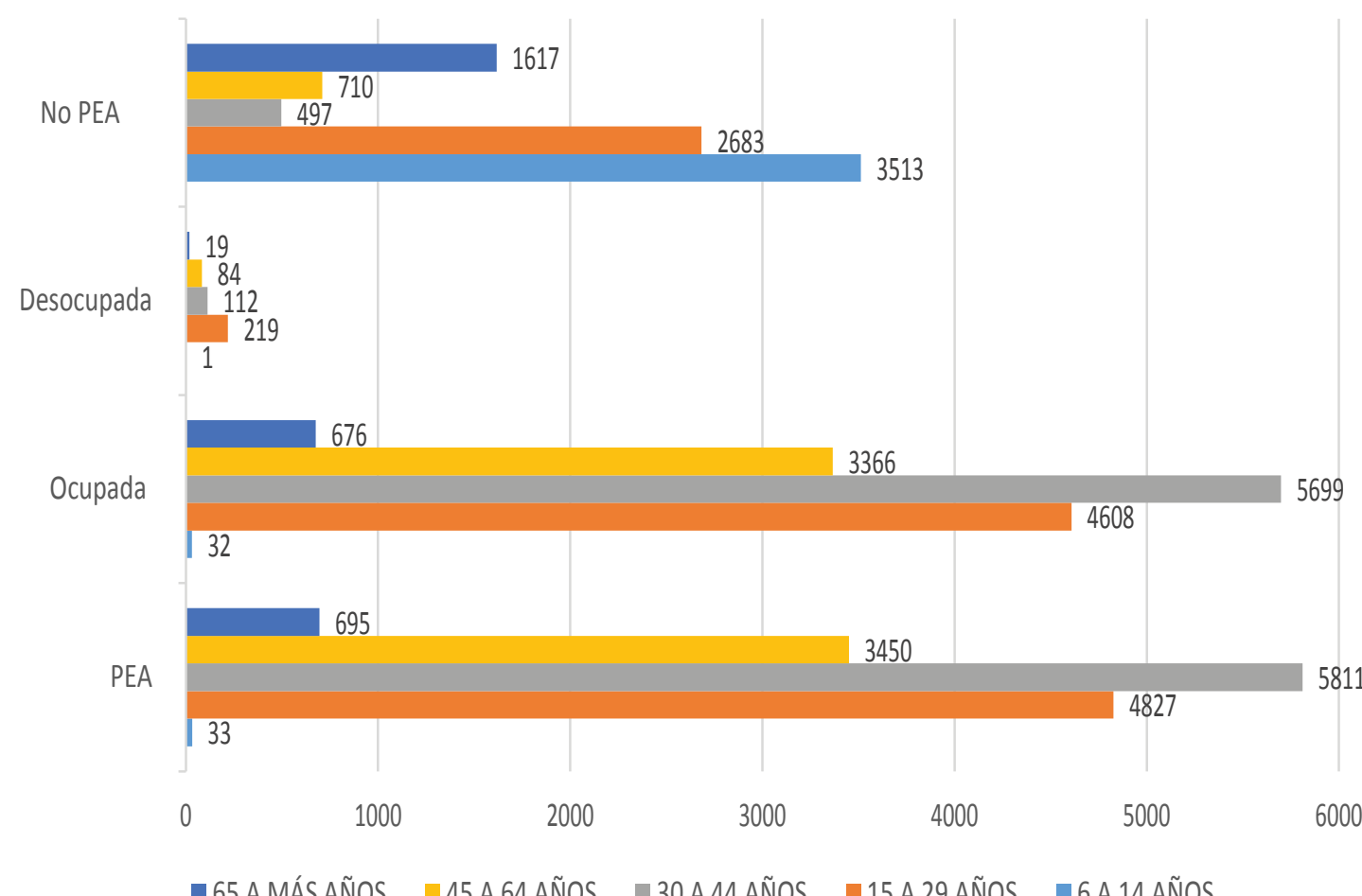

ACTIVIDADES ECONÓMICAS DE LA ZONA

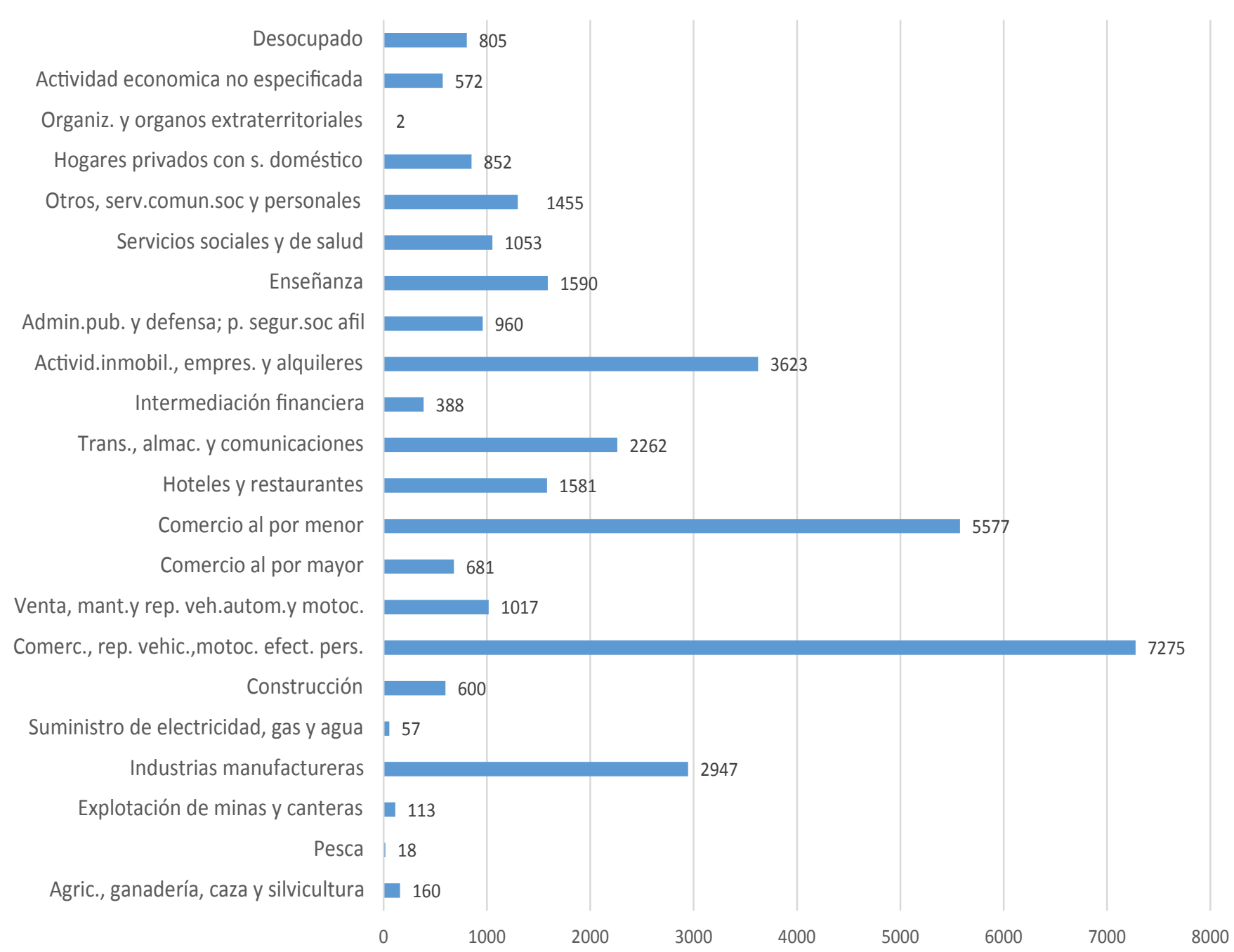

La población de San Luis se reparte casi homogéneamente entre población femenina y masculina, con las mujeres como
mayoria por una ligera diferencia. Adicionalmente se tratat de una población predominantemente joven, siendo la mayoría el

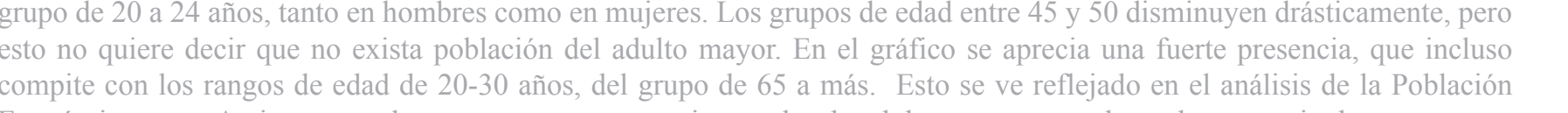

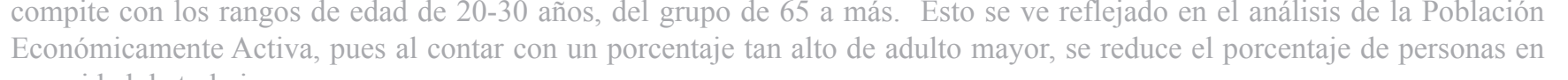

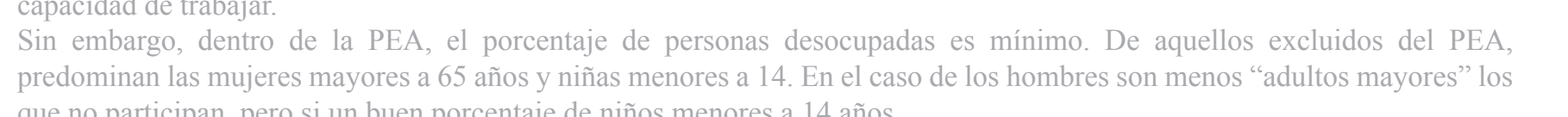

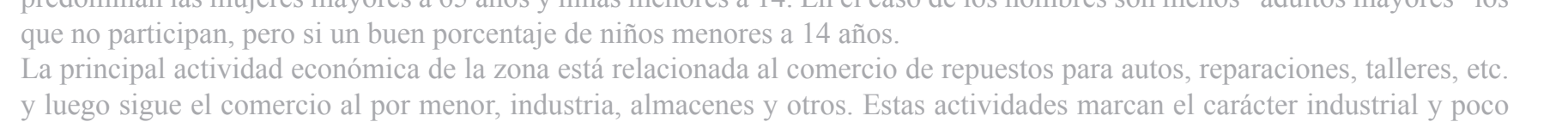
y luego sigue el comercio al por menor, industria, almacenes y otros. Estas actividades marcan el carácter industrial y poco
amigable con el usuario de la ona. 


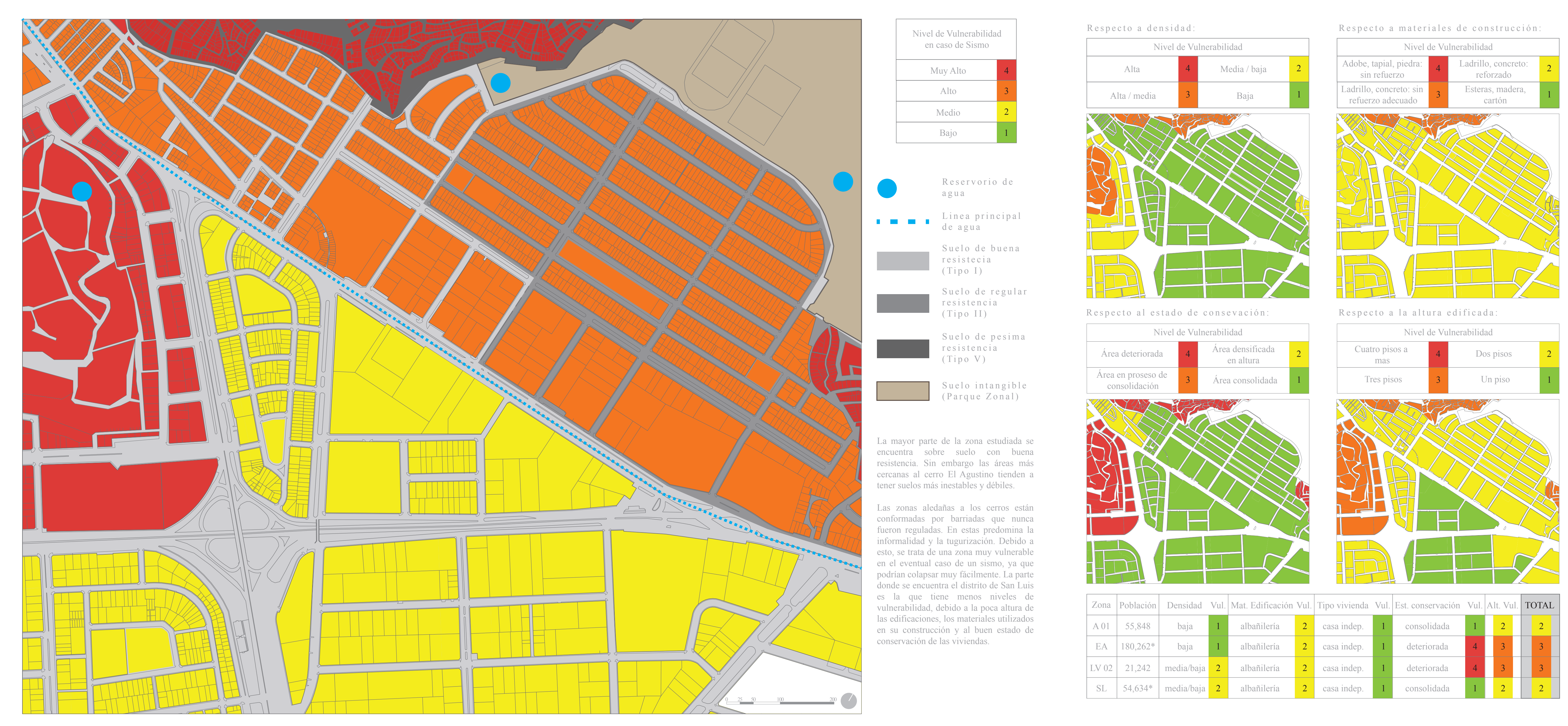




\subsection{Conclusiones Parciales}

Como se analizó en el marco operativo ${ }^{33}$, el Terminal Yerbateros es una parada obligatoria para las empresas transportistas que atienden las rutas de la sierra y selva central. Lamentablemente, un gran número de estas no cumplen con las condiciones mínimas para ofrecer un servicio adecuado a sus usuarios, ya que operan desde la informalidad y no cuentan con la infraestructura necesaria, por lo que resulta indispensable la implementación de un nuevo terminal. En el diseño de este no solo se considerarán las dimensiones adecuadas para atender la demanda creciente y su equipamiento necesario, sino que también se tomarán en cuenta consideraciones de diseño analizadas en el marco referencial y el marco teórico. Es por este motivo que no solo hemos estudiado las variables del lugar relacionadas exclusivamente al transporte, sino que también hemos profundizado en diversos análisis que nos permitirán desarrollar una arquitectura sostenible, que respete su entorno y funcione como un centro regenerador para los barrios circundantes.

La ubicación del proyecto está definida por la posición del actual terminal, la cual, como ya se ha comentado anteriormente, resulta ser bastante estratégica. Esta ubicación permite la conexión con las rutas del transporte interprovincial de la sierra y selva central que operan en la Carretera Central, además de conectarse con todas las rutas del transporte urbano que circulan por esta vía. Adicionalmente, tiene la posibilidad de incorporar a la línea 2 del metro de Lima que actualmente se encuentra en construcción.

Por la naturaleza del proyecto lo primero que se debe contemplar son los flujos de los buses interprovinciales y los buses urbanos, además de vehículos más pequeños como taxis, autos particulares, motos, ciclistas y sobre todo la circulación de los peatones por dentro y por fuera del recinto. Por lo tanto, el diseño de las bahías, al igual que los ingresos y salidas tendrá que responder al análisis de vías realizado. Cuando se trate de buses interprovinciales se incorporará un carril auxiliar al ingreso y salida del terminal, cuidando que no obstruya las vías ni los cruceros peatonales. En el caso específico del carril de salida se procurará que sea lo suficientemente largo para poder ganar velocidad e ingresar sin problemas a la vía principal. En el caso de buses metropolitanos y taxis, se propondrá bahías que respeten los paraderos actuales e

\footnotetext{
${ }^{33}$ Ver capítulo 4.1.1 Terminal Terrestre Yerbateros, Perú.
} 
incentiven al conductor a salir de la vía principal para utilizarlas. Los autos particulares podrán hacer uso de la bahía de taxis y contarán con un estacionamiento interno para evitar congestionar las calles.

Al estudiar el levantamiento fotográfico, se puede apreciar un entorno urbano deteriorado; muchos de los frentes del terreno no cuentan con veredas o son tan angostas que no permiten la fácil circulación de los usuarios. Asimismo, existen grandes muros ciegos que acompañan al peatón por cuadras enteras, creando zonas muertas que luego se convierten en botaderos, baños públicos o estacionamientos informales. Por este motivo, el proyecto incorporará un perímetro que sea inclusivo, amigable y que preste especial atención a su relación con el exterior.

Un objetivo del nuevo terminal terrestre será brindar un confort climático a los usuarios sin la necesidad de recurrir a elementos artificiales, por lo que se realizó un estudio de condiciones medioambientales que nos permitieron determinar las estrategias a seguir. En primer lugar, se determinó que el proyecto se ubica en una zona con topografía en su mayoría plana, por lo que no habrá complicaciones para el desplazamiento de los buses ni de los peatones. Sin embargo, esta característica contribuye a que quede expuesto a vientos provenientes del sudoeste y completamente desprotegido de la radiación solar. Por este motivo, se realizó un estudio de cuerpos edificados para identificar la presencia de elementos de gran altura que puedan distorsionar las condiciones climáticas, pero se determinó que se trata de una zona con edificaciones bajas y cerros posicionados hacia el norte y noroeste, que no interfieren. Esto genera un terreno con exposición directa al sol y al viento por la ausencia de barreras físicas. Por lo tanto, el diseño deberá considerar una orientación adecuada al igual que materiales que permitan mantener una buena temperatura a pesar de la sobre exposición al sol. Los espacios públicos se diseñarán para brindar el confort necesario implementando barreras que generen cobijo de los vientos y diferentes tipos de cubiertas para suministrar sombra.

La incorporación de espacio público dentro del proyecto es sumamente importante, ya que es un elemento clave para la regeneración urbana propuesta. El estudio realizado sobre sistemas de áreas libres resaltó una carencia de espacios para recrear e identificó que la mayoría de parques existentes se encuentran enrejados. Por lo tanto, el nuevo terminal contemplará la inserción de espacio público utilizable, como 
plazas, corredores, zonas de juego, combinados con vegetación adecuada para el clima de la zona. Es así, que se utilizará vegetación para las condiciones climáticas del desierto costero, que requiera poca agua y cuente con alta captación de monóxido, también se implementarán árboles de zonas áridas para brindar protección del sol y generar colchones visuales y auditivos en las avenidas más transitadas.

El espacio público que se incorporará dentro del proyecto no solo servirá para cubrir el déficit de áreas verdes, sino que ayudará a resolver problemas de identidad social; los estudios de lugares de interés y de zonificación determinaron que la zona se encuentra dividida en dos, por un lado, la vivienda taller que incluye el comercio vecinal y por otro la industria. Estos usos son polos opuestos que requieren de ciertas cosas en común, como lo es un espacio de desfogue. No obstante, como se identificó en el estudio de población, hay diferencias entre ambos usuarios: amas de casa, niños y adultos mayores para el caso de la vivienda y trabajadores de diversas edades en la industria. Por este motivo se implementarán espacios de ocio para jóvenes y adultos, además de zonas de descanso para los mayores. Al contar con el equipamiento adecuado, se podrá juntar a los diferentes usuarios en un solo lugar, eliminando poco a poco la brecha existente entre ambos usos. Sin embargo, al comparar el análisis realizado sobre bordes y barrios, con el análisis de hitos, nodos y sendas, se concluyó que la zona también se encuentra fuertemente dividida gracias a las vías arteriales que la atraviesan, las cuales admiten pocos nodos conectores. Por lo tanto, también será necesario que el terminal busque desaparecer cualquier tipo de barrera, haciéndolo funcionar como un elemento articulador de los fragmentos. Es decir, suavizaremos los bordes inmediatos mediante un diseño abierto sin muros perimetrales, para integrar mejor el tejido urbano de las diferentes zonas. Sin descuidar aquellos bordes más agresivos, como la carretera central, donde propondremos límites virtuales, visuales y auditivos a través de árboles y vegetación.

Finalmente, para completar el diseño arquitectónico del terminal se definirá el emplazamiento final en conjunto con las visuales que se tendrán. Para esto se aprovechará la presencia de dos hitos de gran importancia: el cerro el Agustino y el cerro el Pino. Ambos son símbolos de perseverancia, lucha y memoria, que se deben apreciar por su significado. Es así, que parte del trabajo de identidad de la zona se vinculará al reconocimiento de estos hitos, lo cual no solo mejorará la experiencia del pasajero, sino que ayudará a que el proyecto sea apreciado por la comunidad. 


\section{CAPÍTULO VI: CONCLUSIONES FINALES}

Para la implementación del nuevo terminal terrestre de yerbateros fue necesario prestar atención a dos temas principales. Primero se tuvo que contemplar todo aquello relacionado al terminal como una infraestructura de transporte. Es decir, considerar los estudios realizados sobre el transporte interprovincial, la calidad del servicio ofrecido y las problemáticas que genera en la ciudad. El segundo tema se enfoca en sus posibilidades de regeneración urbana, por lo que se tuvieron que estudiar referentes, conceptos y estrategias para saber cómo mitigar el impacto negativo que podría tener.

A continuación, se verán los principales aspectos estudiados que marcarán las decisiones para el diseño del terminal:

\section{$\underline{\text { Ubicación }}$}

Para justificar la ubicación del terminal es importante recalcar lo estudiado en el Marco Referencial $^{34}$, donde se compararon los diversos planes urbanos de Lima y sus respectivos planteamientos para los terminales terrestres. Todos coincidieron en que Lima necesita tres terminales centrales repartidos al Norte, al Sur y al Este. En el mismo capítulo se estudia el concepto de la movilidad, en el cual se justifica una ubicación periférica, pues así se reduce el recorrido, el tiempo de viaje y por ende su huella ambiental. Sin embargo, hacen especial énfasis en la intermodalidad que deberá contemplar un terminal, para no quedar desconectado y obsoleto.

El actual terminal de yerbateros se ubica en un punto medio entre centro y periferia. Es una ubicación ventajosa, ya que, a pesar de estar relativamente cerca al centro de la ciudad, se conecta con vías arteriales de gran importancia e interés. Adicionalmente se encuentra en un área que no pertenece al centro histórico y que está conformada por avenidas y vías de grandes dimensiones, por lo que resulta fácil ingresar y salir de la ciudad evitando zonas densas, avenidas congestionadas, calles estrechas y por consecuencia, horas perdidas en el tráfico. Es por estos motivos que se

\footnotetext{
${ }^{34}$ Ver capítulo 2.2.4 Estrategias de ordenamiento para el transporte público e interprovincial de Lima.
} 
propone utilizar el terminal existente, ampliando y renovando su infraestructura para un mejor funcionamiento.

\section{$\underline{\text { Intermodalidad }}$}

Como mencionado en el desarrollo del Marco Referencial ${ }^{35}$ y Teórico ${ }^{36}$, para garantizar la activación y el uso del terminal terrestre, será indispensable incorporar aspectos intermodales que permitan un fácil intercambio de medios de transporte. Para que esta intermodalidad funcione de manera correcta, se diseñará el terminal priorizando al peatón, garantizando su fácil desplazamiento y accesibilidad, además de habilitar conexiones directas con la línea 2 del metro, líneas de buses, taxis y autos particulares. De esta manera se aprovechará su ubicación ventajosa, para convertirla en un punto de llegada de viajes interprovinciales y a la vez un punto de salida para viajes metropolitanos, funcionando como un punto articulador e intermodal que reúne estas acciones.

\section{Gestión vehicular}

Como mencionado anteriormente, en el Marco Referencial se analizan diversos planes urbanos para Lima, en los que se propone centralizar las rutas de transporte terrestre interprovincial en tres terminales. Al centralizar todas las rutas de Lima Este en un solo terminal, se reducirá el número de buses que ingresan a terminales dispersos por la ciudad, disminuyendo la congestión vehicular generada y también su huella ambiental. Luego se combatirá indirectamente la existencia de terminales informales, al ofrecerles un espacio donde operar formalmente y generar una competencia directa mejor implementada.

Para la reducción de la congestión vehicular en la zona circundante, recurrimos a un análisis más detallado realizado en el Marco Contextual ${ }^{37}$, que nos permitió comprender cómo se manifiesta la mala gestión vehicular. Habiendo identificado los principales problemas, se concluyó que el terminal tendrá que prever sobre todo los flujos que lo abastecen, ya que los principales problemas son generados por el

\footnotetext{
${ }^{35}$ Ver capítulo 2.1 Del Transporte a la Movilidad.

${ }^{36}$ Ver capítulo 3.2 Sobre la intermodalidad.

${ }^{37}$ Ver capítulo 5.1.8 Análisis de vías.
} 
transporte público y la ausencia de paraderos y bahías. Por lo tanto, se diseñará un terminal con bahías para buses y taxis integradas dentro de sus linderos, con los retiros respectivos, para poder crear carriles exclusivos que permitan un flujo ordenado. Esto también se aplicará a los carriles para los buses interprovinciales, los cuales deben ser resguardados del flujo en la carretera central. Con estas medidas se intentará reducir el caos vehicular que se genera en las avenidas circundantes por falta de infraestructura y orden vial.

\section{$\underline{\text { Calidad del servicio }}$}

Como se expuso en el Marco Operativo ${ }^{38}$, la gran mayoría de los usuarios de buses interprovinciales no están satisfechos con el servicio y estarían dispuestos a pagar más a cambio de un mejor servicio. Es así que existen múltiples puntos que se deben considerar, como por ejemplo los servicios básicos ofrecidos, la seguridad del terminal y la calidad de la infraestructura. En cuanto a la infraestructura, fue necesario estudiar los lineamientos y las normas sobre terminales terrestres, al igual que estimar correctamente la demanda para poder ofrecer un terminal con flujos ordenados, espacios bien dimensionados, un programa arquitectónico completo que contemple todas las necesidades básicas del usuario y sobretodo un diseño bien planteado que garantice su seguridad. Adicionalmente, se pudo apreciar cómo la incorporación de servicios adicionales puede ayudar a la activación del terminal y evitar que quede en desuso. Por este motivo, se complementará con diferentes servicios repartidos en el proyecto tanto para atraer a consumidores, como para incluir a los vecinos de la zona.

\section{Espacio público}

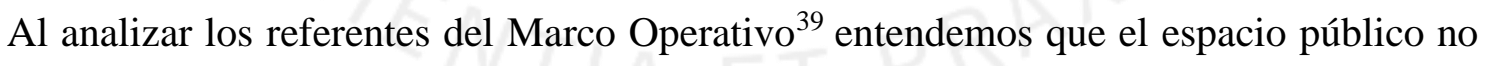
es indispensable, ya que en la mayoría de proyectos se trata como un tema secundario. Como remplazo se utilizan centros comerciales o diferentes tipos de actividades comerciales para activar el espacio. Esto es una técnica que ha demostrado su eficacia, sin embargo, solo se ha contemplado la calidad del espacio generado para el usuario como consumidor y no como ciudadano. Por lo general, los motivos para incluir

\footnotetext{
${ }^{38}$ Ver capítulo 4.1.1 Terminal Terrestre Yerbateros, Perú.

${ }^{39}$ Ver capítulo 4.6 Conclusiones Parciales.
} 
comercio son principalmente económicos, ya que generan un ingreso monetario secundario que permite financiar parte del terminal. Sin embargo, como estudiado en el Marco Teórico ${ }^{40}$, la presencia de espacios públicos bien diseñados nos permitirá activar la zona adyacente, incentivando la interacción entre usuarios. Como se ha ido desarrollando a lo largo de la investigación, los motivos para incorporar espacio público son varios; reactiva el espacio en desuso, aporta calidad de vida, atrae usuarios, genera actividades y por consecuencia se reduce el índice de criminalidad en la zona. En el caso de Yerbateros, esto tiene una gran importancia, ya que la zona a intervenir carece de identidad, espacios para recrear y necesita una mejora en la calidad de vida de los vecinos. Para esto se tendrán en cuenta muchos factores, como la separación entre espacio peatonal y espacio vehicular, barreras visuales y auditivas, generación de sombra, elección de vegetación, velocidades del flujo peatonal y creación de zonas resguardadas. De igual forma se combinará el espacio público con comercio, para garantizar su activación y se considerará la absoluta accesibilidad para todos los usuarios. La decisión de incorporar espacios comerciales tiene que ver con el reconocimiento de la realidad nacional, en la que el usuario aún no aprecia en su totalidad el valor y potencial de un espacio público.

También es importante considerar el caso estudiado de Urbanismo Social en Medellín ${ }^{41}$, ya que demuestran que sí es posible que un proyecto de infraestructura ayude a mejorar la zona. Uno de los motivos es que reflejan la presencia del estado en sectores más marginados. Pero más que eso es la implementación de un buen diseño que entiende el carácter de la zona y que revaloriza la autoestima de esta. Sin embargo, un proyecto del estado en una zona marginada solo tendrá resultados positivos si el vecindario se apropia de este. Por este motivo se habilitará una porción del proyecto como zona para recrear y se incorporarán espacios para ser usados por los vecinos. A esto se le sumará la posibilidad de hacer intervenciones con arte, para generar un mayor sentimiento de pertenencia y actividad en las calles. Estas acciones y sus resultados son vitales, pues hacen que el proyecto sea sostenible en el tiempo, manteniéndolo activo y en constante uso.

\footnotetext{
${ }^{40}$ Ver capítulo 3.3 Sobre el espacio público.

${ }^{41}$ Ver capítulo 3.4.1 Teorías aplicadas para la recuperación de zonas degradadas.
} 


\section{$\underline{\text { Regeneración urbana }}$}

Considerando lo desarrollado a lo largo del Marco Referencial, la responsabilidad y el compromiso de un terminal terrestre con el medio ambiente es bastante alta, ya que las grandes ciudades tienen un pronóstico de seguir creciendo y urbanizándose. Parte de este compromiso se cumplirá aplicando estrategias para reducir el mercado informal de buses, pues el efecto es dominó ${ }^{42}$; se reduce el número de buses en la ciudad, la congestión, la contaminación ambiental y por consecuencia se mejora la calidad de vida. De igual forma, se buscará cumplir con este compromiso al mitigar el impacto que trae un terminal terrestre y al aportar a la regeneración de la zona.

Para finalizar es importante resaltar que muchos proyectos de infraestructura suelen ser mal vistos por los ciudadanos, ya que tienden a emplazarse de manera imponente. Además, requieren de una inversión significativa y por lo general no toman en cuenta al ciudadano. Nosotros queremos demostrar lo contrario: que un terminal terrestre para buses, no tiene que ser contaminante, invasivo, un límite, ni contribuir a la congestión de la ciudad. Más bien puede ser todo lo contrario; aportando a su entorno, reduciendo la congestión inmediata, contribuyendo al ahorro de energía, revitalizando la zona y considerando al ciudadano.

42 “Acción que produce una serie de consecuencias en cadena” (RAE, 2017). 


\section{CAPÍTULO VII: PROYECTO TERMINAL TERRESTRE}

\subsection{Arquitectura}

\subsubsection{Generalidades del proyecto}

Tipo

Proyecto de infraestructura que brinda un servicio de transporte interprovincial con regeneración de la zona aledaña mediante usos complementarios y espacio público.

\section{Ubicación}

El terreno se ubica en el distrito de San Luis en la Av. Manuel Echeandía Manzana C, en la zona límite con el distrito El Agustino, Ate y La Victoria. Es importante resaltar que el terreno se ubica cerca al cruce de varias avenidas estratégicas que lo conectan con el resto de la ciudad y se encuentra rodeado por calles en tres de sus frentes, además de la carretera central. Por su frente más largo, de 360 metros, orientado hacia el norte, pasa la Av. Nicolás Ayllón, prolongación de la carretera central. Hacia el Este cuenta con un frente de 72 metros de largo por el cual pasa la calle Mariscal Eloy Ureta. Por el sudeste, con 284 metros de frente, colinda con el jirón Leónidas la Serre. Finalmente, con 250 metros de largo, pasa la Av. Manuel Echeandía por el sudoeste. La manzana está compuesta por siete diferentes lotes, que serán unificados para la implementación del terminal terrestre equipado con múltiples servicios para el vecindario.

La sumatoria del área de los terrenos es de 52,523.24 $\mathrm{m}^{2}$ que aumenta a $54,701.58 \mathrm{~m}^{2}$ cuando se incluyen las bahías de conexión urbana para buses urbanos, taxis y vehículos particulares.

\section{Planteamiento general}

Se diseñó un terminal terrestre de buses que pudiera organizar y reordenar la zona en la que se emplaza. Se buscó organizar los flujos de los buses y equipar el terminal con la infraestructura y el diseño de vías necesario para organizar dentro del lote los medios de transporte que lo abastecerán, reduciendo la congestión vial generada por el desorden y la informalidad de los medios de transporte público. Se planteó como el terminal oficial 
de Lima Este, con la finalidad de colaborar indirectamente con la erradicación de los terminales informales, dándoles la oportunidad de operar de manera formal. Así el terminal se encuentra equipado con la infraestructura necesaria para un funcionamiento seguro y fluido, favoreciendo a aquellas empresas transportistas que operan bajo la ley. Esta toma de partido se sustentó con algunos estudios realizados que confirmaron la disposición por parte de los viajeros para pagar más a cambio de un mejor sistema de transporte interprovincial.

Adicionalmente, se planteó un espacio público con la capacidad de regenerar la zona adyacente y se buscó mitigar el impacto negativo generado por la implementación de una infraestructura de gran envergadura. Por esto fue de suma importancia reactivar todos los frentes del terreno, enfocándonos principalmente en aquellos que miraban hacia zonas industriales y suavizando la barrera impuesta por la carretera central. El frente ya activado por el comercio zonal, requirió un reordenamiento debido a su funcionamiento caótico, por lo que se propuso la implementación de espacio público con la intención de abrir una zona de desfogue y recreación para el flujo peatonal, revalorizando así la avenida.

\subsubsection{Estrategias proyectuales}

Para el diseño del terminal terrestre fue importante entender cuáles eran los actores principales para así saber priorizar la toma de partido en el diseño. El peatón, siendo el usuario más vulnerable, será el que más prioridad tendrá junto con los pasajeros del terminal mismo. Luego viene el protagonista del terminal terrestre, el bus interprovincial, seguido por aquellos sistemas de transporte público masivo, como el bus urbano y el metro. Al final de la lista se encuentran los medios de transporte menos eficientes, como los taxis y autos particulares.

Una vez identificados los usuarios más importantes del terminal, se procedió a definir las consideraciones de diseño. Para empezar, se generó un anillo peatonal arborizado, el cual se compone por un circuito sin interrupciones y de absoluta accesibilidad. Se diseñó con un ancho mínimo de 5 metros en las partes más angostas, llegando hasta 25 metros en las partes más amplias. A lo largo del circuito se trabajó el espacio público con diversas estrategias: creando diversos caminos, usando diferentes texturas de suelo para demarcar zonas de paso lento y habilitando áreas con bancas. 
También se crearon bermas con diferentes tipos de vegetación y árboles para crear sombra y sobre todo para aislar el anillo peatonal de zonas fuertemente congestionadas como el frente de la carretera central. El anillo peatonal funciona como un amortiguamiento en varios sentidos. Por un lado, disminuye el impacto que podría tener un terminal terrestre de buses en el vecindario, evitando muros ciegos, zonas abandonadas o la misma contaminación de los buses. Sin embargo, también funciona a la inversa, protegiendo el terminal de frentes fuertemente congestionados y caóticos como la carretera central.

Con el objetivo de corregir la mala gestión vehicular, la siguiente consideración de diseño fue determinar la ruta que seguirán los buses interprovinciales dentro del terminal con su respectiva entrada y salida, además de ubicar las conexiones intermodales. Después de hacer un análisis de vías y flujos de buses interprovinciales en la zona, se optó por ubicar tanto el ingreso como la salida en el mismo frente: Av. Nicolás Ayllón prolongación de la carretera central. Para no interrumpir el anillo peatonal y crear una separación de usos, se hundió el circuito de buses al NPT -5.30, motivo por el cual se abrió paso para dos carriles exclusivos que circulen por debajo del anillo peatonal, permitiendo el ingreso y salida de buses sin interrumpir el paso de los peatones. Para el recorrido interno de los buses fue importante respetar una secuencia lógica, primero desembarque, luego mantenimiento y finalmente embarque. Esta secuencia marcó tres puntos importantes para los autobuses dentro del terminal, adicionalmente se propuso un circuito no lineal en forma de "bucle" 43 para que los buses puedan cambiar el orden de los eventos, en caso fuera necesario. Las zonas de desembarque y embarque se ubican en puntos separados del terminal para evitar cruces de flujos y tienen una rápida conexión con el exterior para facilitar la salida y entrada de los usuarios. Por otro lado, la zona de mantenimiento se ubicó hacia un extremo del terminal, con el objetivo de priorizar las zonas de uso de los pasajeros y evitar que los trabajadores tengan que atravesar todo el edificio para llegar a su zona de trabajo.

A continuación, se tuvo que determinar la ubicación de las conexiones intermodales. Primero se identificó un posible empalme con la línea 2 del metro de Lima, para incorporar un punto de ingreso y salida a la zona subterránea del metro. También se estudiaron las diversas rutas de buses urbanos en la zona e identificaron los

\footnotetext{
43 Traducido del inglés “loop”.
} 
paraderos más congestionados al igual que los informales. Debido a su conexión con la carretera central se ubicó el paradero sobre esta misma vía, incorporando bahías bien definidas y segregadas del tránsito vehicular para incentivar su uso y evitar la formación de paraderos informales en la carretera central. Este paradero oficial de buses urbanos permite el embarque y desembarque de pasajeros en un punto cercano al ingreso principal del terminal y a la salida del metro. Luego, se colocó la bahía de taxis y vehículos particulares en la Av. Manuel Echeandía teniendo en cuenta que desembocaran en la misma zona, para evitar flujos dispersos o muy largos.

Con la intención de regenerar la zona intervenida, se retrancó el frente del proyecto en la Av. Manuel Echeandía, con la finalidad de abrir campo para una plaza pública escalonada que funcione como espacio protagonista a la intemperie. Al tratarse del único frente comercial y residencial se buscó que el terminal fuera más abierto y transitable para conectar con el colegio, los restaurantes y los comercios ubicados al otro lado de la avenida. Adicionalmente, estas zonas de recreación y espacio público se complementaron con comercio y otros servicios adicionales generando un nodo activador que asegure su uso constante durante todo el día.

Finalmente, se decidió desarrollar la arquitectura como una pieza icónica de la zona para generar un sentimiento de orgullo en la comunidad y crear en vínculo emocional con esta. Se trabajó el aspecto formal del terminal respetando los elementos del entorno urbano como el cerro El Agustino y el cerro El Pino que funcionan como remates visuales. Asimismo, se utilizó un sistema estructural especial para crear una atmosfera única que cautive a los usuarios; este sistema sigue la lógica de un puente, funcionando con apoyos únicamente en los extremos, lo que genera grandes luces libres, además de espacios corridos y completamente integrados entre sí. Un motivo adicional para utilizar este elemento es la flexibilidad funcional y operativa que brinda en el patio de maniobras y zonas de embarque o desembarque ya que permite el libre tránsito de los buses sin obstrucciones físicas ni visuales.

\subsubsection{Cálculo de usuarios y áreas}

Capacidad y demanda

Para el pre dimensionamiento del terminal se tuvo que analizar la demanda existente y su proyección para estimar la capacidad real de usuarios que necesitaría cubrir. Para empezar, se buscó la proyección del flujo de pasajeros por Lima Este para el 2035, 
previendo su sostenibilidad en el tiempo. Se utilizaron como base los datos del informe de TYPSA 2003 (Instituto Metropolitano de Planificación, 2014) que registraron un flujo de 14,913 pasajeros por día, de los cuales $41 \%$ ingresaban y $59 \%$ dejaban la ciudad mediante buses interprovinciales. Estudiando el crecimiento poblacional y las tendencias de ese medio de transporte, se calculó la proyección para el 2035, con un resultado de 16,000 pasajeros al día, es decir 5,840,000 pasajeros al año.

Tabla 28: Flujo de ingresos y salidas por día

\begin{tabular}{|c|c|c|c|cc|c|}
\hline & \multicolumn{6}{|c|}{ Flujo por día (Lima Este) } \\
\cline { 2 - 7 } & Ingresan & Salen & Total & Ingresan & Salen & Total \\
\hline 2003 & 6,167 & 8,746 & 14,913 & 95 & 135 & 230 \\
\hline 2035 & 6,618 & 9,390 & 16,008 & 102 & 144 & 246 \\
\hline
\end{tabular}

Fuente: Instituto Nacional de Estadística e Informática (2013) e Instituto Metropolitano de Planificación (2014)

Elaboración propia

Tabla 29: Flujo de ingresos y salidas por año

\begin{tabular}{|c|c|c|c|c|c|c|}
\hline & \multicolumn{6}{|c|}{ Flujo por año (Lima Este) } \\
\hline$=$ & \multicolumn{3}{|c|}{ Pasajeros } & \multicolumn{2}{|r|}{ Buses } & $\Rightarrow$ \\
\hline & Ingresan & Salen & Total & Ingresan & Salen & Total \\
\hline 2003 & $2,250,955$ & $3,192,290$ & $5,443,245$ & 34,675 & 49,275 & 83,950 \\
\hline 2035 & $2,415,570$ & $3,427,350$ & $5,842,920$ & 37,230 & 52,560 & 89,790 \\
\hline
\end{tabular}

Fuente: Instituto Nacional de Estadística e Informática (2013) e Instituto Metropolitano de Planificación (2014)

Elaboración propia

Para poder diseñar y dimensionar correctamente el terminal, se tuvo que trabajar con el cálculo de ingresos y salidas en hora punta, momento en el cual el terminal trabajaría a su total capacidad. En base a un cálculo utilizado por la IATA para el dimensionamiento de aeropuertos, se calcularon estos valores, obteniendo un resultado final de 2,920 pasajeros en hora punta ${ }^{44}$. Teniendo los porcentajes de ingresos y salidas de pasajeros, se procedió a repartir el resultado final para determinar la cantidad de buses que ingresarían para embarcar o desembarcar pasajeros. Adicionalmente se estudiaron los diferentes modelos de buses existentes en el mercado y las tendencias de

\footnotetext{
${ }^{44}$ Ver capítulo 3.5.4: Valores y fórmulas para la estimación de áreas.
} 
diseño para determina la capacidad de usuarios que pueden transportar. Finalmente, con una capacidad de 85 pasajeros por autobús, se estimaron 34 buses en hora punta, de los cuales 14 desembarcan y 20 embarcan. Sin embargo, para el cálculo de andenes, se estimó que el tiempo promedio de desembarque es de 15 minutos y de embarque 30 minutos (Ministerio de Comercio Exterior y Turismo [MINCETUR]; Unión Europea [UE], 2009). Para tener una holgura adicional, se optó por trabajar con 30 minutos por desembarque y embarque, reduciendo a la mitad el cálculo de buses que se tendrían que atender en hora punta. De esta manera el resultado final llevó a la implementación de 7 andenes de desembarque y 10 de embarque. Adicionalmente se habilitaron 17 estacionamientos para la espera, mantenimiento y limpieza de los autobuses, pues finalmente el terminal tendría que poder albergar un total de 34 buses en hora punta. Con esta cifra se sacó un ratio de 941 pasajeros al día por andén, que cumple con lo establecido en el estudio de referentes pues el ratio promedio es de 845 , con un rango que varía desde 200 hasta 1704 pasajeros por andén ${ }^{45}$.

\section{Programa arquitectónico y dimensionamiento de ambientes}

Para definir el programa arquitectónico final se utilizó como base el programa estudiado dentro del marco teórico ${ }^{46}$, donde se compararon diferentes fuentes bibliográficas sobre terminales terrestres. Es así que se determinó una serie de ambientes obligatorios y las relaciones programáticas que debían tener (ver ficha 14). Por otro lado, el dimensionamiento de los espacios se realizó con diversas fórmulas, las cuales se pueden ubicar en el compendio de fórmulas (ver ficha 15). Finalmente, en el metrado arquitectónico ${ }^{47}$ se puede encontrar la comparación entre los valores referenciales y los finales del proyecto. Es importante resaltar que los resultados de las fórmulas son aproximados, pues se utilizan principalmente para el dimensionamiento de aeropuertos y no terminales terrestres. Por este motivo los cálculos de áreas son utilizados como referencia. Por otro lado, para el diseño de las vías, estacionamientos y el cálculo de los radios de giro se trabajó con la aplicación "Vehicle Tracking” de AutoCAD.

\footnotetext{
45 Ver Compendio de referentes (ficha 9), ubicado en página 205.

${ }^{46}$ Ver capítulo 3.5.3: Programa requerido.

${ }^{47}$ Ver Metrado arquitectónico (tabla 30), ubicado en página 290.
} 


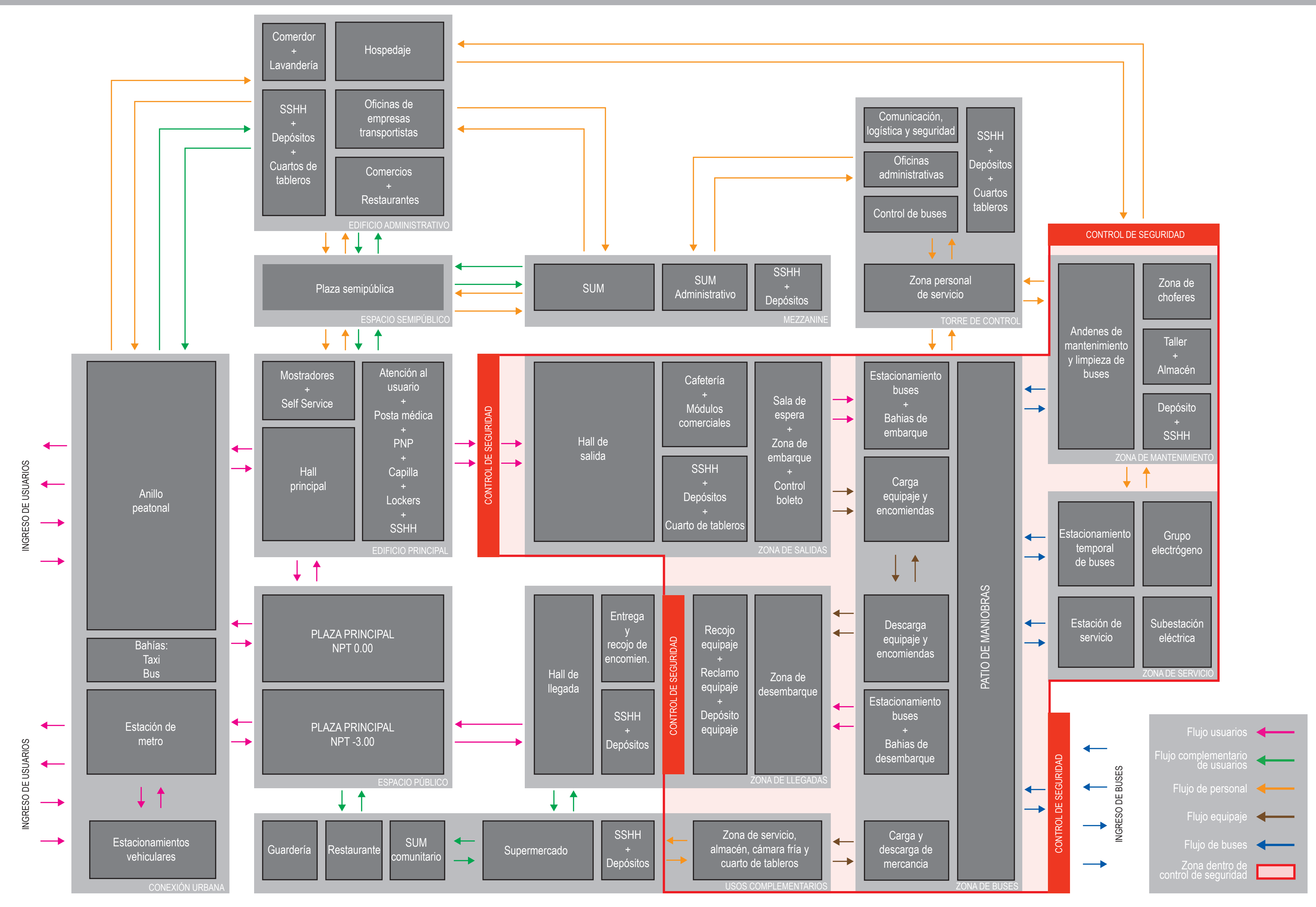




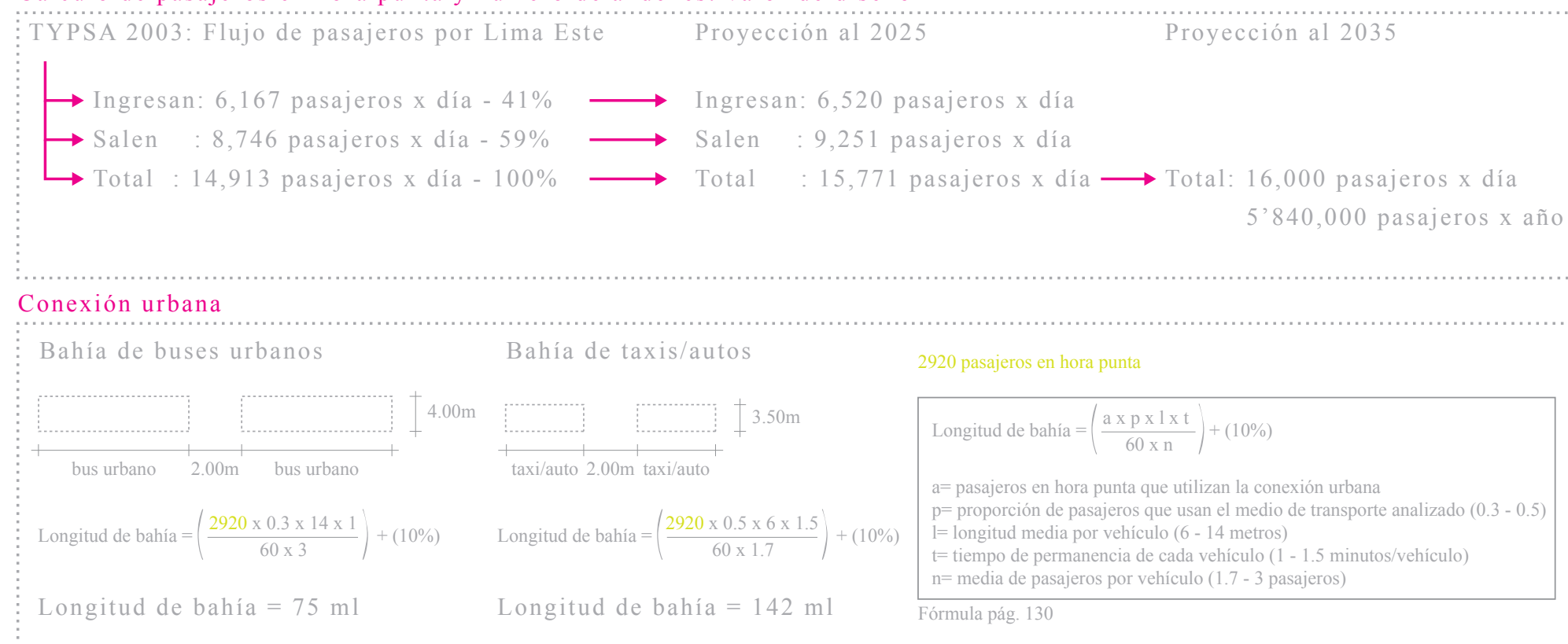

Cálculo de estacionamientos

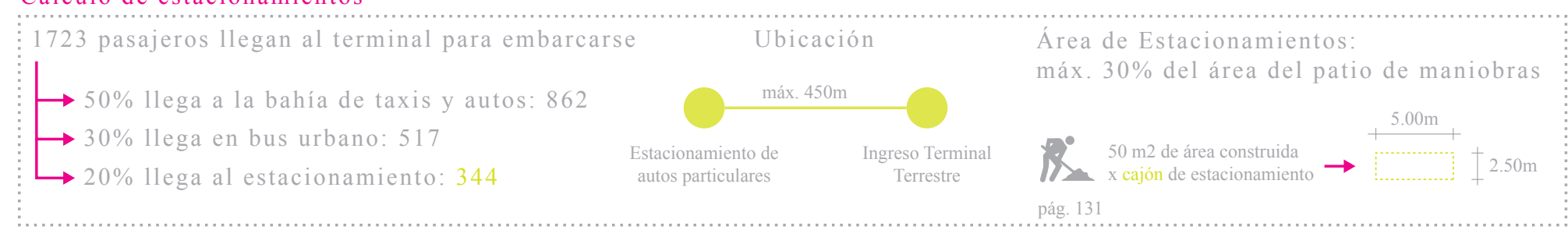

Diseño de espacio püblico

Clasificación del terminal: TP - 2 Anillo de amortiguamiento: Prioridad entre

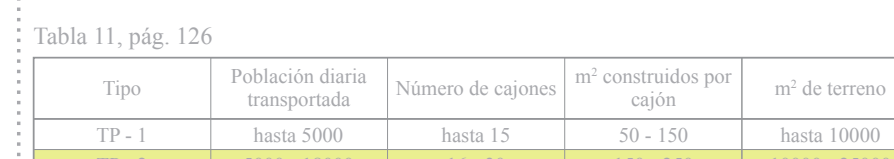

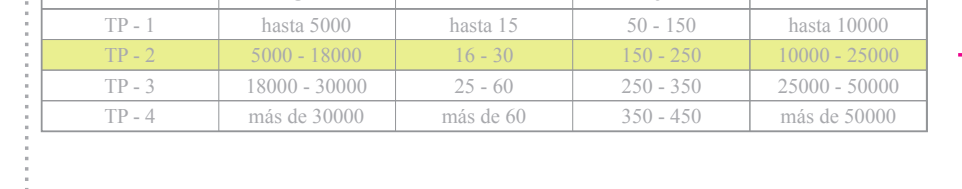

Dimensiones mínimas para tránsito peatonal

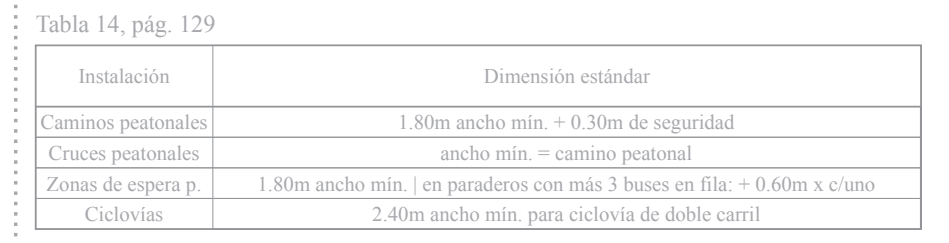

Servicios choferes y buse

Servicios al operad

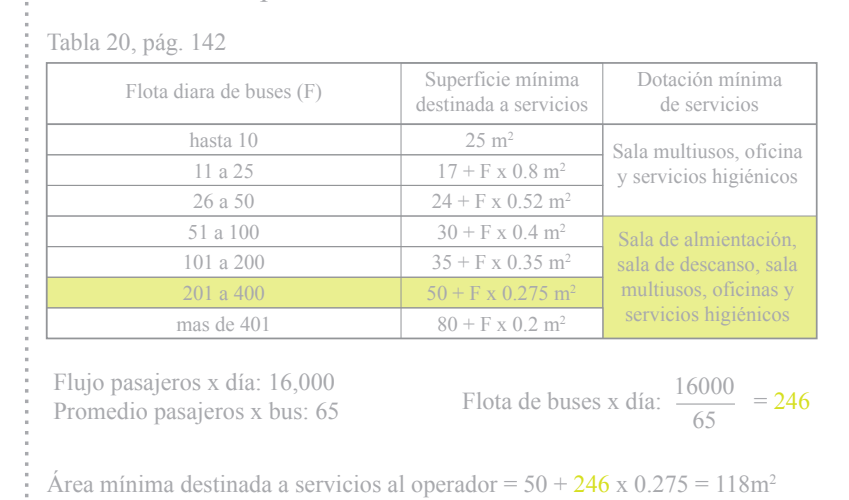

Cálculoulonara onara punta:
Valor de diseño

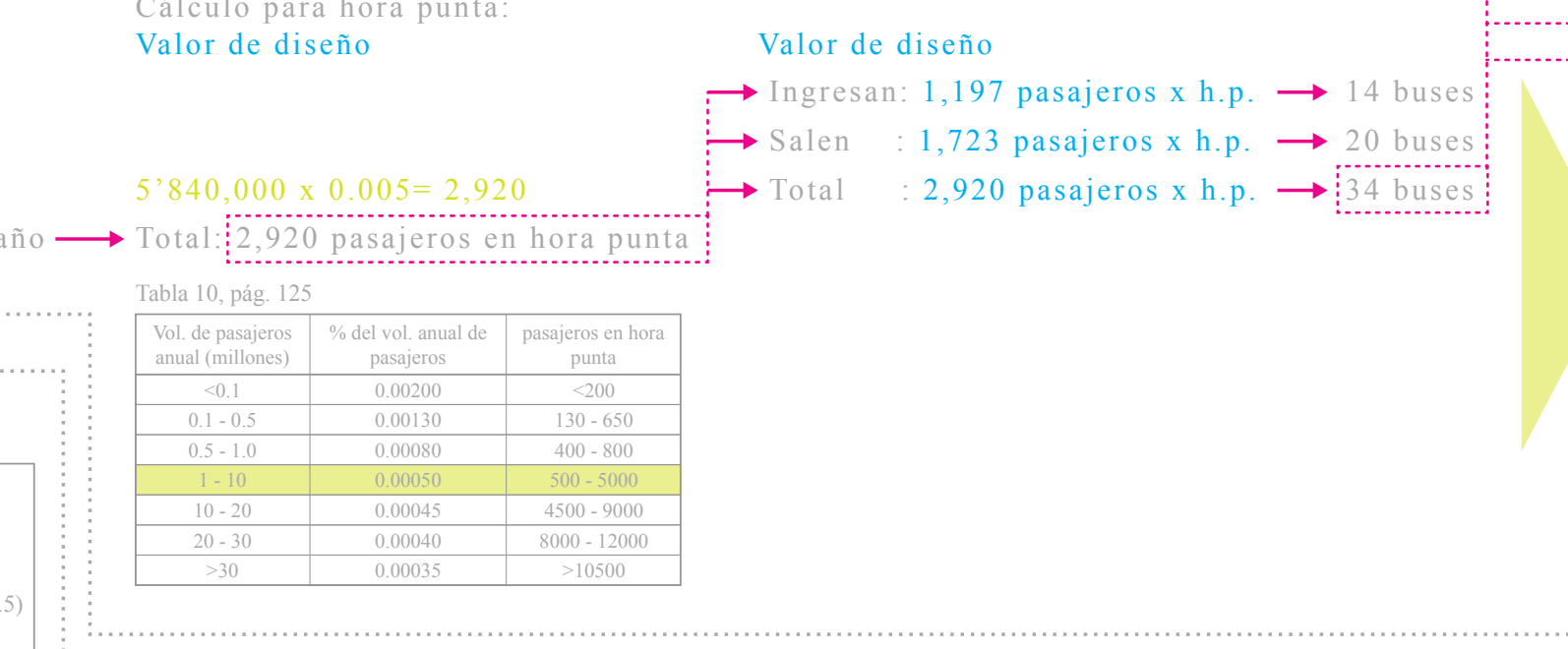

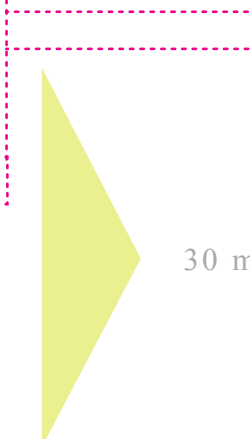

uncionamiento del tern

Vestibulo general

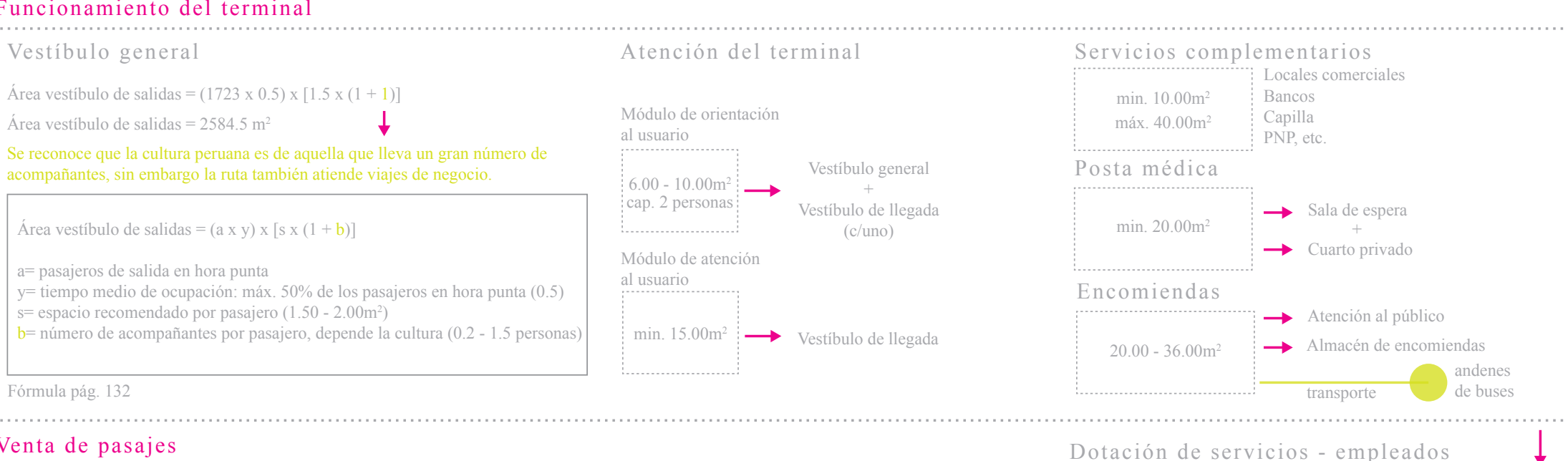

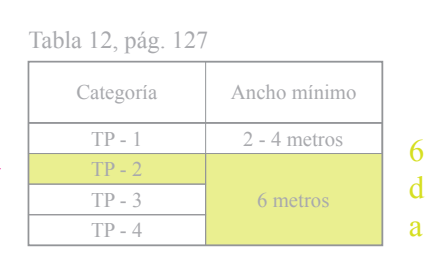

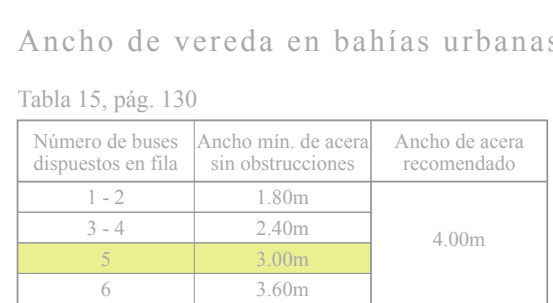

în Peatones

उष्ठ Ciclovía

Ferrovía

䝿 Bus urbano

Taxis

Venta de pasajes

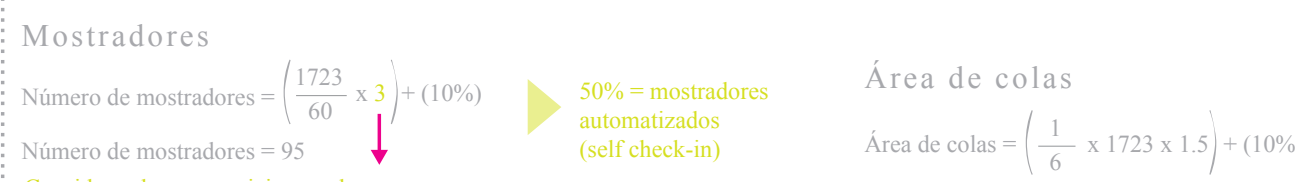

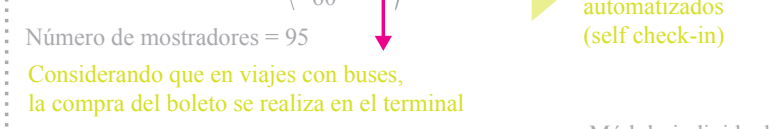

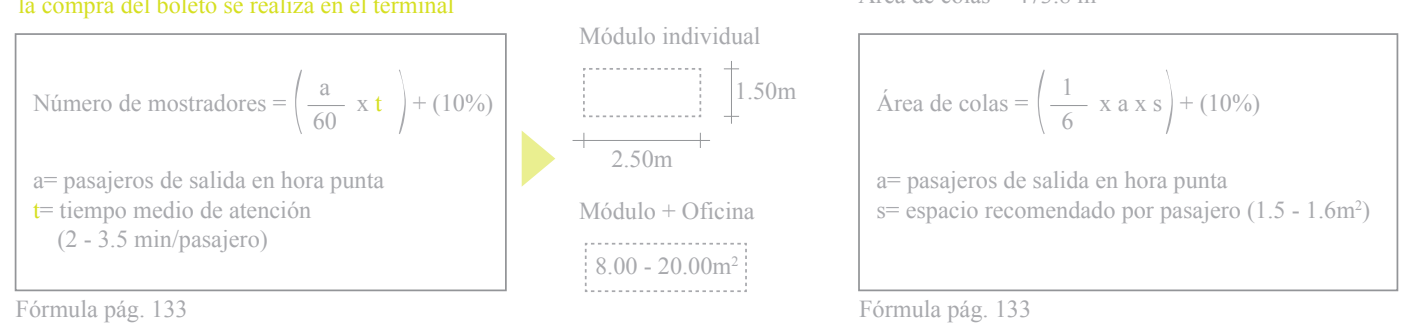

Maquinaria y equipaje
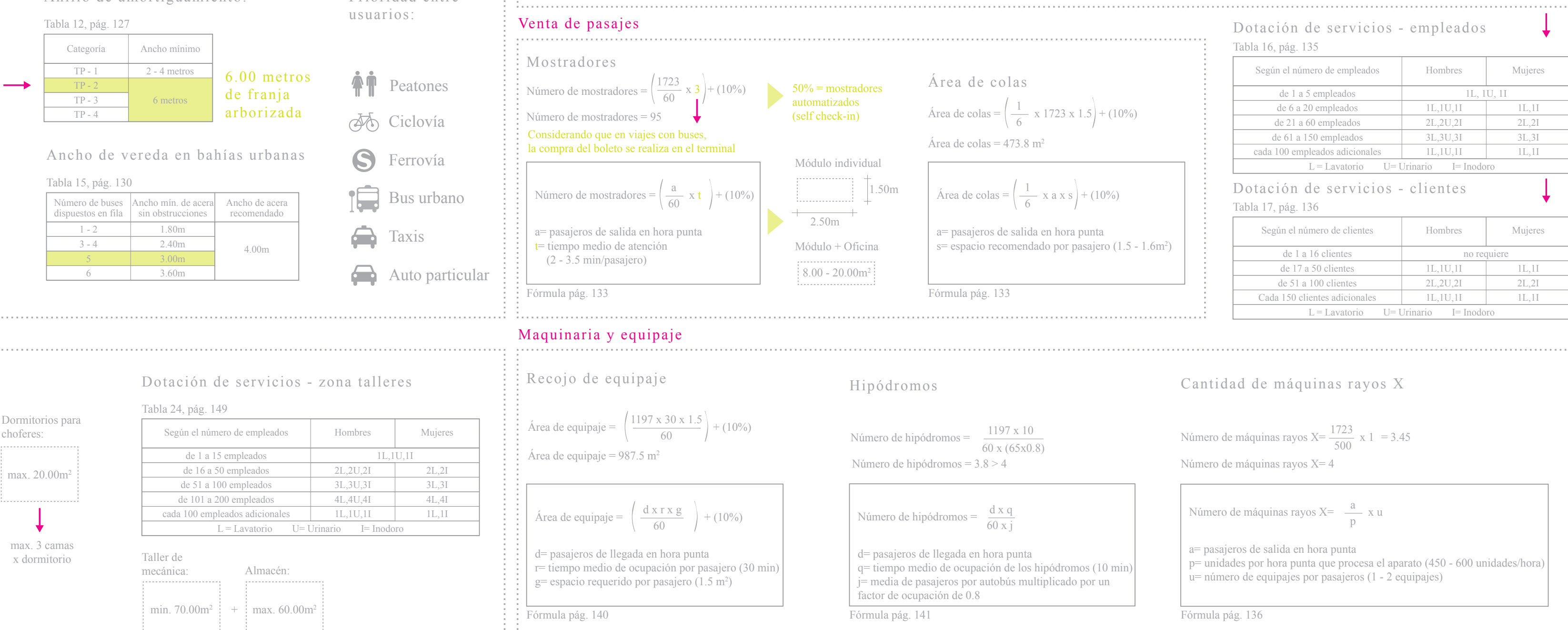
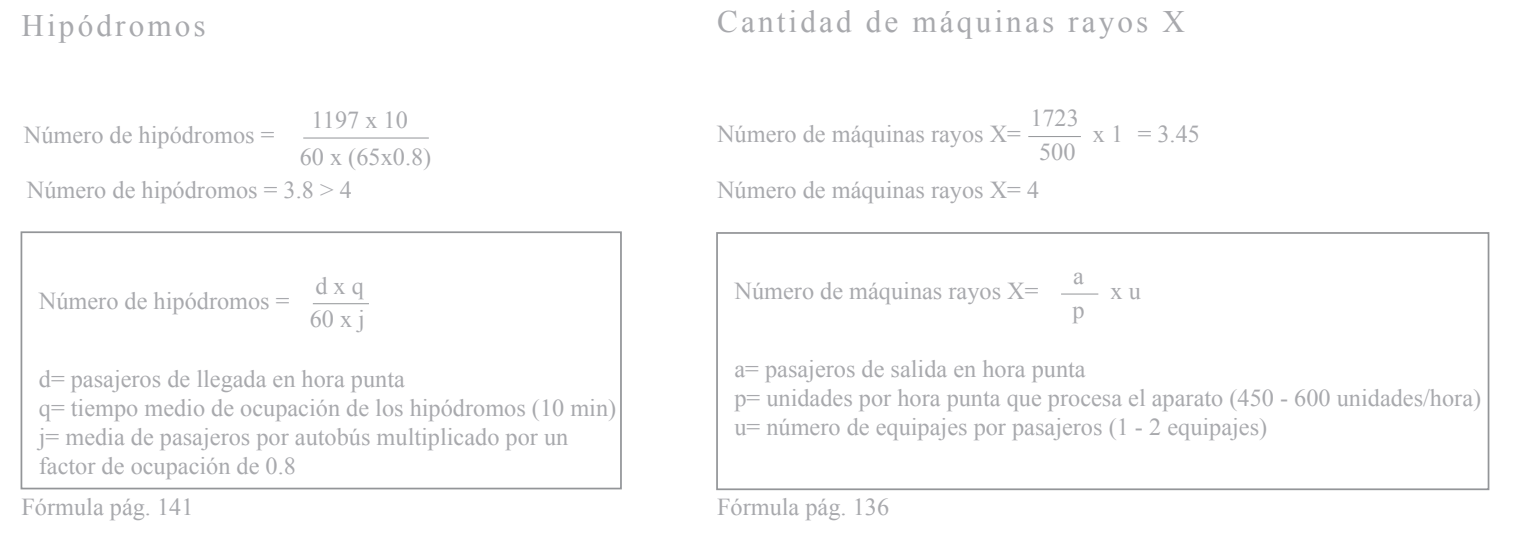

Desembarque: 7 andenes
Embarque : 10 andene
Total $: 17$ andene

$\underset{\text { Ratio: } 941 \text { pasajeros } x \text { andé }}{\downarrow}: 17$ andenes

Ratio: 941 pasajeros $x$ andén
Ratio promedio referentes: 85
Rango: $200-1704$ pasajeresos $x$ andé

Vestibulos de llegandy sulio

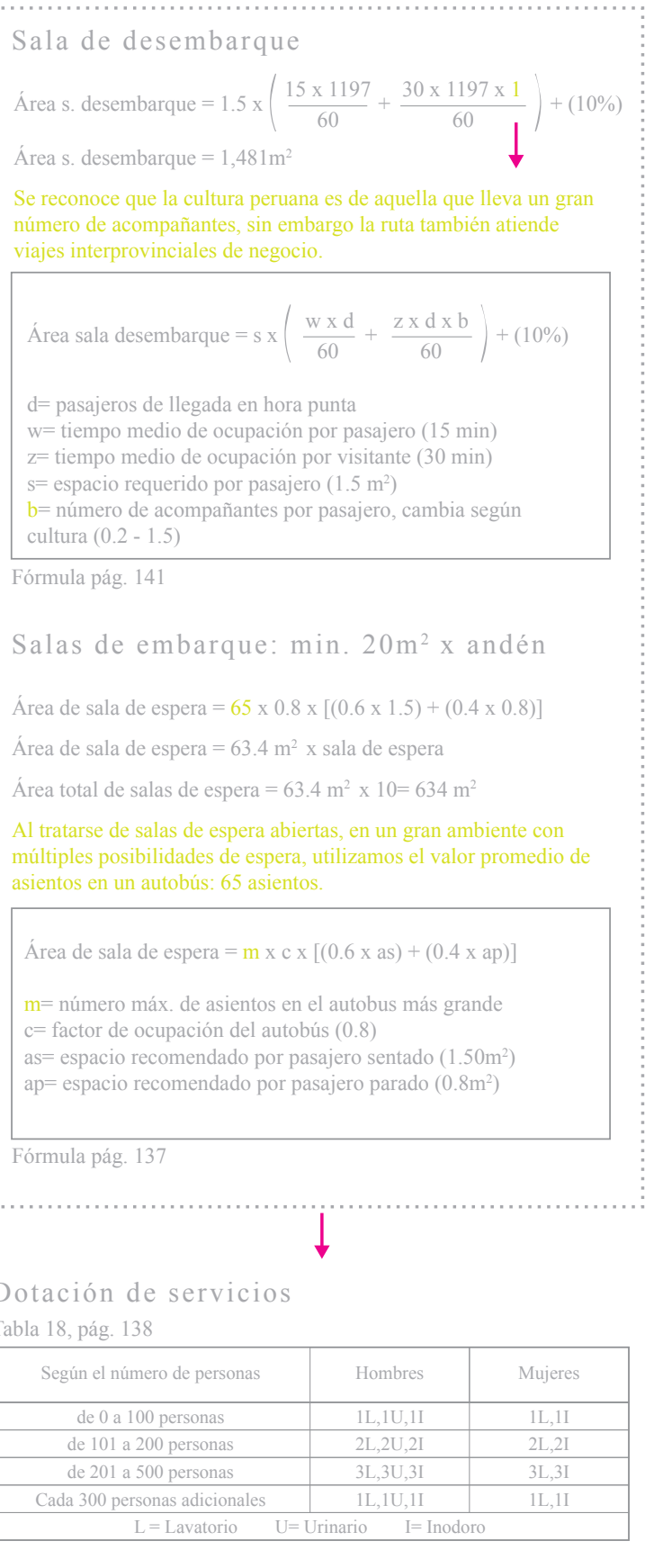

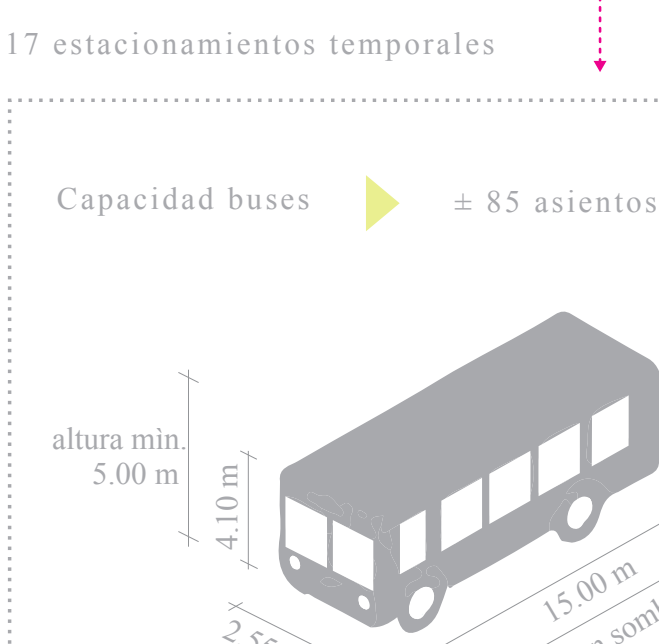

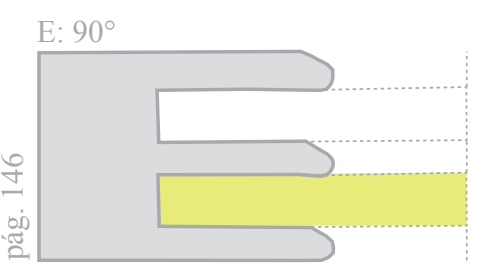

${ }_{0.00 \mathrm{~m}}{ }^{9} \frac{9.00 \mathrm{~m}}{15.00 \mathrm{~m}} \quad{ }_{4.00 \mathrm{~m}}$

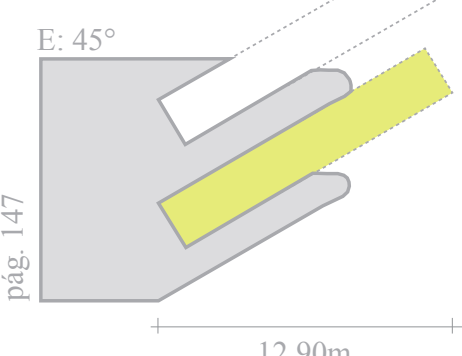

(12.90m

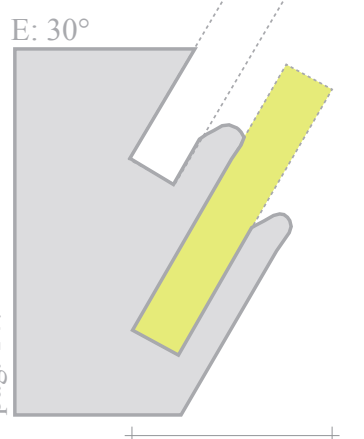




\subsubsection{Memoria descriptiva de arquitectura}

El proyecto se ubica en un terreno con un área de 52,523m2 y consta de un área construida total de 45,393m2. El terminal está conformado por un edificio principal de dos niveles más un mezzanine (volumen tectónico) y otro edificio de un nivel (volumen estereotómico), además de una torre de control de cuatro niveles, un edificio comercial de tres y la infraestructura vial correspondiente. Adicionalmente, cuenta con tres sótanos con estacionamientos más una conexión al metro del Lima. Por último, tiene una serie de anexos compuestos por espacio público y locales comerciales dispersos.

Figura 53: Esquema de zonas

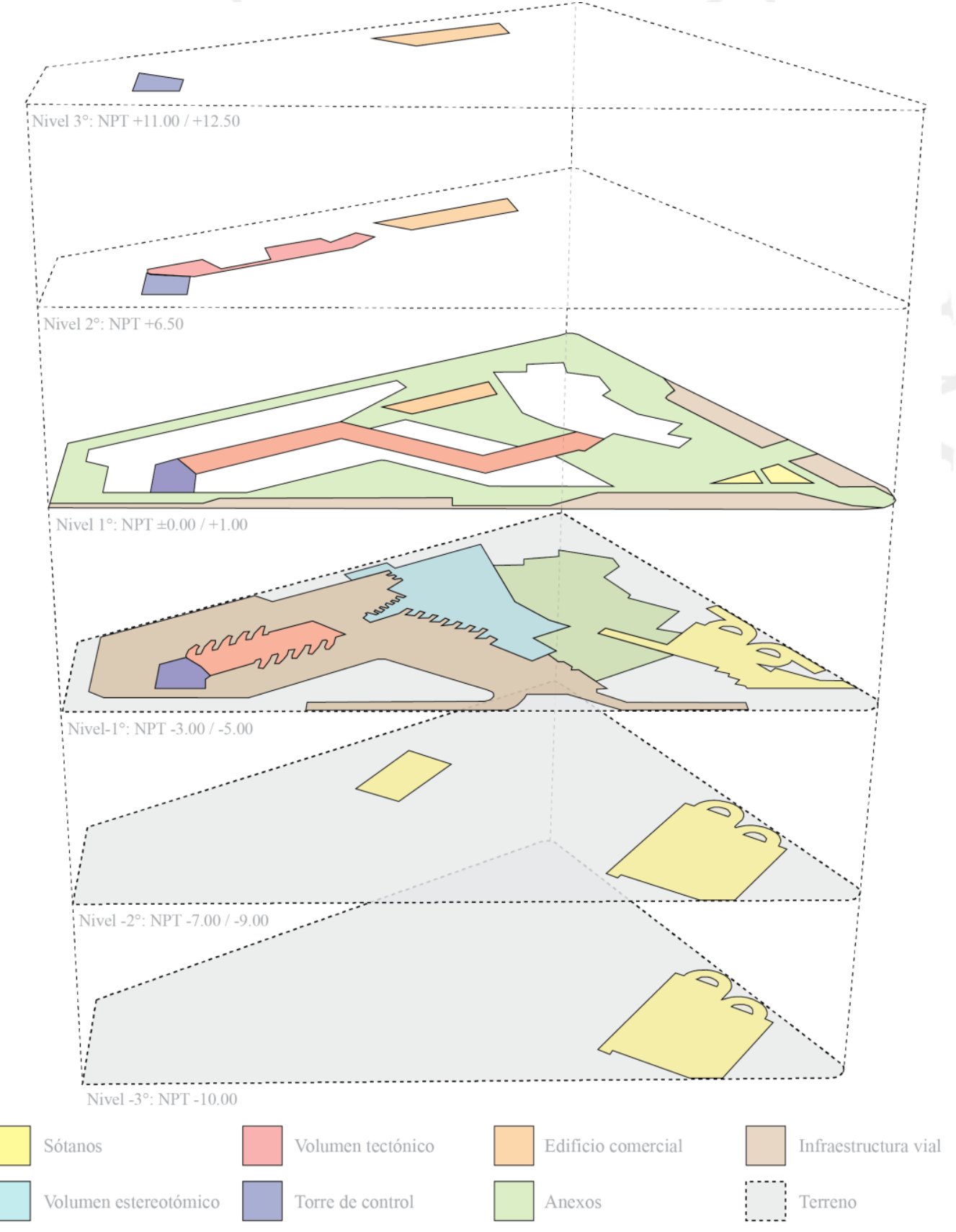




\section{Sótanos}

- Conexión intermodal

- Estacionamientos

- Abastecimiento de agua

El terminal terrestre cuenta con tres niveles de sótanos, los cuales funcionan como estacionamientos vehiculares y una conexión subterránea con el metro de Lima. Su estructura es independiente al resto de zonas del terminal y tiene dos salidas diferentes que lo conectan al terminal, una de las cuales es la única parte visible de este edificio desde el exterior.

Frente a la entrada principal del terminal terrestre se ubica el ingreso a la conexión intermodal y sótanos. Este está situado a nivel de la calle y comparte cubierta con la zona de espera del paradero de buses urbanos, el estacionamiento de bicicletas y con zonas de circulación o descanso. Además, incluye dos escaleras mecánicas, una escalera de evacuación y dos ascensores para comunicarse con los niveles inferiores. Igualmente, posee un área de espera y una conexión visual entre el espacio público y el primer sótano que funciona como iluminación y ventilación natural.

Los estacionamientos de autos se repartieron en los tres niveles del sótano y cuentan con una rampa de ingreso y otra rampa de salida, ambas con dos carriles respectivamente. El primer nivel de estacionamientos comprarte área con la conexión intermodal y se sitúa en el NPT -4.00 , por este motivo solamente cuenta con 32 estacionamientos. Para la conexión con la línea 2 del metro de Lima, se aprovechó la existencia de una salida de emergencia en la Av. Manuel Echeandía, la cual se prolongó con el objetivo de establecer una conexión subterránea sin interrupciones. Vale recalcar que la estación "Circunvalación" de la línea 2 del metro se ubicará al otro lado de la carretera central, motivo por el cual fue importante plantear una conexión subterránea. La salida peatonal de los estacionamientos y de la zona intermodal se da a través de una rampa que desemboca en la plaza pública del terminal, la que se ubica en el NPT -3.00. Los siguientes dos sótanos de estacionamientos, ubicados en el NPT -7.00 y -10.00, cuentan con 144 sitios para estacionamientos cada uno y se conectan a los núcleos de circulación vertical mencionados previamente compuestos por las dos escaleras cerradas y los dos ascensores. 
El abastecimiento de agua potable y agua contra incendio se da mediante un núcleo de cisternas, con su respectivo cuarto de bombas y accesos, ubicado bajo la zona de mantenimiento y el edificio comercial.

\section{$\underline{\text { Volumen estereotómico }}$}

- Desembarque de pasajeros

- Encomiendas

- Zona de mantenimiento

El volumen estereotómico se encuentra parcialmente enterrado y funciona como un gran zócalo que conecta el volumen tectónico con el edificio comercial. Desde el exterior su volumetría se mescla con la topografía del espacio público ya que se compone de una estructura principalmente maciza con grandes muros y pocas ventanas, por lo que desde resulta difícil determinar que partes lo componen.

Su ingreso principal se ubica en el NPT -3.00 y conecta con la plaza pública del terminal, la que funciona como punto de encuentro con los sótanos, la zona de conexión intermodal, las bahías urbanas y todo el frente de la Av. Manuel Echeandía. El edificio tiene un área pública y una privada, la primera se compone de tres zonas conectadas entre sí, el desembarque de pasajeros, el recojo de equipaje y finalmente el hall de recibimiento y zona de encomiendas. Dentro de esta también se ubica el supermercado, el que se revisará luego junto con los usos complementarios. El sector privado se compone por los ambientes dedicados al mantenimiento de buses y del terminal.

La zona de desembarque es la primera parada de los buses, los cuales se estacionan en una de las siete bahías de desembarque y a través de una rampa se llega a la zona de recojo de equipaje. Esta zona cuenta con cuatro carruseles para la distribución de equipaje, una zona de servicio, almacén y depósito. También incluye un mostrador para reclamos, servicios higiénicos y un cuarto de tableros. Desde esta zona se continua al hall de llegada y la zona de espera, donde los familiares pueden esperar para el recojo de pasajeros. Este último se encuentra en el NPT -3.00 y conecta de manera visual con la zona de desembarque a través de una división de vidrio, adicionalmente se ilumina de manera natural, gracias a dos teatinas que lo conectan con la plaza semipública que se ubica en su cubierta. 
La zona de encomiendas se encuentra hacia un extremo del hall de llegada, esta se separa mediante una división de vidrio y cuenta con un área de espera con mostradores para la entrega y recojo de mercancías. A su vez, se conecta mediante una rampa con el NPT -4.00 donde se ubican dos depósitos independientes para las encomiendas de embarque y desembarque. Estos depósitos fueron ubicados facilitando el flujo de mercancías desde y hacia los buses.

El área de mantenimiento se ubica en el NPT -5.00 complemente aislada del resto de zonas, esta se compone de un sector para los trabajadores, una zona de mantenimiento y limpieza de buses, cuartos para el abastecimiento eléctrico y un patio de maniobras. La zona del personal cuenta con una oficina para el jefe de mantenimiento, una sala de descanso, una sala para choferes, servicios higiénicos y un hall que conecta con la circulación vertical. El área de mantenimiento y limpieza de buses cuenta con un depósito, un taller mecánico y un almacén de maquinaria. Adicionalmente hay un depósito de servicio y un cuarto de basura que alberga dos ductos que sirven a la torre comercial. En esta zona se han habilitado nueve estacionamientos para los buses y un estacionamiento adicional para el recojo de basura. Los andenes se diseñaron de manera espaciosa, con un ancho mínimo de 2.40 metros para la circulación del personal de limpieza y en algunos casos se implementaron zanjas soterradas para reparaciones mecánicas. Con acceso desde el patio de maniobras y la calle, se ubicó un cuarto para la subestación eléctrica y otro para dos grupos electrógenos considerando un área para la recarga de combustible. Estos cuentan con una chimenea de extracción de monóxido que sube por el edificio comercial hasta el punto más alto.

\section{Volumen tectónico}

- Hall principal

- Hall de embarque

- Embarque de pasajeros N-1

- Mezzanine

El volumen tectónico se emplaza en el terreno un metro por encima del nivel de la calle, su ingreso principal se da a través de una rampa o seis gradas paulatinas. Adopta este nombre ya que estructuralmente funciona como un puente: sus esquinas son los únicos 
puntos de apoyo, llegando a tener hasta 70 metros de luz libre. Sus fachadas son una gran cercha metálica de 10 metros de altura cuyo cerramiento se da con un gran frente vidriado, aleros que respetan la modulación del vidrio y una malla metálica que reduce el ingreso de radiación solar al interior. La volumetría de este edificio zigzaguea dentro del terreno jugando con el recorrido de los buses del nivel inferior, a veces alineándose y otras intersectándose. Adicionalmente respeta una secuencia lógica de espacios en su interior, pasando de lo más público a lo más privado. A pesar de esto, el volumen mantiene una relación de 360 grados con su entorno, gracias a sus frentes translúcidos. Hubo dos aspectos de gran importancia que se contemplaron al plantear el volumen tectónico. Primero, se optó por un sistema de acondicionamiento pasivo para reducir el impacto energético del terminal, se consideró la orientación del volumen para reducir la radiación solar y también se implementaron aleros y mallas metálicas que funcionan como barreras solares. Luego, al tratarse de un volumen principalmente vidriado, se diseñó un cerramiento que permitiera la ventilación natural, mediante el efecto chimenea y la circulación cruzada para evitar la generación de un efecto invernadero. Para esto, se contemplaron aperturas en las partes superiores de la fachada del volumen, al igual que en zonas bajas para permitir el ingreso de aire fresco. Tanto la fachada vidriada, como la cubierta, fueron diseñadas pensando en estas necesidades, así como sus posibilidades de mantenimiento.

El hall principal del terminal terrestre se encuentra en el NPT +1.00 y se ingresa a través de una rampa con un techado a 11 metros de altura. Este frente mira hacia la carretera central y se compone de una gran escalera que conecta con el nivel inferior, la zona de desembarque; un módulo de orientación al usuario y dos ascensores, además de conectar visualmente con el espacio semipúblico que cubre el volumen estereotómico. Este hall se desarrolla de forma longitudinal albergando diversos recorridos y servicios, como módulos de cuatro y cinco mostradores para la venta de pasajes y máquinas de servicio automatizado para agilizar el proceso. Adicionalmente, siguiendo el diseño de los mostradores se encuentran los servicios higiénicos, casilleros, una capilla, una posta médica y la oficina de la Policía Nacional del Perú. La distribución de estos mostradores y espacios permite dos flujos: uno más amplio para la venta de boletos con circulación lenta y otro un poco más estrecho de carácter contemplativo hacia el exterior que brinda un acceso directo y rápido. Todos los frentes son acompañados por una jardinera exterior que va a lo largo del volumen. Al final del hall principal 
encontramos el control de seguridad previo a la zona de embarque de pasajeros, este cuenta con una escalera de evacuación que desemboca en el patio de maniobras y cuatro máquinas de rayos $\mathrm{X}$ para la revisión de equipaje.

El hall de embarque es accesible únicamente por un ingreso en el NPT +1.00 , luego de pasar seguridad y funciona como una zona previa a las salas de embarque. En este nivel se encuentran dos núcleos de servicios higiénicos, zonas de espera con bancas, tres módulos de venta y una cafetería. Además, cuenta con dos ascensores, dos escaleras mecánicas y dos escaleras para bajar al NPT -5.00, donde se encuentran las salas de embarque. Para casos de emergencia, la zona de embarque del NPT +1.00 cuenta con una ruta de evacuación presurizada que desemboca en el anillo peatonal. De forma anexa a la cafetería y al segundo núcleo de servicios higiénicos, se encuentra una zona de mantenimiento, equipada con un depósito de limpieza, cuarto de basura, ascensor de servicio, depósitos para los comercios y la cocina de la cafetería.

Las salas de embarque, ubicadas en el NPT -5.00 cuentan con dos núcleos de servicios higiénicos, tres depósitos, un cuarto de tableros y se conectan a la circulación vertical mencionada previamente. En esta zona hay diez puertas de embarque, con su respectiva zona de espera equipada con butacas y un control de seguridad. Hacia el exterior, se encuentran las bahías de embarque, cinco a cada lado del edificio. Entre cada bus hay una separación de 3.50 metros, permitiendo una circulación cómoda de pasajeros y equipajes.

El mezzanine del volumen tectónico se encuentra en el NPT +6.50 y espacialmente se conecta con el hall de embarque, pero funcionalmente conecta la torre de control con el edificio comercial. La conexión con la torre de control pasa desapercibida desde el exterior, pero aquella que conecta con el edificio comercial funciona como un puente a la intemperie. Este mezzanine alberga dos salas de usos múltiples para posibles alquileres y eventos. Además, tiene dos dobles alturas que lo conectan con el hall de embarque, la primera parte es parte del vestíbulo del SUM, en el cual se encuentra la recepción, dos ascensores y una escalera de evacuación. La segunda funciona como una división espacial entre las dos salas de usos múltiples, por lo que tiene un puente que funciona como acceso. Escondidos visualmente, hay un depósito y una cocina por cada SUM, una oficina administrativa, un depósito general, 
un depósito de limpieza, un cuarto de basura y un ascensor de servicio, además de la conexión de servicio con la torre de control.

$\underline{\text { Torre de control }}$

- Zona de personal de servicio

- Oficinas de administración

- Oficinas de seguridad, comunicación y logística

- Control de tránsito de buses

La torre de control se ubica a un extremo del terminal y volumétricamente es un remate vertical del edificio tectónico. Por este motivo fue diseñado respetando su mismo ancho, su modulación de vidrios y sus alturas de niveles, las únicas diferencias formales se dan con la aparición de losas que funcionan como aleros o jardineras, además de algunos frentes cerrados por celosías. Su función principal es albergar todas las oficinas necesarias para administrar y controlar la logística del terminal. Se ingresa desde el anillo peatonal a través de unas escaleras que suben al NPT +1.00 , pero también cuenta con un ingreso secundario en el segundo nivel a través del mezzanine. Se habilitaron estos dos accesos para ampliar los posibles flujos de ingreso, permitiendo al personal de servicio, administrativo y/o gerentes ingresar por cualquier lado del terminal. El frente principal de este volumen mira hacia la carretera central y se eleva siete metros por encima de la cubierta del volumen tectónico. La corona del edificio sirve para colocar el nombre del terminal terrestre, funcionando como un hito visible desde la carretera central.

El edificio cuenta con una zona de personal de servicio en el nivel -1, ubicado en el NPT -5.00. Esta zona se compone de un hall abierto con circulación vertical y sirve como punto de distribución para el personal de servicio, así como zona de carga y descarga para mercadería. Para el personal de servicio hay servicios higiénicos con duchas y una zona de casilleros. Además, hay una oficina para el jefe de personal, un cuarto de basura, el ascensor de servicio, un depósito y un cuarto de tableros.

En el NPT +1.00 se encuentran las oficinas administrativas, compuestas por cubículos abiertos para 12 personas, un puesto de recepción y una pequeña zona de espera. A la mitad del volumen se ubica el núcleo de circulación vertical, con una 
escalera y un ascensor. También cuenta con una sala de reuniones, servicios higiénicos y una conexión con la zona de servicio compartida con el volumen tectónico.

En el NPT +6.50, se encuentran las oficinas de seguridad, comunicación y logística. Para esta zona se habilitaron tres oficinas cerradas, una oficina para el gerente del terminal, secretaría y una zona de cubículos abiertos para 10 personas. Adicionalmente se encuentra la zona de circulación vertical, servicios higiénicos y una conexión directa a la zona de servicio de ese nivel, la cual se comparte con el mezzanine del volumen tectónico.

En el último nivel ubicado en el NPT +12.50 , se controla el tránsito de los buses y está equipado con cubículos abiertos para 15 personas, una sala de reuniones, una oficina cerrada y la oficina de secretaría. Adicionalmente cuenta con una zona de archivos y servidores, un cuarto de tableros, la circulación vertical, y una terraza exterior.

\section{$\underline{\text { Edificio Comercial }}$}

- Usos complementarios

- Oficinas de empresas transportistas

- Hospedaje

El edificio comercial se ubica en la zona sur del terreno sobre el edificio estereotómico. Está rodeado por una plaza semipública que también lo vincula con el volumen tectónico. Se trata de una arquitectura con características más sólidas que las del volumen principal, ya que se compone de frentes cerrados con celosías, placas rectangulares de concreto y volados macizos. El volumen tiene la característica de incluir jardineras continuas en todo el perímetro, generando un filtro visual y resguardando los ambientes interiores del sol. Adicionalmente, se conecta con la torre de control a través de un puente que funciona como nexo con el mezzanine.

El primer nivel ubicado en el NPT +1.00 , se compone de múltiples locales comerciales que se relacionan con la plaza semipública y con una serie de micro espacios públicos que se relacionan con la calle Leónidas La Serre y la plaza principal del terminal. En este nivel se encuentran seis comercios, una cafetería y un restaurante, además de servicios higiénicos públicos, un cuarto de tableros y un vestíbulo con circulación vertical para conectarse con los siguientes niveles. Además, cuenta con un 
pasaje abierto a la mitad del volumen, que conecta el anillo peatonal con la plaza semipública y eventualmente el otro lado del terminal.

El siguiente nivel del edificio situado en el NPT +6.50, está pensado para ser tercerizado y arrendado a empresas transportistas que requieran de una o múltiples oficinas. Cuenta con dos escaleras de evacuación, dos ascensores, una recepción, una sala de reuniones compartida, un centro de servidores y 5 oficinas independientes, con una capacidad de 15 a 20 personas y una oficina cerrada cada una. Además, hay un núcleo de servicios equipado con servicios higiénicos, un depósito, un cuarto de tableros y un comedor con vista al puente. Como se mencionó anteriormente, este puente conecta con el mezzanine, que a su vez llega a la torre de control.

En el tercer nivel, NPT +11.00 , se encuentra el hospedaje, equipado con 13 dormitorios dobles y uno cuádruple, orientados hacia el exterior del edificio con vista al vecindario. Hacia el interior del edificio se ubicó la sala de estar, la cual se ilumina a través de teatinas en la cubierta. A través de este ambiente, se accede a la terraza del hospedaje, la cual es de uso común. Los servicios higiénicos son compartidos, cuentan con duchas y se ubican cerca al núcleo de circulación vertical. Hacia el otro lado de la circulación vertical, se encuentra una kitchenette, un comedor con terraza, un depósito y una lavandería.

\section{$\underline{\text { Anexos al Terminal Terrestre }}$}

- Supermercado

- Plaza principal

- Espacio público complementario

Los anexos al terminal terrestre están compuestos por servicios adicionales como comercio y espacio público que lo complementan. La plaza principal está separada del resto de espacios públicos porque es la única que se complementa con locales comerciales y funciona como nexo conector de diferentes áreas del terminal.

El supermercado se ubica en el NPT -4.00 dentro del volumen estereotómico, el cual sirve como un comercio ancla para atraer más usuarios, y atiende tanto a los pasajeros que necesitan una compra de último minuto, como a los usuarios del metro y vecinos de la zona. Se trata de un supermercado exprés, que cuenta con un gran ambiente principal equipado con 5 cajas registradoras, una zona de abarrotes, un área de 
verduras y frutas, otra de carnes y pescados al igual que una panadería. Separado de la zona publica se agregaron servicios higiénicos para los clientes, una zona de atención al usuario y su respectiva zona de servicio para el personal, equipada con camerinos y servicios higiénicos. Además, se implementó un área de servicio, conformada por un depósito de limpieza, dos cuartos de basura, una cámara fría, un almacén de productos, un cuarto de tableros y aire acondicionado, y finalmente bahías de abastecimiento para carga y descarga de proveedores, las que se acceden desde el patio de maniobras.

La plaza principal es otro servicio adicional al terminal que aporta espacio urbano delimitado y controlado por los usos que lo rodean. Esta plaza está equipada con un restaurante, un taller comunitario y una guardería. El restaurante ubicado en el NPT -2.00 tiene un aforo aproximado de 75 personas y está equipado con una zona de mesas, servicios higiénicos, una cocina y un baño para el personal. La zona de mesas, desemboca a un espacio de la plaza delimitado por un cambio de nivel y cuenta con una cubierta verde para un mejor aislamiento térmico. De igual manera se diseñó el taller comunitario ubicado en el NPT -3.00, el cual está equipado con un taller de manualidades, un depósito, servicios higiénicos, una oficina y una zona de atención o venta. La intención es que sea un espacio para el uso, planificado, de los vecinos, para motivar la ocupación de la plaza y generar un sentido de apropiación. Finalmente, en una zona de la plaza más resguardada se encuentra la guardería y su patio de juegos. Esta guardería está ubicada en el NPT -3.30 y fue diseñada para recibir a niños de diversas edades, facilitando el trabajo de muchos trabajadores del terminal mismo o del vecindario en general. La guardería cuenta con una zona para bebés y una zona para niños. Además, cuentan con una oficina, un depósito y servicios higiénicos. Esta guardería también cuenta con una cubierta con vegetación para un mejor aislamiento térmico, al igual que con múltiples árboles en el patio de juegos para reducir la radiación solar recibida.

El espacio público complementario del terminal está compuesto por el anillo peatonal y la plaza semipública ubicada sobre el volumen estereotómico. El anillo peatonal fue diseñado como un circuito con diversos puntos de descanso equipados con bancas y árboles para dar sombra, rescatando diferentes visuales. Durante el recorrido del anillo peatonal se encuentran distribuidas diversas plazas pequeñas generadas por desniveles y jardineras elevadas. 
$\underline{\text { Infraestructura vial }}^{48}$

- Patio de maniobras

- Bahías urbanas

La infraestructura vial del terminal se diseñó, como mencionado anteriormente, con una aplicación computarizada especializada en el cálculo de radios de giro y maniobras. De esta manera se calcularon todos los estacionamientos con suficiente espacio para maniobras con buses de hasta 15 metros de largo. De esta misma forma, el gálibo libre necesario para el paso de los buses, se determinó en base a los buses existentes en el mercado y también con el estudio de los puentes existentes en las vías arteriales de la ciudad de Lima. De esta manera se definió una altura mínima de 4.20 metros y se trabajó con una altura final de 4.45 metros en el punto más bajo. En los espacios residuales de los apoyos estructurales del volumen tectónico, se han ubicado depósitos, cuartos de tableros y circulaciones verticales para los accesos a las cisternas.

Cerca de la rampa de ingreso de buses interprovinciales se ubicó un puesto de seguridad, en el cual se instalará el personal encargado de controlar los ingresos y las salidas de los vehículos al patio de maniobras. Este puesto está equipado con una zona de trabajo y con servicios higiénicos. Las vías de circulación se ubican en el NPT -5.00 y crean un circuito cerrado donde se colocan las bahías de desembarque y embarque, además cuenta con zonas de amortiguamiento que funcionan para las maniobras internas de los buses. En el patio de maniobras también colocaron estacionamientos temporales para buses al igual que una estación de servicio, oculta bajo una cubierta de vegetación que se integra al anillo peatonal en el nivel 1. Finalmente, todo el patio de maniobras se encuentra rodeado por veredas para la circulación segura de peatones.

Las bahías urbanas se ubican en el NPT 0.00 y están formadas por una vía auxiliar de dos carriles que se separa de la calle principal para resguardar a los usuarios y evitar obstrucciones. Se diseñaron dos bahías independientes: la primera, para el uso del transporte público masivo ubicada en la avenida Nicolás Ayllón y la segunda, para el uso de taxis y vehículos particulares ubicada en la avenida Manuel Echeandía.

\footnotetext{
${ }^{48}$ El termino infraestructura vial se refiriere a las vías de circulación vehicular de buses interprovinciales y a las bahías urbanas ubicadas dentro de los linderos del proyecto.
} 
Tabla 30: Metrado arquitectónico y cuadro de áreas

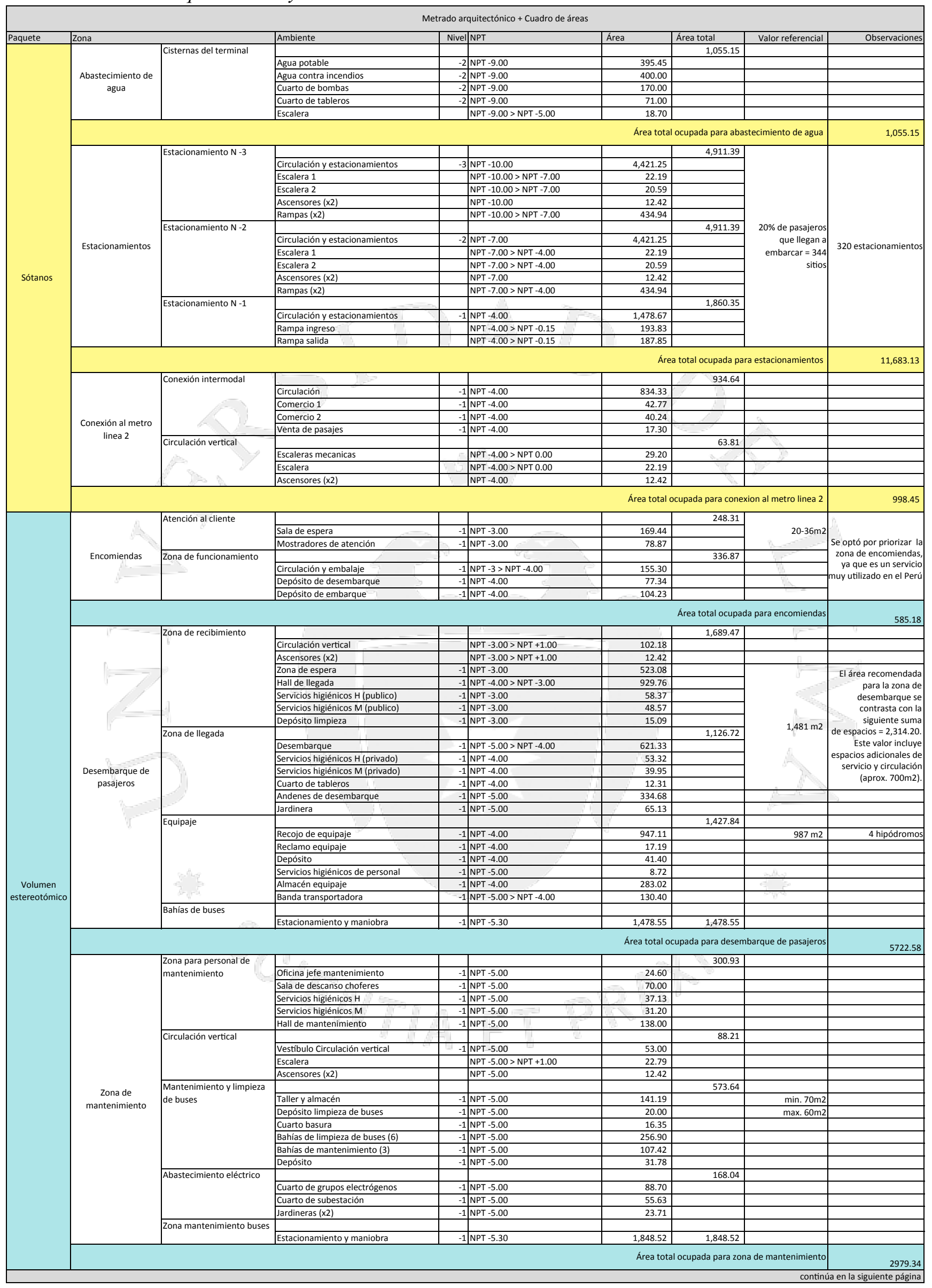


Terminal Terrestre Yerbateros como Regenerador Urbano

Fabrizio Chiappe F. - Claudia Kleffmann G.

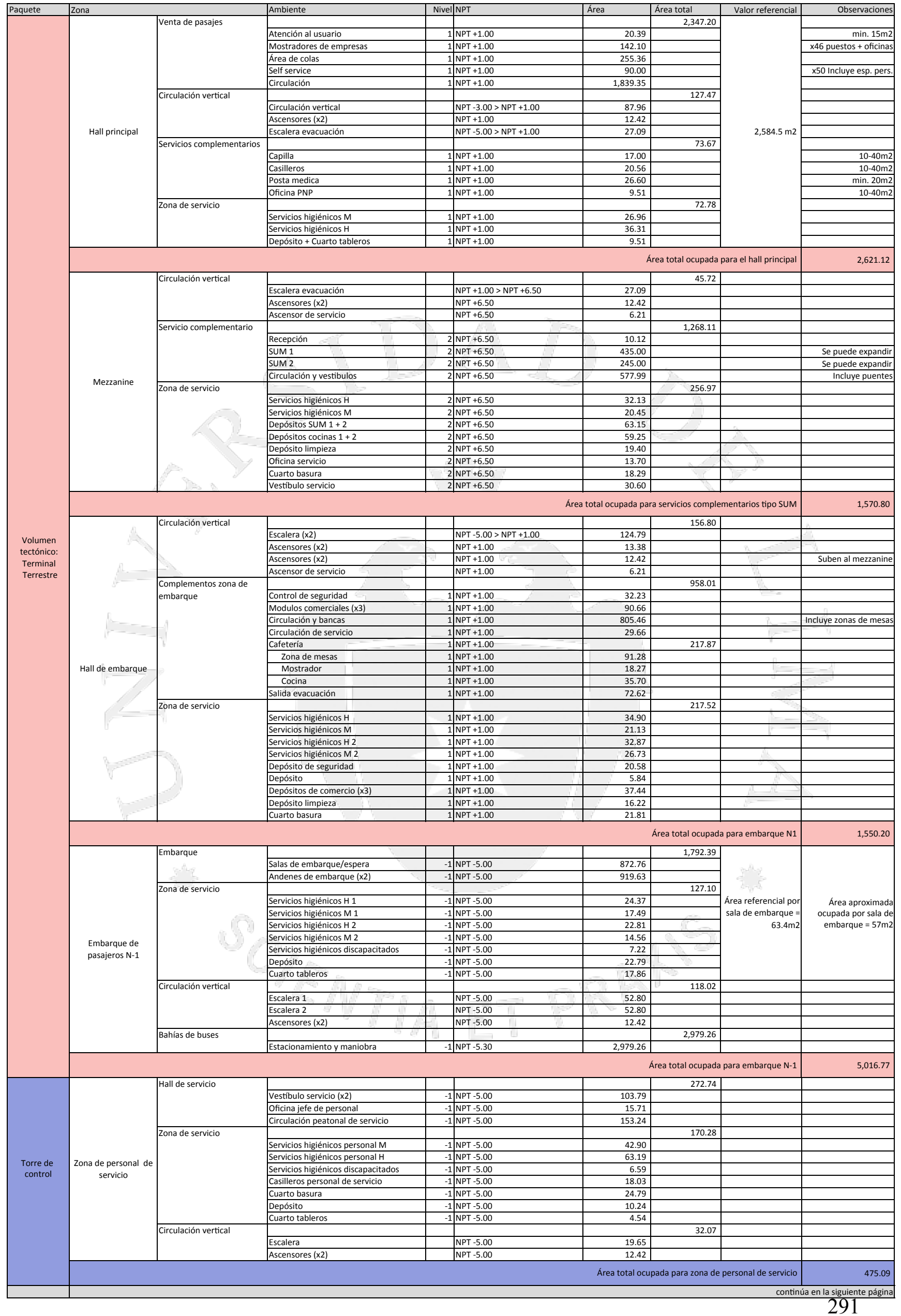


Terminal Terrestre Yerbateros como Regenerador Urbano

Fabrizio Chiappe F. - Claudia Kleffmann G.

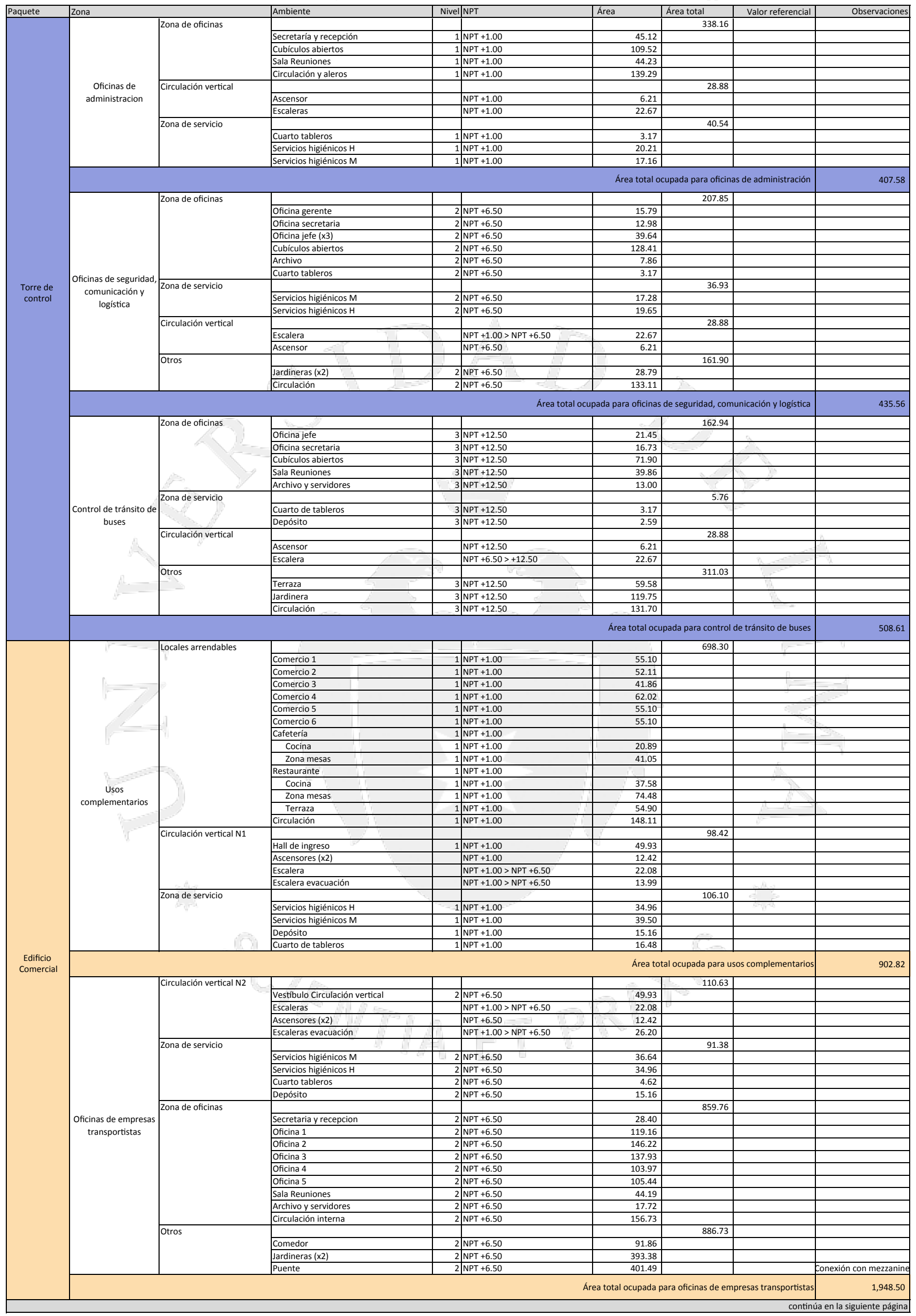


Terminal Terrestre Yerbateros como Regenerador Urbano

Fabrizio Chiappe F. - Claudia Kleffmann G.

\begin{tabular}{|c|c|c|c|c|c|c|c|c|}
\hline Paquete & Zona & & Ambiente & \begin{tabular}{|l|} 
Nivel|NPT \\
\end{tabular} & Área & Área total & \begin{tabular}{l|} 
Valor referencial \\
\end{tabular} & Observaciones \\
\hline \multirow{21}{*}{$\begin{array}{l}\text { Edificio } \\
\text { Comercial }\end{array}$} & & Circulación vertical N3 & & & & 110.63 & & \\
\hline & & & Vestibulo Circulación vertical & \begin{tabular}{l|l}
3 & $\mathrm{NPT}+11.00$ \\
\end{tabular} & 49.93 & & & \\
\hline & & & Ascensores (x2) & NPT +11.00 & 12.42 & & & \\
\hline & & & Escalera & $\mathrm{NPT}+6.50>\mathrm{NPT}+11.00$ & 22.08 & & & \\
\hline & & & Escalera evacuación & $\mathrm{NPT}+6.50>\mathrm{NPT}+11.00$ & 26.20 & & & \\
\hline & & Zona de servicio & & & & 139.48 & & \\
\hline & & & Servicios higiénicos $\mathrm{H}$ & \begin{tabular}{l|l|}
3 & $\mathrm{NPT}+11.00$ \\
\end{tabular} & 53.39 & & & \\
\hline & & & Servicios higiénicos $\mathrm{M}$ & \begin{tabular}{|l|l|} 
NPT +11.00 \\
\end{tabular} & 57.25 & & & \\
\hline & & & Cuarto de tableros & \begin{tabular}{l|l}
3 & NPT +11.00 \\
\end{tabular} & 4.62 & & & \\
\hline & Hosnedaie & & Depósito & \begin{tabular}{l|l}
3 & NPT +11.00 \\
\end{tabular} & 9.80 & & & \\
\hline & Hospeadje & & Lavandería & \begin{tabular}{l|l|}
3 & $\mathrm{NPT}+11.00$ \\
\end{tabular} & 14.42 & & & \\
\hline & & Hospedaje & & & & 501.51 & & \\
\hline & & & Recepción & 3 NPT +11.00 & 28.39 & & $\begin{array}{r}118 \mathrm{~m} 2 \text {, max. } 20 \mathrm{~m} 2 \\
\text { por dormitorio }\end{array}$ & $21.49 \mathrm{~m} 2 \times$ dormitorio \\
\hline & & & \begin{tabular}{|l|} 
Dormitorios \\
\end{tabular} & \begin{tabular}{l|l}
3 & $\mathrm{NPT}+11.00$ \\
\end{tabular} & 329.62 & & por dormitorio, & en promedio, 2 camas \\
\hline & & & Sala de estar & \begin{tabular}{l|l|}
3 & $\mathrm{NPT}+11.00$ \\
\end{tabular} & 76.77 & & max. 3 camas por & \\
\hline & & & Comedor con kitchenette & \begin{tabular}{l|l}
3 & NPT +11.00 \\
\end{tabular} & 66.73 & & & \\
\hline & & Otros & & & & 752.29 & & \\
\hline & & & Terrazas ( $\mathrm{x} 2$ ) & 3 NPT +11.00 & 183.21 & & & \\
\hline & & & Jardinera & \begin{tabular}{l|l}
$3 \mathrm{NPT}+11.00$ \\
\end{tabular} & 402.46 & & & \\
\hline & & & Circulación & \begin{tabular}{l|l|}
3 & $\mathrm{NPT}+11.00$ \\
\end{tabular} & 166.62 & & & \\
\hline & & & & & Área tot & tal ocupada para $\mathrm{h}$ & ospedaje de choferes & $1,503.91$ \\
\hline & & Supermercado & & & & $1,317.93$ & & \\
\hline & & & Vestíbulo + cajas registradoras & \begin{tabular}{l|l|}
-1 & NPT $-3.00>N P T$ \\
\end{tabular} & 285.60 & & & \\
\hline & & & \begin{tabular}{|l|} 
Área de tienda \\
\end{tabular} & \begin{tabular}{l|l|}
-1 & NPT -4.00 \\
\end{tabular} & 951.30 & & & \\
\hline & & & Servicios higiénicos $\mathrm{H}$ & \begin{tabular}{l|l|}
-1 & NPT -4.00 \\
\end{tabular} & 38.65 & & & \\
\hline & & & Servicios higiénicos $\mathrm{M}$ & \begin{tabular}{l|l|}
-1 & NPT -4.00 \\
\end{tabular} & 35.90 & & & \\
\hline & & & \begin{tabular}{|l} 
Depósito limpieza \\
\end{tabular} & \begin{tabular}{l|l|}
-1 & NPT -4.00 \\
\end{tabular} & 6.48 & & & \\
\hline & & Zona de servicio & $-\quad$ & +2 & & 313.50 & & \\
\hline & & & Zona servicio empleados & \begin{tabular}{l|l|}
-1 & NPT -4.00 \\
\end{tabular} & 73.22 & $\bar{C}$ & & \\
\hline & & & Cuarto de tableros & -1 NPT -4.00 & 7.09 & $2=$ & & \\
\hline & Supermercado & & Cuarto de basura 1 & $\begin{array}{ll}-1 & \text { NPT }-4.00 \\
\end{array}$ & 15.15 & +1 & & \\
\hline & & & Cuarto de basura 2 & \begin{tabular}{l|l|}
-1 & NPT -4.00 \\
\end{tabular} & 24.20 & 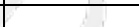 & & \\
\hline & & & \begin{tabular}{|l|} 
Depósito de tienda \\
\end{tabular} & \begin{tabular}{l|l|}
-1 & NPT -4.00 \\
\end{tabular} & 23.71 & 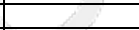 & & \\
\hline & & & Panadería & \begin{tabular}{l|l|}
-1 & NPT -4.00 \\
\end{tabular} & 54.27 & & 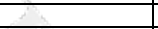 & \\
\hline & & & \begin{tabular}{|l|} 
Camara fría \\
\end{tabular} & \begin{tabular}{l|l|}
-1 & NPT -4.00 \\
\end{tabular} & 42.29 & & 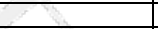 & \\
\hline & & & \begin{tabular}{|l|l|} 
Almacén \\
\end{tabular} & \begin{tabular}{l|l}
-1 NPT -4.00 \\
\end{tabular} & 54.37 & & 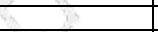 & \\
\hline & & 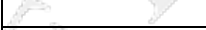 & Cuarto de tablero $+A C$ & \begin{tabular}{l|l|}
-1 & NPT -4.00 \\
\end{tabular} & 19.20 & & $\bar{C}$ & \\
\hline & & \begin{tabular}{|l|} 
Abastecimiento Superm. \\
\end{tabular} & & & & 773.94 & & \\
\hline & & & \begin{tabular}{|l|} 
Circulación de mercadería \\
\end{tabular} & \begin{tabular}{l|l|}
-1 & NPT -4.00 \\
\end{tabular} & 208.88 & & & \\
\hline & & & Estacionamiento y maniobra & \begin{tabular}{l|l|}
-1 & NPT -5.30 \\
\end{tabular} & 565.06 & & & \\
\hline & & & & & & Área total ocupad & para supermercado & $2,405.37$ \\
\hline & & Servicios complementarios & 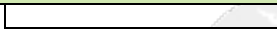 & +2 & & 762.02 & 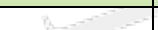 & 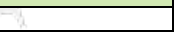 \\
\hline Anexos al & & & Restaurante & \begin{tabular}{l|l|l}
-1 & NPT -2.00 \\
\end{tabular} & 172.16 & & ran & \\
\hline Terminal & & $1+$ & Taller comunitario & \begin{tabular}{l|l|}
-1 & NPT -3.00
\end{tabular} & 185.99 & & (hat & \\
\hline Terrestre & & & Guardería & \begin{tabular}{l|l|}
-1 & NPT -3.30 \\
\end{tabular} & 380.43 & & a & \\
\hline & Plaza principal & & Cuarto de bombas & \begin{tabular}{l|l}
-1 & NPT -3.00
\end{tabular} & 23.44 & & & \\
\hline & & Espacio público & & & & $3,924.35$ & & \\
\hline & & & \begin{tabular}{|l|} 
Plaza de Hall de llegada \\
\end{tabular} & \begin{tabular}{l|l|}
-1 & NPT -3.00 \\
\end{tabular} & $2,634.21$ & & \begin{tabular}{l|l}
$3-0$ \\
\end{tabular} & - \\
\hline & & & \begin{tabular}{|l|} 
Plaza de Restaurante \\
\end{tabular} & \begin{tabular}{l|l}
-1 & NPT -2.00 \\
\end{tabular} & 806.32 & & $t=-$ & प \\
\hline & & & \begin{tabular}{|l|} 
Plaza de Guardería \\
\end{tabular} & \begin{tabular}{l|l|}
-1 & NPT -3.30 \\
\end{tabular} & 483.82 & & & \\
\hline & & & & & & Área total ocu & pada en plaza pública & $4,686.37$ \\
\hline & & Espacio público & & & & $26,605.40$ & & \\
\hline & & & \begin{tabular}{|l} 
Áreas verdes \\
\end{tabular} & $\begin{array}{ll}1 & \text { NPT } 0.00\end{array}$ & $5,952.21$ & & $a+$ & No incluye arboles \\
\hline & & & \begin{tabular}{|l|} 
Anillo peatonal \\
\end{tabular} & $\begin{array}{ll}1 \text { NPT } 0.00 \\
\end{array}$ & $15,799.05$ & & & Incluye arboles \\
\hline & & & Plaza elevada (semipública) & 1 NPT +1.00 & $3,891.65$ & & + & \\
\hline & & & \begin{tabular}{|l|} 
Áreas verdes \\
\end{tabular} & $1 \mathrm{NPT}+1.00$ & 962.49 & & 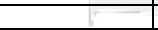 & No incluye arboles \\
\hline & & Conexión urbana & & NPT 0.00 & & $1,089.82$ & & \\
\hline & Espacio público & & Paradero de bus & $\begin{array}{ll}\text { N NPT } 0.00 \\
\end{array}$ & 442.43 & & 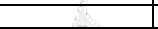 & \\
\hline & complementario & & Estacionamiento Bicicletas & \begin{tabular}{l|l|}
1 & NPT 0.00 \\
\end{tabular} & 31.56 & & 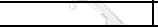 & \\
\hline & & & Circulación & \begin{tabular}{l|l}
1 NPT 0.00 \\
\end{tabular} & 587.12 & & 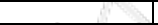 & \\
\hline & & & Cuarto de tableros y máquinas & \begin{tabular}{l|l} 
NPT 0.00 \\
\end{tabular} & 28.71 & & 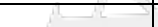 & \\
\hline & & Circulación vertical & & & & 64.08 & & \\
\hline & & & Escaleras mecánicas & NPT $-4.00>$ NPT 0.00 & 29.48 & & & \\
\hline & & & Escaleras evacuación & NPT $-4.00>$ NPT 0.00 & 22.18 & & & \\
\hline & & & Ascensores (x2) & NPT 0.00 & 12.42 & & & \\
\hline & & & & & & Área total ocupada & para espacio público & $27,759.30$ \\
\hline & & Vias buses & & \begin{tabular}{l|l} 
\\
\end{tabular} & & $9,123.39$ & 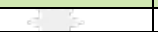 & \\
\hline & & & Vías de Circulación vehicular & \begin{tabular}{l|l}
-1 & NPT -5.30 \\
\end{tabular} & $5,428.06$ & & & \\
\hline & & & \begin{tabular}{|l|} 
Espacio de amortiguamiento vial \\
\end{tabular} & \begin{tabular}{l|l|}
-1 & NPT -5.30 \\
\end{tabular} & $1,064.78$ & & & \\
\hline & & Servicios adicionales & Estacionamiento temp. y maniobra & \begin{tabular}{l|l|}
-1 & NPT -5.30 \\
\end{tabular} & 824.97 & $\ldots$ & & \\
\hline & & & Estación de servicio y maniobra & \begin{tabular}{l|l|}
-1 & NPT -5.30 \\
\end{tabular} & 934.63 & 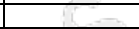 & & \\
\hline & & & Vereda patio maniobras & \begin{tabular}{l|l|}
-1 & NPT -5.15 \\
\end{tabular} & 870.95 & & & \\
\hline & Patio de maniobras & Seguridad & +1 & T & & 104.70 & & \\
\hline & Patio de maniobras & & Caseta control de seguridad & \begin{tabular}{l|l|}
-1 & NPT -5.15 \\
\end{tabular} & 31.38 & & & \\
\hline & & & \begin{tabular}{|l} 
Servicios higiénicos \\
\end{tabular} & \begin{tabular}{l|l} 
& NPT -5.15 \\
\end{tabular} & 8.33 & $\infty$ & & \\
\hline & & & $+\frac{1}{20}$ & \begin{tabular}{l|l|}
-1 & NPT -5.30 \\
\end{tabular} & 64.99 & 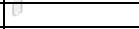 & & \\
\hline & & Circulación vertical & (1) & 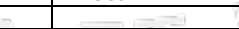 & 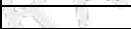 & 73.14 & & \\
\hline $\begin{array}{l}\text { Infraestructura } \\
\text { vial }\end{array}$ & & & \begin{tabular}{|l|} 
Escalera a cisterna \\
\end{tabular} & NPT $-5.30>$ NPT -9.15 & 19.20 & & & \\
\hline & & & Escalera de evac. Mezzanine & \begin{tabular}{l|l}
$\mathrm{NPT}-5.00>\mathrm{NPT}+1.00$ \\
\end{tabular} & 33.35 & & & \\
\hline & & & Escalera 2 de sótanos & \begin{tabular}{|l|l|} 
& NPT -4.00 \\
\end{tabular} & 20.59 & & & \\
\hline & & & & & Área & a total ocupada par & a patio de maniobras & $9,301.23$ \\
\hline & & & & & & $3,494.35$ & & \\
\hline & & & Bahías de buses urbanos & $\begin{array}{ll}\text { NPT }-0.15 \\
\end{array}$ & $1,430.38$ & & $75 \mathrm{ml}$ & \\
\hline & & las urbanas & Bahías de taxis $y$ autos & $\begin{array}{ll}\text { NPT }-0.15 \\
\end{array}$ & $1,311.92$ & & $142 \mathrm{ml}$ & \\
\hline & & & \begin{tabular}{|l} 
Carril de asceleración \\
\end{tabular} & \begin{tabular}{l|l|l|l|l|} 
NPT -0.15 \\
\end{tabular} & 752.05 & & & \\
\hline & & & & & & Área total ocupad & para bahías urbanas & $3,494.35$ \\
\hline
\end{tabular}




\begin{tabular}{|c|c|c|}
\hline Nivel & Zona & Area construida \\
\hline \multirow{3}{*}{$N-2,-3$} & Cuartos tecnicos cisternas & 260.00 \\
\hline & Estacionamiento -3 & $4,985.74$ \\
\hline & Estacionamiento -2 & $4,985.74$ \\
\hline \multirow{11}{*}{$\mathrm{N}-1$} & Estacionamiento -1 & $1,607.21$ \\
\hline & Conexion al metro & 800.00 \\
\hline & Restaruante + SUM plaza & 407.06 \\
\hline & Guarderia & 401.68 \\
\hline & Estacion de servicio & 352.85 \\
\hline & Cuartos grupo electrogeno +subestacion & 194.72 \\
\hline & Zona embarque N-1 & $1,422.62$ \\
\hline & Torre de control: Zona personal servicio & 698.45 \\
\hline & Puente buses + apoyos estructurales & $1,962.67$ \\
\hline & Volumen estereotomico completo & $8,359.78$ \\
\hline & Zonas techadas del patio de maniobras & $1,876.44$ \\
\hline \multirow{4}{*}{ N1 } & Conexion urbana & 457.72 \\
\hline & Torre de control & 593.04 \\
\hline & Zona de embarque + control seguridad & $1,381.49$ \\
\hline & Edificio comercial & $1,994.03$ \\
\hline \multirow{3}{*}{ N2 } & Torre de control & 641.09 \\
\hline & Mezzanine + Hall principal & $8,260.76$ \\
\hline & Edificio comercial & $1,566.44$ \\
\hline \multirow{2}{*}{ N3 } & Torre de control & 451.06 \\
\hline & Edificio comercial & $1,435.89$ \\
\hline \multicolumn{2}{|r|}{ Area total construida } & $45,096.48$ \\
\hline $52,523.24$ & Area terreno & $52,523.24$ \\
\hline & Area techada & $11,579.64$ \\
\hline & Area libre & $40,943.60$ \\
\hline
\end{tabular}




\subsection{Especialidades}

Los planos de estructuras, instalaciones eléctricas, instalaciones mecánicas e instalaciones sanitarias del proyecto del Terminal Terrestre Yerbateros fueron realizados tomando en cuenta las normas establecidas en el reglamento nacional de edificaciones [RNE] y las normas de la National Fire Protection Association [NFPA]. A continuación, presentaremos un breve sustento para cada solución utilizada en las especialidades del proyecto. Adicionalmente, se adjuntan los planos esquemáticos y de detalle ${ }^{49}$.

\subsubsection{Memoria descriptiva de estructuras}

Para el desarrollo del terminal terrestre Yerbateros se trabajaron dos sistemas estructurales diferentes. Cada uno responde a una serie de requisitos establecidos para el correcto funcionamiento de los usos que albergarán. A diferencia de las zonas destinadas para los usuarios que fueron diseñadas con una estructura aporticada de concreto, todas las zonas del terminal que interactúan con los buses interprovinciales se trabajaron con una estructura metálica libre de columnas.

De igual forma existen cuatro zonas con criterios estructurales independientes:

1- Edificio tectónico.

2- Edificio estereotómico.

3- Torre comercial y torre de control.

4- Edificios subterráneos de estacionamiento y comercios de la plaza.

\footnotetext{
${ }^{49}$ Ver anexos: Planos de especialidades.
} 
Figura 54: Criterios estructurales

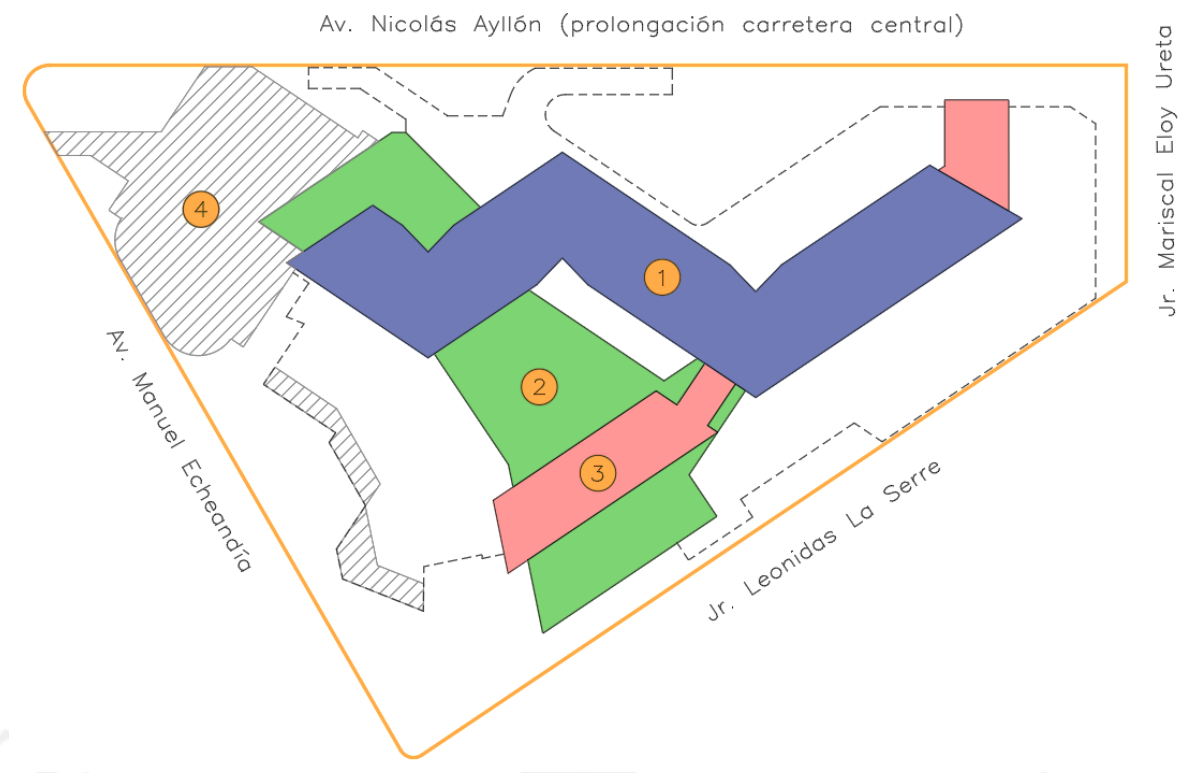

Elaboración propia

Es importante saber de ante mano que el suelo sobre el cual se emplazará el terminal es de muy buena calidad, con estratos de grava de diferentes granulometrías y un manto rocoso no muy profundo, motivo por el cual se trabajara únicamente con zapatas de cimentación. Todos los volúmenes se emplazan en el nivel -5.00 al igual que las vías de circulación y el patio de maniobras de autobuses, motivo por el cual se tendrá que realizar una excavación, compactar el suelo y colocar muros de contención en todo el perímetro (Centro Peruano Japones de Investigaciones Sísmicas y Mitigación de Desastres, 2012).

El edificio tectónico alberga el hall de llegada, la zona de mostradores, el control de seguridad y las salas de embarque, y adicionalmente se intersecta en varios puntos con las vías de circulación de los buses. Para facilitar la libre distribución de espacios interiores y no interrumpir las vías de circulación, se optó por trabajar una estructura libre de columnas. Las tres secciones longitudinales que conforman este edificio funcionan como un gran puente y apoyan únicamente en sus extremos. Para lograr esta estructura se trabajó una cercha metálica de 10 metros de peralte, que funciona a su vez como fachada principal del edificio. Este sistema permite luces libres de 70 metros, que ofrecen una experiencia única tanto para los pasajeros como para a los buses que transitan por el terminal. 
Figura 55: Luces libres del sistema estructural

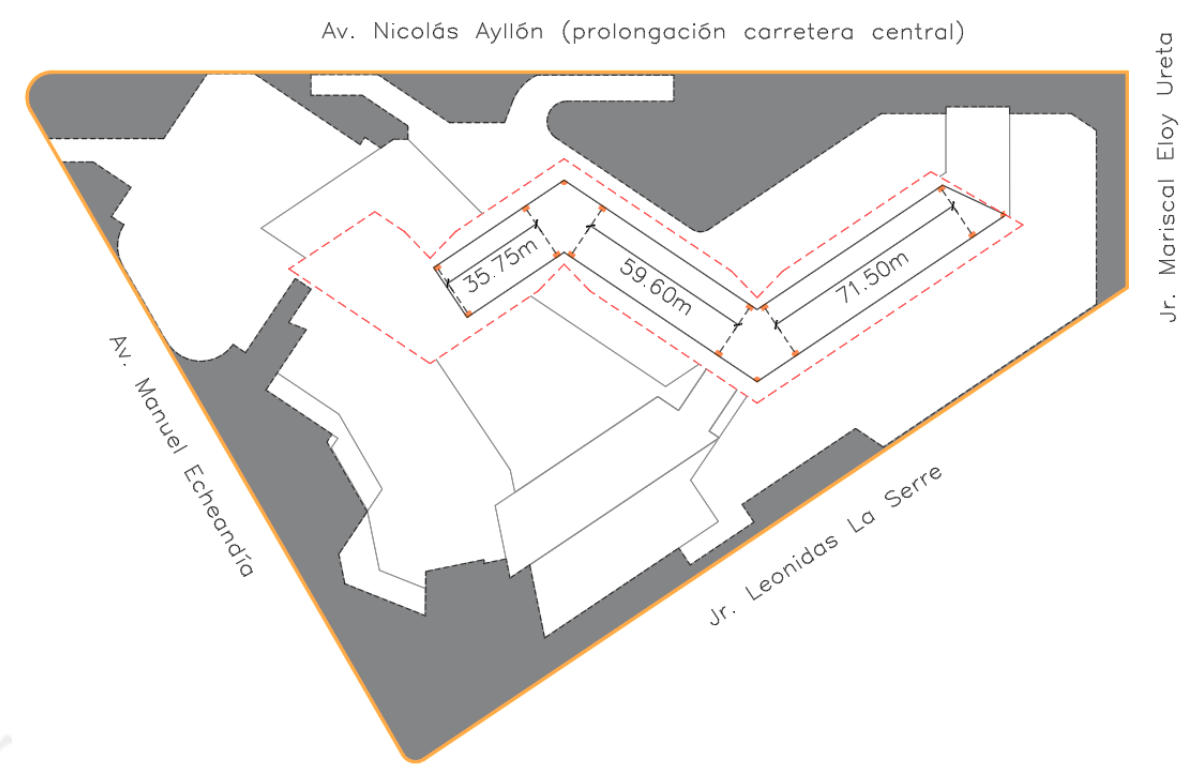

Elaboración propia

El sistema de puentes se apoya únicamente en cuatro puntos, los dos apoyos centrales contienen cinco columnas cada uno para generar una base maciza, capaz de recibir las cargas de los puentes y estructurar la esquina. Los apoyos de los extremos están formados únicamente por dos o tres columnas con la finalidad de generar un soporte final. Se trata de grandes columnas de concreto que permiten el libre apoyo de la estructura puente mediante aisladores sísmicos, con la finalidad de reducir la vibración en caso de sismo.

Las secciones del puente están conformadas por una cercha metálica a cada lado del edificio y se encuentran arriostradas entre sí por vigas metálicas cada 11.92m. Estas forman una serie de anillos trapezoidales, compuestos por dos columnas metálicas inclinadas de sección rectangular y dos vigas metálicas de sección H. Estos arriostres no solo rigidizan la estructura, sino que además - soportan las viguetas metálicas interiores que sirven como base de la losa alveolar pretensada de concreto. Los cerramientos laterales se realizan mediante un muro cortina auto portante, que está compuesto por bastidores de aluminio que se apoyan en las columnas metálicas para soportar los vidrios. Finalmente, se trabajó un techado ligero respetando la misma modulación de los anillos para poder anclarlo a estos. El techo está compuesto por un sistema sándwich de aluminio con capas interiores aislantes que se anclan a un armazón triangular. 
El edificio que está conformado por las zonas de desembarque, recojo de equipaje, hall de salida y supermercado cuenta con un nivel cerrado para estos usos y un segundo nivel al aire libre que funciona como espacio público. La estructura se dimensionó a partir de un aporticado de concreto con luces libres de 15 metros. En este caso se optó por columnas circulares y vigas post-tensadas que soportan sus respectivas viguetas para luego cargar con una losa alveolar pretensada. Se implementó este techado para poder colorar una plaza semipública con jardineras en el nivel superior.

El edificio comercial y la torre de control son los dos edificios de mayor altura, tienen tres y cuatro niveles respectivamente. El primero nace a partir de la grilla estructural generada en la zona de desembarque, respetando las placas estructurales de concreto e incorporándolas en su fachada. Las luces libres son de 15 metros y al igual que en el nivel inferior se utilizan vigas post-tensadas y losas alveolares pretensadas. En el segundo nivel se implementó un puente de estructura metálica que comunica con el mezzanine del edificio principal. La torre de control aparece como un remate para el edificio principal, por lo que respeta las dimensiones de este, trabajando luces libres de 13 metros y un volado de 4 metros a un extremo. La lógica estructural es la misma que la utilizada en el resto de estructuras de concreto: aporticado de concreto con vigas post-tensadas y losas alveolares pretensadas. Ambos edificios cuentan con cerramientos laterales de muro cortina modulado en aluminio de piso a techo.

Finalmente, existen tres sótanos de estacionamiento que se estructuran a partir de una grilla ortogonal de $8 \times 10$ metros, la estructura es un aporticado simple de concreto con losa aligerada. La conexión vehicular entre cada nivel se realiza a través de dos rampas caracol que tienen una estructura maciza de concreto con vigas radiales. Adicionalmente, se deberá contar con un muro de contención en todo el perímetro. Los comercios ubicados en la plaza pública tienen luces libres de 5 x 4 metros y la estructura es aporticada de concreto con losa aligerada. Respetan una lógica similar a la del estacionamiento ya que se encuentran parcialmente enterrados y soportan parte del espacio público. 


\subsubsection{Memoria descriptiva de instalaciones eléctricas}

El proyecto cuenta con una acometida eléctrica para abastecer a las edificaciones que conforman el terminal. Debido a su gran escala y demanda energética, será necesaria la implementación de una subestación eléctrica la cual está ubicada bajo tierra con acceso desde la calle y el patio de maniobras.

La ubicación de la acometida se estableció respetando los alimentadores previamente existentes en el terreno. Como se mencionó anteriormente, para el diseño del terminal terrestre se tuvieron que unificar varios lotes industriales independientes, motivo por el cual existían siete posibles acometidas. Por su ubicación céntrica y alejada de las principales avenidas se escogió la acometida del jr. Leónidas La Serre.

\section{Figura 56: Ubicación de acometida}

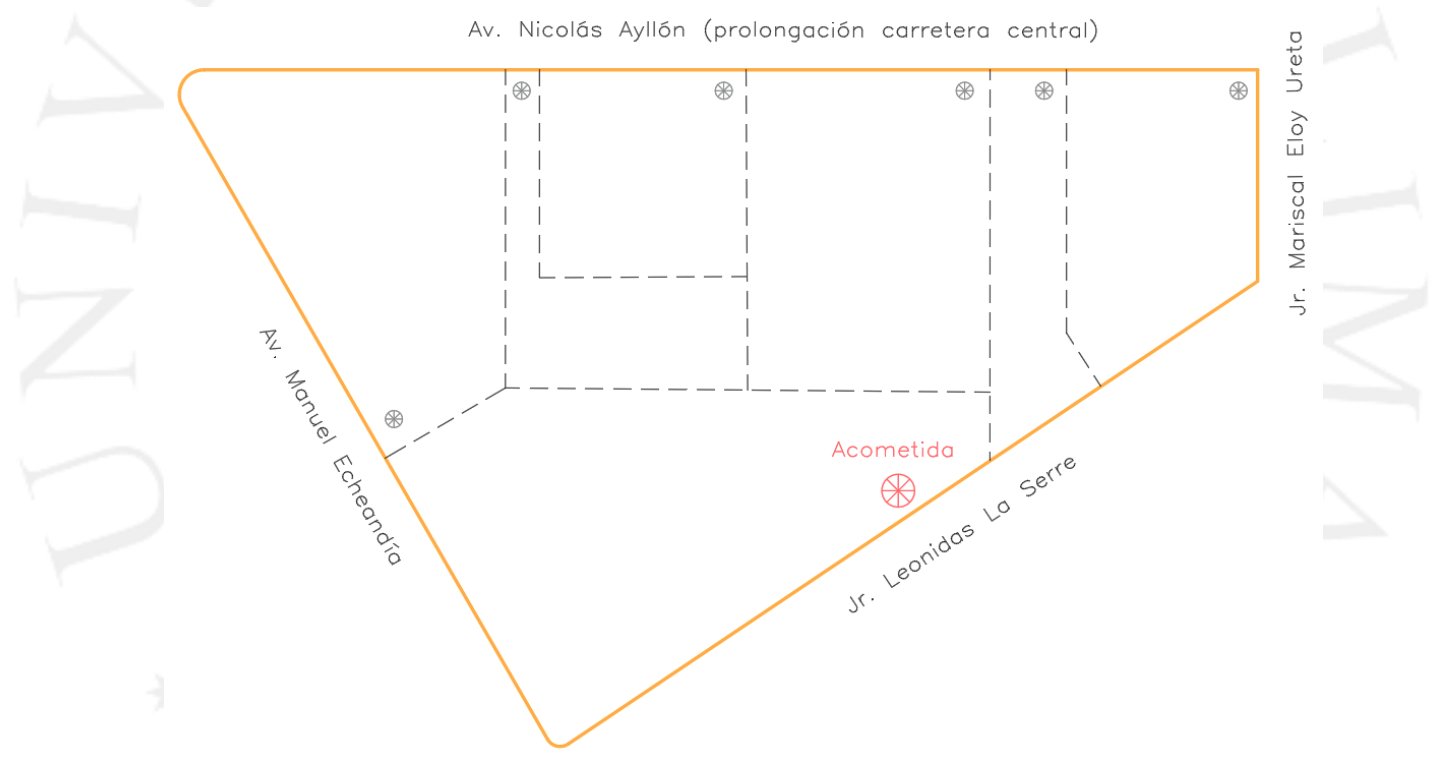

Elaboración propia

Esta acometida tiene su medidor en la zona de servicio del patio de maniobras. Este se encuentra conectado al cuarto de máquinas y tableros donde está ubicada la subestación y dos grupos electrógenos. La subestación está conectada a un tablero $<$ T.S.> conectado a tierra que se divide en ocho tableros generales: Emergencia <T.E.>, Cisternas <T.G.Ci〉, Terminal Terrestre 〈T.G.TT>, Comercio <T.G.Co〉, Oficinas $\langle$ T.G.Of>, Hospedaje <T.G.Ho>, Supermercado <T.G.Su> y Comercio Plaza $\langle$ T.G.CP>. Cada uno de estos alimenta un área específica e independiente del terminal, motivo por el cual se implementaron medidores internos para registrar los gastos 
individuales de cada una de estas áreas. El tablero de emergencia sirve para alimentar el sistema de agua contra incendios que se encuentra centralizado.

Los más importantes y de mayor demanda energética son los tableros de emergencias <T.E.>, cisternas <T.G.Ci $>$ y el terminal terrestre $\langle$ T.G.TT>, razón por la cual estos tienen su propio grupo electrógeno <G.E.1> que entra automáticamente en funcionamiento cuando se corta la energía eléctrica. Los cinco tableros restantes, tienen un rol secundario para el funcionamiento del terminal y pertenecen a las zonas del terminal que se van a tercerizar, motivo por el cual comparten un único grupo electrógeno de emergencia <G.E.2〉.

Las zonas del terminal destinadas a ser tercerizadas cuentan con un tablero general por piso y sus respectivos sub tableros que controlan el sistema de aire acondicionado, los circuitos de fuerza, los puntos de luz y los tomacorrientes de las áreas arrendables. Sin embargo, las áreas comunes son controladas directamente desde un sub tablero del Terminal Terrestre <T.G.TT>.

El tablero del edificio comercial <T.G.Co> se subdivide en ocho sub tableros para abastecer a cada uno de los locales comerciales, además de uno adicional para el aire acondicionado. Por otro lado, las oficinas <T.G.Of>, el hospedaje <T.G.Ho> y el supermercado <T.G.Su> cuentan con tableros independientes que únicamente se subdividen en pisos y sistema de aire acondicionado. Finalmente, el comercio en la plaza <T.G.CP> se subdivide en tres sub tableros para los comercios que atiende: Restaurante $\langle$ ST.CP.R $>$, Taller Comunitario $<$ ST.CP.Tc $>$ y Guardería $<$ ST.CP.G $>$.

El tablero general del terminal <T.G.TT> se subdivide en seis núcleos importantes, ubicados cerca a sus respectivos ductos o montantes: Torre de control $\langle$ ST.G.1>, Hall principal <ST.G.2>, Zona de salidas + SUM <ST.G.3>, Zona de llegadas + mantenimiento + administración 〈ST.G.4〉, Espacio público 〈ST.G.5> y Estacionamientos <ST.G.6>. Gracias a esta distribución, cada zona del terminal tiene control sobre su sistema de bombas de agua potable, así como sobre los ascensores y aires acondicionados que los abastecen. De igual forma, los sub tableros se vuelven a dividir para permitir la colocación de un tablero por cada nivel. Contando con cuartos de tableros para su ubicación. 


\subsubsection{Memoria descriptiva de instalaciones mecánicas}

El terminal terrestre utiliza un sistema de acondicionamiento pasivo para evitar el uso excesivo de aire acondicionado. Se trabajó una ventilación cruzada y efecto chimenea en todo el volumen principal del terminal y en las zonas de comercio de la plaza pública, limitando el uso de aire acondicionado únicamente a tres zonas: el supermercado, la torre de control y el edificio comercial. Este último tiene un uso diferente en cada nivel: recojo de equipaje en el sótano, comercio en el primer nivel, oficinas en el segundo y hospedaje en el tercero. Para atender las tres zonas del terminal equipadas con aires acondicionados se utilizan chillers instalados en el techo de cada edificio, los cuales se conectan a sus puntos de inyección de cada nivel mediante ductos.

Se colocó puntos de inyección de aire fresco en los tres niveles del estacionamiento subterráneo, al igual que un sistema de extracción mecánica de monóxido de carbono, el cual también se utilizó en la sala de máquinas donde se ubican los grupos electrógenos. Todos los sistemas de extracción utilizan ductos herméticos para transportar el monóxido de carbono y expulsarlo en la parte superior de la edificación.

Los servicios higiénicos que no cuentan con ventilación natural, están equipados con un ducto de ventilación mecánica, para la extracción de olores y la recirculación de aire hacia la parte superior del edificio. En el NPT -5.00 estos ductos ventilan directamente hacia el patio de maniobras. Adicionalmente, los dos restaurantes ubicados dentro del terminal, cuentan con un sistema de extracción de aire propio, que atiende el área de cocina.

\subsubsection{Memoria descriptiva de instalaciones sanitarias}

Al tratarse de un proyecto principalmente horizontal con variaciones de pocos niveles no se requiere de instalaciones sanitarias que deban trasladar y soportar grandes presiones de agua. Por este motivo se decidió implementar un único núcleo central de cisternas para el abastecimiento de agua potable y agua contra incendios, el cual se irradiará mediante tuberías troncales y montantes hacia todos los extremos del terminal. El núcleo está conformado por una cisterna de agua potable <Cisterna 1>, una cisterna de agua contra incendios <CACI 1>, un cuarto de bombas, un cuarto de tableros 
eléctricos y los ductos que contienen las montantes de distribución. El abastecimiento de agua hacia la cisterna se da directamente desde la red pública, no sin antes pasar a través de su medidor correspondiente ubicado de forma accesible dentro del anillo público exterior.

Figura 57: Ubicación de cisternas

Av. Nicolás Ayllón (prolongación carretera central)

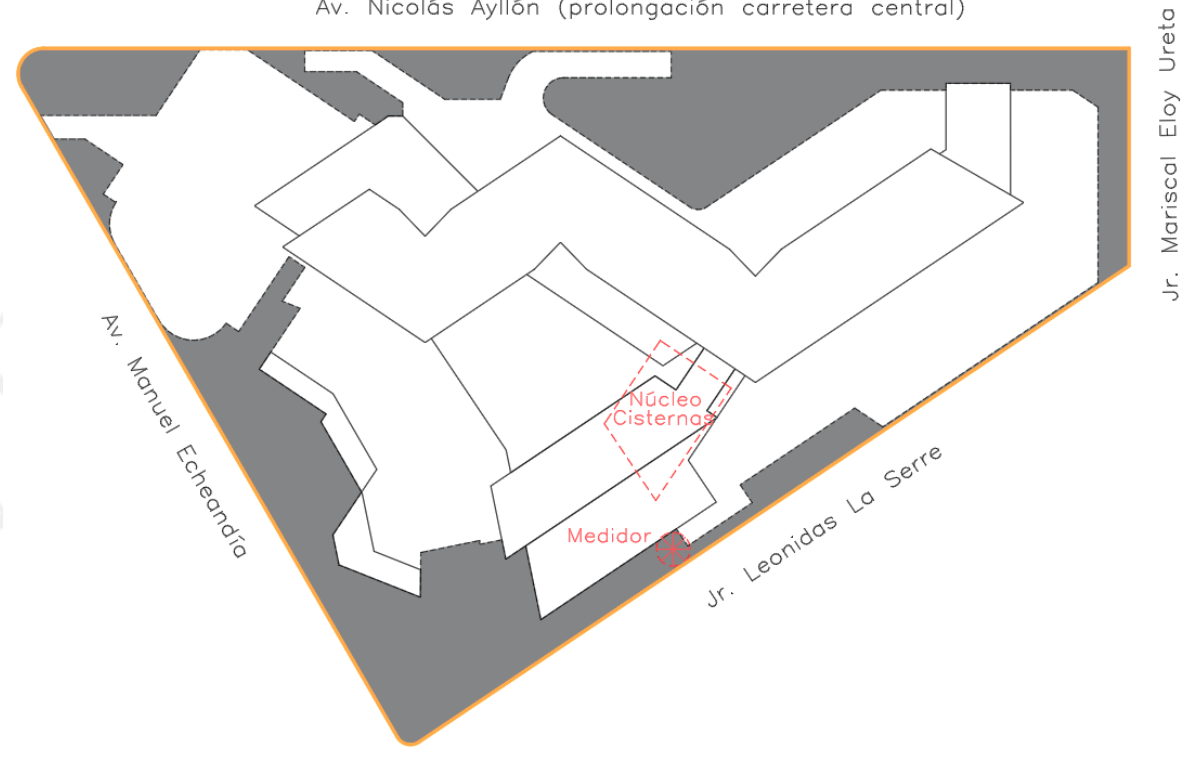

Elaboración propia

Para el cálculo de la dotación diaria de agua potable se utilizaron los valores específicos asignados por el reglamento nacional de edificaciones para cada uso y se multiplicaron por la cantidad de metros cuadrados. Para obtener la capacidad final de la cisterna, los valores se multiplicaron por dos, con la finalidad de conseguir una autonomía de dos días. De igual forma, el dimensionamiento de la cisterna de agua contra incendio se realizó determinando las áreas que debían ser atendidas mediante rociadores como las zonas del terminal con gran flujo de pasajeros y cuales debían contar con gabinetes como las zonas administrativas de oficinas y de bajo flujo de pasajeros. Estas áreas luego fueron multiplicadas por los valores obtenidos de la norma $\mathrm{NFPA}^{50}$.

\footnotetext{
${ }^{50}$ Ver anexos: Planos de especialidades (EP-7).
} 
El cuarto de bombas está compuesto por tres grupos de electrobombas con una función específica. En primer lugar, cuatro electrobombas de presión constante y velocidad variable para abastecer el sistema de agua potable, dos de las cuales se encuentran en funcionamiento y las otras dos son de respaldo. De forma similar el sistema de agua contra incendio está suministrado por una electrobomba principal y su respectiva electrobomba jockey. Finalmente, se colocaron dos electrobombas sumidero para el desagüe del sótano y limpieza de cisternas. Todas conectadas y administradas desde un área de tableros eléctricos.

La cantidad de aparatos necesarios para los servicios higiénicos de cada zona del terminal se calcularon en base a las tablas del reglamento nacional de edificaciones. Estos se encuentran organizados en zonas húmedas a poca distancia de los ductos de distribución para facilitar la llegada y salida de instalaciones. Las montantes de agua y desagüe se encuentran dentro de dichos ductos y se conectan de forma vertical con los cuartos de bombeo y cisternas.

La geometría triangular del techado principal del terminal permite una fácil canalización del agua proveniente de las lluvias, por lo que se instalaron drenajes pluviales en todos los vértices para la correcta reutilización de dicha agua. Además, se colocaron drenajes adicionales en los techos de la torre de control y del edificio comercial, así como en el patio de maniobras y en la plaza pública para evitar la acumulación indeseada de agua.

\subsection{Viabilidad}

Al estudiar la viabilidad del proyecto se busca contrastar múltiples variables para justificar la existencia e implementación de este. Por un lado, el más contundente de todos, es el presupuesto de la obra y todo lo que conlleva. Este es el primer indicador para saber la rentabilidad del proyecto. Luego se analizan los ingresos generados por el proyecto que ayudarán en la recuperación de la inversión. Sin embargo, esto no es lo único que ayuda a definir la viabilidad, ya que hay elementos adicionales que se deberán contemplar. Es de gran importancia considerar todo aquello que mejoraría gracias a la presencia del proyecto, respondiendo preguntas como ¿Qué problemas existen debido a la ausencia de un terminal terrestre bien implementado? o ¿Cómo sufre la población y el estado? Por lo tanto, para estimar la viabilidad del proyecto, se tuvo 
que sustentar la importancia de este en la zona y en la ciudad, y reconocer los beneficios que traería. Varios de estos beneficios se pueden cuantificar, como por ejemplo el ahorro que significaría reducir las horas laborales perdidas en el tráfico, la reducción de accidentes de tránsito o la reducción de contaminación ambiental por la implementación de espacio público. Estos valores son trasladables a un valor monetario, por lo que son de gran interés para el estado, pues en cierto período de tiempo, significan ahorro de grandes sumas monetarias. Este es el argumento para la participación del estado en un proyecto como el propuesto. La viabilidad del proyecto también incluye contemplar el tipo de financiamiento que se propondrá, al igual que la ejecución y los tiempos de cada etapa, en caso se decida dividir en fases. También se debe realizar un análisis FODA para preparar estrategias que puedan solucionar cada debilidad del proyecto y potenciar sus fortalezas. Finalmente se propone un plan de marketing que contemplará estrategias para dar a conocer el proyecto y hacerlo viable.

\subsubsection{Presupuesto}

El principal factor para la viabilidad del proyecto es el presupuesto financiero, una vez calculado se podrá determinar quiénes serán los principales actores en la construcción del terminal y qué tipo de financiamiento se deberá utilizar. Esto se debe a que el presupuesto define la escala final del proyecto y arroja una idea aproximada del tiempo de construcción.

Con el objetivo de un cálculo ordenado de áreas se dividió el proyecto en diferentes zonas, una por cada método constructivo. Para determinar los costos de cada edificación se utilizaron ratios por metro cuadrado cuyo valor varía dependiendo del sistema estructural utilizado y del uso que se desarrollará en su interior.

Los primeros costos a tomar en cuenta son los de la adquisición de los terrenos, por este motivo se realizó un estudio de mercado para determinar el valor del metro cuadrado de en la zona. Esto se logró gracias a búsqueda de terrenos con características similares a los del proyecto, dentro de diversos portales inmobiliarios como Urbania.com (Urbania, 2017) y Adondevivir.com (Adondevivir, 2017). Al tratarse de una zona industrial, el valor varía de $\$ 800$ a $\$ 1600$ dependiendo de la ubicación del terreno y del estado de conservación de las edificaciones existentes en su interior. Para el caso específico de tres de los siete terrenos se consideró un precio menor al del 
mercado ya que las empresas existentes en estos terrenos serían reubicadas dentro del nuevo terminal.

Los siguientes costos a tomar en cuenta son los de la habilitación del terreno, es decir demolición de las edificaciones existentes, excavación preliminar y remoción de escombros, para los cuales se tomaron en cuenta los costos unitarios por cada una de estas partidas. Es importante mencionar este punto ya que el movimiento de tierras es bastante extenso porque el proyecto se ubica cinco metros por debajo del nivel de la calle. Por este motivo también se deberán contemplar muros de contención.

Para las edificaciones del terminal con estructuras más complejas se estudiaron los costos totales de diversos proyectos similares que se detallan en las diversas ediciones de la Revista Costos (Revista Costos, 2016). Es importante mencionar que los ratios utilizados incluyen el costo de diseño, gestión, construcción, instalaciones y acabados. En primer lugar, se presupuestó el edificio tectónico, con estructura metálica de grandes luces libres cuyo sistema estructural asemeja al de un puente. En este caso se analizaron los costos de diversos puentes y se determinó un precio promedio por metro cuadrado de \$3000. En segundo lugar, se costeó el edificio estereotómico con un sistema estructural de concreto, compuesto por vigas post-tensadas de grandes luces. En este caso se estudiaron diversos centros comerciales por las similitudes en luces libres y materialidad determinando un costo de $\$ 1000$ por metro cuadrado.

Para las edificaciones con estructura convencional como la torre de control, el edificio comercial y las construcciones subterráneas se utilizaron ratios estándar de construcción, que varían de los $\$ 600$ hasta los $\$ 750$ dependiendo de los tipos de acabados y las instalaciones sanitarias, eléctricas y electromecánicas con las que cuentan. De igual forma, para los espacios públicos, áreas verdes, vías de circulación y patio de maniobras se utilizó un rango de valores que varía de los $\$ 100$ a los $\$ 150$ por la instalación de superficies especiales, vegetación y sistemas de drenaje de agua pluviales (B. Lagos, comunicación personal, 2017). 
Tabla 31: Presupuesto final del proyecto

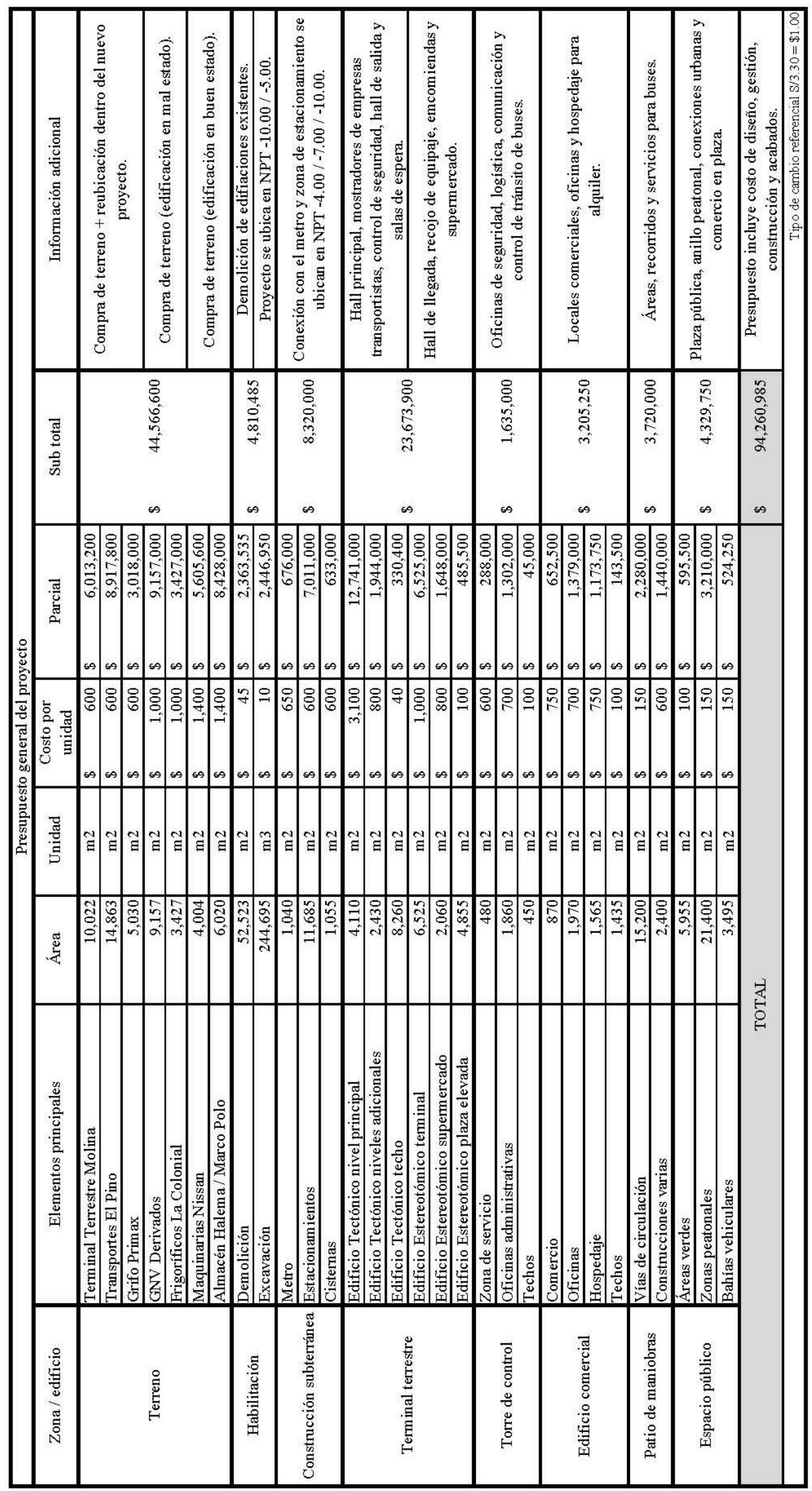

Elaboración propia 


\subsubsection{Financiamiento}

El proyecto Terminal Terrestre Yerbateros será financiado mediante una Asociación Público Privada de carácter cofinanciada. Los dos actores principales serán el privado (inversionista) y el público (estado). El estado contribuirá con una inversión inicial y prestará garantías financieras y no financieras (ProInversión, s.f.). Se iniciará el proyecto mediante la adquisición de los terrenos, los cuales representan un $47 \%$ del costo total del proyecto. A continuación, se iniciará la construcción del terminal, la cual se dará a través de 5 etapas en el transcurso de 6 años. De ser necesario, se podrá buscar apoyo financiero adicional por parte de la Municipalidad Metropolitana de Lima o la Municipalidad de San Luis, ya que el proyecto también trae beneficios para ambas comunas.

En cuanto el grupo inversionista principal haya culminado su parte del contrato, podrá proceder a cobrar una retribución por inversión [RPI] por haber realizado una tarea de interés público. Las garantías financieras que otorgará el estado, funcionan como respaldos o avales, que permitirán que el privado adquiera mejores préstamos o créditos. Por otro lado, el estado otorgará garantías no financieras, con el objetivo de minimizar riesgos e incentivar la inversión del privado. Con estas garantías no financieras, el estado cubre costos en caso la demanda real resulte ser inferior a la demanda calculada y las ganancias finales no sean las proyectadas (ProInversión, s.f.). Es importante aclarar que una vez finalizada la construcción del terminal, el grupo inversionista se hará cargo del mantenimiento y la operación del proyecto durante 20 años, recuperando su inversión con los ingresos de este. Cuando se cumplan los plazos establecidos en el contrato, el estado lanzará un concurso para renovar la licitación, esta vez con el único fin de administrar y operar el terminal terrestre y sus instalaciones. El inversionista que estuvo a cargo de la construcción podrá ser partícipe de este concurso, con un puntaje a favor, según su desempeño en el contrato ya culminado.

Es importante resaltar que se tratará de un APP Cofinanciada, pues hay un ahorro por beneficios sociales significativo que favorecen al poblador de la zona, los usuarios y al estado, sustentado así la existencia del Terminal Terrestre Yerbateros, sus usos complementarios y por lo tanto la participación del estado. 


\subsubsection{Retorno de la inversión}

Para poder justificar una inversión tan grande como la que requiere la construcción del terminal terrestre Yerbateros y sus grandes extensiones de espacio público, así como conexiones urbanas con las que cuenta, se deben analizar algunos factores adicionales para calcular la recuperación de la inversión. Estos van desde los ingresos por alquiler y la utilización de las instalaciones del terminal, hasta los beneficios sociales y ambientales generados a partir de su implementación e impacto en la ciudad y en el transporte.

Como mencionado anteriormente, el sistema de financiamiento se realizará a través de una asociación público - privada, el estado se encargará de gestionar la expropiación y compra de los terrenos, además de ser el respaldo económico del inversionista privado. Por su lado, este último estará a cargo de la construcción y la operación del terminal por un período de 20 años.

Para poder calcular la rentabilidad del proyecto y definir la inversión que deberá realizar cada una de las partes, se ha realizado un cálculo del retorno de la inversión y cuantificado los beneficios.

\section{$\underline{\text { Retorno de la inversión para el inversionista privado }}$}

Para la construcción total del terminal terrestre se necesita una inversión aproximada de \$94’500,000. La cual se realizará en cinco etapas, para poder justificar dicha inversión se realizó un cálculo de los ingresos anuales del terminal por derechos de uso y por el alquiler de los espacios comerciales.

Los derechos de uso están compuestos por el cobro de una tarifa fija por el uso de algunos servicios del terminal. En primer lugar, cada bus deberá pagar una tarifa de $\mathrm{S} / 25$ para dejar o recoger pasajeros, permitiendo a los pasajeros y choferes hacer uso de las instalaciones. De igual forma, se cobrará un derecho de embarque de S/4 a los usuarios, tal como sucede en el Terminal Terrestre de Plaza Lima Norte, para poder ingresar a las salas de espera. También, se realizará un recargo adicional por el envío de encomiendas de $\mathrm{S} / 3$ por cada paquete enviado. Por último, se cobrará una tarifa de $\mathrm{S} / 4$ por hora para el aparcamiento de vehículos en el estacionamiento subterráneo.

Adicionalmente, se realizará un cobro por el alquiler de los mostradores a las empresas transportistas y de los locales comerciales ubicados dentro del terminal. Por el 
uso de las máquinas de self-service no se cobrará una comisión adicional ya que su operación se incluye en el derecho de embarque.

El alquiler de las zonas comerciales ubicadas en el edificio comercial, se realizará de acuerdo a los precios establecidos por el mercado en la zona y se podrán ir ajustando con el paso del tiempo. Estas zonas incluyen los locales comerciales del primer nivel, las oficinas del segundo nivel y el hospedaje ubicado en el nivel superior, así como el supermercado ubicado en el edificio estereotómico.

Es importante resaltar que los valores utilizados en los costos de alquiler de las siguientes áreas por metro cuadrado se obtuvieron realizando una investigación de la oferta existente en la zona adyacente al terminal, tomando en cuenta su uso y su estado de conservación. Al igual que cuando se determinó el costo de los terrenos, se consultaron diversos portales inmobiliarios como Urbania.com (Urbania, 2017) y Adodnevivir.com (Adondevivir, 2017).

Tabla 32: Recuperación de la inversión

\begin{tabular}{|c|c|c|c|c|c|c|c|c|c|}
\hline \multicolumn{10}{|c|}{ Recuperación de inversión (privado) } \\
\hline Posibles ingresos & Cantidad & Unidad & & & Ingres & mensual & & reso anual & Etapa \\
\hline $\begin{array}{c}\text { Alquiler de mostradores de } \\
\text { empresas }\end{array}$ & 46 & módulos / mes & $\$$ & 200 & $\$$ & 9,200 & $\$$ & 110,400 & \multirow{6}{*}{ E2 } \\
\hline Tarifa por ingreso de buses & 7,380 & buses / mes & $\$$ & 7 & $\$$ & 51,660 & $\$$ & 619,920 & \\
\hline $\begin{array}{c}\text { Tarifa por derecho de } \\
\text { embarque (pasajeros salida) }\end{array}$ & 277,530 & personas / mes & $\$$ & 1.2 & $\$$ & 333,036 & $\$$ & $3,996,432$ & \\
\hline $\begin{array}{l}\text { Tarifa por envío de } \\
\text { encomiendas }\end{array}$ & 30,000 & $\begin{array}{l}\text { encomiendas / } \\
\text { mes }\end{array}$ & $\$$ & 1 & $\$$ & 30,000 & $\$$ & 360,000 & \\
\hline Alquiler de supermercado & 1,631 & $\mathrm{~m} 2$ & $\$$ & 10 & $\$$ & 16,310 & $\$$ & 195,720 & \\
\hline Alquiler SUM & 4 & eventos / mes & $\$$ & 800 & $\$$ & 3,200 & $\$$ & 38,400 & \\
\hline Tarifa de estacionamientos & 60,000 & vehículos / mes & $\$$ & 1.2 & $\$$ & 72,000 & $\$$ & 864,000 & E3 \\
\hline Alquiler de restaurante & 172 & $\mathrm{~m} 2$ & $\$$ & 40 & $\$$ & 6,880 & $\$$ & 82,560 & E4 \\
\hline Alquiler de locales comerciales & 805 & $\mathrm{~m} 2$ & $\$$ & 35 & $\$$ & 28,175 & $\$$ & 338,100 & \multirow{3}{*}{ E5 } \\
\hline $\begin{array}{c}\text { Alquiler de oficinas } \\
\text { tercerizadas }\end{array}$ & 860 & $\mathrm{~m} 2$ & $\$$ & 15 & $\$$ & 12,900 & $\$$ & 154,800 & \\
\hline Alquiler de hospedaje & 930 & camas / mes & $\$$ & 15 & $\$$ & 13,950 & $\$$ & 167,400 & \\
\hline \multicolumn{7}{|c|}{ TOTAL } & $\$$ & $6,927,732$ & $\mathrm{EF}$ \\
\hline \multicolumn{10}{|c|}{ Tipo de cambio referencial $\mathrm{S} / 3.30=\$ 1.00$} \\
\hline
\end{tabular}

Elaboración propia 
Como se observa en la tabla, los ingresos totales por año serán aproximadamente de $\$ 6^{\prime} 900,000$. Debido a que se trata de una construcción por etapas, todos los ingresos no serán accesibles desde un primer momento. Cada uno será facturable desde la culminación de su etapa constructiva y su respectiva implementación. Es importante mencionar que la etapa 2 representa cerca del $70 \%$ de los ingresos totales, motivo por el cual será la primera en ser ejecutada, pero sus ganancias recién estarán disponibles a partir del tercer año debido a los tiempos de construcción.

La rentabilidad del proyecto se determina con el valor actual neto [VAN] y la tasa interna de retorno [TIR]. Para obtener estos valores se debe considerar la sumatoria de los egresos e ingresos del proyecto o flujos de caja anuales, durante 20 años. Al contar con el respaldo económico del estado, se consideró una tasa de interés menor a la establecida por el mercado. De igual forma al realizar los cálculos se determinó que, sin una inversión de capital por parte de estado, el proyecto no es rentable para el inversionista privado. Esto se debe a la fuerte inversión inicial, la falta de ingresos durante los primeros años del proyecto y la gran cantidad de tiempo necesario para la recuperación de los gastos iniciales (ver tabla 33).

Tabla 33: Cálculo del VAN y TIR 1

\begin{tabular}{|c|c|c|}
\hline AÑ & FLUJO DE CAJA & VALOR PRESENTE \\
\hline 0 & $-\$ 44,566,600$ & $-\$ 44,566,600$ \\
\hline 1 & $-\$ 15,961,193$ & $-\$ 14,917,002$ \\
\hline 2 & $-\$ 15,961,193$ & $-\$ 13,941,124$ \\
\hline 3 & $-\$ 3,319,528$ & $-\$ 2,709,724$ \\
\hline 4 & $\$ 1,816,722$ & $\$ 1,385,969$ \\
\hline 5 & $\$ 1,388,782$ & $\$ 990,182$ \\
\hline 6 & $\$ 6,889,332$ & $\$ 4,590,653$ \\
\hline 7 & $\$ 6,889,332$ & $\$ 4,290,330$ \\
\hline 8 & $\$ 6,889,332$ & $\$ 4,009,654$ \\
\hline 9 & $\$ 6,889,332$ & $\$ 3,747,340$ \\
\hline 10 & $\$ 6,889,332$ & $\$ 3,502,187$ \\
\hline 11 & $\$ 6,889,332$ & $\$ 3,273,072$ \\
\hline 12 & $\$ 6,889,332$ & $\$ 3,058,946$ \\
\hline 13 & $\$ 6,889,332$ & $\$ 2,858,828$ \\
\hline 14 & $\$ 6,889,332$ & $\$ 2,671,802$ \\
\hline 15 & $\$ 6,889,332$ & $\$ 2,497,011$ \\
\hline 16 & $\$ 6,889,332$ & $\$ 2,333,655$ \\
\hline 17 & $\$ 6,889,332$ & $\$ 2,180,986$ \\
\hline 18 & $\$ 6,889,332$ & $\$ 2,038,305$ \\
\hline 19 & $\$ 6,889,332$ & $\$ 1,904,958$ \\
\hline & VAN & $-\$ 30,800,573$ \\
\hline & TIR & $2 \%$ \\
\hline & Tasa de interés & \\
\hline & & \\
\hline
\end{tabular}

Elaboración propia 
Según la Metodología para la aplicación del análisis cuantitativo en la elección de la modalidad de ejecución de proyectos de inversión cofinanciados (Ministerio de economía y finanzas, 2014), cuando se obtiene un VAN negativo, y el proyecto lo justifica, el estado deberá cubrir parte de la inversión para que el proyecto sea rentable para el privado. En nuestro caso, la etapa más crítica se ubica en la parte inicial del proyecto, donde los ingresos son nulos. Con el fin de rentabilizar el proyecto se propuso una inversión inicial del estado de \$25’000,000 en la compra de terrenos. Además, de una inversión de \$5’000,000 anuales durante los siguientes dos años para amortizar los gastos de construcción. Con estos nuevos valores se obtuvo un proyecto mucho más interesante para los inversionistas privados (ver tabla 34 ).

Tabla 34: Cálculo del VAN y TIR 2

\begin{tabular}{|c|c|c|}
\hline AÑ & FLUJO DE CAJA & VALOR PRESENTE \\
\hline 0 & $-\$ 19,566,600$ & $-\$ 19,566,600$ \\
\hline 1 & $-\$ 10,961,193$ & $-\$ 10,244,105$ \\
\hline 2 & $-\$ 10,961,193$ & $-\$ 9,573,930$ \\
\hline 3 & $-\$ 3,319,528$ & $-\$ 2,709,724$ \\
\hline 4 & $\$ 1,816,722$ & $\$ 1,385,969$ \\
\hline 5 & $\$ 1,388,782$ & $\$ 990,182$ \\
\hline 6 & $\$ 6,889,332$ & $\$ 4,590,653$ \\
\hline 7 & $\$ 6,889,332$ & $\$ 4,290,330$ \\
\hline 8 & $\$ 6,889,332$ & $\$ 4,009,654$ \\
\hline 9 & $\$ 6,889,332$ & $\$ 3,747,340$ \\
\hline 10 & $\$ 6,889,332$ & $\$ 3,502,187$ \\
\hline 11 & $\$ 6,889,332$ & $\$ 3,273,072$ \\
\hline 12 & $\$ 6,889,332$ & $\$ 3,058,946$ \\
\hline 13 & $\$ 6,889,332$ & $\$ 2,858,828$ \\
\hline 14 & $\$ 6,889,332$ & $\$ 2,671,802$ \\
\hline 15 & $\$ 6,889,332$ & $\$ 2,497,011$ \\
\hline 16 & $\$ 6,889,332$ & $\$ 2,333,655$ \\
\hline 17 & $\$ 6,889,332$ & $\$ 2,180,986$ \\
\hline 18 & $\$ 6,889,332$ & $\$ 2,038,305$ \\
\hline 19 & $\$ 6,889,332$ & $\$ 1,904,958$ \\
\hline & VAN & $\$ 3,239,518$ \\
\hline & TIR & $8 \%$ \\
\hline & Tasa de interés & \\
\hline & & \\
\hline
\end{tabular}

Elaboración propia

A continuación, presentamos el cuadro final de cómo sería el retorno de la inversión privada con la inversión inicial del estado (ver tabla 35). Como se mencionó previamente las ganancias iniciarían a partir del tercer año con la puesta en operación del terminal terrestre e irían aumentado gradualmente conforme se complete la construcción del resto de etapas. A partir del sexto año los ingresos ya serían 
constantes, por lo que se calculó que el retorno total se daría aproximadamente en once años, dejado los otros nueve años de contrato como ganancia neta para el inversionista.

Tabla 35: Retorno de la inversión privada

\begin{tabular}{|c|c|c|c|c|c|c|c|}
\hline \multicolumn{8}{|c|}{ Retorno de la inversión privada } \\
\hline \multirow{2}{*}{ Etapas constructivas } & Año 0 & Año 1 & Año 2 & Año 3 & Año 4 & Año 5 & Año 6 - Año 19 \\
\hline & Etapa 1 & \multicolumn{2}{|c|}{ Etapa 2} & Etapa 3 & Etapa 4 & Etapa 5 & \multirow{3}{*}{$\begin{array}{l}\text { Inicia } \\
\text { cuperación } \\
\text { neta }\end{array}$} \\
\hline Egresos & $(\$ 19,566,600)$ & \multicolumn{2}{|c|}{$(\$ 21,922,385)$} & $(\$ 8,602,000)$ & $(\$ 4,329,750)$ & $(\$ 4,840,250)$ & \\
\hline Ingresos & Etapa 1 & \multicolumn{2}{|c|}{ Etapa 2} & Etapa 3 & Etapa 4 & Etapa 5 & \\
\hline Mostradores de venta & & & & 110,400 & 110,400 & 110,400 & 110,400 \\
\hline Tarifa de buses & & & -2 & $\$ \quad 619,920$ & 619,920 & 619,920 & 619,920 \\
\hline Tarifa de pasajeros & & $b$ & & $\$ 3,996,432$ & $\$ 3,996,432$ & $\$ 3,996,432$ & $3,996,432$ \\
\hline Tarifa de encomiendas & I. & & & 360,000 & 360,000 & 360,000 & 360,000 \\
\hline SUM & & & & 38,400 & 38,400 & $\$ \quad 38,400$ & 38,400 \\
\hline Supermercado & & & & $\$ \quad 195,720$ & 195,720 & 195,720 & 195,720 \\
\hline Tarifa Estacionamientos & & & & ris & 864,000 & $\$ \quad 864,000$ & 864,000 \\
\hline Restaurante & & & & & & 82,560 & 82,560 \\
\hline Locales comerciales & & & & & & & 338,100 \\
\hline Oficinas transportistas & & & & & & & 154,800 \\
\hline Hospedaje de choferes & & & & & & & 167,400 \\
\hline Ingreso total anual & & & & $\$ 5,320,872$ & $\$ 6,184,872$ & $\$ 6,267,432$ & $6,927,732$ \\
\hline & & & & & Tipc & e cambio refer & ncial $\mathrm{S} / 3.30=\$ 1.00$ \\
\hline
\end{tabular}

Elaboración propia

Para justificar la inversión del estado, en la siguiente sección se cuantifican los beneficios sociales que se obtendrán a partir de la implementación del terminal terrestre.

\section{$\underline{\text { Retorno de la inversión para el estado }}$}

El estado, como hemos mencionado anteriormente, invertirá una suma de dinero inicial y será el aval económico del inversionista privado, a cambio obtendrá una serie de beneficios sociales. Estos beneficios no solo servirán para cubrir la inversión monetaria, sino que además serán una protección económica para subvencionar al privado en caso la demanda no sea la esperada y los ingresos del este sean menores a lo estimado.

En este proyecto, las ganancias del estado se dan por ahorros económicos por beneficios sociales, es decir costos que el estado evitará gracias a la implementación del terminal terrestre y a los beneficios que este traerá para las zonas aledañas. Entre los valores más importante que se tomaron en cuenta se encuentran la reducción del tiempo de transporte, la reducción de accidentes vehiculares en la zona, la reducción de 
accidentes de buses en la Carretera Central, la absorción de $\mathrm{CO} 2$, la generación de empleo y la revalorización de la zona.

Al no contar con un terminal terrestre bien equipado existe una gran congestión vial en la zona. Esto se debe a que existen múltiples terminales terrestres en un área muy pequeña, que están mal implementados y sin la correcta distribución de espacios ni las bahías correspondientes para todos los medios de transporte (Ministerio de Comercio Exterior y Turismo [MINCETUR]; Unión Europea [UE], 2009). El resultado final es una aglomeración de múltiples vehículos obstruyendo la carretera central, mientras circulan personas y ambulantes. También, se genera una congestión vial en la ciudad ya que se trata de una congestión generada por el ingreso de los buses a zonas densamente pobladas de la ciudad, trayendo consigo contaminación visual, ambiental y auditiva, además de obstruir el flujo en muchas calles.

Para el cálculo del ahorro económico generado por la reducción del tiempo de transporte, es necesario cuantificar cuanto deja de ganar Lima por cada hora perdida por persona en el tráfico. Esto se obtiene utilizando los datos del PBI per cápita y dividiéndolo entre los días y las horas laborables (ver tabla 36).

Tabla 36: Valor de una hora al día

\begin{tabular}{|c|c|c|c|c|c|}
\hline \multicolumn{6}{|c|}{ Valor de una hora al día } \\
\hline $\begin{array}{c}\text { Producto Interno } \\
\text { Bruto de Lima (PBI) }\end{array}$ & $\begin{array}{c}\text { Población } \\
\text { Económicamente } \\
\text { Activa de Lima (PEA) }\end{array}$ & $\begin{array}{l}\text { PBI per cápita de } \\
\text { Lima }\end{array}$ & $\begin{array}{c}\text { Días laborables al } \\
\text { año en Lima }\end{array}$ & $\begin{array}{c}\text { Horas trabajadas al } \\
\text { día en Lima }\end{array}$ & $\begin{array}{c}\text { Valor de hora por } \\
\text { persona }\end{array}$ \\
\hline $66,700,000,000$ & $5,000,000$ & 13,340 & 250 & 9.4 & $\$$ \\
\hline
\end{tabular}

Fuente: Quinto Ausejo (2013)

Elaboración propia

Sabemos que la implementación del nuevo terminal terrestre reducirá en promedio 20 minutos de congestión vehicular a cada usuario, debido a su ubicación periférica y su rápida conexión con múltiples vías arteriales de la ciudad. Multiplicando ese dato por la cantidad de usuarios atendidos por el terminal, al año se podrían ahorrar $\$ 7^{\prime} 720,170$ a la ciudad de Lima (ver tabla 37). 
Tabla 37: Ahorro económico por reducción de tiempo de transporte

\begin{tabular}{|r|r|rr|r|}
\hline \multicolumn{4}{|c|}{ Ahorro económico por reducción de tiempo de trans porte } \\
\hline $\begin{array}{c}\text { Usuarios atendidos } \\
\text { por el terminal al } \\
\text { día }\end{array}$ & $\begin{array}{c}\text { Horas ahorradas } \\
\text { por persona al día }\end{array}$ & $\begin{array}{c}\text { Ahorro económico } \\
\text { total al día }\end{array}$ & $\begin{array}{c}\text { Ahorro económico } \\
\text { total al año }\end{array}$ \\
\hline 16,000 & 0.34 & $\$$ & 30,881 & $\$$ \\
$7,720,170$ \\
\hline
\end{tabular}

Elaboración propia

También se puede cuantificar el ahorro generado para la ciudad de Lima por la disminución de accidentes vehiculares. La Unión Europea calcula el coste de los accidentes a partir del dinero que deja de producir para el país una persona por muerte prematura y cuánto le cuesta al estado en promedio atender a un herido (Fundación Instituto Tecnológico para la Seguridad del Automóvil, 2008).

Tabla 38: Costo por accidentes vehiculares

\begin{tabular}{|c|c|c|c|c|}
\hline \multicolumn{5}{|c|}{ Costo por accidentes vehiculares } \\
\hline $\begin{array}{l}\text { PBI per cápita de } \\
\text { Lima }\end{array}$ & $\begin{array}{l}\text { Edad promedio de } \\
\text { fallecidos en } \\
\text { accidentes }\end{array}$ & $\begin{array}{c}\text { Años laborales } \\
\text { restantes }\end{array}$ & $\begin{array}{c}\text { Pérdida de } \\
\text { producción por } \\
\text { muerte prematura }\end{array}$ & $\begin{array}{l}\text { Costes médicos por } \\
\text { herido en accidente }\end{array}$ \\
\hline 13,340 & 35 & 30 & 400,200 & 400 \\
\hline
\end{tabular}

Fuente: Fundación Instituto Tecnológico para la Seguridad del Automóvil (2008)

Elaboración propia

Estos valores fueron contrastados con datos obtenidos del MTC sobre la cantidad de accidentes vehiculares en la zona del terminal y sus respectivas causas. De esta forma se pudo contabilizar la cantidad de accidentes, muertos y heridos que se pueden evitar con la generación de bahías vehiculares para el transporte urbano y la descongestión de la zona (Ministerio de Transportes y Comunicaciones, 2015).

Tabla 39: Costo de accidente por caos vehicular al año

\begin{tabular}{|c|c|c|c|c|c|}
\hline \multicolumn{6}{|c|}{ Costo de accidentes por caos vehicular al año } \\
\hline $\begin{array}{c}\text { Accidentes en un } \\
\text { radio de } 3 \text { cuadras del } \\
\text { terminal }\end{array}$ & $\begin{array}{c}\text { Muertos en } \\
\text { accidentes }\end{array}$ & $\begin{array}{l}\text { Heridos en } \\
\text { accidentes }\end{array}$ & $\begin{array}{c}\text { Pérdida de } \\
\text { producción por } \\
\text { muertes }\end{array}$ & $\begin{array}{c}\text { Costes médicos } \\
\text { por heridos en } \\
\text { accidentes }\end{array}$ & $\begin{array}{c}\text { Ahorro anual por } \\
\text { prevención de } \\
\text { accidentes }\end{array}$ \\
\hline 103 & 3 & 65 & $1,200,600$ & 26,000 & $1,226,600$ \\
\hline
\end{tabular}

Fuente: Ministerio de Transportes y Comunicaciones (2015)

Elaboración propia 
De forma similar se utilizaron los datos emitidos por la SUTRAN sobre la cantidad de accidentes vehiculares en la Carretera Central y sus respectivas causas, para determinar cuántos accidentes fueron ocasionados por somnolencia y pudieron ser evitados si los conductores hubieran tenido la infraestructura adecuada para poder descansar (Superintendencia de Transporte Terrestre de Personas, Carga y Mercancías, 2014).

Tabla 40: Costo de accidentes de buses por somnolencia al año

\begin{tabular}{|c|c|c|c|c|c|}
\hline \multicolumn{6}{|c|}{ Costo de accidentes de buses por somnolencia al año } \\
\hline $\begin{array}{c}\text { Accidentes en } \\
\text { Carretera Central }\end{array}$ & $\begin{array}{l}\text { Muertos en } \\
\text { accidentes }\end{array}$ & $\begin{array}{l}\text { Heridos en } \\
\text { accidentes }\end{array}$ & $\begin{array}{c}\text { Pérdida de } \\
\text { producción por } \\
\text { muertes }\end{array}$ & $\begin{array}{c}\text { Costes médicos } \\
\text { por heridos en } \\
\text { accidentes }\end{array}$ & $\begin{array}{c}\text { Ahorro anual por } \\
\text { prevención de } \\
\text { accidentes }\end{array}$ \\
\hline 18 & 13 & 79 & $5,202,600$ & 31,600 & $5,234,200$ \\
\hline
\end{tabular}

Fuente: Superintendencia de Transporte Terrestre de Personas, Carga y Mercancías (2014) y Edmundo Rosales Mayor, et al. (2009)

Elaboración propia

Otra forma de evitar gastos para el estado es con la generación de espacio público, este no solo mejora la calidad de vida de los habitantes, sino que trae consigo otros beneficios económicos muy importantes. Primero, se plantan árboles y se crean nuevas áreas verdes que absorben grandes cantidades de $\mathrm{CO} 2$ y otros contaminantes ambientales (ver tabla 41). Estos valores se pueden cuantificar ya que, se evita que el estado tenga que invertir dinero propio para eliminar estos gases nocivos (Schiller, 2013). Adicionalmente, estas nuevas áreas verdes junto con el espacio público revalorizan la zona, aumentando el valor del suelo de las edificaciones circundantes, lo que genera ingresos adicionales para la municipalidad (ver tabla 42).

Tabla 41: Ahorro energético por absorción de CO2

\begin{tabular}{|c|c|r|r|r|}
\hline \multicolumn{7}{|c|}{ Ahorro energético por absorción de CO2 } \\
\hline $\begin{array}{c}\text { Ahorro energético } \\
\text { por árbol }\end{array}$ & $\begin{array}{c}\text { Ahorro energético } \\
\text { por m2 de área verde }\end{array}$ & Árboles & Áreas verdes & Ahorro anual \\
\hline \$ 14 & $\$$ & 160 & 5955 & $\$$ \\
\hline
\end{tabular}

Fuente: Ben Schiller (2013)

Elaboración propia 
Tabla 42: Revalorización de la zona

\begin{tabular}{|c|c|c|c|}
\hline \multicolumn{4}{|c|}{ Revalorización de la zona } \\
\hline $\begin{array}{c}\text { Área revalorizada } \\
\text { directamente }\end{array}$ & $\begin{array}{l}\text { Valor del área sin } \\
\text { revalorización }\end{array}$ & $\begin{array}{l}\text { Valor del área } \\
\text { revalorizada }\end{array}$ & $\begin{array}{c}\text { Valor } \\
\text { incrementado }\end{array}$ \\
\hline 62,979 & $88,170,600$ & $105,804,720$ & $17,634,120$ \\
\hline
\end{tabular}

Elaboración propia

Otro beneficio mucho más tangible y muy valorado por el estado en este tipo de proyectos de gran envergadura es la generación de empleos. La infraestructura por sí sola creará una serie de empleos directos necesarios para su funcionamiento, pero también aumentará las actividades productivas en la zona debido a la generación de un nuevo foco comercial y social.

Tabla 43: Generación de empleo

\begin{tabular}{|c|c|c|}
\hline \multicolumn{3}{|c|}{ Generación de empleo } \\
\hline Empleos directos & Sueldo promedio & Ingresos anuales \\
\hline 260 & 500 & $1,560,000$ \\
\hline
\end{tabular}

Elaboración propia

Si se suman todos los ahorros económicos para el estado por beneficios sociales se obtiene una ganancia anual de \$16’936,683. Vale recalcar que estos valores serán perceptibles para el estado de manera gradual, conforme se vayan completando las diferentes etapas constructivas. De igual forma, estos datos son de vital importancia para darle seguridad al capital del estado y favorecer su respaldo económico al privado. 
Tabla 44: Ahorro económico por beneficio social

\begin{tabular}{|c|c|c|c|}
\hline \multicolumn{4}{|c|}{ Ahorro económico por beneficio social (estado) } \\
\hline Ahorro por reducción de tiempo de transporte & $\$$ & $7,720,170$ & Anual \\
\hline $\begin{array}{l}\text { Ahorro por reducción de accidentes vehiculares en la } \\
\text { zona }\end{array}$ & $\$$ & $1,226,600$ & Anual \\
\hline $\begin{array}{l}\text { Ahorro por reducción de accidentes de buses por } \\
\text { somnolencia }\end{array}$ & $\$$ & $5,234,200$ & Anual \\
\hline Ahorro por absorción de CO2 & $\$$ & 20,105 & Anual \\
\hline $\begin{array}{l}\text { Revalorización de la zona por incremento de calidad de } \\
\text { vida y espacio público }\end{array}$ & $\$$ & $1,175,608$ & Anual \\
\hline Generación de empleo & $\$$ & $1,560,000$ & Anual \\
\hline TOTAL & $\$$ & $16,936,683$ & Anual \\
\hline
\end{tabular}

Elaboración propia

Así como se revisó el retorno de la inversión privada, también se ha realizado un cuadro final para el retorno de la inversión del estado (ver tabla 45). De forma similar al caso anterior, las ganancias por ahorro económico iniciarán a partir del tercer año con la puesta en operación del terminal terrestre e irían aumentado gradualmente conforme se complete la construcción del resto de etapas, hasta el sexto año donde los ingresos ya serán constantes. En esta se aprecia que los beneficios sociales son tan altos que el estado no perdería dinero ni siquiera en un escenario desfavorable, en el cual la demanda estimada fuese incorrecta y este debiera pagar garantías al privado. Con las cifras obtenidas el estado podría recuperar la inversión total en 10 años, sin tomar en cuenta los ingresos propios generados por el terminal. Motivo por el cual se justifica tanto la inversión del estado y su rol de aval económico y mediador. 
Tabla 45: Retorno de la inversión pública

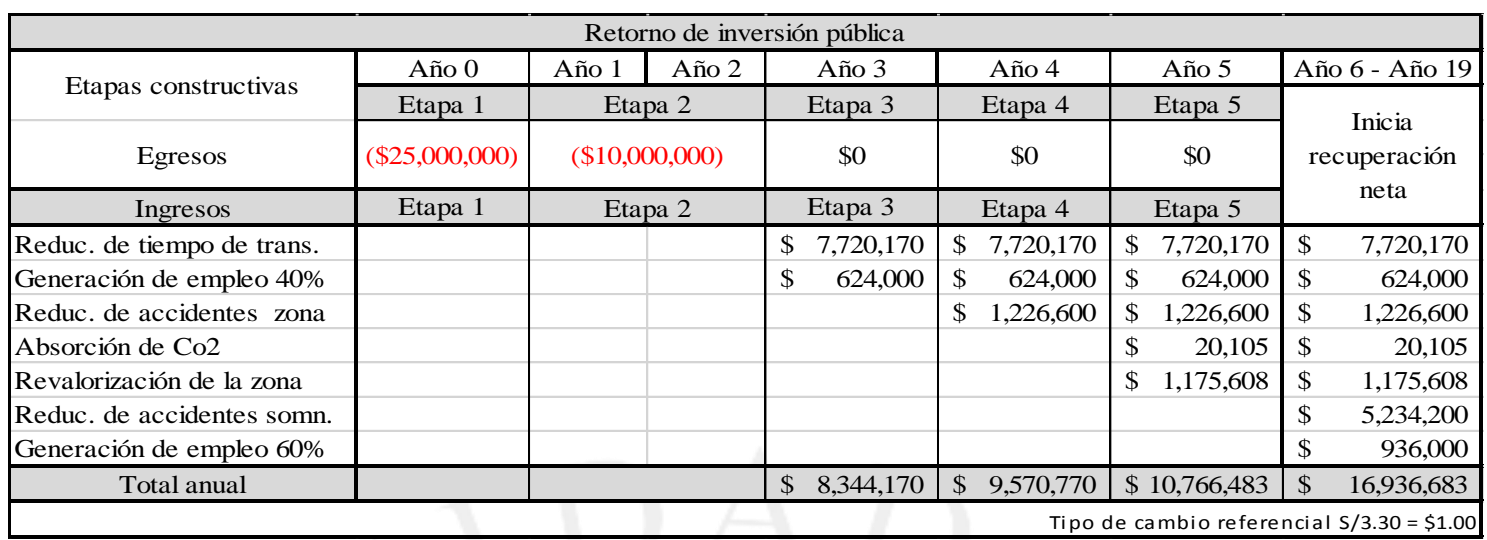

Elaboración propia

\subsubsection{Etapas de ejecución}

La ejecución del proyecto deberá realizarse en etapas debido a su escala y presupuesto. Como se mencionó en el financiamiento, los actores que participarán en la ejecución de este proyecto son el inversionista y el estado. Entre estos dos, se reparten costos y responsabilidades, siendo el privado quien asume la mayor parte de la inversión. El estado, subvencionará algunos de los gastos iniciales y velará por la ejecución del proyecto, otorgando garantías de uso y garantías financieras. Como visto en el desarrollo de la investigación, se determinó que el terminal se ubicaría en el mismo sitio que el actual terminal de yerbateros ${ }^{51}$. Sin embargo, requeriría un área significativamente mayor, motivo por el cual se optó por usar toda la manzana. Por lo tanto, la primera etapa del proyecto es la de realizar la compra de los terrenos a los propietarios, que lo utilizan entre otros como almacenes o talleres de autos. Esta será ejecutada por el estado y se financiará junto al privado, representando un $47 \%$ del costo total del proyecto. De los siete terrenos ubicados en la manzana, tres serían reubicados en el interior del terminal a cambio de un precio inferior al del mercado. Con un valor de $\$ 44.5$ millones y en un período aproximado de un año, se adquirirán los terrenos necesarios para la implementación del terminal en la etapa $\mathrm{N}^{\circ} 1$.

La segunda etapa (ver figura 58) requiere una inversión de \$32 millones, que corresponde a un $34 \%$ del costo total, ya que es la fase constructiva más grande de todo el proyecto. Para su ejecución, antes de iniciar con la construcción, se necesita habilitar el terreno, demoliendo y excavando hasta el NPT -10.00 en las partes más bajas.

\footnotetext{
${ }^{51}$ Ver capítulo 5.1.1: Terreno.
} 
Figura 58: Etapa $N^{\circ} 2$

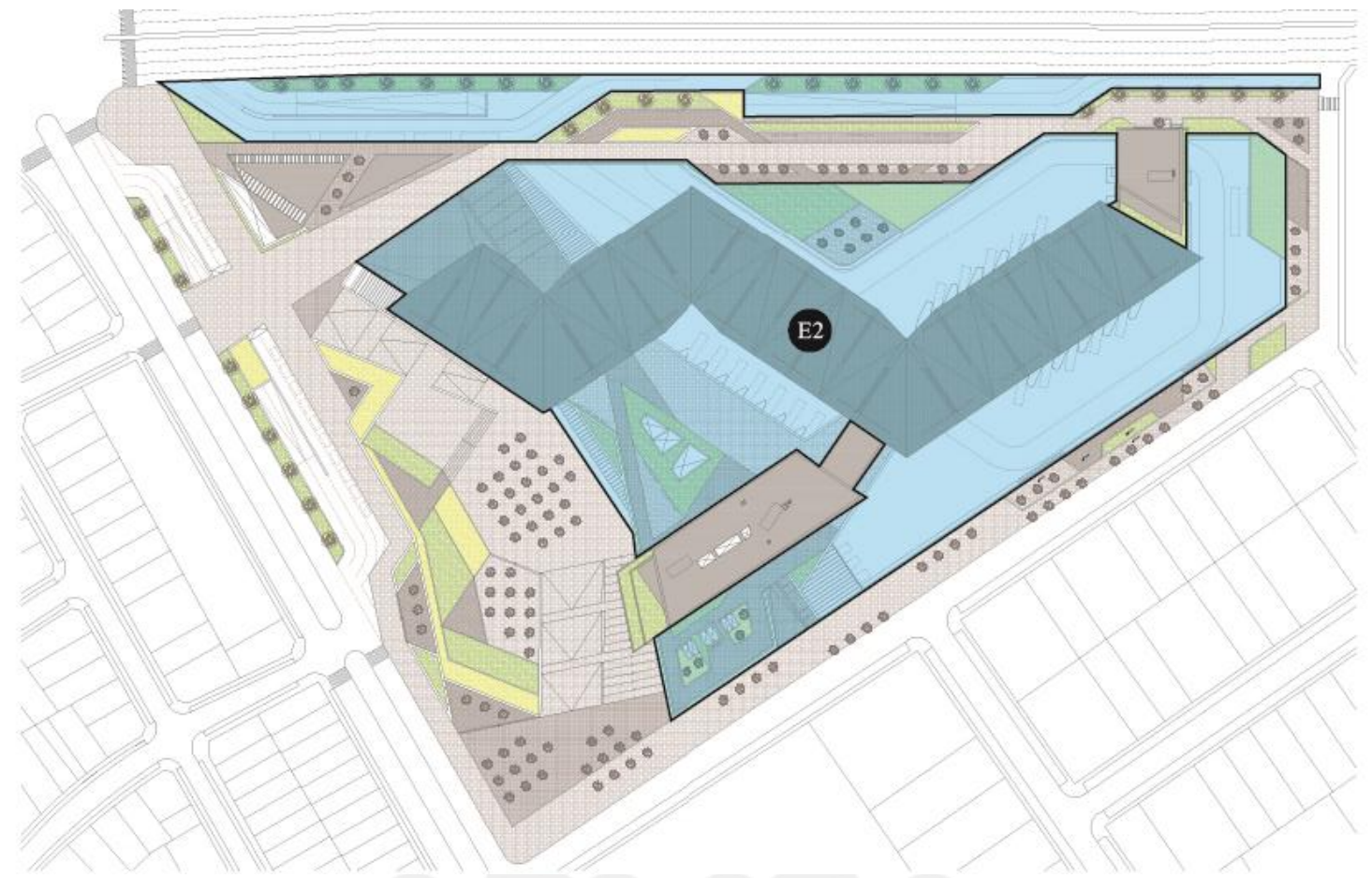

Elaboración propia

A continuación, se construyen los dos volúmenes principales necesarios para el funcionamiento del terminal terrestre. Estos, junto con el patio de maniobras, equivalen aproximadamente a un $50 \%$ de la construcción total. Esta etapa busca ejecutar solo aquella infraestructura indispensable $y$ que no es posible reubicar para el funcionamiento del terminal terrestre. El tiempo estimado para esta etapa es de dos años y una vez construida, podrá empezar a funcionar el terminal, generando ingresos. Es importante resaltar que es una etapa en la que algunos espacios cambiarán de uso, como por ejemplo el mezzanine, reemplazando temporalmente los niveles administrativos de la torre de control, aún no construida. Toda la zona externa, perteneciente al futuro anillo peatonal, podrá ser utilizada temporalmente como bahías urbanas y estacionamientos para no comprometer la accesibilidad del terminal.

La tercera etapa iniciará con las excavaciones necesarias para habilitar los tres niveles de estacionamientos subterráneos y la conexión intermodal al metro de Lima. Esta etapa costará un aproximado de \$8.6 millones y tomará alrededor de un año en ser terminada (ver figura 59). 
Figura 59: Etapa $N^{\circ} 3$

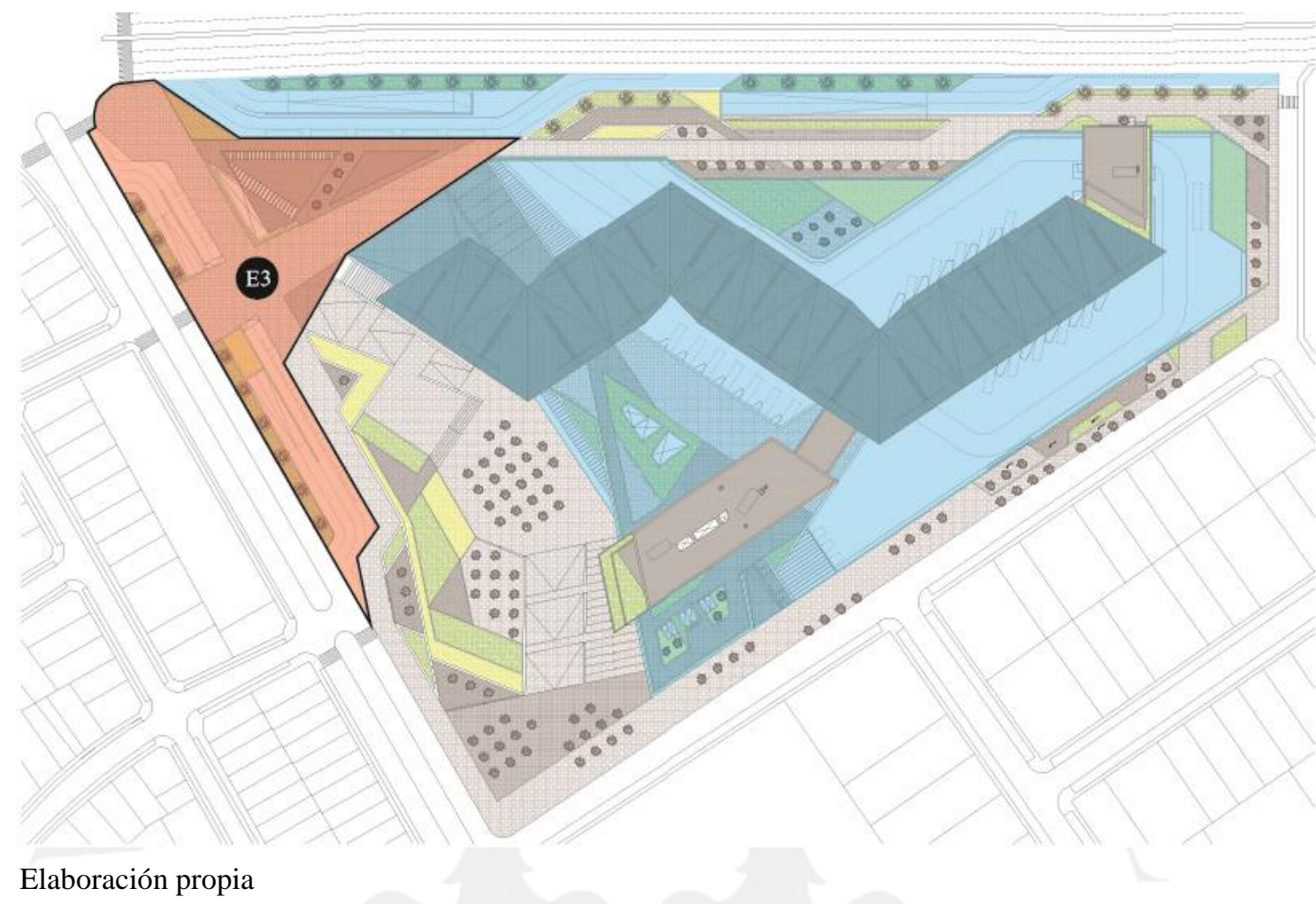

Es de gran importancia que esta etapa se construya antes que el resto, ya que su conectividad con la ciudad de Lima será un punto clave para garantizar el correcto funcionamiento del terminal terrestre y de las siguientes etapas constructivas, las que atraerán un gran número de usuarios.

La cuarta etapa es de carácter público, y se prioriza antes que la torre de control y el edificio comercial, por su aporte al vecindario. El terminal terrestre no solo busca organizar el flujo de buses interprovinciales, sino también revalorizar la zona y mejorar la calidad de vida con una gran contribución de espacio público. Esta etapa, compuesta por un gran anillo peatonal, áreas verdes, espacios de descanso, plazas públicas a diferentes niveles, un restaurante, una guardería y un taller comunitario, esta valorizada en aproximadamente \$4 millones y no tomará más de un año en ser finalizada (ver figura 60). En caso de requerir una inversión adicional, esta etapa podría ser cofinanciada por Lima Metropolitana o la Municipalidad de San Luis, ya que cuentan con un presupuesto asignado para proyectos de infraestructura y espacio público. Es importante resaltar los beneficios sociales ganados por el área verde y el espacio público implementado, generando ahorros significativos por la mejora en la salud y el aumento del valor del metro cuadrado. Como retribución adicional se podría ceder la 
administración del taller comunitario y la guardería a la Municipalidad, con el objetivo de que incorporar ciertos servicios públicos en la zona. Sin embargo, para nuestro cálculo de retorno de la inversión se consideró como un costo asumido por el inversionista privado.

\section{Figura 60: Etapa $N^{\circ} 4$}

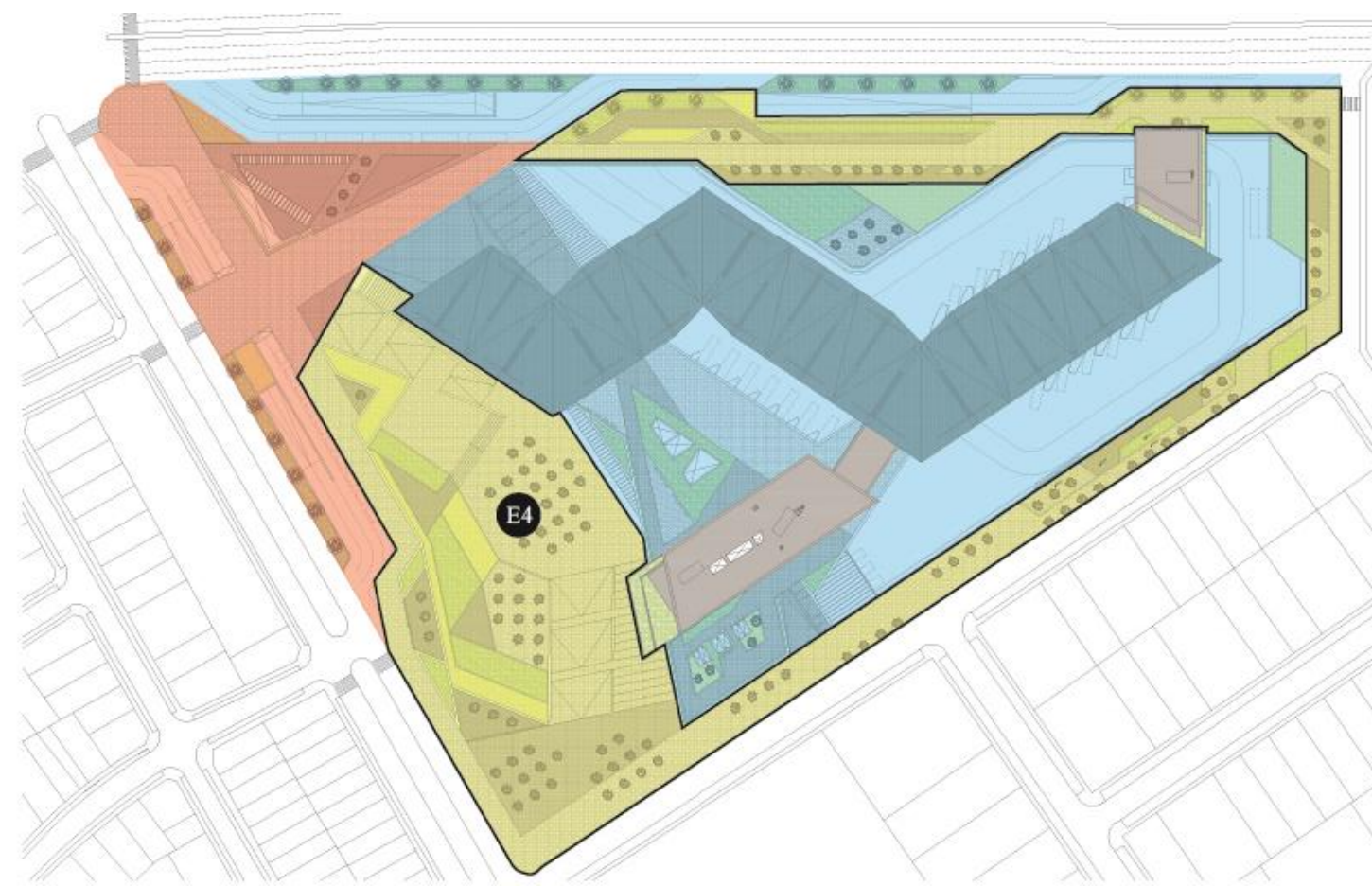

Elaboración propia

Finalmente, en la cuarta etapa se encuentran la torre de control y el edificio comercial. La torre de control costará un aproximado de $\$ 1.5$ millones, a diferencia del edificio comercial que costará unos \$3 millones (ver figura 61). Sin embargo, es importante considerar que este último contará con la mayor cantidad de área arrendable, siendo así el volumen más rentable. Si se ejecutan a la vez, podrán ser terminadas en un plazo aproximado de un año. 


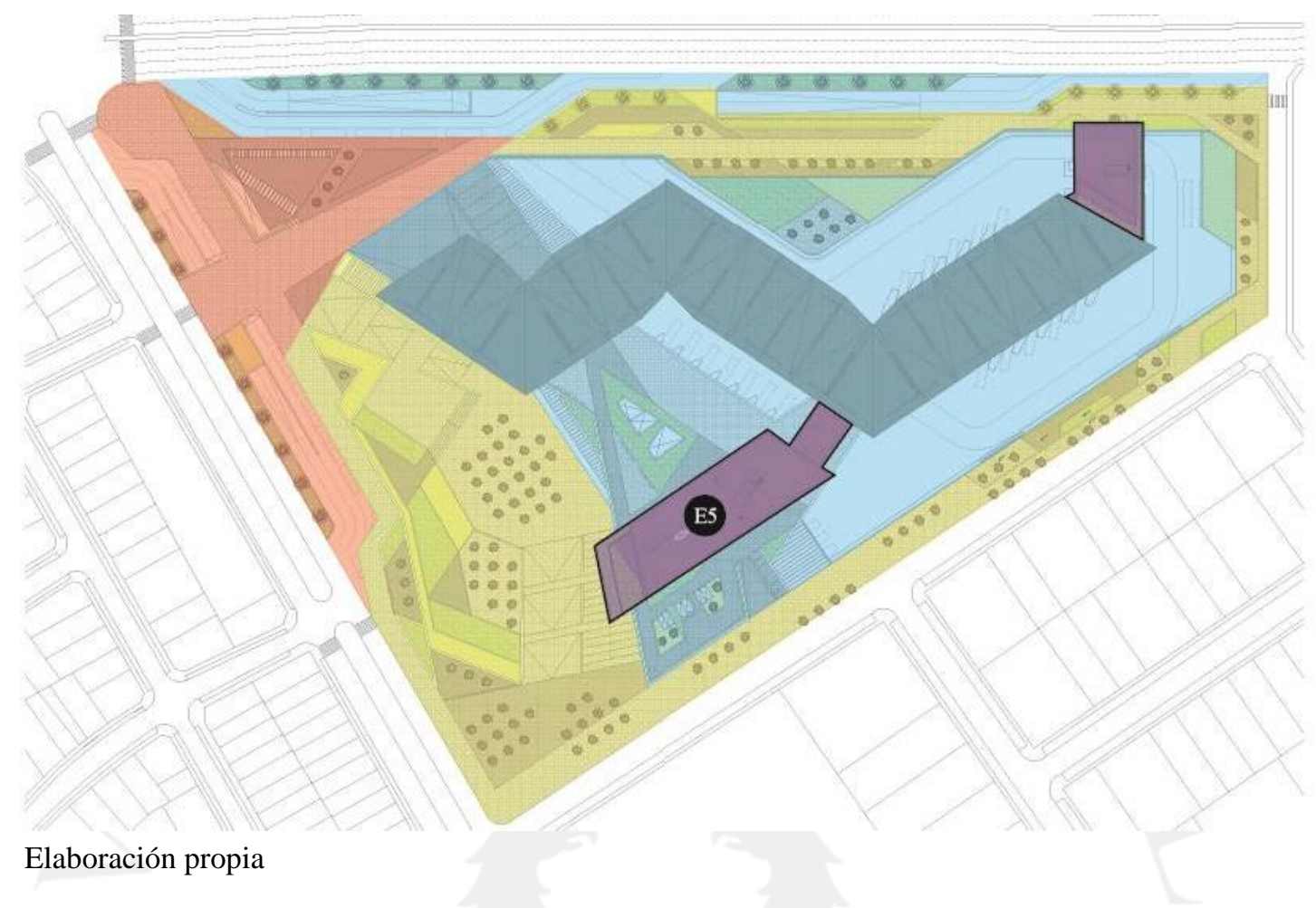

La subdivisión del proyecto en etapas nos ayudó a calcular cuando iniciarían los ingresos por alquiler y cuando se empezarían a generar ahorros por beneficio social. De esta manera se pudo estimar con mayor certeza el tiempo necesitado para el contrato de APP y la recuperación de la inversión, confirmando que un contrato con duración de 20 años sería la mejor opción para este tipo de proyecto.

Este sistema nos permitió calcular un ingreso total de \$114.1 millones por conceptos de alquiler y tarifas de embarque, generando una ganancia de \$55.3 millones sobre el precio de construcción. Adicionalmente, al cabo de los 20 años de contrato se habrá conseguido un ahorro por beneficio social para el estado de \$265.7 millones (ver tabla 46). Si bien estos montos preliminares justifican la inversión para construcción del proyecto, debemos aclarar, que por falta de información hemos considerado que el escenario inicial en el cual se desarrolló el proyecto se mantendrá sin variaciones durante los 20 años de duración del contrato. Por este motivo algunas variables no fueron consideradas, como por ejemplo una curva de eficiencia. 
Tabla 46: Ingresos y ahorros generados en 20 años

\begin{tabular}{|c|c|c|c|}
\hline Costo total del proyecto & $\$$ & $94,409,135.00$ & \multirow{4}{*}{ De interés privado } \\
\hline \multicolumn{3}{|c|}{ Ingresos generados en 20 años } & \\
\hline Ingreso total por alquiler & $\$$ & $114,108,624$ & \\
\hline Recuperación neta & $\$$ & $55,352,289$ & \\
\hline \multicolumn{3}{|c|}{ Ahorros logrados en 20 años } & \multirow{3}{*}{ De interés público } \\
\hline Ahorro total por beneficio social & $\$$ & $265,794,985$ & \\
\hline Recuperación neta & $\$$ & $230,795,985$ & \\
\hline
\end{tabular}

Elaboración propia 


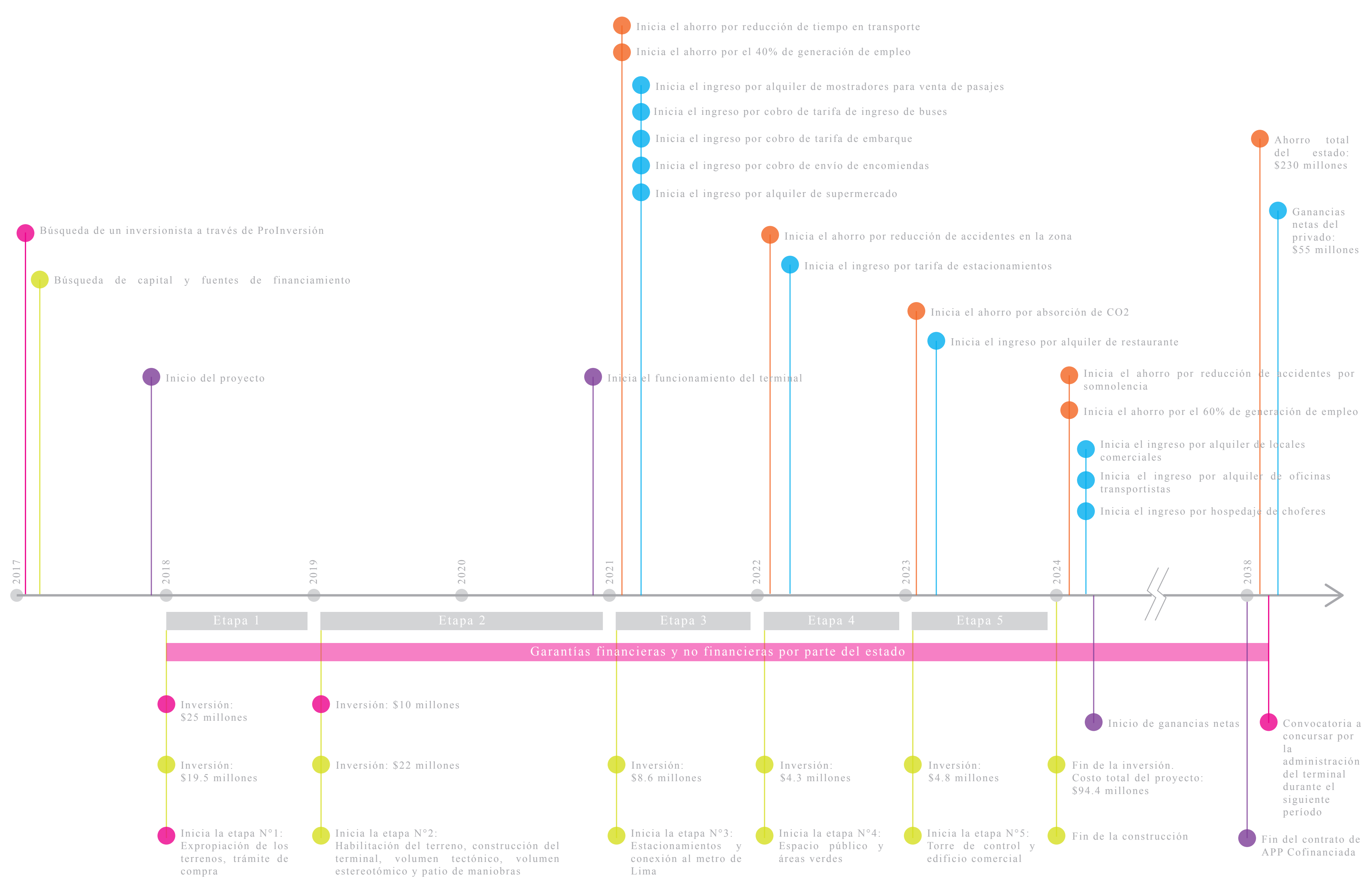




\subsubsection{Análisis FODA del proyecto}

Es importante realizar un análisis de fortalezas, oportunidades, debilidades y amenazas para reconocer potencialidades y problemáticas del proyecto con el objetivo de generar algunas estrategias para justificar su viabilidad.

Figura 62: Análisis FODA

\begin{tabular}{|c|c|}
\hline FORTALEZAS & OPORTUNIDADES \\
\hline - Cuenta con una ubicación estratégica. & - Incremento de viajes y turismo a nivel nacional. \\
\hline $\begin{array}{l}\text { - Ofrece una amplia gama de servicios relacionados al } \\
\text { transporte terrestre bajo un solo techo. }\end{array}$ & - Carencia de un terminal terrestre centralizado para Lima Este. \\
\hline $\begin{array}{l}\text { - Organiza el transporte interprovincial de buses. } \\
\text { - Organiza el transporte público y privado en su entorno. }\end{array}$ & $\begin{array}{l}\text { - Clamor popular para la mejora del servicio de transporte } \\
\text { interprovincial en las rutas de la sierra y selva central. }\end{array}$ \\
\hline - Ofrece un punto intermodal para la zona. & - Hartazgo de la sociedad hacia la fuerte congestión vehicular. \\
\hline $\begin{array}{l}\text { - Aporta espacios para el uso de los vecinos, ya que se compone } \\
\text { en un } 60 \% \text { de espacio público y áreas verdes. }\end{array}$ & - Zona fuertemente industrial prevista a cambiar de zonificación. \\
\hline $\begin{array}{l}\text { - Se complementa con usos comerciales. } \\
\text { - Su arquitectura fue diseñada con un enfoque sostenible. }\end{array}$ & $\begin{array}{l}\text { - Zona en proceso de consolidación con graves problemas de } \\
\text { inseguridad ciudadana y carente de identidad. }\end{array}$ \\
\hline DEBILIDADES & AMENAZAS \\
\hline $\begin{array}{l}\text { - Requiere de una fuerte inversión inicial, tan solo la adquisición } \\
\text { de los terrenos representan un } 47 \% \text { del costo total del proyecto. }\end{array}$ & $\begin{array}{l}\text { - La introducción de aerolíneas de bajo costo podría reducir el uso } \\
\text { del transporte interprovincial terrestre. }\end{array}$ \\
\hline $\begin{array}{l}\text { - Se requerirán expropiaciones por parte del estado, si no se } \\
\text { logran concretar las adquisiciones de terrenos. }\end{array}$ & $\begin{array}{l}\text { - La implementación de una vía férrea para la ruta central } \\
\text { podría reducir el uso del transporte interprovincial terrestre. }\end{array}$ \\
\hline $\begin{array}{l}\text { - El sistema estructural puede necesitar tecnología o ingenieros } \\
\text { del extranjero, incrementando tiempos y costos. }\end{array}$ & $\begin{array}{l}\text { - La aparición de otro terminal terrestre que abastezca la misma } \\
\text { ruta podría reducir el uso del terminal. }\end{array}$ \\
\hline $\begin{array}{l}\text { - Deberá ser construido en etapas, incrementando el tiempo } \\
\text { necesitado para culminarlo. }\end{array}$ & $\begin{array}{l}\text { - Una resistencia por parte del gremio de transporte interprovincial } \\
\text { podría llevar a un rechazo hacia el terminal. }\end{array}$ \\
\hline - Poca área comercial arrendable. & $\begin{array}{l}\text { - Un posible abandono del proyecto del metro de Lima, afectaría } \\
\text { fuertemente la conectividad e intermodalidad del terminal. }\end{array}$ \\
\hline - Poca capacidad de expansión en el tiempo. & $\begin{array}{l}\text { - Una ampliación a gran escala de la carretera central podría } \\
\text { paralizar el flujo de buses en esta ruta durante varios meses. }\end{array}$ \\
\hline
\end{tabular}

Elaboración propia

Lo primero que se pudo determinar al contemplar las fortalezas y oportunidades del análisis FODA es que se ha generado el escenario ideal para la implementación del proyecto.

Esto se debe a que en las últimas décadas se registró un incremento del turismo a nivel nacional, lo que ha evidenciado la falta de un terminal terrestre centralizado que 
abastezca las rutas de la sierra y selva central. Por otro lado, existe un clamor popular para la mejora del servicio de transporte interprovincial, el que genera una presión constante por parte del estado para ordenar y formalizar las empresas transportistas. Es a partir de esta necesidad que la ubicación resulta ser tan estratégica, ya que permite agrupar la amplia gama de servicios relacionados al transporte, que se encuentran dispersos en la zona, bajo un solo techo. Esto no solo organiza el transporte interprovincial de buses en la carretera central, sino que genera la posibilidad de crear un punto intermodal con el metro de Lima y el transporte urbano. Por lo que también se ayudará a ordenar el transporte público y se reducirá la congestión vehicular, mejorando la valoración del usuario sobre su entorno.

Desde el punto de vista social, se determinó que la zona de intervención tiene graves problemas de inseguridad ciudadana y delincuencia, los que se dan por la carencia de espacio público y la zonificación industrial que genera calles poco transitadas. Como se vio en el desarrollo del marco teórico la mejora de estos parámetros es posible con la correcta implementación de zonas de esparcimiento y su constante activación mediante el comercio ${ }^{52}$. Es por este motivo que el terminal terrestre se compone en un $60 \%$ de espacio público y áreas verdes, con el objetivo de reactivar la zona y ayudar a crear una nueva identidad al vecindario. Adicionalmente, se busca generar una integración entre todos los frentes del terminal y las futuras zonas aledañas, evitando la generación de bordes y adelantándose al cambio de zonificación que busca desplazar a la industria hacia las afueras de la ciudad.

De igual forma, para garantizar el éxito del proyecto se desarrollaron las estrategias necesarias para enfrentar las debilidades y las amenazas previamente mencionadas.

Las primeras dos debilidades del proyecto se enfrentarán en la fase de adquisición de terrenos previa a la construcción del terminal. Por un lado, se necesita una fuerte inversión inicial para la compra de terrenos y por el otro se contempla la posibilidad de realizar expropiaciones. Es por este motivo que el principal aliado del inversionista privado será el estado, este último realizará una inversión inicial para amortizar los gastos de compra de terrenos y en caso de ser necesario, se encargará de gestionar las expropiaciones. Además, fungirá un papel de aval económico presentando

\footnotetext{
52 Ver capítulo 3.3: Sobre el espacio público.
} 
garantías al inversionista privado y respaldándolo en la adquisición de préstamos bancarios. Este respaldo por parte del estado se dará gracias a los beneficios sociales que trae consigo la construcción del terminal, ya que no solo mejorará la situación del transporte interprovincial, sino que ayudará a revalorizar la zona aledaña y generará una dinámica comercial nueva. Como se vio en el capítulo del retorno de la inversión ${ }^{53}$, los ingresos y ahorros generados por el terminal permitirán al estado y al privado recuperar su inversión en un plazo aproximado de 10 años.

Otra debilidad identificada en el proyecto es la complejidad de su sistema estructural que generará sobrecostos constructivos, ya que posiblemente requiera de la importación de maquinaria y materiales, así como la contratación de ingenieros del extranjero. Sin embargo, si se cuantifican los beneficios funcionales y operativos que brindará la flexibilidad de esta estructura al terminal, además de considerar que se trata del único terminal terrestre de Lima con un impacto regenerativo gracias al aporte estético de su arquitectura ${ }^{54}$. Se comprende que los beneficios son mayores a los costos, motivo por el cual se justifica la implementación de un elemento estructural especial e innovador.

La siguiente debilidad a tomar en cuenta está relacionada con la poca área comercial disponible dentro del terminal, la que va de la mano con la lenta recuperación de la inversión privada. Esto se debe a que se trata de un proyecto social, donde la calidad y la espacialidad arquitectónica son el elemento más valorado por los usuarios, así como el correcto funcionamiento del terminal. Por este motivo se priorizaron los ambientes relacionados al desarrollo de las actividades del transporte, implementando servicios complementarios únicamente cuando son requeridos o brindan algún tipo de beneficio al usuario, como por ejemplo en los espacios públicos y zonas de espera. Es así, que en el análisis del retorno de la inversión el $85 \%$ de los ingresos del terminal se dan por conceptos relacionados al transporte. Con el objetivo de elaborar un proyecto interesante para el inversionista privado, se realizó un contrato de 20 años donde la primera mitad servirá para cubrir los costos de construcción, mientras que el resto serán ganancias netas.

\footnotetext{
${ }^{53}$ Ver capítulo 7.3.3: Retorno de la inversión.

${ }^{54}$ Ver capítulo 3.4.1.1: Urbanismo Social: Proyectos de infraestructura en barrios marginados.
} 
Finalmente se determinó que existe una debilidad en el proyecto respecto a su posible expansión en el tiempo, ya que la arquitectura no permite la incorporación de nuevas bahías de buses en el caso de un aumento de la demanda. Por este motivo al momento de dimensionar el terminal se realizó una proyección al año 2035 para estimar la futura demanda de pasajeros y buses, con el objetivo de garantizar su correcto funcionamiento durante los próximos 20 años. Igualmente, se sobredimensionó el resultado final para permitir una holgura adicional.

Entre las amenazas se encuentran tres posibles competidores que podrían reducir el uso del terminal terrestre. Sin embargo, dos de estos, la vía férrea y las aerolíneas de bajo costo, requieren de una inversión sustancial y de la implementación de mucha infraestructura para llevarse a cabo. Para el caso de la vía férrea se necesitaría de la implementación de diversas rutas y estaciones, por lo que se trataría de un proyecto en etapas, con muchos años de desarrollo y ejecución, dejando tiempo suficiente para el establecimiento del terminal terrestre. De igual manera, la presencia de aerolíneas de bajo costo es una amenaza con respecto a ciertos destinos de la zona central del país. Sin embargo, también requiere de una gran inversión y tiempo para habilitar todos los destinos con aeropuertos adecuados. Es posible que los destinos más grandes ya cuenten con aeropuertos, sin embargo, existen múltiples destinos que por su reducida escala seguirán utilizando el transporte terrestre en bus como su medio de viaje. El tercer y último competidor sería implementación de un segundo terminal terrestre que abastezca las mismas rutas. El cual, desde un principio se encontraría en desventaja ya que el proyecto posee la ubicación histórica del antiguo terminal Yerbateros además de las conexiones intermodales con el resto de la ciudad.

También se consideró como una posible amenaza el rechazo hacia el terminal por parte de las empresas transportistas existentes, ya que se podrían rehusar a utilizar las instalaciones. Sin embargo, considerando el prolongado pedido de los usuarios para un mejor servicio y la constante presión por parte del estado para organizar a dichas empresas, su incorporación sería relativamente fácil y sin mayores costos, ya que el nuevo proyecto no modifica las rutas existentes.

El resto de amenazas, como el posible abandono en la construcción del metro de Lima y la ampliación de la carretera central, se deberán conversar y prever con la 
entidad a cargo, en este caso la municipalidad de Lima, para planificar soluciones y buscar alternativas específicas que no afecten de manera directa al terminal.

\subsubsection{Plan de Marketing}

Como parte de la estrategia de venta y promoción del proyecto, se optó por desarrollar las 4Ps del Marketing. Este esquema se juntó con el propuesto por Richard Ettenson, Eduardo Conrado y Jonathan Knowles, conocido como S.A.V.E. en el cual se reconsidera el enfoque de cada una de las 4Ps. Estos consideran que las 4Ps se enfocan mucho en el producto mismo, cuando se debería tratar de ampliar la visión. Es así que S.A.V.E. busca atacar la Solución, el Acceso, el Valor y la Educación (Doyer, s.f.).

Con el entendimiento de estas dos técnicas de mercadotecnia, se desarrolló una tabla en la que se plantea una estrategia según los diferentes temas, buscando resaltar todo aquello que hace al terminal único, los beneficios que trae, los medios por los que se dará a conocer y su valor en el mercado.

El primer punto que se estudia es la plaza o el acceso. Con este se busca plantear las diferentes maneras de acceso a la información sobre el proyecto, como por ejemplo páginas web, módulos de atención al usuario y oficinas para atender necesidades específicas. Seguido a esto es importante conocer el plan de promoción y educación, contemplando a través de qué medios se harán las campañas informativas que den a conocer el proyecto hacia el exterior. De igual manera se deberá trabajar con asociaciones de pobladores, comités y sindicatos para evitar futuros conflictos y ver su incorporación dentro del proyecto. Se aprovechará la relevancia del terminal a nivel metropolitano, para ser publicitado a través de medios de la Municipalidad de Lima Metropolitana y la Municipalidad de San Luis. Asimismo, por su conexión intermodal con la Línea 2 del metro de Lima, se harán campañas informativas en conjunto para dar a conocer las posibilidades de conexión entre urbe y provincia, mediante el terminal. También es importante educar al público con respecto a los beneficios generados por el terminal y sobre las tecnologías implementadas para el incremento de bienestar y calidad de servicio. Sustentando con la disposición por parte del viajero para pagar tarifas más altas a cambio de un mejor servicio, se dan a conocer los precios del terminal como infraestructura intermediaria para el funcionamiento del transporte interprovincial. Finalmente, se debe resaltar toda característica que hace al terminal 


\section{único, explicando los problemas que se logran solucionar con su implementación, cómo se diferencia el diseño y la propuesta de usos, y cuáles son los valores agregados del proyecto.}

Figura 63: 4P-S.A.V.E.

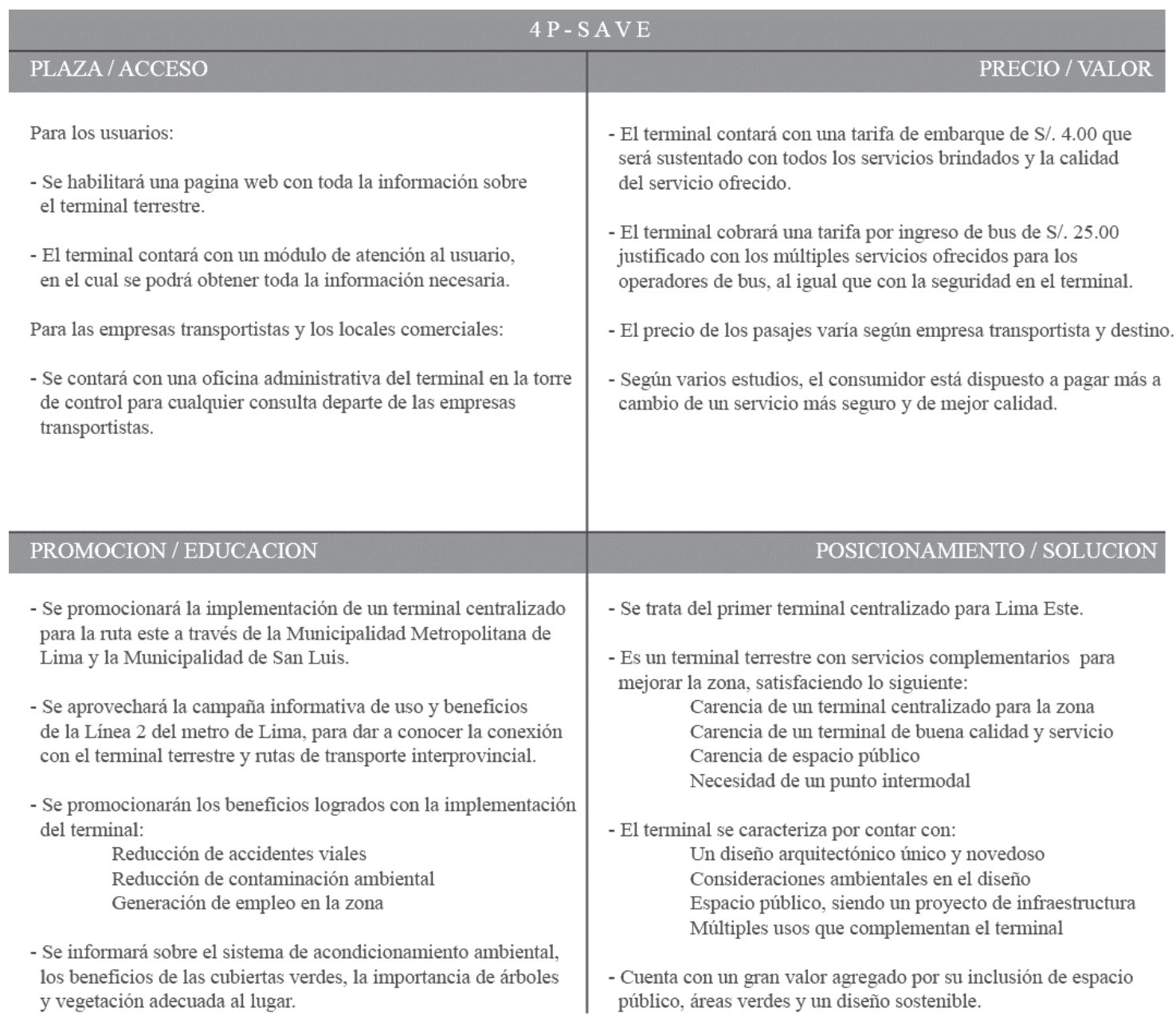

\section{Elaboración propia}




\subsection{Vistas 3D}

Figura 64: Ingreso principal 1

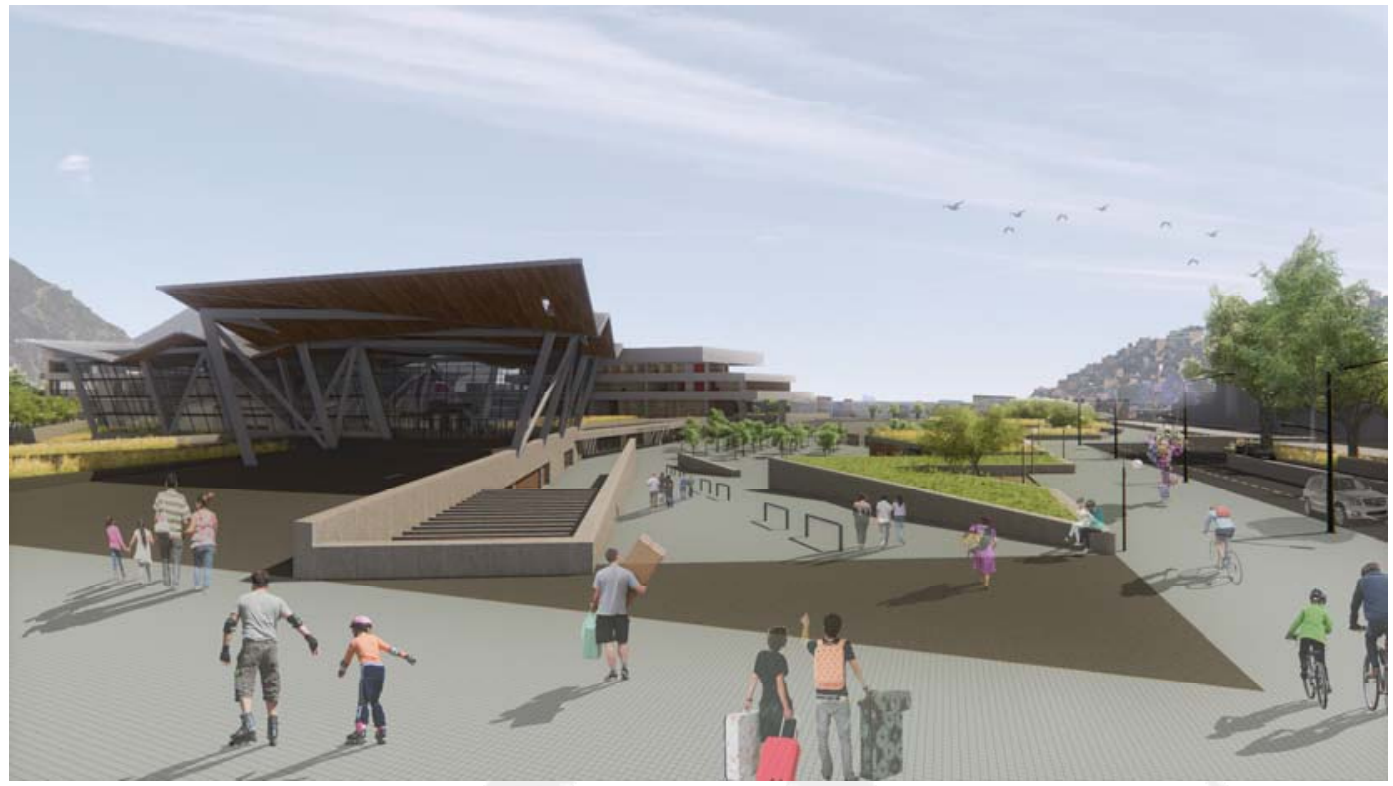

Elaboración propia

Elaboracion propia

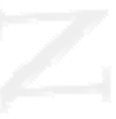

Figura 65: Ingreso principal 2

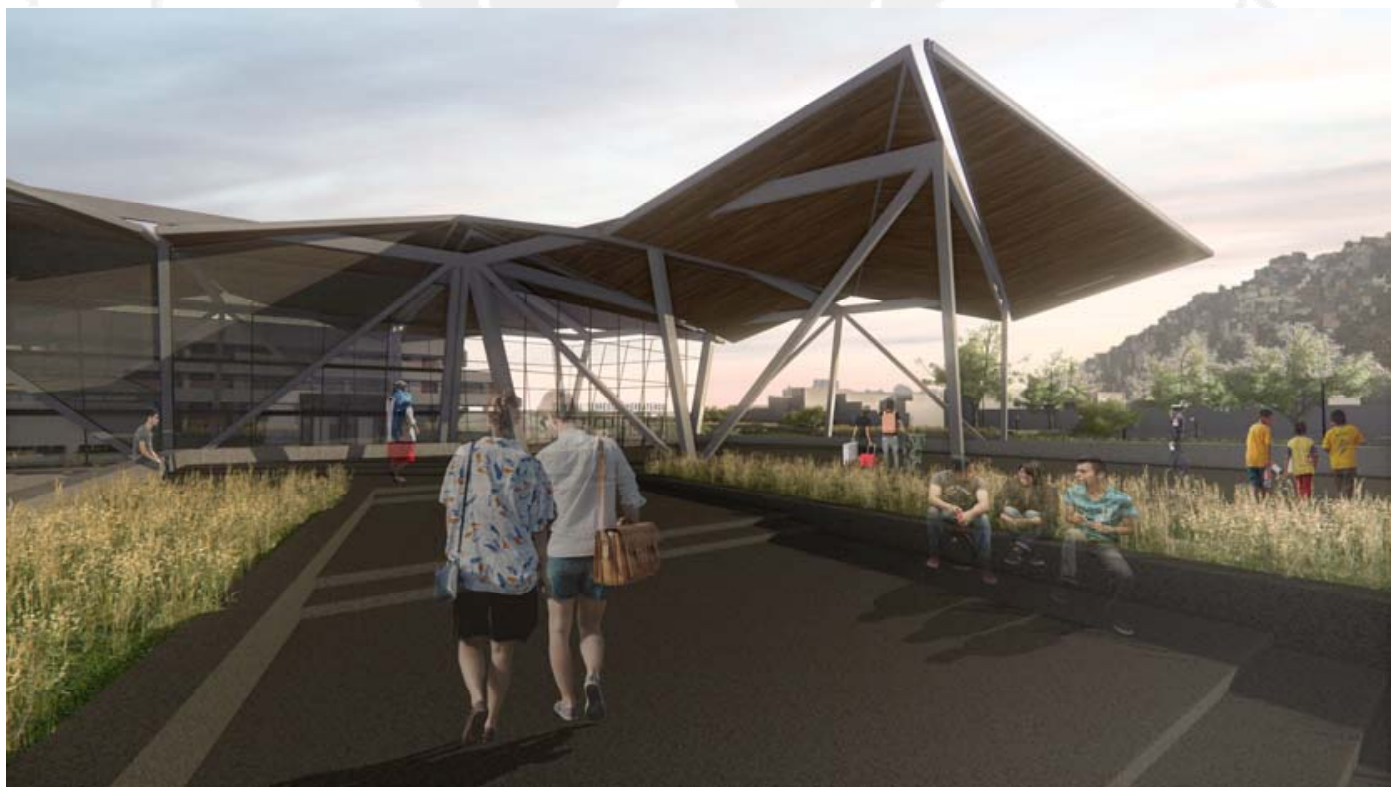

Elaboración propia 
Figura 66: Espacio público

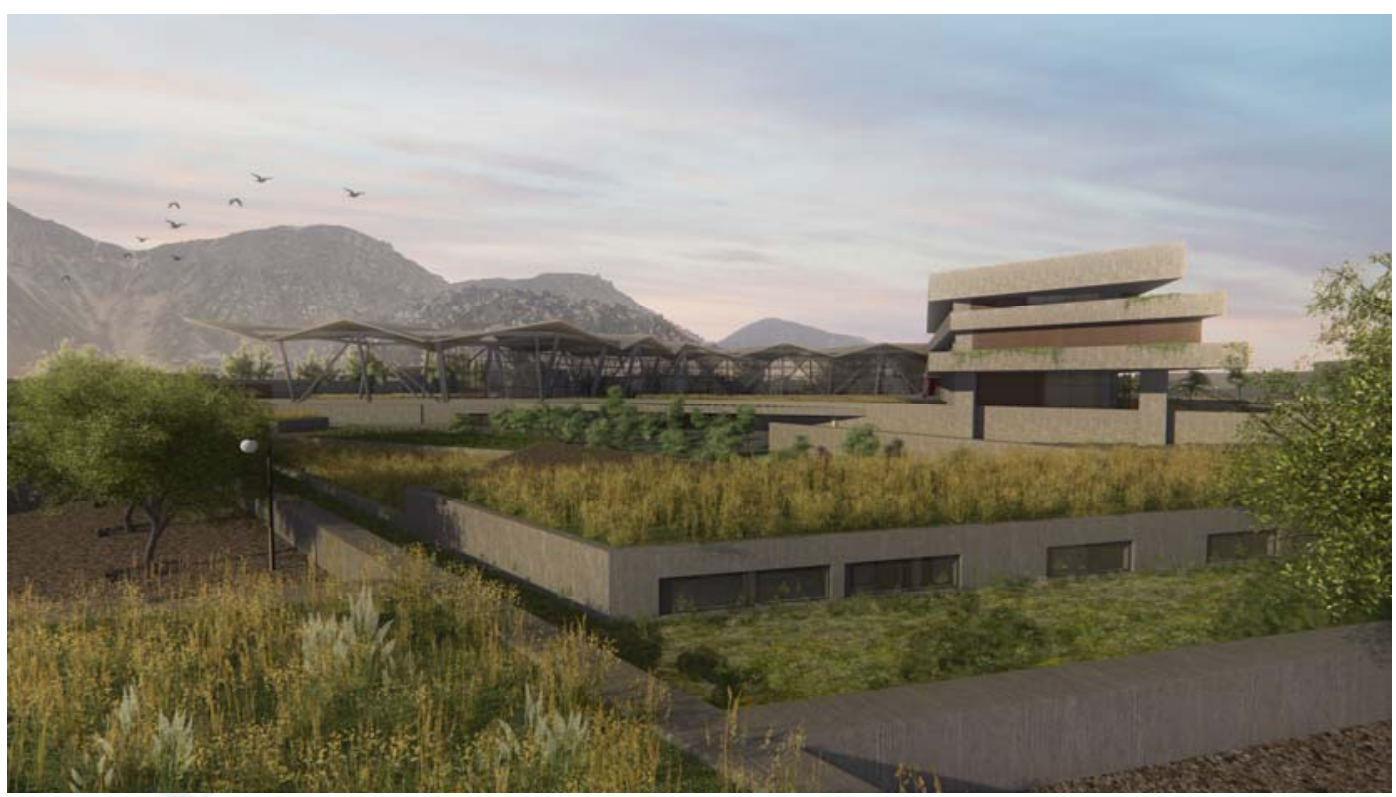

Elaboración propia
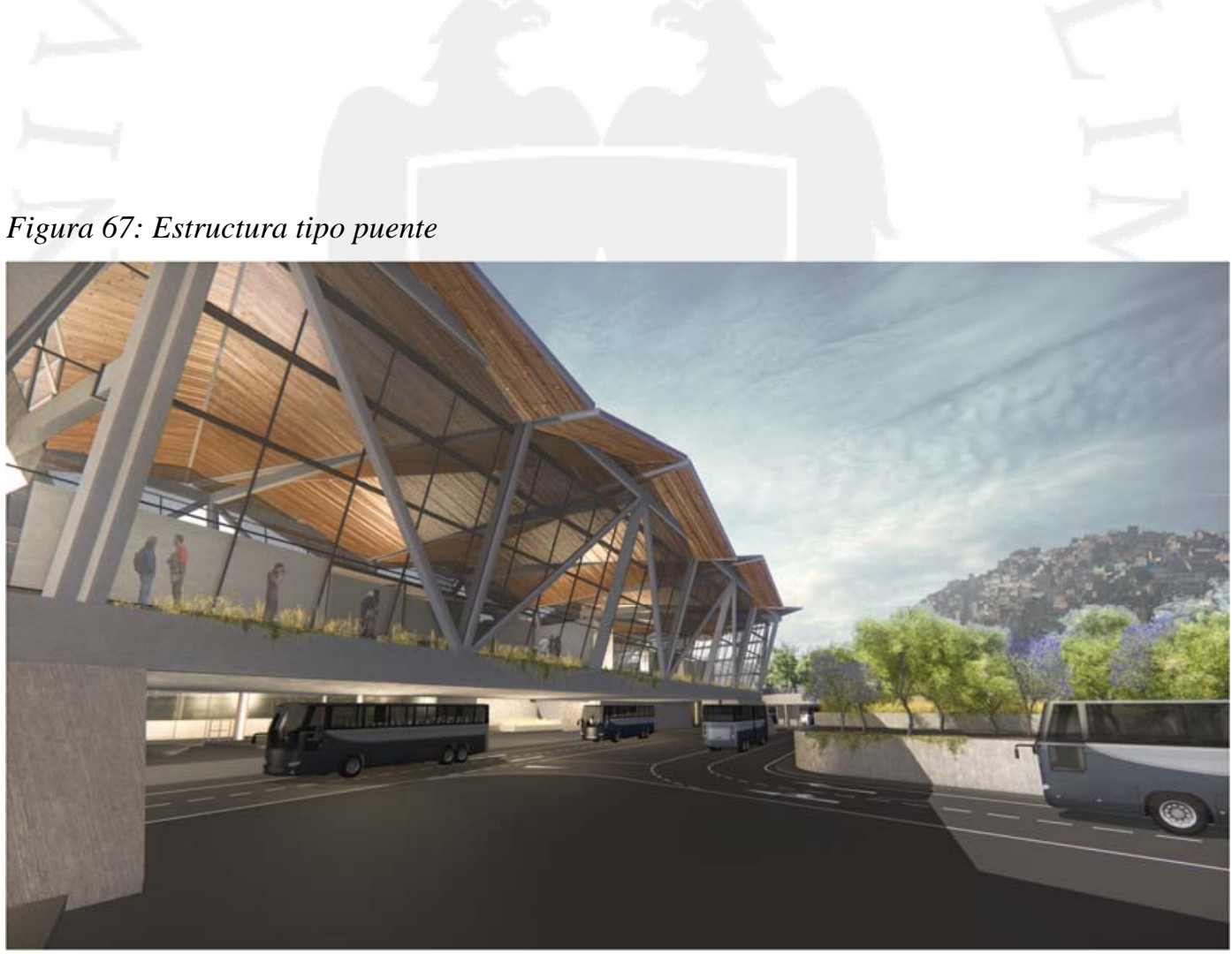

Elaboración propia 
Figura 68: Patio de maniobras 1

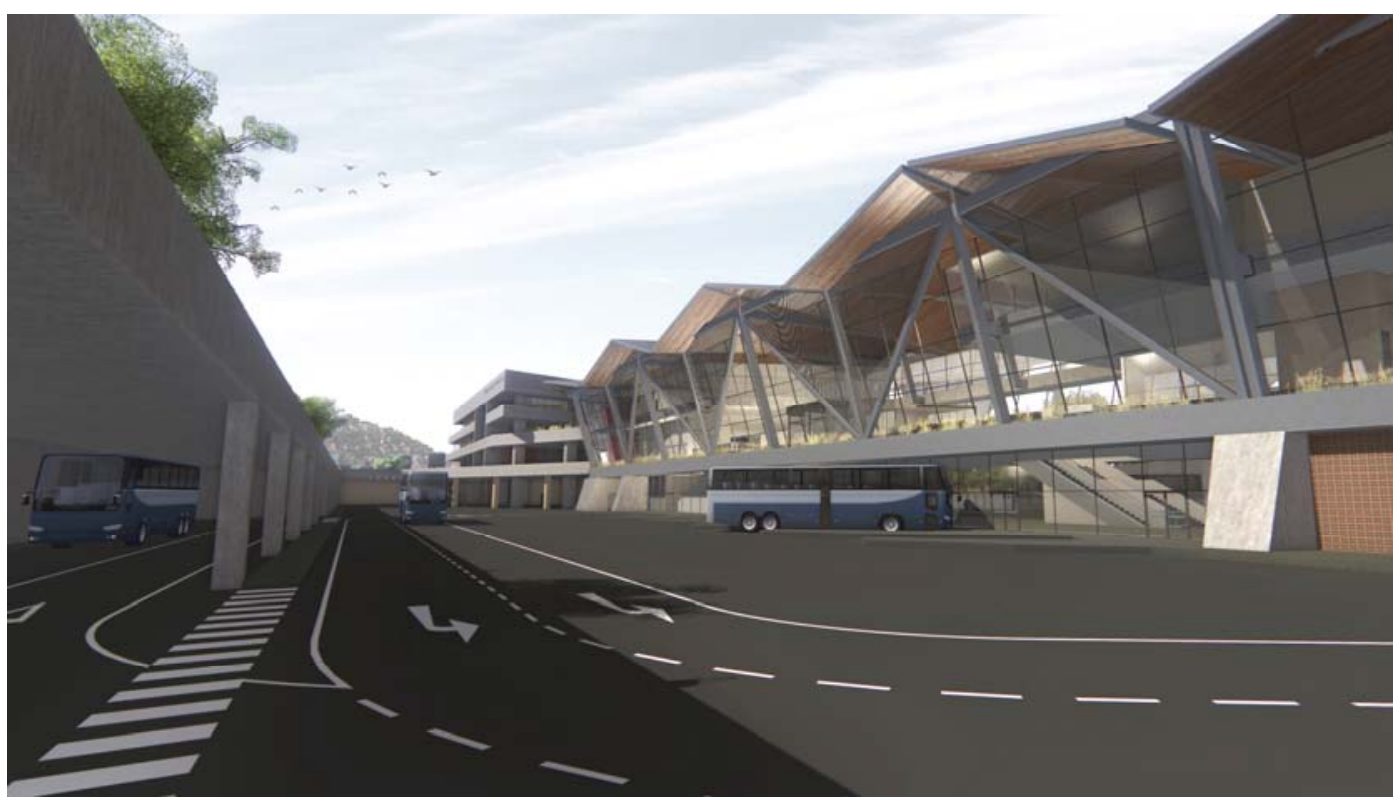

Elaboración propia
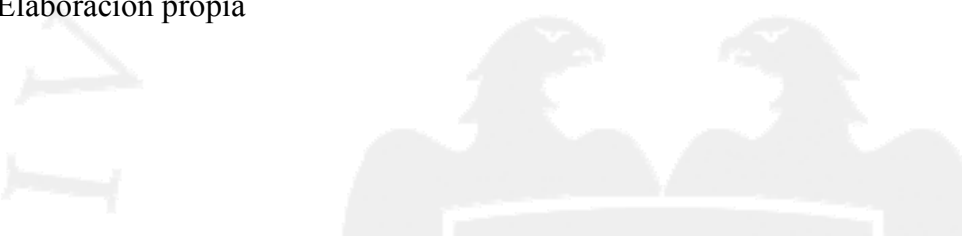

Figura 69: Patio de maniobras 2

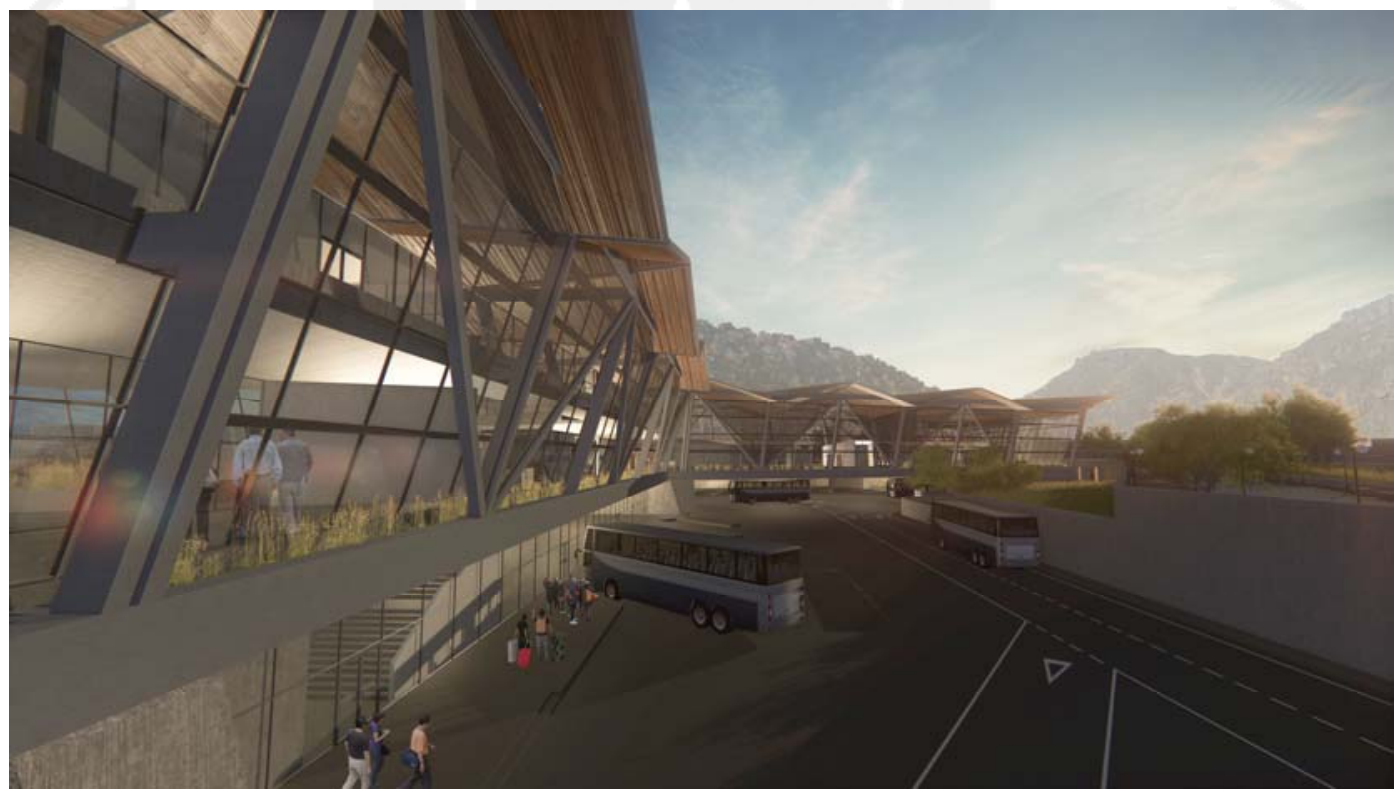

Elaboración propia 
Figura 70: Anillo peatonal y edificio tectónico 1

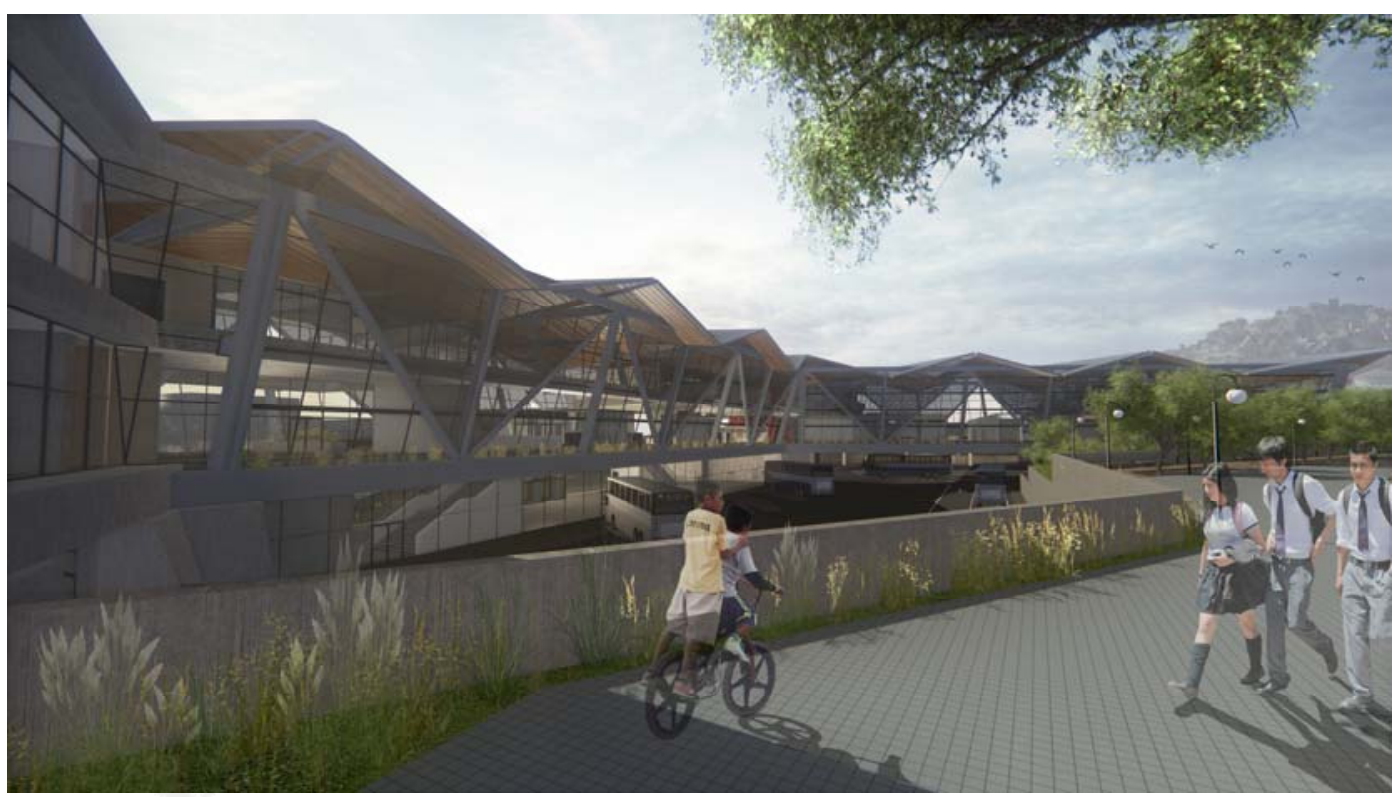

Elaboración propia
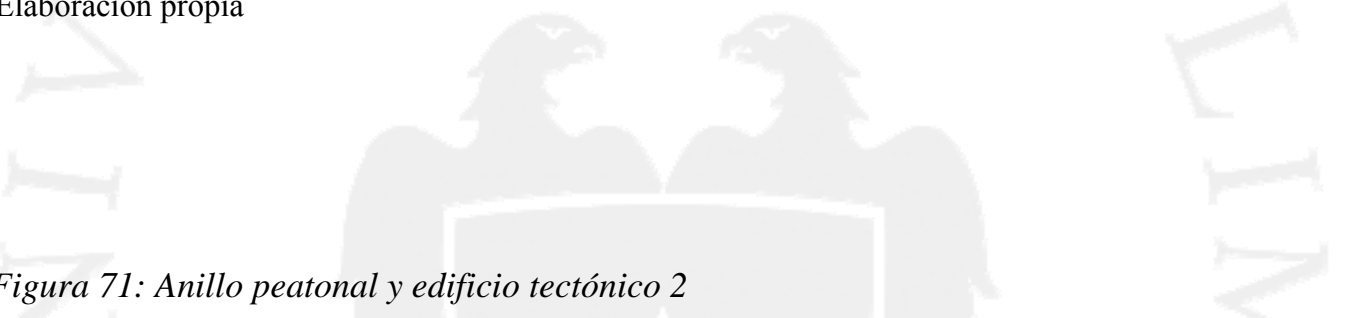

Figura 71: Anillo peatonal y edificio tectónico 2

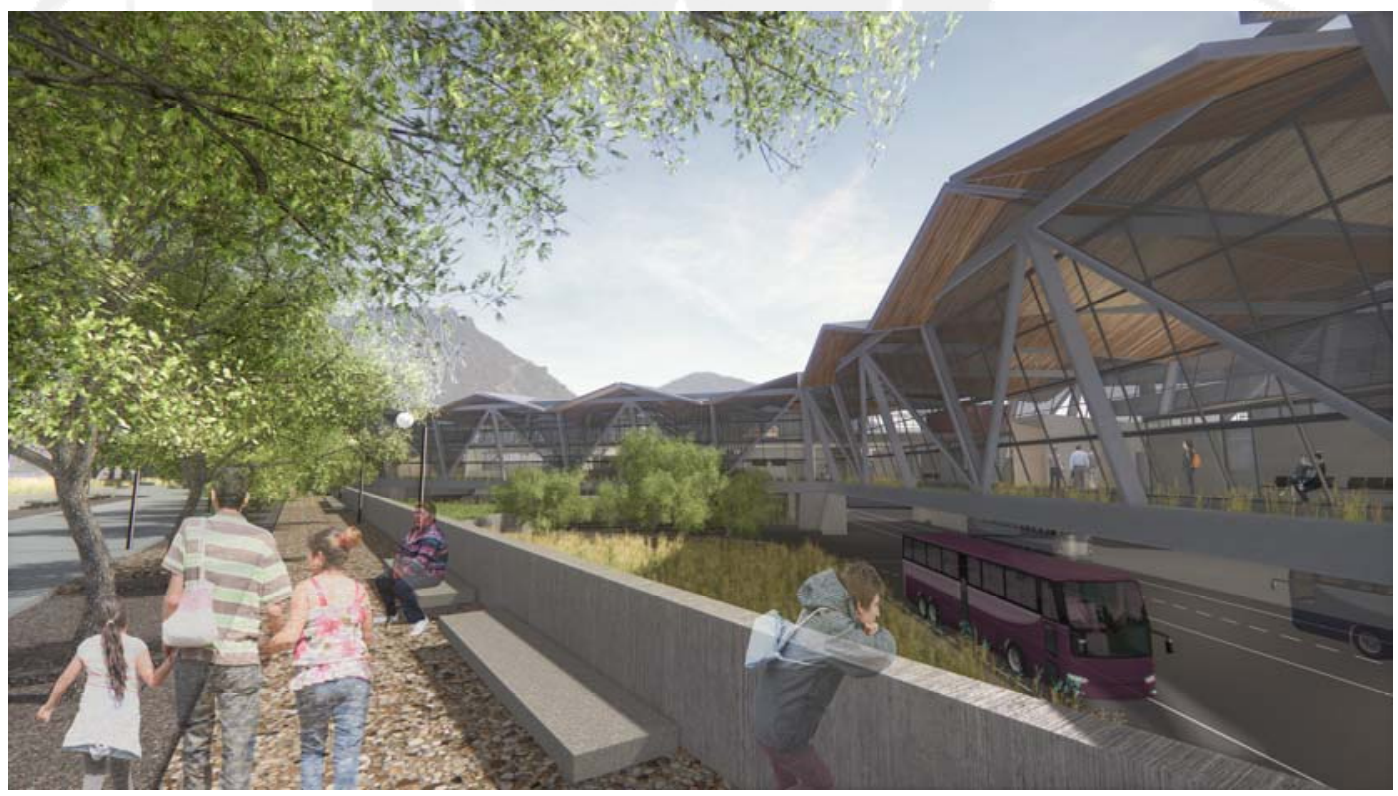

Elaboración propia 


\section{REFERENCIAS BIBLIOGRAFICAS}

Adondevivir. (2017). San Luis. Obtenido de Venta de terrenos: http://www.adondevivir.com/terrenos-en-venta-en-san-luis.html

Advanced Logistics Group. (2006). Proyecto de corredores complementarios. Lima: Andina.

Advanced Logistics Group. (2006). Proyecto de Corredores Complementarios. Lima: Andina.

Agencia de Cooperación Internacional de Japón [JICA]; Consejo de Transporte de Lima y Callao; Ministerio de Transportes y Comunicaciones [MTC]. (2005). Plan Maestro de Transporte Urbano para el área Metropolitana de Lima y Callao en la República del Perú. Lima.

AL21; Ministerio de Medio Ambiente. (2007). Libro verde de medio ambiente urbano.

Antúnez, V. (15 de Enero de 2014). El 77\% del transporte interprovincial es informal. El Comercio. Obtenido de http://elcomercio.pe/economia/peru/77-transporteinterprovincial-informal-noticia-1702839

Arkiplus. (2011). El arquitecto y la sociedad. Obtenido de Arquitectura: http://www.arkiplus.com/el-arquitecto-y-la-sociedad

Arrué, J. J. (2013). La ciudad como espacio público. Gestión Pública y Desarrollo (67), H1-H5.

Arrué, J. J. (2014). Políticas de desarrollo urbano, movilidad, y espacio público orientadas a los sectores más vulnerables en América Latina. Gestión Pública y Desarrollo, G1-G5.

Ashford, N. J., Mumayiz, S., \& Wright, P. H. (2011). Airport Engineering. New Jersey: Wiley.

Asociación Peruana de Empresas de Investigación de Mercados [APEIM]. (2014). Niveles Socioeconómicos. Lima: Apeim.

Associated Press in Pachuca. (2015). Artists in Mexico turn los-income neighborhood into one giant mural. The Guardian. Obtenido de http://www.theguardian.com/world/2015/aug/01/mexico-pachuca-mural-laspalmitas-public-art

Ausejo, Q. (2013). Articulos. Obtenido de Una mejor ciudad es posible: http://unamejorciudadesposible.com/blog/?p=16 
Banco Interamericano de Desarrollo; Banco Mundial. (2003). Programa de Transporte Urbano de Lima Metropolitana - Subsitema Norte - Sur. Lima: Banco Interamericano de Desarrollo.

Barkow Leibinger. (s.f.). Barkow Leibinger. Obtenido de Selected Projects: http://www.barkowleibinger.com/img/projects/95/w/kan_project_1.jpg

Bayerisches Landesamt für Statistik und Datenverarbeitung. (2014). Beiträge zur Statistik Bayerns. München: Bayerisches Landesamt für Statistik und Datenverarbeitung. Obtenido de https://www.statistik.bayern.de/statistik/byrbz/REGION14.pdf

Brand, P. (2009). Governing inequality in the South through the Barcelona model: 'social urbanism' in Medellín, Colombia. Medellín: Universidad Nacional de Colombia. Retrieved from http://www.dmu.ac.uk/documents/business-and-lawdocuments/research/lgru/peterbrand.pdf

Brand, P. (2012). El significado social de la movilidad. In J. Dávila, P. Brand, P. Jirón, H. Vargas, F. Coupé, J. Eliécer, ... Bocarejo, Movilidad urbana y pobreza (pp. 16-22). Medellín: Development Planning Unit UCL, Facultad de Arquitectura Universidad Nacional de Colombia.

Buses y Camiones. (s.f.). Transporte Obtenido de Buses y Camiones: http://www.busesycamiones.pe/transporte-peru/530-bus-camion-vehiculoartesanal

Casagrande, M. (s.f.). Urban Acupuncture. Obtenido de helsinkiaupuncture.blogspot.pe: http://helsinkiacupuncture.blogspot.pe/

Centro de investigación y desarrollo de tecnología [CIDT]. (2010). Fiori y Yerbateros: Percepsión del transporte terrestre interprovincial por los usuarios que acuden a dichos terminales. Lima: Universidad San Ignacio de Loyola.

Centro de Investigación y Desarrollo de Tecnología. (31 de mayo de 2010). World Press. Recuperado el 9 de septiembre de 2015, de Fiori y Yerbaeros: Percepción del transporte terrestre interprovincial por los usuarios que acuden a dichos terminales: htts://cidt.worldpress.com/2010/05/31/fiori-y-yerbateros/

Centro Peruano Japones de Investigaciones Sísmicas y Mitigación de Desastres. (2012). Mapa de suelos en los distritos de Lima. Obtenido de Sistema nacional de información ambiental: http://sinia.minam.gob.pe/mapas/mapa-suelos-distritoslima

Comex. (26 de Junio de 2015). Palmitas: El Macromural mas Grande de México por Germen Nuevo Muralismo. Obtenido de https://www.youtube.com/watch?v=AhyvMs4ZEuI

Coronado Díaz, I. (2012). Moviendo al Perú: Visión del transporte nacional. Lima: Asociación Automotriz del Perú [AAP]. 
Corporación Andina de Fomento CAF (Ed.). (2010). Observatorio de Movilidad Urbana para América Latina. Panamericana Formas e Impresos S.A.

Daily Overview. (2015). Obtenido de http://dailyoverview.tumblr.com/post/114153031284/the-terminal-de-autobusesde-pasajeros-de-oriente

Dávila, J., Brand, P., Jirón, P., Vargas, H., Coupé, F., Eliécer, J., . . Amorium da Silva, V. (2012). Movilidad urbana y pobreza; Aprendizajes de Medellín y Soacha, Colombia. Medellín: The Development Planning Unit, UCL; Facultad de Arquitectura, Universidad Nacional de Colombia. Obtenido de https://www.bartlett.ucl.ac.uk/dpu/metrocables/book/Davila_2012_Movilidad_u rbana_y_pobreza_UCL_UNAL.pdf

Detail. (2009). Cantina de empreza en Ditzingen. Detail: Revista de Arquitectura y Detalles Constructivos, 584-593.

Doyer, M. (s.f.). The new $4 P^{\prime}$ S in marketing: S.A.V.E. Business Models Inc.

Echeverri, A., \& Orsini, F. (2010). Informalidad y Urbanismo Social en Medellín. Medellín: Universidad Eafit. Obtenido de http://upcommons.upc.edu/bitstream/handle/2099/11900/111103_RS3_AEchev erri_\%20P?sequence=1

Echeverri, A., \& Orsini, F. (2012). Informality and social urbanism in Medellín. In M. Hermelin, A. Echeverri, \& J. Giraldo, Medellín: Environment, urbanism and society (pp. 132-157). urbam.

El Comercio. (23 de Junio de 2015). Cercado de Lima: terminales interprovinciales serán retirados. El Comercio. Obtenido de http://elcomercio.pe/lima/ciudad/cercado-lima-terminales-interprovincialesseran-retirados-noticia-1820691

Empresa Municipal Administradora de Peaje de Lima [EMAPE]. (s.f.). Acerca de EMAPE. Obtenido de EMAPE S.A.: http://www.emape.gob.pe/acerca-deemape/

Escala. (1974). Terminales de Transporte. Escala: arquitectura arte ingenieria 63, 312.

Escala. (1974). Terminales Transporte. Revista Escala nº3, 3-12.

Estibal, S. (8 de Agosto de 2015). Massive mural transforms poor Mexico neighborhood. Yahoo News. Obtenido de http://news.yahoo.com/massive-muraltransforms-poor-mexico-neighborhood-040050243.html

European Comission. (2015, Junio 23). Clean transport, Urban transport. Retrieved from Mobility and Transport: ec.europa.eu/transport/themes/urban/urban_mobility/index_en.htm 
Flegenheimer, M. (27 de Junio de 2013). Port Authority to Consider Bus Terminal Renovation. The New York Times. Obtenido de http://www.nytimes.com/2013/06/28/nyregion/port-authority-to-considerredoing-or-replacing-hub.html?_r=0

Flores Fernández, L. E. (2006). Terminales Terrestres Interprovinciales. Lima: Pontificia Universidad Católica del Perú.

Friends of the High Line. (s.f.). History. Obtenido de About the High Line: http://www.thehighline.org/about

Fundación Instituto Tecnológico para la Seguridad del Automóvil. (2008). Valor de la seguridad vial. Madrid.

Fundación Transitemos; Asociación Cruzada Vial; Asociación de Representantes Automotrices del Perú; EMBARQ Andino; Libélula; Lima Cómo Vamos; Luz Ámbar; Pontificia Universidad Católica del Perú; Swiss Contact. (2013). Hacia un ciudad para las personas: Hoja de Ruta para una Movilidad y un Transporte sostenibles en Lima y Callao al 2025. Lima.

Gálvez, V., \& Torre, J. (10 de Noviembre de 2013). Sólo un desvío. Semana Económica, 34-35.

Gehl, J. (2006). La humanización del espacio urbano: la vida social entre los edificios. Barcelona: Editorial Reverté.

Gehl, J. (2010). Cities for People. Washington DC: Island Press.

Germen Colectivo. (2012). Germen Nuevo Muralismo Mexicano. Obtenido de Facebook: https://www.facebook.com/muralismogermen/info/?tab=page_info

Gómez Platero Arquitectos. (s.f.). TTG Guayaquil. Obtenido de Proyectos: http://www.gomezplatero.com.uy/es/?pa=proyecto\&id=40

Gran Terminal Terrestre Plaza Lima Norte. (s.f.). Quienes somos. Obtenido de http://granterminalterrestre.com/nosotros

Grupo Maximixe. (2010). Transporte Interprovincial. Caser: Riesgos de mercado, 4658.

Grupo TYPSA. (2014). Informe Anual 2014. Artes Gráficas Campillo Nevado, S.A. Obtenido de file:///C:/Users/CLAUDIA/Downloads/InformeAnualTypsa2014_ESP.pdf

Gutiérrez, A. (1 de Agosto de 2010). Movilidad, Transporte y Acceso: Una renovación aplicada al ordenamiento territorial. Recuperado el 18 de Septiembre de 2015, de Scripta Nova: Revista electrónica de geografía y ciencias sociales: http://www.ub.edu/geocrit/sn/sn-331/sn-331-86.htm

Haas \& Hahn. (s.f.). Favela Painting Foundation. Obtenido de Projects: http://www.favelapainting.com/ 
Herce, M. (2009). Sobre la movilidad en a ciudad: propuestas para recuperar un derecho ciudadano. Barcelona: Reverté.

Hernandez, R. (5 de Agosto de 2015). Pintan Barrio de Palmitas en Pachuca [Archivo de video]. Obtenido de https://www.youtube.com/watch?v=q1-bbMkCq7g

IATA. (2004). Airport development reference manual. Montreal.

INEI. (2013). Transporte interprovincial de pasajeros, según departamento destino. Lima: INEI.

INEI. (2014). Compendio Estadístico - Provincia de Lima. Lima.

INEI. (2016). Victimización en el Perú 2010-2015. Lima.

Insituto Nacional de Estadística e Informática. (2014). Compendio Estadístico Provincia de Lima. Lima.

Instituto Metropolitano de Planificación. (2007). Ordenanza $N^{\circ} 1082$ - MML. Lima: MML.

Instituto Metropolitano de Planificación. (2014). PLAM Lima y Callao 2035. Lima: Instituto Metropolitano de Planificación.

Instituto Nacional de Estadística e Informática . (2013). Provincia de Lima: Compendio Estadístico. Lima: INEI.

Instituto Nacional de Estadística e Informática. (2009). Planos estratificados de Lima Metropolitana a nivel de manzana. Lima.

Instituto Nacional de Estadística e Informática. (2013). Transporte interprovincial de pasajeros, según departamento destino, 2006-2013. Lima: INEI.

Instituto Nacional de Estadística e Informática. (2014). Una mirada a Lima Metropolitana. Lima: Biblioteca Nacional del Perú.

Instituto Nacional de Estadística e Informática. (2015). Perfil Sociodemográfico del cerro San Cosme. Lima: INEI. Obtenido de http://www.inei.gob.pe/media/MenuRecursivo/publicaciones_digitales/Est/Lib1 206/libro.pdf

International Air Transport Association. (2016). About us. Obtenido de http://www.iata.org/Pages/default.aspx

Ipsos . (2014). Perfiles Socioeconómicos Lima Metropolitana 2014. Lima: Ipsos Perú.

Ipsos. (2015). Perfiles Zonales Lima Metropolitana 2015. Lima: Ipsos Perú.

Ipsos. (2016). Perfiles Zonales - Lima Metropolitana. Lima: Ipsos Perú.

Ipsos Apoyo. (2011). Niveles Socioeconómicos Perú 2011. Lima: Ipsos Apoyo Opinión y Mercado S.A. 
Ipsos Apoyo. (2012). Estudios Multiclientes. Lima: Ipsos Apoyo.

Izquierdo Quispe, P. R. (2012). Propuesta de regulación en los terminales terretres del transporte de ámbito naconal de personas en la provincia de Lima. Lima: Pontificia Universidad Católica del Perú.

Jacobs, J. (1992). The death and life of Great American Cities. New York: Vintage Books.

Jacobs, J. (2011). Muerte y vida de las grandes ciudades (2013 ed.). (Á. Abad, Trans.) Madrid, España: Capitán Swing Libros.

Japan International Cooperation Agency. (2016). About JICA. Obtenido de https://www.jica.go.jp/english/

JICA - DGCA. (1996). Airport Terminal Building Planing: Seminar on airport engineering. Tokyo: JICA Text.

Kahatt, S. S. (Octubre de 2014). Lima: cinco siglos de orden y caos. Breve recuento de crecimiento y transformación socio-espacial. Revista indexada de textos académicos (rita), 2, 38-43. Obtenido de http://ojs.redfundamentos.com/

Kapstein, P., \& Aranda, E. (2014). Las periferias interiores de Lima: Localización e identificación de los barrios focos de vulnerabilidad. El caso de San Cosme. Revista Invi, 19-61.

Koolhaas, J., \& Urhahn, D. (Octubre de 2014). How painting can transform communities [Archivo de Video]. Obtenido de https://www.ted.com/talks/haas_hahn_how_painting_can_transform_communiti es?language $=\mathrm{en}$

Koolhaas, J., \& Urhahn, D. (s.f.). Back to rio. Obtenido de Favela Painting \& other projects: http://www.favelapainting.com/page/backtorio

LAN. (17 de Setiembre de 2015). 8 Key Qualities That Make Zhengzhou Vanke Central Plaza Stand Out as a World Class Design. Obtenido de Landscape Architects Network: http://landarchs.com/8-key-qualities-that-make-zhengzhou-vankecentral-plaza-stand-out-as-a-world-class-design/

Landeshauptstadt München. (2011). Ankünfte Januar mit Dezember 2009. München. Obtenido de https://web.archive.org/web/20110522083426/http://www.muenchen.de/cms/pr od1/mde/_de/rubriken/Rathaus/65_raw/Tourismusamt/pdf/statistik/2009/Touris mus_Gesamt_2009.pdf

Landezine: Landscape Architecture Works. (23 de Julio de 2015). Zhengzhou Vanke Central Plaza. Obtenido de http://www.landezine.com/index.php/2015/07/zhengzhou-vanke-central-plazaby-locus-associates/ 
Lima Airport Partners. (2015). El Aeropuerto en Cifras. Obtenido de Aeropuerto Internacional Jorge Chávez Lima-Perú: https://www.lima-airport.com/esp/lapnegocios-y-proyectos/informacion-financiera/el-aeropuerto-en-cifras

Lima Cómo Vamos. (2014). Encuesta Lima Cómo Vamos: Quinto informe de percepción sobre calidad de vida. Lima: Lima Cómo Vamos.

Lima cómo vamos. (2016). Informe de percepción sobre la calidad de vida. Lima.

Lima Cómo Vamos. (s.f.). Ayuda Memoria. Lima: Lima Cómo Vamos.

Locus Associates. (2014). Zhengzhou Vanke Central Plaza. Obtenido de Landscape: http://www.locusassociates.com/project/zhengzhou-vanke-central-plaza/

Lopez, R. (1 de Agosto de 2015). Working-class barrio turns into huge rainbow mural in Mexico. The Big Story Obtenido de http://bigstory.ap.org/article/664e9c91529344f8b932330ab15d9f02/workingclass-barrio-turns-huge-rainbow-mural-mexico

Ludeña, W. (2002). Lima: poder, centro y centralidad: Del centro nativo al centro neoliberal. EURE. doi:http://dx.doi.org/10.4067/S0250-71612002008300004

Ludeña, W. (2013). Espacios Públicos, Arte Urbano, y Diseño. La otra ciudad peruana. En J. Hamann, Lima: Espacio Público, Arte y Ciudad (págs. 155-185). Lima: Pontificia Universidad Católica del Perú.

Ludeña, W. (2014). Lima y la cuestión del espacio público en su dimensión urbanística. Exploraciones 1990-2011. EST, 93-111.

Macedo, B. (2005). El concepto de sostenibilidad. UNESCO.

Matos Mar, J. (2011). Perú: Estado desbordado y sociedad nacional emergente. Lima: Universidad Ricardo Palma.

Mayo, A. (11 de Febrero de 2015). Minivanes y autos ocasionan 6 de cada 10 accidentes en las carreteras. La República.

McCormick, M. (4 de Diciembre de 2014). The Port Authority Bus Terminal: Myth, Mystery, Mess. Obtenido de Gizmodo: http://gizmodo.com/the-port-authoritybus-terminal-myth-mystery-mess-1666794655

Miguet, J. M. (2014). Public architecture: buildings, terminals, bus stop, train station. Barcelona: Monsa.

Ministerio de Comercio Exterior y Turismo [MINCETUR]; Unión Europea [UE]. (2009). Proyecto UE-Perú/PENX. Lima: Advanced Logistics Group.

Ministerio de economía y finanzas. (2014). Metodología para la aplicación del análisis cuantitativo en la elección de la modalidad de ejecución de proyectos de inversión cofinanciados. Lima. 
Ministerio de Transportes y Comunicaciones [MTC]. (2009). Decreto Supremo $N^{o} 017$ 2009-MTC. Obtenido de Reglamento Nacional de Administración de Transporte: http://transparencia.mtc.gob.pe/idm_docs/normas_legales/1_0_2789.pdf

Ministerio de Transportes y Comunicaciones [MTC]. (2010). Nosotros. Obtenido de Provias Nacional: http://www.proviasnac.gob.pe/frmNosotros.aspx?idmenu=1

Ministerio de Transportes y Comunicaciones [MTC]. (2017). Nosotros. Obtenido de Consejo Nacional de Seguridad Vial: http://www.mtc.gob.pe/cnsv/nosotros.html

Ministerio de Transportes y Comunicaciones [MTC]. (s.f.). Historia. Obtenido de MTC: Ministerio de Transportes y Comunicaciones: http://www.mtc.gob.pe/nosotros/nosotros.html

Ministerio de Transportes y Comunicaciones. (2015). Informe de caracterización de tramos de vía de alta incidencia de accidentes de tránsito en el distrito de San Luis. Lima.

Ministerio de Transportes y Telecomunicaciones. (2005). Manual Explicativo: procedimientos en materia de terminales de servicios de locomoción colectiva urbana. Santiago de Chile.

Ministerio de Vivienda, Construcción y Saneamiento. (2006). Reglamento Nacional de Edificaciones. Lima: El peruano.

Ministerio del Ambiente del Perú. (2016). Datos Históricos. Obtenido de Senamhi: http://www.senamhi.gob.pe/main_mapa.php?t=dHi

Ministerio del Interior. (2015). Observatorio nacional de seguridad ciudadana. Obtenido de Ficha informativa - Lima Metropolitana: http://conasec.mininter.gob.pe/obnasec/index.html

Montestruque, O. (2015). Identificación del 'Espacio de la Movilidad' como articulador entre los sistemas de transporte masivo y el espacio público. Lima: Universidad Nacional de Ingeniería.

Montezuma, R. (2003). Ciudad y Transporte. La movilidad urbana. In M. Balbo, R. Jordán, \& D. Simioni, La Ciudad Inclusiva (pp. 175-185). Santiago de Chile: Comisión Económica para América Latina y el Caribe [CEPAL]; Cooperazione Italiana. http://repositorio.cepal.org/bitstream/handle/11362/2776/S2003002.pdf?sequenc $\mathrm{e}=1$

MTC. (2007). Caminos y Ferrocarriles. Obtenido de Ministerio de Transportes y Comunicaciones:

http://web.archive.org/web/20140924145038/http://www.mtc.gob.pe/portal/tran sportes/caminos_ferro/reglamentos_new.htm

MTC. (Mayo de 2011). Provias Nacional. Obtenido de Viceministerio de Transportes: http://www.proviasnac.gob.pe/frmNosotros.aspx?idmenu=28 
MTC. (Diciembre de 2012). Caminos y Ferrocarriles. Obtenido de Ministerio de Transportes $\mathrm{y}$ http://www.mtc.gob.pe/transportes/caminos/renac.html

Comunicaciones:

MTC. (s.f.). Historia. Obtenido de MTC: Ministerio de Transportes y Comunicaciones: http://www.mtc.gob.pe/nosotros/nosotros.html

Muenchen: Das offizielle Stadtportal. (s.f.). Zentraler Omnibusbahnhof München. Obtenido de http://www.muenchen.de/verkehr/orte/1215607.html

München: Das offizielle Stadtportal. (2014). München in Zahlen. Obtenido de http://www.muenchen.de/sehenswuerdigkeiten/muenchen-in-zahlen.html

Municipalidad de San Luis. (2015). Plano de zonificación. Obtenido de Planos: http://www.munisanluis.gob.pe

Municipalidad de San Luis. (s.f.). Características del distrito de San Luis: Compendio Parte 1. Lima. Obtenido de http://www.munisanluis.gob.pe/portal/wpcontent/uploads/2015/06/Compendio-Parte-1.pdf

Municipalidad de Santiago de Surco. (2007). Plan distrital de seguridad siudadana de Santiago de Surco. Lima.

Municipalidad Metropolitana de Lima [MML]. (2007). Normas Legales. El Peruano.

Municipalidad metropolitana de Lima. (2012). Diseño de escenario sobre el impacto de un sismo de gran intensidad en Lima Metropolitana y Callao. Lima.

Municipalidad Metropolitana de Lima. (2012). Plan Regional de Desarrollo Concertado de Lima. Lima: Instituto Metropolitano de Planificación.

Municipio de Guayaquil. (2015). Guayaquil es mi destino. Obtenido de Terminal Terrestre Jamie Roldós Aguilera: http://www.guayaquilesmidestino.com/es/descubre-guayaquil/comollegar/terminal-terrestre-jaime-roldos-aguilera

Organismo Supervisor de la Inversión en Infraestructura de Transporte de Uso Público [OSITRAN]. (s.f.). Quiénes somos. Obtenido de OSITRAN: https://www.ositran.gob.pe/nosotros/quienes-somos.html

Paz Navarro, C., Tuesta Serrano, J., Graziani Torres, R., \& Reginaldo Medina, J. (octubre de 2010). Evolución del transporte en el Perú. Obtenido de http://evoluciondeltransporte-upc.blogspot.pe/

Peñalosa, E. (Octubre de 2015). Mi hoja de vida. Obtenido de \# Recuperemos Bogotá: http://enriquepenalosa.com/conoceme/

Pico Cedeño, J. V. (2009). Proceso de Planificación de la Fundación Terminal Terrestre de Guayaquil para la Gestión de la Remodelada Terminal Multicomercio de Transporte y Servicios "Dr. Jaime Roldós Aguilera". Guayaquil: Escuela Superior Politécnica del Litoral: FIMCP. 
Plazola Cisneros, A. (1995). Enciclopedia de arquitectura Plazola. México DF: Plazola editores .

Port Authority of New York and New Jersey. (s.f.). About the Port Authority Bus Terminal Midtown Bus Master Plan. Obtenido de Port Authority Bus Terminal: http://www.panynj.gov/bus-terminals/pabt-master-plan-about.html

Port Authority of NY \& NJ. (s.f.). History of the Port Authority Bus Terminal. Obtenido de Port Authority Bus Terminal: http://www.panynj.gov/bus-terminals/pabthistory.html

Pozueta, J. (2000). Movilidad y Planeamiento sostenible: Hacia una considerción inteligente del transporte y la movilidad en el planeamiento y en el diseño urbano. Madrid: Instituto Juan Herrera, Obtenido de http://www.academia.edu/7132353/MOVILIDAD_Y_PLANEAMIENTO_SOS TENIBLE_Hacia_una_consideraci\%C3\%B3n_inteligente_del_transporte_y_la_ movilidad_en_el_planeamiento_y_en_el_dise\%C3\%B1o_urbano

Presidencia de la República de Colombia. (2016). Secretaría de Transparencia. Obtenido de Elefantes Blancos: http://www.secretariatransparencia.gov.co/elefantes-blancos/Paginas/que-eselefante-blanco.aspx

Presidencia de la República Mexicana. (2015). Flickr. Obtenido de Inauguración del Macromural "Pachuca se pinta": https://www.flickr.com/photos/presidenciamx/

ProInversión. (s.f.). Estructuración Financiera de las APPs. Lima: Marca Perú.

Protransporte. (s.f.). Quiénes Somos. Obtenido de Protransporte: http://www.protransporte.gob.pe/index.php/protransporte/quienes-somos

RAE. (2014). Espacio Público . Obtenido de Diccionario Real Academia Española. $22^{\circ}$ edición digital: http://www.rae.es/

RAE. (2017). Bienestar. Obtenido de Real Academia Española: http://dle.rae.es/?id=5TwfW6F

RAE. (2017). Calidad. Obtenido de Real Academia Española: http://dle.rae.es/srv/fetch?id=6nVpk8P

RAE. (2017). Efecto. Obtenido de Real Academia Española: http://dle.rae.es/?id=EOoHYxJ

RAE. (2017). Freelance. Obtenido de Real Academia Española: http://dle.rae.es/?id=IR8w9Z9

RAE. (2017). Sostenible. Obtenido de Real Academia Española: http://dle.rae.es/?id=YSE9w6H

Revista Costos. (2016). Costos: Construcción, Arquitectura e Ingeniería. Lima. 
Rodriguez, A., \& Riofrío, G. W. (1972). De invasores a invadidos *. Revista Latinoamericana de Estudios Urbano Regionales (EURE), 101-139.

Rogers Stirk Harbour + Partners. (s.f.). Rogers Stirk Harbour + Partners. Obtenido de Bodegas Protos: http://www.rsh-p.com/projects/bodegas-protos/\#design

Rogers Stirk Harbour + Partners. (s.f.). RSH-P. Obtenido de Projects: https://www.rshp.com/projects/bodegas-protos/

Rosales Mayor, E., Egoavil Rojas, M., Durand Vila, I., Montes Ccaccro, E., Flores Herrera, E., Rivera García, S., . . . de Castro Mujica, J. (2009). Accidente de carretera y su relación con cansancio y somnolencia en conductores de ómnibus. Revista Médica Herediana, 48-58.

Rutas de Lima. (s.f.). Nosotros. Obtenido de Rutas de Lima: http://rutasdelima.pe/nosotros

Salas, C., \& Carzón, M. (2013). La noción de calidad de vida y su medición . CES Salud Pública, 36-46.

Schiller, B. (2013). Co.Design. Obtenido de Quantifying the economic value of trees to cities: https://www.fastcodesign.com/1681455/quantifying-the-economic-valueof-trees-to-cities

Semana Económica. (2013). Túnel soñado. Semana Económica, 14.

Setra. (2017). Vehicles. Obtenido de Setra: https://www.setra.de/en/vehicles/topclass/dtmodels/s-431-dt.html

SkyscraperPage.com.

(s.f.).

Obtenido

de

Forum: http://forum.skyscraperpage.com/showthread.php?t=160480

Soria y Puig, A. (1980). ¿A qué se llama transporte? Ciudad y territorio: Revista de Ciencia Urbana, 19-31.

Spiegel Online Wirtschaft. (2014). Deutschland-Ranking der Mietpreise: München hängt alle ab. Spiegel. Obtenido de http://www.spiegel.de/wirtschaft/soziales/mietpreise-in-deutschland-wohnen-inmuenchen-ist-am-teuersten-a-951431.html

Sternfeld, J. (2000). Obtenido de http://www.cafleurebon.com/bond-no-9-high-line-thescent-of-urban-renewal-for-new-york-city

Steve. (2011). Flickr. Obtenido de Locomotive on the High Line: https://www.flickr.com/photos/syscosteve/5476852481/

Stgo. (2009). Stgo. Obtenido de Jaime Lerner. Acupuntura Urbana: http://www.stgo.es/2009/08/jaime-lerner-acupuntura-urbana/

Superintendencia de Transporte Terrestre de Personas, Carga y Mercancías [SUTRAN]. (2017). Misión y visión. Obtenido de Organización: http://www.sutran.gob.pe/mision-y-vision/ 
Superintendencia de Transporte Terrestre de Personas, Carga y Mercancías. (2014). Accidentes de tránsito con daños personales de vehículos de servicio de transporte terrestre. Lima.

Tarii Wasi. (1999). Cruz del Sur: terrapuertos en la ciudad. Arquitextos, 9, 88-93.

Terminal de Autobuses de Pasajeros de Oriente. (2007). La cupula . Obtenido de TAPO: http://www.expologistica.com.mx/vuspaginf.cfm?tema_id=985

The World Bank Group. (2001). What is Urban Uprgading? Obtenido de Upgrading Urban Communities: A Resource for Practitioners: http://web.mit.edu/urbanupgrading/upgrading/whatis/what-is.html\#AnchorWhat-41312

Tokeshi, J. (2013). Arte y Espacio Público. Una ventana abierta a la cultura popular. En J. Hamann, Lima: Espacio Público, Arte y Ciudad (págs. 117-137). Lima: Pontificia Universidad Católica del Perú.

U.S. Department of Transportation. (2017). History. Obtenido de Federal Aviation Administration: https://www.faa.gov/about/history/

UNO Habitat. (2012). UNO Habitat: For a better urban future. Obtenido de www.unhabitat.org: http://unhabitat.org/urban-themes/mobility/

Urbania. (2017). San Luis. Obtenido de Venta de Terrenos: http://urbania.pe/buscar/venta-de-terrenos-en-san-luis--lima--lima

Vasconcellos, E. (2010). Análisis de la movilidad urbana. Espacio, medio ambiente y equidad. Bogotá: Corporación Andina de Fomento CAF. Obtenido de http://omu.caf.com/media/14683/an\%C3\%A1lisis_movilidad_urbana.pdf

Vidal, L. (. (2013). Urban Rail Transit Design Manual. Florida: Design Media Publishing Limite.

Villa Moya, N. (7 de Abril de 2013). Sergio Fajardo, a political biography. Obtenido de http://www.colombia-politics.com/sergio-fajardo-a-political-biography/

Wilson, J. Q., \& Kelling, G. L. (1982). Broken Windows. The Atlantic.

WMATA. (2008). Station site and access planning manual. Washinton.

Zentraler Omnibusbahnhof München. (s.f.). ZOB: Zentraler Omnibusbahnhof München. Obtenido de http://www.muenchen-zob.de 


\section{ANEXOS}

\section{ANEXO I}

PLOT PLAN

ANEXO II

DETALLE 1

ANEXO III

FLUJOS VEHICULARES 


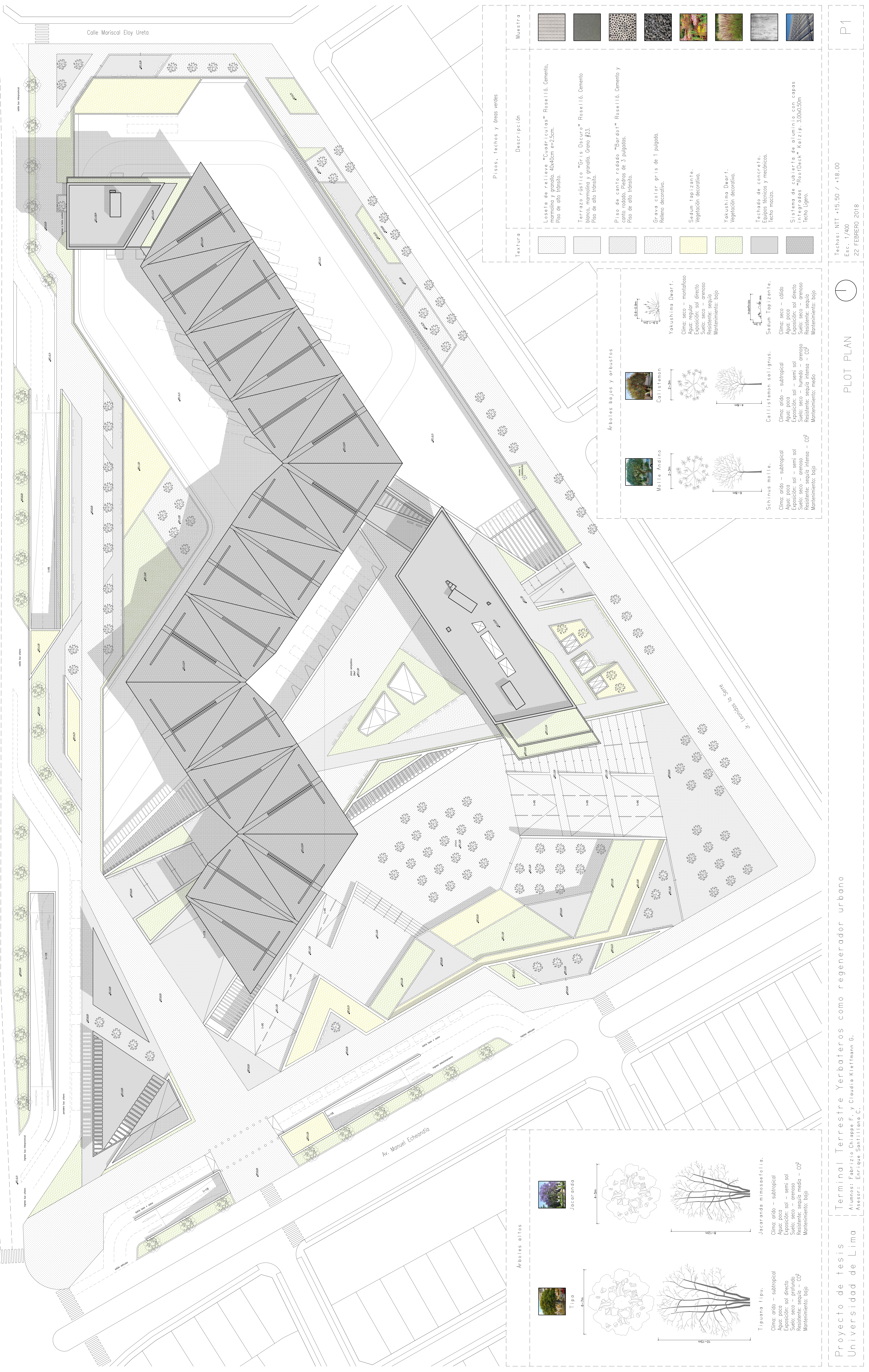


$\lambda$

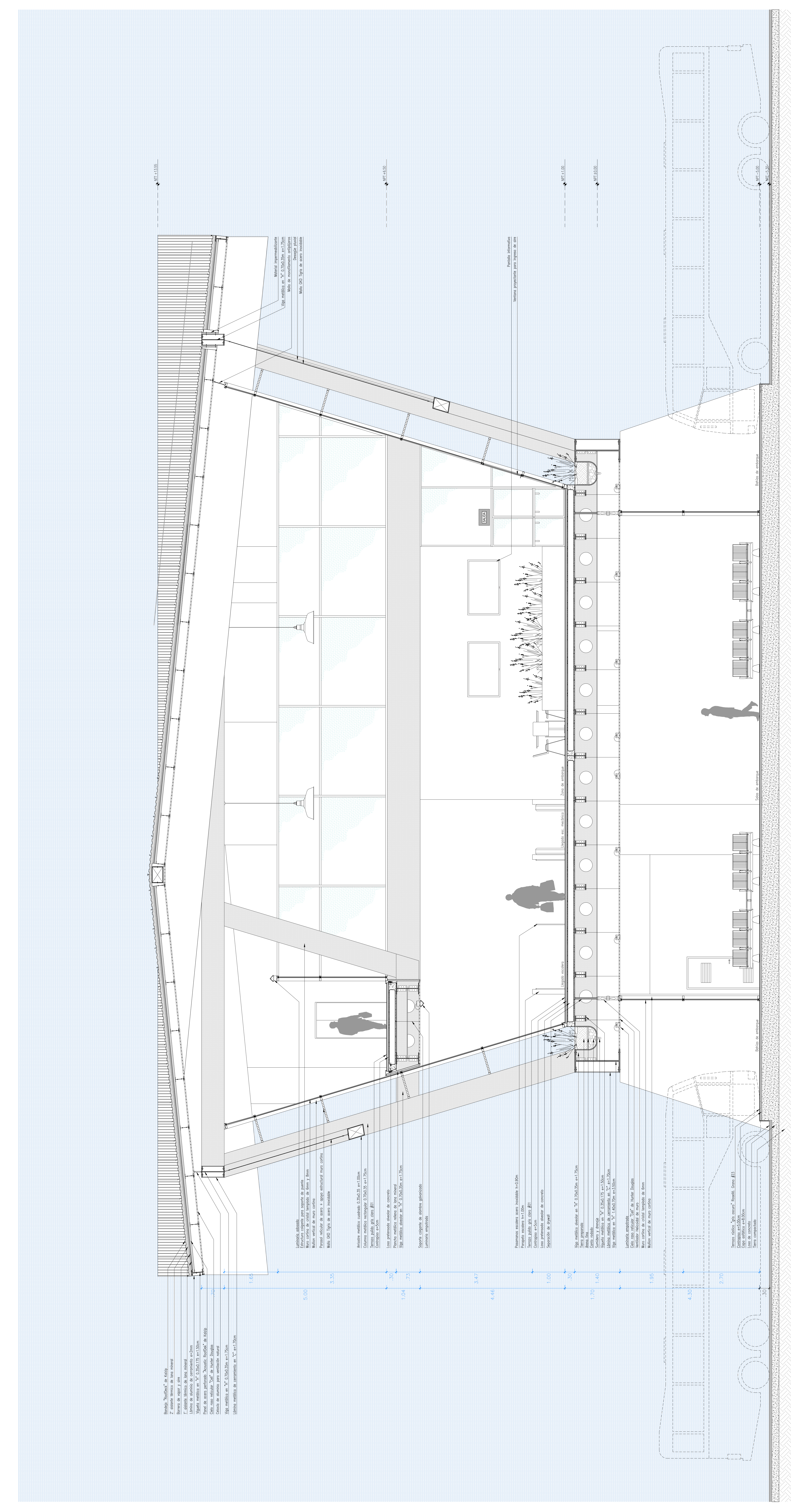




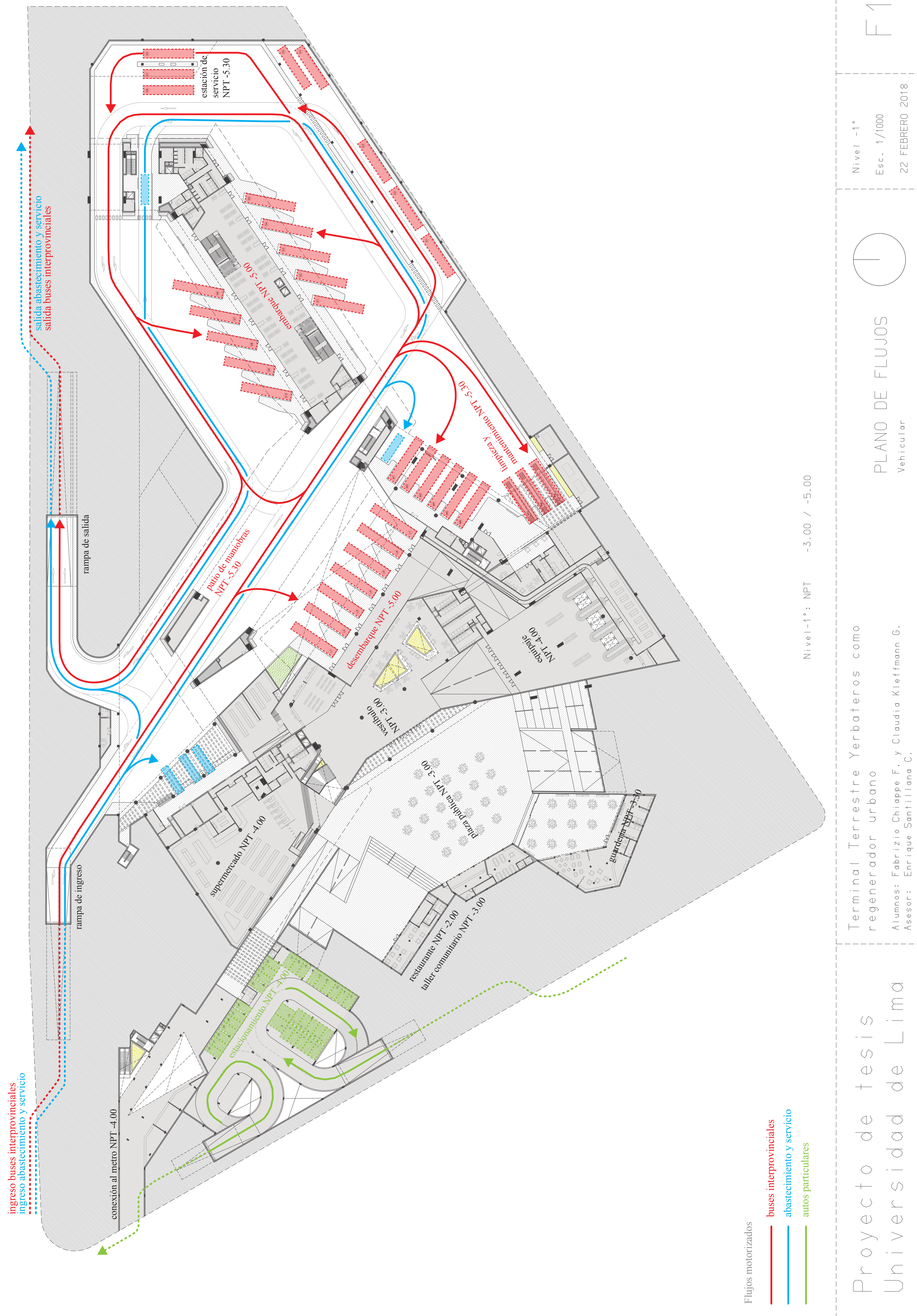




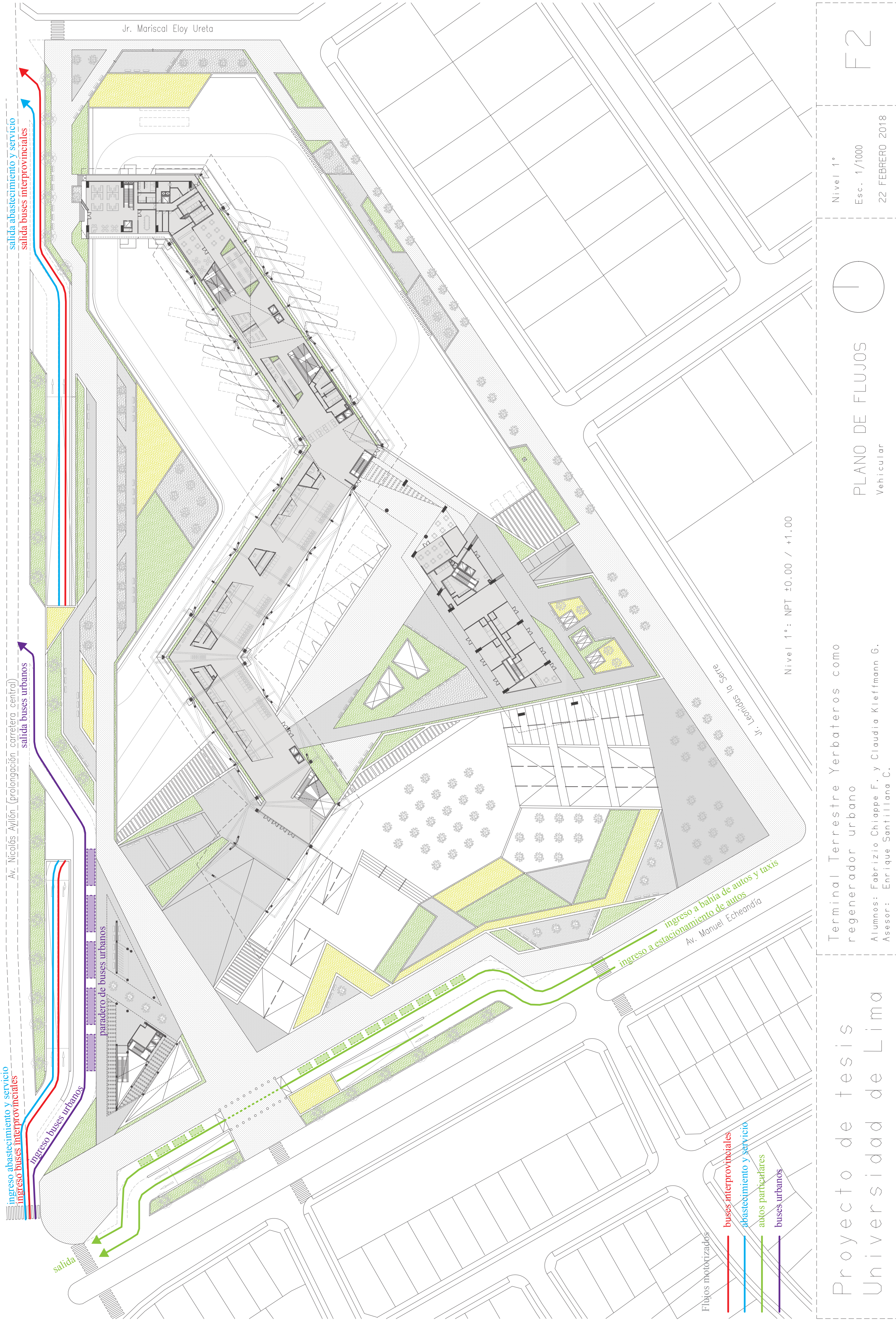

